Nevada

Environmental

Restoration

Project

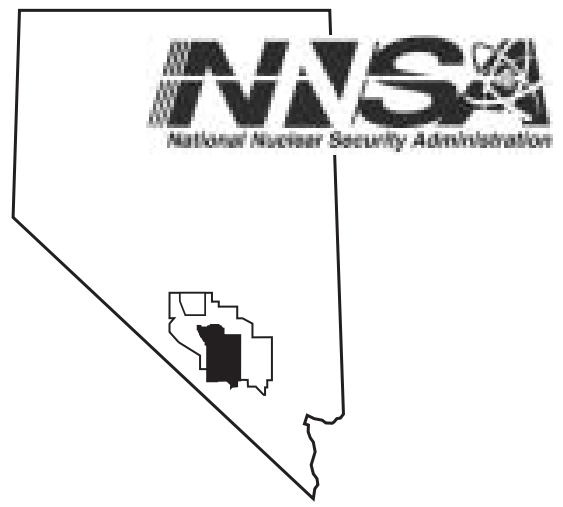

Closure Report for Corrective

Action Unit 330: Areas 6, 22, and 23 Tanks and Spill Sites, Nevada Test Site, Nevada

Controlled Copy No.:

Revision: 0

July 2003

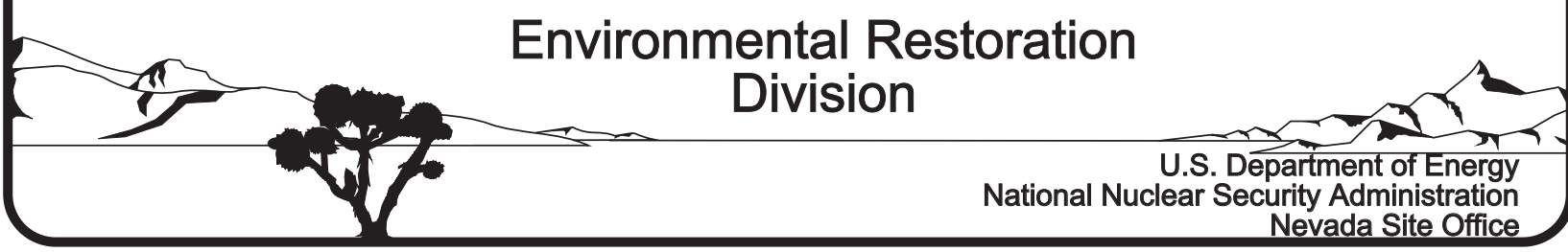




\section{DISCLAIMER STATEMENT}

Reference herein to any specific commercial product, process, or service by trade name, trademark, manufacturer, or otherwise, does not necessarily constitute or imply its endorsement, recommendation, or favoring by the U.S. Government or any agency thereof or its contractors or subcontractors.

\section{AVAILABILITY STATEMENT}

Available for sale to the public from-

U.S. Department of Commerce

National Technical Information Service

5285 Port Royal Road

Springfield, VA 22161-0002

Telephone: 800.553 .6847

Fax: 703.605.6900

E-mail: orders@ntis.fedworld.gov

Online ordering: http://www.ntis.gov/ordering.htm

Available electronically at http://www.doe.gov/bridge

Available for a processing fee to U.S. Department of Energy and its contractors, in paper, from-

U.S. Department of Energy

Office of Scientific and Technical Information

P.O. Box 62

Oak Ridge, TN 37831-0062

Telephone: 865.576.8401

Fax: 865.576.5728

E-mail: reports@,adonis.osti.gov 


\title{
CLOSURE REPORT \\ FOR CORRECTIVE ACTION UNIT 330: AREAS 6, 22, AND 23 TANKS AND SPILL SITES, NEVADA TEST SITE, NEVADA
}

\author{
Prepared for: \\ U.S. Department of Energy \\ National Nuclear Security Administration \\ Nevada Site Office \\ Work Performed Under Contract No. DE-AC08-96NV11718
}

Controlled Copy No:

Revision: 0

July 2003 
THIS PAGE INTENTIONALLY LEFT BLANK 


\section{CLOSURE REPORT FOR CORRECTIVE ACTION UNIT 330: AREAS 6, 22, AND 23 TANKS AND SPILL SITES, NEVADA TEST SITE, NEVADA}
Approved by: SIGNATURE APPROVED
Janet Appenzeller-Wing, Project Manager Industrial Sites Project

\footnotetext{
Approved by: SIGNATURE APPROVED

Runore C. Wycoff, Director

Environmental Restoration Division
}

Date: $\quad 7 / 23 / 2003$

Date: $7 / 23 / 2003$ 
THIS PAGE INTENTIONALLY LEFT BLANK 
EXECUTIVE SUMMARY ix

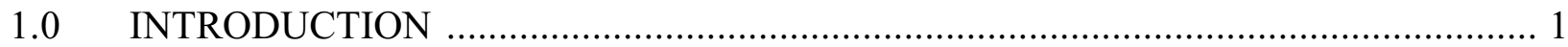

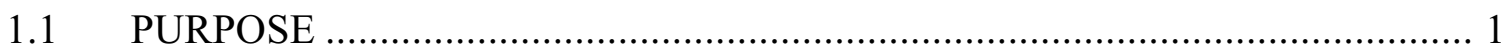

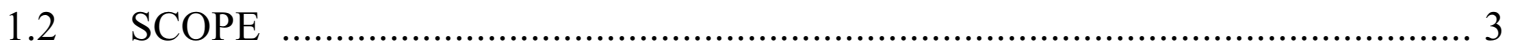

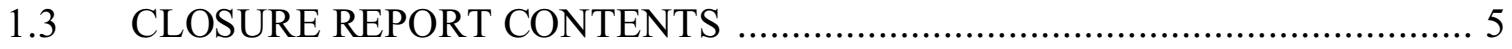

1.3.1 Data Quality Objectives ................................................................. 6

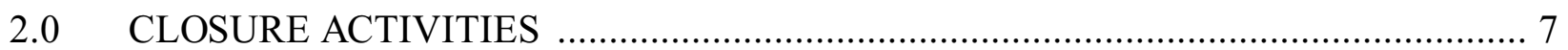

2.1 DESCRIPTION OF CORRECTIVE ACTION ACTIVITIES ......................... 7

2.1.1 Preplanning and Site Preparation ................................................ 7

2.1.2 CAS 06-02-04: UST and Piping ..................................................... 7

2.1.3 CAS 22-99-06: Fuel Spill ............................................................. 12

2.1.4 CAS 23-01-02: Large AST Farm ................................................... 14

2.1.4.1 Pre-demolition Activities ................................................... 14

2.1.4.2 Demolition Activities ....................................................... 14

2.1.4.3 Post-demolition Activities ................................................... 17

2.1.5 CAS 23-25-05: Asphalt Oil Spill/Tar Release ................................... 17

2.2 DEVIATIONS FROM SAFER PLAN AS APPROVED ................................ 23

2.3 CORRECTIVE ACTION SCHEDULE AS COMPLETED .......................... 23

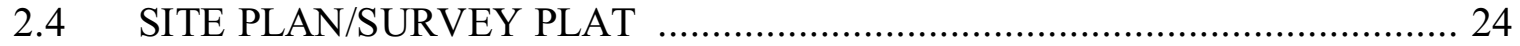

WASTE DISPOSITION .............................................................................. 25

4.0 CLOSURE VERIFICATION RESULTS ............................................................... 27

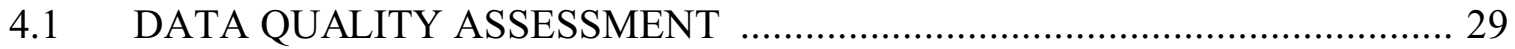

4.2 USE RESTRICTIONS ........................................................................ 30

5.0 CONCLUSIONS AND RECOMMENDATIONS .............................................. 31

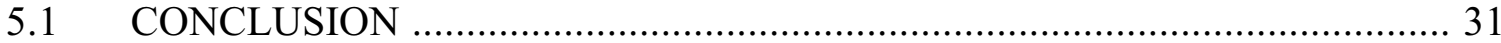

5.2 RECOMMENDATIONS ….................................................................. 32

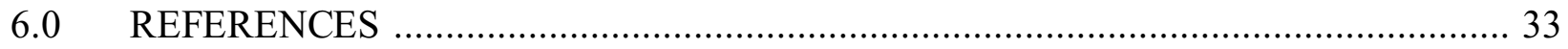

\section{FIGURES}

FIGURE 1 - CAU 330 CORRECTIVE ACTION SITE LOCATIONS .................................. 2

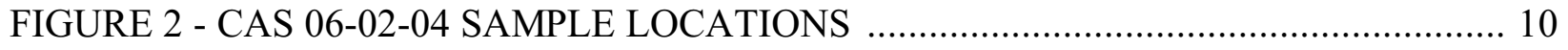

FIGURE 3 - CAS 22-99-06 SAMPLE LOCATIONS .................................................... 15 


\section{TABLE OF CONTENTS ( continued)}

FIGURE 4 - CAS 23-01-02 SAMPLE LOCATIONS ................................................... 18

FIGURE 5 - CAS 23-25-05 SAMPLE LOCATIONS ........................................................ 21

\section{TABLES}

TABLE 1 - ANALYTICAL RESULTS OF LIQUID FOR CAS 06-02-04 ........................... 8

TABLE 2 - ANALYTICAL RESULTS OF SLUDGE FOR CAS 06-02-04 .......................... 11

TABLE 3 - ANALYTICAL RESULTS OF SOIL FOR CAS 06-02-04

(Soil Underneath Piping)

TABLE 4 - ANALYTICAL RESULTS OF SOIL FOR CAS 06-02-04

(Soil Surrounding UST)

TABLE 5 - ANALYTICAL RESULTS FOR CAS 22-99-06 ............................................. 16

TABLE 6 - ANALYTICAL RESULTS FOR CAS 23-01-02 ............................................. 19

TABLE 7 - ANALYTICAL RESULTS FOR CAS 23-25-05 (Drum Contents) ...................... 20

TABLE 8 - ANALYTICAL RESULTS FOR CAS 23-25-05 (Soil Around Drum) ................. 22

\section{APPENDICES}

APPENDIX A: DATA QUALITY OBJECTIVES FOR CAU 330

APPENDIX B: SAMPLE ANALYTICAL RESULTS

APPENDIX C: WASTE DISPOSITION DOCUMENTATION

APPENDIX D: FIELD PHOTOGRAPHS

APPENDIX E: CLOSURE CERTIFICATION

APPENDIX F: AS-BUILT DOCUMENTATION

APPENDIX G: MODIFICATIONS TO THE POST-CLOSURE PLAN

APPENDIX H: NEVADA ENVIRONMENTAL RESTORATION PROJECT DOCUMENT REVIEW SHEET

DISTRIBUTION LIST 


\begin{tabular}{|c|c|}
\hline AIP & Animal Investigation Program \\
\hline AST & Aboveground Storage Tank \\
\hline $\mathrm{BN}$ & Bechtel Nevada \\
\hline bgs & below ground surface \\
\hline CAS & Corrective Action Site(s) \\
\hline CAU & Corrective Action Unit \\
\hline $\mathrm{CR}$ & Closure Report \\
\hline $\mathrm{cm}$ & centimeter(s) \\
\hline $\mathrm{COC}$ & contaminant(s) of concern \\
\hline COPC & contaminant(s) of potential concern \\
\hline CSM & conceptual site model(s) \\
\hline $\mathrm{DOE} / \mathrm{NV}$ & U.S. Department of Energy, Nevada Operations Office \\
\hline DQO & Data Quality Objective(s) \\
\hline EPA & U.S. Environmental Protection Agency \\
\hline FFACO & Federal Facility Agreement and Consent Order \\
\hline $\mathrm{ft}$ & foot(feet) \\
\hline gal & gallon(s) \\
\hline in & $\operatorname{inch}(e s)$ \\
\hline $\mathrm{L}$ & liter(s) \\
\hline $\mathrm{m}$ & meter(s) \\
\hline $\mathrm{m}^{3}$ & cubic meter(s) \\
\hline $\mathrm{mg} / \mathrm{kg}$ & milligram(s) per kilogram \\
\hline $\mathrm{mg} / \mathrm{L}$ & milligram(s) per Liter \\
\hline NAC & Nevada Administrative Code \\
\hline NDEP & Nevada Division of Environmental Protection \\
\hline NNSA/NSO & U.S. Department of Energy, National Nuclear Security Administration Nevada \\
\hline & Site Office \\
\hline NNSA/NV & $\begin{array}{l}\text { U.S. Department of Energy, National Nuclear Security Administration Nevada } \\
\text { Operations Office }\end{array}$ \\
\hline NTS & Nevada Test Site \\
\hline PCB & Polychlorinated Biphenyls \\
\hline $\mathrm{pCi} / \mathrm{g}$ & picocurie per gram \\
\hline $\mathrm{pCi} / \mathrm{L}$ & picocurie per Liter \\
\hline
\end{tabular}




\begin{tabular}{ll} 
ACRONYMS AND ABBREVIATIONS (co \\
\hline RCRA & Resource Conservation and Recovery Act \\
SAA & Satellite Accumulation Area \\
SAFER & Streamlined Approach for Environmental Restoration \\
SVOC & Semi-volatile Organic Compound(s) \\
TCLP & Toxicity Characteristic Leaching Procedure \\
TPH & Total Petroleum Hydrocarbons \\
$\mu \mathrm{g} / \mathrm{kg}$ & microgram(s) per kilogram \\
$\mu \mathrm{g} / \mathrm{L}$ & microgram(s) per Liter \\
UST & Underground Storage Tank \\
VOC & Volatile Organic Compound(s) \\
$\mathrm{yd}^{3}$ & cubic yard(s)
\end{tabular}


Corrective Action Unit (CAU) 330 consists of four Corrective Action Sites (CASs) located in Areas 6, 22, and 23 of the Nevada Test Site (NTS). The unit is listed in the Federal Facility Agreement and Consent Order (FFACO, 1996) as CAU 330: Areas 6, 22, and 23 Tanks and Spill Sites. CAU 330 consists of the following CASs:

- $\quad$ CAS 06-02-04, Underground Storage Tank (UST) and Piping

- $\quad$ CAS 22-99-06, Fuel Spill

- $\quad$ CAS 23-01-02, Large Aboveground Storage Tank (AST) Farm

- $\quad$ CAS 23-25-05, Asphalt Oil Spill/Tar Release

CAU 330 was closed in accordance with the FFACO and the Nevada Division of Environmental Protection-approved Streamlined Approach for Environmental Restoration Plan for CAU 330: Areas 6, 22, and 23 Tanks and Spill Sites, Nevada Test Site, Nevada (U.S. Department of Energy, National Nuclear Security Administration Nevada Operations Office [NNSA/NV], 2001). CAU 330 was closed by implementing the following corrective actions:

- CAS 06-02-04 was a UST and piping associated with Building 660. Total Petroleum Hydrocarbons (TPH) at concentrations greater than action levels were identified in the sludge at the bottom of the UST. The site was clean closed by excavating, removing, and disposing of the UST, the contents of the UST, and all associated piping. The excavations were backfilled with clean fill.

- CAS 22-99-06 was a waste oil release that occurred when Camp Desert Rock was an active facility (NNSA/NV, 2001). The site was clean closed by the removal and disposal of approximately 49.7 cubic meters ( 65 cubic yards) of TPH-impacted soil. The excavation was backfilled with clean fill.

- CAS 23-01-02 was a large AST Farm that provided gasoline and diesel storage in Area 23. The site was clean closed by demolishing the two ASTs, a fill stand, and associated piping using hydraulic shears. The metal was cut into manageable sized pieces with the majority of the scrap metal being recycled by a scrap metal vendor. The remaining smaller pieces were disposed of in the NTS Area 23 Sanitary Landfill. In addition, a small section of concrete, which was removed from the concrete pad to access the underground piping was disposed of in the NTS Area 9 U10c Landfill.

- CAS 23-25-05 is an asphalt oil spill/tar release located in a wash. The spill may be a result of the operation of an asphalt plant or an area where asphalt oil was stored in tanks (NNSA/NV, 2001). The site was clean closed by excavating the asphalt oil/ tar and removing all of the reinforced concrete from the wash. In addition, the site contained a 208 liter (55-gallon) drum containing a petroleum hydrocarbon product that exhibited a hazardous characteristic for ignitability was identified (U.S. Environmental Protection 
Agency, 2002a). The contents of the drum were transferred to a Satellite Accumulation Area (SAA) and then transported to the Area 5 Hazardous Waste Storage Pad for off-site disposal. 
This Closure Report (CR) documents the activities performed to close Corrective Action Unit (CAU) 330: Areas 6, 22, and 23 Tanks and Spill Sites, in accordance with the Federal Facility Agreement and Consent Order (FFACO of 1996), and the Nevada Division of Environmental Protection (NDEP)-approved Streamlined Approach for Environmental Restoration (SAFER) Plan for CAU 330: Areas 6, 22, and 23 Tanks and Spill Sites, Nevada Test Site (NTS), Nevada (U.S. Department of Energy, National Nuclear Security Administration Nevada Operation Office [NNSA/NV], 2001). CAU 330 consists of the following four Corrective Action Sites (CASs): 06-02-04, 22-99-06, 23-01-02, and 23-25-05 (Figure 1).

\subsection{PURPOSE}

The purpose of this CR is to document that the closure of CAU 330 complied with all of the closure requirements as stated in the NDEP-approved CAU 330 SAFER Plan (NNSA/NV, 2001). CAU 330 consists of four CASs which are located in Areas 6, 22, and 23 of the NTS. All four CASs were clean closed by removal of all impacted soil, material, concrete, tanks, piping, and a drum.

CAS 06-02-04 included a Underground Storage Tank (UST) and piping located in Area 6 near an area that was part of the Animal Investigation Program (AIP) conducted by the U.S. Public Health Service. The purpose of the AIP was to study and perform tests on the cattle and wild animals on the NTS that were exposed to radionuclides. It is unknown if this tank was part of these operations (NNSA/NV, 2001). The site was clean closed by pumping the liquid and sludge from the UST for disposal, removing the UST and associated piping for disposal, and then backfilling excavations with clean fill to the existing grade.

CAS 22-99-06 was a waste oil release near the T-1001 concrete foundation in Area 22, which occurred when Camp Desert Rock was an active facility (NNSA/NV, 2001). This site was clean closed by excavating and disposing of the Total Petroleum Hydrocarbons (TPH)-impacted soil followed by backfilling the excavation with clean fill to match the existing grade. In addition, general housekeeping debris was removed including wood and scrap metal.

CAS 23-01-02 was a large Aboveground Storage Tank (AST) Farm in Area 23 that was constructed to provide gasoline and diesel storage. The site consisted of two 1,893 cubic meters $\left(\mathrm{m}^{3}\right)(500,000$ gallon [gal]) ASTs (gasoline and diesel), associated piping, fill stand, and a surrounding earthen berm (NNSA/NV, 2001). This site was clean closed by demolishing the two ASTs, associated piping, and fill stand using hydraulic shears. All scrap metal was cut into manageable sized pieces and then recycled by a scrap metal vendor. The soil from the earthen berm was used as clean fill for backfilling the CAS 22-99-06 excavation. The remaining soil from the earthen berm containing small scrap pieces of metal that could not be recycled was hauled to the NTS Area 23 Sanitary Landfill. A small section of the concrete pad that was removed to access a portion of the underground piping was disposed of in the NTS Area 9 U10c Landfill. In addition, six fuel pumps were disconnected from the system and were processed through the excess system as excess material. 


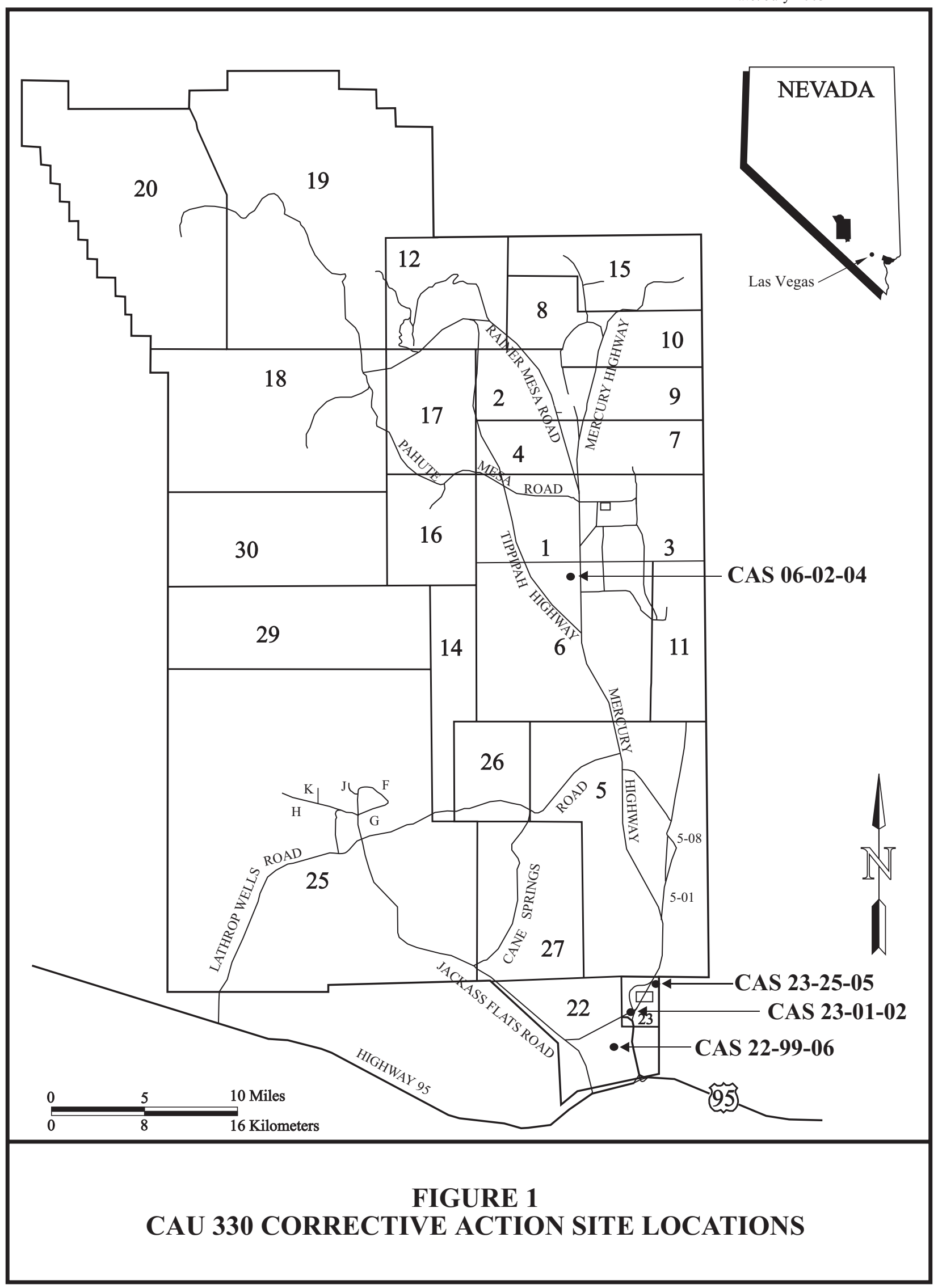


CAS 23-25-05 was an asphalt oil spill/tar release located in a wash behind warehouse row in Area 23 and was believed to be an area where an asphalt plant was in operation or where asphalt oil may was stored in tanks (NNSA/NV, 2001). In addition, a 208 liter (L) (55-gal) drum and large pieces of reinforced concrete were present in the wash. This site was clean closed by excavating the asphalt oil/tar and removing the large pieces of reinforced concrete from the wash. Although typical asphalt oil/tar contains TPH as the predominant contaminant, no Contaminants of Concern (COC) above action levels were identified in the soil directly underneath the spill/release. This was confirmed by past analytical sampling activities performed at the site (NNSA/NV, 2001). The contents of the drum were sampled and identified as being a petroleum hydrocarbon product that exhibited the hazardous characteristic for ignitability (U.S. Environmental Protection Agency [EPA], 2002a). The contents were repackaged, transferred to a Satellite Accumulation Area (SAA), and then transported to the Area 5 Hazardous Storage Pad for off-site disposal. No COC were identified in the area around the drum, confirming that the drum had not leaked to the ground.

\subsection{SCOPE}

The closure strategy for CAU 330 was specified in the NDEP-approved SAFER Plan for CAU 330 (NNSA/NV, 2001). The implemented closure strategy consisted of the following activities.

\section{CAS 06-02-04, UST and Piping}

- $\quad$ Samples of liquid and sludge were collected from the tank to identify any COC. TPH (diesel/oil) was identified in the sludge at levels slightly greater than the Nevada State Action Level of 100 milligrams per kilogram $(\mathrm{mg} / \mathrm{kg})$. The liquid contained no other COC above action levels.

- $\quad$ The liquid and sludge were pumped from the tank and disposed of in the NTS Area 23 Sewage Lagoon.

- $\quad$ The tank and associated piping were excavated. The tank was disposed of in the NTS Area 9 U10c Sanitary Landfill and the piping was disposed of in the NTS Area 6 Hydrocarbon Landfill.

- Samples were collected from the excavated soil, underneath the tank, and from each end of the tank to verify that the tank had not leaked into the surrounding soil. The excavated soil was used as clean fill for backfilling, as well as some additional clean fill from a borrow pit.

- $\quad$ The piping was removed from the excavation using a back-hoe. No staining was identified during the excavation activities.

- $\quad$ Soil samples were collected from underneath the piping at two different pipe joints to verify that the surrounding soil was free of COC.

- $\quad$ The pipe excavation was backfilled with clean fill to match the existing grade. 


\section{CAS 22-99-06, Fuel Spill}

- The TPH-impacted soil was excavated and disposed of in the NTS Area 6 Hydrocarbon Landfill.

- $\quad$ Soil samples were collected from the excavation to verify that clean up levels were met. As a result, TPH was not present in the soil at levels greater than the Nevada State Action Level of $100 \mathrm{mg} / \mathrm{kg}$.

- The excavation was backfilled with clean fill transported from the CAS 23-01-02 earthen berm and then graded to the approximate surrounding topography.

\section{CAS 23-01-02, Large AST Farm}

- The man-ways on the tanks were opened to verify that both ASTs were empty and clean. In addition, various spool covers and valve covers were opened on the associated piping to determine if any residual liquid remained in the piping.

- The two ASTs, fill stand, and associated piping were demolished using hydraulic shears.

- $\quad$ The scrap metal was cut into manageable sized pieces and recycled by a scrap metal vendor.

- The remaining smaller pieces of scrap metal that were mixed in the dirt from the earthen berm were transported to the NTS Area 23 Sanitary Landfill.

- The section of the concrete pad that was removed to access the underground piping was disposed of in the NTS Area 9 U10c Landfill.

- $\quad$ Samples were collected from underneath the asphalt pads to verify that fuel had not leaked from either AST. TPH was not present in the soils underneath the asphalt pads at levels greater than the Nevada State Action Level of $100 \mathrm{mg} / \mathrm{kg}$.

- The site was graded to match the surrounding topography.

\section{CAS 23-25-05, Asphalt Oil Spill/Tar Release}

- The asphalt oil/tar material was removed from the wash and disposed of in the NTS Area 6 Hydrocarbon Landfill.

- The large pieces of reinforced concrete were removed from the wash and disposed of in the NTS Area 9 U10c Sanitary Landfill.

- $\quad$ Samples were collected from the contents of the 208-L (55-gal) drum to characterize for disposal purposes. The contents were transferred to a container with no rust, stored in an SAA, and subsequently transported to the Area 5 Hazardous Storage Pad for off-site disposal. 
- $\quad$ Soil samples were collected from around the drum to verify that the soil had not been contaminated by leaks or spills from the drum. Analytical results verified that the soil was clear of any COC.

\subsection{CLOSURE REPORT CONTENTS}

This CR is divided into the following sections:

- Section 1.0 - Introduction

- $\quad$ Section 2.0 - Closure Activities

- $\quad$ Section 3.0 - Waste Disposition

- Section 4.0 - Closure Verification Results

- $\quad$ Section 5.0 - Conclusions and Recommendations

- $\quad$ Section 6.0 - References

- $\quad$ Appendix A - Data Quality Objectives (DQOs) for CAU 330

- $\quad$ Appendix B - Verification Sample Analytical Results

- Appendix C - Hazardous Waste Disposition Documentation

- $\quad$ Appendix D - Field Photographs

- Appendix E - Closure Certification

- $\quad$ Appendix F - As-Built Documentation

- $\quad$ Appendix G - Modifications to the Post-Closure Plan

- $\quad$ Appendix H - Nevada Environmental Restoration Project Document Review Sheet

- Distribution List

The following standard appendices are included in this CR per the FFACO CR outline but do not contain any material because they do not apply to closure of CAU 330:

- $\quad$ Closure Certification - Not applicable.

- As-Built Documentation - Not applicable, no engineered structures were constructed.

- Modifications to the Post-Closure Plan - Not Applicable. CAU 330 was clean closed; no post-closure monitoring is required. 
This report was developed using information and guidance from the following documents:

- $\quad$ Streamlined Approach for Environmental Restoration Plan for Corrective Action Unit 330: Areas 6, 22, and 23 Tanks and Spill Sites, Nevada Test Site, Nevada (NNSA/NV, 2001).

- $\quad$ Nevada Environmental Restoration Project, Industrial Sites Quality Assurance Project Plan, Nevada Test Site, Nevada (NNSA/NV, 2002).

\subsubsection{Data Quality Objectives}

The DQOs used for closure of CAU 330 were presented in Appendix A of the CAU 330 SAFER Plan (NNSA/NV, 2001) and are included as Appendix A of this report.

The general conceptual site models (CSM) as presented in the SAFER Plan (NNSA/NV, 2001) was applied to all the CASs in CAU 330 and assumed that any additional contamination was the result of both designed and accidental releases. The potential contamination would be restricted to those areas immediately beneath and/or adjacent to the system components (i.e., UST or AST). The extent of the potential contamination was dependent upon such variables as release volume, system design, geologic conditions, and nature of contaminants.

CAU 330 characterization activities determined that actual site conditions were in agreement with the CSM with the exception of CAS 23-01-02. No diesel spill was identified near the location of the diesel AST. This information is presented in the SAFER Plan (NNSA/NV, 2001).

Details of the DQO assessment are included in Section 4.1 of this report. 


\subsection{CLOSURE ACTIVITIES}

This section details the specific corrective action activities completed during the closure of CAU 330: Areas 6, 22, and 23 Tanks and Spill Sites. Copies of the analytical data for all collected soil samples are included in Appendix B.

\subsection{DESCRIPTION OF CORRECTIVE ACTION ACTIVITIES}

\subsubsection{Preplanning and Site Preparation}

Closure of CAU 330 was completed using the NDEP-approved SAFER Plan (NNSA/NV, 2001). Prior to beginning closure activities, the following pre-field activities were completed:

- $\quad$ Preparation of National Environmental Policy Act documentation (checklist).

- $\quad$ Preparation of the Field Management Plan for Corrective Action Unit 330: Areas 6, 22, and 23 Tanks and Spill Sites, Nevada Test Site, Nevada, (Bechtel Nevada [BN], 2002a).

- $\quad$ Preparation of the Site-Specific Health and Safety Plan for Corrective Action Unit 330: Areas 6, 22, and 23 Tanks and Spill Sites, Nevada Test Site, (BN, 2002b).

- $\quad$ Preparation of the U.S. Department of Energy, National Nuclear Security Administration Nevada Operations Office (NNSA/NV) Real Estate/Operations Permit.

- $\quad$ Preparation of a BN Excavation and Penetration Permit.

The following is the scope of the closure actions implemented for CAU 330.

\subsubsection{CAS 06-02-04: UST and Piping}

During site characterization activities conducted in 1994 by Reynolds Electrical and Engineering Company, Incorporated, one sample was collected of the liquid in the tank and analyzed for TPH, Toxicity Characteristic Leaching procedure (TCLP) Volatile Organic Compounds (VOCs), TCLP Semi-Volatile Organic Compounds (SVOCs), TCLP Resource Conservation and Recovery Act (RCRA) metals, $\mathrm{pH}$, chlorinated compounds using a Clor-d-tect kit, gamma spectroscopy, plutonium 238/239, and tritium. All analytical results were below action levels for the liquid (NNSA/NV, 2001).

In December 2002, additional characterization samples were collected from the liquid and no COC were detected in the liquid. These samples (060204-T1, 060204-T2, and 060204-T) were analyzed for TPH, TCLP VOCs, TCLP SVOCs, TCLP RCRA metals, Polychlorinated Biphenyls (PCBs), gamma emitters, tritium, and gross alpha/beta emitters. The liquid sample results provided in Table 1 show that all analytical results were below action levels. 

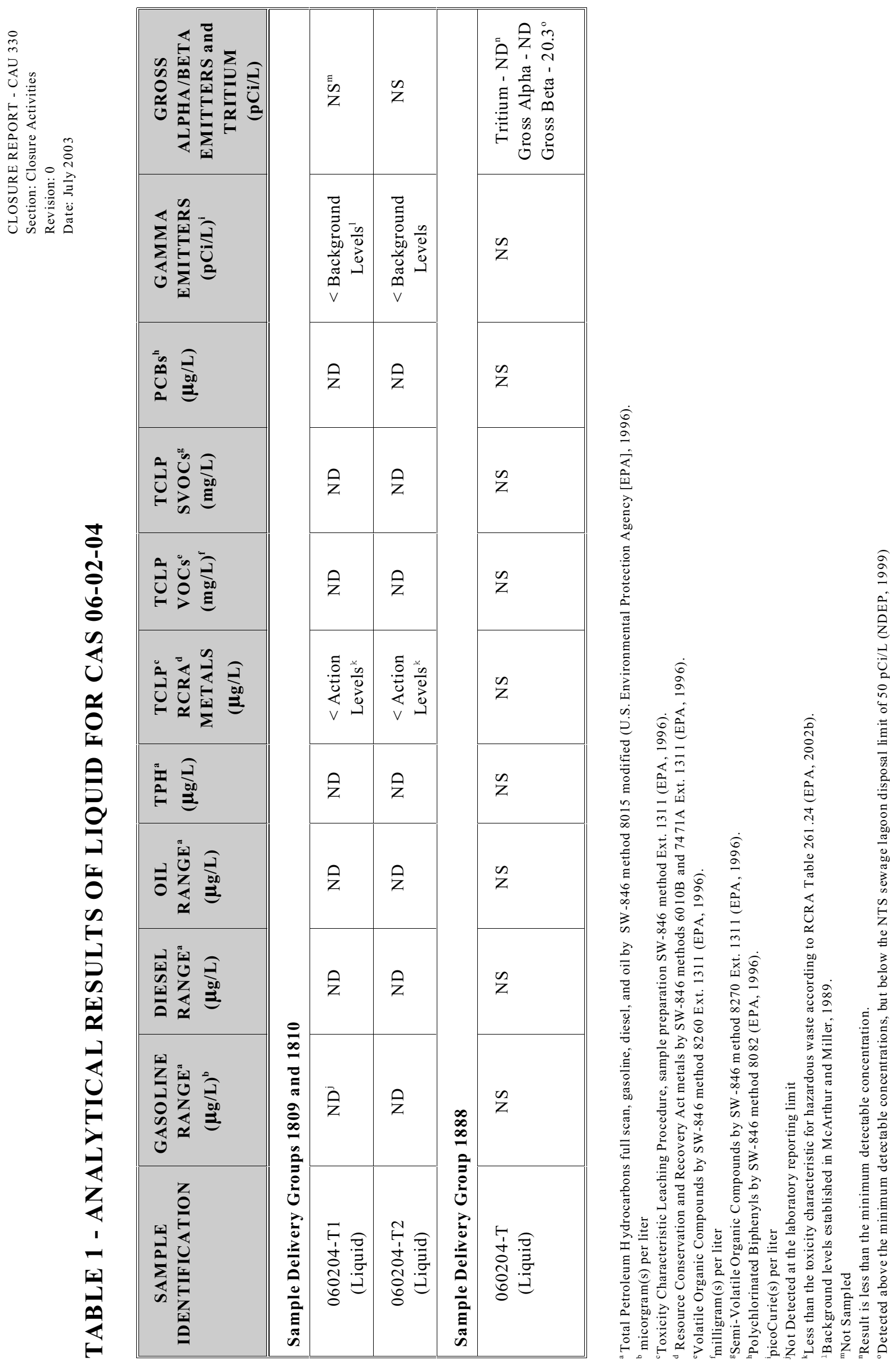
In February 2003 the top of the tank was excavated to determine the structure and the dimensions of the tank and to locate access ports. The top of the tank was found to be metal, cylindrical in shape with two small ports measuring approximately 12.7 centimeters $(\mathrm{cm})$ (5 inches [in]) in diameter protruding from the top of the tank. The tank dimensions were approximately 8.8 meters $(\mathrm{m})$ (29 feet [ft]) in length with a diameter of $0.9 \mathrm{~m}(3 \mathrm{ft})$. One of the ports had a pipe connected to the top of the tank that protruded above the ground surface. The second port was identified once the top of the tank was exposed and was determined to be an inlet pipe from Building 660.

In March 2003, the top portion of the liquid was pumped from the tank and disposed of in the NTS Area 23 Sewage Lagoon. Approximately 4,000 L (1,056.7 gal) of the liquid was pumped from the tank (top two-thirds). This was done to reduce the potential of a liquid release when cutting the tank to determine if any sludge was present. A small hole was cut in the top of the tank measuring 0.6 by $0.3 \mathrm{~m}(2$ by $1 \mathrm{ft})$. The hole was used to inspect the inside of the tank. A 2.5 to $5 \mathrm{~cm}$ ( 1 to $2 \mathrm{in})$ thick layer of sludge was identified at the bottom of the tank. Two sludge samples (060204-T3 and 060204-T4) were collected and analyzed for TPH, TCLP VOCs, TCLP SVOCs, TCLP RCRA metals, PCBs, gamma emitters, tritium, and gross alpha/beta emitters. The sample locations are shown in Figure 2. Both sample results provided in Table 2 indicate that TPH (diese1/oil) in the sludge was slightly greater than the Nevada State Action Level of $100 \mathrm{mg} / \mathrm{kg}$. The TPH level for samples $060204-\mathrm{T} 3$ and $060204-\mathrm{T} 4$ were $191 \mathrm{mg} / \mathrm{kg}$ and $156 \mathrm{mg} / \mathrm{kg}$. All other analytical results were below action levels.

In April 2003, the remaining liquid (bottom one-third) and the sludge were pumped from the tank and disposed of in the NTS Area 23 Sewage Lagoon. The amount of liquid and sludge removed was approximately 2,000 L (528.3 gal) making the total liquid and sludge pumped from the tank at approximate 6,000 L (1,585 gal). The piping was constructed of vitrified clay and was excavated and disposed of in the NTS Area 6 Hydrocarbon Landfill. While the piping was being excavated, it was determined to be connected to a drain that had been previously grouted closed inside of Building 660. No staining or odors were identified in the soil surrounding the piping during excavation. The soil samples (060204-P1 [060204-P0-duplicate] and 060204-P2) were collected from beneath the pipeline at approximately 1 and $0.6 \mathrm{~m} \mathrm{(3} \mathrm{and} 2 \mathrm{ft})$ below ground surface (bgs). The samples were collected from soil taken by backhoe bucket from two different pipe joint locations to verify that there was no TPH contamination in the surrounding soil. The sample locations are shown in Figure 2. The two soil sample results provided in Table 3 show that TPH (diesel/oil) was below laboratory detection limits.

The soil surrounding the tank was stockpiled and two grab samples (060204-T5 and 060204-T6) were collected by hand from the stockpiles (Figure 2). The samples were analyzed for TPH, VOCs, SVOCs, RCRA metals, PCBs, and gamma emitters. The sample results provided in Table 4 show that TPH was below detection limits. All other analyses were below action levels. The empty tank was removed and disposed of in the NTS Area 9 U10c Sanitary Landfill, the excavation was backfilled, and the site was graded to match the existing topography.

Soil samples (060204-T7 and 060204-T8) were collected under each end of the tank (directly below the two original openings) and were field screened for TPH using a PetroFlag ${ }^{\circledR}$ test kit. The samples were collected from soil taken by backhoe bucket from approximately $3 \mathrm{~m}$ (10 ft) bgs and were submitted to an offsite laboratory and analyzed for TPH, VOCs, SVOCs, RCRA metals, PCBs, and gamma emitters (Figure 2). The sample results provided in Table 4 show that 


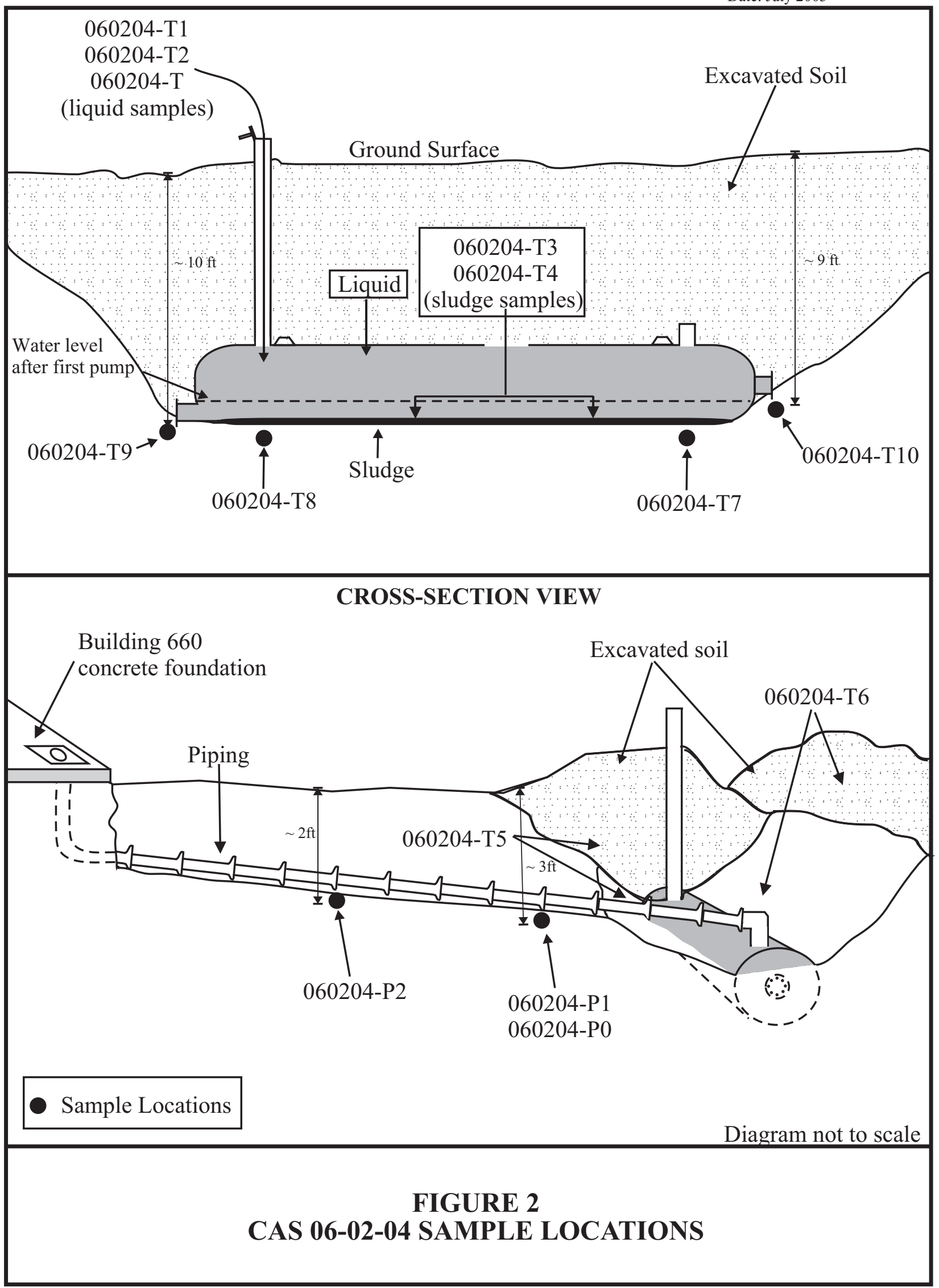



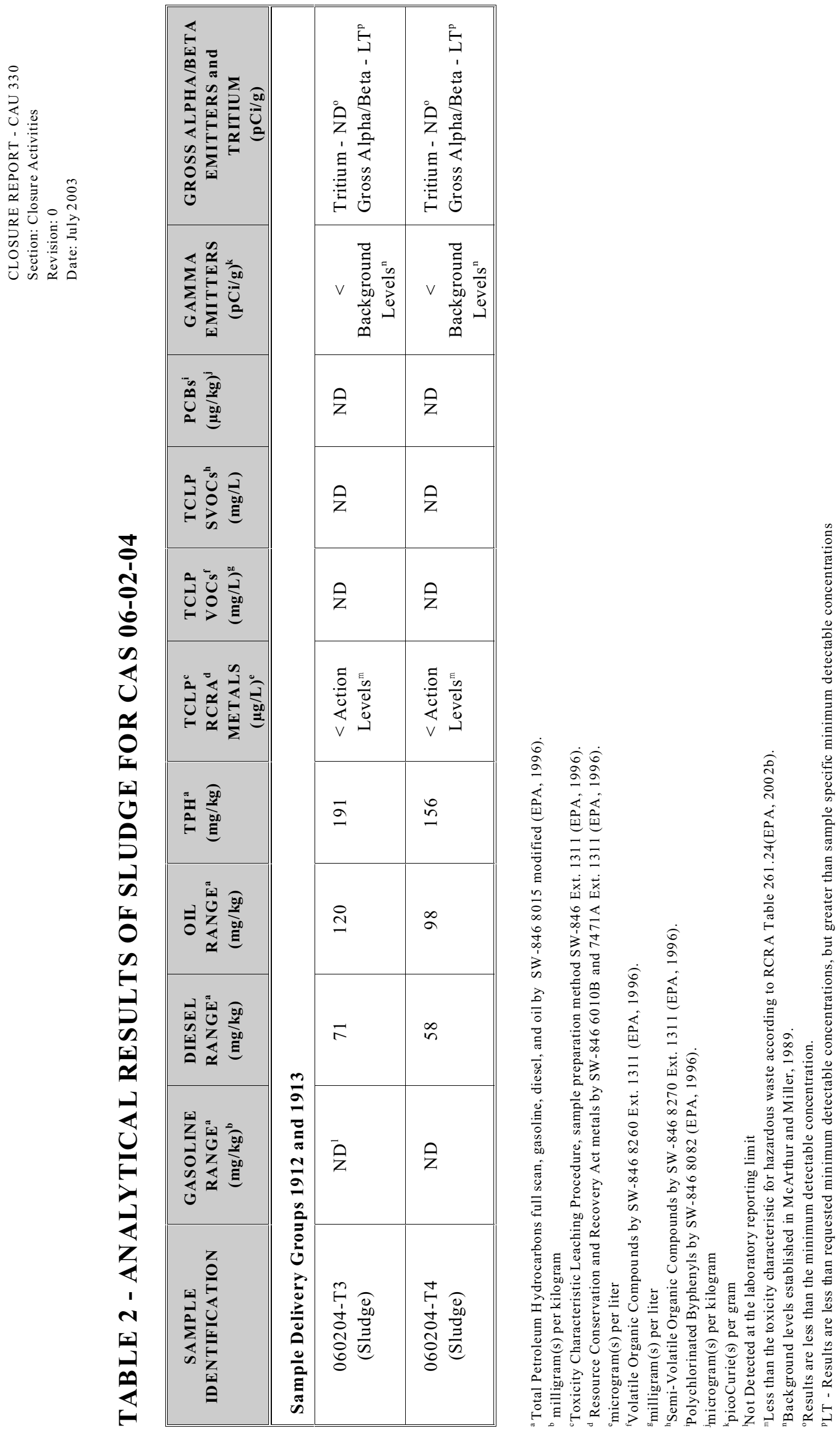


\section{TABLE 3 - ANALYTICAL RESULTS OF SOIL FOR CAS 06-02-04 (Soil Underneath Piping)}

\begin{tabular}{|c|c|c|c|c|}
\hline $\begin{array}{c}\text { SAMPLE } \\
\text { IDENTIFICATION }\end{array}$ & $\begin{array}{c}\text { GASOLINE } \\
\text { RANGE } \\
\left(\mathrm{mg} / \mathbf{k g}^{\mathrm{b}}\right. \\
\end{array}$ & $\begin{array}{r}\text { DIESEL } \\
\text { RANGE }^{\mathrm{a}} \\
(\mathrm{mg} / \mathrm{kg}) \\
\end{array}$ & $\begin{array}{c}\text { OIL } \\
\text { RANGE }^{\mathrm{a}} \\
(\mathrm{mg} / \mathrm{kg}) \\
\end{array}$ & $\begin{array}{c}\mathrm{TPH}^{\mathrm{a}} \\
(\mathrm{mg} / \mathrm{kg})\end{array}$ \\
\hline \multicolumn{5}{|c|}{ Sample Delivery Group 1958} \\
\hline 060204-P1 & $\mathrm{NS}^{\mathrm{c}}$ & $\mathrm{ND}^{d}$ & ND & ND \\
\hline $\begin{array}{c}\text { 060204-P0 } \\
\text { (Duplicate of 060204-P1) }\end{array}$ & NS & ND & ND & ND \\
\hline 060204-P2 & NS & ND & ND & ND \\
\hline
\end{tabular}

${ }^{\mathrm{a}}$ Total Petroleum Hydrocarbons full scan, gasoline, diesel, and oil by method SW-846 8015 modified (EPA, 1996).

${ }^{\mathrm{b}}$ milligram(s) per kilogram

${ }^{\mathrm{c}}$ Not Sampled

${ }^{\mathrm{d}}$ Not Detected at the laboratory reporting limit

TPH was below detection limits. All other analytical results were below action levels. After the tank was removed from the excavation, additional openings were found that had been previously closed off with metal plates. The plates were bolted to the tank and had rubber gaskets to seal the connection. Additional soil samples (060204-T9 and 060204-T10) were collected from underneath the openings at approximately 2.7 and $2.4 \mathrm{~m}$ ( 9 and $8 \mathrm{ft}$ ) bgs, and field screened for TPH using a PetroFlag ${ }^{\circledR}$ test kit to determine if the openings had leaked (Figure 2). The samples were submitted to an offsite laboratory and analyzed for TPH. The sample results provided in Table 4 show that TPH concentrations for both samples were below detection limits.

In June 2003, the tank and piping excavations were backfilled with clean fill material and the site was then graded to the surrounding topography

\subsubsection{CAS 22-99-06: Fuel Spill}

During a site visit in 1996, samples were collected by Shaw Environmental Incorporated (formerly International Technologies Corporation [IT]) and TPH (oil) and lead were identified as being Contaminants of Potential Concern (COPC) (NNSA/NV, 2001). In addition, general housekeeping debris was identified and included wood and scrap metal.

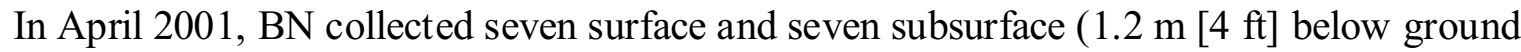
surface) soil samples. The soil samples were analyzed for TPH. TPH (oil) was identified in the surface soil at five of the seven locations at levels greater than the Nevada State Action Level of $100 \mathrm{mg} / \mathrm{kg}$. TPH results for the seven subsurface samples were below detection limits (NNSA/NV, 2001).

In October 2002, BN collected two soil samples (330L-0-1 and 330L-0-2), including one duplicate (330L-0-0) from the locations previously sampled by IT and analyzed for TCLP-lead. The results provided in Table 5 show that the soil is not a hazardous waste for lead. 

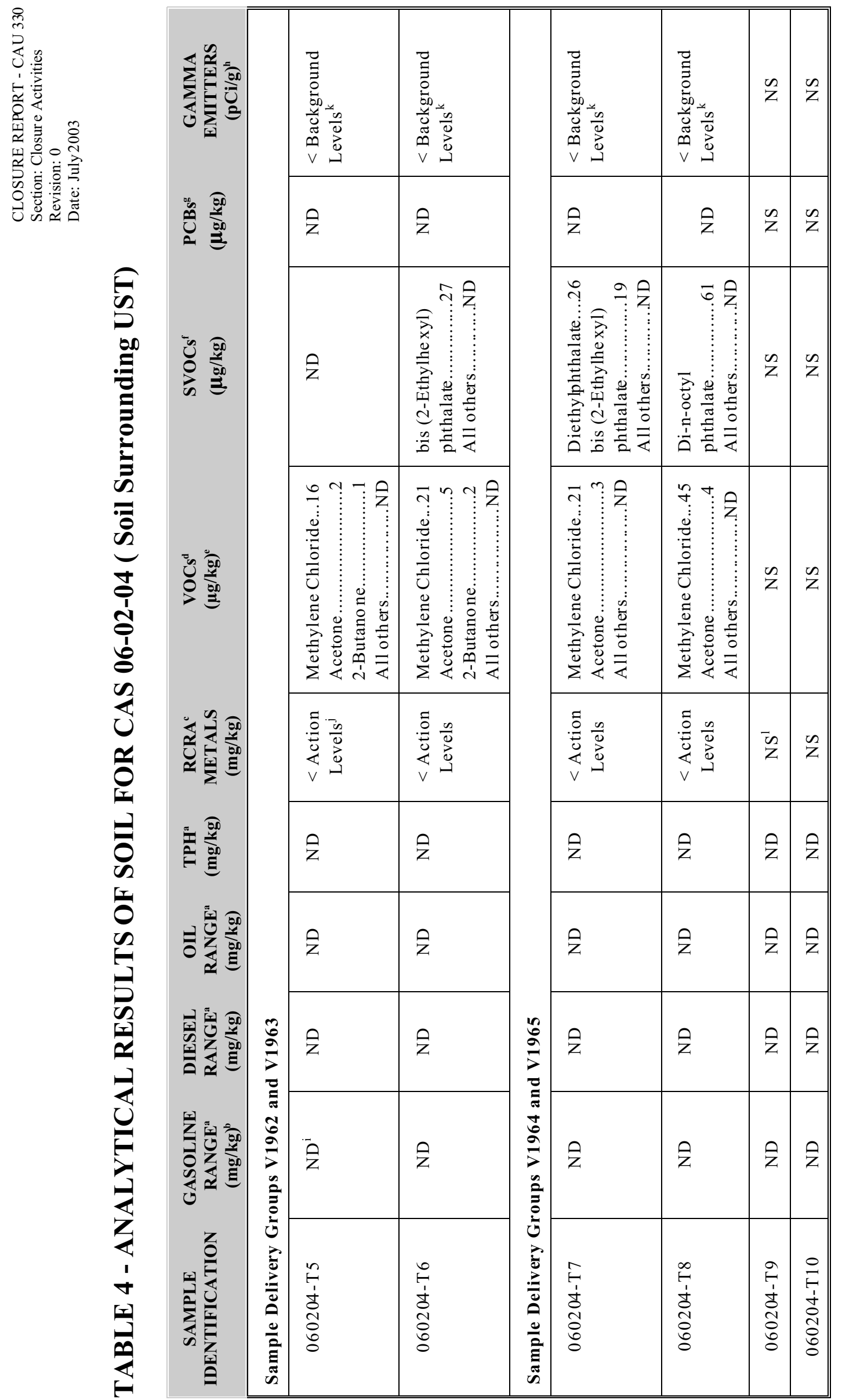

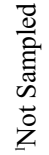

$\dot{0} \quad \dot{0} \quad n$

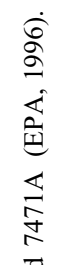


In March 2003 the site was clean closed by excavating and disposing of TPH-impacted soil following the NDEP-approved SAFER Plan (NNSA/NV, 2001). Approximately $49.7 \mathrm{~m}^{3}$ (65 cubic yards $\left[\mathrm{yd}^{3}\right]$ ) of TPH-impacted soil was excavated from the site and disposed of at the NTS Area 6 Hydrocarbon Landfill. Sixteen soil samples were collected by hand from the bottom of the excavation at approximately $1 \mathrm{~m}(3 \mathrm{ft})$ bgs. The sample locations are shown in Figure 3. The samples were field screened for TPH using a PetroFlag ${ }^{\circledR}$ test kit and then submitted to an offsite laboratory for TPH oil analysis. The sample results provided in Table 5 show that TPH (oil) was not present in the soil at levels greater than the Nevada State Action Level of $100 \mathrm{mg} / \mathrm{kg}$. In addition, as a best management practice, all housekeeping debris was removed from the site and disposed of as sanitary waste.

In April 2003 the excavation was backfilled with clean fill and graded to the surrounding topography.

\subsubsection{CAS 23-01-02: Large AST Farm}

CAS 23-01-02 consisted of two large 1,893 $\mathrm{m}^{3}$ (500,000 gal) ASTs, a fill stand, associated piping, and surrounding earthen berm. In February and March of 2003, the site was clean closed by using hydraulic shears to demolish both tanks, the fill stand, and associated piping. In addition, soil samples were collected around and underneath both asphalt pads that the tanks sat on prior to removal. The metal from the demolition activities was recycled by a scrap metal vendor. The remaining earthen berm containing the smaller pieces of scrap metal was disposed of in the NTS Area 23 Sanitary Landfill. The earthen berm was used as fill material in the landfill. Some additional earthen berm material was hauled to CAS 22-99-06 and used as clean fill for the excavation. Three separate phases were undertaken to complete the clean closure of CAS 23-01-02: pre-demolition, demolition/removal, and post-demolition activities.

\subsubsection{Pre-demolition Activities}

In January 2003, drain valves, access ports to both tanks, and check valve covers were opened to inspect the system. This information was critical to plan for required safety precautions during the dismantlement of the system. Both tanks and the majority of the piping were found to be clean, with the exception of a small section of the diesel piping that was located underneath the concrete pad.

\subsubsection{Demolition Activities}

In February and March 2003, both tanks, the fill stand, and associated piping were demolished/removed using hydraulic shears and the metal was cut into manageable sized pieces. Prior to demolishing the fill stand, a small portion of gasoline and diesel piping, which was located underneath a concrete pad was removed. This was accomplished by removing a section of the concrete pad to expose the piping using heavy equipment. The gasoline pipe was found to be clean and dry, while the diesel portion contained approximately $68.1 \mathrm{~L}$ (18 gal) of diesel/soapy water mixture resulting from past cleaning efforts. The liquid was pumped into a 208-L (55-gal) drum. The liquid was then solidified using soil and vermiculite and transported to the NTS Area 6 Hydrocarbon Landfill for disposal. In addition, six fuel pumps were disconnected and set aside to be processed through the excess system. 


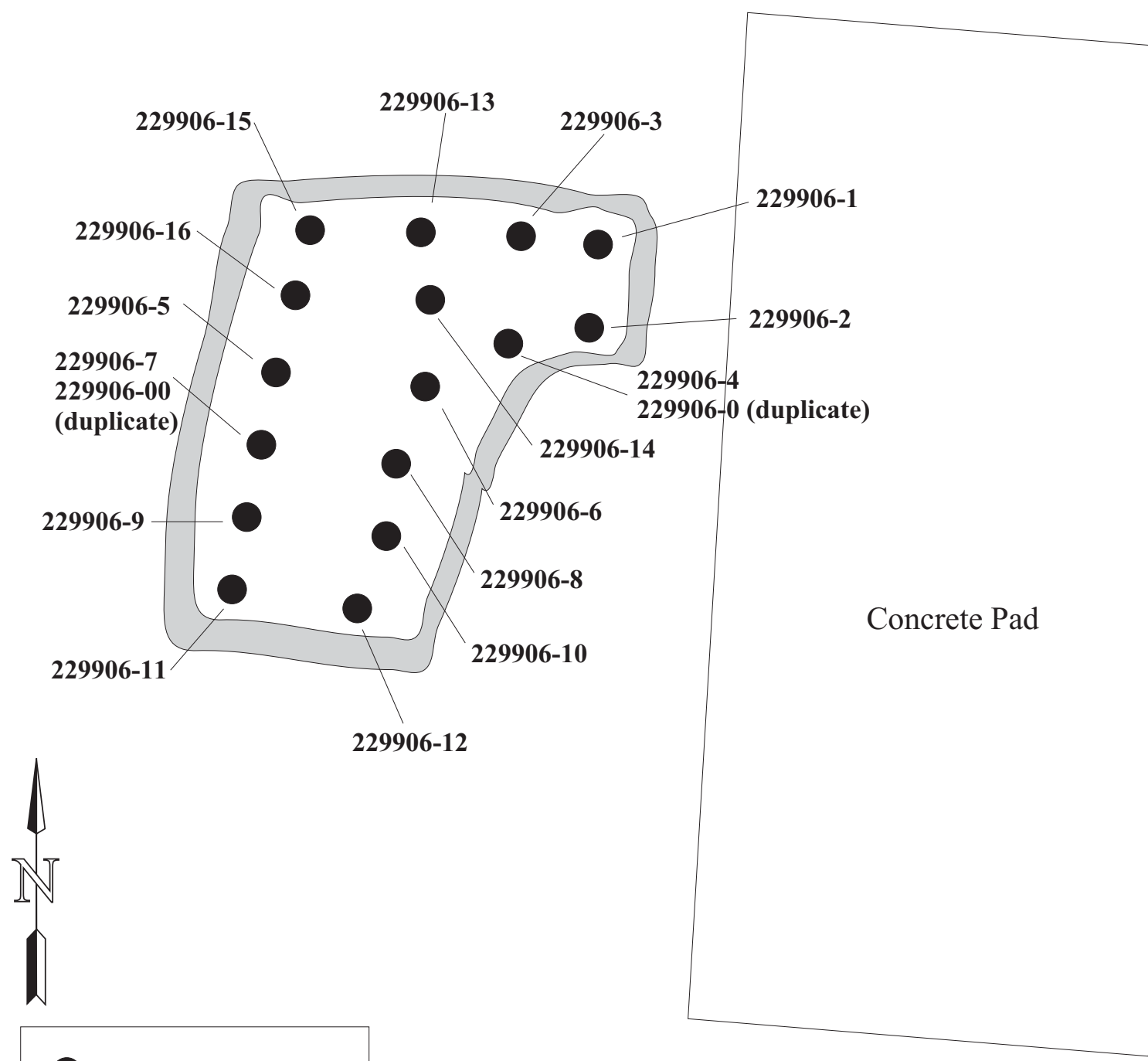

Sample Locations

FIGURE 3

CAS 22-99-06 SAMPLE LOCATIONS 
TABLE 5 - ANALYTICAL RESULTS FOR CAS 22-99-06

\begin{tabular}{|c|c|}
\hline $\begin{array}{c}\text { SAMPLE } \\
\text { IDENTIFICATION }\end{array}$ & $\begin{array}{c}\text { TPH } \\
\text { OIL RANGE } \\
(\mathbf{m g} / \mathbf{k g})^{\mathbf{b}}\end{array}$ \\
\hline \multicolumn{2}{|c|}{ Sample Delivery Group V1916 } \\
\hline 229906-1 & $\mathrm{ND}^{\mathrm{c}}$ \\
\hline $229906-2$ & ND \\
\hline $229906-3$ & ND \\
\hline $229906-4$ & 14 \\
\hline $\begin{array}{c}229906-0 \\
\text { (duplicate of 229906-4) }\end{array}$ & ND \\
\hline $229906-5$ & ND \\
\hline $229906-6$ & ND \\
\hline $229906-7$ & ND \\
\hline $\begin{array}{c}229906-00 \\
\text { (duplicate of 229906-7) }\end{array}$ & 16 \\
\hline $229906-8$ & 16 \\
\hline $229906-9$ & ND \\
\hline 229906-10 & ND \\
\hline $229906-11$ & 13 \\
\hline $229906-12$ & ND \\
\hline $229906-13$ & ND \\
\hline 229906-14 & ND \\
\hline $229906-15$ & ND \\
\hline 229906-16 & 18 \\
\hline
\end{tabular}

\begin{tabular}{|c|c|}
\hline $\begin{array}{c}\text { SAMPLE } \\
\text { IDENTIFICATION }\end{array}$ & $\begin{array}{c}\text { TCLPa }{ }^{\mathbf{a}} \text { LEAD } \\
(\mathbf{m g} / \mathbf{L})^{\mathbf{b}}\end{array}$ \\
\hline \multicolumn{2}{|c|}{ Sample Delivery Group V1755 } \\
\hline 330L-0-1 & 0.77 \\
\hline 330L-0-0* & 1.2 \\
\hline 330L-0-2 & 0.62 \\
\hline
\end{tabular}

${ }^{a}$ Toxicity Characteristic Leaching Procedure, sample preparation method SW-846 Ext. 1311 (EPA, 1996).

${ }^{\mathrm{b}}$ milligram(s) per liter

*Dup licate sample of 330 L-0 - 1

${ }^{\mathrm{a}}$ Total Petroleum Hydrocarbons - oil range by SW-846 method 8015 modified (EPA, 1996).

${ }^{\mathrm{b}}$ milligram(s) per kilogram

${ }^{c}$ Not Detected at the laboratory reporting limit 


\subsubsection{Post-demolition Activities}

CLOSURE REPORT - CAU 330

Section: Closure Activities

Revision: 0

Date: July 2003

In March 2003 soil samples were collected at approximately $0.3 \mathrm{~m}$ (1 ft) below both asphalt pads (approximately $0.45 \mathrm{~m}[1.5 \mathrm{ft}] \mathrm{bgs}$ ) to verify that no leaks had occurred from the tanks. Six soil samples (230102-1 through 230102-6) were collected underneath the diesel AST asphalt pad and one additional biased (grab) soil sample (230102-7) was collected at the outside edge of the concrete ring where a minor leak was reported to have occurred sometime in the past (Figure 4). All samples were collected using a Geoprobe ${ }^{\circledR}$ direct push apparatus. The samples were field screened for TPH using a PetroFlag ${ }^{\circledR}$ test kit and then submitted to an offsite laboratory for TPH diesel analysis. The sample results provided in Table 6 show that TPH (diesel) was not present in the soil at levels greater than the Nevada State Action Level of $100 \mathrm{mg} / \mathrm{kg}$. In addition, three soil samples (230102-1G through 230102-3G) were collected from underneath the gasoline AST asphalt pad at approximately $0.3 \mathrm{~m}$ (1 ft) bgs to verify that no leaks had occurred from the tank. The sample locations are shown in Figure 4. The samples were field screened for TPH using a PetroFlag ${ }^{\circledR}$ test kit and then submitted to an offsite laboratory for TPH (gasoline) analysis. The sample results provided in Table 6 show that TPH (gasoline) was not present in the soil at levels greater than the Nevada State Action Level of $100 \mathrm{mg} / \mathrm{kg}$.

The scrap metal was moved into piles at the southern end of the site and was transported off-site by a metal recycler. The total amount of scrap metal recycled equated to approximately $306 \mathrm{~m}^{3}\left(400 \mathrm{yd}^{3}\right)$. The remaining soil from the earthen berm that contained small pieces of scrap metal was transported to the NTS Area 23 Sanitary Landfill for disposal. Approximately $27.5 \mathrm{~m}^{3}\left(36 \mathrm{yd}^{3}\right)$ of concrete removed from the concrete pad was transported to the NTS Area 9 U10c Landfill for disposal. The six fuel pumps were disconnected from the system and were processed through the excess system as excess material.

\subsubsection{CAS 23-25-05: Asphalt Oil Spill/Tar Release}

During the site sampling activities conducted by IT in 1997, two soil samples were collected from the soil underneath the asphalt oil spill/tar release and were analyzed for TPH, VOCs, SVOCs, RCRA metals, PCBs, gamma emitters, and gross alpha/beta emitters. All analytical results were below action levels (NNSA/NV, 2001). In addition to the spill, a 208-L (55-gal) drum was present in the wash, partially buried in a dirt mound.

In December 2002, during sampling activities, it was apparent that the contents of the 208-L (55-gal) drum had separated into two distinct layers, a whitish liquid with a viscosity similar to water at the bottom and a thick black tar-like material with a viscosity similar to syrup at the top. Samples (232505-1 and 232505-2) were collected from each layer using a coliwasa and both samples were analyzed for TPH, TCLP VOCs, TCLP SVOCs, TCLP RCRA metals, PCBs, gamma emitters, and flash point. The sample locations are shown in Figure 5. The sample results provided in Table 7 show that TPH was present in both samples and the top layer exhibited a hazardous characteristic for ignitability (EPA, 2002a). All other analytical results were below RCRA hazardous waste levels.

In January 2003, the contents inside of the 208-L (55-ga)1 drum were transferred to a new 208-L (55-gal) drum that was set up as an SAA. The new drum was then moved out of the wash and onto level ground. After the drum was removed from the wash, two soil samples (232505-3 and 

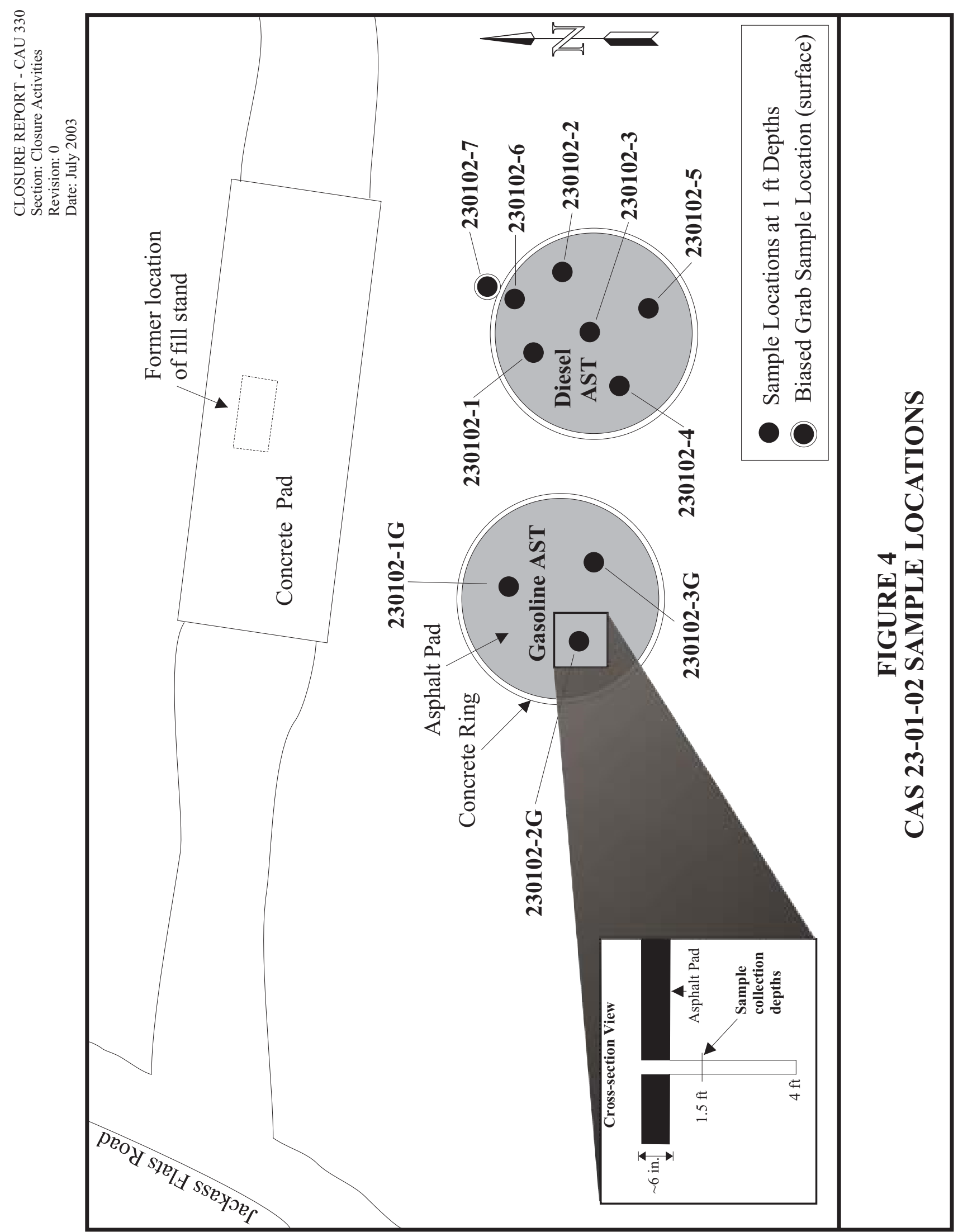
TABLE 6 - ANALYTICAL RESULTS FOR CAS 23-01-02

\begin{tabular}{|c|c|c|}
\hline $\begin{array}{c}\text { SAMPLE } \\
\text { IDENTIFICATION }\end{array}$ & $\begin{array}{c}\text { TPH - DIESEL RANGE } \\
(\mathbf{m g} / \mathbf{k g})^{\mathbf{b}}\end{array}$ & $\begin{array}{c}\text { TPH - GASOLINE RANGE } \\
(\mathbf{m g} / \mathbf{k g})\end{array}$ \\
\hline \hline \multicolumn{3}{|c|}{ Diesel AST $^{\mathbf{2}}$} \\
\hline Sample Delivery Group V1926 & ND $^{\mathrm{c}}$ & NS $^{\mathrm{d}}$ \\
\hline $230102-1$ & ND & NS \\
\hline $230102-2$ & ND & NS \\
\hline $230102-3$ & ND & NS \\
\hline $230102-4$ & ND & NS \\
\hline $230102-5$ & 17 & NS \\
\hline $230102-6$ & ND & NS \\
\hline $230102-7$ & Gasoline AST & ND \\
\hline $230102-1 G$ & NS & ND \\
\hline $230102-2 G$ & NS & ND \\
\hline $230102-3 G$ & NS & \\
\hline
\end{tabular}

${ }^{a}$ Total Petroleum Hydrocarbons - diesel/gasoline ranges by SW-846 method 8015 modified (EPA, 1996).

${ }^{b}$ milligrams(s) per kilogram

${ }^{c}$ Not Detected at the laboratory reporting limit

${ }^{\mathrm{d}}$ Not Sampled

232505-4) were collected by hand from the soil directly beneath the former drum location. The samples were analyzed for TPH, VOCs, SVOCs, RCRA metals, PCBs, and gamma emitters. The sample locations are shown in Figure 5. The soil sample results provided in Table 8 show that TPH was not present in the soil at levels greater than the Nevada State Action Level of 100 $\mathrm{mg} / \mathrm{kg}$. All other analytical results were below action levels.

In March 2003, approximately $523.7 \mathrm{~m}^{3}\left(685 \mathrm{yd}^{3}\right)$ of asphalt oil/tar were excavated from the wash and disposed of in the NTS Area 6 Hydrocarbon Landfill. Approximately $224 \mathrm{~m}^{3}$ $\left(293 \mathrm{yd}^{3}\right)$ of reinforced concrete was removed from the wash and disposed of in the NTS Area 9 U10c Landfill. The 55-gal drum in the SAA was transported to the Area 5 Hazardous Waste Storage Pad for off-site disposal. 

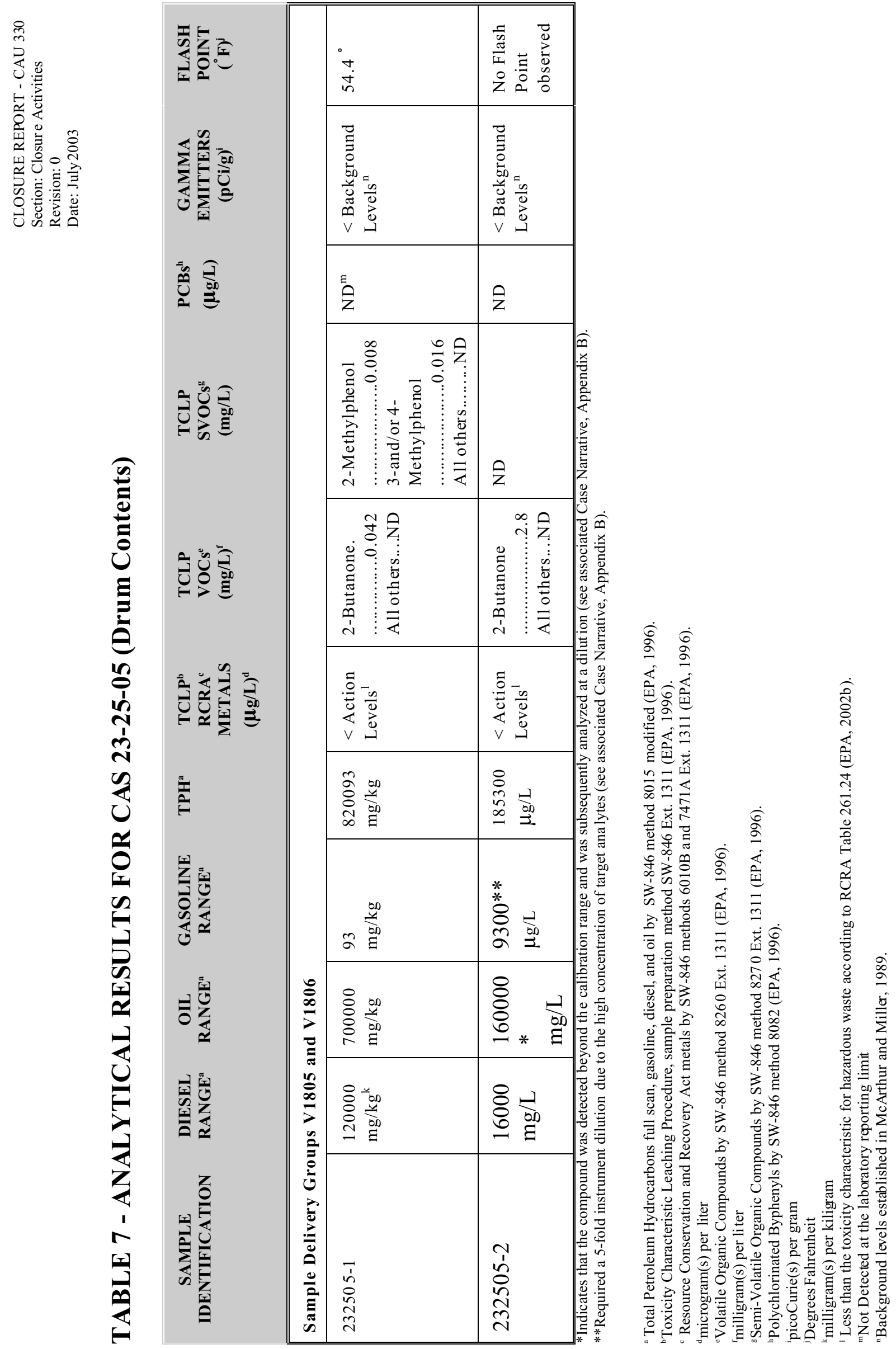

ำ 


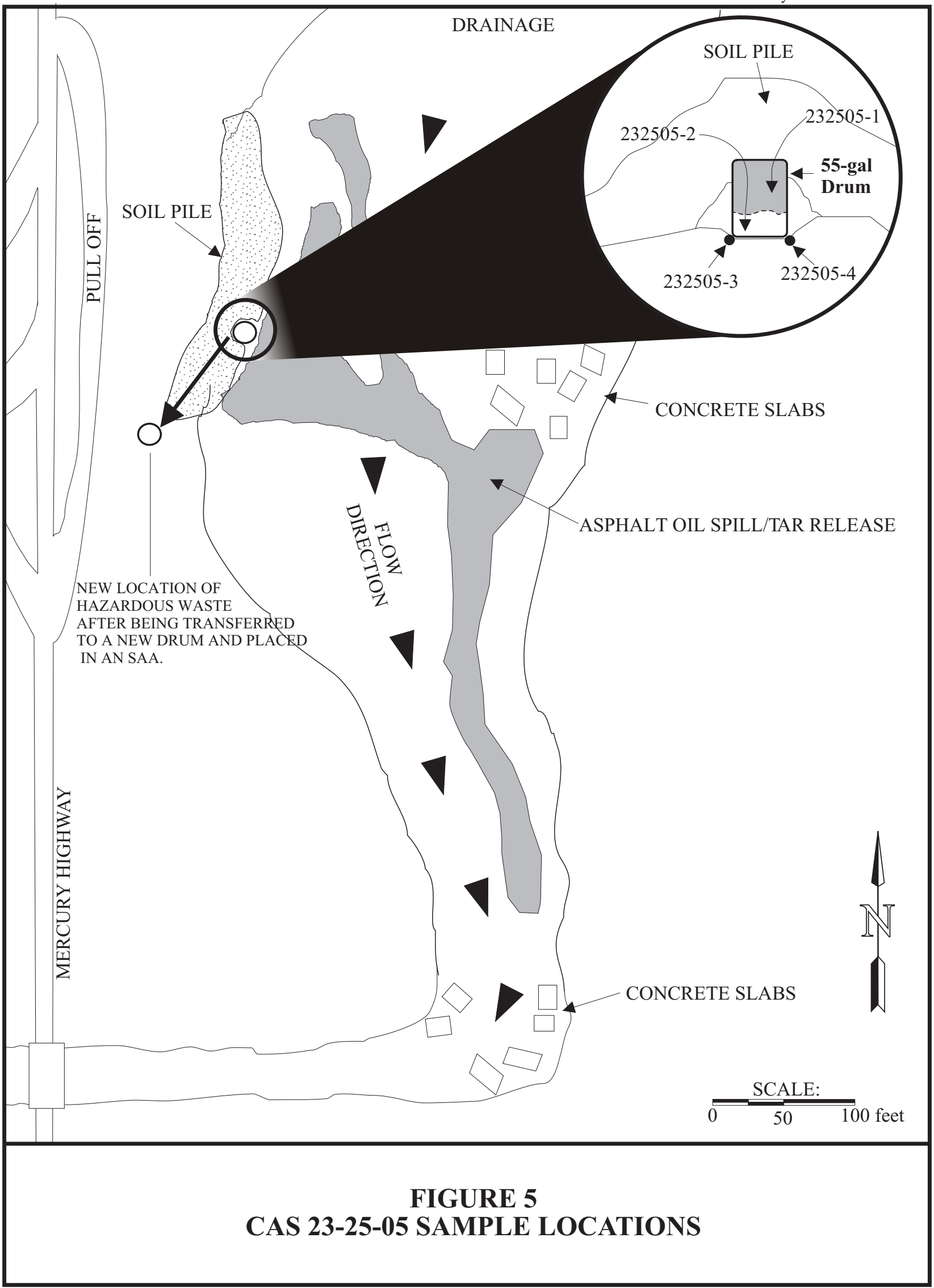



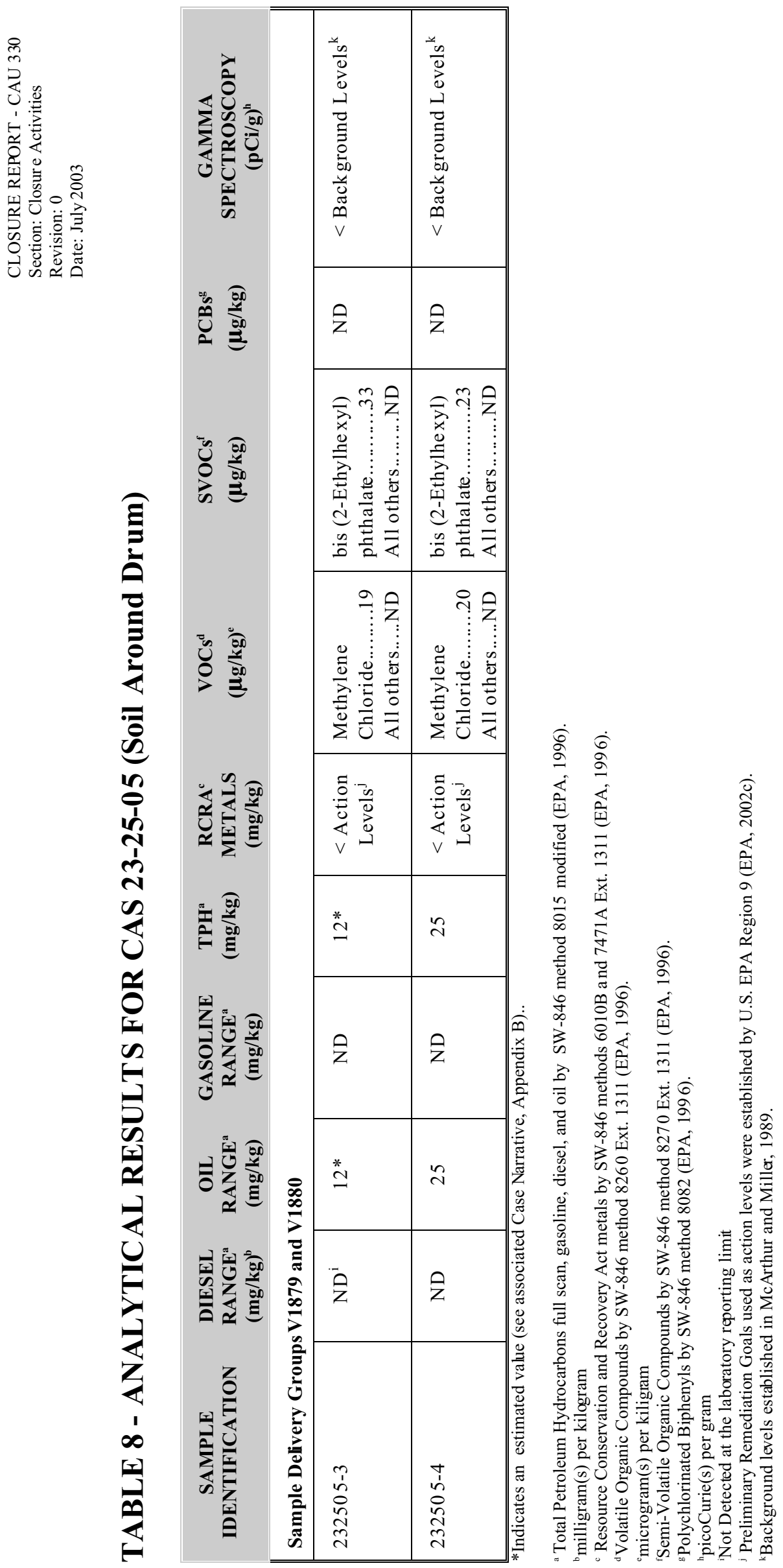


\subsection{DEVIATIONS FROM SAFER PLAN AS APPROVED}

There were no deviations from the NDEP-approved SAFER plan (NNSA/NV, 2001).

\subsection{CORRECTIVE ACTION SCHEDULE AS COMPLETED}

The corrective action field activities began January 2003 and were completed in June 2003. Details of the closure field activities schedule are provided below.

CAS 06-02-04 closure activities:

- $\quad$ Sample liquid

- $\quad$ Mobilize equipment/personnel to site

- $\quad$ Complete excavating soil above UST

- $\quad$ Pump top portion of liquid from tank and sample sludge

- $\quad$ Pump remaining liquid and sludge from tank

- $\quad$ Excavate piping, remove tank, and sample soil

- $\quad$ Backfill and demobilize

CAS 22-99-06 closure activities:

- $\quad$ Excavate and sample soil

- $\quad$ Backfill and demobilize site

CAS 23-01-02 closure activities:

- Pre-demolition activities

- Mobilize equipment/personnel and site set-up

- Demolition activities

- $\quad$ Sample soil

- Remove scrap metal from site and haul earthen berm to landfill

- $\quad$ Grade site
December 12, 2002 and February 6, 2003

February 5, 2003

February 5 - 6, 2003

March 5, 2003

April 14, 2003

April 17 - 23, 2003

June 4, 2003

March 6 - 11, 2003

April 9, 2003

January 14 - 16, 2003

February $11-12,2003$

February 13 - April 17, 2003

March 12, 2003

April - May 2003

April - May 2003 
CAS 23-25-05 closure activities:

- $\quad$ Sample contents inside drum

December 11, 2002

- $\quad$ Sample soil around drum

- Mobilize equipment/personnel and site set-up

January 29, 2003

- $\quad$ Excavate asphalt oil/tar and concrete

March 11, 2003

- $\quad$ Remove drum for disposal

March 11 - 20, 2003

March 18, 2003

- Demobilize site

March 20, 2003

\subsection{SITE PLAN/SURVEY PLAT}

Because engineered construction was not required as part of this closure, as-built drawings were not generated, and therefore, are not included in this CR. 


\subsection{WASTE DISPOSITION}

The following types of waste were produced at CAU 330 during closure activities: hydrocarbon, hazardous, sanitary, and construction debris. The majority of the scrap metal that resulted from the demolition activities was recycled. All waste was managed in accordance with state and federal regulations, U.S. Department of Energy orders, and BN procedures.

\section{CAS 06-02-04}

During closure activities at CAS 06-02-04, approximately $42.6 \mathrm{~m}$ (140 ft) of vitrified clay pipe was excavated and transported to the NTS Area 6 Hydrocarbon Landfill for disposal as hydrocarbon waste. Approximately $6 \mathrm{~m}^{3}$ (1,585 gal) of liquid and slightly TPH-impacted sludge was pumped from the tank and disposed of in the NTS Area 23 Sewage Lagoon. The UST was excavated and disposed of in the NTS Area 9 U10c Landfill.

\section{CAS 22-99-06}

During closure activities at CAS 22-99-06, approximately $49.7 \mathrm{~m}^{3}\left(65 \mathrm{yd}^{3}\right)$ of TPH-impacted soil was excavated and transported to the NTS Area 6 Hydrocarbon Landfill for disposal. Debris in the area, including wood and scrap metal was removed and disposed of in the NTS Area 9 U10c Landfill.

\section{CAS 23-01-02}

During closure activities at CAS 23-01-02, approximately $306 \mathrm{~m}^{3}\left(400 \mathrm{yd}^{3}\right)$ of scrap metal was recycled through a scrap metal vendor. The smaller pieces of scrap metal were disposed of in the NTS Area 23 Sanitary Landfill.

Approximately $27.5 \mathrm{~m}^{3}\left(36 \mathrm{yd}^{3}\right)$ of concrete was removed from a section of the concrete pad and disposed of in the NTS Area 9 U10c Landfill.

Approximately $68.1 \mathrm{~L}$ (18 gal) of diesel/soapy water mixture was pumped from a portion of the piping into a 55-gal drum. After the liquid was solidified, it was transported to the NTS Area 6 Hydrocarbon Landfill for disposal.

\section{CAS 23-25-05}

During closure activities at CAS 23-25-05, approximately $523.7 \mathrm{~m}^{3}\left(685 \mathrm{yd}^{3}\right)$ of asphalt/tar was excavated and disposed of in the NTS Area 6 Hydrocarbon Landfill. Approximately $224 \mathrm{~m}^{3}$ (293 $\left.\mathrm{yd}^{3}\right)$ of reinforced concrete pieces were removed from the wash and disposed of in the NTS Area 9 U10c Landfill. In addition, the 55-gal drum containing a petroleum substance was transported to the Area 5 Hazardous Storage Pad for disposal because the contents exhibited a hazardous characteristic for ignitability (EPA, 2002a). Hazardous waste disposition for the 55-gal drum is provided in Appendix C. 
CLOSURE REPORT - CAU 330

Section: Waste Disposition

Revision: 0

Date: July 2003

THIS PAGE INTENTIONALLY LEFT BLANK 


\subsection{CLOSURE VERIFICATION RESULTS}

CAU 330 closure was verified through the following actions:

- $\quad$ CAS 06-02-04: The CAU 330 NDEP-approved SAFER plan (NNSA/NV, 2001) DQOs presented as Appendix A of this report specified that at least four verification samples would be collected at this site. A total of eight soil samples were collected and analyzed to confirm PetroFlag ${ }^{\mathbb{R}}$ results and to verify that COCs had not leaked from the tank or piping (Tables 3 and 4). Two of the soil samples were collected by hand from the soil stockpiles removed from each side of the tank; this soil was used as clean fill for the excavation. The remaining soil samples were biased (grab) and collected in the vicinity and underneath the UST and piping at approximately 2.7 to $3 \mathrm{~m}$ ( 9 to $10 \mathrm{ft}$ ) and 0.6 to $1 \mathrm{~m}(2$ to $3 \mathrm{ft})$ respectively. Samples from under the UST and piping were collected from soil retrieved by backhoe bucket from the excavations. All samples were collected by hand using sterile sampling supplies and were placed on ice for transport and storage. Figure 2 shows the locations of the soil samples. The samples collected from underneath the UST were analyzed for a full suite analysis according to the NDEP-approved SAFER plan (NNSA/NV, 2001). The samples collected from underneath the piping and underneath the UST near the two end caps were analyzed for TPH because TPH diesel/oil was the only COC present in the sludge from the UST. Sample results showed that the remaining soil in the vicinity and underneath the tank and piping were below action levels. The action level for TPH in soil is $100 \mathrm{mg} / \mathrm{kg}$ as established by the state of Nevada (Nevada Administrative Code [NAC], 2002).

CAS 22-99-06: The CAU 330 NDEP-approved SAFER plan (NNSA/NV, 2001) DQOs presented as Appendix A of this report specified that 16 verification samples would be collected at this site. The removal of soil with TPH levels greater than $100 \mathrm{mg} / \mathrm{kg}$ was verified by collecting and analyzing 16 verification samples (Table 5) collected from the

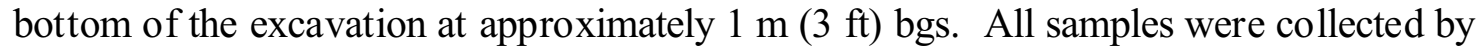
hand using sterile sampling supplies and were placed on ice for transport and storage. Figure 3 shows the locations of the verification samples. Verification sample results showed that the remaining soil was below the action level for TPH (oil) and the site was backfilled with approximately $49.7 \mathrm{~m}^{3}\left(65 \mathrm{yd}^{3}\right)$ of clean fill.

CAS 23-01-02: The CAU 330 NDEP-approved SAFER plan (NNSA/NV, 2001) DQOs presented as Appendix A of this report specified that ten verification samples would be collected at this site. Six Geoprobe ${ }^{\circledR}$ soil samples were collected underneath the diesel AST asphalt pad at approximately $0.45 \mathrm{~m}(1.5 \mathrm{ft}) \mathrm{bgs}$, and one additional biased (grab) sample was collected from the soil surface surrounding the asphalt pad. These soil samples were collected and analyzed to confirm PetroFlag ${ }^{\circledR}$ results and to verify that diesel was not present at concentrations greater than the action level of $100 \mathrm{mg} / \mathrm{kg}$ in the soil beneath the diesel asphalt pad (Table 5) (NAC, 2002). In addition, three Geoprobe ${ }^{\circledR}$ soil samples were collected underneath the gasoline AST asphalt pad. These soil samples were collected and analyzed to confirm PetroFlag ${ }^{\circledR}$ results and to verify that gasoline was not present at concentrations greater than the action level of $100 \mathrm{mg} / \mathrm{kg}$ in the soil beneath the gasoline asphalt pad (Table 6) (NAC, 2002). Figure 4 shows the locations of the samples. Nine of the ten soil samples were collected using a Geoprobe ${ }^{\circledR}$ drill rig. All 
samples were collected using sterile sampling supplies and were placed on ice for transport and storage.

- CAS 23-25-05: Two soil samples were collected by hand from directly beneath the former location of the 208-L (55-gal) drum to verify that TPH was not present in the soil surrounding the drum at levels greater than the Nevada State Action Level of $100 \mathrm{mg} / \mathrm{kg}$. Figure 5 shows the locations of the soil samples. Sample results showed that the remaining soil in the vicinity of the 208-L (55-gal) drum were below action levels (Table 8). All other analytical results were below action levels. All samples were collected using sterile sampling supplies and were placed on ice for transport and storage. 


\subsection{DATA QUALITY ASSESSMENT}

All samples were collected with disposable polyethylene dippers and placed in appropriately labeled sample containers secured with custody seals. All samples were labeled with a unique sample number, placed on ice in coolers, and transported under chain-of-custody to an off-site laboratory.

During collection of all samples, standard quality assurance/quality control (QA/QC) samples were also collected; e.g., one field duplicate per 20 samples submitted blind to the analytical laboratory for analysis. Also, the analytical laboratory followed standard QA/QC procedures during sample analysis. This included matrix spike/matrix spike duplicate and spiked surrogate percent recovery analysis.

CAU 330 closure activities were performed to the criteria specified in the DQOs provided in the NDEP-approved CAU 330 SAFER Plan (NNSA/NV, 2001), which are also provided in Appendix A of this CR. The DQOs primary CSMs are considered the probable scenarios for the conditions at the four CASs.

\section{CAS 06-02-04}

The primary CSM assumed that the contents inside the tank would not contain radionuclides or hazardous chemicals above action levels. This was confirmed through sample analyses. Additional site characterization provided further confirmation that no radionuclides or hazardous chemicals were inside the tank; however, TPH was identified slightly above action levels in the sludge only. The CSM for CAS 06-02-04 was an accurate representation of the site and the data collected for the site met all the DQOs.

\section{CAS 22-99-06}

The primary CSM assumed that TPH was the COC at the site. Soil sample results from the site showed this to be the case. The conceptual site model for CAS 22-99-06 was an accurate representation of the site, and the data collected met all DQOs.

\section{CAS 23-01-02}

The primary CSM assumed gasoline and diesel were the COCs identified at the site. A potential diesel spill had been documented in historical records. The alternative site model assumed that diesel did not leak from the tank. Soil sampling and field screening results from the site showed this to be the case. The alternative site model of CAS 23-01-02 was an accurate representation of the site and the data collected met all the DQOs.

\section{CAS 23-25-05}

The primary CSM assumed that no COC were associated with the soil underneath the asphalt oil/tar spill based on previous characterization sampling and process knowledge. The site was clean closed. The primary CSM for CAS 23-25-05 was an accurate representation of the site. 


\subsection{USE RESTRICTIONS}

CAU 330 was clean closed and the land use is, therefore, unrestricted. Because CAU 330 has been clean closed, no land use restrictions or post-closure monitoring requirements are applicable. 


\subsection{CONCLUSIONS AND RECOMMENDATIONS}

\subsection{CONCLUSION}

The following site closure activities were performed at each CAS included in CAU 330 and are documented in the report:

\section{CAS 06-02-04}

The UST, contents inside the UST, and piping have been disposed of appropriately. All soil samples collected in the vicinity of the UST and underneath the piping show that COCs were not present above action levels. The excavations were backfilled and graded to match the existing topography. CAS 06-02-04 has been clean closed with no restrictions on the use of the site.

\section{CAS 22-99-06}

The TPH-impacted soil has been removed from the site and disposed of in the NTS Area 6 Hydrocarbon Landfill. Verification samples collected from the excavation indicated that TPH concentrations in the soil are no longer present above the Nevada State Action Level of 100 $\mathrm{mg} / \mathrm{kg}$. The excavation was backfilled with clean fill and graded to match the existing topography. CAS 22-99-06 has been clean closed with no restrictions on the use of the site.

\section{CAS 23-01-02}

The two ASTs, fill stand, and associated piping were demolished and the majority of the scrap metal was recycled by a scrap metal vendor (approximately $306 \mathrm{~m}^{3}\left[400 \mathrm{yd}^{3}\right]$ ). The remaining smaller pieces of metal mixed with the earthen berm material were disposed of in the NTS Area 23 Sanitary Landfill. A small portion of the concrete pad was excavated during the removal of underground piping and disposed of in the NTS Area 9 U10c Landfill. Soil samples were collected underneath both AST asphalt pads to verify that diesel and gasoline concentrations in the remaining soil are below the Nevada State Action Level of $100 \mathrm{mg} / \mathrm{kg}$. The asphalt pads were left in place and the remainder of the site was graded to match the existing topography. In addition, six fuel pumps were disconnected from the system and processed through the excess system. CAS 23-01-02 has been clean closed with no restrictions on the use of the site.

\section{CAS 23-25-05}

This site was clean closed by excavating and properly disposing of the asphalt/tar and reinforced concrete from the wash. In addition, a 55-gal drum that was present in the wash was transferred to an SAA, ultimately being transported to the Area 5 Hazardous Storage Pad for off-site disposal. Sample results indicated the material in the drum to be a petroleum hydrocarbon substance and exhibited a hazardous characteristic for ignitability (EPA, 2002a). Additional soil samples were collected in the vicinity of the drum and the results showed the substance to be below action levels. CAS 23-25-05 has been clean closed with no restrictions on the use of the site instituted. 


\subsection{RECOMMENDATIONS}

Based on completion of site closure activities as documented by this $\mathrm{CR}$, it is requested that a Notice of Completion be provided by the NDEP for CAU 330. Upon closure approval, CAU 330 will be promoted from Appendix III to Appendix IV of the FFACO (1996), "Closed Corrective Action Units." 


\subsection{REFERENCES}

BN, see Bechtel Nevada.

Bechtel Nevada. 2002a. Field Management Plan for Corrective Action Unit 330: Areas 6, 22, and 23 Tanks and Spill Sites, Nevada Test Site, Nevada, Las Vegas, NV.

Bechtel Nevada. 2002b. Site-Specific Health and Safety Plan for Corrective Action Unit 330: Areas 6, 22, and 23 Tanks and Spill Sites, Nevada Test Site, Nevada, Las Vegas, NV.

EPA, see U.S. Environmental Protection Agency.

FFACO, see Federal Facility Agreement and Consent Order.

Federal Facility Agreement and Consent Order. 1996 (as amended). Agreed to by the State of Nevada, U.S. Department of Energy, and U.S. Department of Defense.

McArthur, R.D. Miller, F.L., Jr. 1989. Off-site Radiation Exposure Review Project (ORERP), Phase II Soil Program, DOE/NV/10384-23. Las Vegas, NV.

NAC, see Nevada Administrative Code.

NDEP, see Nevada Division of Environmental Protection.

Nevada Administrative Code. 2002. Section 445A.2272, "Contamination of Soil: Establishment of Action Levels." Carson City, NV.

Nevada Division of Environmental Protection. 1999. Water Pollution Control General Permit. GNEV 93001, Rev. iii., P. Liebendorfer. Carson City, NV.

NNSA/NV, see U.S. Department of Energy, National Nuclear Security Administration Nevada Operations Office.

U.S. Department of Energy, National Nuclear Security Administration Nevada Operations Office. 2001. Streamlined Approach for Environmental Restoration Plan for Corrective Action Unit 330: Areas 6, 22, and 23 Tanks and Spill Sites, Nevada Test Site, Nevada; Revision 1, DOE/NV--745, Las Vegas, NV.

U.S. Department of Energy, National Nuclear Security Administration Nevada Operations Office, 2002. Nevada Environmental Restoration Project, Industrial Sites Quality Assurance Project Plan, Nevada Test Site, Nevada, Revision 3, DOE/NV--372-Rev. 3 , Las Vegas, NV.

U.S. Environmental Protection Agency. 1996. Test Methods for Evaluating Solid Waste, Physical/Chemical Methods, EPA Publication SW-846, Third Edition. Washington, D.C. 
U.S. Environmental Protection Agency. 2002a. Title 40 Code of Federal Regulations 261.21, "Characteristic of ignitability," Washington D.C.

U.S. Environmental Protection Agency. 2002b. Title 40 Code of Federal Regulations 261.24, "Toxicity Characteristic," Washington D.C.

U.S. Environmental Protection Agency. 2002c. Region IX Preliminary Remediation Goals (PRGs), San Francisco, CA. 


\section{APPENDIX A}

\section{DATA QUALITY OBJECTIVES FOR CAU 330*}

*As presented and published in the approved U.S. Department of Energy, National Nuclear Security Administration Nevada Operation Office, Streamlined Approach for Environmental Restoration Plan for Corrective Action Unit 330: Area 6, 22, and 23 Tanks and Spill Sites, Nevada Test Site, Nevada, DOE/NV--745-REV1. Las Vegas, NV. (NNSA/NV, 2001). 
CLOSURE REPORT - CAU 330

Section: Appendix H

Revision: 0

Date: July 2003

THIS PAGE INTENTIONALLY LEFT BLANK 


\section{ACRONYMS AND ABBREVIATIONS}

AIP

AST

CAS

CAU

$\mathrm{COC}$

DQO

EPA

$\mathrm{mg} / \mathrm{L}$

$\mathrm{mg} / \mathrm{kg}$

$\mathrm{ml}$

NAC

PA

$\mathrm{pCi} / \mathrm{g}$

ppm

PRGs

QA

QC

RCRA

RPD

SAFER

SVOC

TCLP

$\mathrm{TPH}$

VOC
Animal Investigation Program

Aboveground Storage Tank

Corrective Action Site

Corrective Action Unit

Constituents of Concern

Data Quality Objective(s)

U.S. Environmental Protection Agency

milligram(s) per liter

milligram(s) per kilogram

milliliter

Nevada Administrative Code

Preliminary Assessment

picoCuries(s) per gram

parts per million

Preliminary Remediation Goals

Quality Assurance

Quality Control

Resource Conservation and Recovery Act

Relative percent difference

Streamlined Approach for Environmental Restoration

Semivolatile Organic Compound(s)

Toxicity Characteristic Leaching Procedure

Total Petroleum Hydrocarbons

Volatile Organic Compound(s) 
CLOSURE REPORT - CAU 330

Section: Appendix A

Revision: 0

Date: July 2003

THIS PAGE INTENTIONALLY LEFT BLANK

A1-ii 


\section{DATA QUALITY OBJECTIVES (DQOs)}

\section{DQO Overview}

The goal of the DQO process is to ensure that a sufficient amount of technically and legally valid data is collected to characterize a site, prepare a defensible corrective action, and executed according to the objectives. The U.S. Environmental Protection Agency (EPA) DQO guidance outline (EPA, 1994) should be followed. The DQO is to be integrated into the project life cycle of each project. Quality Assurance/Quality Control (QA/QC) must be incorporated into the scope, budget, schedule, pre-field activities, field work, sampling, and post field-activities, including the review of analytical data. This will begin in the planning stages/phases of a project. Steps used in this process build on the background research and previously acquired data which support the development of a Streamlined Approach for Environmental Restoration (SAFER) Plan.

The following characteristics are used in establishing DQOs:

Accuracy - Closeness of a measurement or the mean of a set of results to the true value. Accuracy is a measure of the bias of the measurement system. Indicators for measurement are based on the percent recoveries associated with the laboratory analytical control spikes, surrogate spikes, or matrix spikes.

Comparability - A qualitative judgement which expresses the confidence with which one set can be compared to another. Items used to determine comparability include the analytical method and reporting units.

Completeness - Indicators for this measurement are the amount of valid data obtained from a measurement system compared to the amount that was expected and needed to be obtained to meet the project data goals.

Precision - A measurement which represents the repeatability of the analytical system. Indicators for measurement are based on the relative percent difference (RPD) between field duplicates, laboratory splits, or laboratory replicate analysis. It is usually expressed as the RPD or standard deviation.

Representativeness - A qualitative judgement which refers to a sample or group of samples that reflect the characteristics of the media at the sampling point. It also includes how well the sampling point represents the actual parameter variations which are under study. 


\section{Planning Team Members}

$\begin{array}{lll}\text { 1. National Nuclear Security Administration } & & \text { Nevada Division of } \\ \begin{array}{ll}\text { Nevada, Las Vegas } & \text { Environmental Protection } \\ \text { Kanet Appenzeller-Wing } & \text { Mike McKinnon }\end{array} \\ \begin{array}{ll}\text { Bechtel Nevada } & \\ \text { Thomas Fitzmaurice } & \text { Marcus Dixon }\end{array}\end{array}$

2. Core Decision Team

Janet Appenzeller-Wing

Kevin Cabble

Mike McKinnon

Thomas Fitzmaurice

3. $\quad \frac{\text { Primary Decision Maker }}{\text { Janet Appenzeller- Wing }}$

\section{Step 1: State the Problem}

Constituents of Concern (COCs) could be present at Corrective Action Unit (CAU) 330 and be a threat to workers and the environment.

\section{Field Sampling Strategy}

The field sampling strategy is to use biased sampling only. Verification samples will be taken directly from excavations where soils have been removed.

\section{Constituents of Concern}

\section{CAS 06-02-04 Underground Tank and Piping}

The primary source of these COCs would be from the Animal Investigation Program (AIP) if the tank is associated with this study. Consequently, this CAS may contain the following COCs: cesium-137, strontium-90, plutonium-90, tritium, iodine-131, iodine-129 (radionuclides), and chemicals associated with cleaning activities. However, a sample was collected from the tank on October 3, 1998, as part of the preliminary assessment activities. The analysis consisted of total petroleum hydrocarbons (TPH), volatile organic compounds (VOC), semivolatile organic compounds (SVOC), Resource Conservation and Recovery Act (RCRA) metals, pH, chlorine, gamma, plutonium, and tritium. The results indicated that no radiological or hazardous COCs were detected above detection limits. It is unlikely, however, that the listed radionuclides associated with the AIP would be present at this Corrective Action Site (CAS). The study dealt with natural exposure to nuclear test fallout. Concentrations of radionuclides within the animals was shown to be low and not a health risk. 


\section{CAS 22-99-06 Fuel Spill}

The Performance Assessment (PA) group sampled this CAS on August 19, 1998. The only COC identifiable from this list is petroleum hydrocarbon.

\section{CAS 23-01-02 Large Aboveground Storage Tank (AST) Farm}

There are no COCs found at this site. However, a diesel spill has been documented in historical records.

\section{CAS 23-25-05 Asphalt Oil Spill/Tar Release}

Samples collected in 1997 indicated the presence of TPH, VOCs, SVOCs, RCRA metals, and radionuclides present above laboratory detection limits. Radionuclides were comparable to background levels. All analytical results were below the EPA region 9 Preliminary Remediation Goals (PRGs) (EPA, 2000). The soil beneath the tar/asphalt spill is not considered impacted with any COCs.

\section{Step 2: Identify the Decision}

Determine the extent of COCs at or above the action level(s) before and after remediation.

Prior to developing this SAFER plan, the PA group compiled the available historical data and collected samples from the CASs. This information was used to develop the DQOs for closure activities. As a result of this planning phase, it was determined that only a limited number of samples were required to develop a closure strategy. All field sampling will be biased. Data verification/validation will be accomplished by the following:

Accuracy - Closeness of a measurement or the mean of a set of results to the true value.

Accuracy is a measure of the bias of the measurement system. Indicators for measurement are based on the percent recoveries associated with the laboratory analytical control spikes, surrogate spikes, or matrix spikes.

Comparability - A qualitative judgement which expresses the confidence with which one set can be compared to another. Items used to determine comparability include the analytical method and reporting units.

Completeness - Indicators for this measurement are the amount of valid data obtained from a measurement system compared to the amount that was expected and needed to be obtained to meet the project data goals.

Precision - A measurement which represents the repeatability of the analytical system. Indicators for measurement are based on the relative percent difference (RPD) among field duplicates, laboratory splits, or laboratory replicate analysis. It is usually expressed as the RPD or standard deviation. 
Representativeness - A qualitative judgement which refers to a sample or group of samples that reflect the characteristics of the media at the sampling point. It also includes how well the sampling point represents the actual parameter variations which are under study.

\section{Laboratory Control Samples}

One matrix spike and one matric spike duplicate will be required for each batch of VOCs, SVOCs analysis and TPH run. One replicate and one lab blank will be run per batch of samples.

\section{Field Control Samples}

Field duplicates will be taken for not less than 10 percent of the samples. One trip blank will accompany every batch of VOC samples. One rinse blank will be completed per day. Field blanks will be provided for not less than 5 percent of the samples.

All of the sample analytical data will be provided in a SAFER Closure Report at the end of the project.

\section{Step 2A: Alternative Actions to the Decision}

Further assessment of the site would be required if the action levels are exceeded after cleanup or if the completeness criteria is missed.

\section{Step 3: Identify the Inputs to the Decision}

Professional judgement, process knowledge, and historical knowledge have been used to determine the possible COCs present at CAU 330. In this case, because sufficient information exists, biased sampling will be performed where contamination is likely to be present.

Environmental variables or characteristics that may be important in biased sampling:

1. Records of COC releases. Known or suspected location(s) of the release(s).

2. Configuration of CAS. This includes building, concrete pad, or other items that could direct the flow or been the source of releases.

3. Configuration of tanks, piping, or other utilities.

4. Observation of the surface features, or sub-surface features if a trench, hole, or ditch is present.

5. Field-screening results.

6. Previous sampling/characterization.

The suspected COCs and detection methods are shown in the following tables. 

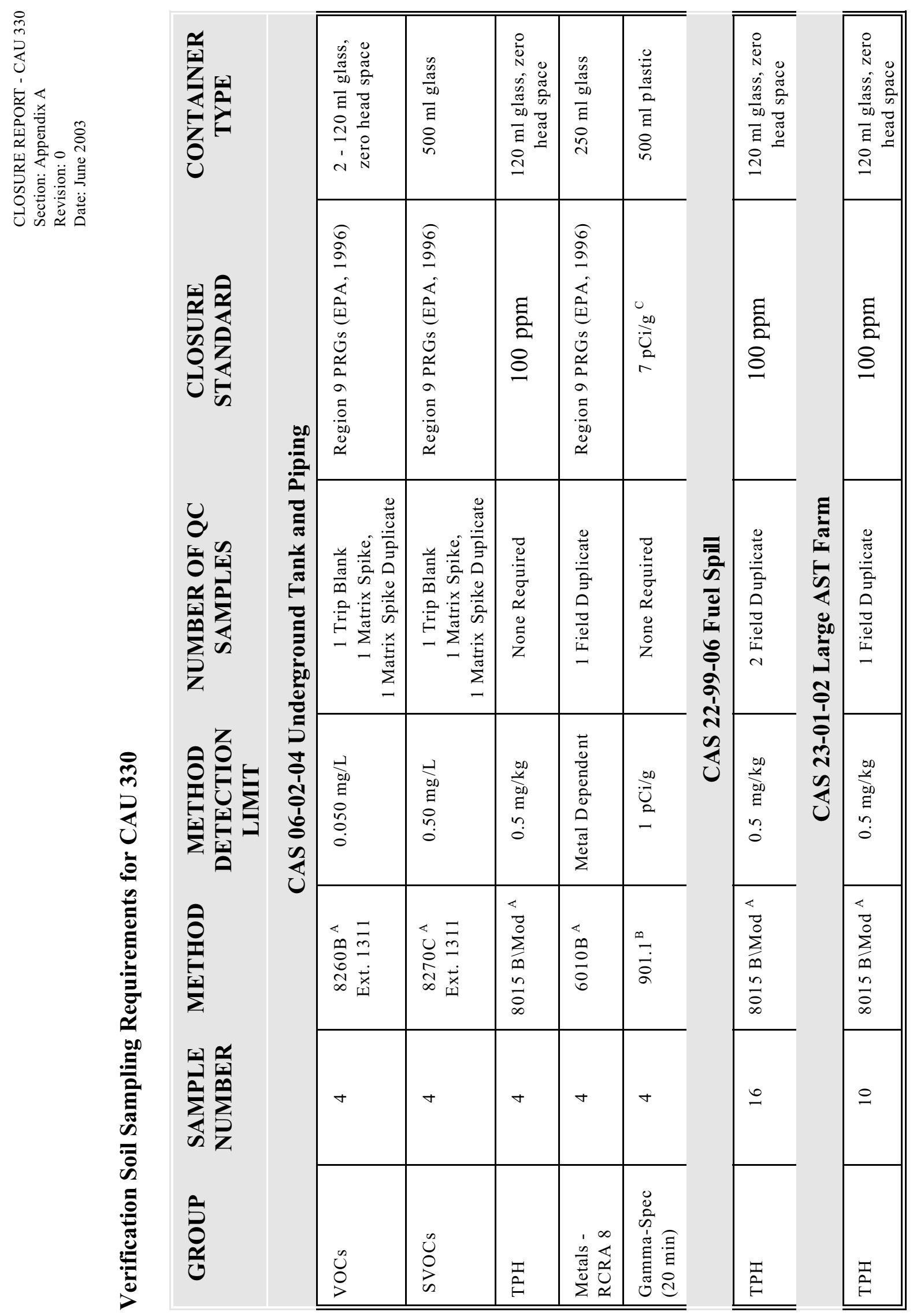

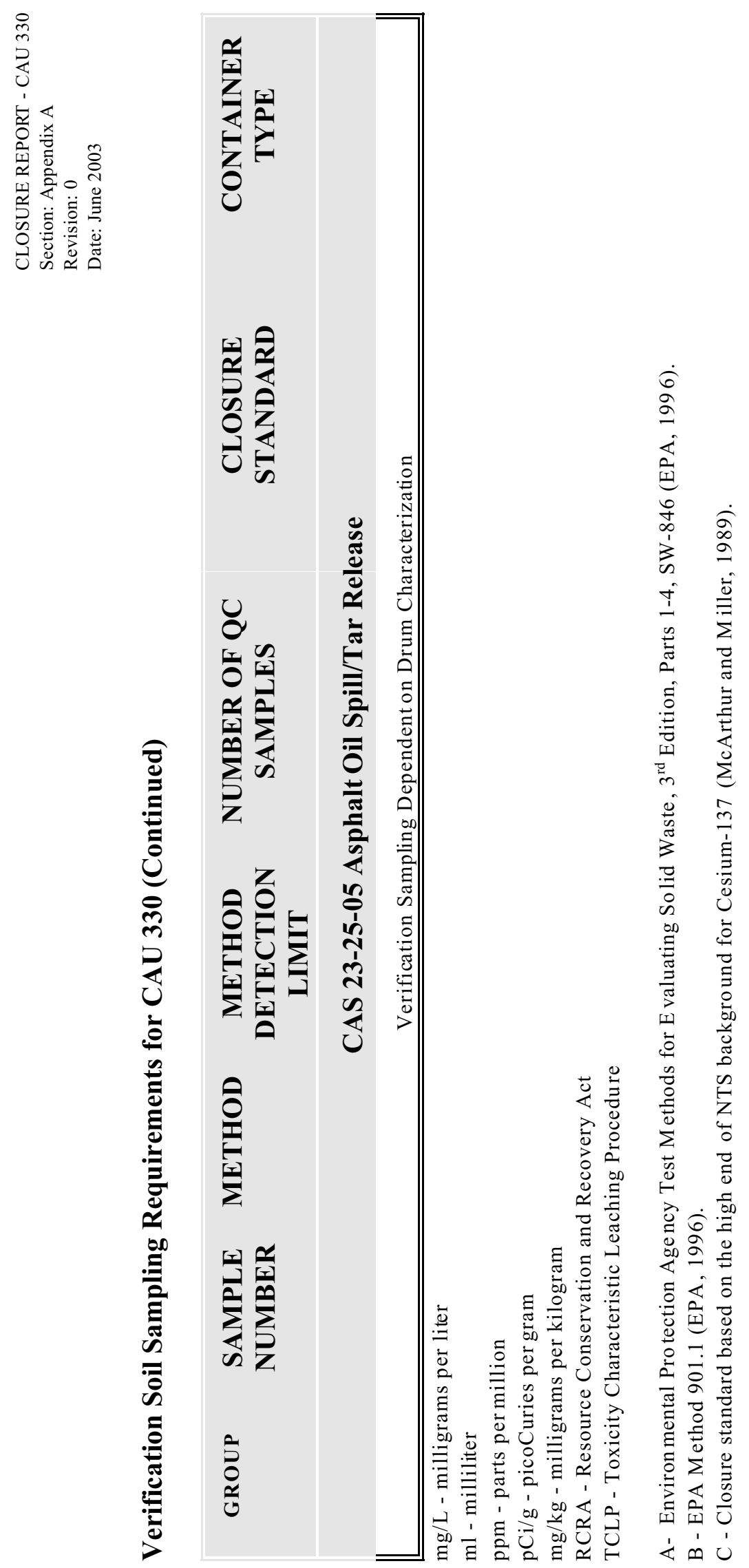

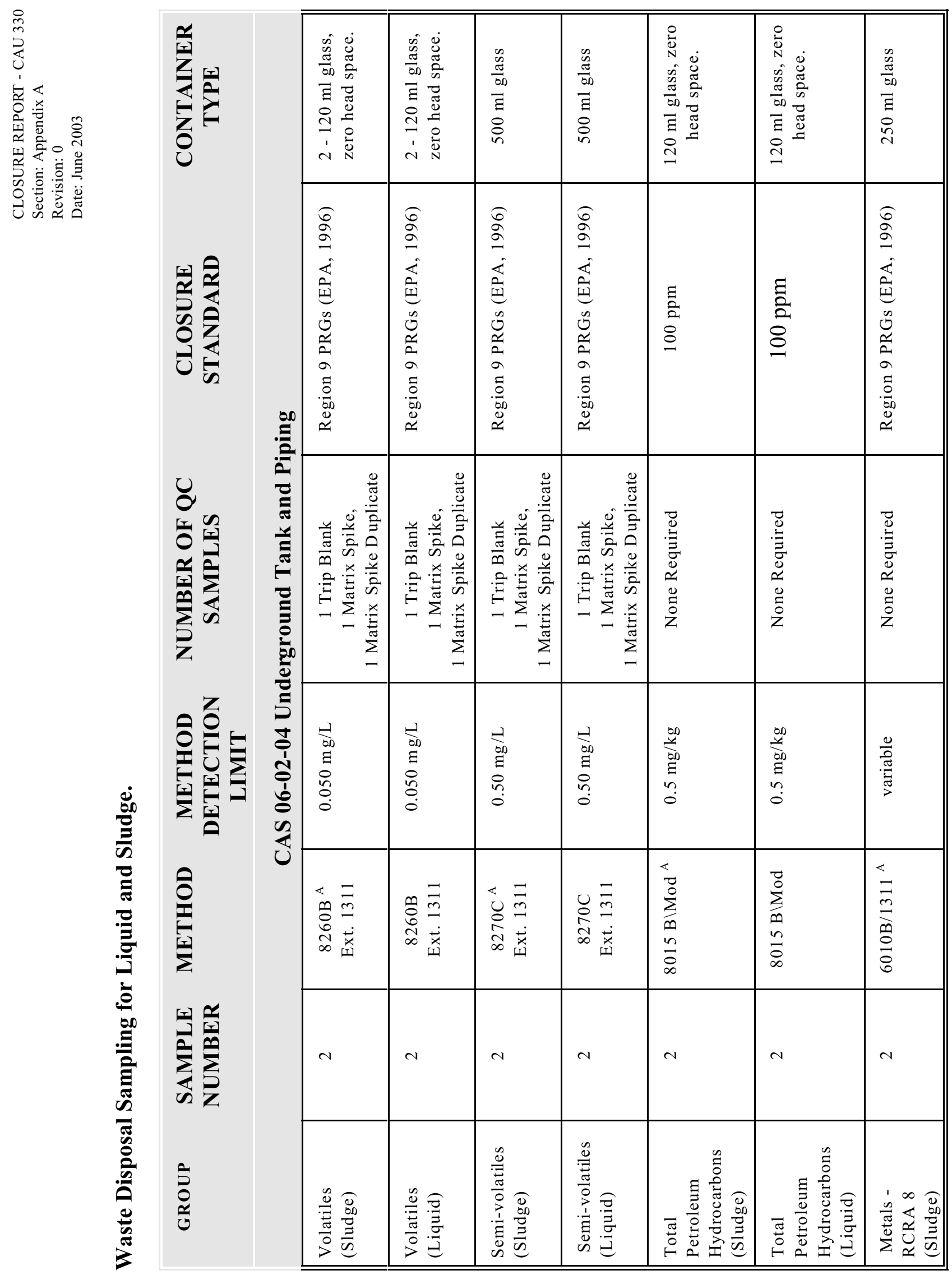

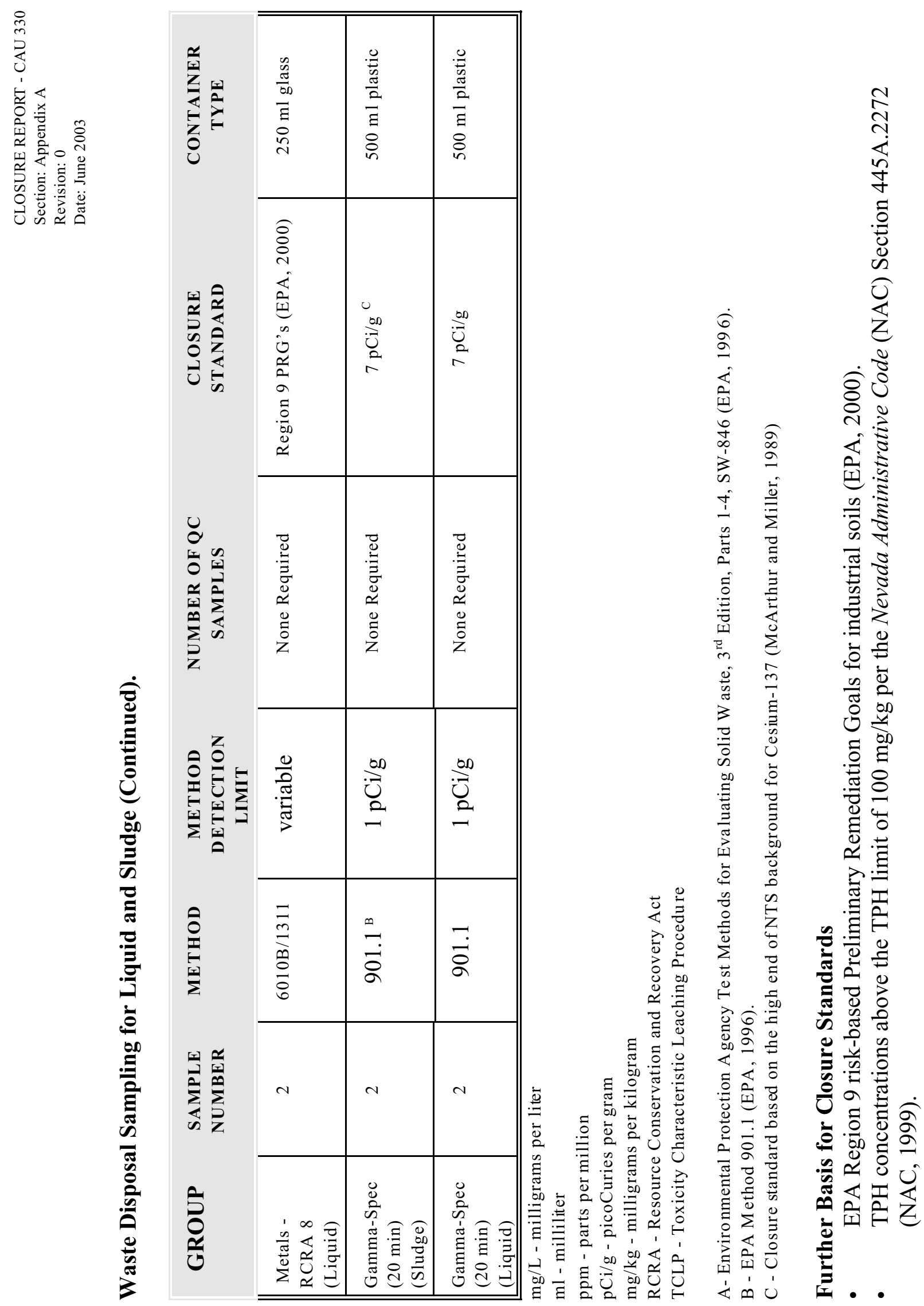


\section{Step 4: Define the Boundaries}

The target populations are different for each CAS

- CAS 06-02-04 consists of an underground tank and piping. The population of interest includes the liquids and sludge within the tank and the soils in the vicinity of the tank.

- CAS 22-99-06 consists of an area that involves a fuel spill that was believed to be a result of a waste oil release that occurred when Camp Desert Rock was an active facility. The population of interest is the soil impacted by the fuel spill, but not to exceed 10 feet beyond the depression used to dump waste oil.

- CAS 23-01-02 consists of a large AST farm that was constructed to provide a gasoline and diesel storage location. All tank farm structures will be removed. The population of interest for remediation consists of diesel-impacted soil beneath the AST.

- CAS 23-25-05 consists of a wash covered with asphalt oil/tar material, a half buried 55-gallon drum, rebar, and concrete located in the vicinity. All of these elements are included in the population. However, remediation of these site can be determined by visual inspection because no COCs are present.

Because each CAS is geographically independent, the domain of the field remediation activities is restricted to the four different CAS-themselves. The decision constraints will be confined to the physical location and descriptions of the four separate CASs independently. Temporal boundaries for the remediation activities include those constraints set up by weather conditions, availability of resources, and project schedules set in the baseline. Weather conditions at the Nevada Test Site may impact scheduled activities in the baseline. Unforseen resource conflicts could also cause delays. The current deadline for submitting the SAFER Plan is September 28, 2001. The field remediation will not occur until fiscal year 2002.

\section{Step 5: Develop a Decision Rule}

If the observed concentrations exceed the closure standards in the populations as described in Step 4, then further remediation will be required, followed by a new set of verification sampling. If the observed concentrations do not exceed the closure standards for the above population, then remediation activities will cease and a SAFER Closure Report will be developed.

Analytical results from a contract laboratory will be compared to the Closure Standards, as previously defined, to determine if the site has been sufficiently cleaned. If any COC exceeds its limits described in Step 4, additional material will be excavated and additional samples collected for analysis. This process will continue until the site has been cleaned of COCs to concentrations less than its respective action level. 
In addition analytical results will have at least an 80 percent completeness. That is, the number of samples which have acceptable data divided by the total number of samples taken times 100 will be at least 80 percent. Factors affecting QA/QC are discussed in Section 6. Legal factors affecting sample acceptability include a proper chain of custody and a custody tape seal on the sample. If this completeness criteria is not met, then sampling will be made as close as possible to the samples which failed and analysis performed until the 80 percent criteria is met.

Measurement methods, action levels, sample quantities and volumes have been defined in Step 3. In all cases the measurement method detection limit is less than the closure standard.

\section{Step 6: Specify Acceptable Limits on Decision Error}

Since the CAU has been identified in the Federal Facilities and Consent Order as being a site with potential contamination, the null hypothesis is that COCs are above action levels. The alternative statement is therefore that COCs are not above action levels.

The false rejection (alpha error) is to reject the null hypothesis in error. This means COCs would incorrectly be determined to be below action levels. This is also known as a false negative. This is the more serious error as contamination would be left in place without knowing about it. This possibility is minimized in biased sampling, as the most likely sites for contamination have been chosen for analysis. (This possibility is minimized in unbiased sampling by requiring analytical results to be at the $95^{\text {th }}$ percentile for the upper confidence limit that the action level is not exceeded.) Because biased sampling is being used. a statistical analysis in not appropriate.

The false acceptance (beta error) is to accept the null hypothesis in error. This means COCs would incorrectly be determined to be above action levels. This is also known as a false positive. This is the less serious error as an extra amount of uncontaminated material would be removed and disposed of as contaminated. QA/QC sample results and checking of raw results when a hit above the action level occurs can help reduce this type of error. Scrupulous adherence to using clean sampling equipment and good sample collection techniques also help eliminate contamination of samples.

\section{Step 7: Optimize Sampling and Analysis Design}

\section{CAS 06-02-04 Underground Tank and Piping}

Fluids within the tank will be removed, sampled for waste disposal, solidified (if necessary), and disposed of accordingly. Prior to sampling, the liquids will be agitated in order to homogenize the contents of the tank. If the contents can not be homogenized, then samples will also be collected from the sludge. Once liquids have been removed, the tank will be excavated and removed for disposal. Soil removed during the excavation will be stockpiled on plastic sheets. This soil will be characterized for disposal. If, however, the soil is found to be clean, it will be used to back fill the excavation. Inlet and outlet piping (if found to exist) will be grouted closed 
and left in place if COCs are not identified in the tank, otherwise they will be removed for disposal. Although previous sampling has shown the contents of the tank to be nonhazardous and nonradioactive, soils in the vicinity of both ends of the tank will be sampled for TPH, VOC, SVOC, RCRA metals, and gamma. If COCs are present above established clean-up levels (Section 3.3 Verification) these constituents will be removed by excavating more soil. The excavated areas will be resampled to verify that no COCs remain. Once verification samples indicate that COCs have been removed to below the established level, the inlet and outlet lines (if present) will be grouted closed or removed as the case may be. The excavation will be back filled with clean fill. Impacted soils will be removed for waste disposal.

\section{CAS 22-99-06 Fuel Spill}

The TPH-impacted soils will be removed and disposed of accordingly. Once TPH has been removed, verification sampling will be done on all sides of the excavation. Sixteen samples within an estimated 400-square-foot area will be collected. If samples indicate that TPH remains above the established remediation level, additional soils will be excavated for disposal. Once verification samples indicate that TPH has been removed below the established remediation level, the excavation will be filled with clean fill material.

\section{CAS 23-01-02 Large AST Farm}

Initial phases of the remedial action for this CAS will include the dismantlement/demolition of two large fuel tanks, associated piping, and fill stand. Where possible metal scrap will be salvaged. Once the tanks and piping have been removed, the soils in the vicinity of the diesel tank will be sampled for TPH impacts. If sampling analytical data indicate that TPH for diesel is present, these soils will be removed for disposal. Additional sampling will be done to verify that diesel has been removed below the established remediation level. Once verification samples indicate that TPH has been removed below the established remediation level, the excavation will be filled with clean fill material.

\section{CAS 23-25-05 Asphalt Oil Spill/Tar Release}

Visible tar will be excavated and hauled away. In addition, the drum, concrete slabs and rebar will be removed from this site. Verification sampling will not be required unless COCs are identified in the drum. If COCs are identified within the drum, samples will be collected to verify that the soils have not been impacted by the drum contents. 


\section{REFERENCES}

EPA, see U.S. Environmental Protection Agency.

McArthur, R. D. and Miller, F. L., Jr. 1989. Off-site Radiation Exposure Review Project (ORERP), Phase II Soil Program, DOE/NV/10384-23. Las Vegas, NV.

NAC, see Nevada Administrative Code.

Nevada Administrative Code. 1999. Section 445a.2272: "Contamination of Soil: Establishment of Action Levels." Carson City, NV.

U.S. Environmental Protection Agency. 1994. Guidance for the Data Quality Objectives Process, EPA AQ/ G-4. Washington D.C.

U.S. Environmental Protection Agency. 1996. Test Methods for Evaluating Solid Waste Physical/Chemical Methods (SW-846) Third Edition. Washington D.C.

U.S. Environmental Protection Agency. 2000. Region IX Preliminary Remediation Goals (PRGs), San Francisco, CA. 
CLOSURE RE PORT - CAU 330

Section: Appendix B

Revision : 0

Date: July 2003

\section{APPENDIX B}

\section{SAMPLE ANALYTICAL RESULTS}


CLOSURE RE PORT - CAU 330

Section: Appendix B

Revision : 0

Date: July 2003

\section{THIS PAGE INTENTIONALLY LEFT BLANK}




\section{TABLE OF CONTENTS - SAMPLE ANALYTICAL RESULTS BY SAMPLE DELIVERY GROUP}

Note: Analytical results are presented in this Appendix in the order indicated below.

CAS 06-02-04

SDG V1809: Liquid samples from UST 060204-T1 and 060204-T2

Trip Blanks (VOC) 330-TB3 and 330-TB4

SDG V1810: Liquid samples from UST 060204-T1 and 060204-T2 SDG V1888: Liquid samples from UST 060204-T

SDG V1912: Sludge samples from UST 060204-T3 and 060204-T4

Trip Blanks (VOC) 330-TB7 and 330-TB8

SDG V1913: Sludge samples from UST 060204-T3 and 060204-T4

SDG V1958: Soil samples from underneath piping 060204-P0, P1, and P2

SDG V1962: Soil samples from each side of the UST 060204-T5 and 060204-T6 Trip Blanks (VOC) 330-TB9 and 330-TB10

SDG V1963: Soil samples from each side of the UST 060204-T5 and 060204-T6

SDG V1964: Soil samples collected at each end of the UST 060204-T7, T8, T9, and T10 Trip Blanks (VOC) 330-TB11 and 330-TB12

SDG V1965: Soil samples collected at each end of the UST 060204-T7 and 060204-T8

CAS 22-99-06

SDG V1755: Soil samples from fuel spill 330L-0-0, 330L-0-1, and 330L-0-2

SDG V1916: Soil samples from excavation 229906-1 through 229906-16

CAS 23-01-02

SDG V1926: Soil samples from underneath asphalt pads 230102-1 through $3 \mathrm{G}$

CAS 23-25-05

SDG V1805: Samples of contents from inside the drum 232505-1 and 232505-2 Trip Blanks (VOC) 330-TB1 and 330-TB2

SDG V1806: Samples of contents from inside the drum 232505-1 and 232505-2

SDG V1879: Soil samples from around the drum 232505-3 and 232505-4

Trip Blanks (VOC) 330-TB5 and 330-TB6 SDG V1880: Soil samples from around the drum 232505-3 and 232505-4 
CLOSURE RE PORT - CAU 330

Section: Appendix B

Revision : 0

Date: July 2003

\section{THIS PAGE INTENTIONALLY LEFT BLANK}


CLOSURE REPORT - CAU 330

Section: Appendix B

Revision: 0

Date: July 2003

\title{
SAMPLE DELIVERY GROUP
}

\author{
V1809
}


CLOSURE REPORT - CAU 330

Section: Appendix B

Revision: 0

Date: July 2003

\section{THIS PAGE INTENTIONALLY LEFT BLANK}


Mr. Theodore Redding

Bechtel Nevada Corporation

2621 Losee Road

Mail Stop NTS273

Las Vegas, NV 89030-4134

RE: Subcontract No. 30028, Task Order No. 1

Data Report for LVL Batch 0212L340

SDG\#: V1809

Chain: None (Project CAU330)

Dear Mr. Redding:

Enclosed please find the data report for 4 water samples received 13 December 2002 for analysis for TPH, metals, VOAs, SVOAs and PCBs on a 14 day turnaround time. The invoice is enclosed. The EDD is being emailed. These data were faxed 24 and 26 December.

Please do not hesitate to contact me at (610) 280-3029 with any questions or at any time we may be of service.

Very truly yours,

Lionville Laboratory Incorporated

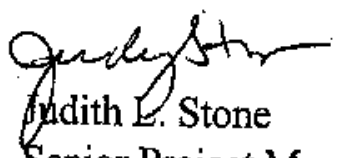

Senior Project Manager

Enclosure: 


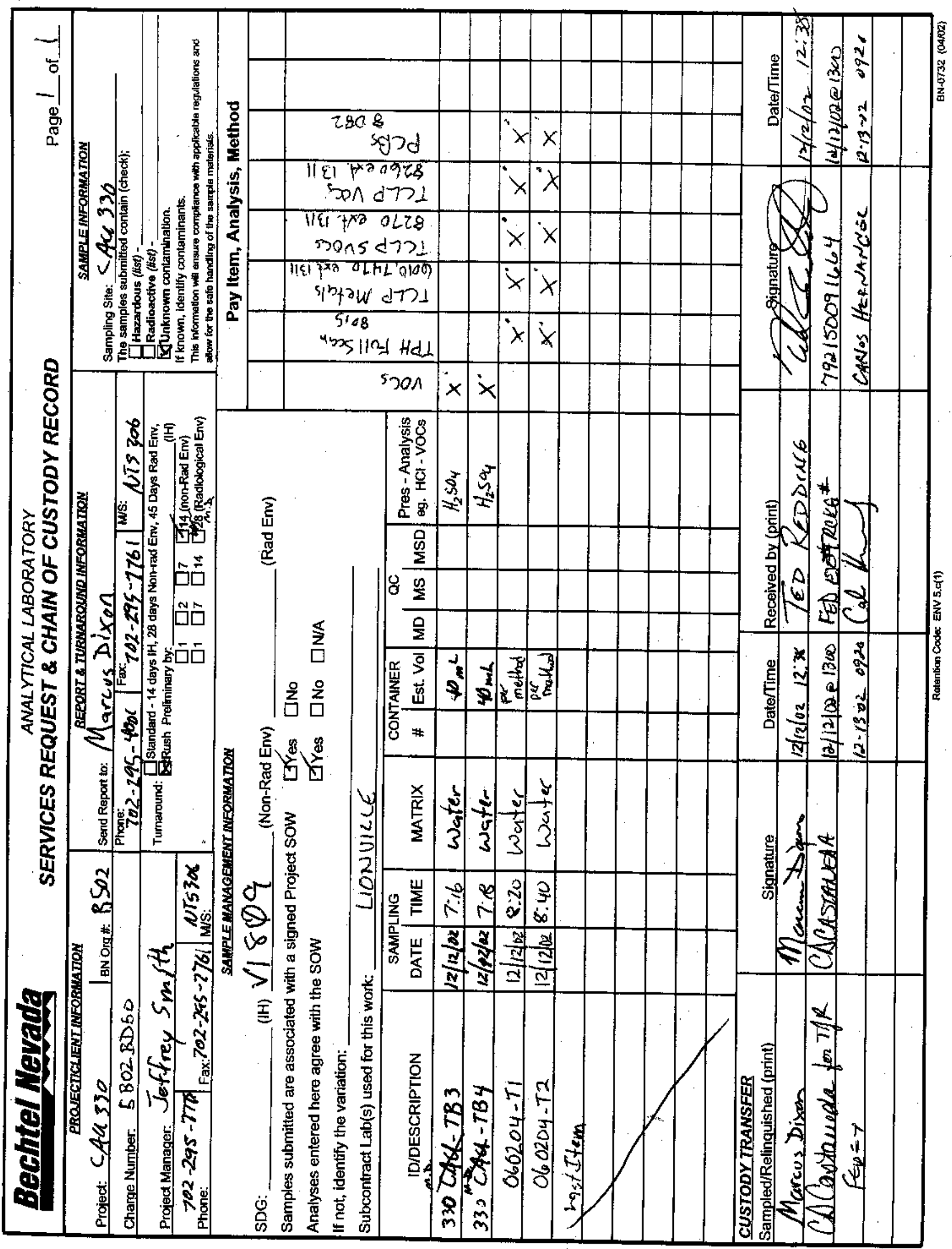


Case Narrative 


\section{Analytical Report}

IIONVILE LABORATORY INC.

Client: BECHTEL NEVADA V1809

LVL\#: 0212L340

W.O.\#: 60052-001-001-0001-00

Date Received: 12-13-2002

PCB

Two (2) water samples were collected on 12-12-2002.

The samples and their associated QC samples were extracted on 12-16-2002, and analyzed according to Lionville Laboratory OPs based on SW846, 3rd Edition procedures on 12-18-2002. The extraction procedures were based on methods 3520 and the extracts were analyzed based on method 8082 for Aroclors only.

. The following is a summary of the QC results accompanying the sample results and a description of any problems encountered during their analyses:

1. All results presented in this report are derived from samples that met LVLI's sample acceptance policy.

2. The required holding time for extraction and analysis has been met.

3. The samples and their associated QC samples received a Sulfuric acid cleanup.

4. The method blank was below the reporting limits for all target compounds.

5. All surrogate recoveries were within acceptance criteria.

6. All blank spike recoveries were within acceptance criteria.

7. All initial calibrations associated with this data set were within acceptance criteria.

8. All continuing calibration standards analyzed prior to sample extracts were within acceptance criteria.

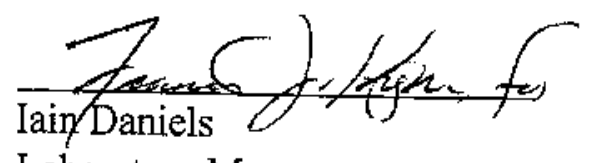

Laboratory Manager

Lionville Laboratory Incorporated

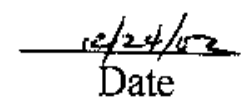

somitrigroupldatalpestibechte\}li2L-340..pcb

The resuls presented in this report selate only to the analytical testing and conditions of the sansples at receipt and during stonge 


\section{GLOSSARX OF PESTICIDE/PCB DATA}

\section{DATA QUALIFIERS}

$\mathrm{U}=$ Indicates that the compound was analyzed for but not detected. The minimum detection limit for the sample (not the method detection limit) is reported with the $U$ (e.g., 10U).

$\mathbf{J}=$ Indicates an estimated value. This flag is used in cases where a target analyte is detected at a level less than the lower quantification level. If the limit of quantification is $10 \mathrm{ug} / \mathrm{L}$ and a concentration of $3 \mathrm{ug} / \mathrm{L}$ is calculated, it is reported as $3 J$.

B = This flag is used when the analyte is found in the associated blank as well as in the sample. It indicates possible/probable blank contamination.

$\mathbf{E}=$ Indicates that the compound was detected beyond the calibration range and was subsequently analyzed at a dilution.

I $=$ Interference.

\section{ABBREVIATIONS}

BS = Indicates blank spike in which reagent grade water is spiked with the CLP matrix spiking solutions and carried through all the steps in the method. Spike recoveries are reported.

BSD $=$ Indicates blank spike duplicate.

MS = Indicates matrix spike.

MSD = Indicates matrix spike duplicate.

DL = Indicates that recoveries were not obtained because the extract had to be diluted for analysis.

NA $=$ Not Applicable.

DF $=$ Dilution Factor.

$\mathrm{NR}=$ Not Required.

SP $=$ Indicates Spiked Compound. 


\section{GLOSSARY OF PESTICIDE/PCB DATA}

$\mathbf{P}=\quad$ This flag is used for an PESTICIDE/PCB target analyte when there is greater than $25 \%$ difference for detected concentrations between the two $\mathrm{GC}$ columns (see Form $\mathrm{X}$ ). The lower of the two values is reported on Form I and flagged with a "P".

D $=$ This flag identifies all compounds identified in an analysis at a secondary dilution factor.

C = This flag applies to a compound that has been confirmed by GC/MS. 
Sample Data 
1D

PESTICIDE ORGANICS ANALYSIS SHEET

Lab Name: Lionville Labs. Inc, Work Order: 60052001001

\section{Client: BECHTEL NEVADA V1809.....}

Matrix:

WATER

Sample wt/vol:

$970(\mathrm{~g} / \mathrm{mL}) \mathrm{ML}$

Level: (low/med) LيW

dec.

\% Moisture: not dec.

dec.

Extraction: (SepF/Cont/Sonc) CONT

GPC Cleanup: $\quad(Y / N) \mathbb{N}$

$\mathrm{pH}: \quad 7.0$
Lab Sample ID: 02.22 $340-003$

Lab File ID

BLKO8330.01

Date Received: $12 / 13 / 02$

Date Extracted: $12 / 16 / 02$

Date Analyzed: 12/18/02 :

Dilution Factor: 1.00
CAS NO.

COMPOUND
CONCENTRATION UNITS:

$(\mathrm{ug} / \mathrm{L}$ or $\mathrm{ug} / \mathrm{Kg}) \mathrm{UG} / \mathrm{L}$

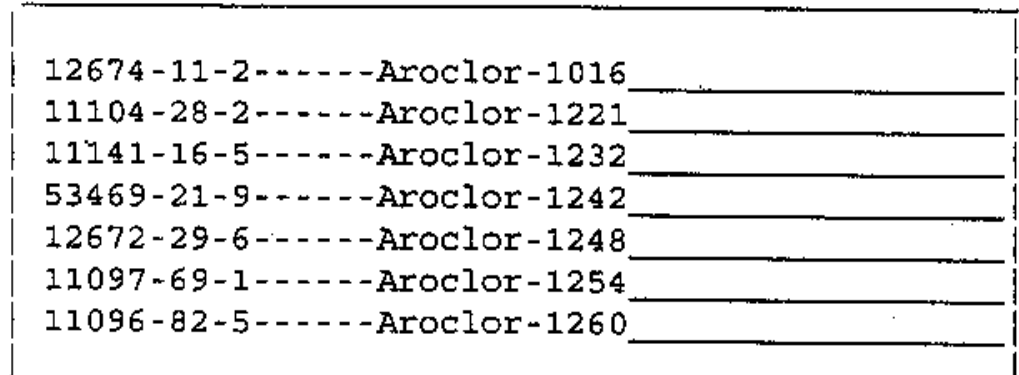

FORM I PEST
1.0
2.1
1.0
1.0
1.0
1.0
1.0 
Lab Name: Lionville Labs, Inc. Work Ordex: 60052001001 CLIENT SAMPLE NO. $060204-\mathrm{T} 2$

Client: BECHTEL NEVADA V1809

Matrix:

WATER

Sample wt/vol: $\underline{970}(\mathrm{~g} / \mathrm{mL}) \underline{\mathrm{ML}}$

Level: (low/med) LOW

Moisture: not dec. dec.

Extraction: (SepF/Cont/Sonc)

CONT GPC Cleanup: (Y/N) $\underline{\underline{N}}$

$\mathrm{pH}:-7.0$
Lab Sample ID

Lab File ID:

Date Received: $12 / 13 / 02$

Date Extracted: $12 / 16 / 02$

Date Analyzed: $12 / 18 / 02$

Dilution Factor: 1.00

CAS NO.

COMPOUND

CONCENTRATION UNITS :

(ug/L or $\mathrm{ug} / \mathrm{Kg}) \underline{\mathrm{UG} / \mathrm{L}}$

\begin{tabular}{|l|}
$12674-11-2----A r o c l o r-1016$ \\
$11104-28-2----$ Aroclor -1221 \\
$11141-16-5----$ Aroclor -1232 \\
$53469-21-9----$ Aroclor -1242 \\
$12672-29-6----$ Aroclor -1248 \\
$11097-69-1----$ Aroclor -1254 \\
$11096-82-5 \cdots---$ Aroclor -1260
\end{tabular}

FORM 1 PEST
1.0

2. 1

1.0

1.0

1.0

1.0

I. 0 


\section{Case Narrative}

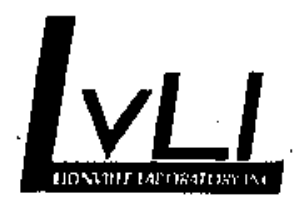

$\therefore \quad 09$ 


\section{3) $/ V L I$ \\ LIONVIIIF LABORAIORY INC:}

\section{Analytieat Report}

Client : BECHTEL NEVADA V1809

LVL\# : 0212L340
W.O.\# : 60052-001-001-0001-00

Date Received : 12-13-02

\section{SW846 METALS}

1. This narrative covers the analyses of 2 water samples.

2. The samples were prepared and analyzed in accordance with SW-846 protocol and reported with a CLP deliverable.

3. ICVs, CCVs, and LCSs stock standards were purchased from Inorganic Ventures Laboratory and High Purity.

4. All analyses were performed within the required holding times.

5. All results presented in this report are derived from samples that met LvLI's sample acceptance policy.

6. All Initial and Continuing Calibration Verifications (ICV/CCVs) were within control limits.

7. All Initial and Continuing Calibration Blanks (ICB/CCBs) were within method criteria.

8. All preparation/method blanks were within method criteria. Refer to form 3 .

9. All ICP Interference Check Standards were within control limits. Refer to form 4.

10. All laboratory control samples (LCS) were within the $80-120 \%$ control limits. Refer to form 7 .

11. All serial dilution percent differences were within $\underline{\mathrm{SW}-846}$ control limits. Refer to form 9 .

12. All matrix spike (MS) recoveries were within the $75-125 \%$ control limits. Refer to form $5 \mathrm{~A}$.

13. The duplicate analysis for 1 analyte was outside the $20 \%$ Relative Percent Difference (RPD) control limits. Refer to form 6 . 
14. All sample IDs were changed to accommodate the EPA naming convention which allows a maximum of 6 characters on all CLP Forms. Refer to the comments section of form 1 for the original ID.

15. Recoveries on the Laboratory Summary Report and CLP forms will vary depending on the number of significant figures used in the recovery calculation.

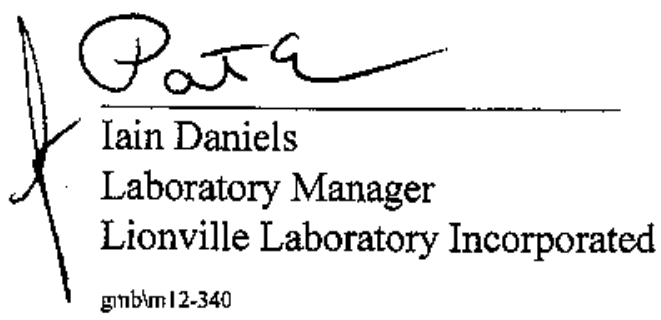

12.20 .02

Date 


\section{METHOD REFERENCES AND DATA QUALIFIERS}

\section{DATA QUALIFIERS}

$\mathrm{U}=$ Indicates that the parameter was not detected at or above the reported limit. The associated numerical value is the sample detection limit.

$B=$ Indicates that the parameter was between the Instrument Detection Limit (IDL) and the Contract Required Detection Limit (CRDL)

\section{QQUALIFIERS}

$E=$ The reported value is estimated because of the presence of interference.

$\mathbf{M}=$ Duplicate injection precision not met.

$\mathrm{N}=\quad$ Spiked sample recovery not within control limits.

$S=$ The reported value was determined by the Method of Standard Additions (MSA).

$W=\quad$ Post Digestion spike for Fumace AA analysis is out of control limits $(85-115 \%)$, while sample absorbance is less than $50 \%$ of spike absorbance.

$* \quad$ Duplicate analysis not within control limits.

$+=$ Correlation coefficient for the MSA is less than 0.995 .

\section{ABBREVIATIONS}

PB $=$ Method or Preparation Blank.

S = Matrix Spike.

$T=$ Matrix Spike Duplicate.

R or D = Sample Replicate

\section{ANALYTICAL MITAL METHODS}

1. Not included in the method element list.

2. Modified $\mathrm{Hg}$ : $\mathrm{Hg} 1$ and $\mathrm{Hg} 2$ require less total volume of digestate due to the autosampler analysis. Sample volumes and reagents for mercury determinations in water and soil have been proportionately scaled down to adapt to this semiautomated technique. The sample volume used for water analysis is $33 \mathrm{~mL}$. For soils, 0.1 grams of sample is taken to a final volume of $50 \mathrm{~mL}$ (including all reagents).

3. Modified $\mathrm{Hg}$ : $\mathrm{Hg} 1$ and $\mathrm{Hg} 2$ require less total volume of digestate due to the autosampler analysis. Sample volumes and reagents for mercury determinations in water and soil have been proportionately scaled down to adapt to this semiautomated technique. The sample volume used for water analysis is $33 \mathrm{~mL}$. For soils, three 0.1 gram of sample is taken to a final volume of $50 \mathrm{~mL}$ (including all reagents).

4. Flame AA.

5. Graphite Furnace AA.

RFW 21-21L-033/0-01/97 


\section{U.S. EPA}

1 INORGANIC ANALYSES DATA SHEET
Lab Name: LIONVILLE_LABORATORY

Lab Code: IVLI Matrix (soil/water) : WATER

Level (low/med): LOW

: Solids :
Contract: 60052 SAS NO.:

SDG NO: 060204
EPA SAMPLE NO.

T1

Sample ID: 0232L340-003

Date Received: 12/13/02

Concentration Units (ug/I or $\mathrm{mg} / \mathrm{kg}$ dry weight): UG/L_

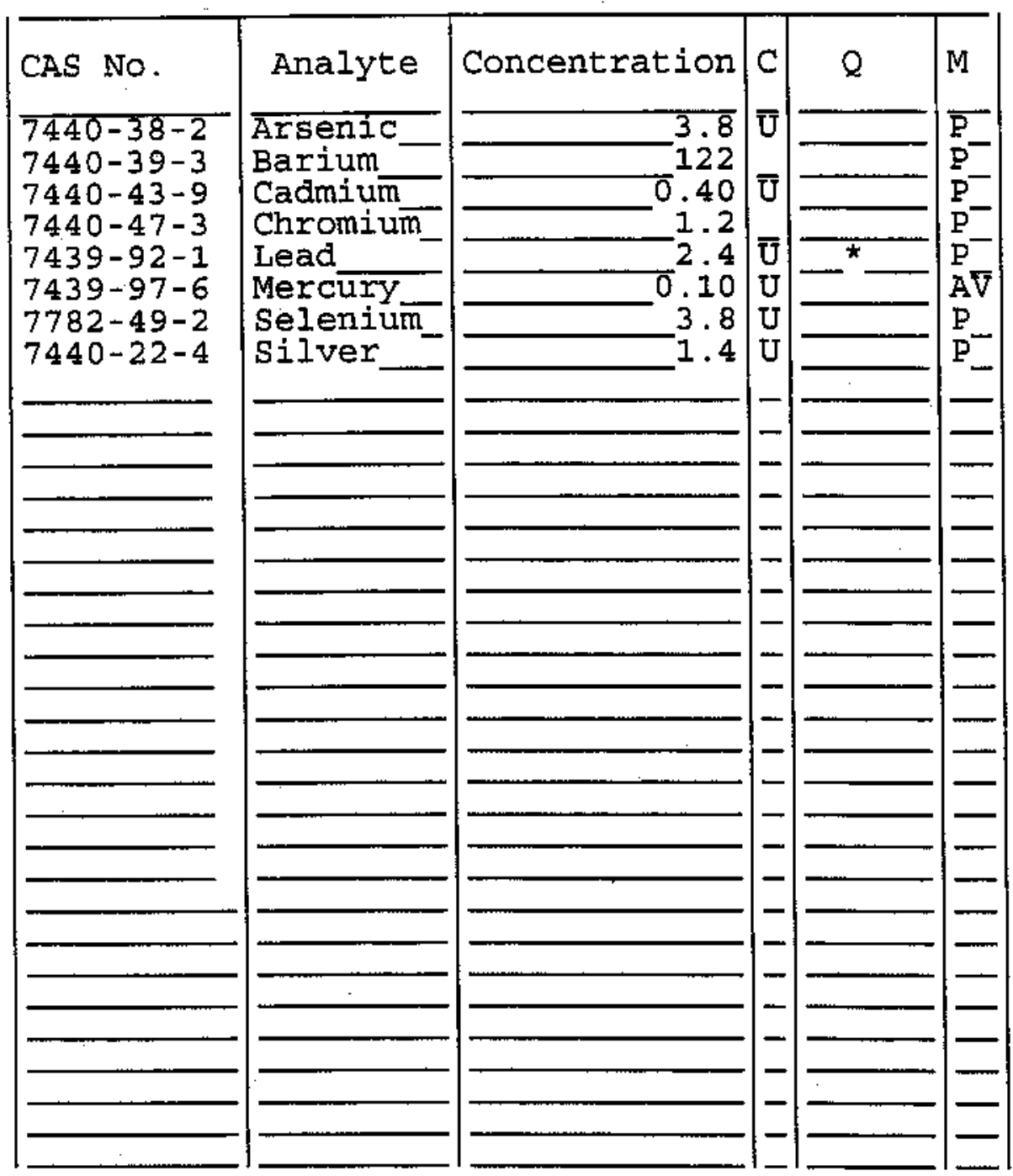

Color Before: Color After:
Clarity Before:

Clarity After:
Texture:

Artifacts :

Comments :

$050204-\mathrm{T} 1$ 
1

INORGANIC ANALYSES DATA SHEET
EPA SAMPLE NO.

$\mathrm{T} 2$

Contract: 60052

SAS NO.:

SDG NO.: 060204 WATER LOW $0 \overline{0}$

Date Received: 12/13/02

Concentration Units (ug/L or $\mathrm{mg} / \mathrm{kg}$ dry weight): $\mathrm{UG} / \mathrm{L}_{-}$

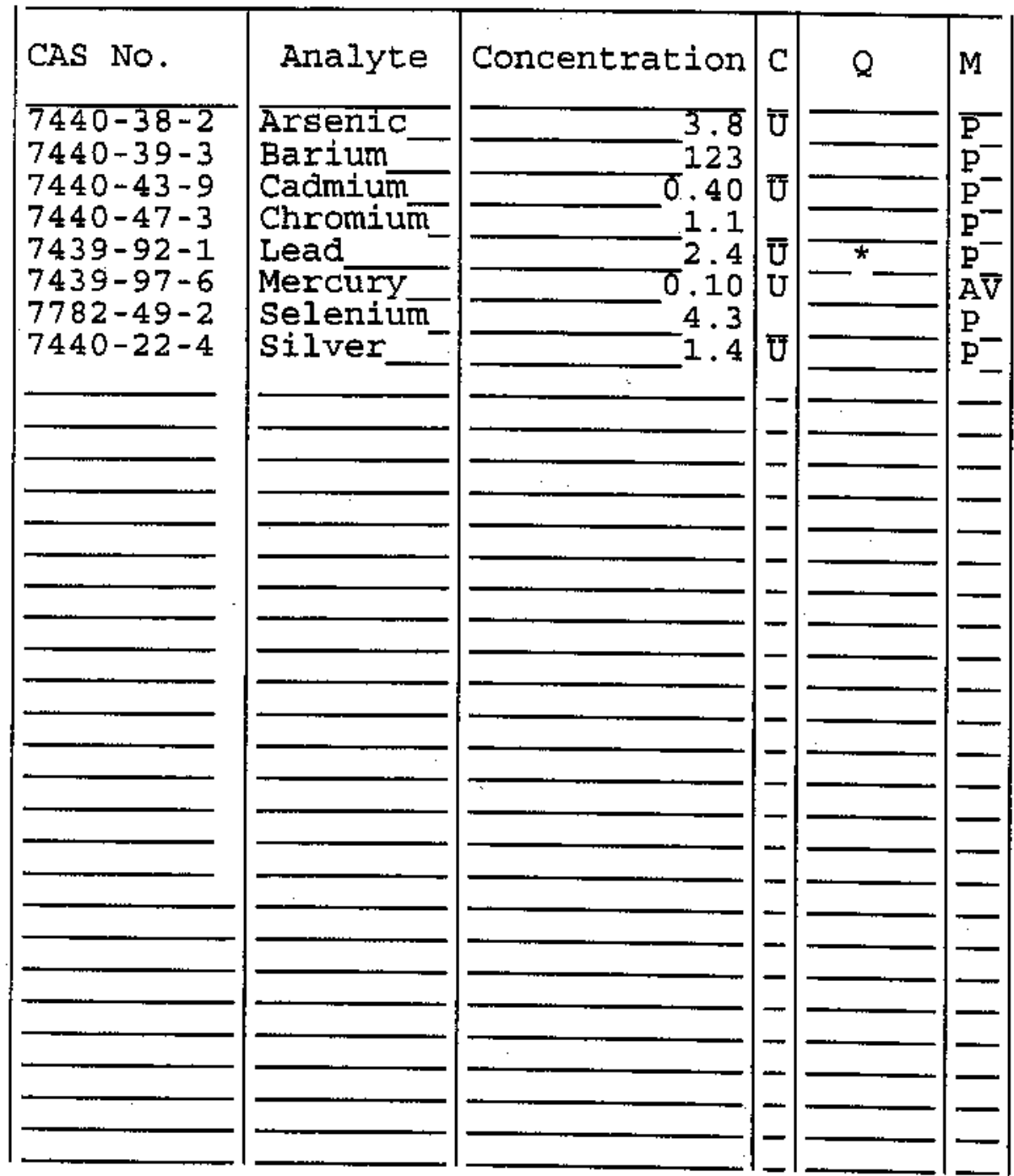

Clarity Before: Clarity After:
Texture:

Artifacts:

Comments :

$060204-\mathrm{T} 2$ 
Case Narrative 


\section{$3 / V L I$ \\ IIONVILL TABORATORY INC:}

Client: BECHTEL-NEVADA V1809

LVL \#: 0212L340

W.o. \#: 60052-001-001-0001-00

Date Received: 12-13-2002

\section{GC/MS VOLATILE-TCLP}

Four (4) water samples were collected on 12-12-2002.

The samples and their associated QC samples were analyzed according to criteria set forth in Lionville Laboratory OPs based on SW 846 Method 8260B for TCLP Volatile target compounds on 12-16,172002.

The following is a summary of the QC results accompanying the sample results and a description of any problems encountered during their analyses:

1. All results presented in this report are derived from samples that met LvLI's sample acceptance policy.

2. The required holding time for analysis was met.

3. All surrogate recoveries were within EPA QC limits.

4. All matrix spike recoveries were within EPA QC limits.

5. All blank spike recoveries were within EPA QC limits.

6. Internal standard area and retention time criteria were met.

7. Manual integrations are performed according to OP L-QA-125 to produce quality data with the utmost integrity. All manual integrations are required to be technically valid and properly documented. Appropriate technical flags are defined in the Glossary ("Technical Flags For
Manual Integration").

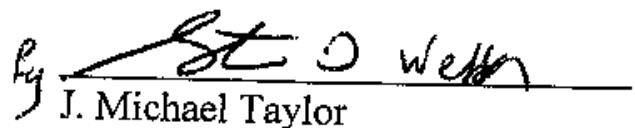

J. Michael Taylor

President

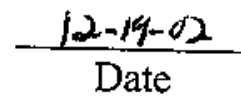

Lionville Laboratory Incorporated

sorn'groupidataibna'bectel-nevadai02 $12-340$.doc

The results presented it this report relate only to the analytical testing and conditions of the samples at receipt and during storage. 


\section{GLOSSARY OF VOA DATA}

\section{DATA QUALIFIERS}

U = Compound was analyzed for but not detected. The associated numerical value is the estimated sample quantitation limit which is included and corrected for dilution and percent moisture.

$\mathbf{J}=$

Indicates an estimated value. This flag. is -used under the following circumstances: 1) when estimating a concentration for tentatively identified compounds (TICs) where 8 .:1 response is assumed; or 2) when the mass spectral data indicate the presence of a compound that meets the identification criteria but the result is jess than the specified detection limit but greater thari zero. For example, if the limit of detection is $10 \mathrm{ug} / \mathrm{L}$ and a concentration of $3 \mathrm{ug} / \mathrm{L}$ is calculated, it is reported as $3 \mathrm{~J}$.

B = This flag is used when the analyte is found in the associated blank as well as in the sample. It indicates possible/probable blank contamination. This flag is also used for a TIC as well as for a positively identified TCL compound.

E = Indicates that the compound was detected beyond the calibration range and was subsequently analyzed at a dilution.

D = Identifies all compounds identified in an analysis at a secondary dilution factor.

$1 .=$ interference.

NQ - Result qualitatively confirmed but not able to quantify.

N = Indicates presumptive evidence of a compound. This flag is only used for tentatively identified compounds (TJCs), where the identification is based on a mass spectral library search. It is applied to all TIC results. For generic characterization of a TIC, such as chlorinated hydrocarbon, the N code is not used.

X $\quad=\quad$ This flag is used for a TIC compound which is quantified relative to a response factor generated from a daily calibration standard (rather than quantified relative to the closest internal standard).

$\mathbf{Y}=$ Additional qualifiers used as required are explained in the case narrative. 
Sample Data for each Sample 


\section{VOLATILE ORGANICS ANALYSIS SHEET}

Lab Name: Lionville Labs, Inc. Work Order: 60052001001

Client: BECHTEL NEVADA V1809

\section{$\operatorname{Matr\pm x:}$}

Sample wt/vol:

Level

(low/med) LOW

WATER

Lab Sample ID: 0212工340m00I

Lab File ID:

9121612

Date Received: $\underline{12 / 13 / 02}$

\% Moisture: not dec.

Date Analyzed: $12 / 16 / 02$

Colums: (pack/cap) CAP
Dilution Factor: 1.00

CAS NO.

COMPOUND

(ug/L or $\mathrm{ug} / \mathrm{Kg}$ ) $\mathrm{MG} / \mathrm{L}$

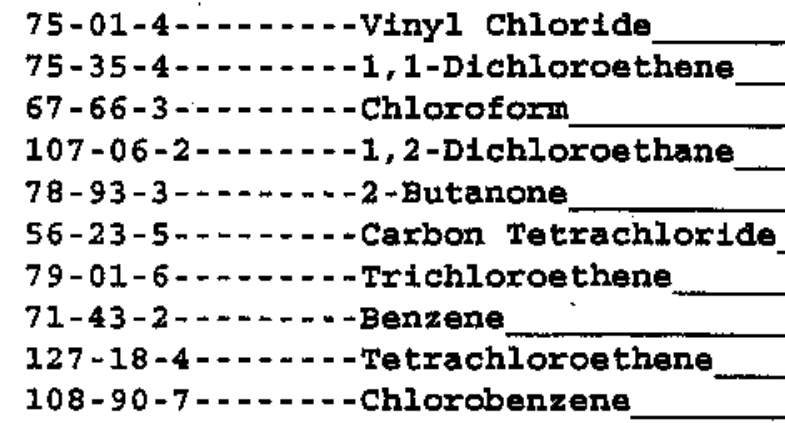

0.010

0.005

0.005

0.005

0.010

0.005

0.005

0.005

0.005

0.005 
$1 \mathbf{A}$

VOLATILE ORGANICS ANALYSIS SHEET

Lab Name: Lionville Labs, Inc. Work Order: 60052001001

\section{Client: BECHTEL NFVADA V1809}

Matr1x:

WATER

$5.00(\mathrm{~g} / \mathrm{mI}) \mathrm{ML}$

Sample wt/vol:

(low/med) LOW

Level:

\& Molsture: not dec.

Column: (pack/cap) CAP
Lab Sample ID: $02121,340-002$

Lab File ID: $\quad$ 9121613

Date Recelved: $12 / 13 / 02$

Date Analyzed: $12 / 16 / 02$

Dilution Factor: 1.00

CONCENTRATION UNITS:

CAS NO.

COMPOUND

(ug/L or ug/Rg) MG/L

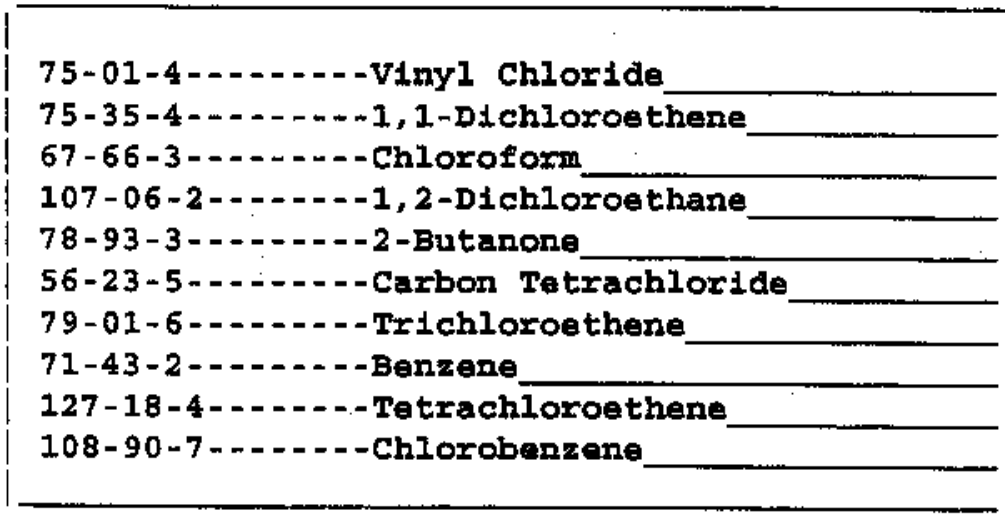

FORM $1 \mathrm{~V}-1$
0.010

0.005

0.005

0.005

0.010

0.005

0.005

0.005

0.005

0.005

. 
$1 \mathrm{~A}$

VOLATILE ORGANICS ANALYSIS SHEET

Lab Name: Iionville Labs, Inc, Work Order: 60052001001

Client: BECHTEL NEVADA V1809

Matrix :

Sample wt/vol:

Level:

(1ow/med)

IOW

\% Molsture: not dec.

Column: (pack/cap) CAP
Lab Sample ID: 0212L340-003

Lab File ID:

9121614

Date Recelved: $12 / 13 / 02$

Date Analyzed: $12 / 16 / 02$

Dilution Factor: 1.00
CONCENTRATION UNITS:

(ug/I or ug/Kg) $\mathrm{MG} / \mathrm{I}$
CAS No.

COMPOUND
0.010

0.005

0.005

0.005

0.010

0.005

0.005

0.005

0.005

0.005 
$1 \mathrm{~A}$

VOLATILE ORGANICS ANALYSIS SHEET

Lab Name: Iionvilie Labs, Inc. Work Order: 60052001001

CLIENT SAMPLE NO.

$1060204-T 2$

Client: BECHTEL NEVADA V1809

Matrix:

WATER

$5.00(\mathrm{~g} / \mathrm{mL}) \mathrm{ML}$

Sample wt/vol:

(low/med) LOW

Level:

(10w/med) now

\& Moisture: not dec.

Column: (pack/cap) CAP
Lab Sample ID: 0212I340-004

Lab File ID: g121615

Date Received: $12 / 13 / 02$

Date Analyzed: $12 / 16 / 02$

Dilution Factor: 1.00
CAS NO.
COMPOUND

\section{CONCENTRATION UNITS:}

(ug/L or $u g / \mathrm{kg}$ ) $\mathrm{MG} / \mathrm{L}$

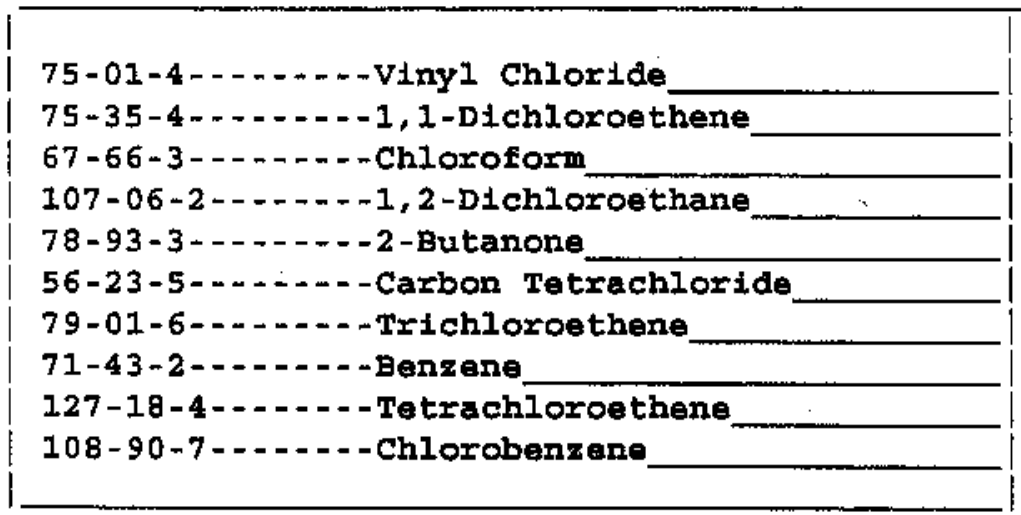

FORM $1 \mathrm{~V}-1$

\begin{tabular}{l|l|}
0.010 & $\mid \mathrm{U}$ \\
0.005 & $\mid \mathrm{U}$ \\
0.005 & $\mid \mathrm{U}$ \\
0.005 & $\mathrm{U}$ \\
0.010 & $\mathrm{U}$ \\
0.005 & $\mathrm{U}$ \\
0.005 & $\mathrm{U}$ \\
0.005 & $\mathrm{U}$ \\
0.005 & $\mid \mathrm{U}$ \\
0.005 &
\end{tabular}

12/88 Rev. 
Case Narrative 


\section{$3 / V L I$ \\ LIONVILI LABORATORV INC.}

\section{Analytical Report}

Client: BECHTEL NEVADA V1809

W.O.\#: 60052-001-001-0001-00

LVL \#: 0212L340

Date Received: 12-13-02

\section{SEMIVOLATILE}

The set of samples consisted of two (2) water samples collected on 12-12-02.

The samples and their associated QC samples were extracted according to Lionville Laboratory OPs based on method 3520 on 12-18-02 and analyzed according to criteria set forth in Lionville Laboratory OPs based on SW 846 Method 8270 C for client specified TCLP Semivolatile target compounds on 1220-02.

The following is a summary of the $\mathrm{QC}$ results accompanying the sample results and a description of any problems encountered during their analyses:

1. All results presented in this report are derived from samples that met LvLI's sample acceptance policy.

2. Samples were extracted and analyzed within required holding time.

3. Non-target compounds were not reported as per client request.

4. All surrogate recoveries were within EPA QC limits.

5. One (1) of twenty-four (24) blank spike recoveries was outside EPA QC limits.

6. Internal standard area and retention time criteria were met.

7. Manual integrations are performed according to OP L-QA-125 to produce quality data with the utmost integrity. All manual integrations are required to be technically valid and properly documented. Appropriate technical flags are defined in the Glossary ("Technical Flags For Manual Integration").

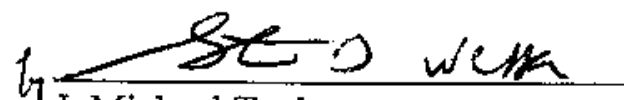

J. Michael Taylor

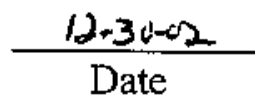

President

Lionville Laboratory Incorporated

pefiligroupldataibraibeclitel Nevadai-0212-340.doc

The results presented is this repolt rejate only to the analytical testing and conditions of the samples at receipt and duving storage. 


\section{GLOSSARY OF BNA DATA}

\section{DATA OUALIFIERS}

$\mathrm{v}=$ Compound was analyzed for but not detected. The associated numerical value is the estimated sample quantitation limit which is included and corrected for dilution and percent moisture.

J = Indicates an estimated value. This flag is used under the following circumstances: 1) when estimating a concentration for tentatively identified compounds (TICs) where a $1: 1$ response is assumed; or 2) when the mass spectral data indicate the presence of a compound that meets the identification criteria but the result is less than the specified detection limit but greater than zero. For example, if the limit of detection is $10 \mathrm{ug} / \mathrm{L}$ and a concentration of $3 \mathrm{ug} / \mathrm{L}$ is calculated, it is reported as $3 \mathrm{~J}$.

B = This flag is used when the analyte is found in the associated blank as well as in the sampie. It indicates possible/probable blank contamination. This flag is also used for a TIC as well as for a positively identified TCL compound.

E - . Indicates that the compound was detected beyond the colibration range and was subsequently analyzed at a dilution.

D $\quad$ Jdentifies all compounds identified in an analysis at a secondary dilution factor.

$1 . \quad$ interference.

NQ = Result qualitatively confirmed but not able to quantify.

A $\quad=\quad$ Indicates that a TJC is a suspected aldol-condensation product.

N . = Indicates presumptive evidence of a compound. This flag is only used for tentatively identified compounds (TJCs), where the identification is based on a mass spectral library search. It is applied to all TIC results. For generic characterization of a TIC, such as chlorinated hydrocarbon, the N code is not used.

$\mathbf{X}=\quad$ This flag is used for a TIC compound which is quantified relative to a response factor generated from a daily calibration standard (rather than quantified relative to the closest internal standard).

Y $=$ Additional qualifiers used as required are explained in the case narrative. 
Sample Data for each Sample 
IB

SEMIVOLATILE ORGANICS ANALYSIS DATA SHEET

Lab Name: Lionville Labs, Inc. Work Oxder: 60052001001
CLIENT SAMPLE NO.

$060204-T 1$

Client: BECHTEL NEVADA V1809

Matrix: (soil/water) WATER

Lab Sample ID: 0212L340-003

Sample wt/vol: 1000

$(\mathrm{g} / \mathrm{mL}) \quad \underline{\mathrm{MI}}$

Lab File ID: $\quad$ A122009

Level: (low/med) LOW

Date Received: $\underline{12 / 13 / 02}$

Moisture:

decanted: $(\mathrm{Y} / \mathrm{N})$

Date Extracted: 12/18/02

Concentrated Extract Volume: 1000(uL)

Date Analyzed: $12 / 20 / 02$

Injection volume: $\underline{2.0}(\mathrm{LI})$

Dilution Factor: 1.00

GPC Cleanup: (Y/N) $\underline{\underline{N}}$

$\mathrm{pH}: \quad 7.0$

CAS NO.

COMPOUND

CONCENTRATION UNITS:

(ug/L or $\mathrm{ug} / \mathrm{Kg}) \mathrm{MG} / \mathrm{L} \quad Q$

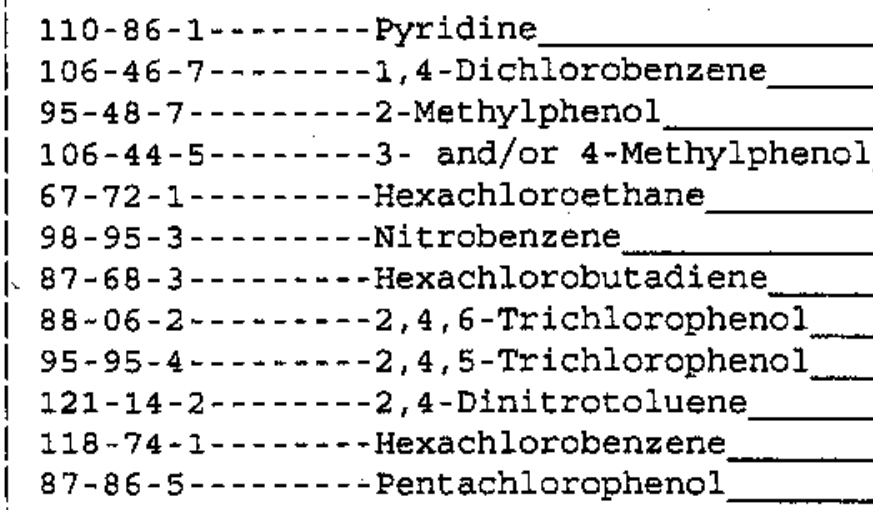

FORM 1 SV-1

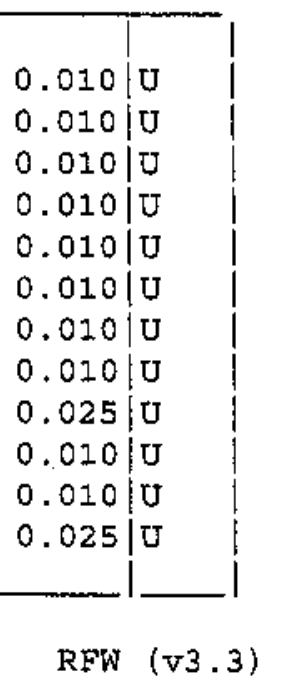


$1 \mathrm{~B}$

SEMIVOLATILE ORGANICS ANAIYSIS DATA SHEET

Lab Name: Lionville Labs, Inc, Work Order: 60052001001

CLIENT SAMPLE NO.

$$
1060204-T 2
$$

Client: BECHTEL NEVADA V1809

Matrix: (soil/water) WATER

Sample wt/vol: 1000

$(g / m L) \quad M L$

Level: $\quad$ (low/med) LOW

号 Moisture: decanted: $(\mathrm{Y} / \mathrm{N})$

Concentrated Extract Volume: 2000 (uL)

Injection volume: 2.0 (uI)
Lab Sample ID: 0212L340-004

Lab File ID: $\underline{\underline{\text { 122010 }}}$

Date Received: $12 / 13 / 02$

Date Extracted: $\underline{12 / 18 / 02}$

Date Analyzed: $12 / 20 / 02$

Dilution Factor: 1.00

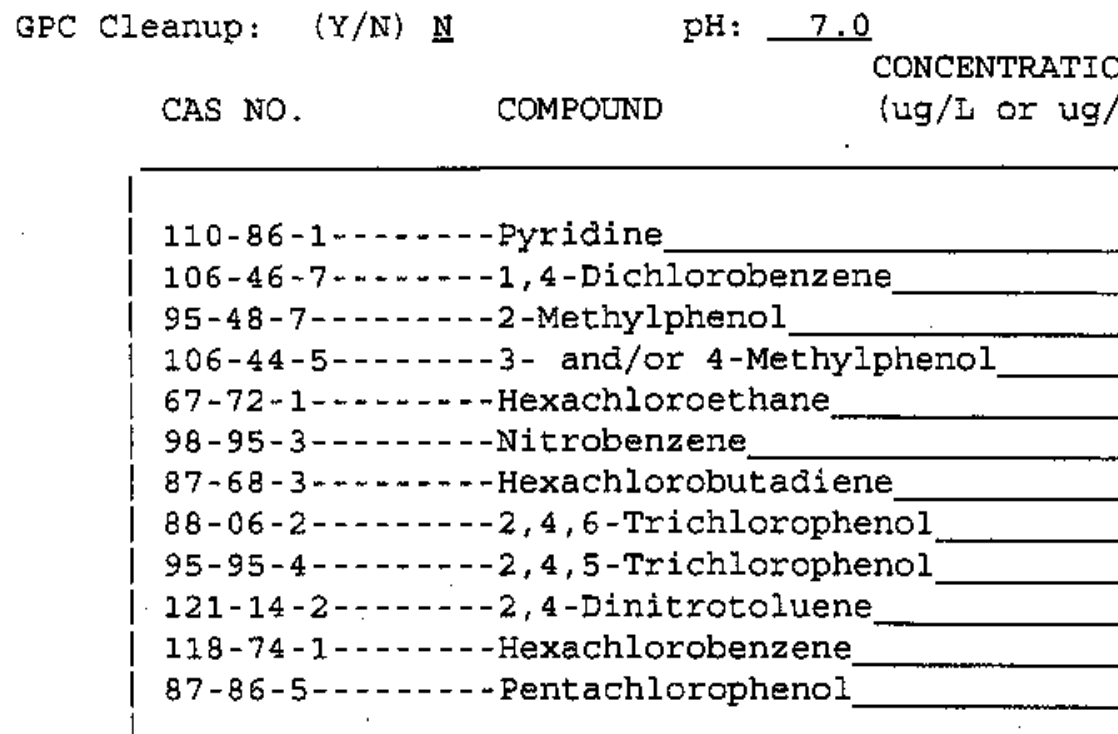

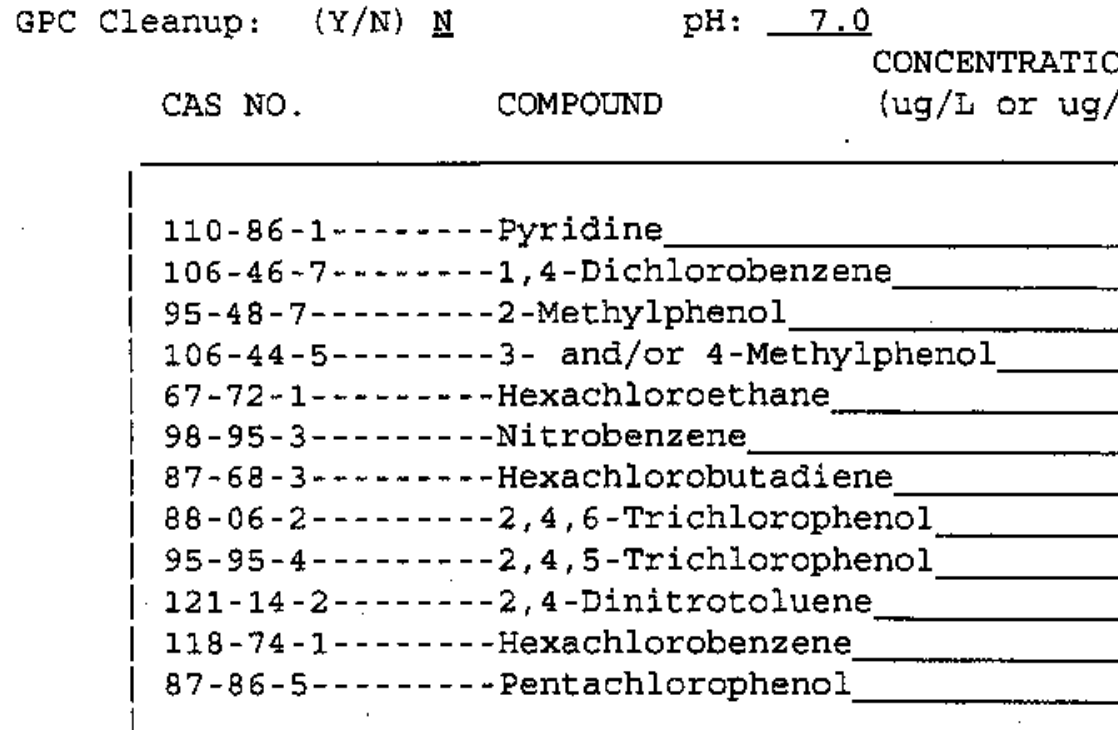

FORM 1 SV-I
RFW (v3.3) 
Case Narrative 


\section{Analytical Report}

LIONVILL LALORATORY INC:

Client: BECHTEL NEVADA V1809

LVL\#: 0212L340

W.O.\#: 60052-001-001-0001-00

Date Received: $12-13-2002$

\section{GRO}

Two (2) water samples were collected on 12-12-2002.

The samples and their associated QC samples were analyzed according to Lionville Laboratory OPs based on SW-846 method 8015 for Gasoline range organics (GRO) on 12-17-2002.

The following is a summary of the QC results accompanying these sample results and a description of any problems encountered during their analyses:

1. All results presented in this report are derived from samples that met LVLI's sample acceptance policy.

2. The required holding time for analysis has been met.

3. The method blank was below the reporting limits for all target compounds.

4. All surrogate recoveries were within acceptance criteria.

5. The blank spike recoveries were within acceptance criteria.

6. All initial calibrations associated with this data set were within acceptance criteria.

7. All continuing calibration standards analyzed prior to sample extracts were within acceptance criteria.

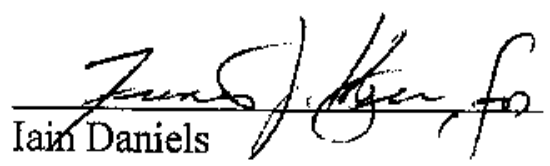

Laboratory Manager

Lionville Laboratory Incorporated

somiRrerouphdatalGRO\{12-340.doc

The resulss presented in this repont relate only to the analytical testing and conditions of the samples at receipt and duings storage. 


\section{DATA QUALIFIERS}

$\mathbf{U}=$ Indicates that the compound was analyzed for but not detected. The minimum detection limit for the sample (not the method detection limit) is reported with the $\mathrm{U}$ (e.g., 10U).

$\mathbf{J}=$ Indicates an estimated value. This flag is used in cases where a target analyte is detected at a level less than the lower quantification level. If the limit of quantification is $10 \mathrm{ug} / \mathrm{L}$ and a concentration of $3 \mathrm{ug} / \mathrm{L}$ is calculated, it is reported as $3 \mathrm{~J}$.

B = This flag is used when the analyte is found in the associated blank as well as in the sample. It indicates possible/probable blank contamination.

$\mathbf{E}=$ Indicates that the compound was detected beyond the calibration range and was subsequently analyzed at a dilution:

I $=$ Interference.

\section{ABBREVIATIONS}

BS = Indicates blank spike in which reagent grade water is spiked with the CLP matrix spiking solutions and carried through all the steps in the method. Spike recoveries are reported.

BSD $=$ Indicates blank spike duplicate.

MS = Indicates matrix spike.

MSD $=$ Indicates matrix spike duplicate.

DL = Indicates that recoveries were not obtained because the extract had to be diluted for analysis.

NA $=$ Not Applicable.

DF $=$ Dilution Factor.

$\mathbf{N R}=\quad$ Not Required.

SP $=$ Indicates Spiked Compound. 


\section{GLOSSARY OF GASOLINE RANGE ORGANICS DATA}

D $=$ This flag identifies all compounds identified in an analysis at a secondary dilution factor.

C $=$ This flag applies to a compound that has been confirmed by GC/MS. 
Sample Data 
Lab Name: Lionville Labs, Inc, Work Oxder: 60052001001

Client: BECHTEL NEVADA V1809

Matrix:

WATER

Sample wt/vol:

$5.00(\mathrm{~g} / \mathrm{mL}) \underline{\mathrm{ML}}$

Level: (low/med) LOW

음 Moisture: not dec.

Column: (pack/cap) CAP

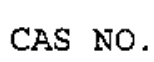

COMPOUND
Lab Sample ID: $0212 \mathrm{~L} 340.003$

Lab File ID: BLKLACHJ

Date Received: $12 / 13 / 02$

Date Analyzed: 12/17/02

Dilution Factor: 1.00

CONCENTRATION INITS :

(ug/L or $\mathrm{ug} / \mathrm{Kg}$ ) $\mathrm{UG} / \mathrm{L}$

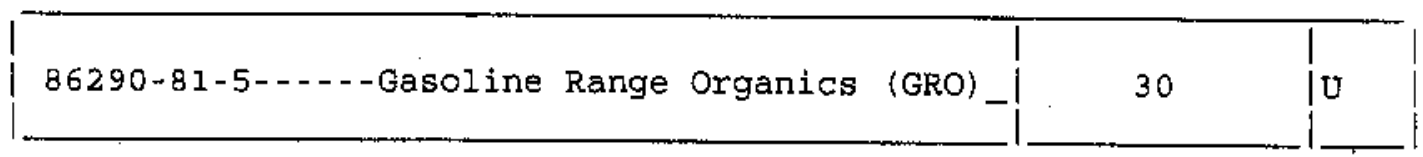

12/88 Rav. 
Lab Name: Lionville Labs, Inc. Work order: 60052001001

Client: BECHTEL NEVADA V1809

Matrix:

WATER -

Sample wt/vol: $\quad 5.00(\mathrm{~g} / \mathrm{mL}) \underline{\mathrm{ML}}$

Level: (low/med) LOW

\&oisture: not dec.

Columi: (pack/cap) CAP

CAS NO.

COMPOUND
Lab Sample ID: 02125340-004

Lab File ID: BLKIACHJ

Date Recejved: $12 / 13 / 02$

Date Analyzed: $12 / 17 / 02$

Dilution Factor: 1.00

CONCENTRATION UNITS: (ug/L or $\mathrm{ug} / \mathrm{Kg}$ ) $\mathrm{UG} / \mathrm{L}$

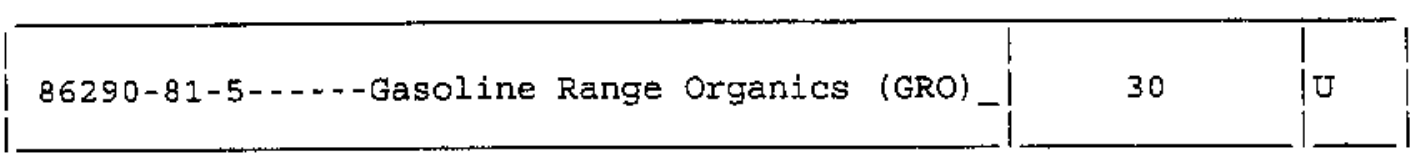

12/88 Rev. 
Case Narrative 


\section{Analytical Report}

LIONVILL LABORAIOKY INC

Client: BECHTEL NEVADA V1809

LVL\#: 0212L340
W.O.\#: 60052-001-001-0001-00

Date Received: 12-13-2002

\section{DIESEL RANGE ORGANICS}

Two (2) water samples were collected on 12-12-2002.

The samples and their associated QC samples were extracted on 12-16-2002 and analyzed according to Lionville Laboratory OPs on 12-18-2002. The extraction procedure was based on method 3520 and the extracts were analyzed based on method 8015B for Diesel Range Petroleum. Hydrocarbons.

1. All results presented in this report are derived from samples that met LvLI's sample acceptance policy.

2. The required holding time for extraction and analysis has been met.

3. The method blank was below the reporting limits for all target compounds.

4. All surrogate recoveries were within acceptance criteria.

5. The blank spike recoveries were within acceptance criteria.

6. All initial calibrations associated with this data set were within acceptance criteria.

7. All continuing calibration standards analyzed prior to sample extracts were within acceptance criteria.

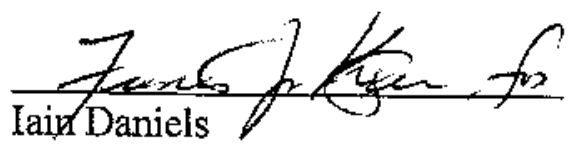

Laboratory Manager

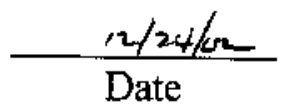

Lionville Laboratory Incorporated

som\}r:htroup tolatatdrotbechteltbech12L-340,doc

The results presented in this repont relate only to the analytical testing and conditions of the samples at receipt and during stonage. $f$ 


\section{GLOSSARY OF DIESEL RANGE ORGANICS DATA}

\section{DATA QUALIFIERS}

$\mathbf{U}=$ Indicates that the compound was analyzed for but not detected. The minimum detection limit for the sample (not the method detection limit) is reported with the $\mathrm{U}$ (e.g., 10U).

J = Indicates an estimated value. This flag is used in cases where a target analyte is detected at a level less than the lower quantification level. If the limit of quantification is $10 \mathrm{ug} / \mathrm{L}$ and a concentration of $3 \mathrm{ug} / \mathrm{L}$ is calculated, it is repotted as $3 \mathrm{~J}$.

B = This flag is used when the analyte is found in the associated blank as well as in the sample. It indicates possible/probable blank contamination.

$\mathrm{E}=$ Indicates that the compound was detected beyond the calibration range and was subsequently analyzed at a dilution.

I $=$ Interference.

\section{ABBREVLATIONS}

BS $=$ Indicates blank spike in which reagent grade water is spiked with the CLP matrix spiking solutions and carried through all the steps in the method. Spike recoveries are reported.

BSD $=$ Indicates blank spike duplicate.

MS = Indicates matrix spike.

MSD = Indicates matrix spike duplicate.

DL $=$ Indicates that recoveries were not obtained because the extract had to be diluted for analysis.

NA $=$ Not Applicable.

DF $=$ Dilution Factor.

NR $=\quad$ Not Required.

SP $=$ Indicates Spiked Compound. 


\section{GLOSSARY OF DIESEL RANGE ORGANICS DATA}

D $=$ This flag identifies all compounds identified in an analysis at a secondary dilution factor.

C = This flag applies to a compound that has been confirmed by GC/MS. 
Sample Data 
Lab Name: Lionville Labs, Inc. Work Order: 60052001001

Client: BECHTEL NEVADA V1809

Matrix:

WATER

Sample $w t / v o l:$ $990(\mathrm{~g} / \mathrm{mL}) \mathrm{ML}$

Level: (low/med) LOW

\% Moisture: not dec.

Column: (pack/cap) CAP

COMPOUND

Lab Sample ID: 0212L340-003

Lab File ID:

BLKI_ACHJ

Date Received: 12/13/02

Date Analyzed: 12/18/02

Dilution Factor: 1.00

CONCENTRATION UNITS:

(ug/L or $\mathrm{ug} / \mathrm{Kg}) \mathrm{ug} / \mathrm{L}$

68334-30-5---.-Diesel Range Organics

00-00-0000----Motor Oil

303

303

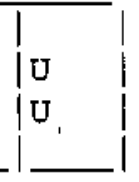

$12 / 88$ Rev. 
Lab Name: Lionville Labs, Inc. Work Order: 60052001001

Client: BECHTEL NEVADA V1809

Matrix:

WATER

Lab Sample ID: .0212L340-004

Sample wt/vol:

$990(\mathrm{~g} / \mathrm{mL}) \mathrm{MI}$

Lab File ID:

BLKIACHJ

Leve 1: $\quad$ (low/med) LOW

Date Received: $12 / 13 / 02$

Moisture: not dec.

Date Analyzed: $12 / 18 / 02$

Column: (pack/cap) CAP

Dilution Factor: 1.00

CONCENTRATION UNITS:

CAS NO. COMPOUND

(ug/L or $u g / \mathrm{Kg}) \underline{u g} / \mathrm{L}$

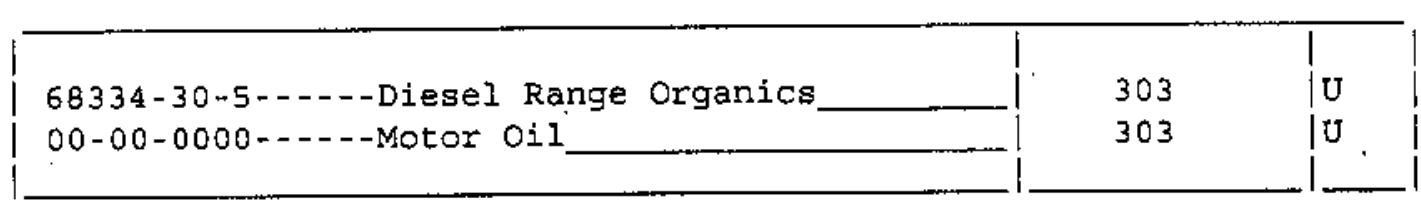

$12 / 88$ Rev. 
CLOSURE REPORT - CAU 330

Section: Appendix B

Revision: 0

Date: July 2003

\section{THIS PAGE INTENTIONALLY LEFT BLANK}


CLOSURE REPORT - CAU 330

Section: Appendix B

Revision: 0

Date: July 2003

\title{
SAMPLE DELIVERY GROUP
}

\author{
V1810
}


CLOSURE REPORT - CAU 330

Section: Appendix B

Revision: 0

Date: July 2003

\section{THIS PAGE INTENTIONALLY LEFT BLANK}




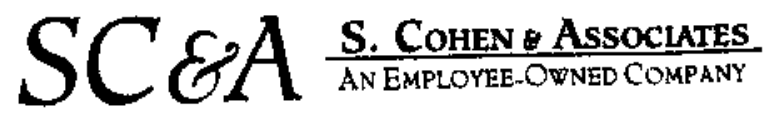

\author{
January 9, 2003
}

Mr. Ted Redding

USDOE Zone 1

Bldg. 652, Room 2

M/S NTS 273

Mercury, NV 89023

Dear Mr. Redding:

On December 13, 2002, two water samples, (SDG V1810) were received for analysis at the Sanford Cohen and Associates (SC\&A) Southeastern Environmental Laboratory. The samples were assigned Laboratory Report Identification Code 3847. Enclosed the Sample Data Package containing the results of the analyses of these samples.

If you have any questions please do not hesitate to call.

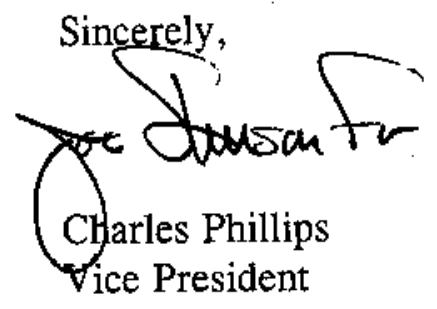




\title{
COVER PAGE
}

\author{
Sanford Cohen \& Associates \\ Southeastern Environmental Laboratory \\ 1000 Monticello Court \\ Montgomery, Alabama 36117
}

Laboratory Code: SCA Subcontract Number: 30025

Laboratory Report Identification Code: 3847 SDG: V1810

Sample Matrix: Water

\begin{tabular}{||l|l|}
\hline \multicolumn{1}{|c|}{ Site Sample Numbers } & \multicolumn{1}{|c|}{ Laboratory Sample Number } \\
\cline { 2 - 2 } & \multicolumn{1}{|c|}{ Gamma Spectrometry } \\
\hline \hline $060204-\mathrm{T} 1$ & NTS02-3847-01 \\
\hline $060204-\mathrm{T} 2$ & NTS02-3847-02 \\
\hline Laboratory Control Sample (LC) & SCAQC-3847-LC1 \\
\hline Duplicate (LD) & SCAQC-3847-LD1 \\
\hline Preparation Blank (PB) & SCAQC-3847-PB \\
\hline
\end{tabular}

Comments: There were no problems encountered during sample receiving.

"I certify that this sample data package is in compliance with SOW requirements, both technically and for completeness, other than the conditions detailed above. Release of the data contained in this hard-copy sample data package and the computer-readable EDD, as applicable, submitted on diskette or by modem, has been authorized by the laboratory Manager or the Manager's designee, as verified by the following signature."

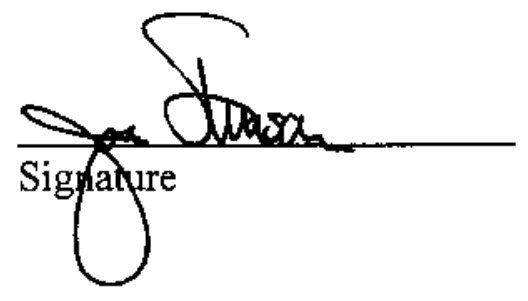

Joe Stinson

Name
Laboratory Manager

Title $\underline{1 / 9 / 03}$

Date 



\section{CASE NARRATIVE \\ SDG V1810 \\ Laboratory Report Identification Number: 3847}

January 9,2003

\section{Introduction}

On December 13, 2002, two water samples, (SDG V1810), were received for analysis at the Sanford Cohen and Associates (SC\&A) Southeastern Environmental Laboratory, located in Montgomery, Alabama. The chain-of-custody accompanying the sample requested that it be analyzed within seven days of receipt at the laboratory. The samples were analyzed in accordance with the Bechtel Nevada Services Subcontract Task Order Agreement Form, Exhibit B, Statement of Work and Specifications, Rev 1, 1/23/01.

\section{Analytical Methodology}

The radioanalytical results reported for each sample include the site and laboratory sample identification numbers, collection date, method of analysis, and the quality control samples that were analyzed concurrently. Samples were analyzed in accordance with the following method.

\begin{tabular}{||c|c|l|l||}
\hline Radionuclide & $\begin{array}{c}\text { Method } \\
\text { Number }\end{array}$ & \multicolumn{1}{|c|}{$\begin{array}{c}\text { Method } \\
\text { Name }\end{array}$} & \multicolumn{1}{c|}{$\begin{array}{c}\text { Counting } \\
\text { Method }\end{array}$} \\
\hline \hline $\begin{array}{l}\text { Gamma Emitting } \\
\text { Radionuclides }\end{array}$ & EPA 901.1 & $\begin{array}{l}\text { Gamma Emitting } \\
\text { Radionuclides }\end{array}$ & $\begin{array}{l}\text { Gamma } \\
\text { Spectrometry }\end{array}$ \\
\hline
\end{tabular}

\section{Analytical Results}

\section{Deficiencies}

None.

Matrix Interferences

There were no indications of matrix interference.

\section{Dilutions}

There were no dilutions. 


\section{Detection Limits}

The required detection limits (RDL) were met for all analyses.

Reanalysis

There were no reanalysis.

Deviations from Protocols

There were no deviations from the written protocols and analytical methods.

Contacts with the CTR

There was no contact with the CTR regarding these samples.

\section{Quality Control}

Site Samples Used for Quality Control Samples:

\begin{tabular}{||c|c|c||}
\hline Site Sample Number & Laboratory Sample Number & $\begin{array}{c}\text { Type of Quality Control Analysis } \\
\text { Sample }\end{array}$ \\
\hline \hline Laboratory Type II Water & SCAQC-3847-LCI & Laboratory Control Sample \\
\hline 060204-Tl & SCAQC-3847-LDI & Laboratory Duplicate Sample \\
\hline Laboratory Type Il Water & SCAQC-3847-PB & Preparation Blank \\
\hline
\end{tabular}

The analytical results of all quality control samples met the acceptance criteria specified in the SOW.

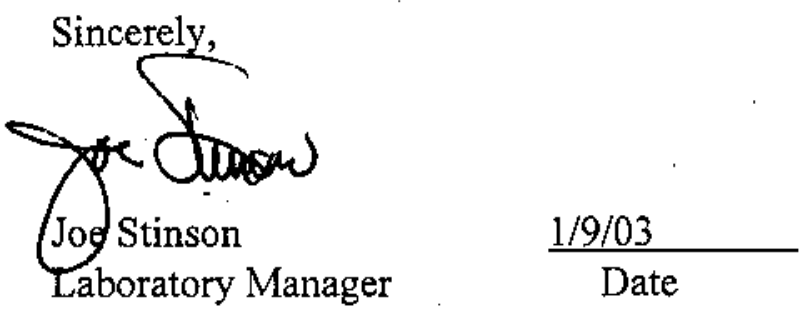




\section{Sanford Cohen \& Associates Southeastern Environmental Laboratory}

\section{Radioanalytlcal Results}

Report Identification Number: V1810

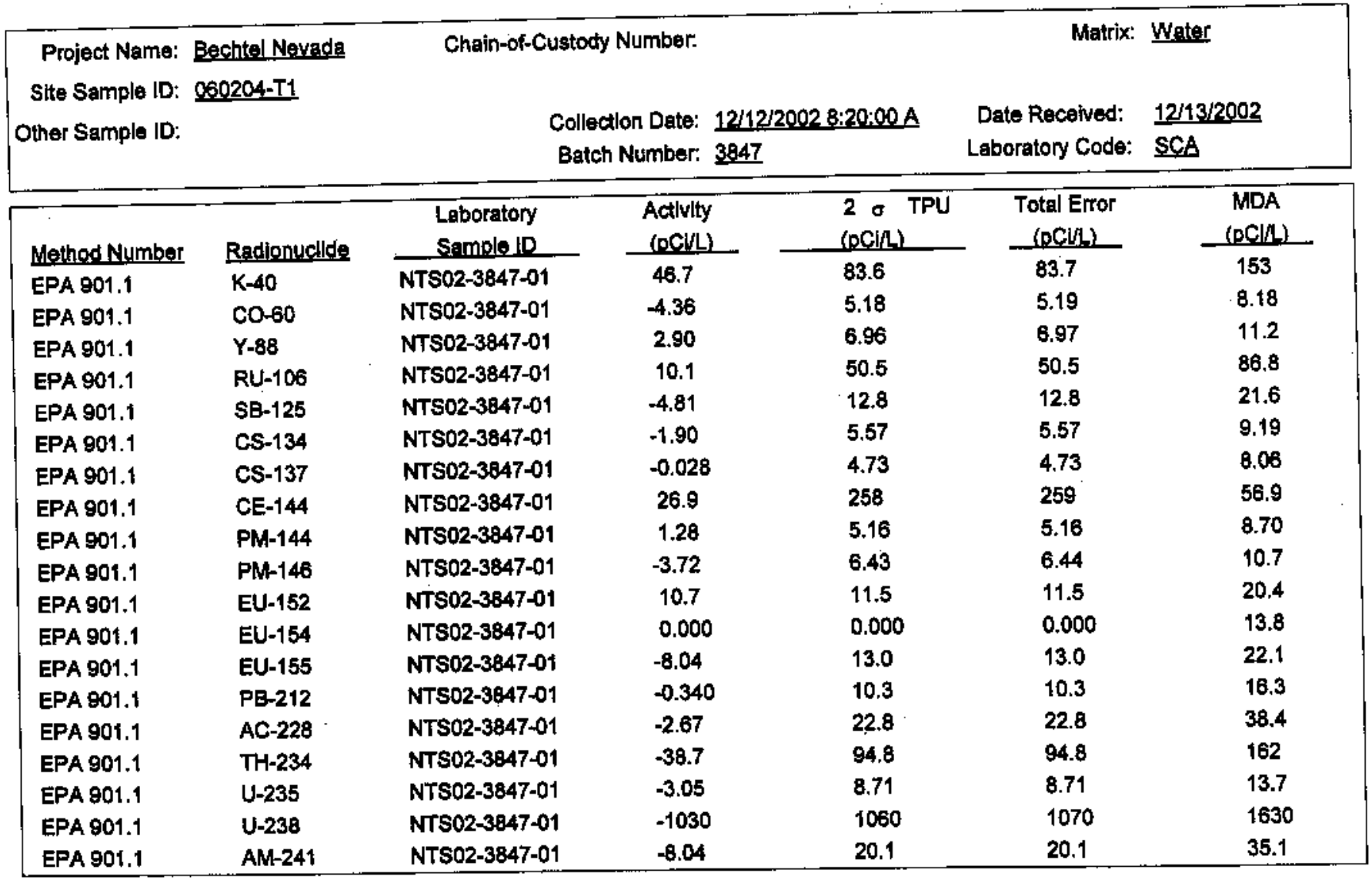

\begin{tabular}{|c|c|c|c|c|}
\hline \multicolumn{5}{|c|}{ Qually Control Samples } \\
\hline Radionuclide & Laboratory Control (LC) & Laboratory Duplicate (D) & Matrix Spike (MS) & Preparation Blank (PB) \\
\hline Gamma & SCAQC-3847-LC1 & SCAQC-3847-LD1 & & SCAQC-3847-PB \\
\hline
\end{tabular}




\section{Sanford Cohen \& Associates \\ Southeastern Environmental Laboratory \\ Radloanalytical Results}

Report Identification Number: V1810

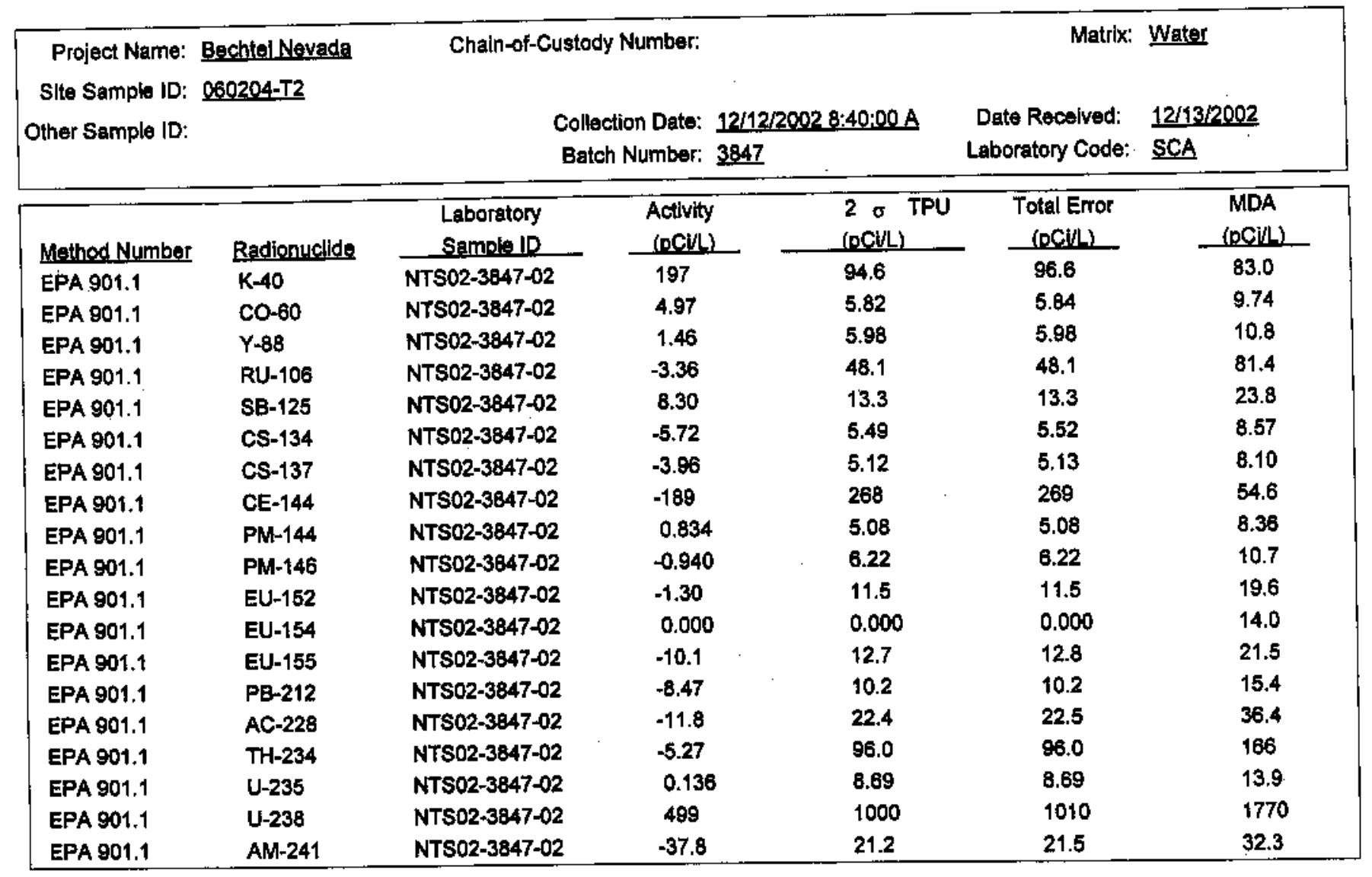

\begin{tabular}{|c|c|c|c|c|}
\hline \multicolumn{5}{|c|}{ Quallty Control Samples } \\
\hline Radionuclide & Laborator Control (LC) & Laboratory Duplicate (LD) & Matrix Spike (MS) & Preparatlon Blank (PB) \\
\hline Gamma & SCAQC-3847-LC1 & SCAQC-3847-LD1 & & SCAQC-3847-PB \\
\hline
\end{tabular}


CLOSURE REPORT - CAU 330

Section: Appendix B

Revision: 0

Date: July 2003

\section{THIS PAGE INTENTIONALLY LEFT BLANK}


CLOSURE REPORT - CAU 330

Section: Appendix B

Revision: 0

Date: July 2003

\section{SAMPLE DELIVERY GROUP}

\section{V1888}


CLOSURE REPORT - CAU 330

Section: Appendix B

Revision: 0

Date: July 2003

\section{THIS PAGE INTENTIONALLY LEFT BLANK}


225 Commerce Drive $\bullet$ Fort Collins, CO $80524 \bullet(800)$ 443-1511 $\bullet$ (970) 490-1511 • FAX (970) 490-1522

February 27, 2003

Mr. Ted Redding

Bechtel Nevada

US DOE Zone 1, Bldg 652,

Rm 2.M/S NTS273

Mercury, NV, 89023

RE: Paragon Workorder: 03-02-040

Client Project Name: CAU 330

Client Project Number: V1888

Dear Mr. Redding;

One water sample was received from Bechtel Nevada on February 11, 2003. The samples were scheduled for Tritium (pages 1-48) and Gross Alpha/Beta (pages 1-146) analyses.

The results for these analyses are contained in the enclosed reports.

Thank you for your confidence in Paragon Analytics, Inc. Should you have any questions, please call.

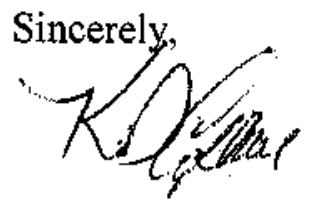

Paragon Analytics, Inc.

Ken Campbell

Project Manager

$\mathrm{KDC} / \mathrm{mc}$

Enclosure; Report 


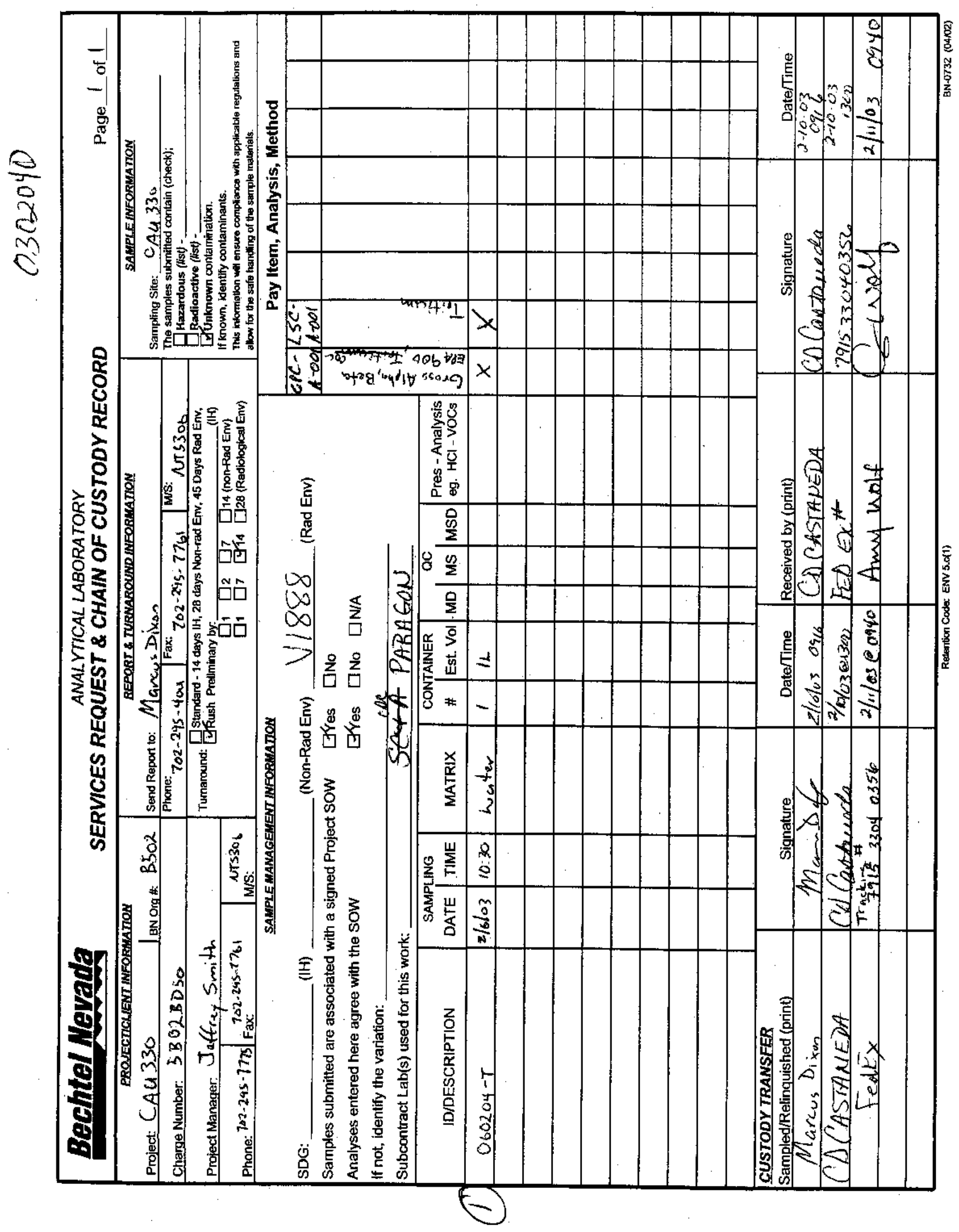




\section{Paragon Analytics, Inc. Radiochemistry Case Narrative Tritium}

\section{Bechtel Nevada \\ CAU 330 / V1888 \\ PAI WO 0302040}

1. This report consists of one water sample received by Paragon on $2 / 11 / 03$.

2. This sample was prepared according to Paragon Analytics, Inc. procedures SOP700R7.

3. The sample was analyzed for the presence of tritium according to Paragon Analytics, Inc. procedure SOP704R5. The analysis was completed on 2/21/03.

4. The analysis result for this sample is reported in units of $\mathrm{pCi} / \mathrm{L}$. The sample was not filtered prior to analysis.

5. Due to current software limitations, the DER determinations in this report were calculated using the 2 sigma TPU. The SOW indicates that the 1 sigma TPU be used in the DER determination. However, the requested DER limit of less than 3 at the 1 sigma level (which is equivalent to 1.5 at the 2 sigma level) was achieved. Data quality is not affected.

6. The matrix spike for this batch was performed on Bechtel Nevada sample PAI ID 0301164-1, from PAI WO\# 0301164. This matrix spike is shared with WO\# 0302040, as they were both prepared in batch LS01572. Results for the matrix spike are in Section 2 of the following report.

7. For this analysis, "Window 2 " is monitored for high energy beta contamination. Sample 060204-T (PAI ID 0302040-1), laboratory control sample LS01572LCS1; and reagent blank LS01572RB1 had a "Window 2" count rates above the upper control limit of 38.49, at 38.70, 38.54, and 39.15 respectively. Sample 060204-T (PAI ID 0302040-1) and LS01572RB1 had measured activity less than the achieved MDC, therefore data quality is not believed to be affected for these samples. Due to the spiked nature and elevated activity of LS01572LCS1, any bias is insignificant compared to sample activity. Data is reported without further qualification. Please refer to QASS 252620.

8. No further anomalous situations were noted during the preparation and analysis of this sample. All remaining quality control criteria were met. 
The data contained in the following report have been reviewed and approved by the personnel listed below. In addition, Paragon Analytics, Inc. certifies that the analyses reported herein are true, complete and correct within the limits of the methods employed.

Canfemich

Clare Lenich

Radiochemistry Instrument Technician

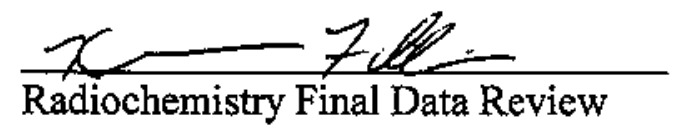

2124/6s

Date

$2-25-03$ 


\section{PARAGON ANALYTICS, INC. Radiochemistry Data Package}

Section 3

\section{INDIVIDUAL SAMPLE RESULTS}




\section{Paragon Analytics, Inc. Radiochemistry Case Narrative Gross Alpha/Beta}

\section{Bechtel Nevada \\ CAU 330 / V1888 \\ PAI WO 0302040}

1. This report consists of one water sample received by Paragon on 2/11/03.

2. This sample was prepared according to Paragon Analytics, Inc. procedure PAI SOP702R15.

3. The sample was analyzed for gross alpha and beta activity by gas flow proportional counting according to Paragon Analytics, Inc. procedure PAI SOP724R7. The analyses were completed on $2 / 20 / 03$. Gross alpha results are referenced to ${ }^{241} \mathrm{Am}$. Gross beta results are referenced to ${ }^{90} \mathrm{Sr} / \mathrm{Y}$.

4. The analysis results for this sample are reported in units of $\mathrm{pCi} / \mathrm{L}$. The sample was not filtered prior to analysis.

5. Due to current software limitations, the DER determinations in this report were calculated using the 2 sigma TPU. The SOW indicates that the 1 sigma TPU be used in the DER determination. However, the requested DER limit of less than 3 at the 1 sigma level (which is equivalent to 1.5 at the 2 sigma level) was achieved. Data quality is not affected.

6. No anomalous situations were encountered during the preparation or analysis of this sample. All quality control criteria were met.

The data contained in the following report have been reviewed and approved by the personnel listed below. In addition, Paragon Analytics, Inc. certifies that the analyses reported herein are true, complete and correct within the limits of the methods employed.

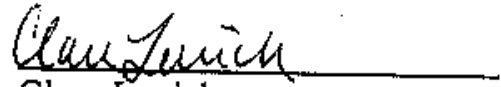

Clare Lenich

Radiochemistry Instrument Technician

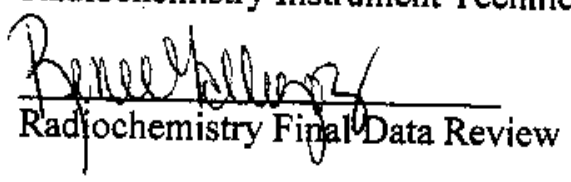

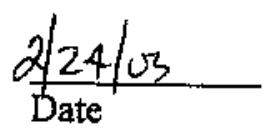

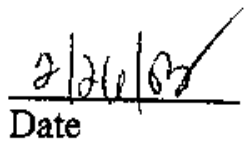




\section{PARAGON ANALYTICS, INC. Radiochemistry Data Package}

Section 1

\section{SAMPLE RESULTS SUMMARY}




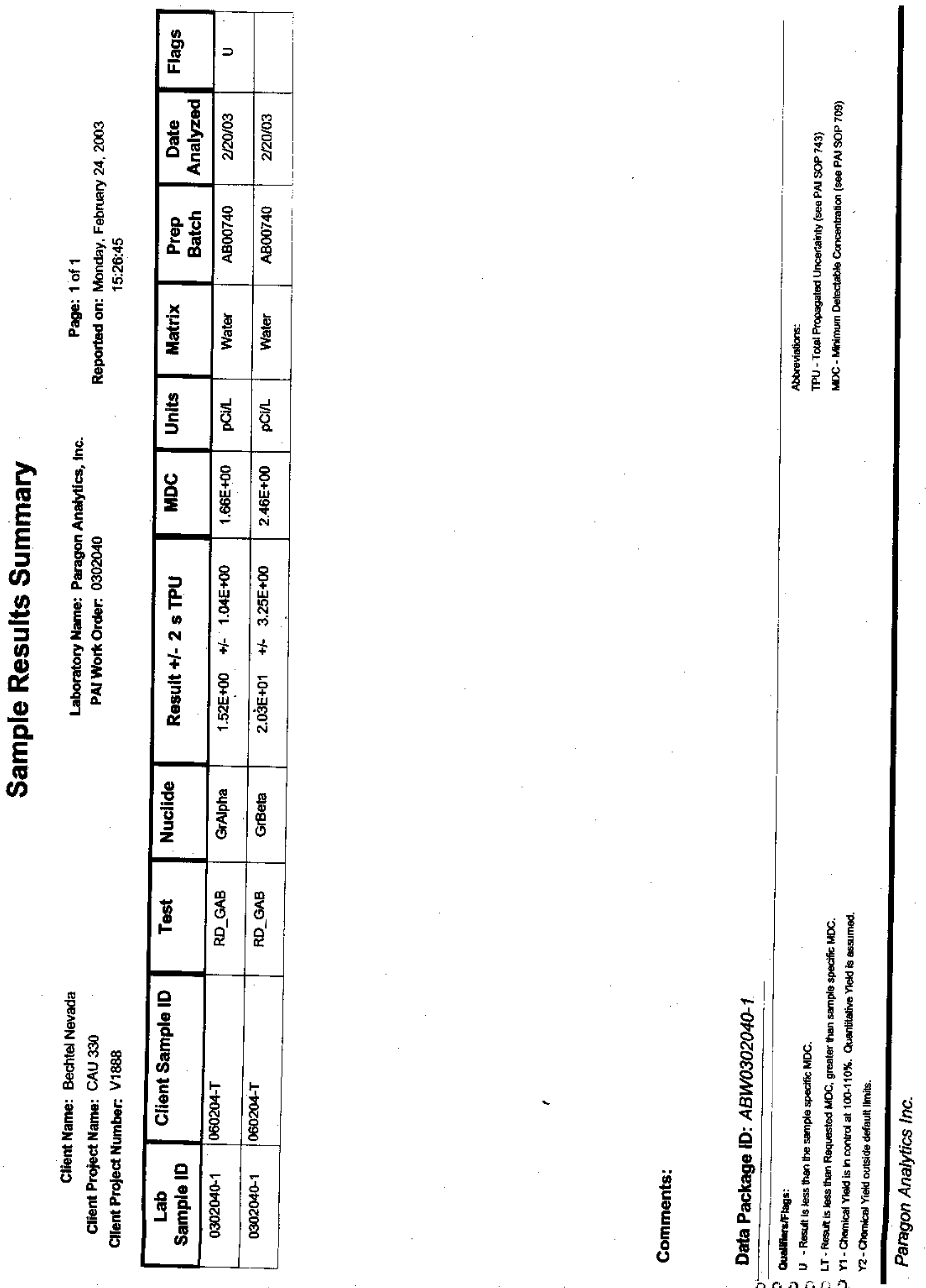




\title{
Tritium Analysis By Liquid Scintillation
}

\author{
Method 906.0M
}

Sample Results

Cllent Name: Bechtel Nevada

Client Project Name: CAU 330

Cllent Project Number: V1888
Page: 1 of 1

Reported on: Monday, February 24, 2003

16:31:24

Laboratory Name: Paragon Analytics, Inc.

PAl Work Order: 0302040

$060204-T$
0
0

Sample Matrix: Water

Date Prepared: 20-Fob-03

Prep soP: PAI 700R7

Prep Batch: LSO1572
Date Collected: 06-Feb-03

Date Analyzed: 21-Feb-03

Analytical SOP: PAI 704R5
Final Aliquot: $0.01000 \mathrm{~L}$

Report Basis: As Received

Count TIme (min.): 80

\begin{tabular}{|c|c|c|c|c|}
\hline Target Nuclide & Result +l- 2 s TPU & MDC & $\begin{array}{c}\text { Reporting } \\
\text { Units }\end{array}$ & Lab Quallfier \\
\hline $\mathrm{H}-3$ & $7.53 \mathrm{E}+01+/-2.31 \mathrm{E}+02$ & $3.84 \mathrm{E}+02$ & $\mathrm{pC} / \mathrm{L}$ & $\mathrm{U}$ \\
\hline
\end{tabular}

\section{Comments:}

Qualifierastage:

$U$ - Result is less then the sample specific MDC.

Yq . Chemical Yield lo in control at 100- $110 \%$. Quentitative Yleld ls assumed.

Y2 - Chemical Yield outside default Ilmits.

LT - Result is lass than Requested MDC, grester than sample specific MDC.
Abbreviations:

TPU - Total Propagated Uncertainty (eee PA SOP 743)

MDC - Minimum Detectable Concentration (ses PAI SOP 709) 
CLOSURE REPORT - CAU 330

Section: Appendix B

Revision: 0

Date: July 2003

\section{THIS PAGE INTENTIONALLY LEFT BLANK}


CLOSURE REPORT - CAU 330

Section: Appendix B

Revision: 0

Date: July 2003

\title{
SAMPLE DELIVERY GROUP
}

\author{
V1912
}


CLOSURE REPORT - CAU 330

Section: Appendix B

Revision: 0

Date: July 2003

\section{THIS PAGE INTENTIONALLY LEFT BLANK}




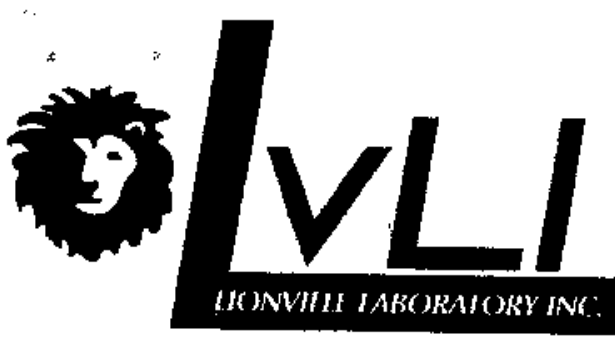

25 March 2003

Mr. Theodore Redding

Bechtel Nevada Corporation

2621 Losee Road

Mail Stop NTS273

Las Vegas, NV 89030-4134

RE: Subcontract No. 30028, Task Order No. 1

Data Report for LVL Batch 0303L897

SDG\#: V1912 Chain: Project CAU 330

Dear Mr. Redding:

Enclosed please find the data report for 2 sludge samples and 2 water samples received 7 March 2003 for analysis for TCLP VOAs, TCLP SVOAs, PCBs, TCLP metals, and TPH GRO/DRO/ORO on a 14 day turnaround time. The invoice is enclosed. An EDD is not required. Data were faxed 20 and 21 March.

Please do not hesitate to contact me at (610) 280-3029 with any questions or at any time we may be of service.

Very truly yours,

Lionville Laboratory Incorporated

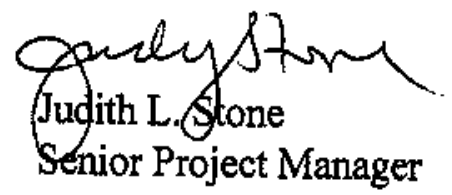

Enclosure: 


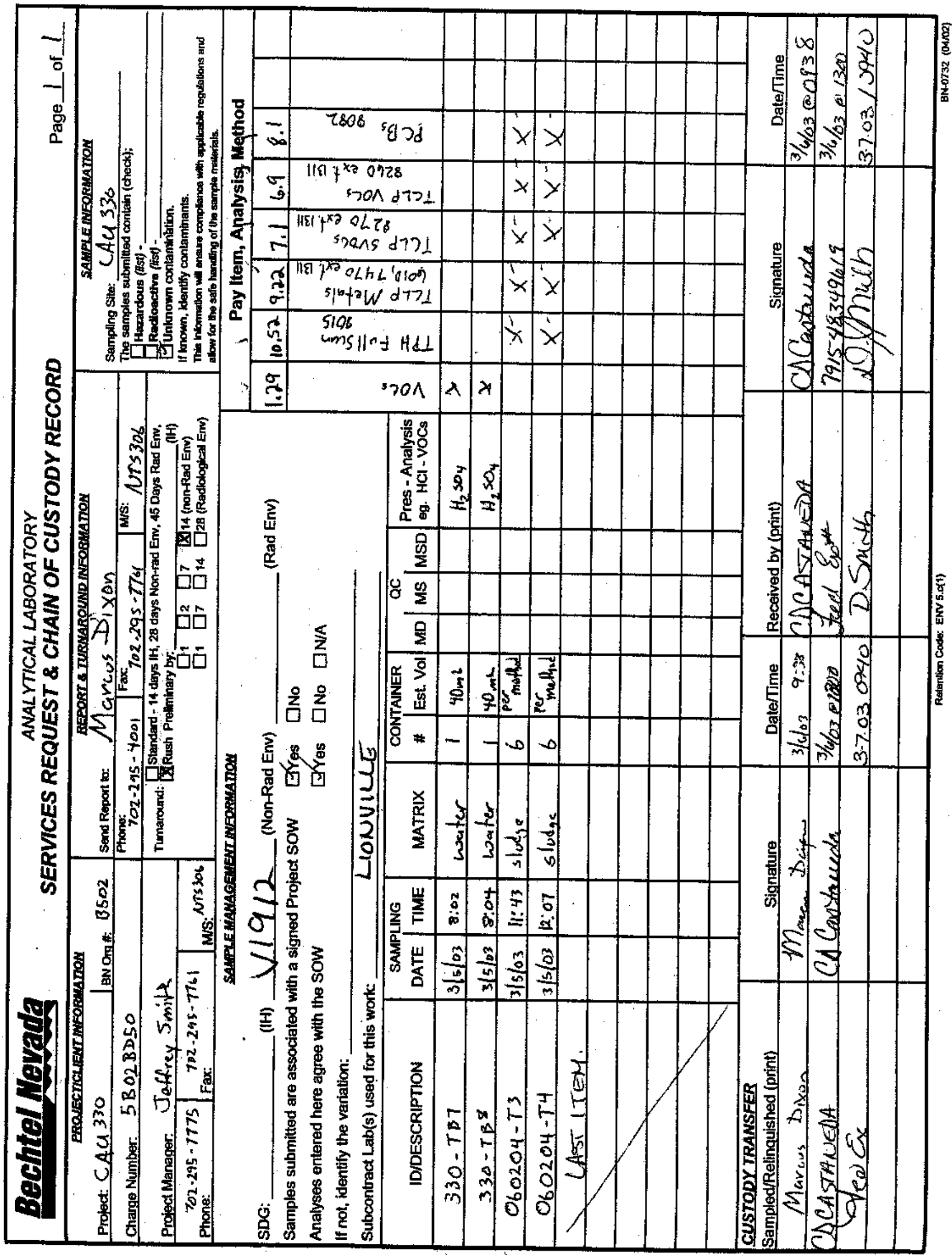


Case Narrative 


\section{olvLI \\ UONVHLL IABOHAIRY INC}

Client: BECHTEL-NEVADA V1912

LVL \#: 0303L897

W.O. \#: 60052-001-001-0001-00

Date Received: 03-07-2003

\section{GC/MS VOLATILE-TCLP}

The set of samples consisted of two (2) water and two (2) leachate samples.

The leachate samples were generated on 03-11-2003 from sludge samples. All samples were collected on 03-05-2003.

The samples and their associated QC samples were analyzed according to criteria set forth in Lionville Laboratory OPs based on SW 846 Method 8260B for TCLP Volatile target compounds on 03-12-2003.

The following is a summary of the QC results accompanying the sample results and a description of any problems encountered during their analyses:

1. All results presented in this report are derived from samples that met LvLI's sample acceptance policy.

2. The required holding time for analysis was met.

3. The leachate samples were analyzed at a 5-fold dilution due to the sample matrix.

4. All surrogate recoveries were within EPA QC limits.

5. All matrix spike recoveries were within EPA QC limits.

6. All blank spike recoveries were within EPA QC limits.

7. Internal standard area and retention time criteria were met.

8. Manual integrations are performed according to OP L-QA-125 to produce quality data with the utmost integrity. All manual integrations are required to be technically valid and properly documented. Appropriate technical flags are defined in the Glossary ("Technical Flags For Manual Integration").

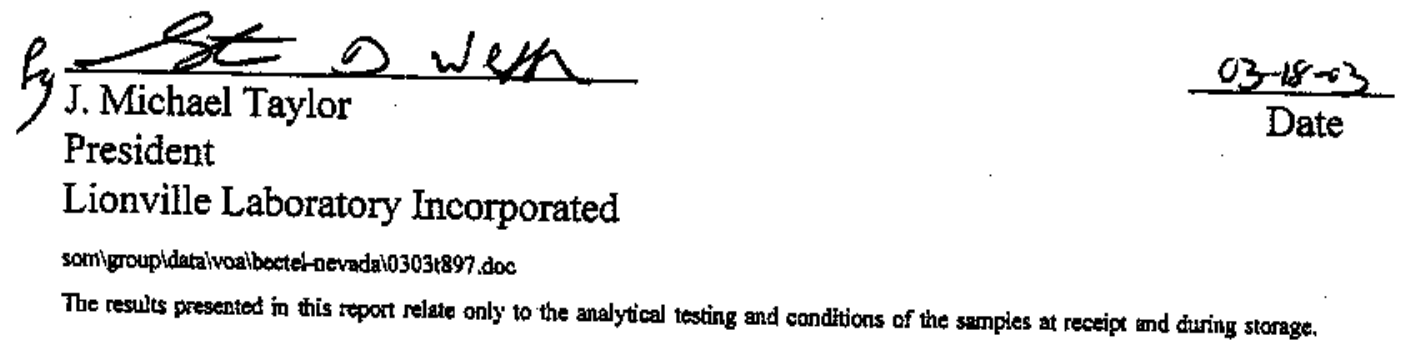




\section{GLOSSARY OF VOA DATA}

\section{DATA OUALIFIERS}

U - Compound was analyzed for but not detected. The associated numerical value is the estimated sample quantiation limit which is included and corrected for dilution and percent moisture.

Indicates an estimated value. 'This flag. is 'used under the following circumstances: 1) when estimating a concentration for tentatively identified compounds (TICs) where a $1: 1$ response is assumed; or 2) when the mass spectral data indicate the presence of a compound that meets the identification criteria but the result is less than the specified detection limit but greater thari zero. For example, if the limit of detection is $10 \mathrm{ug} / \mathrm{L}$ and a concentration of $3 \mathrm{ug} / \mathrm{L}$ is calculated, it is reported as $3 \mathrm{~J}$.

B - This flag is used when the analyte is found in the associated blank as well as in the sample. It indicates possible/probable blank contamination. This flag is also used for a TJC as well as for a positively identified TCL compound.

$\mathbf{E}=$ Indicates that the compound was detected beyond the calibration range and was subsequently analyzed at a dilution.

D - Identifies all compounds identified in an analysis al a secondary dilution factor.

$1-\quad$ interference.

NQ = Result qualitatively confirmed but not able to quantify.

N a Indicates presumprive evidence of a compound. This flag is only used for tentatively identified compounds (TICs), where the identification is based on a mass spectral librery search. it is applied to all TIC results. For generic characterization of a TIC, such as chlorinated hydrocarbon, the $N$ code is not used.

$\mathbf{X}$. This flag is used for a TIC compound which is quantified relative to a response factor generated from a daily calibration standard (rather than quantified relative to the closest intemal standard).

$\mathbf{Y}=$ Additional qualifiers used as required are explained in the case narrative. 


\section{GLOSSARY OF VOA DATA}

\section{ABBREVIATIONS}

BS = Indicates blank spike in which reagent grade water is spiked with the CLP matrix spike solutions and carried through all the steps in the method. Spike recoveries are teported.

BSD = Indjeates blark spike duplicate.

MS = Indicates matrix spike.

MSD = Indicates matrix spike duplicate.

DL = Suffix added to sample number to indicate that results are from a diluted analysis.

NA = Not Applicable.

DF - Dilution Factor.

NR Not Required.

SP, Z = Indicates Spiked Compound. 
Sample Data for each Sample 
Lab Name: Iionv111e Labs, Inc, Work Order: 60052001001

Client: BECHTEL NBVADA V1912

Matrix:

WATrER

Sample wt/vol: $5.00(\mathrm{~g} / \mathrm{mr}) \mathrm{MI}$

Level: (low/med) LOW

\% Molsture: not dec.

Column: (pack/cap) CAP
Lab sample ID: 03031997-001

Iab File ID: $\quad x 031209$

Date Received: $03 / 07 / 03$

Date Analyzed: $03 / 12 / 03$

Dilution Factor: 1.00
CAS NO.

COMPOUND
CONCFNTRATION OAITS;

(ug/L or ug/Kg) $\underline{M G / L}$ 75-0.1-4--.---vinyl Chloride 75-35-4----n-1, 1-Dichloroethene

$67-66-3-------C h l o r o f o r m$

107-06-2--n--1, 2-Dichloroethane

78-93-3---2---2-Butanone

56-23-5------Caxbon Tetrachloride

79-01-6--n---Trichloroe thene

71-43-2-...---Benzene

127-18-4--2-- - -Tetrachloroethene

108-90-7 -...--Chlorobenzere
0.010

0.005

0.005

0.005

0.010

0.005

0.005

0.005

0.005

0.005

FORM 1 V-1

12/88 Rev. 
Lab Name: Lionville Labs, Inc., Work oxder: 60052001001

Client: BECHTRI NEVADA V1912

Matrtx:

FATER

Sample wt/vol: $5.00(\mathrm{~g} / \mathrm{mL}) \mathrm{MI}$

Ievel: (low/med) LOW

\% Molsture: not dec.

Column: (pack/cap) CAP
Lab Sample ID: 0303L897-002

Lab File ID:

$\times 031208$

Date Recetred: $03 / 07 / 03$

Date Aralyzed: $\quad 03 / 12 / 03$

Dilution Eactor: 1.00

CAS NO.

COMPOUMD

CONCFRTRATION UNITS :

(ug/L or ug/Rg) $\mathrm{MG} / \mathrm{L}$

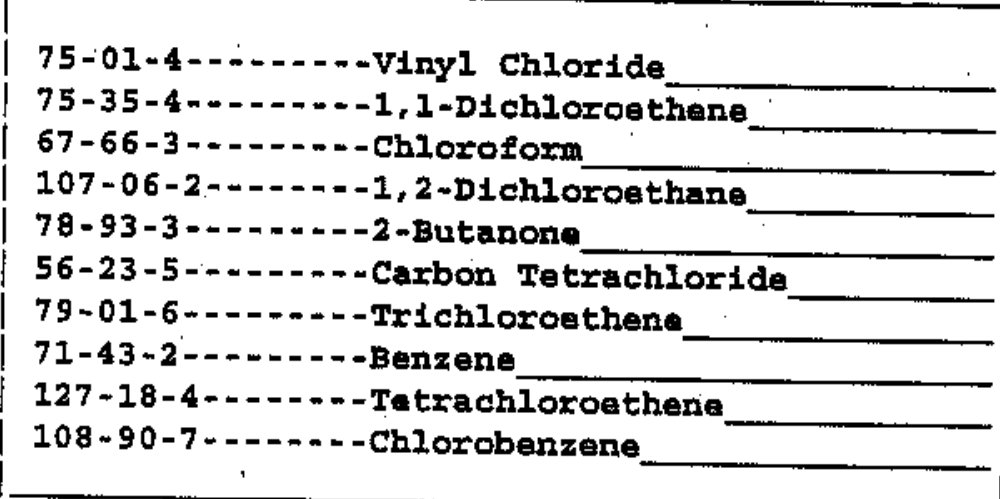

FORM $1 \mathrm{~V}-1$

12/88 Rev.

0.010

0.005

0.005

0.005

0.010

0.005

0.005

0.005

0.005

0.005

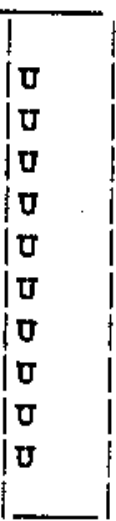


Lab Name: Itonvilie Labs, Inc, Work Order: 60052001001

Client: BECHTEL NEVADA V1912

Matrix:

WATYR

Lab Sample ID: 03035897-005

Sample wt/vol:

$5.00(\mathrm{~g} / \mathrm{mL}) \mathrm{ML}$

Isab File ID:

$\times 0,31210$

Level: (low/med) Lor

Date Recelved: $03 / 07 / 03$

\% Moisture: not dec.

Date Analyzed: $03 / 12 / 03$

Column: (pack/cap) 소

Dilution Factor: 5.00

CAS No.

COMPOUND

CONCBNTRATION ONITS:

(ug/L or ug/Kg) $\mathrm{MC} / \mathrm{L}$

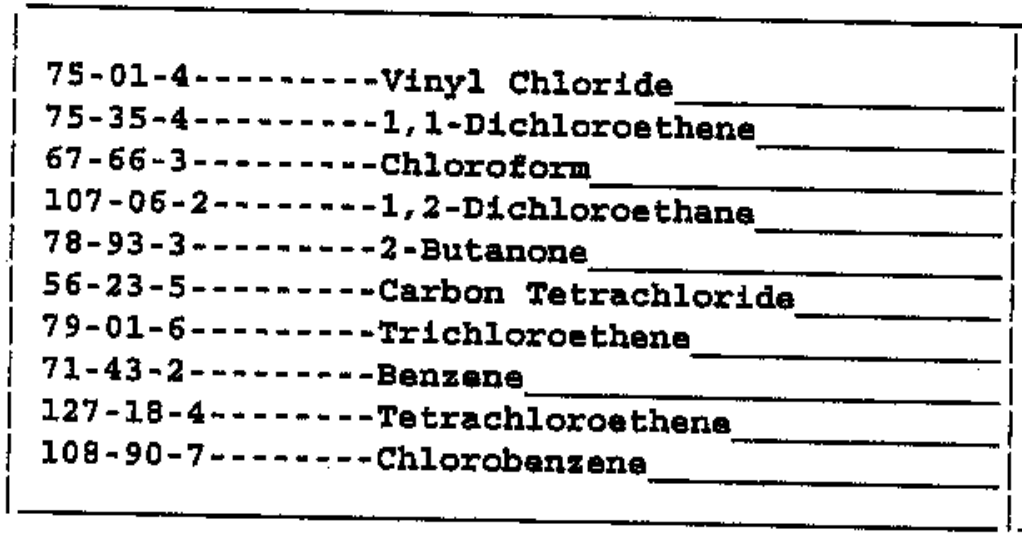

FORM $1 \quad \mathrm{~V}-1$

$12 / 88$ Rev. 
Lab Name: Lfonvilie Labs, Inc, Work oxder: 60052001001

Client: BECHTEI NEVADA V1912

Matrix:

Sample wt/vol:

WATER

Lab Sample ID:

$0303+897-006$

Level: (low/med) Iow

\% Molsture: not dec.

Column: (pack/cap) CAP
Lab File ID:

$\times 031211$

$5.00(\mathrm{~g} / \mathrm{mL}) \mathrm{ML}$

Date Received: $03 / 07 / 03$

Date Analyzed: $03 / 12 / 03$

Dilution Factor: 5.00

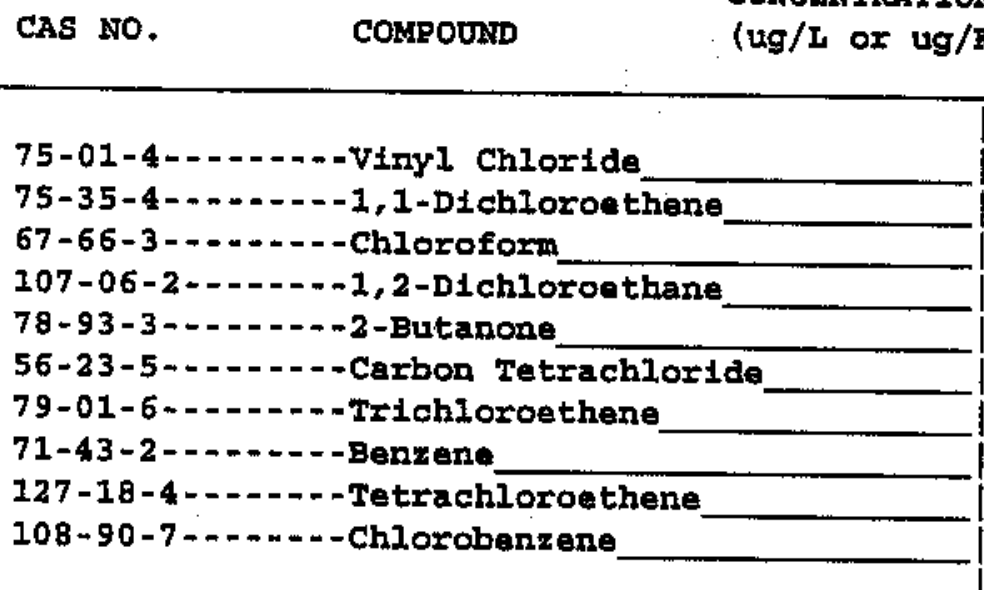

FORM 1 V-1

0.050
0.025
0.025
0.025
0.050
0.025
0.025
0.025
0.025
0.025

0.050

0.025

0.050

0.025

0.025

0.025

0.025

0.025

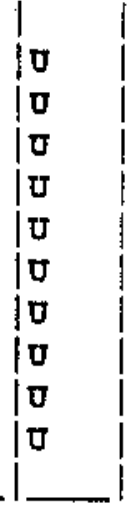

12/88 Rev. 
Case Narrative 


\section{- $/ V L I$ \\ IIONVHIL LABORATOKY INC.}

\section{Analytical Report}

Client : BECHTEL NEVADA V1912

LVL\# : 0303L897
W.0.\# : 60052-001-001-0001-00

Date Received : 03-07-03

\section{SW846 METALS}

1. This narrative covers the analyses of 2 TCLP leachate samples.

2. The samples were prepared and analyzed in accordance with SW-846 protocol and reported with a CLP deliverable. All samples were reported with six fold dilutions due to sample matrix.

3. ICVs, CCVs, and LCSs stock standards were purchased from Inorganic Ventures Laboratory and High Purity. .

4. All analyses were performed within the required holding times.

5. All results presented in this report are derived from samples that met LvLI's sample acceptance policy.

6. All Initial and Continuing Calibration Verifications (ICV/CCVs) were within control limits.

7. All Initial and Continuing Calibration Blanks (ICB/CCBs) were within method criteria.

8. All preparation/method blanks were within method criteria. Refer to form 3.

9. All ICP Interference Check Standards were within control limits. Refer to form 4.

10. All laboratory control samples (LCS) were within the $80-120 \%$ control limits. Refer to form 7 .

11. All serial dilution percent differences were within $\underline{\mathrm{SW}-846}$ control limits. Refer to form 9.

12. The TCLP extract from sample 060204-T3 was selected for the matrix spike (MS) for this analytical batch. The MS recoveries for all analytes in the TCLP extract were above $50 \%$ per method criteria. 
13. All sample IDs were changed to accommodate the EPA naming convention which allows a maximum of 6 characters on all CLP Forms. Refer to the comments section of form 1 for the original ID.

14. Recoveries on the Laboratory Summary Report and CLP forms will vary depending on the number of significant figures used in the recovery calculation.

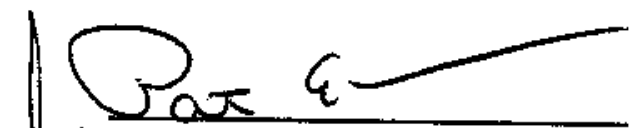

Iain Daniels

Laboratory Manager

Lionville Laboratory Incorporated

gmbtm03-897

\section{$03-19 \cdot 03$ \\ Date}




\section{METHOD REFERENCES AND DATA QUALIFIERS}

\section{DATA QUALIFIERS}

$\mathrm{U}=$ Indicates that the parameter was not detected at or above the reported limit. The associated numerical value is the sample detection limit.

$B=$ Indicates that the parameter was between the Instrument Detection Limit (IDL) and the Contract Required Detection Limit (CRDL)

\section{Q QUALIFIERS}

$E=\quad$ The reported value is estimated because of the presence of interference.

$M=$ Duplicate injection precision not met.

$\mathrm{N}=$ Spiked sample recovery not within control limits.

$S=$ The reported value was determined by the Method of Standard Additions (MSA).

$W=$ Post Digestion spike for Furnace AA analysis is out of control limits $(85-115 \%)$, while sample absorbance is less than $50 \%$ of spike absorbance.

* = Duplicate analysis not within control limits.

$+=$ Comrelation coefficient for the MSA is less than 0.995 .

\section{ABBREVIATIONS}

$\mathrm{PB}=$ Method or Preparation Blank.

$S=$ Matrix Spike.

$T=$ Matrix Spike Duplicate.

$\mathrm{R}$ or $\mathrm{D}=$ Sample Replicate

\section{ANALYTICAL METAL METHODS}

1. Not included in the method element list.

2. Modified $\mathrm{Hg}$ : $\mathrm{Hg} 1$ and $\mathrm{Hg} 2$ require less total volume of digestate due to the autosampler analysis. Sample volumes and reagents for mercury determinations in water and soil have been proportionately scaled down to adapt to this semiautomated technique. The sample volume used for water analysis is $33 \mathrm{~mL}$. For soils, approximately 0.3 grams of sample is taken to a final volume of $50 \mathrm{~mL}$ (including all reagents).

3. Flame AA.

4. Graphite Fumace AA.

RFW 21-21L-033/O-01/97 
U.S. EPA

\section{INORGANIC ANALYSSES DATA SHEET}

Lab Name: LIONVILIE LABORATORY

Lab Code: LVII

Matrix (soil/water) : WATER

Level (low/med): LOW

Solids :
Contract: 60052

SAS No.:

: SDE NO.: 204T3

$204 \mathrm{T3}$

Lab Sample ID: 0303L897-007

Date Received: 03/07/03

Concentration Units (ug/L or $\mathrm{mg} / \mathrm{kg}$ dry weight): UG/L_

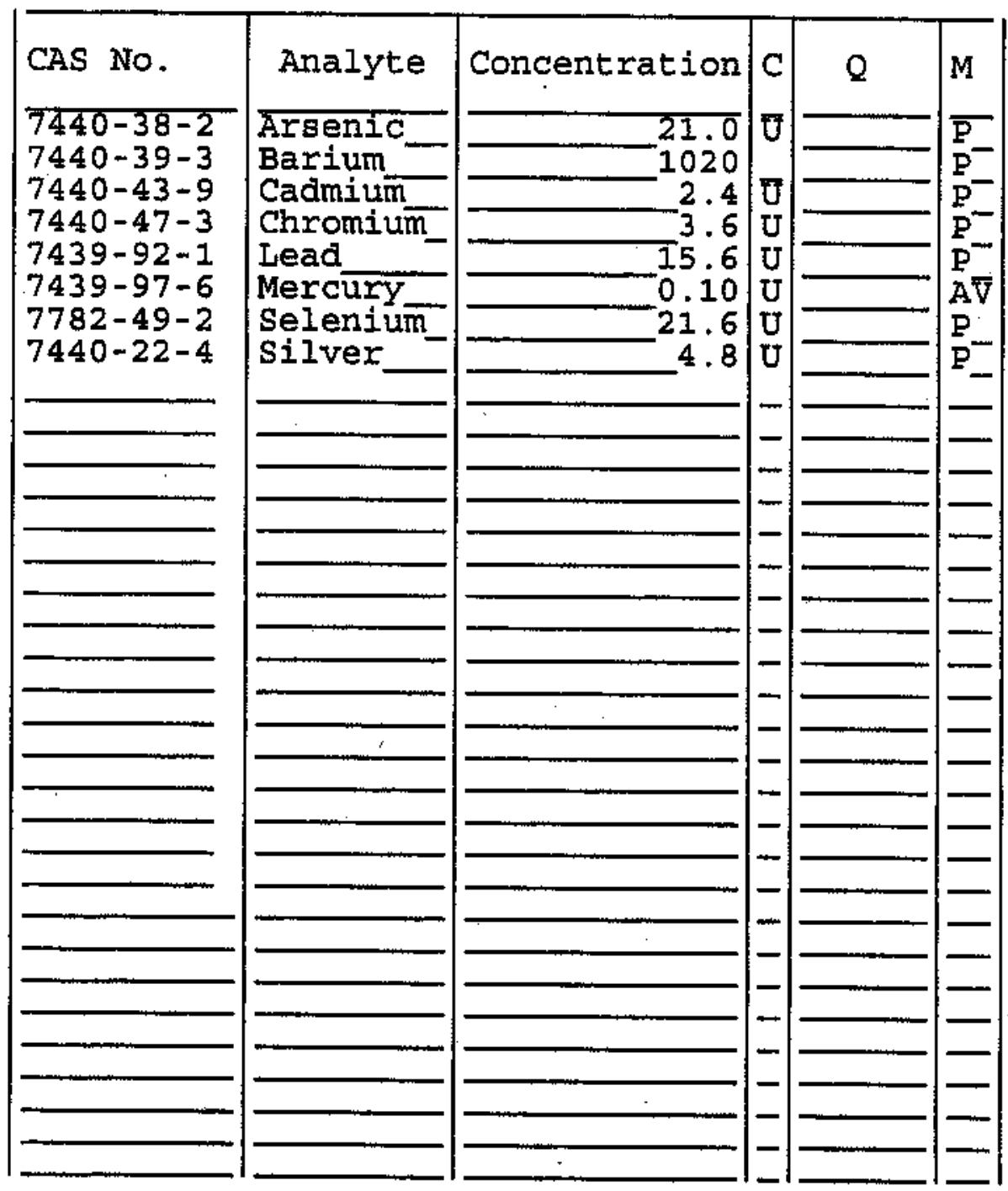

Color Before:

Color After:
Clarity Before:

Clarity After:
Texture:

Artifacts :

Comments :

060204-T3

TCIP_OF_0 
Lab Name: LIONVILLE LABORATORY

Lab Code: LVII Matrix (soil/water): Level (low/med): o Solids :

\section{WATER}

IOW
Contract: 60052

Case No.: V1912 SAS No.:

$0 . \overline{0}$

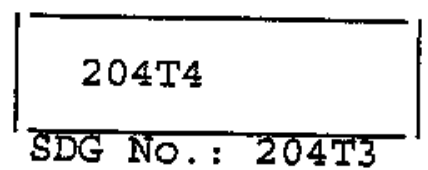

Lab Sample ID: 0303L897-ס08

Date Received: 03/07/03

Concentration Units (ug/L or $\mathrm{mg} / \mathrm{kg}$ dry weight) : UG/L_

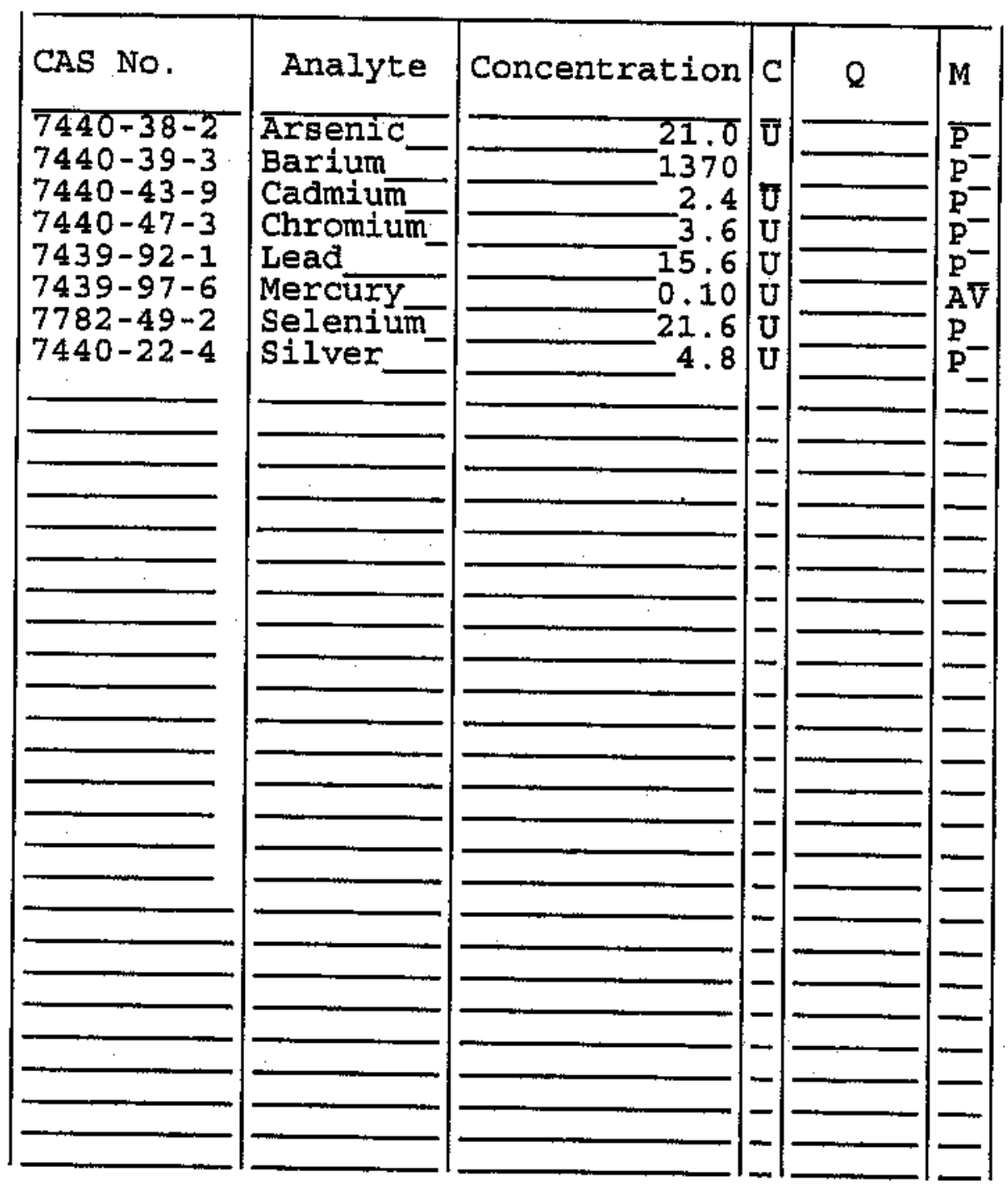

Color Before: Color After:

\section{Comments :}

$060204-T 4$
Clarity Before: Clarity After:
Texture:

Artifacts:

TCLP_OF_OT 


\section{Case Narrative}




\section{인I \\ IIONVIII LARCRAIORY INC}

\section{Analytical Report}

Client: BECHTEL NEVADA V1912

LVL \#: 0303L897

W.O. \#: 60052-001-001-0001-00

Date Received: 03-07-03

\section{GRO}

The set of samples consisted of two (2) solid samples collected on 03-05-03.

The samples and their associated QC samples were analyzed according to Lionville Laboratory OPs based on SW-846 method 8015 for Gasoline range organics (GRO) on 03-12-03.

The following is a summary of the QC results accompanying these sample results and a description of any problems encountered during their analyses:

1. All results presented in this report are derived from samples that met LVLI's sample acceptance policy.

2. All required holding times for analysis have been met.

3. The method blank was below the reporting limits for all target compounds.

4. All surrogate recoveries were within acceptance criteria.

5. All blank spike recoveries were within acceptance criteria.

6. All initial calibrations associated with this data set were within acceptance criteria.

7. All continuing calibration standards analyzed prior to sample extracts were within acceptance criteria.

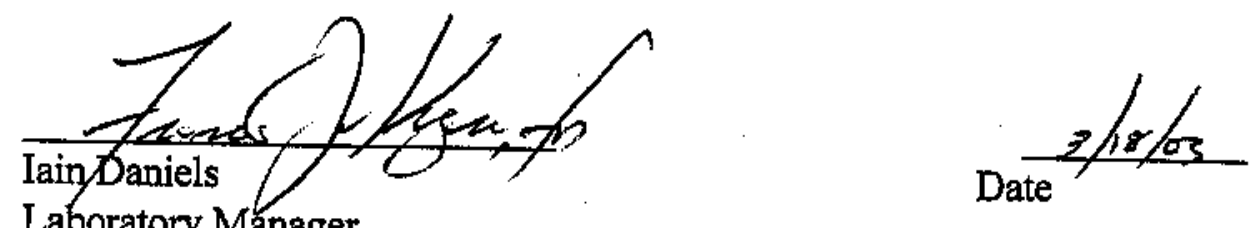

Laboratory Manager

Lionville Laboratory Incorporated

pefRrgroupldatilGRO103-897.doc

The results presented in this report reiate only to the analytical testing and conditions of the samples at receipt and during storage. 


\section{GLOSSARY OF GASOLINE RANGE ORGANICS DATA}

\section{DATA QUALIFIERS}

$\mathbf{U}=$ Indicates that the compound was analyzed for but not detected. The minimum detection limit for the sample (not the method detection limit) is reported with the $U$ (e.g., 10U).

$\mathbf{J}=$ Indicates an estimated value. This flag is used in cases where a target analyte is detected at a level less than the lower quantification level. If the limit of quantification is $10 \mathrm{ug} / \mathrm{L}$ and a concentration of $3 \mathrm{ug} / \mathrm{L}$ is calculated, it is reported as $3 J$.

B $=$ This flag is used when the analyte is found in the associated blank as well as in the sample. It indicates possible/probable blank contamination.

$\mathbf{E}=$ Indicates that the compound was detected beyond the calibration range and was subsequently analyzed at a dilution.

I $=$ Interference.

\section{ABBREVIATIONS}

BS = Indicates blank spike in which reagent grade water is spiked with the CLP matrix spiking solutions and carried through all the steps in the method. Spike recoveries are reported.

BSD $=$ Indicates blank spike duplicate.

MS $=$ Indicates matrix spike.

MSD $=$ Indicates matrix spike duplicate.

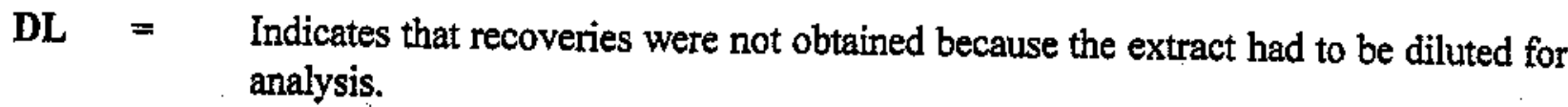

NA $=$ Not Applicable.

DF $=$ Dilution Factor.

$\mathbf{N R}=$ Not Required.

SP = Indicates Spiked Compound. 


\section{GLOSSARY OF GASOLINE RANGE ORGANICS DATA}

D $=\quad$ This flag identifies all compounds identified in an analysis at a secondary
dilution factor.

C = This flag applies to a compound that has been confirmed by GC/MS. 
Sample Data 
Lab Name: Lionvilie Labs, Inc. Work Order: 60052001001 1060204-T3

Client: BECHTEI NEVADA V1912

Matrix:

SOLID

$\underline{5.02}(\mathrm{~g} / \mathrm{mL}) \mathrm{G}$

Sample wt/vol:

Level: (low/med) LOW

if Moisture: not dec. 42

Column: (pack/cap) CAP

CAS NO.

COMPOUND
Lab Sample ID: 0303L897-003

Lab File ID: BLKLACHJ

Date Received: $03 / 07 / 03$

Date Analyzed: $03 / 12 / 03$

Dilution Factor: 1,00

CONCENTRATION UNITS:

(ug/L or $u g / \mathrm{Kg}$ ) UG/KG

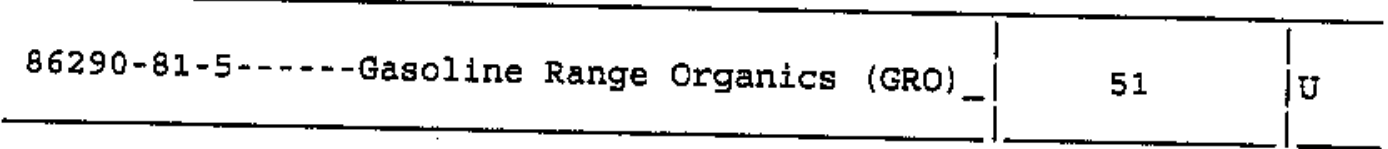

12/88 Rev. 
GC VOLATILES SHEET

I ab Name: Lionville Labs. Inc. Work Order: 60052001001 Client: EECHTEL NEVADA V1912

Matrix: SOLID

Sample wt/vol: $\underline{5.68}(\mathrm{~g} / \mathrm{mI}) \mathrm{G}$

Level: (low/med) LOW

\& Moisture: not dec. 51

Column: (pack/cap) CAP

CAS NO.

COMPOUND

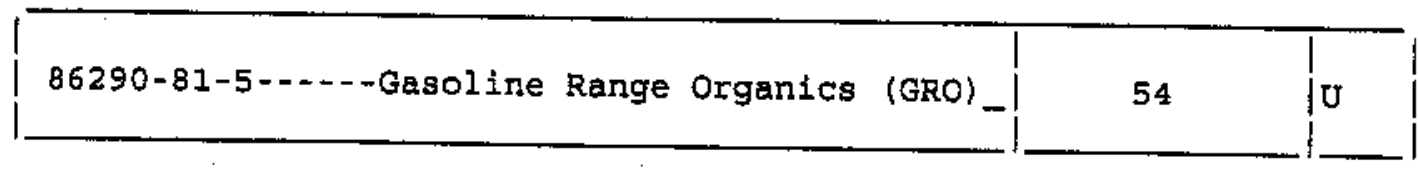

12/88 Rev.
CLIENT SAMPLE NO.

$1060204-T 4$

Lab Sample ID: 03035897-004

Lab File ID: BLKLACHJ

Date Received: $03 / 07 / 03$

Date Analyzed: $03 / 12 / 03$

Dilution Factor: 1.00

CONCENTRATION UNITS :

(ug/L or $\mathrm{ug} / \mathrm{kg}$ ) UG/KG 


\section{Case Narrative}




\section{$9 / V L I$ \\ IIONVIII LABOKAYOKY INC:}

\section{Analytical Report}

Client: BECHTEL-NEVADA V1912

LVL \#: 0303L897

W.O. \#: 60052-001-001-0001-00

Date Received: 03-07-03

\section{DIESEL RANGE ORGANICS}

The set of samples consisted of two (2) sludge samples collected on 03-05-03.

The samples and their associated QC samples were extracted on 03-10-03 and analyzed according to Lionville Laboratory OPs on $03-11,12-03$. The extraction procedure was based on method 3540 and the extracts were analyzed based on method 8015B for Diesel Range Petroleum Hydrocarbons.

1. All results presented in this report are derived from samples that met LvLI's sample acceptance policy.

2. All required holding times for extraction and analysis have been met.

3. The method blank was below the reporting limits for all target compounds.

4. All surrogate recoveries were within acceptance criteria.

5. The blank spike recovery was within acceptance criteria.

6. All initial calibrations associated with this data set were within acceptance criteria.

7. All continuing calibration standards analyzed prior to sample extracts were within acceptance criteria.

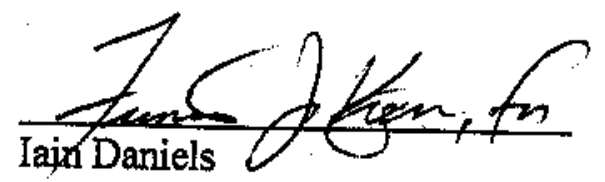

Laboratory Manager

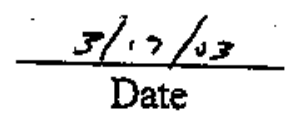

Lionville Laboratory Incorporated

pefr: troupldataldrolbechteet $03 \mathrm{~L}-897 \mathrm{doc}$

The results presented in this report relare only to the analytical testing and conditions of the sampies an receipt and derring storage. 


\section{GLOSSARY OF DIESEL RANGE ORGANICS DATA}

\section{DATA QUALIFIERS}

$\mathbf{U}=$ Indicates that the compound was analyzed for but not detected. The minimum detection limit for the sample (not the method detection limit) is reported with the $U$ (e.g., 10U).

$\mathbf{J}=$ Indicates an estimated value. This flag is used in cases where a target analyte is detected at a level less than the lower quantification level. If the limit of quantification is $10 \mathrm{ug} / \mathrm{L}$ and a concentration of $3 \mathrm{ug} / \mathrm{L}$ is calculated, it is reported as 3J.

B $=$ This flag is used when the analyte is found in the associated blank as well as in the sample. It indicates possible/probable blank contamination.

$\mathbf{E}=$ Indicates that the compound was detected beyond the calibration range and was subsequently analyzed at a dilution.

I $=$ Interference.

\section{ABBREVIATIONS}

BS $=$ Indicates blank spike in which reagent grade water is spiked with the CLP matrix spiking solutions and carried through all the steps in the method. Spike recoveries are reported.

BSD = Indicates blank spike duplicate.

MS = Indicates matrix spike.

MSD = Indicates matrix spike duplicate.

DL = Indicates that recoveries were not obtained because the extract had to be diluted for analysis.

$\mathbf{N A}=$ Not Applicable.

DF $=$ Dilution Factor.

$\mathbf{N R}=\quad$ Not Required.

SP $=$ Indicates Spiked Compound. 


\section{GLOSSARY OF DIESEL RANGE ORGANICS DATA}

D = This flag identifies all compounds identified in an analysis at a secondary
dilution factor.

C $=$ This flag applies to a compound that has been confirmed by GC/MS. 
Sample Data 
Lab Name: Lionville Labs, Inc. Work Order: 60052001001

Client: BECHTEL NEVADA V1912

Matrix:

Sample wt/vol:

SOLID

$25,0(\mathrm{~g} / \mathrm{mL}) \mathrm{G}$

Level: (low/med) LOW

\% Moisture: not dec.

42

Column: (pack/cap) CAP
Lab Sample ID: 0303I897-003

Lab File ID: BLKIACHJ

Date Received: $\quad 03 / 07 / 03$

Date Analyzed: $03 / 12 / 03$

Dilution Factor: 1,00

CONCENTRATION UNITS ; (ug/L or $u g / \mathrm{Kg}$ ) ma/kg

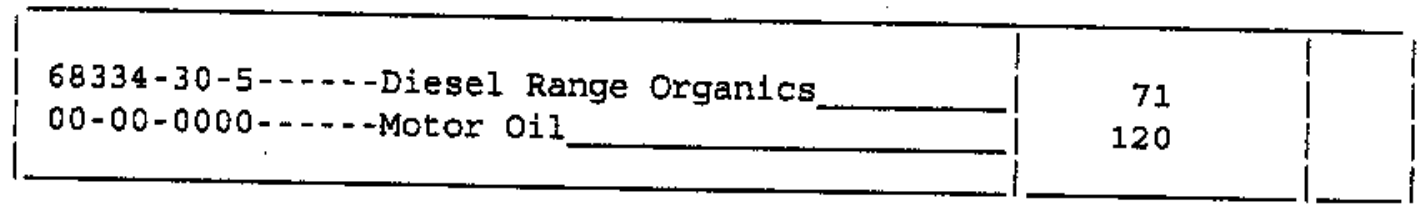

12/88 Rev. 
ORGANICS ANAZYSIS SHEET

Lab Name: Lionville Labs. Inc. Work Order: 60052001001
CLIENT SAMPLE NO.

$060204-\mathrm{T} 4$

Client: BECHTEL NEVADA V1912

Matrix:

SOIID

Lab Sample ID: 0303L897-004

Sample wt/vol: $\underline{25.0}(\mathrm{~g} / \mathrm{mL}) \mathrm{G}$

Lab File ID:

BLKLACHJ

Level: (low/med) LOW

Date Received: $03 / 07 / 03$

\& Moisture: not dec.

51

Date Analyzed: $03 / 12 / 03$

Column: (pack/cap) CAP.

Dilution Factor: 1.00

CONCENTRATION UNITS:

CAS NO.

COMPOUND

(ug/L or $\mathrm{ug} / \mathrm{kg}$ ) $\mathrm{mg} / \mathrm{kg}$

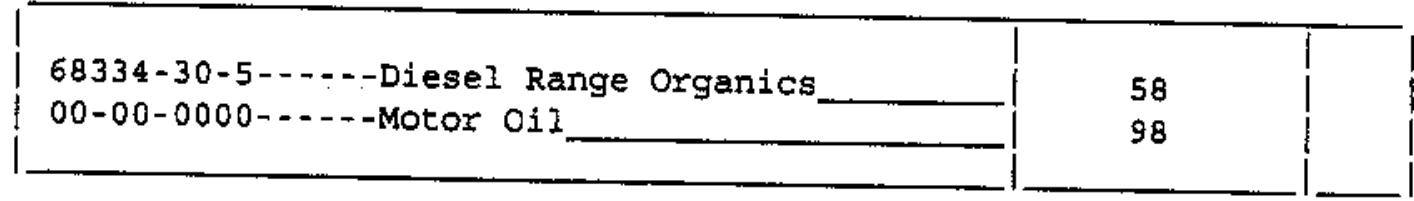

12/88 Rev. 
CASE NARRATIVE 


\section{Analytical Report}

IONVIIT LABC IRATOKY INC:

Client: BECHTEL-NEVADA V1912

LVL \#: 0303L897

W.O. \#: 60052-001-001-0001-00

Date Received: 03-07-2003

PCB

Two (2) solid samples were collected on 03-05-2003.

The samples and their associated QC samples were extracted on 03-10-2003 and analyzed according to Lionville Laboratory OPs on 03-19-2003. The extraction procedure was based on method 3540 and the extracts were analyzed based on method 8082 for Aroclors only.

The following is a summary of the QC results accompanying the sample results and a description of any problems encountered during their analyses:

1. All results presented in this report are derived from samples that met LVLI's sample acceptance policy.

2. The required holding time for extraction and analysis has been met.

3. Samples and their associated QC samples received a Sulfuric Acid cleanup.

4. The method blank was below the reporting limits for all target compounds.

5. One (1) of twelve (12) surrogate recoveries was outside acceptance criteria. However, EPA CLP surrogate recovery criteria were met (i.e., no more than one outlier per sample).

6. The blank spike recoveries were within acceptance criteria.

7. All matrix spike recoveries were within acceptance criteria.

8. All initial calibrations associated with this data set were within acceptance criteria.

9. All continuing calibration standards analyzed prior to sample extracts were within acceptance
criteria.

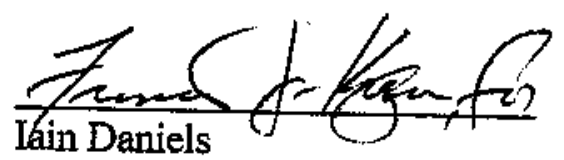

Laboratory Manager

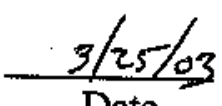

Lionville Laboratory Incorporated

sombigroupldataipest ibechtelito303-897.pcb

The results presented in this repont relate onty to the analytical testing and conditions of the samples ut receipt and during storage. . 


\section{GLOSSARY OF PESTICIDE/PCB DATA}

\section{DATA QUALIFIERS}

$\mathrm{U}=$ Indicates that the compound was analyzed for but not detected. The minimurn detection limit for the sample (not the method detection limit) is reported with the $U$ (e.g., 10U).

$\mathbf{J}=$ Indicates an estimated value. This flag is used in cases where a target analyte is detected at a level less than the lower quantification level. If the limit of quantification is $10 \mathrm{ug} / \mathrm{L}$ and a concentration of $3 \mathrm{ug} / \mathrm{L}$ is calculated, it is reported as $3 \mathrm{~J}$.

B = This flag is used when the analyte is found in the associated blank as well as in the sample. It indicates possible/probable blank contamination.

$\mathbf{E}=$ Indicates that the compound was detected beyond the calibration range and was subsequently analyzed at a dilution.

I $=$ Interference.

\section{ABBREVIATIONS}

BS = Indicates blank spike in which reagent grade water is spiked with the CLP matrix spiking solutions and carried through all the steps in the method. Spike recoveries are reported.

BSD $=$ Indicates blank spike duplicate.

MS $=$ Indicates matrix spike.

MSD $=$ Indicates matrix spike duplicate.

DL = Indicates that recoveries were not obtained because the extract had to be diluted for analysis.

NA $=$ Not Applicable.

DF $=$ Dilution Factor.

NR $=$ Not Required.

SP $=$ Indicates Spiked Compound. 


\section{GLOSSARY OF PESTICIDE/PCB DATA}

$P=$ This flag is used for an PESTICIDE/PCB target analyte when there is greater than $25 \%$ difference for detected concentrations between the two GC columns (see Form X). The lower of the two values is reported on Form I and flagged with a."P".

D $=$ This flag identifies all compounds identified in an analysis at a secondary dilution factor.

C = This flag applies to a compound that has been confirmed by GC/MS. 
SAMPLE DATA FOR EACH SAMPLE 
$1 D$

PESTICIDE ORGANICS ANALYSIS SHEET

Lab Name: Lionville Labs, Inc. Work Order: 60052,001001

Client: BECHTEL NEVADA V1912

Matrix: $\quad$ SOIID

Sample wt/vol: $\quad 30.0(\mathrm{~g} / \mathrm{mL}) \mathrm{G}$

Level: (low/med) LOW

: Moisture: not dec. 42 dec.

Extraction: (SepF/Cont/Sonc) CONT

GPC Cleanup: $\quad(\mathrm{Y} / \mathrm{N}) \underline{\mathrm{N}}$

$\mathrm{pH}: \underline{7,0}$
Lab Sample ID: 0303L897-003

Lab File ID: BIKIACHJ.02

Date Received: $\quad 03 / 07 / 03$

Date Extracted: $03 / 10 / 03$

Date Analyzed: $03 / 19 / 03$

Dilution Factor: 1,00

CONCENTRATION UNITS:

CAS NO.

COMPOUND

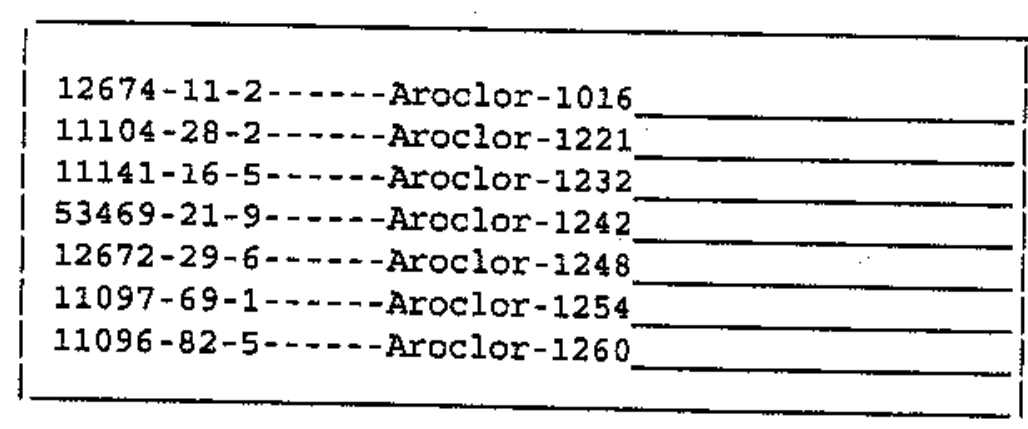

FORM 1 PEST

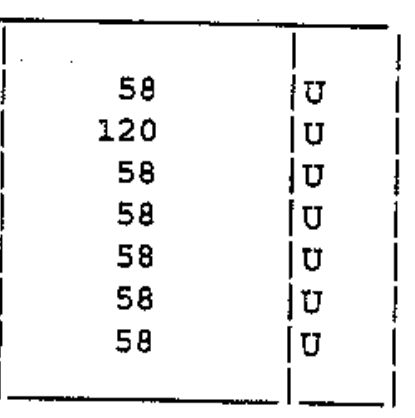

12/88 Rev. 
Lab Name: Lionville Labs. Ine. Work Order: 60052001001

\section{Client: BECHTEL NEVADA VI912}

Matrix :

SOLID

Sample wt/vol: $30.0(g / m L) G$

Level: (low/med) LOW

\& Moisture: not dec. 515 dec.

Extraction: (SepF/Cont/Sonc) CoNT

GPC Cleanup: (Y/N) $\mathbb{N}$

$\mathrm{pH}: \quad 7.0$
Lab Sample ID: 0303L897-004

Iuab File ID: $\quad$ BLKLACHU,02

Date Received: $03 / 07 / 03$

Date Extracted: $03 / 10 / 03$

Date Analyzed: $03 / 19 / 03$

Dilution Factor: 1.00
CAS NO.

COMPOUND

CONCENTRATION UNTTS:

〈ug/L or $\mathrm{ug} / \mathrm{Kg}$ ) $\mathrm{GG} / \mathrm{KG}$.

\begin{tabular}{|l|}
$12674-11-2-\ldots-$ Aroclor -1016 \\
$11104-28-2-\ldots-$ Aroclor -1221 \\
$11141-16-5-\ldots-$ Aroclor -1232 \\
$53469-21-9-\ldots--$ Aroclor -1242 \\
$12672-29-6-\ldots-$ Aroclor -1248 \\
$11097-69-1-\ldots-$ Aroclor -1254 \\
$11096-82-5 \cdots-\ldots-$ Aroclor -1260
\end{tabular}

FORM 1 PEST

\begin{tabular}{r|r|}
69 & $\mid$ \\
140 & $\mid \mathrm{U}$ \\
69 & $\mid \mathrm{U}$ \\
69 & $\mid \mathrm{U}$ \\
69 & $\mathrm{U}$ \\
69 & $\mathrm{U}$ \\
69 & $\mathrm{U}$ \\
\hline
\end{tabular}

12/88 Rev. 
Case Narrative 


\section{- $/ V L I$ \\ IUONVHII IABORATORY INC:}

Client: BECHTEL-NEVADA V1912

LVL \#: 0303L897

W.O. \#: 60052-001-001-0001-00

Date Received: 03-07-2003

\section{SEMIVOLATILE-TCLP}

Two (2) leachate samples were generated on 03-11-2003 from sludge samples collected on 03-05-2003.

The samples and their associated QC samples were extracted according to Lionville Laboratory OPs based on method 3520 on 03-12-2003 and analyzed according to criteria set forth in Lionville Laboratory OPs based on Method 8270C for TCLP Semivolatile target compounds on 03-19,20-2003.

The following is a summary of the $\mathrm{QC}$ results accompanying the sample results and a description of any problems encountered during their analyses:

1. All results presented in this report are derived from samples that met LvLI's sample acceptance policy.

2. The required holding time for extraction and analysis was met.

3. Samples were extracted at 5 -fold dilution $(200 \mathrm{~mL}$, has been used instead of $1000 \mathrm{~mL})$ due to leachate sample matrix.

4. One (1) of forty-two (42) surrogate recoveries was outside EPA QC limits. However, EPA CLP surrogate recovery criteria were met (i.e., no more than one outlier per fraction \{acid and base neutral $\}$ and no recoveries less than $10 \%$ ).

5. All matrix spike recoveries were within EPA QC limits.

6. All blank spike recoveries were within EPA QC limits.

7. Internal standard area and retention time criteria were met.

8. Manual integrations are performed according to OP 21-06A-125 to produce quality data with the utmost integrity. All manual integrations are required to be technically valid and properly documented. Appropriate technical flags are defined in the Glossary ("Technical Flags For Manual Integration").

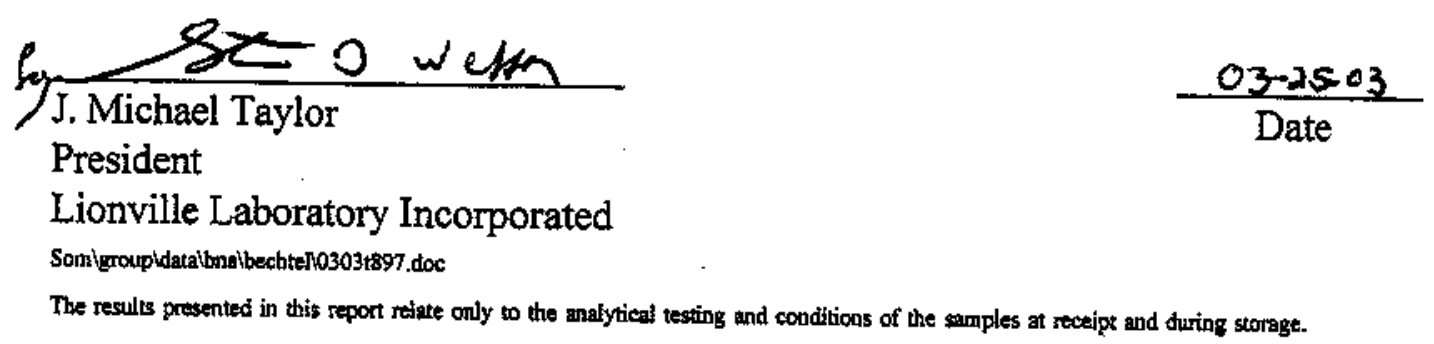




\section{GLOSSARY OF BNADATA}

\section{DATA QUALIFIERS}

$\mathrm{U}=$ Compound was analyzed for but not detected. The associated numerical value is the estimated sample quantitation limit which is included and corrected for dilution and percent moisture.

J = Indicates an estimated value. This flag is used under the following circumstances: 1) when estimating a concentration for tentatively identified compounds (TICs) where a $1: 1$ response is assumed; or 2) when the mass spectral data indicate the presence of a compound that meets the identification criteria but the result is less than the specified detection limit but greater than zero. For example, if the limit of detection is $10 \mathrm{ug} / \mathrm{L}$ and a concentration of $3 \mathrm{ug} / \mathrm{L}$ is calculated, it is reported as 33 .

B - This flag is used when the analyte is found in the associated blank as well as in the sarnple. It indicates possible/probable blank contamination. This tlag is also used for \& TIC as well as for a positively identified TCL compound.

E $=$.. indicates that the compound was detected beyond the calibration range and was subsequently analyzed at a dilution.

D $\quad=\quad$ Jdentifies all compounds identified in an analysis at a secondary dilution factor.

$1 . \quad$ Interference.

NQ - Result qualitatively confimed but not able to quasitify.

A $\quad=\quad$ Indicates that $8 \mathrm{TIC}$ is a suspected aldol-condensation product.

N = Indicates presumptive evidence of a compound. This flag is only used for tentatively identified compounds (JICs), where the identification is based on a mass spectral library search. It is applied to all TIC results. For generic characterization of a TJC, such as chlorinated bydrocarbon, the $\mathrm{N}$ code is not used.

$\mathbf{X}=\quad$ This flag is used for a TIC compound which is quantified relative to a response factor generated from a daily calibration standard (rather than quantified relative 10 the closest internal standard).

$Y \quad-\quad$ Additional qualifiers used as required are explained in the case narrative. 
Sample Data for each Sample

28 
Lab Name: Lionville Labs. Inc. Work Order: 60052001001 $1060204-T 3$

Client: BECHTEL NEVADA V1912

Matrix: (soil/water) WATER

Sample wt/vol: $200 \quad(\mathrm{~g} / \mathrm{mL}) \mathrm{ML}$

Level: (low/med) LOW

Moisture: decanted: $(\mathrm{Y} / \mathrm{N})$

Concentrated Extract Volume: 1000(ut)

Injection Volume: 2.0 (uL)
Lab Sample ID: 0303L897-007

Lab File ID: $\underline{\text { A031916 }}$

Date Received: 03/07/03

Date Extracted: $03 / 12 / 03$

Date Analyzed: 03/19/03

Dilution Factor: 1,00
GPC Cleanup: $\langle\mathrm{Y} / \mathrm{N}\rangle \mathbb{N}$

CAS NO.
COMPOUND
$\mathrm{pH}: \quad 7.0$

CONCENTRATION UNITS:

(ug/L or $\mathrm{ug} / \mathrm{Kg}$ ) $\mathrm{MG} / \mathrm{L}$

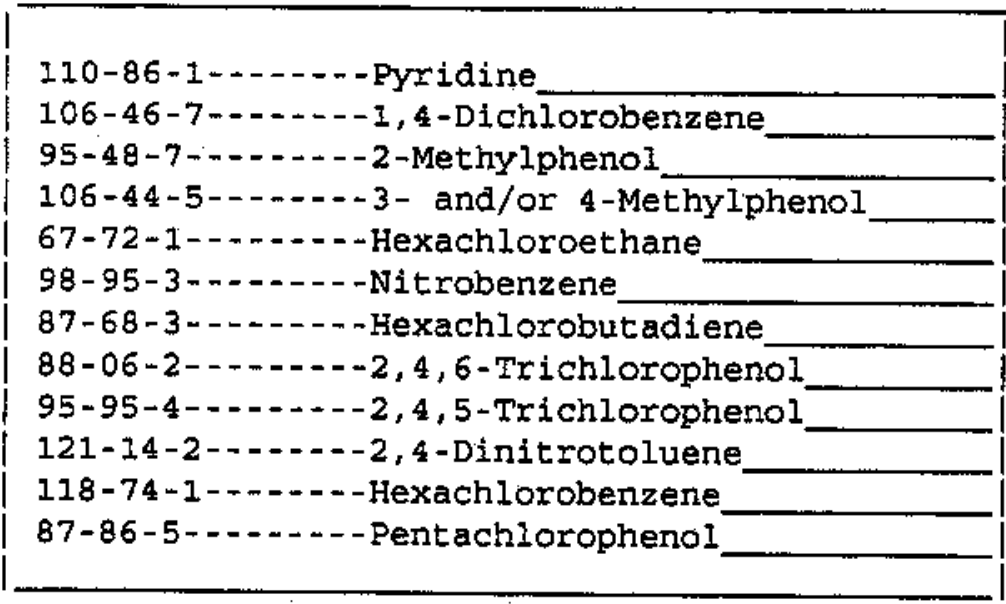

FORM 1 SV-1

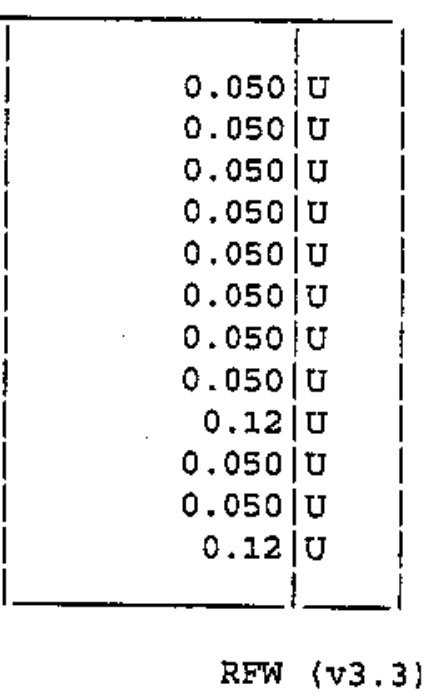


Lab Name: Lionvilie Labs, Inc. Work Order: 60052001001 $060204-T 4$

Client: BECHTEI,NEVADA V1912

Matrix: (soi1/water) WATER

Sample wt/vol: _ـ 200 (g/mL) ML

Level: $\quad$ (Low/med) L LOW

Moisture :

decanted: $(\mathrm{Y} / \mathrm{N})$

Concentrated Extract volume: 1000(uL)

Injection volume: $2.0(u L)$

GPC Cleanup: $(Y / N) \mathbb{N}$

CAS NO.
$\mathrm{pH}:-7.0$
Lab Sample ID: 03035897-008

Lab File ID; $\quad$ A032006

Date Received: $\underline{03 / 07 / 03}$

Date Extracted: 03/12/03

Date Analyzed: $03 / 20 / 03$

Dilution Factor: 1.00

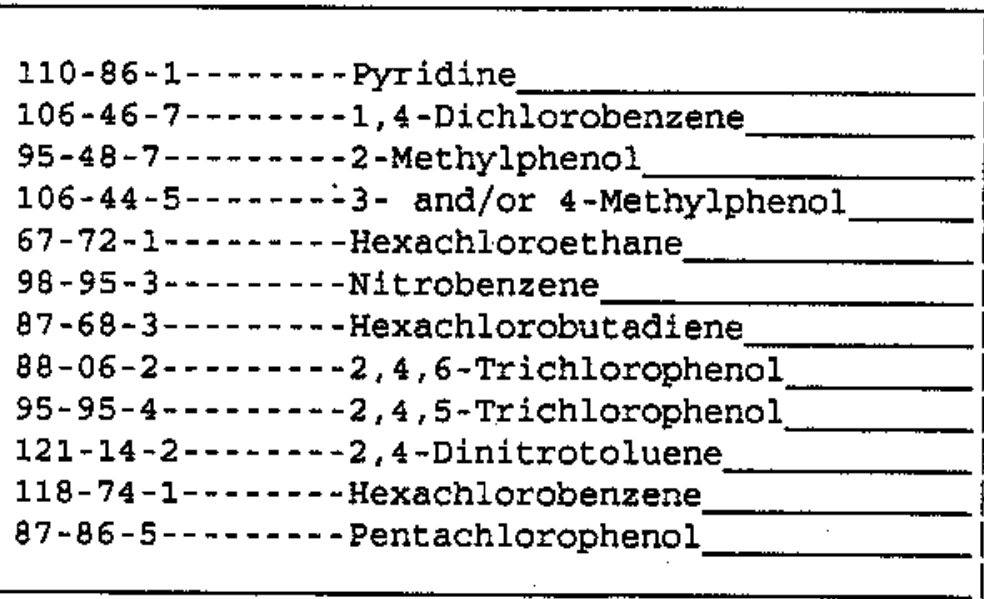

FORM 1 SV-1
CONCENTRATION UNITS :

(ug/L or $\mathrm{ug} / \mathrm{Kg}$ ) MG/L Q 
CLOSURE REPORT - CAU 330

Section: Appendix B

Revision: 0

Date: July 2003

\section{SAMPLE DELIVERY GROUP}

\section{3}


CLOSURE REPORT - CAU 330

Section: Appendix B

Revision: 0

Date: July 2003

\section{THIS PAGE INTENTIONALLY LEFT BLANK}


April 1, 2003

Mr. Ted Redding

Bechtel Nevada

US DOE Zone 1, Bldg. 652,

RM 2, M/S NTS273

Mercury, NV 89023

RE: Paragon Workorder: 03-03-017

Client Project Name: CAU 350

Client Project Number: V1913

Dear Mr. Redding:

Two sludge samples were received from Bechtel Nevada on March 7, 2003. The samples were scheduled for the following analyses:

Tritium

Gross Alpha/Beta

Gamma Spectroscopy pages $1-47$

pages $1-149$

pages $1-124$

The results for these analyses are contained in the enclosed reports.

Thank you for your confidence in Paragon Analytics, Inc. Should you have any questions, please call.

Sincerely,

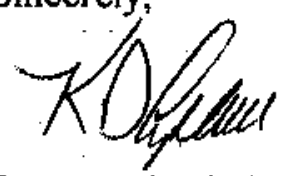

Paragon Analytics, Inc.

Ken Campbell

Project Manager

$\mathrm{KDC} / \mathrm{mc}$

Enclosure: Report 
$\hat{1}$
0
$\tilde{0}$
$M$
0

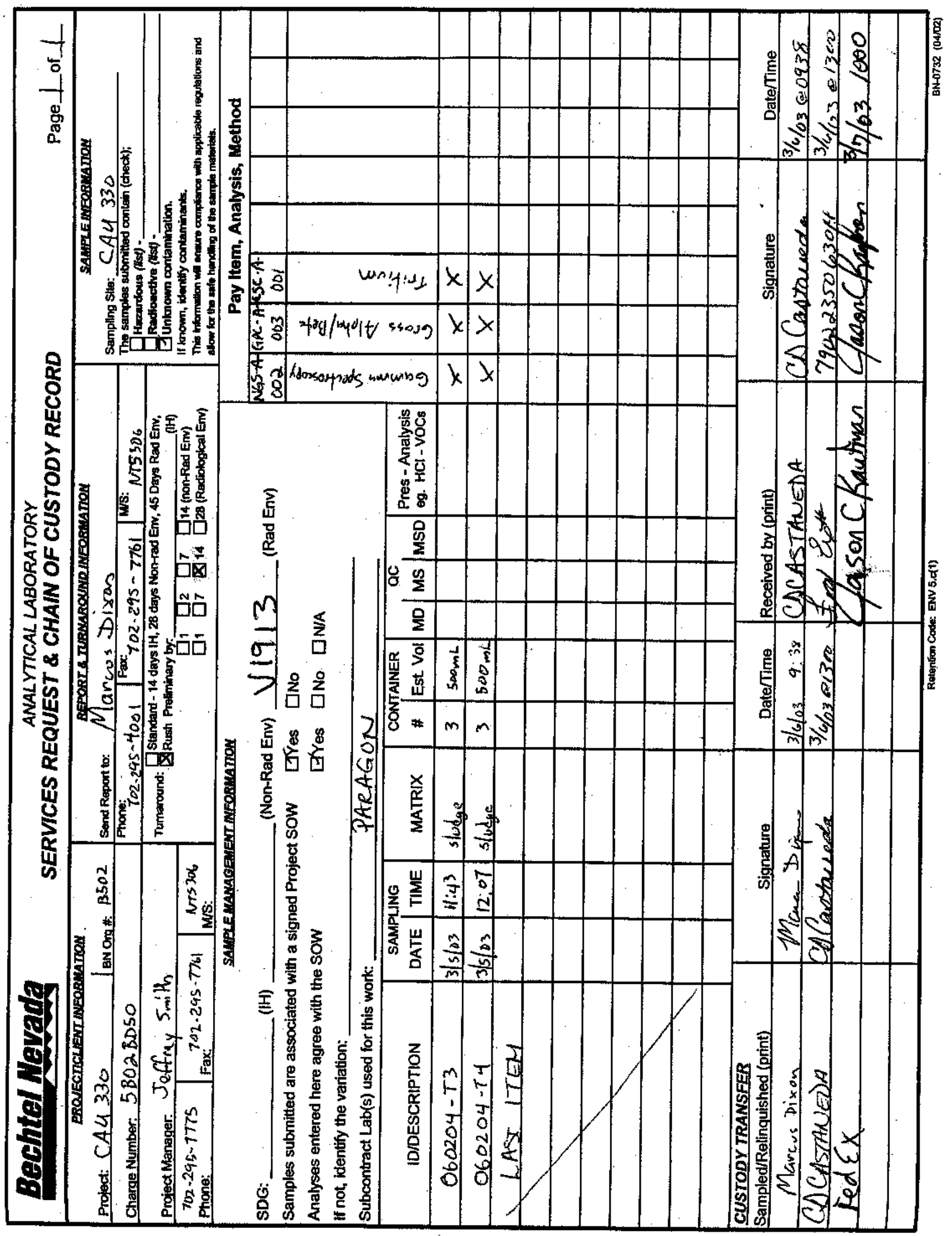




\section{Paragon Analytics, Inc. Radiochemistry Case Narrative Tritium}

\section{Bechtel Nevada \\ CAU 330 / V1913 \\ PAI WO 0303017}

1. This report consists of 2 sludge samples received by Paragon on $3 / 7 / 03$.

2. These samples were prepared according to Paragon Analytics, Inc. procedures SOP700R7.

3. The samples were analyzed for the presence of tritium according to Paragon Analytics, Inc. procedure SOP704R5. The analyses were completed on $3 / 12 / 03$.

4. The analysis results for these samples are reported on an 'as received' basis in units of $\mathrm{pCi} / \mathrm{gram}$.

5. Sample from this work order were received as a sludge, with a liquid and solid phase. Due to an oversight, the liquid phase was decanted, and the tritium analysis was performed on this fraction of the sample. The client requested the samples be analyzed and reported on an 'as received' basis including the liquid phase. The moisture content was determined including the liquid phase, and was used to calculate the equivalent analysis volume. Please refer to QASS 256651 for sample calculations.

6. Due to current software limitations, the DER determinations in this report were calculated using the 2 sigma TPU. The SOW indicates that the 1 sigma TPU be used in the DER determination. However, the requested DER limit of less than 3 at the I sigma level (which is equivalent to 1.5 at the 2 sigma level) was achieved. Data quality is not affected.

7. No further anomalous situations were noted during the preparation and analysis of these samples. All remaining quality control criteria were met.

The data contained in the following report have been reviewed and approved by the personnel listed below. In addition, Paragon Analytics, Inc. certifies that the analyses reported herein are true, complete and correct within the limits of the methods employed.
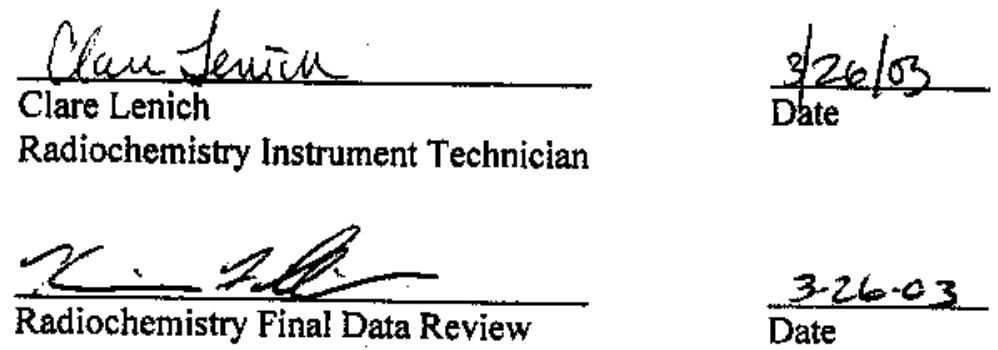

$\frac{3 \cdot 26.03}{\text { Date }}$




\title{
PARAGON ANALYTICS, INC. Radiochemistry Data Package
}

\author{
Section 3
}

\section{INDIVIDUAL \\ SAMPLE RESULTS}




\title{
Tritium Analysis By Liquid Scintillation
}

\author{
Method 906.0M
}

Sample Results

Client Name: Bechtel Nevada

Client Project Name: CAU 330

Cltent Project Number: V1913
Page: 1 of 2

Reported on: Tuesday, March 25, 2003

15:11:03

Laboratory Name: Paragon Analytics, Inc.

PAI Work Order: 0303017
Flold ib, 060204-T3

Cab 10:0303017-1
Sample Matrix: Sludge

Date Prepared: 11-Mar-03

Prep sOP: PAJ 700R7

Prop Batch: LS01596
Date Collected: 05-Mar-03

Date Analyzed: 12-Mar-03

Analytical SOP: PAl $704 R 5$
Final Aliquot: $1.744 \mathrm{~g}$

Report Basis: As Recelved

Count Time (min.): 30

\begin{tabular}{|c|c|c|c|c|}
\hline Target Nuclide & Result $+/-2$ s TPU & MDC & $\begin{array}{c}\text { Reporting } \\
\text { Units }\end{array}$ & Lab Qualifler \\
\hline $\mathrm{H}-3$ & $-4.27 \mathrm{E}-01+/-2,13 \mathrm{E}+00$ & $3.64 \mathrm{E}+00$ & $\mathrm{pCl} / \mathrm{g}$ & $\mathrm{U}$ \\
\hline
\end{tabular}

\section{Comments:}

Quaffiwra/fiege:

$U$ - Result to shan the samplo specift MDC.

Y1 - Chemical Ylodd is in control at 100-110\%. Quenthtative Yiefd is ascumed.

Y2 - Chamical Yield outolite defoull innlts.

LT - Resull ta loss then Requesied MDC, groater then agmple specific MDC.
Abereviations:

TPU - Total Propegesed Uncerteinty (soe PA SOP 743)

MDC - Minlmum Dotoctable Concentration (s0e PAI SOP 709) 


\section{Paragon Analytics, Inc.}

\section{Radiochemistry Case Narrative . Gamma Spectroscopy}

\section{Bechtel Nevada \\ CAU 330 / V1913 \\ Paragon Work Order 0303017}

1. This report consists of analysis results for two sludge samples received by Paragon on 3/7/03. . The analysis results for these samples are reported on an 'as received' basis in units of $\mathrm{pCi} / \mathrm{gram}$.

2. These samples were prepared according to Paragon Analytics, Inc. procedure PAI SOP739R5.

3. The samples were analyzed for the presence of gamma emitting radionuclides according to Paragon Analytics, Inc. procedure PAI SOP7I3R7. The analyses were completed on 3/14/03.

4. The samples were analyzed using Seeker Version 2.2, which is a product of Vertechs Software Solutions, Inc.

5. Sample volumes were insufficient to allow preparation of a duplicate. A duplicate analysis of sample 060204-T3 (PAI ID 0303017-1) was performed in lieu of a preparation duplicate.

6. Due to current software limitations, the DER determinations in this report were calculated using the 2 sigma TPU. The SOW indicates that the 1 sigma TPU be used in the DER determination. However, the requested DER limit of less than 3 at the 1 sigma level (which is equivalent to 1.5 at the 2 sigma level) was achieved. Data quality is not affected.

7. Activity concentrations above the $2 \sigma$ TPU are reported in some instances where minimum nuclide identification criteria are not met. Such tentative identifications result when the software attempts to calculate net activity concentrations for analytes where either one or both of the following criteria are not satisfied: the 'diagnostic' peak for a nuclide must be identified above critical level (generally the most abundant, interference-free photopeak), or the minimum library peak tolerance of $75 \%$ must be attained. These data have been flagged with a "Tl" qualifier.

8. No problems were encountered with either the client samples or the associated quality control samples. All quality control criteria were met.

The data contained in the following report have been reviewed and approved by the personnel listed below. In addition, Paragon Analytics, Inc. certifies that the analyses reported herein are true, complete and correct within the limits of the methods employed.
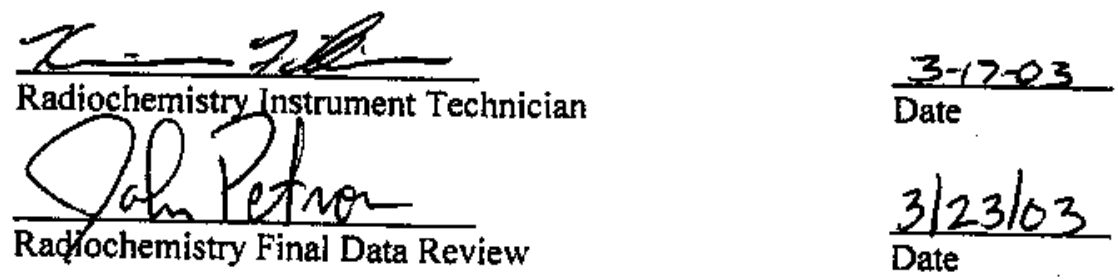


\section{PARAGON ANALYTICS, INC. Radiochemistry Data Package}

Section 3

\section{INDIVIDUAL \\ SAMPLE RESULTS}




\section{Gamma Spectroscopy Results}

\section{Method PAI 713R7}

Sample Results

Cllent Name: Bechtel Nevada

Cllent Project Narne: CAU 330

Cllent Project Number: V1913
Page: 1 of 4

Reported on: Monday, March 17, 2003

13:58:47

Laboratory Name: Paragon Analytics, Inc.

PAl Work Order: 0303017
Fleid 10:060204-T3

Lab iD:0303017-1
Sample Matrix: Sludge

Date Prepared: 10-Mar-03

Prep 80P: PAI 739R5

Prep Batch: GS01922
Date Collected: 05-Mar-03

Date Analyzed: 14-Mar-03

Analytlcal SOP; PAI 713R7

Spectrum Code: 030257003A
FInal Allquot: $507.3 \mathrm{~g}$

Report Basis: As Received Count TIme (min.): 30

Llbrary: GAM-A-001.LI

\begin{tabular}{|c|c|c|c|c|}
\hline Target Nucllde & Result + 2 s TPU & MDC & $\begin{array}{c}\text { Reporting } \\
\text { Units }\end{array}$ & Lab Quallfier \\
\hline Ac-228 & 8.63E-01 +/- 2.73E-01 & $4.76 \mathrm{E}-01$ & $\mathrm{pCl} / \mathrm{g}$ & \\
\hline Am-241 & $-2.12 E-01+/-4.20 E-01$ & $7.46 \mathrm{E}-01$ & $\mathrm{pCl} / \mathrm{g}$ & $\mathrm{U}$ \\
\hline Ce-144 & 4.44E-01 +/- 3.43E-01 & $5.30 E-01$ & pCi/g & U \\
\hline $\operatorname{co-60}$ & $-5.50 \mathrm{E}-02+1-6.52 \mathrm{E}-02$ & $1.37 E-01$ & $\mathrm{pCl} / \mathrm{g}$ & $\mathbf{U}$ \\
\hline Cs-134 & $-5.51 E-03+/-5.49 E-02$ & $1.00 \mathrm{E}-01$ & $\mathrm{pCi} / \mathrm{g}$ & $\mathrm{U}$ \\
\hline C8-137 & $1.39 E+00+/-2.78 E-01$ & $1.05 E-01$ & $\mathrm{pCV} / \mathrm{g}$ & \\
\hline Eu-152 & 4.16E-01 +/-2.78E-01 & $3.38 E-01$ & $\mathrm{pCH} / \mathrm{g}$ & TI \\
\hline$E u-154$ & $2.58 E-02+/-2.78 E-01$ & $5.18 E-01$ & $\mathrm{pCl} / \mathrm{g}$ & $U$ \\
\hline Eu-155 & $7.77 \mathrm{E}-02+1-2.00 \mathrm{E}-01$ & 3.38E-01 & $\mathrm{pCl} / \mathrm{g}$ & U \\
\hline $\mathrm{K}-40$ & $1.64 E+01+/ .3 .39 E+00$ & $1.30 E+00$ & $\mathrm{pCl} / \mathrm{g}$ & \\
\hline $\mathrm{Pb}-212$ & 9.87E-01 +/- 2.23E-01 & 1.71E-01 & $\mathrm{pCl} / \mathrm{g}$ & \\
\hline Pm-144 & $-4.19 E-02+1-6.24 E-02$ & 1.19E-01 & $\mathrm{pCl} / \mathrm{g}$ & U \\
\hline Pm-146 & $2,96 E-02+/-8.18 E-02$ & $1.40 E-01$ & $\mathrm{pCi} / \mathrm{g}$ & $\mathbf{U}$ \\
\hline Ru-106 & $-9.97 \mathrm{E}-02+1-5.02 \mathrm{E}-01$ & 9.37E-01 & $\mathrm{pCl} / \mathrm{g}$ & $\mathrm{U}$ \\
\hline Sb-125 & $-5.65 \mathrm{E}-02+1-1.66 \mathrm{E}-01$ & 3.03E-01 & $\mathrm{pCV} / \mathrm{g}$ & $\mathrm{U}$ \\
\hline Th-234 & $1.65 E+00+1-1.42 E+00$ & $2.25 E+00$ & $\mathrm{pCl} / \mathrm{g}$ & $\mathrm{U}$ \\
\hline U-235 & $-1.11 \mathrm{E}-02+/-3.09 \mathrm{E}-01$ & 5.39E-01 & $\mathrm{pCV} / \mathrm{g}$ & $\mathbf{U}$ \\
\hline$Y-88$ & 4.35E-03 +/. 6.79E-02 & $1.24 \mathrm{E}-01$ & $\mathrm{pCl} / \mathrm{g}$ & $\mathrm{U}$ \\
\hline
\end{tabular}

Data Package ID: GSS0303017-1 


\section{Gamma Spectroscopy Results}

\section{Method PAl 713R7}

\section{Sample Results}

Client Name: Bechtel Nevada

Client Project Name: CAU 330

Client Project Number: V1913
Page: 2 of 4

Reported on: Monday, March 17, 2003

13:58:47

Laboratory Name: Paragon Analytics, inc.

PAl Work Order: 0303017
Fidid 10,060204-T3

Lab : 10:0303017-1
Sample Matrlx: Siudge

Date Prepared: 10-Mar-03

Prep 8OP: PAI 739R5

Prep Batch: GS01922
Date Collected: 05-Mar-03

Date Analyzed: 14-Mar-03

Analytical SOP: PAI 713R7

Spectrum Code: 030257003A
Final Aliquot: $507.3 \mathrm{~g}$

Report Basis: As Received

Count TIme (min.): 30

Library: GAM-A-00t.LI

\begin{tabular}{|l|l|l|l|l|}
\hline Target Nuclide & Result +1-2 \& TPU & MDC & $\begin{array}{c}\text { Reporting } \\
\text { Units }\end{array}$ & Lab Qualfiler \\
\hline
\end{tabular}

\section{Comments:}

\footnotetext{
Quallitionafiflegs:

U - Result is less than the sample spectif MDC or less than the assoclated TPU.

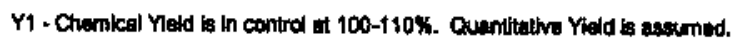

Y2 - Chemical Yitd oulside default limits.

LT - Recult is loes than Requeated MOC, groater than sampie apedilc MOC.

SQ - Spectral quellty preventa eccurale quantitation.

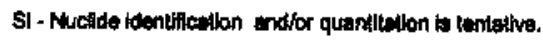

TI - Nucilde kentification Is tentalive.

R- Nuclisa has oxcoeded 8 hallives.
}

Abbrewations:

TFU - Total Propugated Uncertainty (904 PAI SOP 743) 


\section{Gamma Spectroscopy Results}

\section{Method PAI 713R7}

\section{Sample Results}

Client Name: Bechtel Novada

Client Project Name: CAU 330

Client Project Number: V1913
Page: 3 of 4

Reported on: Monday, March 17, 2003

13:58:47

Laboratory Name: Paragon Analytics, Inc.

PAI Work Order: 0303017
Flold iD:060204-T4

Lab 10:0303017-2
Somple Matrix: Siudge

Date Propared: 10-Mar-03

Prep sOP: PAI 739R5

Prep Batch: Gs01922
Date Collected: 05-Mar-03

Date Analyzed: 14-Mar-03

Analytical 8OP: PAI 713R7

Spectrum Code: 030402D08A
Final Allquot: $501.2 \mathrm{~g}$

Report Basis: As Received Count Time (min.): 30

Library: GAM-A-C01.LI

\begin{tabular}{|c|c|c|c|c|}
\hline Target Nuclide & Result +/- 2 \& TPU & MDC & $\begin{array}{l}\text { Reporting } \\
\text { Units }\end{array}$ & Lab Qualifier \\
\hline Ac-228 & $7,59 E-01+/ 2.52 E-01$ & $3.46 \mathrm{E}-01$ & $\mathrm{pCl} / \mathrm{g}$ & \\
\hline Ant-241 & $-2.22 \mathrm{E}-03+1-9.31 \mathrm{E}-02$ & $1.62 E-01$ & $\mathrm{pCl} / \mathrm{g}$ & $\mathrm{U}$ \\
\hline $\mathrm{Ce}-144$ & $7.20 \mathrm{E}-02+1-2.72 \mathrm{E}-01$ & $4.66 \mathrm{E}-01$ & pClig & $U$ \\
\hline Co-60 & $-1.78 E-02+1-4.90 \mathrm{E}-02$ & $1.03 E-01$ & $\mathrm{pCl} / \mathrm{g}$ & $\mathrm{u}$ \\
\hline Cs-134 & $-1.27 \mathrm{E}-02+1-4.78 \mathrm{E}-02$ & 8.99E-02 & $\mathrm{pCl} / \mathrm{g}$ & $u$ \\
\hline Cs-137 & $1.10 \mathrm{E}+00+1-2.29 \mathrm{E}-01$ & $9.18 E-02$ & $\mathrm{pCl} / \mathrm{g}$ & \\
\hline$E(1-152$ & $2.95 E-02+/ 2.06 E-01$ & $5.74 E-01$ & $\mathrm{pCl} / \mathrm{g}$ & $\mathrm{U}$ \\
\hline EU-154 & $-2.08 \mathrm{E}-01+1-2.87 \mathrm{E}-01$ & $5.98 E-01$ & pCilg & $U$ \\
\hline$E u-155$ & $4.34 E-02+/-1.36 E-01$ & 2.31E-01 & $\mathrm{pCl} / \mathrm{g}$ & $u$ \\
\hline$K-40$ & $1.24 E+01+1-2.69 E+00$ & 8.94E-01 & $\mathrm{pClg}$ & \\
\hline $\mathrm{Pb}-212$ & $8.60 \mathrm{E}-01+1-1.99 \mathrm{E}-01$ & 1.49E-01 & $\mathrm{pCl} / \mathrm{g}$ & \\
\hline$P m-144$ & $-3,42 E-02+/-5.53 E-02$ & 1.07E-01 & $\mathrm{pCivg}$ & $U$ \\
\hline $\mathrm{Pm}-146$ & $1.51 \mathrm{E}-02+\%-6.43 \mathrm{E}-02$ & 1.13E-01 & $\mathrm{pCl} / \mathrm{g}$ & U \\
\hline Ru-106 & $-4.58 \mathrm{E}-01+1-4.87 \mathrm{E}-01$ & $9.77 \mathrm{E}-01$ & $p C l / g$ & $\mathrm{u}$ \\
\hline Sb-125 & $1.40 \mathrm{E}-01+/ .1 .22 \mathrm{E}-01$ & $2.11 E-01$ & $\mathrm{pC} / \mathrm{g}$ & $\bar{U}$ \\
\hline Th-234 & $2.69 \mathrm{E}-01+/-7.77 \mathrm{E}-01$ & $1.31 \mathrm{E}+00$ & $\mathrm{pCv}$ & $\mathbf{u}$ \\
\hline U-235 & $-2.66 \mathrm{E}-01+/-2.81 \mathrm{E}-01$ & $5.17 E-01$ & $\mathrm{pCing}$ & $\mathrm{U}$ \\
\hline$Y-88$ & $1.91 E-02+/-5.48 E-02$ & $.9 .73 E-02$ & $\mathrm{pCl} / \mathrm{g}$ & U \\
\hline
\end{tabular}

Data Package ID: GSS0303017-1

Paragon Analytics Inc. 


\section{Gamma Spectroscopy Results}

\section{Method PAI 713R7}

\section{Sample Results}

Cllent Name: Bechtel Nevada

Client Project Name: CAU 330

Cllent Project Number: V1913
Page: 4 of 4

Reported on: Monday, March 17, 2003

13:58:48

Laboratory Name: Paragon Analytics, inc.

PAJ Work Order: 0303017

Fleld 10:060204-T4
Lab ID:0303017-2

Sample Matrix: Sludge

Date Prepared: 10-Mar-03

Prep \$OP: PAI 739R5

Prep Eatch: GS01922
Dato Coltected: 05-Mar-03

Date Analyzed: 14-Mar-03

Analytical SOP: PAI 713R7

Spectrum Code: 030402D08A
Final Aliquot: $501.2 \mathrm{~g}$

Report Basis: As Recelved Count TIme (mln.): 30

LIbrary: GAM-A-001.LI

\begin{tabular}{|c|c|c|c|c|}
\hline Target Nucllde & Result +/- 2 s TPU & MDC & $\begin{array}{c}\text { Reporting } \\
\text { Units }\end{array}$ & Lab Quallfier \\
\hline
\end{tabular}

\section{Comments:}

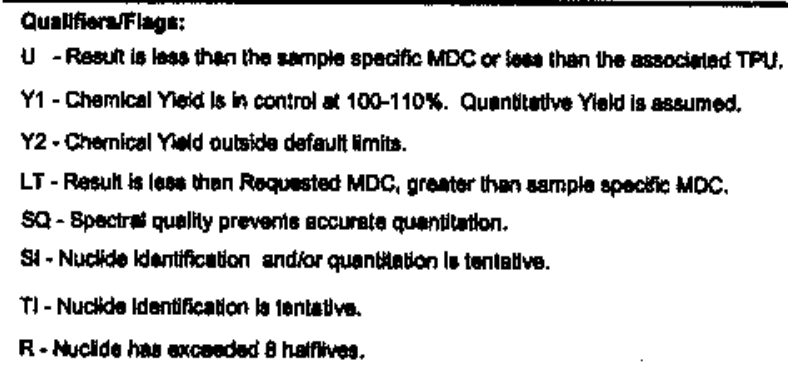

Abbreviations:

TPU - Toted Propagated Uncertaindy (goe PM SOP 743)

MOC - Minimam Delectuble Concentration (aee PAI SOP 709) 


\section{Paragon Analytics, Inc. Radiochemistry Case Narrative Gross Alpha/Beta}

\section{Bechtel Nevada \\ CAU 330 / V1913 \\ PAI WO 0303017}

1. This report consists of two sludge samples received by Paragon on 03/07/03.

2. These samples were prepared according to Paragon Analytics, Inc. procedure PAI SOP702R15.

3. The samples were analyzed for gross alpha and beta activity by gas flow proportional counting according to Paragon Analytics, Inc. procedure PAI SOP724R7. The analyses were completed on $03 / 25 / 03$. Gross alpha results are referenced to ${ }^{241} \mathrm{Am}$. Gross beta results are referenced to ${ }^{90} \mathrm{Sr} / \mathrm{Y}$.

4. The analysis results for these samples are reported on an 'as received' weight basis in units of $\mathrm{pCi} / \mathrm{gram}$. The samples were weighed out on a dry weight basis and were converted to an 'as received' weight basis by using the percent moisture. Please refer to QASS 256650.

5. These samples were flamed, as prescribed in EPA Methods 900.0 and 9310 for samples which demonstrate hygroscopicity. This could reduce the beta activity if the samples contained ${ }^{137} \mathrm{Cs}$, or other beta emitters, that may be volatile under the conditions associated with flaming.

6. Due to current software limitations, the DER determinations in this report were calculated using the 2 sigma TPU. The SOW indicates that the 1 sigma TPU be used in the DER determination. However, the requested DER limit of less than 3 at the 1 sigma level (which is equivalent to 1.5 at the 2 sigma level) was achieved. Data quality is not affected.

7. No anomalous situations were encountered during the preparation or analysis of these samples. All quality control criteria were met. 
The data contained in the following report have been reviewed and approved by the personnel listed below. In addition, Paragon Analytics, Inc. certifies that the analyses reported herein are true, complete and correct within the limits of the methods employed.
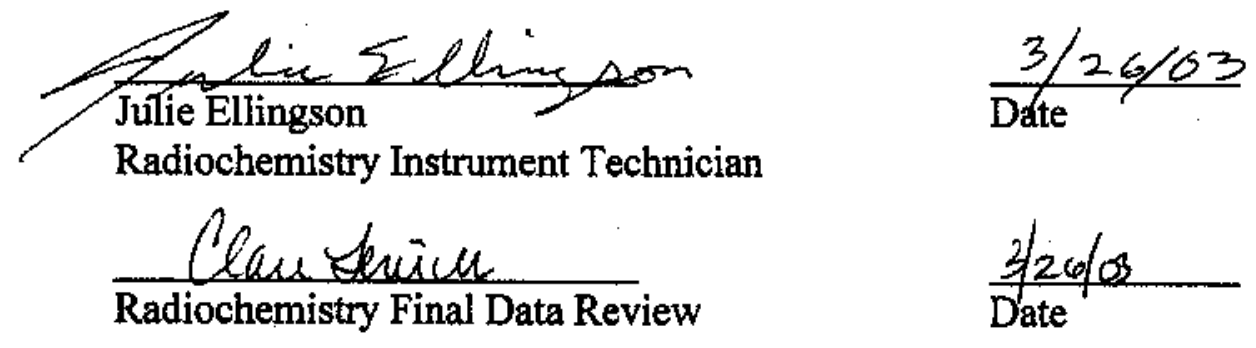


\title{
PARAGON ANALYTICS, INC. Radiochemistry Data Package
}

\author{
Section 3
}

\section{INDIVIDUAL \\ SAMPLE RESULTS}




\section{Gross Alpha/Beta Analysis}

\section{Method PAI SOP 724R7}

\section{Sample Results}

Client Name: Bechtel Nevada Client Project Name: CAU 330 Client Project Number: V1913
Page: 1 of 2

Reported on: Wednesday, March 2B, 2003 12:38:33

Laboratory Name: Paragon Analytics, Inc.

PAl Work Order: 0303017
Fold 10 060204-T3

Lab 1D:0303017-1
Sample Matrix: Sludge

Date Prepared: 17-Mar-03

Prep sOP: PAI 702R15

Prep Batch: AB00769
Date Collected: 05-Mar-03

Dato Analyzed: 25-Mar-03

Analytical SOP: PAl 724R7
Final Aflquot: $0.8900 \mathrm{~g}$

Report Bacis: As Received Count Time (min.): 60

\begin{tabular}{|c|c|c|c|c|}
\hline Target Nuclide & Result +1- 2 s TPU & MDC & $\begin{array}{c}\text { Reporting } \\
\text { Units }\end{array}$ & Lab Qualifier \\
\hline GrAlpha & $3.35 \mathrm{E}+00+/-9.88 \mathrm{E}-01$ & $8.41 \mathrm{E}-01$ & $\mathrm{pC} / \mathrm{g}$ & $\mathrm{LT}$ \\
\hline GrBeta & $4.93 \mathrm{E}+00+/ \cdot 1.14 \mathrm{E}+00$ & $1.21 \mathrm{E}+00$ & $\mathrm{pCl} / \mathrm{g}$ & $\mathrm{LT}$ \\
\hline
\end{tabular}

\section{Comments:}

Qualifiane Fiagla:

U - Reout is less than the sanple tpectic MDC.

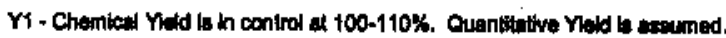

Y2 - Chemical Yeld outside defoult limits.

LT - Result is leas than Raquested MOC, greater than sample apectilc MOC.
Abbrewlators:

TPU - Total Propagaled Lincerteinty (uce PAI SOP 743)

WDC - Mhimum Detectuble Concentration (24) PAI SOP 709) 


\section{Gross Alpha/Beta Analysis}

\section{Method PAI SOP 724R7}

\section{Sample Results}

Paga: 2 of 2

Cllent Name: Bechtel Nevada

Cllent Project Name: CAU 330

Client Project Number: V1913
Reported on: Wednesday, March 26, 2003

12:38:33

Laboratory Name: Paragon Analytlcs, Ine.

PAl Work Order: 0303017
Fidd LO:060204-T4

Kab ID:0303017-2
Sample Metrix: Sludge

Date Prepared: 17-Mar-03

Prep SOP: PAI 702R15

Prop Batch: AB00769
Date Collected: 05-Mar-03

Date Analyzed: 25-Mar-03

Analytical SOP: PAI 724R7
Final Allquot: $0.9700 \mathrm{~g}$

Report Basis: As Recelved Count Tlme (min.): 60

\begin{tabular}{|c|c|c|c|c|}
\hline Target Nuclide & Result $+/ \cdot 2$ s TPU & MDC & $\begin{array}{c}\text { Reporting } \\
\text { Units }\end{array}$ & Lab Qualifler \\
\hline GrAjpha & $2.76 \mathrm{E}+00+/-8.69 \mathrm{E}-01$ & $7.03 \mathrm{E}-01$ & $\mathrm{pCi} / \mathrm{g}$ & $\mathrm{LT}$ \\
\hline GrBeta & $5.00 \mathrm{E}+00+1-1.09 \mathrm{E}+00$ & $1.06 \mathrm{E}+00$ & $\mathrm{DCV} / \mathrm{g}$ & $\mathrm{LT}$ \\
\hline
\end{tabular}

\section{Comments:}

\section{Qualifierefrituge:}

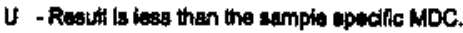

Y1 - Cherricel Yieid is in control at 100-110\%. Ouantitative Veld is coumed.

Y2 - Chemical Yietd ouadide defuult Imnlto.

LT - Reault is leas than Recuxisted MDC, grenter than anmple eptcific MDC.
Abbrevialion:

TPU - Tot:d Propagated Uncertainty (sab PN SOP 743)

MDC - MAnimum Datectable Concentration (seo PA SOP 709) 
CLOSURE REPORT - CAU 330

Section: Appendix B

Revision: 0

Date: July 2003

\section{THIS PAGE INTENTIONALLY LEFT BLANK}


CLOSURE REPORT - CAU 330

Section: Appendix B

Revision: 0

Date: July 2003

\title{
SAMPLE DELIVERY GROUP
}

\author{
V1958
}


CLOSURE REPORT - CAU 330

Section: Appendix B

Revision: 0

Date: July 2003

\section{THIS PAGE INTENTIONALLY LEFT BLANK}




\section{SLI}

14 May 2003

Mr. Theodore Redding

Bechtel Nevada Corporation

2621 Losee Road

Mail Stop NTS273

Las Vegas, NV 89030-4134

RE: Subcontract No. 30028, Task Order No. 1

Data Report for LVL Batch 0304L254

SDG\#: V1958 Chain: CAU 330

Dear Mr. Redding:

Enclosed please find the data report for 3 soil samples received 23 April 2003 for analysis for TPH DRO on a 28 day turnaround time. The invoice is enclosed. An EDD is not required.

Please do not hesitate to contact me at (610) 280-3029 with any questions or at any time we may be of service.

Very truly yours,

Lionville Laboratory Incorporated

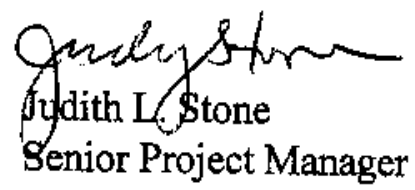

Enclosure: 


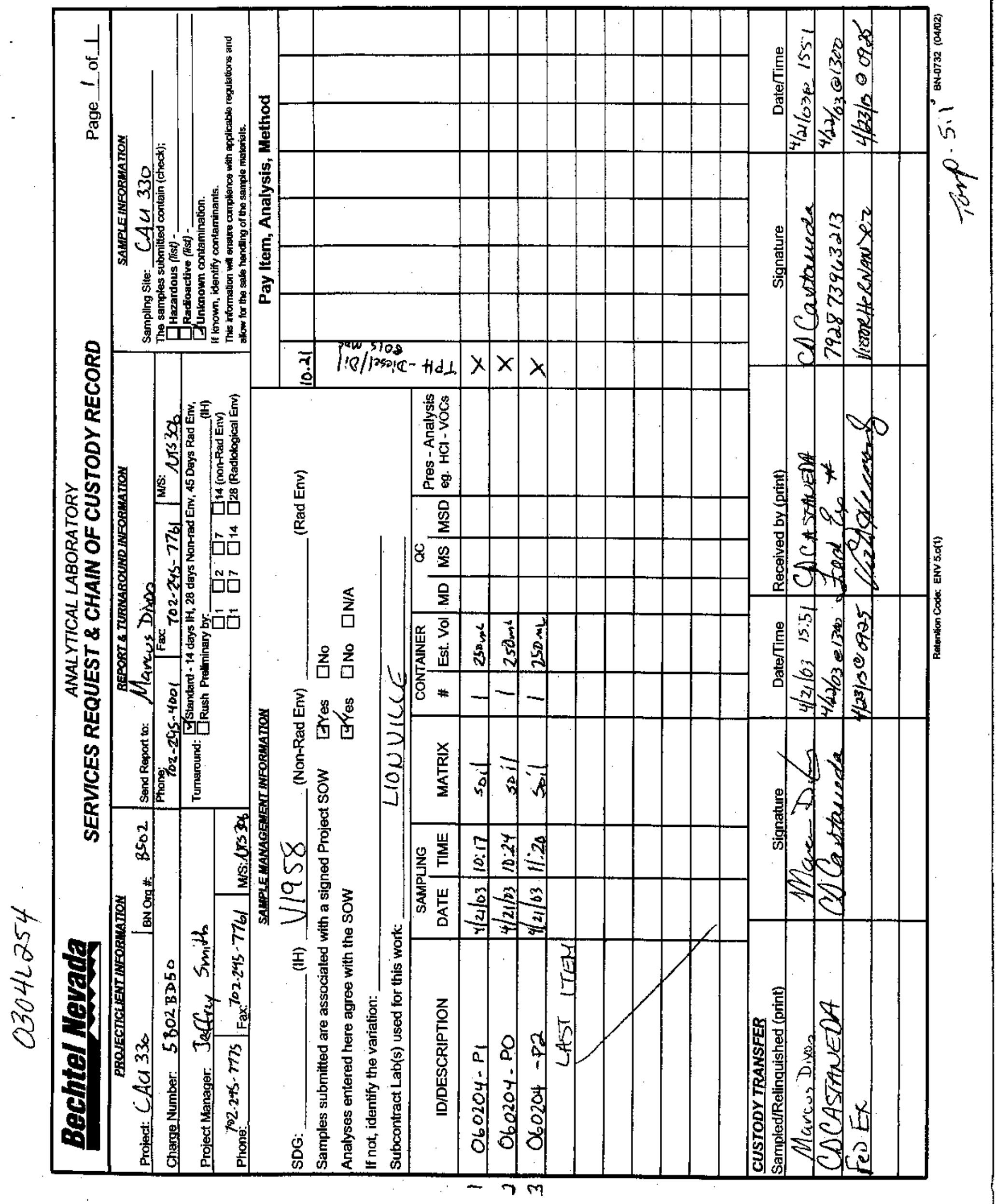


CASE NARRATIVE 


\section{- IVLI \\ LIONVILL LABORAIORY INC:}

\section{Analytical Report}

Client: BECHTEL-NEVADA V1958

LVL \#: 0304L254
W.O. \#: 60052-001-001-0001-00

Date Received: 04-23-03

\section{DIESEL RANGE ORGANICS}

The set of samples consisted of three (3) soil samples collected on 04-21-03.

The samples and their associated QC samples were extracted on 04-24-03 and analyzed according to Lionville Laboratory OPs on 05-09-03. The extraction procedure was based on method 3540 and the extracts were analyzed based on method 8015B for Diesel Range Petroleum Hydrocarbons.

1. All results presented in this report are derived from samples that met LvLI's sample acceptance policy.

2. All required holding times for extraction and analysis have been met.

3. The method blank was below the reporting limits for all target compounds.

4. All surrogate recoveries were within acceptance criteria.

5. The blank spike recovery was within acceptance criteria.

6. All matrix spike recoveries were within acceptance criteria.

7. All initial calibrations associated with this data set were within acceptance criteria.

8. All continuing calibration standards analyzed prior to sample extracts were within acceptance criteria.

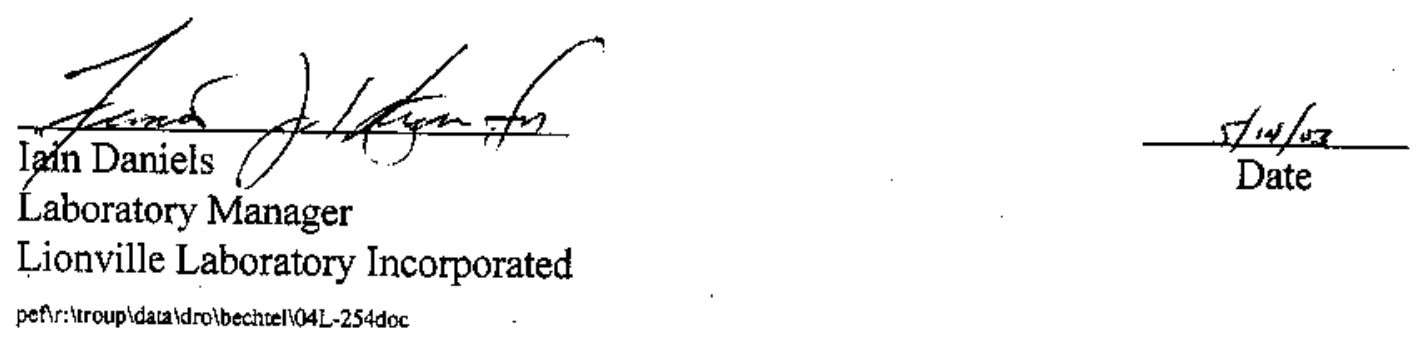

The results presented in this report relate only to the aralytical testing and conditions of the samples at receipt and during storage. 
GLOSSARY OF DIESEL RANGE ORGANICS DATA

\section{DATA QUALIFIERS}

$\mathrm{U}=$ Indicates that the compound was analyzed for but not detected. The minimum detection limit for the sample (not the method detection limit) is reported with the $\mathrm{U}$ (e.g., 10U).

$\mathbf{J}=$ Indicates an estimated value. This flag is used in cases where a target analyte is detected at a level less than the lower quantification level. If the limit of quantification is $10 \mathrm{ug} / \mathrm{L}$ and a concentration of $3 \mathrm{ug} / \mathrm{L}$ is calculated, it is reported as $3 \mathrm{~J}$.

B $=$ This flag is used when the analyte is found in the associated blank as well as in the sample. It indicates possible/probable blank contamination.

$\mathbf{E}=$ Indicates that the compound was detected beyond the calibration range and was subsequently analyzed at a dilution.

I $=$ Interference.

\section{ABBREVIATIONS}

BS = Indicates blank spike in which reagent grade water is spiked with the CLP matrix spiking solutions and carried through all the steps in the method. Spike recoveries are reported.

BSD $=$ Indicates blank spike duplicate.

MS $=$ Indicates matrix spike.

MSD $=\quad$ Indicates matrix spike duplicate.

DL = Indicates that recoveries were not obtained because the extract had to be diluted for analysis.

NA $=$ Not Applicable.

DF $=$ Dilution Factor.

$\mathbf{N R}=$ Not Required.

SP = Indicates Spiked Compound. 


\section{GLOSSARY OF DIESEL RANGE ORGANICS DATA}

D $=$ This flag identifies all compounds identified in an analysis at a secondary dilution factor.

C = This flag applies to a compound that has been confirmed by GC/MS. 
Lab Name: Lionvilie Labs, Inc. Work Order: 60052001001

Client: BECHTEL NEVADA V1958

Matrix:

SOIL

Lab Sample ID: 0304L254-001

Sample wt/vol:

$\underline{25.0}(\mathrm{~g} / \mathrm{mL}) \mathrm{G}$

Lab File ID:

BLKLACHJ

Level: (low/med) Low

Date Received: $04 / 23 / 03$

\%oisture: not dec.

5

Date Analyzed: $05 / 09 / 03$

Column: (pack/cap) CAP

Dilution Factor: 1.00

CONCENTRATION UNITS :

CAS NO.

COMPOUND

(ug/L or $\mathrm{ug} / \mathrm{Kg}$ ) $\mathrm{mc} / \mathrm{kg}$

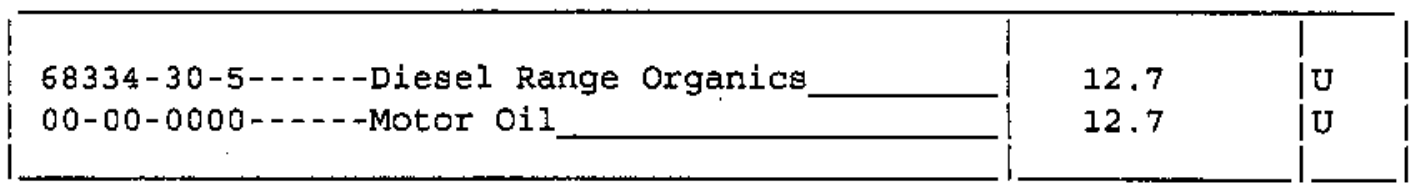

12/88 Rev. 


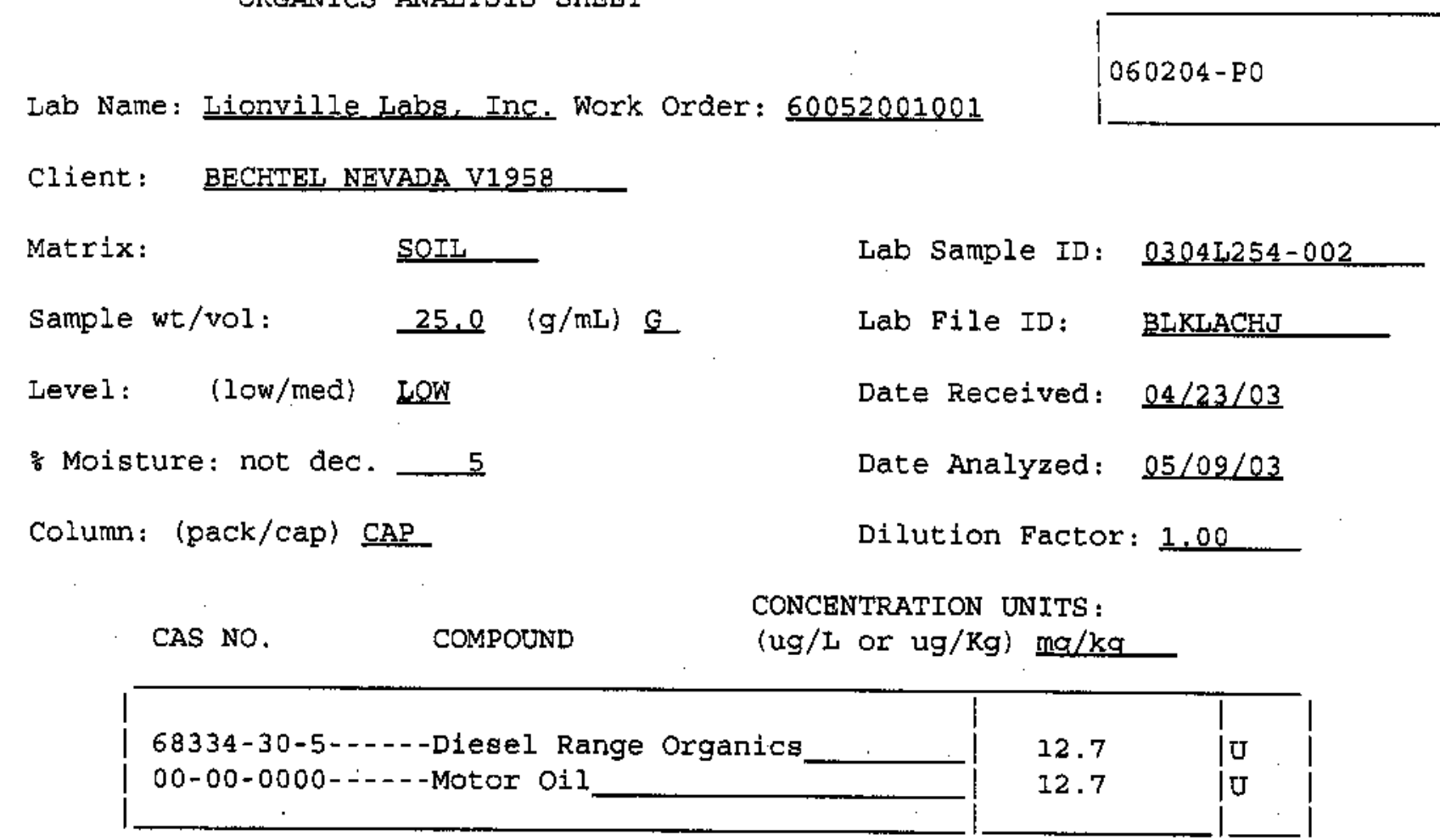

12/88 Rev. 
Lab Name: Lionville Labs. Inc. Work Order: 60052001001

Client: BECHTEL NEVADA V1958

Matrix:

SOII

sample wt/vol:

$25.0(\mathrm{~g} / \mathrm{mL}) \mathrm{G}$

Level: (low/med) LOW

\& Moisture: not dec. 5

Column: (pack/cap) CAP

CAS NO.

COMPOUND
Lab Sample ID: 0304I254-003

Lab File ID: BLKLACHJ

Date Received: $04 / 23 / 03$

Date Analyzed: $\quad 05 / 09 / 03$

Dilution Factor: 1.00

CONCENTRATION UNITS:

(ug/L or $\mathrm{ug} / \mathrm{Kg}$ ) $\mathrm{mg} / \mathrm{kg}$
68334-30-5-..-Diesel Range Organics

00-00-0000-..-Motor Oil
12.6

12.6

|

U

12/88 Rev. 
CLOSURE REPORT - CAU 330

Section: Appendix B

Revision: 0

Date: July 2003

\section{THIS PAGE INTENTIONALLY LEFT BLANK}


CLOSURE REPORT - CAU 330

Section: Appendix B

Revision: 0

Date: July 2003

\title{
SAMPLE DELIVERY GROUP
}

\author{
V1962
}


CLOSURE REPORT - CAU 330

Section: Appendix B

Revision: 0

Date: July 2003

\section{THIS PAGE INTENTIONALLY LEFT BLANK}




\section{$3 / V L I$ \\ HONVHIS IABOHAROKY INC}

21 May 2003

Mr. Theodore Redding

Bechtel Nevada Corporation

2621 Losee Road

Mail Stop NTS273

Las Vegas, NV 89030-4134

RE: Subcontract No. 30028, Task Order No. 1

Data Report for LVL Batch 0304L269

SDG\#: V1962 Chain: Project CAU 330

Dear Mr. Redding:

Enclosed please find the data report for 2 soil samples and 2 water samples received 24 April 2003 for analysis for VOAs, SVOAs, PCBs, TPH GRO/DRO and metals on a 28 day turnaround time. The invoice is enclosed. An EDD is not required.

Please note that the pay items for VOAs and SVOAs were revised after sample receipt; all were requested as "without TICs" per your instructions. Copies of the emails are enclosed. Please do not hesitate to contact me at (610) 280-3029 with any questions or at any time we may be
of service.

Very truly yours,

Lionville Laboratory Incorporated

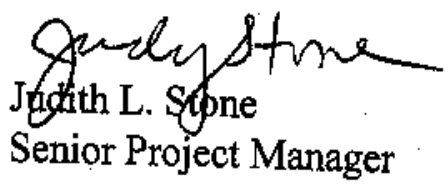

Enclosure: 


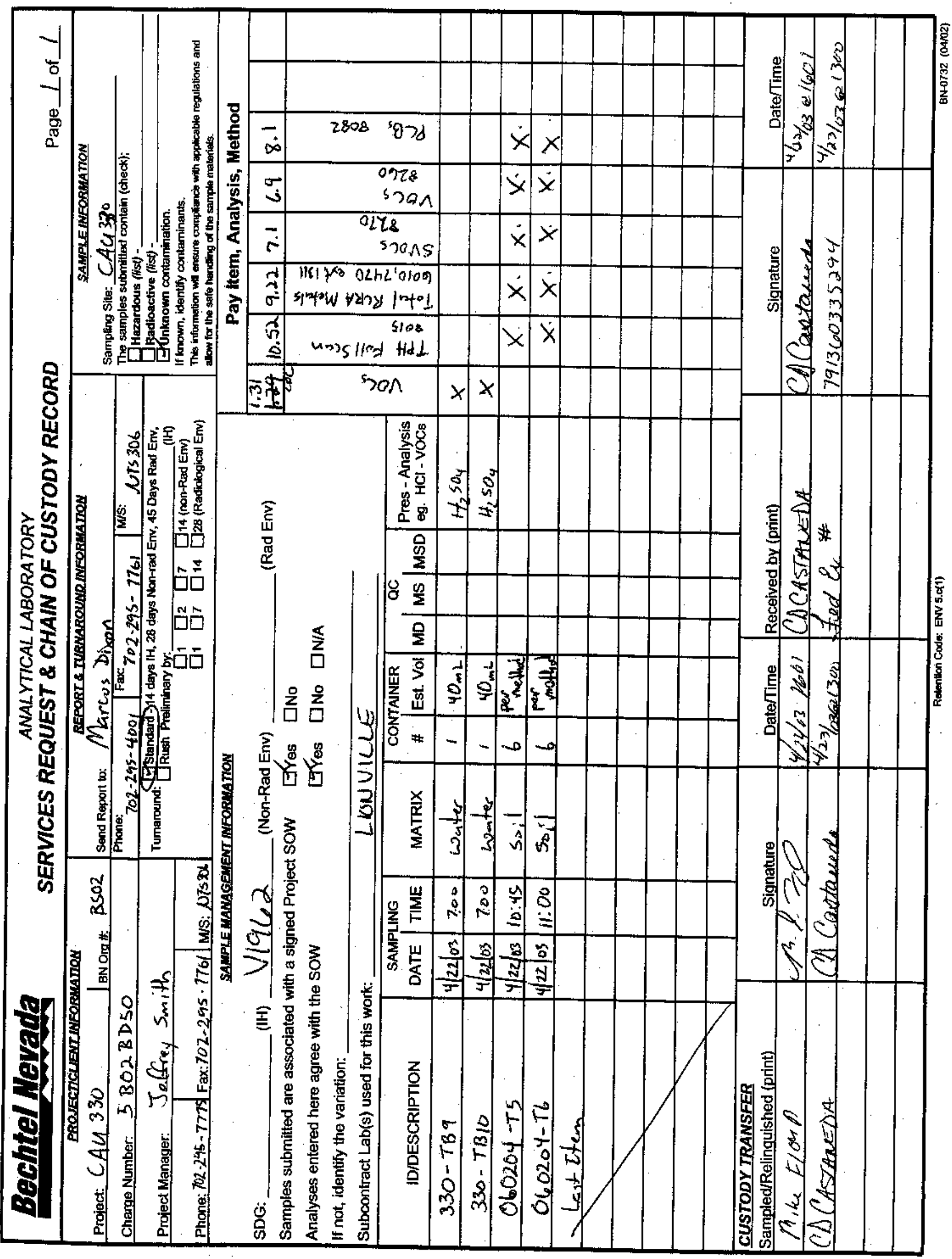


Case Narrative 


\section{( $\mid V L I$ \\ IIONVILL LABORAGORV INC:}

\section{Analytical Report}

Client : BECHTEL NEVADA V1962

LVL\# : 0304L269
W.O.\# : 60052-001-001-0001-00

Date Received : 04-24-03

\section{SW846 METALS}

1. This narrative covers the analyses of 2 soil samples.

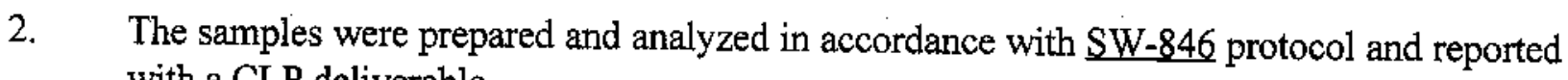
with a CLP deliverable.

3. ICVs, CCVs, and LCSs stock standards were purchased from Inorganic Ventures Laboratory and High Purity.

4. All analyses were performed within the required holding times.

5. All results presented in this report are derived from samples that met LvLI's sample acceptance policy.

6. All Initial and Continuing Calibration Verifications (ICV/CCVs) were within control limits.

7. All Initial and Continuing Calibration Blanks (ICB/CCBs) were within method criteria.

8. All preparation/method blanks were within method criteria. Refer to form 3 .

9. All ICP Interference Check Standards were within control limits. Refer to form 4.

10. All laboratory control samples (LCS) were within the $80-120 \%$ control limits. Refer to form 7 .

11. All sample IDs were changed to accommodate the EPA naming convention which allows a maximum of 6 characters on all CLP Forms. Refer to the comments section of form 1 for the original ID.

12. All matrix spike, duplicate and serial dilution analyses were performed on BECHTEL NEVADA V1964, LVL batch\# 0304L282 within the same digestion batch. Please refer to this package for the associated $\mathrm{QC}$ forms. 

13. Recoveries on the Laboratory Summary Report and CLP forms will vary depending on the
number of significant figures used in the recovery calculation.

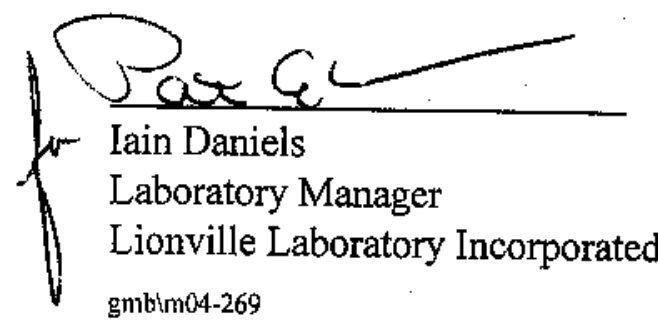

$$
\frac{05-16-03}{\text { Date }}
$$

gmbim04-269 


\section{METHOD REFERENCES AND DATA QUALIFIERS}

\section{DATA QUALIFIERS}

$\mathrm{U}=$ Indicates that the parameter was not detected at or above the reported limit. The associated numerical value is the sample detection limit.

$\mathrm{B}=\quad$ Indicates that the parameter was between the Instrument Detection Limit (IDL) and the Contract Required Detection Limit (CRDL)

\section{Q OUALIEIERS}

$E=$ The reported value is estimated because of the presence of interference.

$M=$ Duplicate injection precision not met.

$N=$ Spiked sample recovery not within control limits.

$\mathrm{S}=\quad$ The reported value was determined by the Method of Standard Additions (MSA).

$\mathrm{W}=$ Post Digestion spike for Furnace AA analysis is out of control limits (85-115\%), while sample absorbance is less than $50 \%$ of spike absorbance.

* = Duplicate analysis not within control limits.

$t=$ Correlation coefficient for the MSA is less than 0.995 .

\section{ABBREVIATIONS}

$\mathrm{PB}=$ Method or Preparation Blank.

$S$ = Matrix Spike.

$T=$ Matrix Spike Duplicate.

$\mathrm{R}$ or $\mathrm{D}=$ Sample Replicate

\section{ANALYTICAL METAL METHODS}

1. Not included in the method element list.

2. Modified $\mathrm{Hg}$ : $\mathrm{Hg} 1$ and $\mathrm{Hg} 2$ require less total volume of digestate due to the autosampler analysis. Sample volumes and reagents for mercury determinations in water and soil have been proportionately scaled down to adapt to this semiautomated technique. The sample volume used for water analysis is $33 \mathrm{~mL}$. For soils, approximately 0.3 grams of sample is taken to a final volume of $50 \mathrm{~mL}$ (including all reagents).

3. Flame AA.

4. Graphite Furnace AA.

RFW 21-21L-033/O-01/97 
U.S. EPA

INORGANIC ANALYSES DATA SHEET

Lab Name: IIONVILLE_LABORATORY Lab Code: LVII Matrix (soil/water) : SoIL Level (low/med): \% Solids :
Contract: 60052

SAS NO.:

SDG No.: 204T5

$204 \mathrm{T5}$

LOW

Lab Sample ID: 0304L269-0003

Date Received: 04/24/03

Concentration Units (ug/L or $\mathrm{mg} / \mathrm{kg}$ dry weight): MG/KG

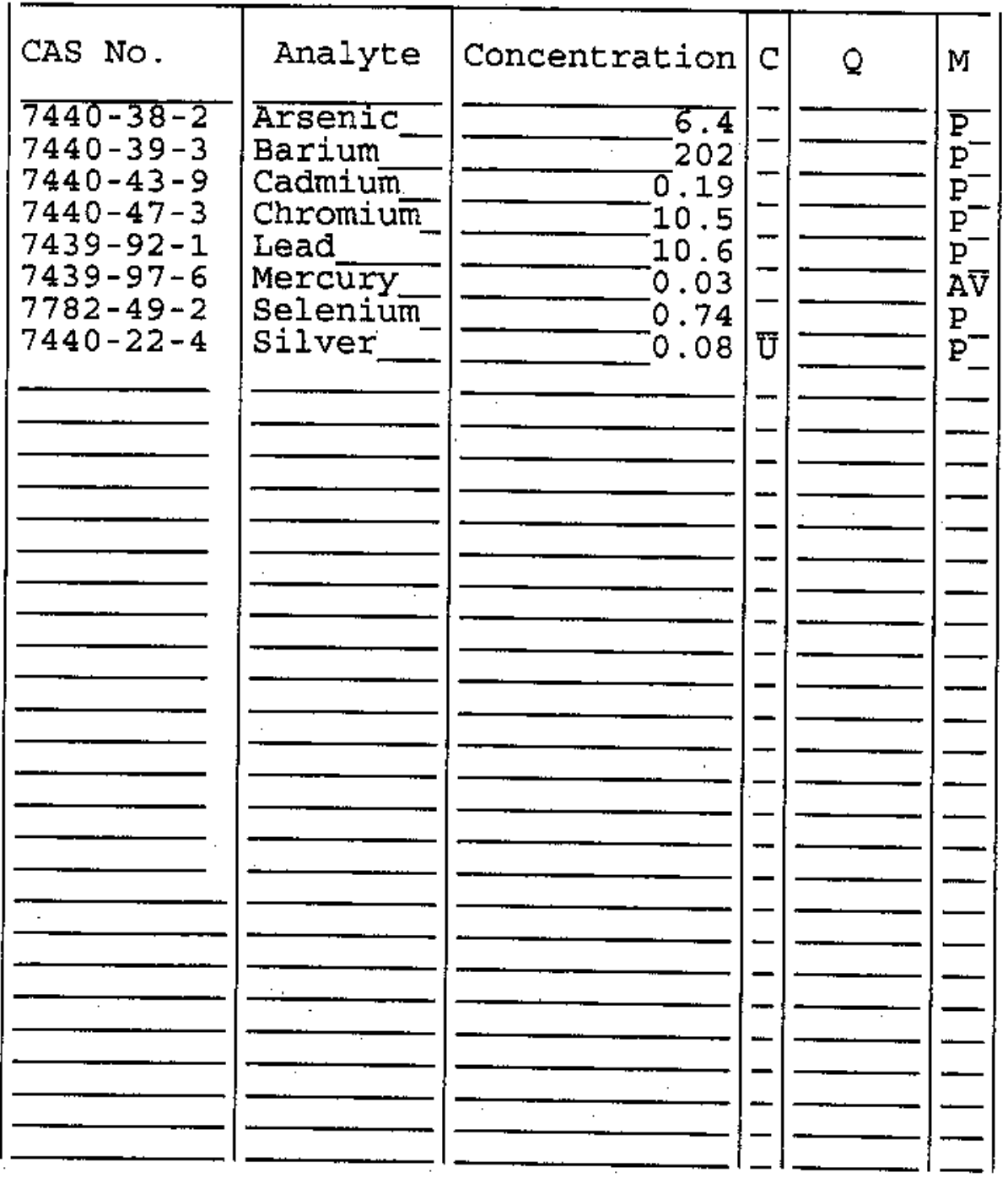

Color Before: Color After:
Clarity Before: Clarity After:
Texture:

Artifacts :

Comments :

$060204-T 5$ 
1

INORGANIC ANALYSES DATA SHEET
EPA SAMPLE NO.

Contract: 60052

SAS No.:

SDE NO : $204 \mathrm{T5}$

Case No.: V1962 SOIL LOW -92.1

Date Received: 04/24/03
Lab Code: LVLI
Matrix (soil/wat

Level (low/med): 음 Solids :

Concentration Units (ug/L or $\mathrm{mg} / \mathrm{kg}$ dry weight): MG/KG

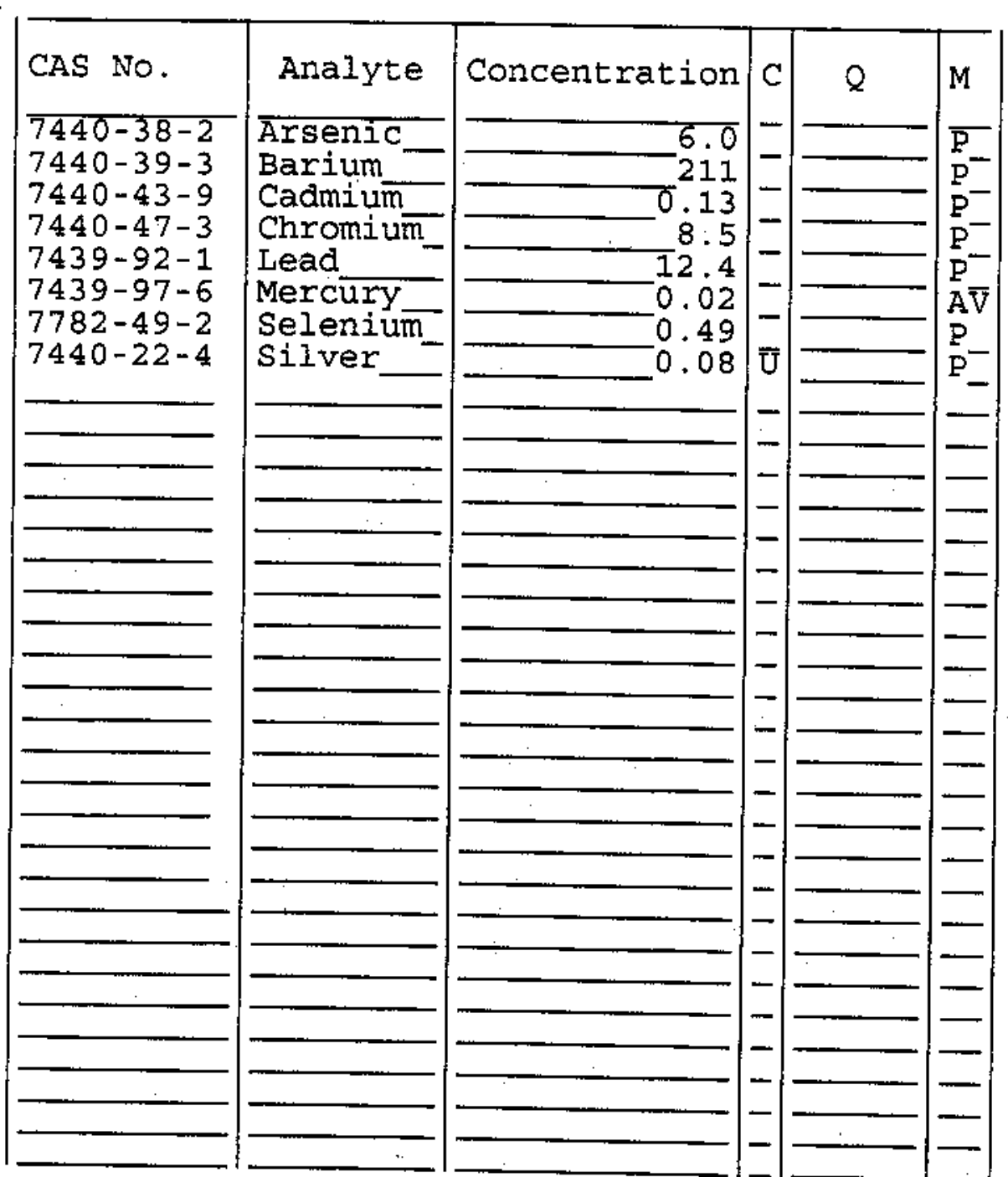

Clarity Before:

Clarity After:
Texture:

Artifacts:

Comments:

$060204-\mathrm{T} 6$ 
Case Narrative 


\section{- IVLI \\ HONVILLE LABOKAYORY INC:}

Client: BECHTEL-NEVADA V1962

LVL \#: 0304L269
W.O. \#: 60052-001-001-0001-00

Date Received: 04-24-2003

\section{GC/MS VOLATILE}

Two (2) water and two (2) soil samples were collected on 04-22-2003.

The samples and their associated QC samples were analyzed according to criteria set forth in Lionville Laboratory OPs based on SW 846 Method 8260B for TCL Volatile target compounds on 05-01-2003.

The following is a summary of the $\mathrm{QC}$ results accompanying the sample results and a description of any problems encountered during their analyses:

1. All results presented in this report are derived from samples that met LvLI's sample acceptance policy.

2. The required holding time for analysis was met.

3. Non-target compounds were not reported as per client request.

4. All surrogate recoveries were within EPA QC limits.

5. All matrix spike recoveries were within EPA QC limits.

6. All blank spike recoveries were within EPA QC limits.

7. The method blanks contained the common laboratory contaminants Methylene Chloride and/or Acetone at levels less than $2 \mathrm{x}$ the CRQL. The method blank 02LVG098-MB1 also contained the target compound 2-Butanone at a level less than the CRQL.

8. Internal standard area criteria were not met for sample 060204-T6 and 060204-T6 MSD. The analysis of associated matrix spike sample fulfills the reanalysis requirements.

9. Manual integrations are performed according to OP L-QA-125 to produce quality data with the utmost integrity. All manual integrations are required to be technically valid and properly documented. Appropriate technical flags are defined in the Glossary ("Technical Flags For
Manual Integration"). 


\section{GLOSSARY}

\section{DATA QUALIFIERS}

$\mathrm{U}=$ Compound was analyzed for but not detected. The associated numerical value is the estimated sample quantitation limit which is included and corrected for dilution and percent moisture.

$\mathbf{J}=$ Indicates an estimated value. This flag is used under the following circumstances: 1) when estimating a concentration for tentatively identified compounds (TICs) where a $1: 1$ response is assumed; or 2) when the mass spectral data indicate the presence of a compound that meets the identification criteria but the result is less than the specified detection limit but greater than zero. For example, if the limit of detection is $10 \mathrm{ug} / \mathrm{L}$ and a concentration of $3 \mathrm{ug} / \mathrm{L}$ is calculated, it is reported as $3 \mathrm{~J}$.

B $=$ This flag is used when the analyte is found in the associated blank as well as in the sample. It indicates possible/probable blank contamination. This flag is also used for a TIC as well as for a positively identified TCL compound.

E = Indicates that the compound was detected beyond the calibration range and was subsequently analyzed at a dilution.

D = Jdentifies all compounds identified in an analysis at a secondary dilution factor.

I $=$ Interference.

NQ = Result qualitatively confirmed but not able to quantify.

A $=$ Indicates that a TIC is a suspected aldol-condensation product.

N $\quad=\quad$ Indicates presumptive evidence of a compound. This flag is only used for tentatively identified compounds (TICs), where the identification is based on a mass spectral library search. It is applied to all TIC results. For generic characterization of a TIC, such as chlorinated hydrocarbon, the N code is not used.

$\mathrm{X} \quad=\quad$ This flag is used for a TIC compound which is quantified relative to a response factor generated from a daily calibration standard (rather than quantified relative to the closest internal standard).

$Y=$ Additional qualifiers used as required are explained in the case narrative. 


\section{GLOSSARY}

\section{ABBREVIATIONS}

BS = Indicates blark spike in which reagent grade water is spiked with the CLP matrix spike solutions and carried through all the steps in the method. Spike recoveries are reported.

$\mathrm{BSD}=\quad$ Indicates blank spike duplicate.

MS $\quad=\quad$ Indicates matrix spike.

MSD $=$ Indicates matrix spike duplicate.

DL = Suffix added to sample number to indicate that results are from a diluted analysis.

NA $=\quad$ Not Applicable.

DF $\quad=\quad$ Dilution Factor.

NR $=\quad$ Not Required.

$\mathrm{SP}, \mathrm{Z}=$ Indicates Spiked Compound. 
Sample Data for each Sample 
$1 \mathrm{~A}$

VOLATILE ORGANICS ANALYSIS SHEET
EPA SAMPLE NO.

Lab Name: Lionville Labs, Inc. Contract: 60052001001

Lab Code: Iionvi Case No.:

Matrix: (soil/water) WATER

Sample wt/vol: $\quad \underline{5.00}(\mathrm{~g} / \mathrm{mL})$ ML

Level: $\quad(10 \mathrm{w} / \mathrm{med})$ LOW

\% Moisture: not dec.

Column: (pack/cap) CAP
SAS NO. :

SDG No.:

Lab Sample ID: $\quad$ 8304L269-001

Lab File ID:

.0050112

Date Received: $04 / 24 / 03$

Date Analyzed: 05/01/03

Dilution Factor: 1.00
CAS NO.

COMPOUND
CONCENTRATION UNITS:

(ug/L or $u g / \mathrm{Kg}$ ) $\mathrm{ug} / \mathrm{L}$

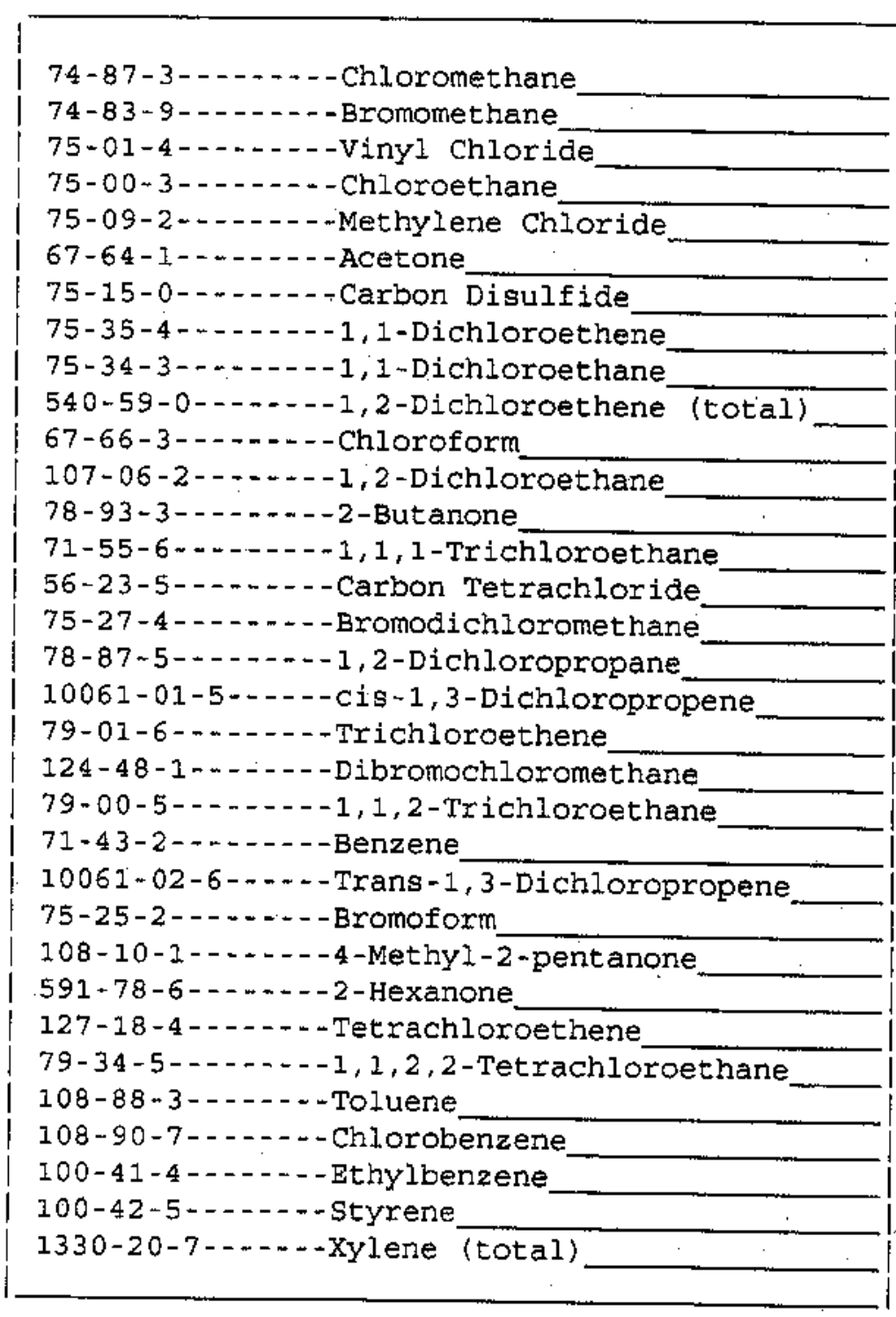

FORM $1 \mathrm{~V}-1$

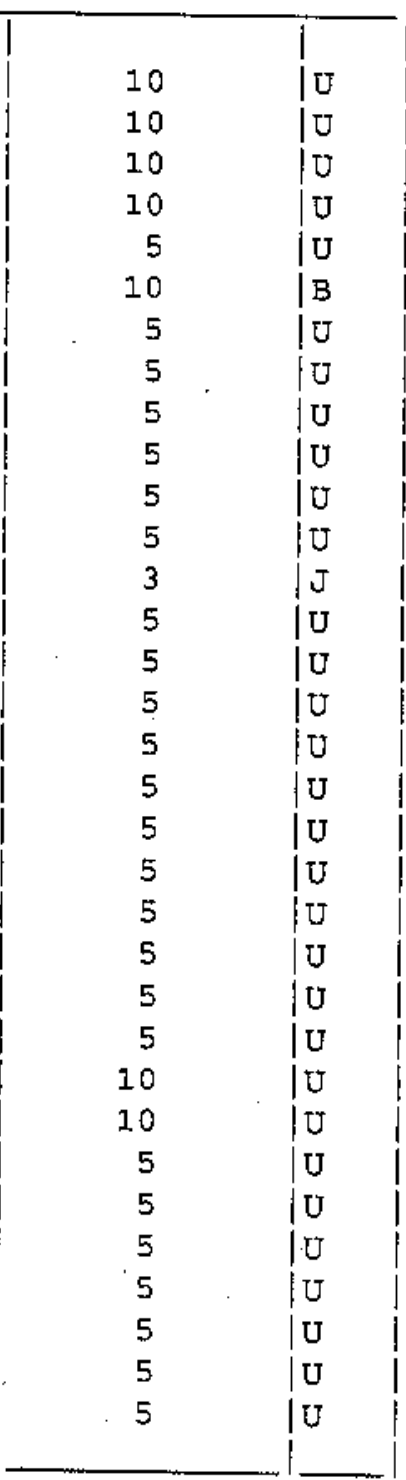

1/87 Rev. 
Lab Name: Iionvilie Labs, Inc, Contract: 60052001001

Lab Code: Lionvi Case No.:

Matrix: (soil/water) WATER

Sample wt/vol: $\quad 5.00 \cdot(\mathrm{g} / \mathrm{mL}) \mathrm{ML}$

Leve1: (low/med) LOW

\%oisture: not dec.

Column: (pack/cap) CAP
SAS NO.:

Lab Sample ID: 0304L259-002

Lab File ID: 9050113

Date Received: $\underline{04 / 24 / 03}$

Date Analyzed: $\underline{05 / 01 / 03}$

Dilution Factor: 1.00
CAS NO.

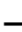

74-87-3--..-- - Chloromethane

74-83-9--------Bromomethane

| 75-01-4-------vinyl Chloride

| 75-00-3-------Chloroethane

| 75-09-2-------Methylene Chloride

| 67-64-1-...-.-Acetone

| 75-15-0-...-.-Carbon Disulfide

| 75-35-4--.....1,1-Dichloroethene

| 75-34-3-n....1,1-Dichloroethane

| 540-59-0......1,2-Dichloroethene

67-66-3--.--Chloroform

107-06-2----1, 2-Dichloroethane

78-93-3--------2-Butanone

| 71-55-6.....-1, 1, 1-Trichloroethane

56-23-5---.--Carbon Tetrachloride

75-27-4------Bromodichloromethane

78-87-5--...-1, 2-Dichloropropane

10061-01-5--.-cis-1,3-Dichloropropene

79-01-6--.--.-Trichloroethene

124-48-1-------Dibromochloromethane

79-00-5------1, 1,2-Trichloroethane

71-43-2-------Benzene

10061-02-6-----Trans-1, 3-Dichloropropene

75-25-2---- - - Bromoform

108-10-1--.--4-Methyl-2-pent anone

591-78-6------2-Hexanone

127-18-4------Tetrachloroethene

79-34-5-..---1, 1,2, 2-Tetrachloroethane

108-88-3------Toluene

| 108-90-7-...--Chlorobenzene

100-41-4-...... Ethylbenzene

100-42-5-------Styrene

1330-20-7-----xylene (total)

CONCENTRATION UNITS:

(ug/I or $u g / \mathrm{kg}$ ) ug/I

(total)

- 
IA

VOLATILE ORGANICS ANALYSIS SHEET

Lab Name: Lionville Labs, Inc. Contract: 60052001001 EPA SAMPLE NO.

Lab Code: Lionvi Case No.:

Matrix: (soil/water) SOIL

Sample wt/vol:

Level: (low/med) LoW

\% Moisture: not dec. 9

Column: (pack/cap) CAP

\section{$060204-T 5$}

SAS NO.:

SDG NO.:

Lab Sample ID: 0304L269-003

Lab File ID: g050114

Date Received: $\underline{04 / 24 / 03}$

Date Analyzed: $\underline{05 / 01 / 03}$

Dilution Factor: 1.09

CAS NO.

COMPOUND

CONCENTRATION UNITS:

(ug $/ \mathrm{L}$ or $\mathrm{ug} / \mathrm{Kg}$ ) ugg/Kg.

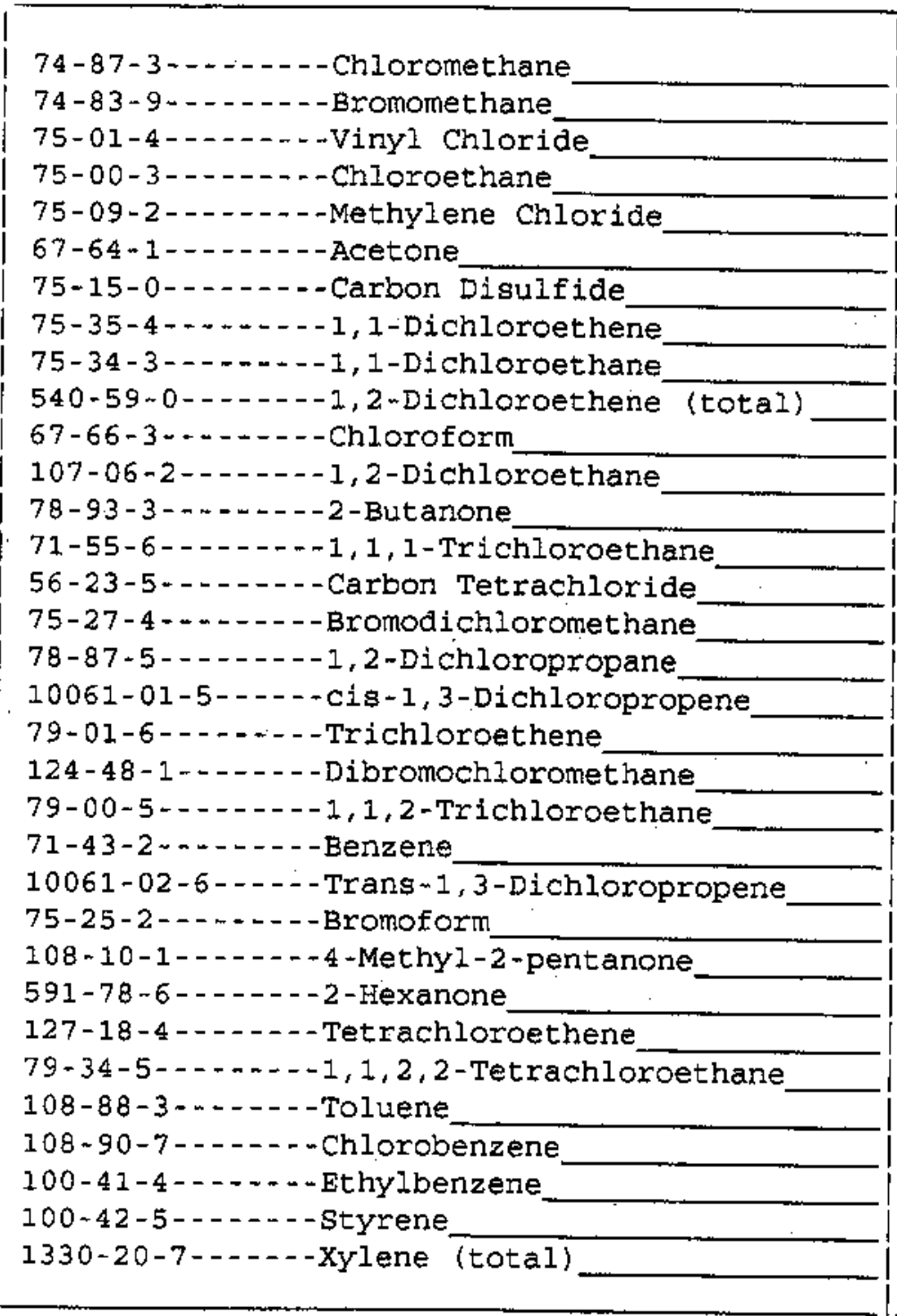

FORM I V-1

\begin{tabular}{r|l}
12 & $\mid \mathrm{U}$ \\
12 & $\mid \mathrm{U}$ \\
12 & $\mid \mathrm{U}$ \\
12 & $\mid \mathrm{U}$ \\
16 & $\mathrm{~B}$ \\
2 & $\mid \mathrm{J}$ \\
6 & $\mid \mathrm{U}$ \\
6 & $\mid \mathrm{U}$ \\
6 & $\mid \mathrm{U}$ \\
6 & $\mid \mathrm{U}$ \\
6 & $\mid \mathrm{U}$ \\
6 & $\mid \mathrm{U}$ \\
1 & $\mid \mathrm{JB}$ \\
6 & $\mid \mathrm{U}$ \\
6 & $\mid \mathrm{U}$ \\
6 & $\mid \mathrm{U}$ \\
6 & $\mid \mathrm{U}$ \\
6 & $\mid \mathrm{U}$ \\
6 & $\mid \mathrm{U}$ \\
6 & $\mid \mathrm{U}$ \\
6 & $\mid \mathrm{U}$ \\
6 & $\mid \mathrm{U}$ \\
6 & $\mid \mathrm{U}$ \\
6 & $\mid \mathrm{U}$ \\
12 & $\mid \mathrm{U}$ \\
12 & $\mid \mathrm{U}$ \\
6 & $\mid \mathrm{U}$ \\
6 & $\mid \mathrm{U}$ \\
6 & $\mid \mathrm{U}$ \\
6 & $\mid \mathrm{U}$ \\
6 & $\mid \mathrm{U}$ \\
6 & $\mid \mathrm{U}$ \\
6 & $\mid \mathrm{U}$ \\
\hline & $\mid \mathrm{I}$ \\
\hline
\end{tabular}

1/87 Rev. 
Lab Name: Lionville Labs, Inc. Contract: 60052001001

Lab Code: Lionvi Case No.:

Matrix: (soil/water) SOIL

Sample wt/vol:

Level: (low/med) LOW

․ Moisture: not dec. 8

Column: (pack/cap) cAp
SAS NO.:

SDG NO. :

Lab Sample ID: 0304L269-004

Lab File ID: g050115

Date Received: $04 / 24 / 03$

Date Analyzed: 05/01/03

Dilution Factor: 1.09

CAS NO.

COMPOUND

CONCENTRATION UNITS:

(ug/L or $\mathrm{ug} / \mathrm{Kg}$ ) $\mathrm{kg} / \mathrm{Kg}$

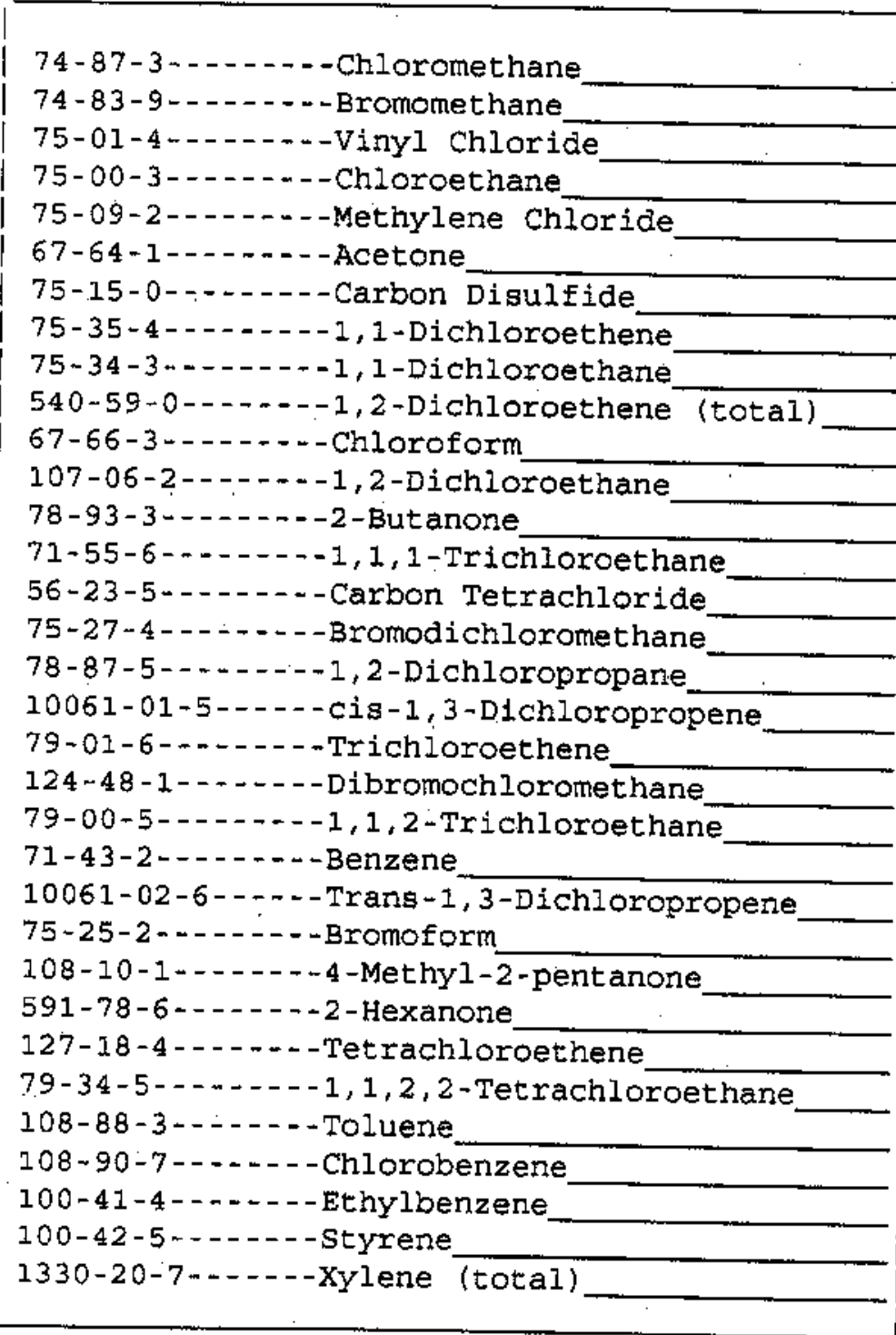

FORM $1 \mathrm{~V}-1$
12

12

12

12

21

5

6

6

6

6

6

6

2

6

6

6

6

6

6

6

6

6

6

6

12

12

6

6

6

6

6

6

6

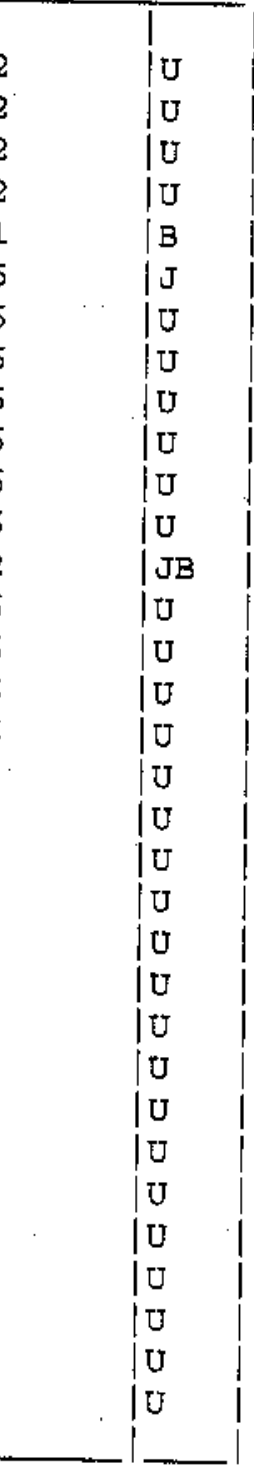

1/87 Rev. 


\section{Case Narrative}




\section{( VLI \\ HONVILLE LABORATORY INC}

Client: BECHTEL-NEVADA V1962

LVL \#: 0304L269
W.O. \#: 60052-001-001-0001-00

Date Received: 04-24-2003

\section{SEMIVOLATILE}

Two (2) soil samples were collected on 04-22-2003.

The samples and their associated QC samples were extracted according to Lionville Laboratory OPs based on method 3550 on $04-25-2003$ and analyzed according to criteria set forth in Lionville Laboratory OPs based on SW 846 Method 8270 C for TCL. Semivolatile target compounds on 04-302003 and 05-02,05-2003.

The following is a summary of the QC results accompanying the sample results and a description of any problems encountered during their analyses:

1. . All results presented in this report are derived from samples that met LvLI's sample acceptance policy.

2. Samples were extracted and analyzed within required holding time.

3. Non-target compounds were not reported as per client request.

4. All surrogate recoveries were within EPA QC limits.

5. All matrix spike recoveries were within EPA QC limits.

6. One (1) of eleven (11) blank spike recoveries was outside EPA QC limits.

7. Internal standard area criteria were not met for sample 060204-T5; however, the GC/MS instrument was inspected for possible malfunction and was judged to be functioning properly and all surrogate recoveries were within QC limits; consequently, the sample was not reanalyzed.

8. Manual integrations are performed according to OP L-QA-125 to produce quality data with the utmost integrity. All manual integrations are required to be technically valid and properly documented. Appropriate technical flags are defined in the Glossary ("Technical Flags For Manual Integration").

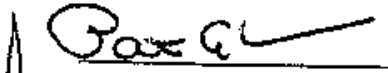

J. Michael Taylor

President

Lionville Laboratory Incorporated

som'grouphdata'braibected-1sevada-0304-269.doc

The results presented in this repout rejare only to the analytical testing and conditions of the samples at receipt and during storage. .

\section{$05-13-03$ \\ Date}




\section{GLOSSARY}

\section{DATA QUALIFIERS}

$\mathrm{U}=$ Compound was analyzed for but not detected. The associated numerical value is the estimated sample quantitation limit which is included and corrected for dilution and percent moisture.

$\mathrm{J}=$

Indicates an estimated value. This flag is used under the following circumstances: 1) when estimating a concentration for tentatively identified compounds (TICs) where a 1:1 response is assumed; or 2) when the mass spectral data indicate the presence of a compound that meets the identification criteria but the result is less than the specified detection limit but greater than zero. For example, if the limit of detection is $10 \mathrm{ug} / \mathrm{L}$ and a concentration of $3 \mathrm{ug} / \mathrm{L}$ is calculated, it is reported as $3 \mathrm{~J}$.

B = This flag is used when the analyte is found in the associated blank as well as in the sample. It indicates possible/probable blank contamination. This flag is also used for a TIC as well as for a positively identified TCL compound.

$\mathbf{E}=$ Indicates that the compound was detected beyond the calibration range and was subsequently analyzed at a dilution.

D $\quad=\quad$ Identifies all compounds identified in an analysis at a secondary dilution factor.

$1=$ Interference.

NQ = Result qualitatively confirmed but not able to quantify.

A $\quad=\quad$ Indicates that a TIC is a suspected aldol-condensation product.

$\mathrm{N}=$ Indicates presumptive evidence of a compound. This flag is only used for tentatively identified compounds (TICs), where the identification is based on a mass spectral library search. It is applied to all TIC results. For generic characterization of a TIC, such as chlorinated hydrocarbon, the N code is not used.

$X \quad$ This flag is used for a TIC compound which is quantified relative to a response factor generated from a daily calibration standard (rather than quantified relative to the closest internal standard).

$\mathbf{Y}=\quad$ Additional qualifiers used as required are explained in the case narrative. 


\section{GLOSSARY}

\section{ABBREVIATIONS}

BS = Indicates blank spike in which reagent grade water is spiked with the CLP matrix spike solutions and carried through all the steps in the method. Spike recoveries are reported.

BSD $=$ Indicates blank spike duplicate.

MS = Indicates matrix spike.

MSD $=$ Indicates matrix spike duplicate.

DL = Suffix added to sample number to indicate that results are from a diluted analysis.

NA $=$ Not Applicable.

DF = Dilution Factor.

NR $\quad=\quad$ Not Required.

$\mathrm{SP}, \mathrm{Z}=\quad$ Indicates Spiked Compound. 
Sample Data for each Sample 
Lab Name: Lionville Labs, Inc. Work Order: 60052001001

\section{Client: BECHTEL NEVADA V1962}

Matrix: (soil/water) SOIL

Sample wt/vol: $30.0 \quad(\mathrm{~g} / \mathrm{mL}) \mathrm{G}$

Level: (low/med) LOW

\& Moisture:

9 decanted: $(\mathrm{Y} / \mathrm{N})$

Concentrated Extract volume: 1000 (uL)

Injection volume: 2.0 (UL)
Lab Sample ID: 0304L269-003

Lab File ID: $\quad$ C050214

Date Received: $\underline{04 / 24 / 03}$

Date Extracted: 04/25/03

Date Analyzed: $\underline{05 / 02 / 03}$

Dilution Factor: 1.00
GPC Cleanup: $(\mathrm{Y} / \mathrm{N}) \underline{\mathrm{N}}$

CAS NO.

COMPOUND

$\mathrm{pH}: \quad 7.0$

CONCENTRATION UNITS :

( $\mathrm{ug} / \mathrm{L}$ or $\mathrm{ug} / \mathrm{kg}$ ) $\mathrm{UG} / \mathrm{KG}$

Q

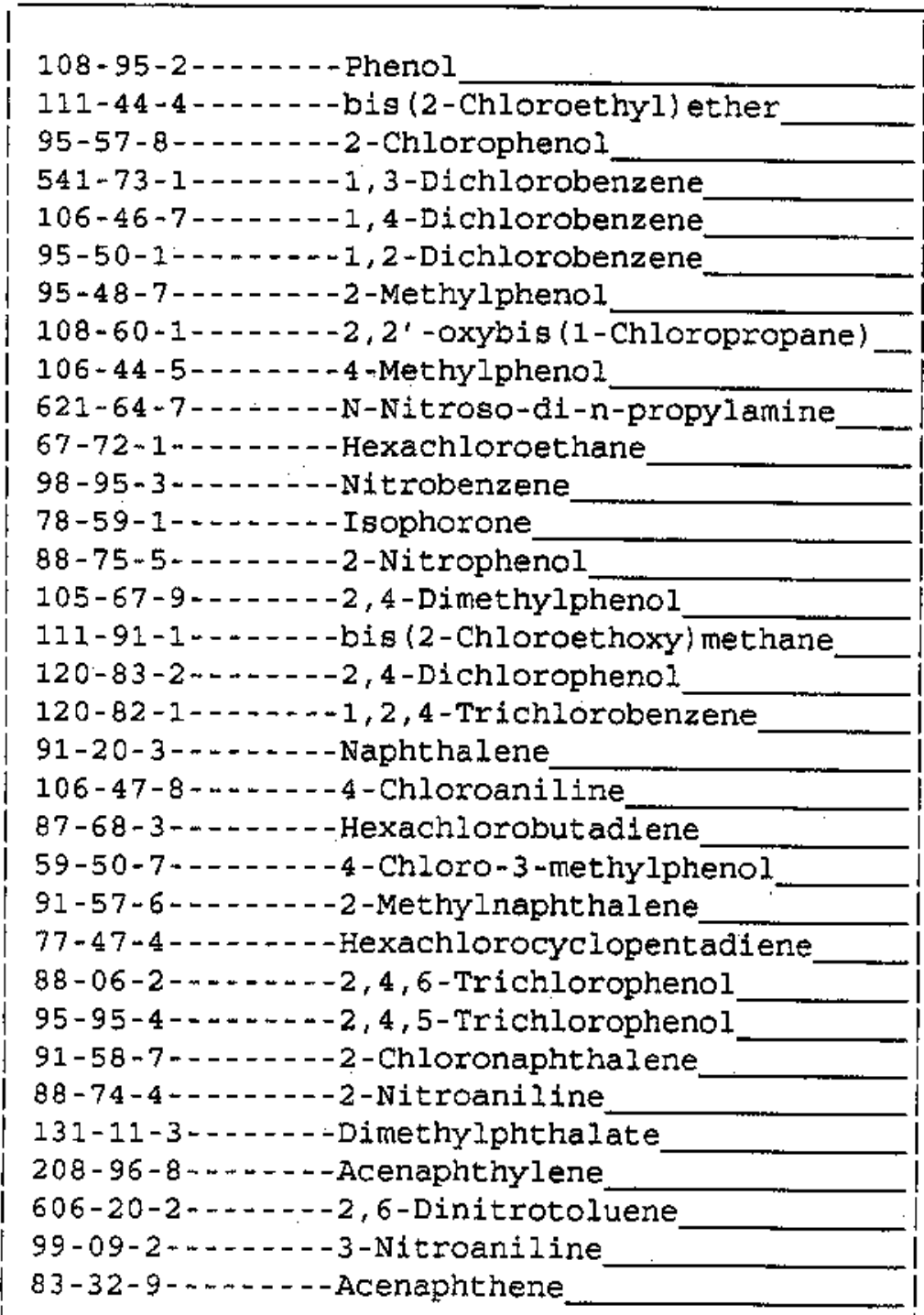


$1 \mathrm{C}$

SEMIVOLATILE ORGANICS ANALYSIS DATA SHEET

Lab Name: Lionville Labs, Inc. Work Order: 60052001001

\section{Client: BECHTEL NEVADA V1962}

Matrix: (soil/water) SOIL

Sample wt/vol: $30.0 \quad(\mathrm{~g} / \mathrm{mL}) \mathrm{G}$

Level: (low/med) LoW

\&oisture:

2 decanted: $(\mathrm{Y} / \mathrm{N})$

Concentrated Extract Volume: $1000(\mathrm{uL})$

Injection volume: $\underline{\underline{2.0}}(\mathrm{uL})$
Lab Sample ID: 0304L269-003

Lab File ID: $\quad \underline{\cos 0214}$

Date Received: $\underline{04 / 24 / 03}$

Date Extracted: 04/25/03

Date Analyzed: 05/02/03

Dilution Factor: 1.00

GPC Cleanup: (Y/N) $\underline{\mathrm{N}} \quad \mathrm{pH}: \underline{7,0}$

CONCEmTRATION UNITS:

CAS NO. COMPOUND $(\mathrm{ug} / \mathrm{L}$ or $\mathrm{ug} / \mathrm{kg}) \mathrm{UG} / \mathrm{KG}$

\begin{tabular}{|c|}
\hline $51-28-5------2,4-$ Dinitrophenol. \\
\hline 100-02-7-----4-Nitrophenol \\
\hline I32-64-9----Dibenzofuran \\
\hline $121-14-2-\cdots \cdots-2,4$-Dinitrotoluene. \\
\hline $84-66-2-\ldots---D i e t h y l p h t h a l a t e$ \\
\hline 7005-72-3-----4-Chlorophenyl-phenylether \\
\hline 86-73-7--1----Fluorene \\
\hline 100-01-6-...-.-Nitroaniline \\
\hline $534-52-1 \cdots-\cdots-4,6$-Dinitro-2-methylphenol \\
\hline $86-30-6-\cdots-N-N 1$ trosodiphenylamine (1) \\
\hline $101-55-3--1-4$-Bromophenyl-phenylether \\
\hline 118-74-1-----Hexachlorobenzene \\
\hline 87-86-5-----Pentachlorophenol \\
\hline 85-01-8---1--Phenanthrene \\
\hline $120-12-7-\cdots-$ Anthracene \\
\hline 86-74-8-------Carbazole \\
\hline 84-74-2--n-n-ni-nutylphthalate \\
\hline $206-44-0--\ldots--$ Fluoranthene_ \\
\hline $129-00-0 \ldots . . .-$-Pyrene_ \\
\hline $85-68-7-\cdots--B$ - Butylbenzylphthalate \\
\hline 91-94-1-n...-3, 3'-Dichlorobenzidine \\
\hline 56-55-3-----Benzo (a) anthracene \\
\hline 218-01-9------Chrysene. \\
\hline 117-81-7----bis (2-Ethylhexy 1$)$ phthalate \\
\hline 117-84-0-----Di-n-octy1 phthalate_ \\
\hline 205-99-2-----Benzo (b) fluoranthene. \\
\hline 207-08-9-..--Benzo $(k)$ fluoranthene \\
\hline $50-32-8-----$-Benzo (a) pyrene \\
\hline $193-39-5 \ldots \ldots$ Indeno $(1,2,3$-cd) pyrene_ \\
\hline $53-70-3 \ldots \ldots \ldots$ Dibenz $(a, h)$ anthracene \\
\hline $191-24-2-\ldots-B e n z o(g, h, i)$ perylene \\
\hline
\end{tabular}

(1) - Cannot be separated from Diphenylamine FORM 1 SV-2

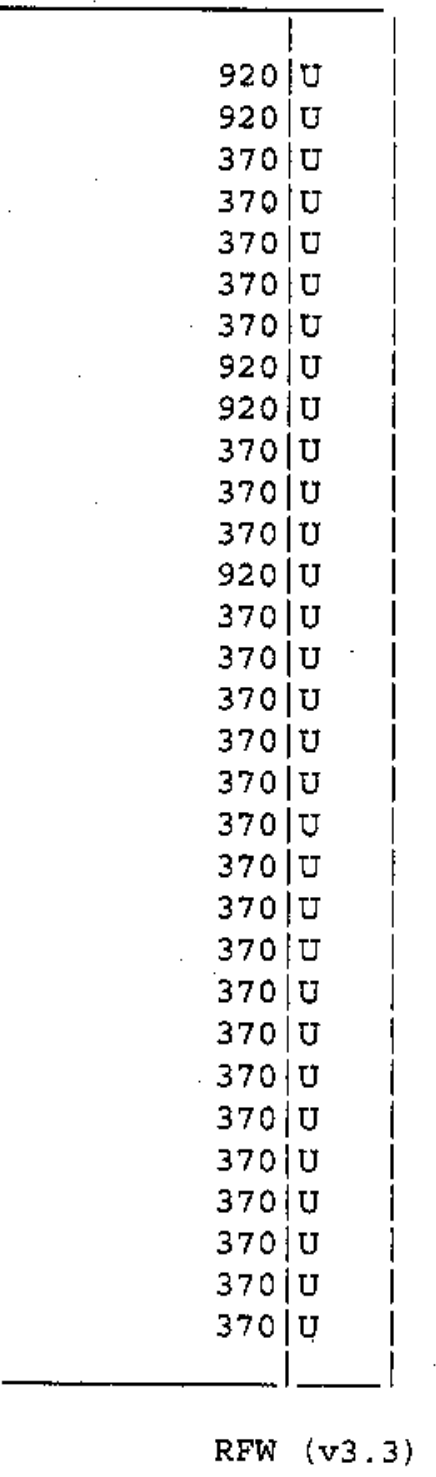


Lab Name: Lionville Labs, Inc. Work Order: 60052001001

Client: BECHTEL NEVADA V1962

Matrix: (soil/water) SorL

Lab Sample ID: 0304L269-004

Sample wt/vol: $30.0 \quad(\mathrm{~g} / \mathrm{mL}) \mathrm{G}$

Lab File ID: $\quad$ C050215

Level: $\quad($ low/med $) \quad$ LOW

Date Received: $04 / 24 / 03$

Moisture:

8 decanted: $(\mathrm{Y} / \mathrm{N})$

Date Extracted: 24/25/03

Concentrated Extract Volume: 1000 (uL)

Date Analyzed: $05 / 02 / 03$

Injection volume: $\underline{2.0}(u L)$

Dilution Factor: 1,00

GPC Cleanup: $(Y / N) \underline{N}$

$\mathrm{pH}: \quad 7.0$

CAS NO.

COMPOUND

CONCENTRATION UNITS:

(ug/L or $\mathrm{ug} / \mathrm{Kg}$ ) $\mathrm{UG} / \mathrm{KG}$

Q

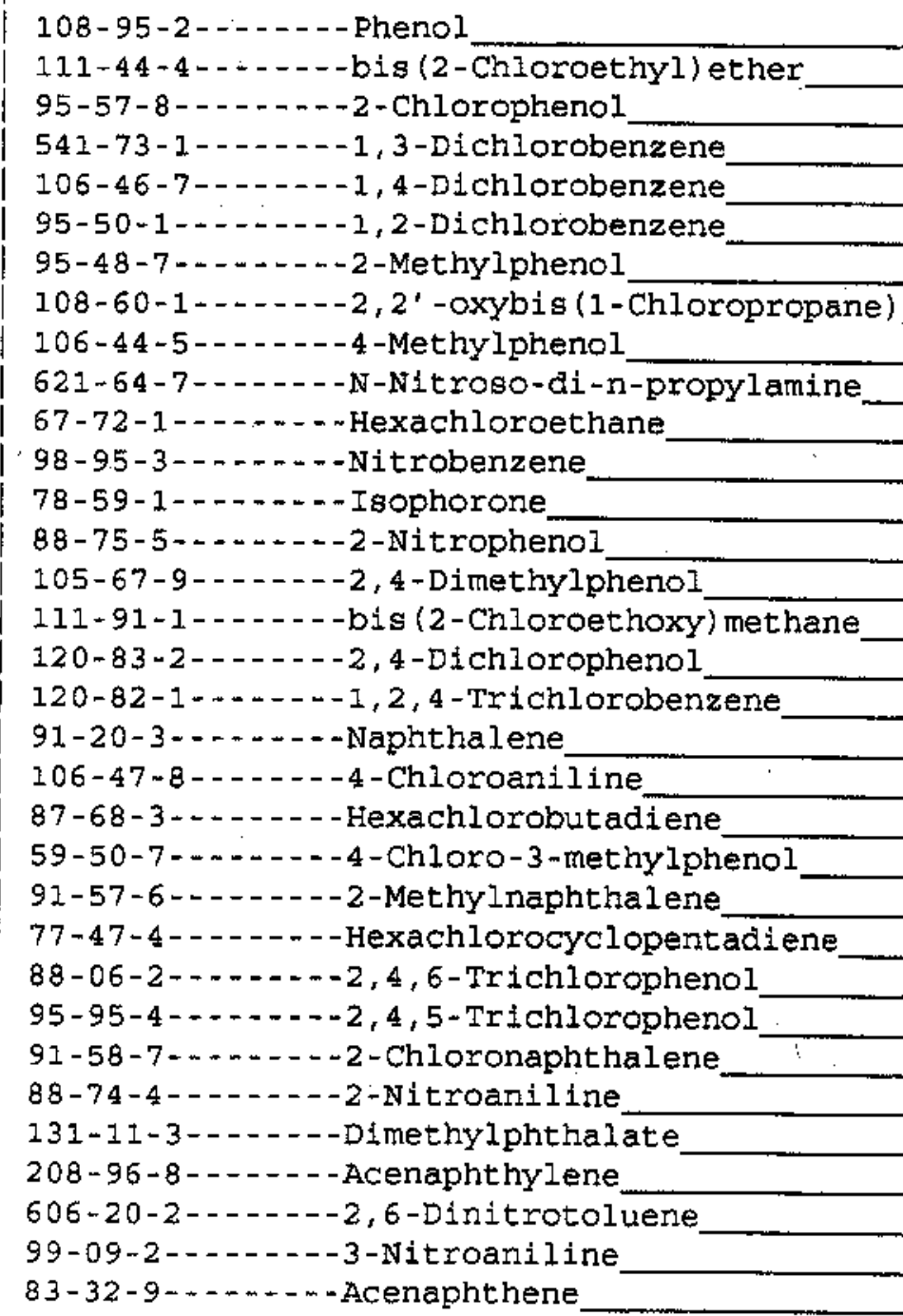

$360 \mid \mathrm{U}$

$360 \mid \mathrm{J}$

$360 \mid \mathrm{U}$

$360 \mid \mathrm{U}$

$360 \mid \mathrm{U}$

$360 \mid \mathrm{U}$

$360 \mid \mathrm{U}$

$360 / \mathrm{U}$

$360 \mid \mathrm{U}$

$360 \mid \mathrm{U}$

$360 \mid \mathrm{U}$

$360 \mid \mathrm{U}$

$360 \mid \mathrm{U}$

$360 \mid \mathrm{U}$

$3601 \mathrm{U}$

$360 \mid \mathrm{U}$

$360 \mid \mathrm{U}$

$360 \mid \mathrm{U}$

$360 \mid \mathrm{J}$

$360 \mid \mathrm{U}$

$360 / \mathrm{J}$

$360 / 0$

$360, \mathrm{U}$

$360 ! \mathrm{U}$

$360 \mid \mathrm{U}$

$900 \mid \mathrm{U}$

$360 \mid \mathrm{U}$

$900 \mid \mathrm{U}$

$360: \mathrm{J}$

$360 \mid \mathrm{U}$

$360 . \mathrm{U}$

$900 \mid \mathrm{U}$

$360 . \mathrm{U}$

RFW (v3.3) 
Lab Name: Lionville Labs. Inc. Work Order: $6005200100 \mathrm{l}$

\section{Client: BECHTEL NEVADA V1962}

Matrix: (soil/water) SOIL

Sample wt/vol: $30.0 \quad(\mathrm{~g} / \mathrm{mL}) \mathrm{G}$

Level: (low/med) LOW

8 Moisture: $\_$_ 8 decanted: $(\mathrm{Y} / \mathrm{N})$

Concentrated Extract Volume: 1000 (uL)

Injection volume: 2.0(uL)
Lab Sample ID: 0304L269-004

Lab File ID: .

Date Received: 04/24/03

Date Extracted: 04/25/03

Date Analyzed: $\underline{05 / 02 / 03}$

Dilution Factor: 1.00

GPC Cleanup: $(\mathrm{Y} / \mathrm{N}) \underline{\mathrm{N}} \quad \mathrm{pH}: \underline{7.0}$

CONCENTRATION UNITS:

CAS NO. COMPOUND (ug/L or $\mathrm{ug} / \mathrm{kg}$ ) UG/KG

$Q$

\begin{tabular}{|c|}
\hline $51-28-5 \cdots-2,4-$ Dinitrophenol. \\
\hline 100-02-7--1-4-Nitrophenol. \\
\hline $132-64-9-----$-Dibenzofuran \\
\hline 121-14-2-----2,4-Dinitrotoluene. \\
\hline $84-66-2 \cdots--1-$ Diethylphthalate \\
\hline $7005-72-3---4$-Chlorophenyl-phenylether \\
\hline $86-73-7---1-$ Fluorene. \\
\hline 100-01-6-- m. - Nitroaniline \\
\hline 534-52-1------4, 6-Dinitro-2-methylphenol \\
\hline 86-30-6--1) \\
\hline 101-55-3--1--4-Bromophenyl-phenylether \\
\hline 118-74-1--...-Hexachlorobenzene \\
\hline 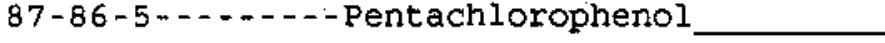 \\
\hline $85-01-8 \ldots \ldots-\ldots$ - Phenanthrene, \\
\hline $120-12-7-----$ Anthracene. \\
\hline $86-74-8--1--$ Carbazole \\
\hline 84-74-2-----Di-n-butylphthalate. \\
\hline 206-44-0------Fluoranthene. \\
\hline $129-00-0-\ldots-1-$ - Pyrene. \\
\hline 85-68-7--1patylbenzylphthalate \\
\hline $91-94-1--1--3,3^{\prime}$-Dichlorobenzidine. \\
\hline 56-55-3--1--Benzo (a) anthracene. \\
\hline 218-01-9--.--Chrygene. \\
\hline 117-81-7-..-bis (2-Ethylhexyl) phthalate \\
\hline 117-84-0----Di-n-octyl phthalate \\
\hline 205-99-2-.--Benzo (b) fluoranthene \\
\hline 207-08-9-1--Benzo(k) fluoranthene \\
\hline 50-32-8------Benzo (a) pyrene. \\
\hline $193-39-5 \ldots \ldots-$ - Indeno $(1,2,3-c d)$ pyrene \\
\hline 53-70-3-..-Dibenz $(a, h)$ anthracene. \\
\hline $191-24-2-\cdots-B e n z o(g, h, 1)$ perylene. \\
\hline
\end{tabular}

(1) * Cannot be separated from Diphenylanine 
CASE NARRATIVE 


\section{Analytical Report}

LONVIIF LABORATOKY INC.

Client: BECHTEL-NEVADA V1962

LVL \#: 0304L269
W.O. \#: 60052-001-001-0001-00

Date Received: 04-24-2003

\section{PCB}

Two (2) soil samples were collected on 04-22-2003.

The samples and their associated QC samples were extracted on 04-25-2003 and analyzed according to Lionville Laboratory OPs on 05-01,03-2003. The extraction procedure was based on method 3550 and the extracts were analyzed based on method 8082 for Aroclors only.

The following is a summary of the QC results accompanying the sample results and a description of any problems encountered during their analyses:

1. All results presented in this report are derived from samples that met LVLI's sample acceptance policy.

2. The required holding time for extraction and analysis has been met.

3. Samples and their associated QC samples received a Sulfuric Acid and Sulfur cleanup.

4. The method blank was below the reporting limits for all target compounds.

5. Three (3) of fourteen (14) surrogate recoveries were outside acceptance criteria. A copy of the Sample Discrepancy Report (SDR) has been enclosed.

6. All blank spike recoveries were within acceptance criteria.

7. All matrix spike recoveries were within acceptance criteria.

8. All initial calibrations associated with this data set were within acceptance criteria.

9. All continuing calibration standards analyzed prior to sample extracts were within acceptance criteria.
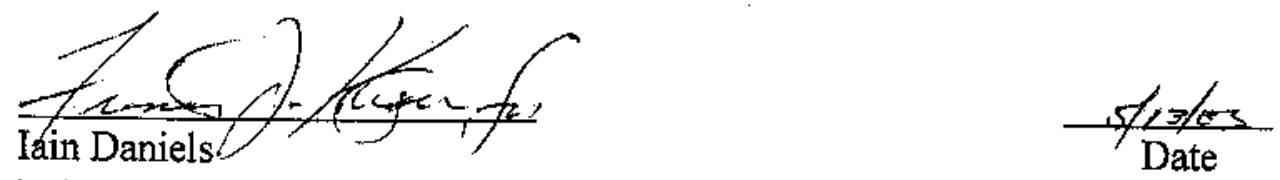

Laboratory Manager

Lionville Laboratory Incorporated

son tritgroupldataipestibechtet:0304-269.pcb

The results presented in this report relate only to the analytical testing and conditions of the samples at receipt and during storage. 


\section{GLOSSARY OF PESTICIDE/PCB DATA}

\section{DATA QUALIFIERS}

$\mathrm{U}=$ Indicates that the compound was analyzed for but not detected. The minimum detection limit for the sample (not the method detection limit) is reported with the $U$ (e.g., 10U).

$\mathbf{J}=$ Indicates an estimated value. This flag is used in cases where a target analyte is detected at a level less than the lower quantification level. If the limit of quantification is $10 \mathrm{ug} / \mathrm{L}$ and a concentration of $3 \mathrm{ug} / \mathrm{L}$ is calculated, it is reported as $3 J$.

B = This flag is used when the analyte is found in the associated blank as well as in the sample: It indicates possible/probable blank contamination.

$\mathbf{E}=$ Indicates that the compound was detected beyond the calibration range and was subsequently analyzed at a dilution.

$\mathbf{I}=$ Interference.

\section{ABBREVIATIONS}

BS = Indicates blank spike in which reagent grade water is spiked with the CLP matrix spiking solutions and carried through all the steps in the method. Spike recoveries are reported.

BSD $=$ Indicates blank spike duplicate.

MS $=$ Indicates matrix spike.

MSD $=$ Indicates matrix spike duplicate.

DL = Indicates that recoveries were not obtained because the extract had to be diluted for analysis.

$\mathrm{NA}=$ Not Applicable.

DF $=$ Dilution Factor.

NR $=$ Not Required.

SP $=$ Indicates Spiked Compound. 

SAMPLE DATA FOR EACH SAMPLE 
Lab Name: Lionville Labs. Inc. Work Order: 60052001001

Client: $\quad$ BECHTEI, NEVADA V1962

Matrix:

SOIL

Sample wt/vol: $\quad 30.0(\mathrm{~g} / \mathrm{mL}) \mathrm{G}$

Leve1: (low/med) LOW

Moisture: not dec. 9 dec.

Extraction: (SepF/Cont/Sonc) SONC

GPC Cleanup: (Y/N) $\underline{\underline{N}}$ $\mathrm{pH}: \quad 7.0$
Lab Sample ID: 0304L269-003

Lab File ID: BLKLACHJ.02

Date Received: $\quad 04 / 24 / 03$

Date Extracted: $04 / 25 / 03$

Date Analyzed: 05/01/03

Dilution Factor: 1,00
CONCENTRATION UNITS:

CAS NO.

COMPOUND
(ug/L or $u g / \mathrm{Kg}$ ) JG/KG.

$\left\{\begin{array}{l|}12674-11-2-\ldots-\text { Aroclor }-1016 \\ 11104-28-2-\ldots-\text { Aroclor }-1221 \\ 11141-16-5 \cdots \cdots-\text { Aroclor }-1232 \\ 53469-21-9-\cdots-\text { Aroclor }-1242 \\ 12672-29-6 \cdots-\text { Aroclor }-1248 \\ 11097-69-1-\cdots-\text { Aroclor }-1254 \\ 11096-82-5-\cdots-\text { Aroclor }-1260\end{array}\right.$

FORM 1 PEST

\begin{tabular}{l|l|}
37 & $\mid \mathrm{U}$ \\
74 & $\mathrm{U}$ \\
37 & $\mathrm{U}$ \\
37 & $\mathrm{U}$ \\
37 & $\mathrm{U}$ \\
37 & $\mathrm{U}$ \\
37 & $\mathrm{U}$ \\
\hline
\end{tabular}

12/88 Rev. 
1D

PESTICIDE ORGANICS ANALYSIS SHEET

Lab Name: Lionville Labs. Inc. Work Order: 60052001001

\title{
Client: BECHTEL NEVADA V1962
}

Matrix:

Sample wt/vol:

Level:

(low/med)

$30.0(\mathrm{~g} / \mathrm{mL}) \mathrm{G}$

\% Moisture: not dec.

LOW

dec.

(SepF/Cont/Sonc)

SONC

Lab Sample ID: 0304J269-004

Lab File ID

BLKLACHJ .02

Date Received: $\underline{04 / 24 / 03}$

Date Extracted: $04 / 25 / 03$

\begin{abstract}
Extraction:
\end{abstract}
Date Analyzed: $05 / 01 / 03$

GPC Cleanup: $\quad(\mathrm{Y} / \mathrm{N}) \underline{\underline{N}}$

$$
\mathrm{pH}:-7.0
$$

CONCENTRATION UNITS:

CAS NO.

COMPOUND

(ug/L or $u g / \mathrm{kg}$ ) Ug $/ \mathrm{KG}$

$\left\{\begin{array}{l}12674-11-2 \ldots-\ldots \text { Aroclor }-1016 \\ 11104-28-2-\ldots-\text { Aroclor }-1221 \\ 11141-16-5-\ldots-\text { Aroclor }-1232 \\ 53469-21-9-\ldots-\text { Aroclor }-1242 \\ 12672-29-6 \ldots-\ldots-\text { Aroclor }-1248 \\ 11097-69-1 \ldots \ldots-\text { Aroclor }-1254 \\ 11096-82-5-\ldots-\text { Aroclor }-1260\end{array}\right.$

FORM 1 PESI

\begin{tabular}{|l|l|}
36 & $\mid$ \\
72 & $\mid \mathrm{U}$ \\
36 & $\mathrm{U}$ \\
36 & $\mathrm{U}$ \\
36 & $\mathrm{U}$ \\
36 & $\mathrm{U}$ \\
36 & $\mathrm{U}$ \\
\hline
\end{tabular}

12/88 Rev. 
CASE NARRATIVE 


\section{SLI \\ WONVHLE LABORAIORY INC.}

\section{Analytical Report}

Client: BECHTEL-NEVADA V1962

LVL \#: 0304L269

W.0. \#: 60052-001-001-0001-00

Date Received: 04-24-03

\section{DIESEL RANGE ORGANICS}

The set of samples consisted of two (2) soil samples collected on 04-22-03.

The samples and their associated QC samples were extracted on 04-29-03 and analyzed according to Lionville Laboratory OPs on 05-09-03. The extraction procedure was based on method 3540 and the extracts were analyzed based on method 8015B for Diesel Range Petroleum Hydrocarbons.

1. All results presented in this report are derived from samples that met LvLI's sample acceptance policy.

2. All required holding times for extraction and analysis have been met.

3. The method blank was below the reporting limits for all target compounds.

4. All surrogate recoveries were within acceptance criteria.

5. The blank spike recovery was within acceptance criteria.

6. All matrix spike recoveries were within acceptance criteria.

7. All initial calibrations associated with this data set were within acceptance criteria.

8. All continuing calibration standards analyzed prior to sample extracts were within acceptance criteria.

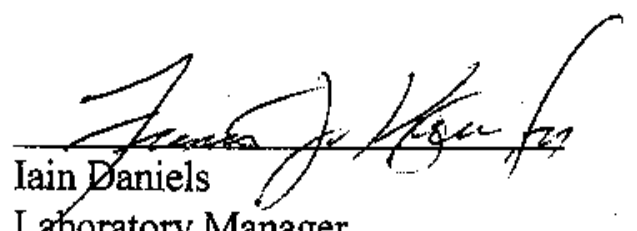

Laboratory Manager

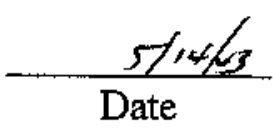

Lionville Laboratory Incorporated

pefir:troupldataldro bechtel104L-26900

The results presented in this report relate only to the analytical testing and conditions of the samples at receipt and during storage. t 


\section{GLOSSARY OF DIESEL RANGE ORGANICS DATA}

\section{DATA QUALIFIERS}

$\mathbf{U}=$ Indicates that the compound was analyzed for but not detected. The minimum detection limit for the sample (not the method detection limit) is reported with the $\mathrm{U}$ (e.g., 10U).

$\mathbf{J}=$ Indicates an estimated value. This flag is used in cases where a target analyte is detected at a level less than the lower quantification level. If the limit of quantification is $10 \mathrm{ug} / \mathrm{L}$ and a concentration of $3 \mathrm{ug} / \mathrm{L}$ is calculated, it is reported as $3 \mathrm{~J}$.

B = This flag is used when the analyte is found in the associated blank as well as in the sample. It indicates possible/probable blank contamination.

$\mathbf{E}=$ Indicates that the compound was detected beyond the calibration range and was subsequently analyzed at a dilution.

I $=$ Interference.

\section{ABBREVIATIONS}

BS = Indicates blank spike in which reagent grade water is spiked with the CLP matrix . spiking solutions and carried through all the steps in the method. Spike recoveries are reported.

BSD = Indicates blank spike duplicate.

MS $=$ Indicates matrix spike.

MSD $=$ Indicates matrix spike duplicate.

DL = Indicates that recoveries were not obtained because the extract had to be diluted for analysis.

NA $=$ Not Applicable.

DF $=$ Dilution Factor.

$\mathrm{NR}=$ Not Required.

SP $=$ Indicates Spiked Compound. 
SAMPLE DATA FOR EACH SAMPLE 
Lab Name: Lionville Labs, Inc. Work Order: 60052001001

Client: BECHTEL NEVADA V1962

Matrix :

SOIL

Sample wt/vol: $\underline{25.0}(\mathrm{~g} / \mathrm{mL}) \mathrm{G}$

Ievel:

(low/med) IOW

\%oisture: not dec. 9

Column: (pack/cap) cAP

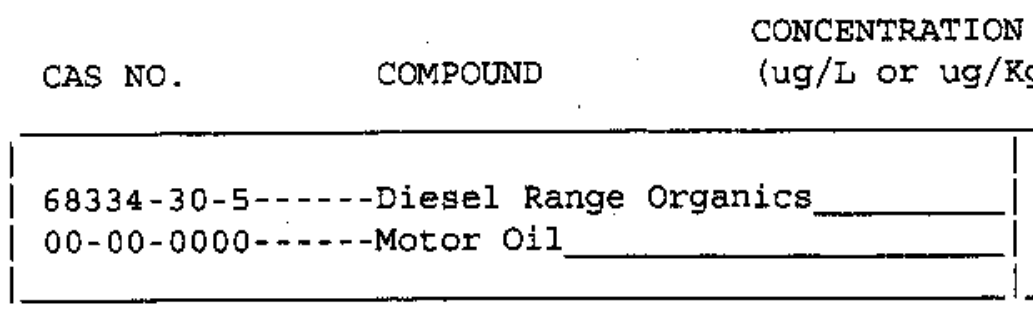

Lab Sample ID: 0304L269-003

Lab File ID: BIKIACHJ

Date Received: 04/24/03

Date Analyzed: $05 / 09 / 03$

Dilution Factor: 1.00

$12 / 88$ Rev. 
Lab Name: Lionville Labs, Inc. Work Order: 60052001001

Client: BECHTEL NEVADA V1962

Matrix:

SOIL

$\underline{25.0}(\mathrm{~g} / \mathrm{mL}) \underline{\mathrm{G}}$

Sample wt/vol:

Level: (low/med) LOW

\% Moisture: not dec.

8

Column: (pack/cap) $\mathrm{CAP}$

CAS NO.

COMPOUND
Lab Sample ID: 0304L269-004

Lab File ID: BLKLACHI

Date Received: $04 / 24 / 03$

Date Analyzed: $05 / 09 / 03$

Dilution Factor: 1.00

CONCENTRATION UNITS:

(ug/L or $u g / \mathrm{kg}$ ) $\mathrm{mg} / \mathrm{kg}$
68334-30-5-..-Diesel Range Organics 00-00-0000-...--Motor 0il
13.0

13.0

io

$\mathrm{u}$

12/88 Rev. 
CASE NARRATIVE 


\section{VLI \\ HONVILL IABORAIOKY INC:}

\section{Analytical Rēport}

Client: BECHTEL NEVADA V1962

LVL \#: 0304L269
W.O. \#: 60052-001-001-0001-00

Date Received: 04-24-03

\section{GRO}

The set of samples consisted of two (2) soil samples collected on 04-22-03.

The samples and their associated QC samples were analyzed according to Lionville Laboratory OPs based on SW-846 method 8015 for Gasoline range organics (GRO) on 05-06-03.

The following is a summary of the $\mathrm{QC}$ results accompanying these sample results and a description of any problems encountered during their analyses:

1. All results presented in this report are derived from samples that met LVLI's sample acceptance policy.

2. All required holding times for analysis have been met.

3. The method blank was below the reporting limits for all target compounds.

4. All surrogate recoveries were within acceptance criteria.

5. All blank spike recoveries were within acceptance criteria.

6. All initial calibrations associated with this data set were within acceptance criteria.

7. All continuing calibration standards analyzed prior to sample extracts were within acceptance criteria.
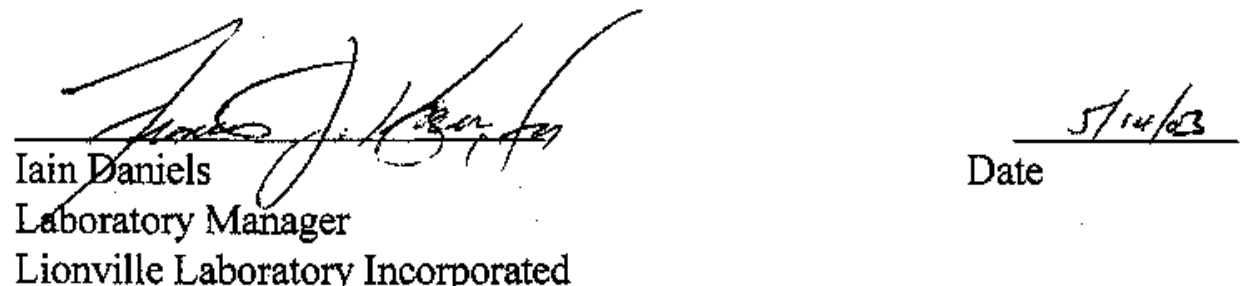

Lionville Laboratory Incorporated

pefRrgrouphdatalgrolbechteltio4L-269.doc 


\section{DATA QUALIFIERS}

$\mathbf{U}=$ Indicates that the compound was analyzed for but not detected. The minimum detection limit for the sample (not the method detection limit) is reported with the $\mathrm{U}$ (e.g., 10U).

$\mathbf{J}=$ Indicates an estimated value. This flag is used in cases where a target analyte is detected at a level less than the lower quantification level. If the limit of quantification is $10 \mathrm{ug} / \mathrm{L}$ and a concentration of $3 \mathrm{ug} / \mathrm{L}$ is calculated, it is reported as $3 J$.

B = This flag is used when the analyte is found in the associated blank as well as in the sample. It indicates possible/probable blank contamination.

$\mathbf{E}=$ Indicates that the compound was detected beyond the calibration range and was subsequently analyzed at a dilution.

$\mathbf{I}=$ Interference.

\section{ABBREVIATIONS}

BS = Indicates blank spike in which reagent grade water is spiked with the CLP matrix spiking solutions and carried through all the steps in the method. Spike recoveries are reported.

BSD $=$ Indicates blank spike duplicate.

MS $=$ Indicates matrix spike.

MSD $=\quad$ Indicates matrix spike duplicate.

DL = Indicates that recoveries were not obtained because the extract had to be diluted for analysis.

NA $=$ Not Applicable.

DF $=$ Dilution Factor.

$\mathbf{N R}=$ Not Required.

SP $=$ Indicates Spiked Compound. 
SAMPLE DATA FOR EACH SAMPLE 
Lab Name: Iionville Labs, Inc, Work Order: 60052001001

Client: BECHTEL NEVADA V1962

Matrix :

SOIL

$\underline{5.06}(\mathrm{~g} / \mathrm{mL}) \mathrm{G}$

Sample wt/vol:

(1ow/med)

$\underline{\text { LOW }}$

\% Moisture: not dec. 9

Column: (pack/cap) CAP.

CAS NO.

COMPOUND

CONCENTRATION UNITS:

(ug/L or $u g / \mathrm{kg}$ ) UG/KG
Lab Sample ID: 0304L269-003

Lab File ID: BLKLACHJ

Date Received: $\underline{04 / 24 / 03}$

Date Analyzed: $05 / 06 / 03$

Dilution Factor: 1.00

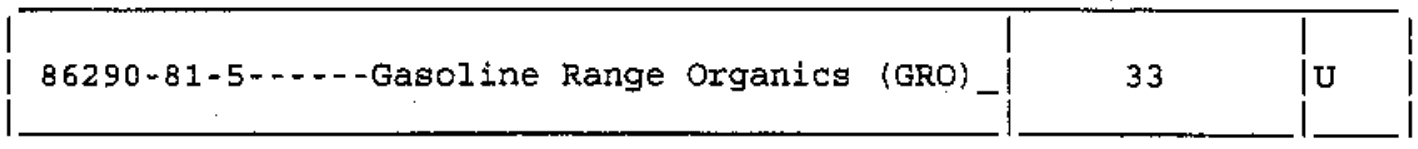

12/88 Rev. 
Lab Name: Lionville Labs, Inc. Work Oroer: 60052001001

\section{Client: BECHTEL NEVADA V1962}

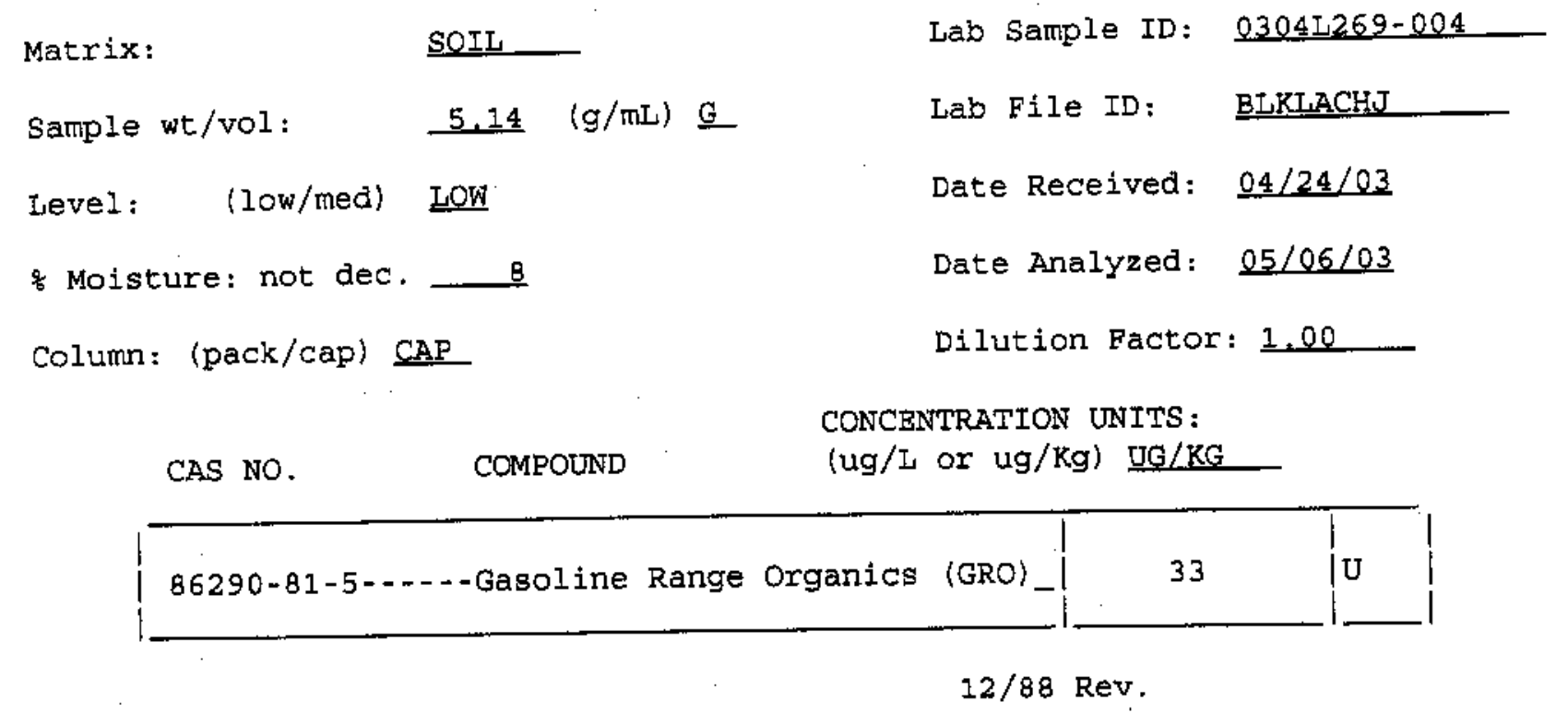


CLOSURE REPORT - CAU 330

Section: Appendix B

Revision: 0

Date: July 2003

\section{SAMPLE DELIVERY GROUP}

\section{V1963}


CLOSURE REPORT - CAU 330

Section: Appendix B

Revision: 0

Date: July 2003

\section{THIS PAGE INTENTIONALLY LEFT BLANK}




\section{$S C E A$ S. Conteve Assoconsts}

May 22, 2003

Mr. Ted Redding

USDOE Zone 1

Bldg. 652, Room 2

M/S NTS 273

Mercury, NV 89023

Dear Mr. Redding:

On April 24, 2003, two soil samples, (SDG V1963) were received for analysis at the Sanford Cohen and Associates (SC\&A) Southeastern Environmental Laboratory. The samples were assigned Laboratory Report Identification Code 4272. Enclosed the Sample Data Package containing the results of the analyses of these samples.

If you have any questions please do not hesitate to call.

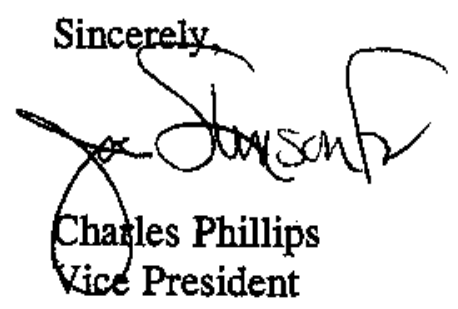




\section{COVER PAGE}

Sanford Cohen \& Associates
Southeastern Environmental Laboratory
1000 Monticello Court
Montgomery, Alabama 36117
Laboratory Code: SCA Subcontract Number: 30025
Laboratory Report Identification Code: $4272 \quad$ SDG: V1963
\begin{tabular}{|l|c|}
\hline Sample Matrix: Soil \\
\hline Site Sample Numbers & Laboratory Sample Number \\
\hline & Gamma Spectrometry \\
\hline $060204-T 5$ & NTS03-4272-01 \\
\hline N60204-T6 & NTS03-4272-02 \\
\hline
\end{tabular}

Comments: There were no problems encountered during sample receiving.

"I certify that this sample data package is in compliance with SOW requirements, both technically and for completeness, other than the conditions detailed above. Release of the data contained in this hard-copy sample data package and the computer-readable EDD, as applicable, submitted on diskette or by modem, has been authorized by the laboratory Manager or the Manager's designee, as verified by the following signature."

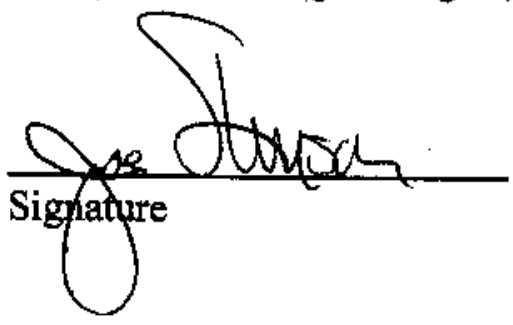

Joe Stinson

Name

Laboratory Manager

Title $\underline{5 / 22 / 03}$

Date 
06

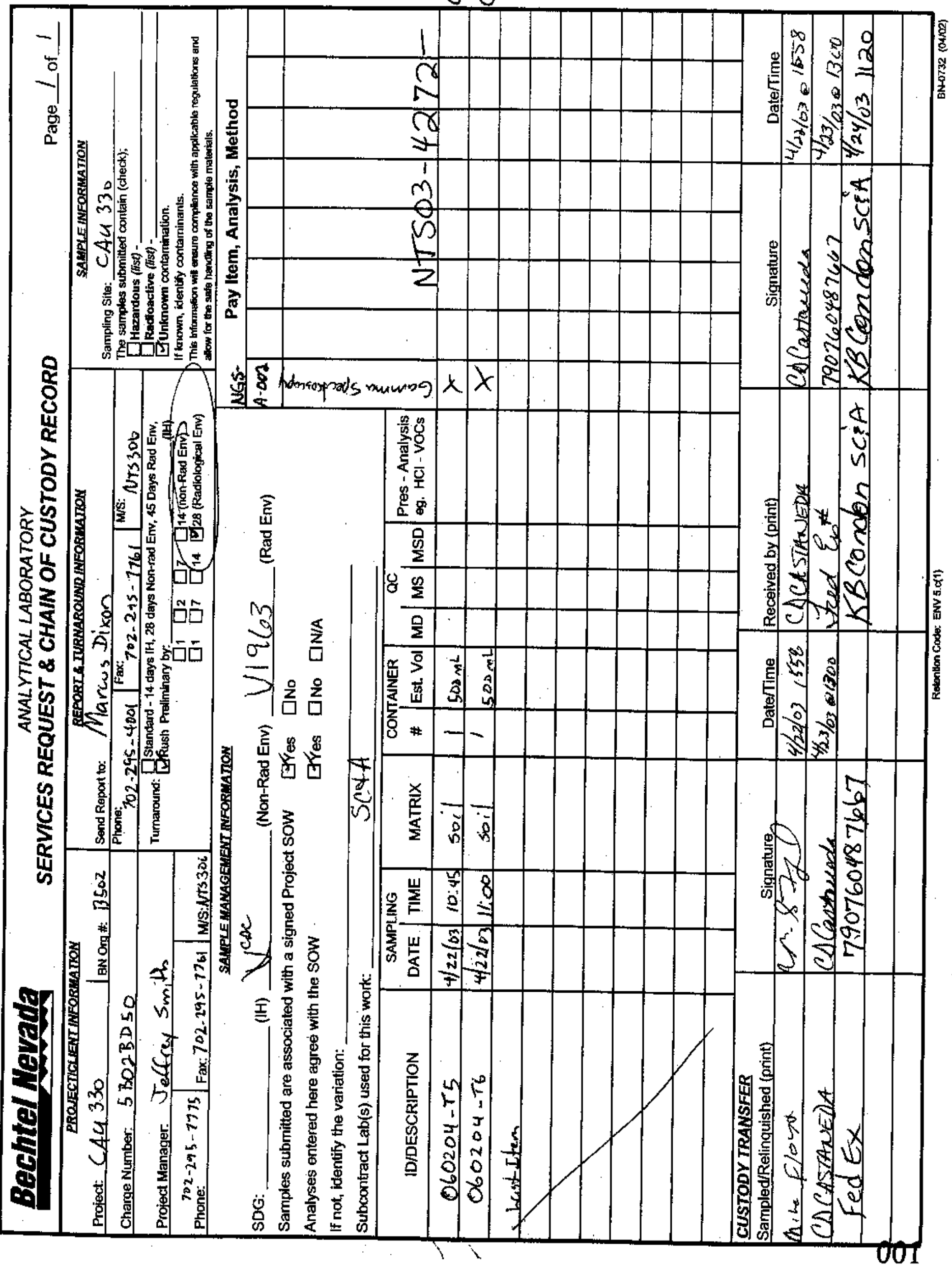




\section{CASE NARRATIVE \\ SDG V1963 \\ Laboratory Report Identification Number: $\mathbf{4 2 7 2}$}

May 22, 2003

\section{Introduction}

On April 24, 2003, two soil samples, (SDG V1963), were received for analysis at the Sanford Cohen and Associates (SC\&A) Southeastern Environmental Laboratory, located in Montgomery, Alabama. The chain-of-custody accompanying the sample requested that it be analyzed within seven days of receipt at the laboratory. The samples were analyzed in accordance with the Bechtel Nevada Services Subcontract Task Order Agreement Form, Exhibit B, Statement of Work and Specifications, Rev 1, 1/23/01.

\section{Analytical Methodology}

The radioanalytical results reported for each sample include the site and laboratory sample identification numbers, collection date, method of analysis, and the quality control samples that were analyzed concurrently. Samples were analyzed in accordance with the following method.

\begin{tabular}{||c|c|c|c||}
\hline \hline Radionuclide & $\begin{array}{c}\text { Method } \\
\text { Number }\end{array}$ & \multicolumn{1}{|c|}{$\begin{array}{c}\text { Method } \\
\text { Name }\end{array}$} & \multicolumn{1}{c|}{$\begin{array}{c}\text { Counting } \\
\text { Method }\end{array}$} \\
\hline \hline $\begin{array}{l}\text { Gamma Emitting } \\
\text { Radionuclides }\end{array}$ & EPA 901.1 & $\begin{array}{l}\text { Gamma Emitting } \\
\text { Radionuclides }\end{array}$ & $\begin{array}{l}\text { Gamma } \\
\text { Spectrometry }\end{array}$ \\
\hline
\end{tabular}

\section{Analytical Results}

\section{$\underline{\text { Deficiencies }}$}

None.

\section{Matrix Interferences}

There were no indications of matrix interference.

\section{Dilutions}

There were no dilutions. 


\section{Detection Limits}

The required detection limits (RDL) were met for all analyses.

$\underline{\text { Reanalysis }}$

There were no reanalysis.

Deviations from Protocols

There were no deviations from the written protocols and analytical methods.

Contacts with the CTR

There was no contact with the CTR regarding these samples.

\section{Quality Control}

Site Samples Used for Quality Control Samples:

\begin{tabular}{|c|c|c|}
\hline Site Sample Number & Laboratory Sample Number & $\begin{array}{c}\text { Type of Quality Control Analysis } \\
\text { Sample }\end{array}$ \\
\hline Laboratory Type II Water & SCAQC-4214-LCl & Laboratory Control Sample \\
\hline $12-202115(5 \mathrm{~cm})$ & SCAQC-4214-LD1 & Laboratory Duplicate Sample \\
\hline Laboratory Type II Water & SCAQC-4214-PB & Preparation Blank \\
\hline
\end{tabular}

The analytical results of all quality control samples met the acceptance criteria specified in the SOW.

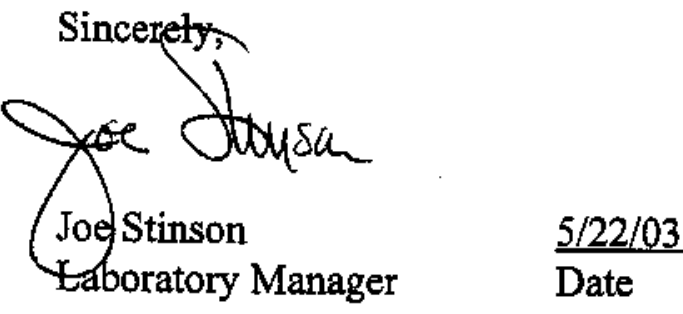




\section{Sanford Cohen \& Associates Southeastern Environmental Laboratory \\ Radioanalytical Results}

Report Identification Number: V1963

\begin{tabular}{|c|c|c|c|c|c|c|}
\hline \multicolumn{2}{|c|}{$\begin{array}{l}\text { Project Name: Bechtei Nevadg } \\
\text { Site Sample ID: } \underline{060204-T 5} \\
\text { Other Sample ID: }\end{array}$} & \multicolumn{3}{|c|}{ Chain-of-Custody Number: NONE } & \multicolumn{2}{|c|}{ Matrix: Soll } \\
\hline Method Number & Radionuclide & $\begin{array}{l}\text { Laboratory } \\
\text { Sample ID }\end{array}$ & $\begin{array}{l}\text { Actlvity } \\
\text { (pclig) }\end{array}$ & $\begin{array}{l}2 \quad \sigma \quad \mathrm{TPU} \\
(0 \mathrm{C} / / 9)\end{array}$ & $\begin{array}{l}\text { Total Error } \\
(\mathrm{OC} / \mathrm{g})\end{array}$ & $\begin{array}{c}\text { MDA } \\
(\mathrm{pCi} /(\alpha)\end{array}$ \\
\hline EPA 901.1 & $\mathrm{~K}-40$ & NTS03-4272-01 & 24.9 & 2.35 & 3.42 & 0.261 \\
\hline EPA 901:1 & $c 0-60$ & NTS03-4272-01 & 0.019 & 0.024 & 0.024 & 0.032 \\
\hline EPA 901.1 & Y-88 & NTS03-4272-01 & -0.005 & 0.015 & 0.015 & 0.025 \\
\hline EPA 901.1 & RU-106 & NTS03-4272-01 & 0.084 & 0.164 & 0.164 & 0.278 \\
\hline EPA 901.1 & SE-125 & NTS03-4272-01 & 0.019 & 0.045 & 0.045 & 0.078 \\
\hline EPA 901.1 & $\operatorname{cs}-134$ & NTS03-4272-01 & 0.005 & 0.018 & 0.018 & 0.027 \\
\hline EPA 901.1 & CS-137 & NTS03-4272-01 & -0.022 & 0.018 & 0.018 & 0.029 \\
\hline EPA 901.1 & CE-144 & NTS03-4272-01 & 0.501 & 1.86 & 1.86 & 0.221 \\
\hline EPA 901.1 & $P M-144$ & NTS03-4272-01 & 0.005 & 0.017 & 0.017 & 0.027 \\
\hline EPA 901.1 & PM-146 & NTS03-4272-01 & 0.017 & 0.021 & 0.021 & 0.037 \\
\hline EPA 901.1 & EU-152 & NTS03-4272-01 & 0.025 & 0.045 & 0.045 & 0.076 \\
\hline EPA 901.1 & EU-154 & NTS03-4272-01 & 0.000 & 0.000 & 0.000 & 0.053 \\
\hline EPA 901.1 & EU-155 & NTS03-4272-01 & 0.518 & 0.108 & 0.120 & 0.120 \\
\hline EPA 901.1 & $\mathrm{~PB}-212$ & NTS03-4272-01 & 1.65 & 0.405 & 0.437 & 0.051 \\
\hline EPA 901.1 & AC-2228 & NTS03-4272-01 & 1.63 & 0.231 & 0.283 & 0.109 \\
\hline EPA 901.1 & TH-234 & NTS03-4272-01 & 2.83 & 0.602 & 0.665 & 0.513 \\
\hline EPA 901.1 & U-235 & NTS03-4272-01 & 0.157 & 0.047 & 0.050 & 0.040 \\
\hline EPA 901.1 & U-238 & NTS03-4272-01 & 3.92 & 3.40 & 3.42 & 6.10 \\
\hline EPA 901.1 & AM-241 & NTS03-4272-01. & -0.095 & 0.119 & 0.119 & 0.181 \\
\hline
\end{tabular}

\begin{tabular}{|cllll|}
\hline Radionuclide & Laboratory Control (LC) & Laboratory Duplliate (LD) & Matrix Spike (MS) & Preparation Blank (PB) \\
\hline Gamma & SCAQC-4214-LC1 & SCAQC-4214-LD1 & & SCAQC-4214-PB \\
\hline
\end{tabular}


Radloanalytical Results

Report Identification Number: V1963

\begin{tabular}{|c|c|c|c|c|c|c|}
\hline $\begin{array}{l}\text { Project Name: } \\
\text { Site Sample ID: } \\
\text { Other Sample ID: }\end{array}$ & $\begin{array}{l}\text { Bechtel Nevada } \\
\text { 060204-T6 }\end{array}$ & \multicolumn{3}{|c|}{ Chain-of-Custody Number: NONE } & \multicolumn{2}{|c|}{ Matrix; Soil } \\
\hline Method Number & Radionuclide & $\begin{array}{l}\text { Laboratory } \\
\text { Sample ID }\end{array}$ & $\begin{array}{l}\text { Activity } \\
\text { (ocilg) }\end{array}$ & $\begin{array}{l}2 \sigma \text { TPU } \\
(\mathrm{pC} / / 9)\end{array}$ & $\begin{array}{c}\text { Total Error } \\
(0 \mathrm{Ci} / \mathrm{g})\end{array}$ & $\begin{array}{c}\mathrm{MDA} \\
\text { (pCi/g) }\end{array}$ \\
\hline EPA 901.1 & $\mathrm{~K}-40$ & NTS03-4272-02 & 28.6 & 2.68 & 3.92 & 0.298 \\
\hline EPA 901.1 & $\mathrm{co-60}$ & NTS03-4272-02 & 0.004 & 0.025 & 0.025 & 0.036 \\
\hline EPA 901.1 & Y-88 & NTSO3-4272-02 & 0.010 & 0.015 & 0.015 & 0.029 \\
\hline EPA 901.1 & RU-106 & NTS03-4272-02 & -0.107 & 0.178 & 0.178 & 0.300 \\
\hline EPA 901.1 & SB-125 & NTSO3-4272-02 & 0.062 & 0.052 & 0.053 & 0.091 \\
\hline EPA 901.1 & CS-134 & NTSO3-4272-02 & -0.004 & 0.020 & 0.020 & 0.030 \\
\hline EPA 901.1 & CS-137 & NTSO3-4272-02 & -0.026 & 0.020 & 0.020 & 0.033 \\
\hline EPA 901.1 & CE-144 & NTS03-4272-02 & 0.313 & 2.13 & 2.13 & 0.242 \\
\hline EPA 901.1 & PM-144 & NTSO3-4272-02 & -0.009 & 0.019 & 0.019 & 0.032 \\
\hline EPA 901.1 & PM-146 & NTS03-4272-02 & 0.029 & 0.024 & 0.024 & 0.041 \\
\hline EPA 901.1 & EU-152 & NTS03-4272-02 & 0.001 & 0.053 & 0.053 & 0.087 \\
\hline EPA 901.1 & EU-154 & NTSO3-4272-02 & 0.000 & 0.000 & 0.000 & 0.062 \\
\hline EPA 901.1 & EU-155 & NTS03-4272-02 & 0.350 & 0.128 & 0.133 & 0.104 \\
\hline EPA 901.1 & PB-212 & NTS03-4272-02 & 1.82 & 0.536 & 0.566 & 0.055 \\
\hline EPA $901 . t$ & AC-228 & NTS03-4272-02 & 1.71 & 0.264 & 0.314 & 0.120 \\
\hline EPA 901.1 & TH-234 & NTS03-4272-02 & 2.56 & 0.594 & 0.646 & 0.558 \\
\hline EPA 901.1 & U-235 & NTS03-4272-02 & 0.193 & 0.057 & 0.060 & 0.043 \\
\hline EPA 901.1 & $\mathrm{U}-238$ & NTS03-4272-02 & 4.36 & 3.59 & 3.62 & 6.41 \\
\hline EPA 901.1 & AM-241 & NTSO3-4272-02 & 0.048 & 0.113 & 0.114 & 0.170 \\
\hline
\end{tabular}

\begin{tabular}{|cllll|}
\hline & & \multicolumn{2}{c|}{ Quality Control Samples } \\
Radionuclide & Laborator Control (LC) & Laboratory Dupdicate (LD) & Matrix Spike (MS) & Preparation Blank (PB) \\
Gamma & SCAQC-4214-LC1 & SCAQC-4214-LD1 & & SCAQC-4214-PB \\
\hline
\end{tabular}


CLOSURE REPORT - CAU 330

Section: Appendix B

Revision: 0

Date: July 2003

\section{THIS PAGE INTENTIONALLY LEFT BLANK}


CLOSURE REPORT - CAU 330

Section: Appendix B

Revision: 0

Date: July 2003

\section{SAMPLE DELIVERY GROUP}

\section{V1964}


CLOSURE REPORT - CAU 330

Section: Appendix B

Revision: 0

Date: July 2003

\section{THIS PAGE INTENTIONALLY LEFT BLANK}




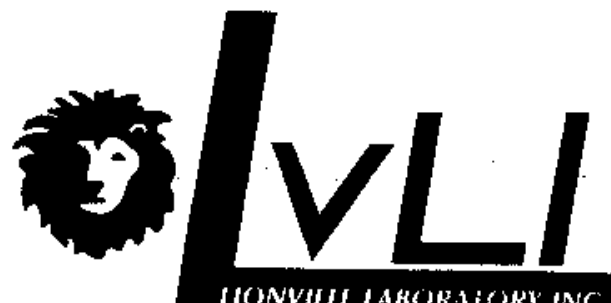

16 May 2003

Mr. Theodore Redding

Bechtel Nevada Corporation

2621 Losee Road

Mail Stop NTS273

Las Vegas, NV 89030-4134

RE: Subcontract No. 30028, Task Order No. 1

Data Report for LVL Batch 0304L282

SDG\#: V1964 Chain: CAU 330

Dear Mr. Redding:

Enclosed please find the data report for 4 soil samples and 2 water samples received 25 April 2003 for analysis for TPH GRO/DRO, metals, VOAs, SVOAs and PCBs on a 28 day turnaround time. The invoice is enclosed. An EDD is not required.

Please do not hesitate to contact me at (610) 280-3029 with any questions or at any time we may be of service.

Very truly yours,

Lionville Laboratory Incorporated

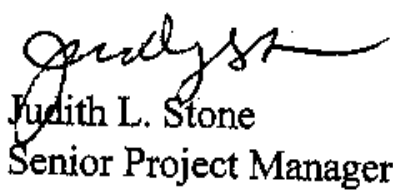

Enclosure: 


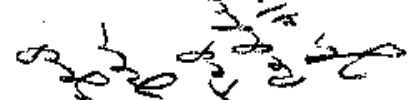

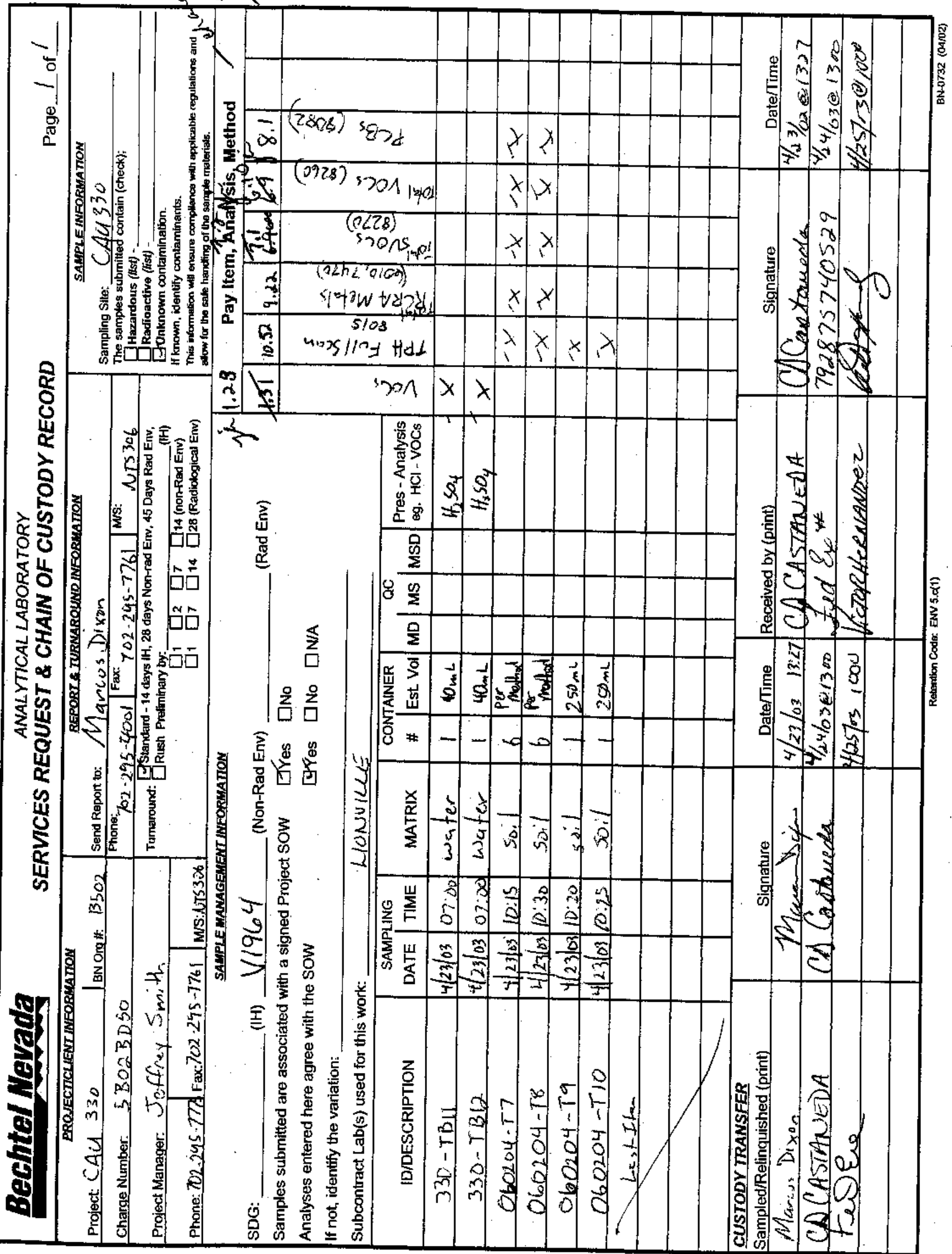


Case Narrative 


\section{olvLI \\ UONVILF IABORATORY INC}

\section{Anatyticat Report}

Client : BECHTEL NEVADA V1964

LVL\# : 0304L282
W.O.\# : 60052-001-001-0001-00

Date Received : 04-25-03

\section{SW846 METALS}

1. This narrative covers the analyses of 2 soil samples.

2. The samples were prepared and analyzed in accordance with $\underline{\mathrm{WW}-846}$ protocol and reported with a CLP deliverable.

3. ICVs, CCVs, and LCSs stock standards were purchased from Inorganic Ventures Laboratory and High Purity.

4. All analyses were performed within the required holding times.

5. All results presented in this report are derived from samples that met LvLI's sample acceptance policy.

6. All Initial and Continuing Calibration Verifications (ICV/CCVs) were within control limits.

7. All Initial and Continuing Calibration Blanks (ICB/CCBs) were within method criteria.

8. All preparation/method blanks were within method criteria. Refer to form 3 .

9. All ICP Interference Check Standards were within control limits. Refer to form 4.

10. All laboratory control samples (LCS) were within the $80-120 \%$ control limits. Refer to form 7 .

11. All serial dilution percent differences were within $\underline{\mathrm{SW}-846}$ control limits. Refer to form 9 .

12. All matrix spike (MS) recoveries were within the $75-125 \%$ control limits. Refer to form. 5 A.

13. The duplicate analysis for 1 analyte was outside the $20 \%$ Relative Percent Difference (RPD) control limits. Refer to form 6 . 
14. All sample IDs were changed to accommodate the EPA naming convention which allows a maximum of 6 characters on all CLP Forms. Refer to the comments section of form 1 for the original ID.

15. Recoveries on the Laboratory Summary Report and CLP forms will vary depending on the number of significant figures used in the recovery calculation.

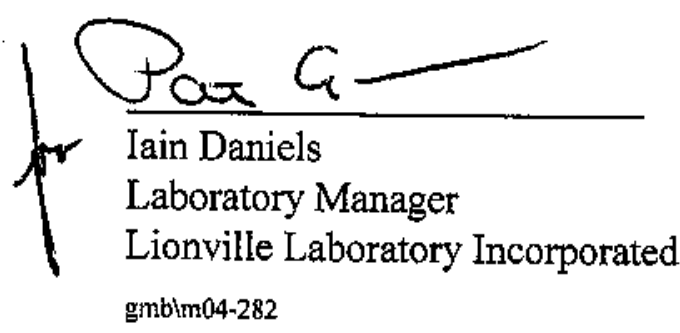

$$
\frac{05-16.03}{\text { Date }}
$$

Laboratory Manager

gmbim04-282 


\section{METHOD REFERENCES AND DATA QUALIFIERS}

\section{DATA QUALIFIERS}

$\mathrm{U}=$ Indicates that the parameter was not detected at or above the reported limit. The associated numerical value is the sample detection limit.

$\mathrm{B}=$ Indicates that the parameter was between the Instrument Detection Limit (IDL) and the Contract Required Detection Limit (CRDL)

\section{Q OUALIEIERS}

$E=$ The reported value is estimated because of the presence of interference.

$M=$ Duplicate injection precision not met.

$\mathrm{N}=$ Spiked sample recovery not within control limits.

$S=\quad$ The reported value was determined by the Method of Standard Additions (MSA).

$\mathrm{W}=$ Post Digestion spike for Fumace AA analysis is out of control limits (85-115\%), while sample absorbance is less than $50 \%$ of spike absorbance.

* = Duplicate analysis not within control limits.

$+=$ Correlation coefficient for the MSA is less than 0.995 .

\section{ABBREVIATIONS}

$\mathrm{PB}=$ Method or Preparation Blank.

$S=$ Matrix Spike.

$T=$ Matrix Spike Duplicate.

R or D = Sample Replicate

\section{ANALYTICAL METAL METHODS}

1. Not included in the method element list.

2. Modified $\mathrm{Hg}$ : $\mathrm{Hgl}$ and $\mathrm{Hg} 2$ require less total volume of digestate due to the autosampler analysis. Sample volumes and reagents for mercury determinations in water and soil have been proportionately scaled down to adapt to this semiautomated technique. The sample volume used for water analysis is $33 \mathrm{~mL}$. For soils, approximately 0.3 grams of sample is taken to a final volume of $50 \mathrm{~mL}$ (including all reagents).

3. Flame AA.

4. Graphite Furnace AA.

RFW 21-2JL-033/O-01/97 
1

INORGANIC ANALYSES DATA SHEET
EPA SAMPLE NO.

\section{$204 \mathrm{~T} 7$}

Lab Name: LIONVILLE_LABORATORY

Contract: 60052

Lab Code: LVLI

Matrix (soil/water): SOIL

Level (low/med):

solids:
SAS No.:

SDG No : : $204 \overline{\mathrm{T}} 7$

Lab Sample ID: 0304L282-003

Date Received: 04/25/03

Concentration Units (ug/L or $\mathrm{mg} / \mathrm{kg}$ dry weight): MG/KG

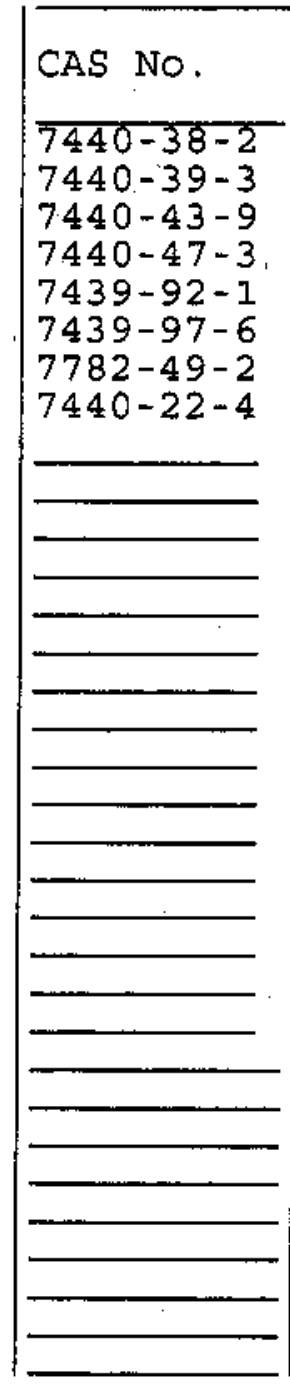

Color Before: Color After: Comments:

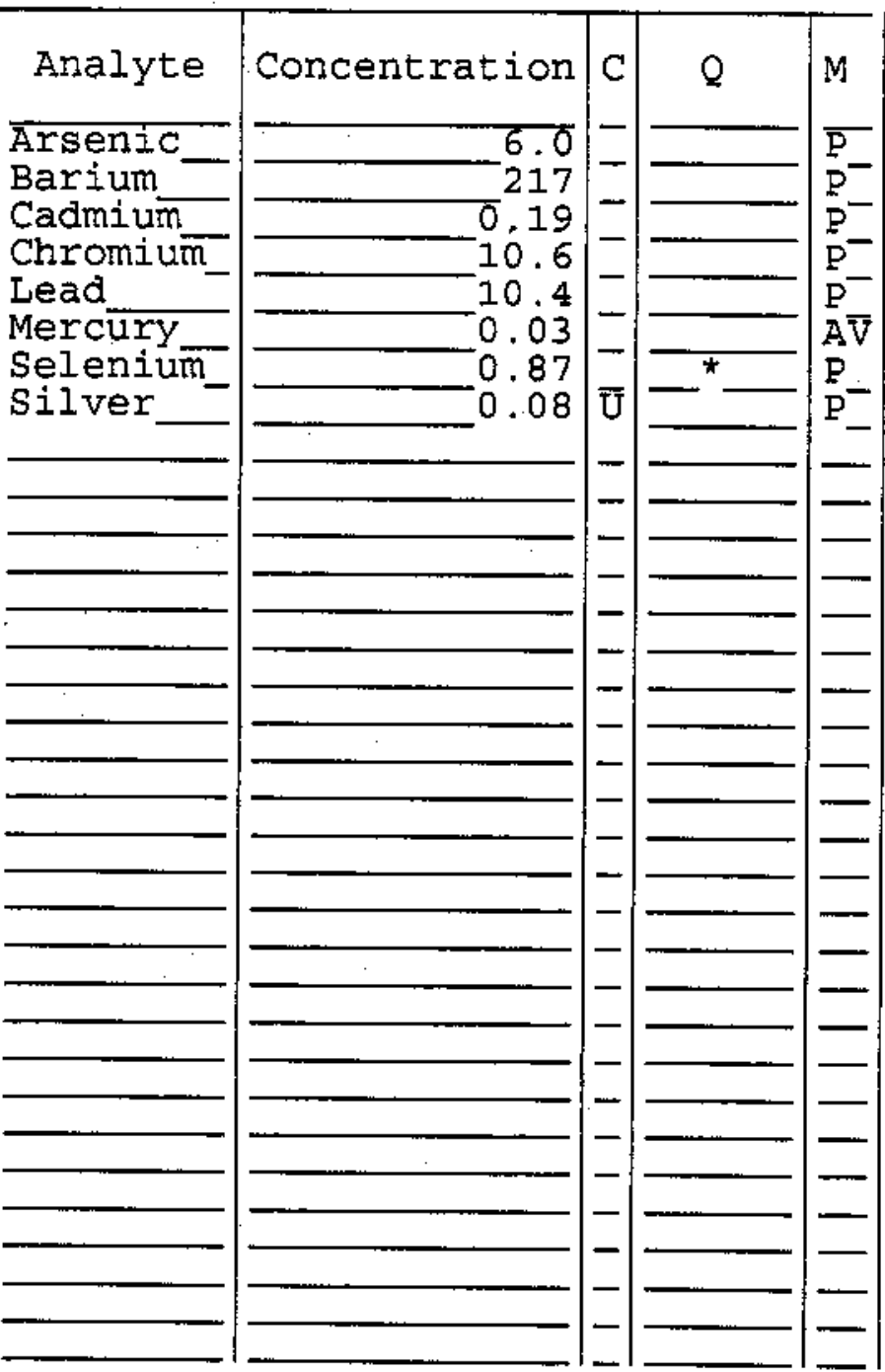

Clarity Before: Clarity After:
Texture:

Artifacts :

$060204-\mathrm{T} 7$ 
1

\section{INORGANIC ANALYSES DATA SHEET}

EPA SAMPLE NO.

$204 \mathrm{~T} 8$

Lab Name: LIONVILLE LABORATORY

Lab Code: LVLI

Case No.: V1964

Matrix (soil/water): SOIL

Level (low/med):

웋 Solids:
SAS NO.:

Lab Sample ID: 0304L282-0̄04

Date Received: 04/25/03
Contract: 60052

Concentration Units (ug/L or $\mathrm{mg} / \mathrm{kg}$ dry weight): MG/KG

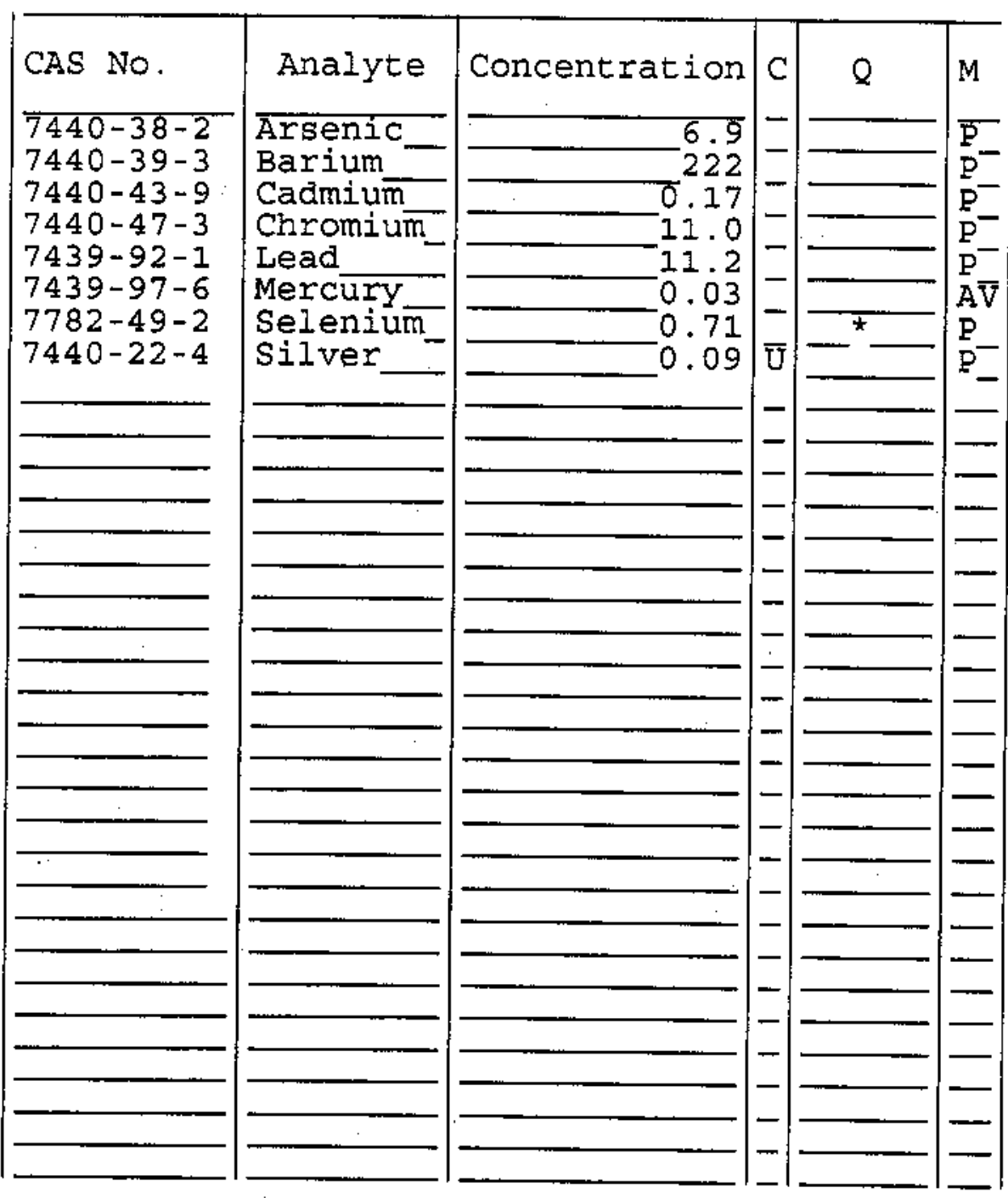

Color Before: Color After: Comments :

$060204-\mathrm{T} 8$
Clarity Before:

Clarity After:
Texture:

Artifacts: 
Case Narrative 


\section{- $/ v L I$ \\ LUONVILE LABORATORV INC.}

Client: BECHTEL-NEVADA V1964

LVL \#: 0304L282

W.O. \#: 60052-001-001-0001-00

Date Received: 04-25-2003

\section{GC/MS VOLATILE}

Two (2) water and two (2) soil samples were collected on 04-23-2003.

The samples and their associated QC samples were analyzed according to criteria set forth in Lionville Laboratory OPs based on SW 846 Method 8260B for TCL Volatile target compounds on 05-02,05,062003.

The following is a summary of the QC results accompanying the sample results and a description of any problems encountered during their analyses:

1. All results presented in this report are derived from samples that met LvLI's sample acceptance policy.

2. The required holding time for analysis was met.

3. Non-target compounds were not reported as per client request.

4. All surrogate recoveries were within EPA QC limits.

5. Matrix spike analyses are associated with LVL \# 0304L269.

6. All blank spike recoveries were within EPA QC limits.

7. The method blanks contained the common laboratory contaminants Methylene Chloride and/or Acetone at levels less than $3 x$ the CRQL. The method blank 02LVG102-MB1 also contained the target compound 2-Butanone at a level less than the CRQL.

8. Internal standard area and retention time criteria were met.

9. Manual integrations are performed according to OP L-QA-125 to produce quality data with the utmost integrity. All manual integrations are required to be technically valid and properly documented. Appropriate technical flags are defined in the Glossary ("Technical Flags For Manual Integration").

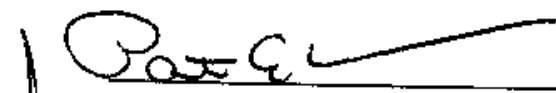

J. Michael Taylor

$0 \underline{5.13-03}$

President

Date

Lionville Laboratory Incorporated

sonnigroupldatalbnaibectel-sevadat0304-282.doc

The results presented in this report relate only to the anglytical testing and conditions of the samples at receipt and during storage. 


\section{GLOSSARY}

\section{DATA QUALIFIERS}

$\mathrm{U}=$ Compound was analyzed for but not detected. The associated numerical value is the estimated sample quantitation limit which is included and corrected for dilution and percent moisture.

$\mathrm{J}=$ Indicates an estimated value. This flag is used under the following circumstances: 1) when estimating a concentration for tentatively identified compounds (TICs) where a $1: 1$ response is assumed; or 2) when the mass spectral data indicate the presence of a compound that meets the identification criteria but the result is less than the specified detection limit but greater than zero. For example, if the limit of detection is $10 \mathrm{ug} / \mathrm{L}$ and a concentration of $3 \mathrm{ug} / \mathrm{L}$ is calculated, it is reported as $3 \mathrm{~J}$.

B = This flag is used when the analyte is found in the associated blank as well as in the sample. It indicates possibje/probable blank contamination. This flag is also used for a TIC as well as for a positively identified TCL compound.

$\mathbf{E}=$ Indicates that the compound was detected beyond the calibration range and was subsequently analyzed at a dilution.

D = Identifies all compounds identified in an analysis at a secondary dilution factor.

I $=$ Interference.

NQ $=$ Result qualitatively confirmed but not able to quantify.

A = Indicates that a TIC is a suspected aldol-condensation product.

$\mathrm{N}=$ Indicates presumptive evidence of a compound. This flag is only used for tentatively identified compounds (TICs), where the identification is based on a mass spectral library search. It is applied to all TIC results. For generic characterization of a TIC, such as chlorinated hydrocarbon, the N code is not used.

$\mathrm{X}=\quad$ This flag is used for a TIC compound which is quantified relative to a response factor generated from a daily calibration standard (rather than quantified relative to the closest intemal standard).

$\mathbf{Y}=$ Additional qualifiers used as required are explained in the case narrative. 


\section{GLOSSARY}

\section{ABBREVIATIONS}

BS = Indicates blank spike in which reagent grade water is spiked with the CLP matrix spike solutions and carried through all the steps in the method. Spike recoveries are reported.

BSD $=$ Indicates blank spike duplicate.

MS $=\quad$ Indicates matrix spike.

MSD = Indicates matrix spike duplicate.

DL = Suffix added to sample number to indicate that results are from a diluted analysis.

NA $=$ Not Applicable.

DF $=$ Dilution Factor.

NR $=\quad$ Not Required.

SP, Z = Indicates Spiked Compound. 
Sample Data for each Sample 
$1 \mathrm{~A}$

VOLATILE ORGANICS ANALYSIS SHERT
CLIENT SAMPLE NO.

|330-TB1I

Lab Name: Ifonville Labs, Inc. Work Order: 60052.001001

Client: BECHTEL NEVADA VI964

Metrix:

Sample wt/vol:

Level: (low/med) IOW

\& Molsture: not dec.

Column: (pack/cap) CAP
Iab Sample ID: 0304L282-001

Lab File ID: $\quad$ g050219

Date Received: $04 / 25 / 03$

Date Analyzed: $05 / 02 / 03$

D1lution Factor: 1.00

CAS NO.

COMPOUND

CONCENTRATION ONITS:

(ug/L or ug/Kg) ug/L

\begin{tabular}{|c|c|}
\hline \multicolumn{2}{|l|}{$74-87-3--4---$ Chloromethane } \\
\hline \multicolumn{2}{|l|}{$74-83-9=-----$-Bromomethane } \\
\hline \multicolumn{2}{|l|}{ 75-01-4------Vinyl Chloride } \\
\hline \multicolumn{2}{|l|}{ 75-00-3--..-Chloroethane } \\
\hline \multicolumn{2}{|c|}{ 75-09-2--n--Methylene Chlortde } \\
\hline \multicolumn{2}{|c|}{$67-64-1-\ldots-\ldots-$ Acetone } \\
\hline \multicolumn{2}{|l|}{ 75-15-0-...-Carbon D1sulf1de } \\
\hline \multicolumn{2}{|c|}{ 75-35-4-n---1,1-D1chloroethene } \\
\hline \multicolumn{2}{|c|}{$75-34-3-\cdots--1,1-D 1$ chloroethane } \\
\hline \multicolumn{2}{|c|}{ 540-59-0-2..-1,2-Dichloroethene (total) } \\
\hline \multicolumn{2}{|c|}{$67-66-3-\ldots$ Chloroform } \\
\hline \multicolumn{2}{|c|}{ 107-06-2---n-1,2-Dichloroethane } \\
\hline \multicolumn{2}{|l|}{$78-93-3-------2-$ - $u$ tanone. } \\
\hline \multicolumn{2}{|c|}{ 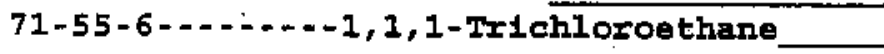 } \\
\hline \multicolumn{2}{|c|}{ 56-23-5------Carbon Tetrachloride } \\
\hline \multicolumn{2}{|c|}{$75-27-4-------B r o m o d 1$ chlorome thane } \\
\hline \multicolumn{2}{|c|}{$78-87-5---1,2-D 1$ chloropropane } \\
\hline \multicolumn{2}{|c|}{ 10061-01-5--n-c18-1,3-Dichloropropene } \\
\hline \multicolumn{2}{|c|}{$79-01-6-\ldots-1 r i c h l o r o e t h e n e$} \\
\hline \multicolumn{2}{|c|}{$124-48-1-\ldots-n-D 1 b r o m o c h l o x$ me thane } \\
\hline \multicolumn{2}{|c|}{$79-00-5-\cdots-1,1,2-T r 1$ chloroethane } \\
\hline \multicolumn{2}{|l|}{$71-43-2-\ldots---$-Benzene } \\
\hline \multicolumn{2}{|c|}{ 10061-02-6----Trans-1,3-Dichloropropene } \\
\hline \multicolumn{2}{|l|}{$75-25-2-\ldots \ldots-n$} \\
\hline \multicolumn{2}{|c|}{ 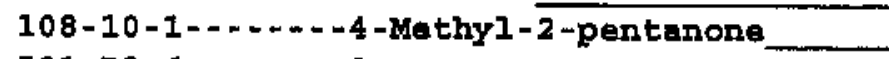 } \\
\hline \multicolumn{2}{|l|}{$591-78-6-\ldots-2-2$-Hexanone } \\
\hline \multicolumn{2}{|l|}{ 127-18-4--2--Tetrachloroethene } \\
\hline \multicolumn{2}{|c|}{ 79-34-5-----1,1,2,2-Tetrachloroethane } \\
\hline \multicolumn{2}{|l|}{ 108-88-3--n-m-Toluene } \\
\hline \multicolumn{2}{|l|}{ 108-90-7 ...--Chlorobenzene } \\
\hline \multicolumn{2}{|l|}{ 100-41-4--..--gthylbenzene } \\
\hline \multicolumn{2}{|l|}{$100-42-5------s$ tyrene } \\
\hline $1330-20-7-\cdots--x y$ lene (tota] & \\
\hline
\end{tabular}


Lab Name: LIonv1110 Labs, Inc. Work Order: 60052001001

33.0-TE12

Client: BECHTRL NEVADA V1964

Matrix:

Sample wt/vol:

Level: (Iow/med) LOW

r Moisture: not dec.

Column: (pack/cap) chp
Lab Sample ID: 0304 L282-002

Iab File ID: $\quad$ g050220

Date Recetred: $\underline{04 / 25 / 03}$

Date Analyzed: $\underline{05 / 02 / 03}$

Dilution Factor: 1.00
CAS NO.

COMPOUND

CONCENTRATION UNITS:

(ug/L or $u g / \mathrm{kg}$ ) $\mathrm{ug} / \mathrm{L}$

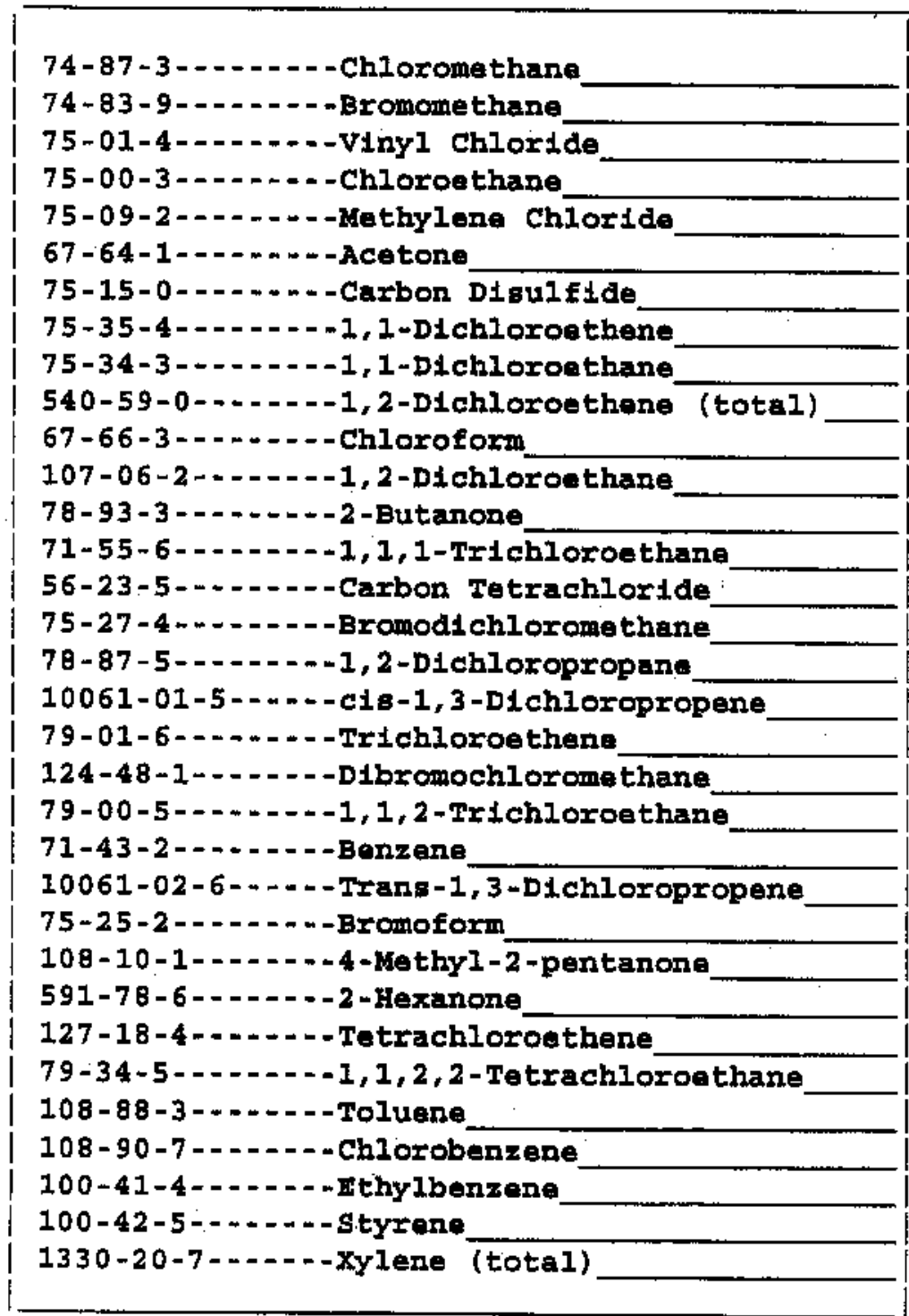

FORM $1 \mathrm{~V}-1$

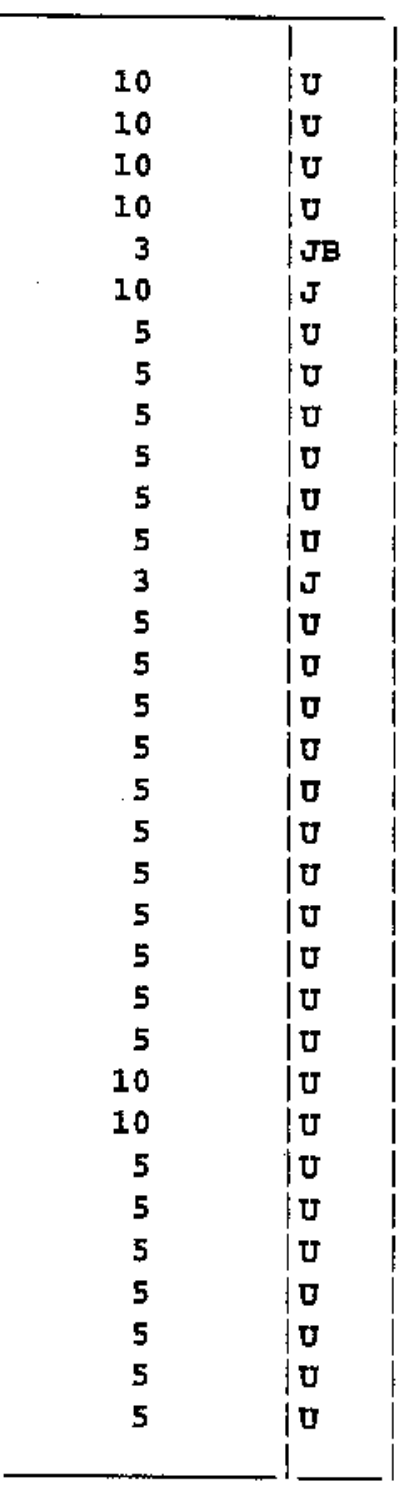

12/88 Rev. 
$1 \mathrm{~A}$

VOLATILE ORGANICS ANAIYSIS SHEET
CLIENT SAMPLE NO.

Lab Name: Lionville Labs, Inc. Work Order: 60052001001

client: BECHTEI NEFADA V1964

Matrix:

Sample wt/vol:

Level:

(low/med)

4.90

(g/mL) $\underline{\mathrm{G}}$

IOW

7

CoIums: (pack/cap) CAP
Lab Sample ID: 0304L2B2-003

Iab File ID: g050610

Date Received: $04 / 25 / 03$

Date Analyzed: 05/06/03

Dilution Factor: 1.02

CAS NO.

COMPOUND

CONCENTRATION WNITS :

(ug/L or $u g / \mathrm{Kg}$ ) ug/Kg

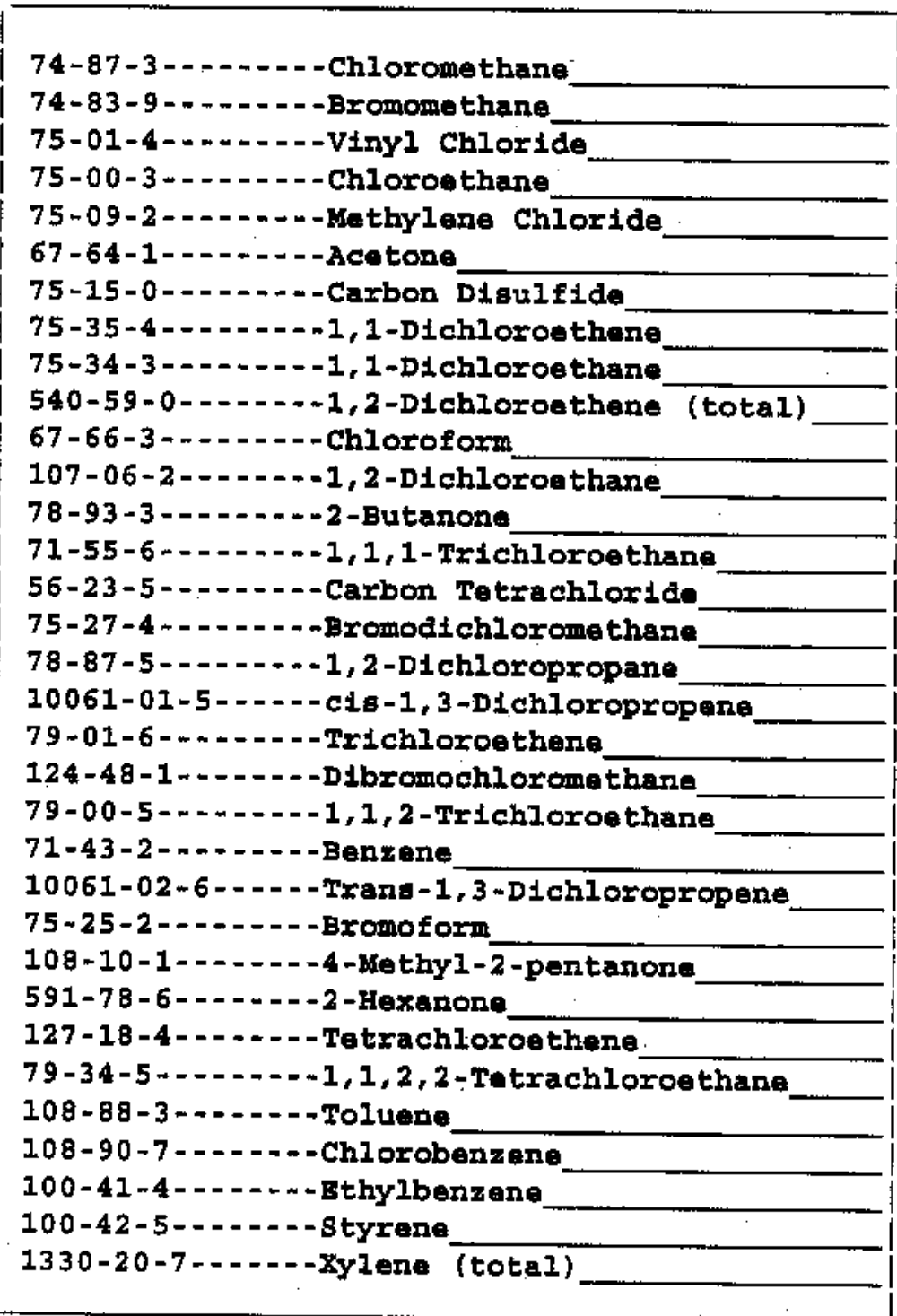

\begin{tabular}{|c|c|}
\hline 11 & 0 \\
\hline 11 & 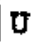 \\
\hline 11 & U \\
\hline 11 & U \\
\hline 21 & B \\
\hline 3 & 5 \\
\hline 6 & 0 \\
\hline 6 & ס \\
\hline 6 & $\mid \boldsymbol{\sigma}$ \\
\hline 6 & 0 \\
\hline 6 & J \\
\hline 6 & U \\
\hline 11 & U \\
\hline 6 & | \\
\hline 6 & 0 \\
\hline 6 & 0 \\
\hline 6 & 0 \\
\hline 6 & U. \\
\hline 6 & |ن \\
\hline 6 & U \\
\hline 6 & U \\
\hline 6 & U \\
\hline 6 & $\mathbf{0}$ \\
\hline 6 & U \\
\hline 11 & U \\
\hline 11 & U \\
\hline 6 & U \\
\hline 6 & $\mathrm{U}$ \\
\hline 6 & 0 \\
\hline 6 & 0 \\
\hline 6 & U \\
\hline 6 & U \\
\hline 6 & $U$ \\
\hline
\end{tabular}

12/88 Rev. 
IA

VOLATILE ORGANICS ANAIYSIS SHEET
CLIENT SAMPLE NO.

$1060204-T 8 R E$

Lab Name: Lionv1lle Labs, Inc. Work Order: 60052001001

Client: BECHTEI NTVADA V1964

Matrix:

Sample wt/vol:

Level: (low/med) Iow

\% Molsture: not dec. 10

Column: (pack/cap) CAP
Iab Sample ID: 0304L282-0.04

Lab File ID:

0050521

Date Recelved: $\underline{04 / 25 / 03}$

Date Analyzed: $05 / 05 / 03$

Dilution Factor: 1.06

CAs No.

COMPOUND

CONCENTRATION WNITS:

(ug/t or ug/Kg) ug/Kg

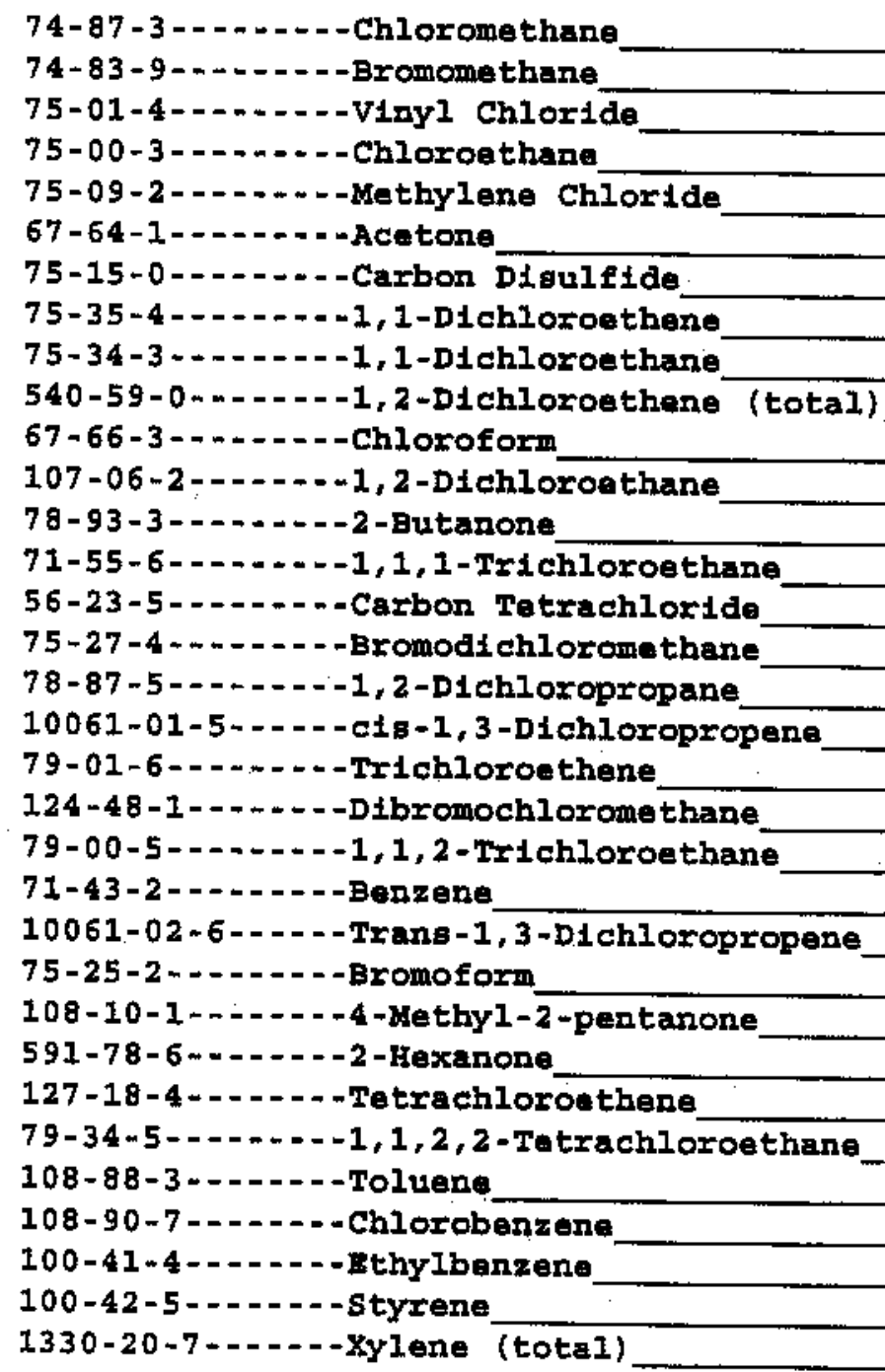


Case Narrative 


\section{( $\mid V L I$ \\ IIONVILL LABOKAIOKY INC.}

Client: BECHTEL-NEVADA V1964

LVL \#: 0304L282
W.O. \#: 60052-001-001-0001-00

Date Received: 04-25-2003

\section{SEMIVOLATILE}

Two (2) soil samples were collected on 04-23-2003.

The samples and their associated QC samples were extracted according to Lionville Laboratory OPs based on method 3550 on 04-28-2003 and analyzed according to criteria set forth in Lionville Laboratory OPs based on SW 846 Method 8270C for TCL Semivolatile target compounds on 05-062003.

The following is a summary of the QC results accompanying the sample results and a description of any problems encountered during their analyses:

1. All results presented in this report are derived from samples that met LvLI's sample acceptance policy.

2. Samples were extracted and analyzed within required holding time.

3. Non-target compounds were not reported as per client request.

4. All surrogate recoveries were within EPA QC limits.

5. All matrix spike recoveries were within EPA QC limits.

6. All blank spike recoveries were within EPA QC limits.

7. The method blank contained the common laboratory contaminant Bis (2-Ethylhexyl) phthalate at a level less than the CRQL.

8. Internal standard area and retention time criteria were met.

9. Manual integrations are performed according to OP L-QA-125 to produce quality data with the utmost integrity. All manual integrations are required to be technically valid and properly documented. Appropriate technical flags are defined in the Glossary ("Technical Flags For Manual Integration").

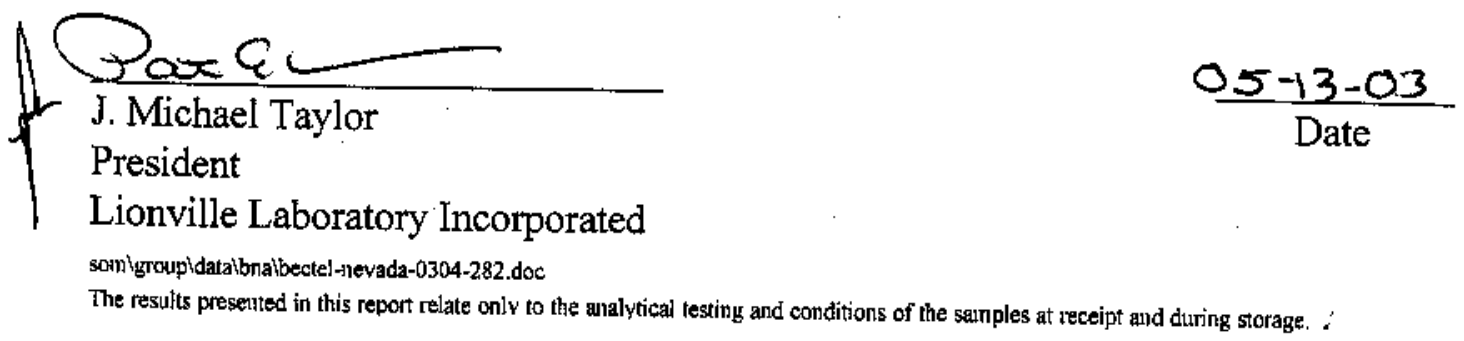




\section{GLOSSARY}

\section{DATA OUALIFIERS}

$\mathrm{U}=$ Compound was analyzed for but not detected. The associated numerical value is the estimated sample quantitation limit which is included and corrected for dilution and percent moisture.

$\mathrm{J}=$ Indicates an estimated value. This flag is used under the following circumstances: 1) when estimating a concentration for tentatively identified compounds (TICs) where a $1: 1$ response is assumed; or 2) when the mass spectral data indicate the presence of a compound that meets the identification criteria but the result is less than the specified detection limit but greater than zero. For example, if the limit of detection is $10 \mathrm{ug} / \mathrm{L}$ and a concentration of $3 \mathrm{ug} / \mathrm{L}$ is calculated, it is reported as $3 \mathrm{~J}$.

B $\quad=\quad$ This flag is used when the analyte is found in the associated blank as well as in the sample. It indicates possible/probable blank contamination. This flag is also used for a TIC as well as for a positively identified TCL compound.

$\mathbf{E}=$ Indicates that the compound was detected beyond the calibration range and was subsequently analyzed at a dilution.

D = Identifjes all compounds identified in an analysis at a secondary dilution factor.

$1=$ Interference.

NQ $\quad$ Result qualitatively confirmed but not able to quantify.

A = Indicates that a TIC is a suspected aldol-condensation product.

$\mathrm{N}=$ Indicates presumptive evidence of a compound. This flag is only used for tentatively identified compounds (TICs), where the identification is based on a mass spectral library search. It is applied to all TJC results. For generic characterization of a TIC, such as chlorinated hydrocarbon, the $\mathrm{N}$ code is not used.

$\mathrm{X}=\quad$ This flag is used for a TIC compound which is quantified relative to a response factor generated from a daily calibration standard (rather than quantified relative to the closest internal standard).

Y $=\quad$ Additional qualifiers used as required are explained in the case narrative. 


\section{GLOSSARY}

\section{ABBREVIATIONS}

BS = Indicates blank spike in which reagent grade water is spiked with the CLP matrix spike solutions and carried through all the steps in the method. 'Spike recoveries are reported.

BSD $=$ Indicates blank spike duplicate.

MS = Indicates matrix spike.

MSD $=$ Indicates matrix spike duplicate.

DL = Suffix added to sample number to indicate that results are from a diluted analysis.

NA $=$ Not Applicable.

DF $=$ Dilution Factor.

NR $=$ Not Required.

$\mathrm{SP}, \mathrm{Z}=$ Indicates Spiked Compound. 
Sample Data for each Sample 
Lab Name: Lionville Labs, Inc, Work Order: 60052001001

Client: BECHTEL NEVADA V2964

Matrix: (soil/water) soIL

Sample wt/vol: $30.0 \quad(\mathrm{~g} / \mathrm{mL}) \mathrm{G}$

Leve 1: $\quad$ (low/med) LOW

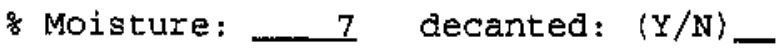

Concentrated Bxtract Volume: 1000(uL)

Injection volume: $\underline{2.0}(\mathrm{uL})$

GPC Cleanup: (Y/N) Nㅡㄴ

$\mathrm{pH}:-7.0$
CAS NO.

COMPOUND
Lab Sample ID: 0304L282-003

Lab File ID: $\quad \underline{6050607}$

Date Received: $\quad 04 / 25 / 03$

Date Extracted: $04 / 28 / 03$

Date Analyzed: $05 / 06 / 03$

Dilution Factor: 1.00

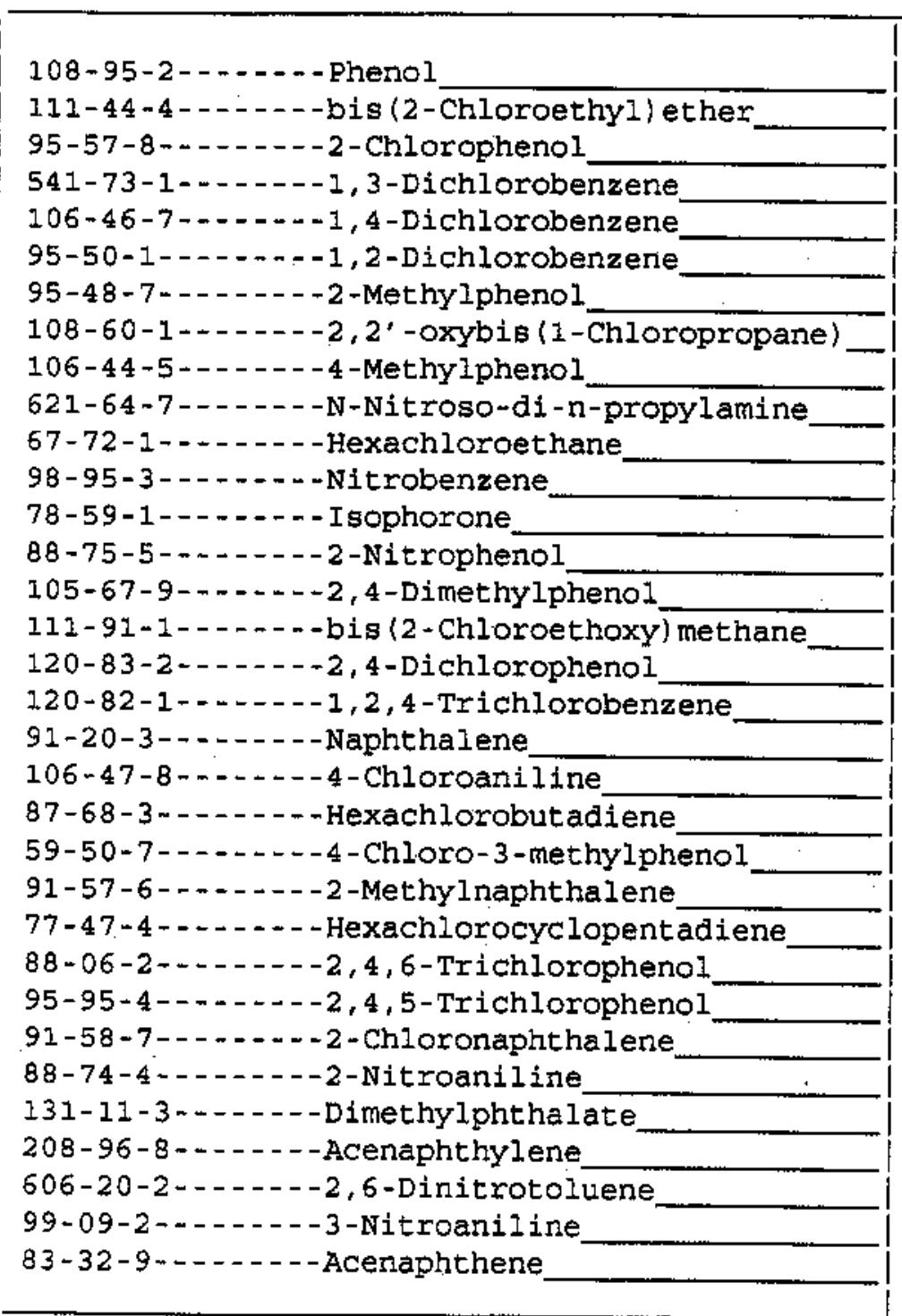

$360 \mid \mathrm{U}$

$360 \mid \mathrm{U}$

$360 \mid \mathrm{J}$

$360 / \mathrm{U}$

$360 \mid 0$

$360 \mid \mathrm{U}$

$360 \mid \mathrm{U}$

$360 \mid \mathrm{U}$

$360^{\prime} \mathrm{U}$

$360: \mathrm{U}$

$360 \mid \mathrm{U}$

$360 \mid \mathrm{U}$

$360 \mid \mathrm{J}$

$360 \mid \mathrm{U}$

$360 / 0$

360,0

$360 \mid \mathrm{U}$

$360 \mid \mathrm{U}$

$360 \mid \mathrm{J}$

$360 / \mathrm{U}$

$360 \mid \mathrm{U}$

$360 \mid \mathrm{U}$

$360 \mid \mathrm{U}$

$360 \mid \mathrm{U}$

$360 \mid \mathrm{U}$

$900: \mathrm{U}$

$360 / \mathrm{U}$

$900 \mid \mathrm{U}$

$360 \mid \mathrm{v}$

$360 / \mathrm{U}$

$360 \mid \mathrm{U}$

$900 / \mathrm{U}$

$360 \mid \mathrm{t}$ 
Lab Name: Lionville Labs, Inc, work order: 60052001001

Client: BECHTEL NEVADA V1964

Matrix: (soil/water) SOIL

Lab Sample ID: 0304L282-003

Sample wt/vol: $30.0 \quad(\mathrm{~g} / \mathrm{mL}) \mathrm{G}$

Lab File ID: $\quad \underline{\operatorname{co50607}}$

Level: (low/med) IOW

Date Received: 04/25/03

: Moisture:

7 decanted: $(\mathrm{Y} / \mathrm{N})$

Date Extracted: $04 / 28 / 03$

Concentrated Extract Volume: 1000(uL)

Date Analyzed: 05/06/03

Injection volume: 2.0 (uI)

Dilution Factor: 1.00

GPC Cleanup: $\quad(\mathrm{Y} / \mathrm{N}) \underline{\underline{N}}$

$\mathrm{pH}:-7.0$

CAS NO.

COMPOUND

CONCENTRATION TNITS:

(ug/L or $\mathrm{ug} / \mathrm{Kg}$ ) $\underline{\mathrm{UG} / \mathrm{KG}}$

\begin{tabular}{|c|}
\hline $51-28-5-\cdots---2,4-$ Dinitrophenol \\
\hline $100-02-7-\ldots-4-N i t r o p h e n o l$ \\
\hline $132-64-9 \cdots--$-Dibenzofuran \\
\hline $121-14-2 \cdots-2-2,4$-Dinitrotoluene. \\
\hline 84-66-2---..-Diethylphthalate_ \\
\hline 7005-72-3--1-4-Chlorophenyl-phenylether \\
\hline $86-73-7------$ Fluorene \\
\hline 100-01-6------4-Nitroaniline \\
\hline 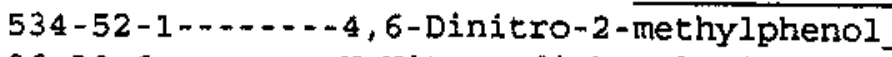 \\
\hline $86-30-6-\cdots-N-N i t r o s o d 1 p h e n y l a m i n e(1)$ \\
\hline 101-55-3----4-Bromophenyl-phenylether_ \\
\hline $118-74-1-\cdots-$-Hexachlorobenzene. \\
\hline 87-86-5-----Pentachlorophenol \\
\hline 85-01-8-...-. - Phenanthrene \\
\hline $120-12-7-\cdots-$ Anthracene \\
\hline $86-74-8---1--$ Carbazole \\
\hline $84-74-2-\cdots-1-$ Di-n-butylphthalate \\
\hline 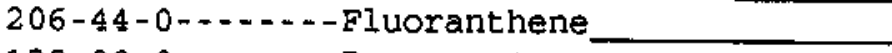 \\
\hline $129-00-0-\ldots-1-$-Pyrene \\
\hline 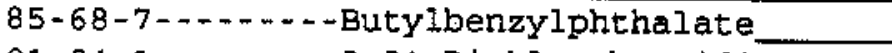 \\
\hline $91-94-1-\cdots-3,3^{\prime}$-Dichlorobenzidine \\
\hline $56-55-3--1$-Benzo (a) anthracene_ \\
\hline 218-01-9--n-Chrysene \\
\hline 117-81-7--- bis (2-EthylhexyI) phthalate \\
\hline 117-84-0------Di-n-octyl phthalate \\
\hline 205-99-2----Benzo (b) fluoranthene \\
\hline 207-08-9-----Benzo (k) fluoranthene \\
\hline $50-32-8 \ldots---$-Benzo (a) pyrene \\
\hline 193-39-5--- Indeno $(1,2,3-c d)$ pyrene \\
\hline 53-70-3-------Dibenz $(a, h)$ anthracene \\
\hline $191-24-2----$ Benzo $(g, h, i)$ perylene \\
\hline
\end{tabular}

(1) - Cannot be separated from Diphenylamine 
$1 \mathrm{~B}$

SEMIVOLATILE ORGANICS ANALYSIS DATA SHEET
CLIENT SAMPLE NO.

$060204-T 8$

Lab Name: Lionville Labs, Inc. Work Order: 60052001001

Client: BECHTEL NEVADA V1964

Matrix: (soil/water) SoIt

Sample wt/vol: $30.0 \quad(\mathrm{~g} / \mathrm{mL}) \mathrm{G}$

Level: $\quad$ low/med) LOW

Moisture: 10 decanted: $(\mathrm{Y} / \mathrm{N})$

Concentrated Extract Volume: 1000(uL)

Injection volume: $2.0(\mathrm{uL})$

Lab sample ID: $03041282-004$

Lab File ID: $\quad \underline{C 050610}$

Date Received: $04 / 25 / 03$

Date Extracted: 04/28/03

Date Analyzed: 05/06/03

Dilution Factor: 1.00

GPC Cleanup: (Y/N) $\mathrm{N} \quad \mathrm{pH}: \underline{7,0}$

CAS NO.

COMPOUND

CONCENTRATION UNITS:

(ug/L or $\mathrm{ug} / \mathrm{Kg}$ ) UG/KG

$Q$

108-95-2-- - - - Phenol.

$111-44-4-\ldots-\ldots$ bis (2-Chloroethyl) ether

95-57-8----.-2-Chlorophenol

$541-73-1-----1,3-D i c h l o r o b e n z e n e$

106-46-7-----1, 4-Dichlorobenzene

95-50-1-----1,2-Dichlorobenzene

95-48-7-------2-Methylphenol

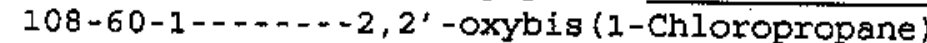

$106-44-5-\cdots---4-$ Methylphenol

$621 \sim 64-7-\cdots-N-N i t r o s o-d i-n-p r o p y l a m i n e$

67-72-1-------Hexachloroethane

98-95-3--.---N1trobenzene

78-59-1--..--- Isophorone

88-75-5---2--2-Nitrophenol

105-67-9---.--2, 4-Dimethylphenol

1I1-91-1--.--bis (2-Chloroethoxy) methane

120-83-2--..-2, 4-Dichlorophenol

120-82-1-..--1,2,4-Trichlorobenzene

$91-20-3-\ldots-2-N a p h t h a l e n e$

106-47-8---.-4-Chloroaniline

87-68-3----.-Hexachlorobutadiene

59-50-7-----4-Chloro-3-methylphenol

91-57-6-n.--2-Methylnaphthalene

77-47-4 - - --- -Hexachlorocyclopentadiene

88-06-2---n-2,4,6-Trichlorophenol

95-95-4------2, 4, 5-Trichlorophenol

91-58-7----m-2-Chloronaphthalene

88-74-4--n.-2-Nitroaniline

131-11-3-..---Dimethylphthalate

208-96-8-...--Acenaphthylene

$606-20-2-\ldots-2,6-$ Dinitrotoluene

99-09-2--...-3-Nitroaniline

83-32-9--..---Acenaphthene
$370 \mid \mathrm{U}$

$370 \mid 0$

$370 \mid \mathrm{U}$

$370 \mid \mathrm{U}$

$370 \mid 0$

$370 \mid 0$

$370 \mid \mathrm{v}$

$370 \mid \mathrm{U}$

$370 \mid \mathrm{U}$

$370 / \mathrm{U}$

$370 \mid \mathrm{U}$

$370 \mid \mathrm{U}$

$370 \mid \mathrm{U}$

$370 . \mathrm{U}$

$370 \mid \mathrm{U}$

$370 \mid \mathrm{U}$

$370 / \mathrm{U}$

$370 \mid \mathrm{U}$

$370 \mid \mathrm{U}$

$370 \mid \mathrm{J}$

$370 \mid \mathrm{U}$

$370 \mid \mathrm{U}$

$370 \mid 0$

$370 \mid \mathrm{U}$

$370 \mid \mathrm{U}$

$920 / \mathrm{U}$

$370 \mid \mathrm{J}$

$920 \mid \mathrm{U}$

$370 \mid \mathrm{U}$

$370 \mid \mathrm{U}$

$370 \mid \mathrm{U}$

92010

$370\} \mathrm{U}$

FORM 1 SV-1 
Lab Name: Lionville Labs, Inc. Work Order: 60052001001

Matrix: (soil/water) SOIL

Sample wt/vol: $30.0 \quad(\mathrm{~g} / \mathrm{mI}) \mathrm{G}$

Level: (low/med) LOW

\% Moisture: 10 decanted: $(\mathrm{Y} / \mathrm{N})$

Concentrated Extract Volume: 1000(uL)

Injection volume: $\underline{2.0}$ (uL)
Lab Sample ID: 0304L282-004

Lab File ID: $\quad$ C050610

Date Received: $\underline{04 / 25 / 03}$

Date Extracted: $\underline{04 / 28 / 03}$

Date Analyzed: $05 / 06 / 03$

GPC Cleanup: (Y/N) $\underline{\mathrm{N}} \quad \mathrm{pH}: \underline{7.0}$

CONCENTRATION UNITS :

CAS NO. COMPOUND (ug/L or $\mathrm{ug} / \mathrm{kg})$ UG/KG

$Q$

\begin{tabular}{|c|}
\hline 51-28-5------2,4-Dinitrophenol. \\
\hline 100-02-7--1-4-Nitrophenol. \\
\hline 132-64-9-----Dibenzofuran \\
\hline $121-14-2---1-2,4$-Dinitrotoluene. \\
\hline 84-66-2---n-Diethylphthalate. \\
\hline 7005-72-3--1--4-Chlorophenyl -phenylether \\
\hline $86-73-7-\ldots-m$-Fluorene. \\
\hline 100-01-6------4-Nitroaniline. \\
\hline 534-52-1----4, 6-Dinitro-2-methylphenol \\
\hline $86-30-6 \ldots \ldots-N$-Nitrosodiphenylamine (1) \\
\hline $101-55-3-1-4-$-Bromophenyl-phenylether \\
\hline 118-74-1--- - Hexachlorobenzene \\
\hline $87-86-5 \cdots--1$ \\
\hline 85-01-8--nenanthrene_ \\
\hline 120-12-7-----Anthracene. \\
\hline 86-74-8-------Carbazole \\
\hline $84-74-2---1-$-Di-n-butylphthalate. \\
\hline 206-44-0-------Fluoranthene. \\
\hline 129-00-0------Pyrene. \\
\hline 85-68-7-----Butylbenzylphthalate. \\
\hline $91-94 \sim 1-\cdots-3,3^{\prime}$-Dichlorobenzidine. \\
\hline $56-55-3 \ldots \ldots-1 . \cdots$ Benzo (a) anthracene. \\
\hline 218-01-9--n--.-Chrysene. \\
\hline 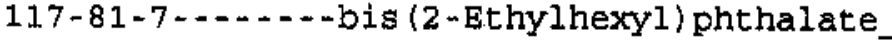 \\
\hline 117-84-0------Di-n-octyl phthalate. \\
\hline 205-99-2-1b--Benzo (b) fluoranthene. \\
\hline 207-08-9--1--Benzo $(k)$ fluoranthene, \\
\hline $50-32-8-\cdots---$-Benzo (a) pyrene. \\
\hline 193-39-5--..-Indeno $(1,2,3-c d)$ pyrene. \\
\hline $53-70-3-\cdots-D i b e n z(a, h)$ anthracene. \\
\hline 191-24-2-----Benzo $(g, h, i)$ perylene. \\
\hline
\end{tabular}

(1) - Cannot be separated Erom Diphenylamine FORM 1 SV-2 
CASE NARRATIVE 


\section{( $\mid V L I$ \\ LONVILLF LABORAIORV INC:}

Client: BECHTEL NEVADA V1964

Analytical Report

LVI\#: 0304L282

W.O.\#: 60052-001-001-0001-00

Date Received: 04-25-03

\section{PCB}

The set of samples consisted of two (2) soil samples collected on 04-23-03.

The samples and their associated QC samples were extracted on 05-06-03 and analyzed on 05-13-03 according to Lionville Laboratory OPs. The extraction procedure was based on method 3540 and the extracts were analyzed based on method 8082 .

The following is a summary of the QC results accompanying the sample results and a description of any problems encountered during their analyses:

1. All results presented in this report are derived from samples that met LVLI's sample acceptance policy.

2. All required holding times for extraction and analysis have been met.

3. The samples and their associated QC samples received Sulfuric Acid and Sulfur cleanups.

4. The method blank was below the reporting limits for all target compounds.

5. Two (2) of twelve (12) surrogate recoveries were outside acceptance criteria. A copy of the Sample Discrepancy Report (SDR) has been enclosed.

6. All blank spike recoveries were within acceptance criteria.

7. One (1) of four (4) matrix spike recoveries was outside acceptance criteria. A copy of the Sample Discrepancy Report (SDR) has been enclosed.

8. All initial calibrations associated with this data set were within acceptance criteria.

9. All continuing calibration standards analyzed prior to sample extracts were within acceptance criteria.

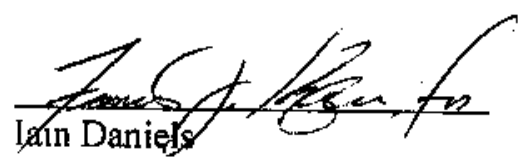

Laboratory Manager

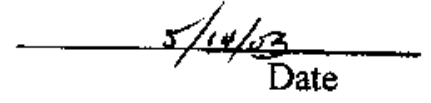

Lionville Laboratory Incorporated

pefvilgroupidataipestibechteli04L-282..pcb

The tesults presented in this report relate only to the analytical testing and conditions of the samples at receipt and duning storage. . 


\section{GLOSSARY OF PESTICIDE/PCB DATA}

\section{DATA QUALIFIERS}

$\mathrm{U}=$ Indicates that the compound was analyzed for but not detected. The minimum detection limit for the sample (not the method detection limit) is reported with the $\mathrm{U}$ (e.g., 10U).

$\mathbf{J}=$ Indicates an estimated value. This flag is used in cases where a target analyte is detected at a level less than the lower quantification level. If the limit of quantification is $10 \mathrm{ug} / \mathrm{L}$ and a concentration of $3 \mathrm{ug} / \mathrm{L}$ is calculated, it is reported as 3J.

B $=$ This flag is used when the analyte is found in the associated.blank as well as in the sample. It indicates possible/probable blank contamination.

$\mathbf{E}=$ Indicates that the compound was detected beyond the calibration range and was subsequently analyzed at a dilution.

I $=$ Interference.

\section{ABBREVIATIONS}

BS = Indicates blank spike in which reagent grade water is spiked with the CLP matrix spiking solutions and carried through all the steps in the method. Spike recoveries are reported.

BSD $=$ Indicates blank spike duplicate.

MS $=$ Indicates matrix spike.

MSD $=$ Indicates matrix spike duplicate.

DL = Indicates that recoveries were not obtained because the extract had to be diluted for analysis.

NA $=$ Not Applicable.

DF $=$ Dilution Factor.

$\mathrm{NR}=$ Not Required.

SP $=$ Indicates Spiked Compound. 
SAMPLE DATA FOR EACH SAMPLE 
10

PESTICIDE ORGANICS ANALYSIS SHEET

Lab Name: Lionville Labs, Inc, Work Order: 60052001001

Client: BECHTEL NEVADA V1964

Matrix:

Sample wt/vol:

Level: (low/med) LOW

\% Moisture: not dec. $\frac{7}{7}$ dec.

Extraction: (SepF/Cont/Sonc) $\underline{\text { SONC }}$

GPC Cleanup: $\quad(\mathrm{Y} / \mathrm{N}) \underline{\mathrm{N}}$

CAS NO.

COMPOUND
Lab Sample ID: $0304 L 282-003$

Iab File ID:

BLKLACHJ .02

Date Received: $\underline{04 / 25 / 03}$

Date Extracted: 모/06/03

Date Analyzed: $05 / 13 / 03$

Dilution Factor: 1.00

CONCENTRATION UNITS: (ug/L or $u g / \mathrm{kg}$ ) UG/KG

$\left\{\begin{array}{l}12674-11-2-\cdots-\text { Aroclor }-1016 \\ 11104-28-2---- \text { Aroclor }-1221 \\ 11141-16-5-\ldots-\text { Aroclor }-1232 \\ 53469-21-9-\ldots-\text { Aroclor }-1242 \\ 12672-29-6-\ldots-\text { Aroclor }-1248 \\ 11097-69-1-\ldots-\text { Aroclor }-1254 \\ 11096-82-5-\ldots-\text { Aroclor }-1260\end{array}\right.$

FORM 1 PEST

\begin{tabular}{ll|}
36 & $\mid \mathrm{U}$ \\
72 & $\mid \mathrm{U}$ \\
36 & $\mathrm{U}$ \\
36 & $\mathrm{U}$ \\
36 & $\mathrm{U}$ \\
36 & $\mathrm{U}$ \\
36 & $\mathrm{U}$ \\
\hline
\end{tabular}

12/88 Rev. 
1D

PESTICIDE ORGANICS ANALYSIS SHEET

Lab Name: Lionville Iabs, Inc, work Order: 60052001001

Client: BECHTEL NEVADA V1964

Matrix:

SOIL

Lab Sample ID: $0304 \mathrm{~L} 282-004$

Sample wt/vol: $\quad 30.0(\mathrm{~g} / \mathrm{mL}) \mathrm{G}$

Level: (low/med) LOW

\% Moisture: not dec. 10 dec.

Extraction: (SepF/Cont/Sonc) SONC

GPC Cleanup: (Y/N) $\underline{\mathrm{N}}$

$\mathrm{pH}:-7.0$
Lab File ID: BLKLACHO, 02

Date Received: $\quad 04 / 25 / 03$

Date Analyzed: $05 / 13 / 03$

Dilution Factor: 1.00
Date Extracted: 05/06/03
CLIENT SAMPLE NO.

$060204-T 8$
CAS NO.

COMPOUND
CONCENTRATION UNITS : (ug/I or $u g / \mathrm{Kg}$ ) uG/KG

$12674-11-2-\ldots-$ Aroclor -1016
$11104-28-2-\cdots-$ Aroclor -1221
$11142-16-5-\ldots-$ Aroclor -1232
$53469-21-9 \ldots--$ Aroclor -1242
$12672-29-6-\ldots-$ Aroclor -1248
$11097-69-1-\ldots-$ Aroclor -1254
$11096-82-5-\ldots-$ Aroclor -1260

FORM 1 PBST

\begin{tabular}{|l|l|}
37 & $\mid$ \\
74 & $\mathrm{U}$ \\
37 & $\mathrm{U}$ \\
37 & $\mathrm{U}$ \\
37 & $\mathrm{U}$ \\
37 & $\mathrm{U}$ \\
37 & $\mathrm{U}$ \\
\hline
\end{tabular}

12/88 Rev. 
1

CASE NARRATIVE 


\section{( $\mid V L I$}

Analytical Report

Client: BECHTEL-NEVADA V1964

LVL \#: 0304L282

W.O. \#: 60052-001-001-0001-00

Date Received: 04-25-03

\section{DIESEL RANGE ORGANICS}

The set of samples consisted of four (4) soil samples collected on 04-23-03.

The samples and their associated QC samples were extracted on 04-29-03 and analyzed according to Lionville Laboratory OPs on 05-09-03. The extraction procedure was based on method 3540 and the extracts were analyzed based on method 8015B for Diesel Range Petroleum Hydrocarbons.

1. All results presented in this report are derived from samples that met LvLI's sample acceptance policy.

2. All required holding times for extraction and analysis have been met.

3. The method blank was below the reporting limits for all target compounds.

4. All surrogate recoveries were within acceptance criteria.

5. The blank spike recovery was within acceptance criteria.

6. All initial calibrations associated with this data set were within acceptance criteria.

7. All continuing calibration standards analyzed prior to sample extracts were within acceptance criteria.

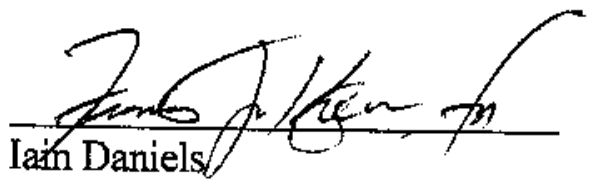

Laboratory Manager

Lionville Laboratory Incorporated

pefir: throuptdatatidrotbechteltio4L-282doc

The results presented in this report relate only to the analytical resting and conditions of the samples at receipt and during storage. 


\section{GLOSSARY OF DIESEL RANGE ORGANICS DATA}

\section{DATA QUALIFIERS}

$\mathbf{U}=$ Indicates that the compound was analyzed for but not detected. The minimum detection limit for the sample (not the method detection limit) is reported with the $U$ (e.g., 10U).

$\mathbf{J}=$ Indicates an estimated value. This flag is used in cases where a target analyte is detected at a level less than the lower quantification level. If the limit of quantification is $10 \mathrm{ug} / \mathrm{L}$ and a concentration of $3 \mathrm{ug} / \mathrm{L}$ is calculated, it is reported as $3 J$.

B = This flag is used when the analyte is found in the associated blank as well as in the sample. It indicates possible/probable blank contamination.

$\mathbf{E}=$ Indicates that the compound was detected beyond the calibration range and was subsequently analyzed at a dilution.

$\mathbf{I}=$ Interference.

\section{ABBREVIATIONS}

BS = Indicates blank spike in which reagent grade water is spiked with the CLP matrix spiking solutions and carried through all the steps in the method. Spike recoveries are reported.

BSD = Indicates blank spike duplicate.

MS $=$ Indicates matrix spike.

MSD $=$ Indicates matrix spike duplicate.

DL $=$ Indicates that recoveries were not obtained because the extract had to be diluted for analysis.

$\mathbf{N A}=$ Not Applicable.

DF $=$ Dilution Factor.

$\mathrm{NR}=\quad$ Not Required.

SP $=$ Indicates Spiked Compound. 

Lab Name: Lionville Labs. Inc. Work Order: 60052001001

Client: BECHTEL NEVADA V1964

Matrix:

SOIJ

Sample wt/vol: $25.0(\mathrm{~g} / \mathrm{mL}) \mathrm{G}$

Level: (low/med) LOW

\% Moisture: not dec. 7

Column: (pack/cap) CAP

COMPOUND

(ug/L or $\mathrm{ug} / \mathrm{Kg}$ ) $\mathrm{mg} / \mathrm{kg}$
Lab Sample ID: 0304L282-003

Lab File ID: BLKIACHU

Date Received: $\underline{04 / 25 / 03}$

Date Analyzed: $05 / 09 / 03$

Dilution Factor: 1,00

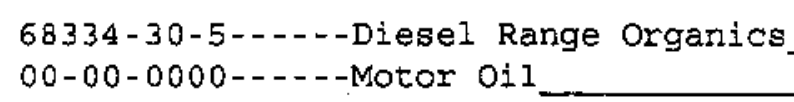

12.9

12.9

$\mid$\begin{tabular}{l}
$\mathrm{U}$ \\
$\mathrm{u}$ \\
\hline
\end{tabular}

$12 / 88$ Rev. 
Lab Name: Lionville Labs, Inc. Work Order: 60052001001

Client: BECHTEL NEVADA V1964

Matrix:

SOIL

Lab Sample ID: $0304 \mathrm{03} 22-004$

Sample wt/vol:

$25.0(\mathrm{~g} / \mathrm{mL}) \underline{\mathrm{G}}$

Lab File ID: BLKIACHJ

Level: (low/med) LOW

Date Received: $04 / 25 / 03$

\% Moisture: not dec.

10

Date Analyzed: $05 / 09 / 03$

Column: (pack/cap) CAP

Dilution Factor: 1,00

CONCENTRATION UNITS :

CAS NO.

COMPOUND

(ug/L or $u g / \mathrm{Kg}$ ) $\mathrm{mg} / \mathrm{kg}$

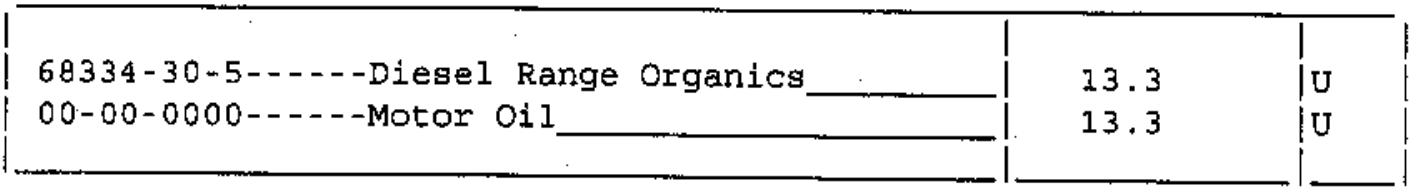

12/88 Rev. 
Lab Name: Lionvilie Labs, Inc. Work Order: 60052001001

Client: BECHTEL NEVADA V1964

Matrix:

SOIL

$\underline{25.0}(\mathrm{~g} / \mathrm{mL}) \underline{\mathrm{G}}$

Sample wt/vol:

(low/med)

LOW

: Moisture: not dec. 6

Column: (pack/cap) CAP

CAS NO.

COMPOUND
Lab Sample ID: 0304L282-005

Lab File ID: BLKTACHJ

Date Received: $\underline{04 / 25 / 03}$

Date Analyzed: 05/09/03

Dilution Factor: 1.00

CONCENTRATION UNITS:

(ug/L or $u g / \mathrm{Kg}$ ) $\mathrm{mg} / \mathrm{kg}$

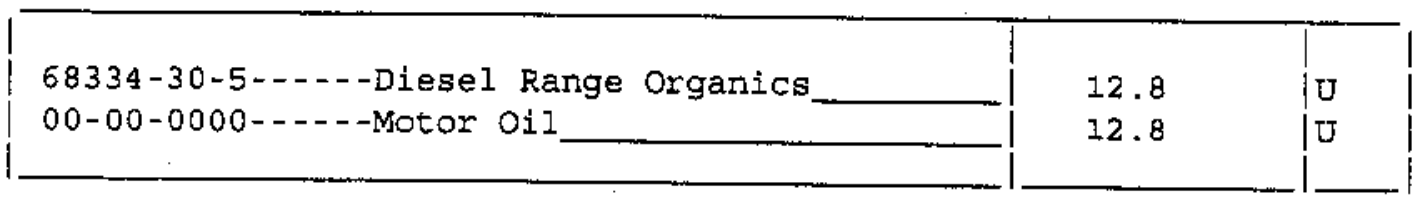

$12 / 88$ Rev. 
Lab Name: Lionville Labs, Inc. work order: 60052001001

Client: BECHTEL NEVADA V1964

Matrix :

SOII

Sample wt/vol: $\underline{25.0}(\mathrm{~g} / \mathrm{mL}) \mathrm{G}$

Level: $\quad(10 \mathrm{w} / \mathrm{med})$ LOW

告 Moiature: not dec. 7

Column: (pack/cap) CيP

CAS NO.

COMPOUND
Lab Sample ID: 0304I282-006

Lab File ID: BLKLACHJ

Date Received: $\underline{04 / 25 / 03}$

Date Analyzed: $05 / 09 / 03$

Dilution Factor: 1.00

CONCENTRATION UNITS :

(ug/L or $u g / \mathrm{kg}) \mathrm{mg} / \mathrm{kg}$

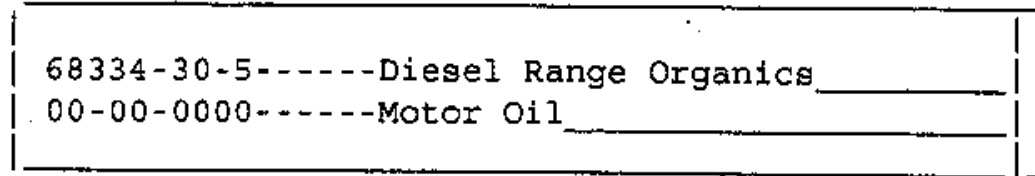

12.9

12.9

12/88 Rev. 
CASE NARRATIVE 


\section{( $\mid V L I$ \\ IIONVIIF LABORAIORY INC:}

\section{Analytical Report}

Client: BECHTEL NEVADA V1964

LVL \#: 0304L282

W.o. \#: 60052-001-001-0001-00

Date Received: 04-25-03

\section{GRO}

The set of samples consisted of four (4) soil samples collected on 04-23-03.

The samples and their associated QC samples were analyzed according to Lionville Laboratory

OPs based on SW-846 method 8015 for Gasoline range organics (GRO) on 05-06-03.

The following is a summary of the $\mathrm{QC}$ results accompanying these sample results and a description of any problems encountered during their analyses:

1. All results presented in this report are derived from samples that met LVLI's sample acceptance policy.

2. All required holding times for analysis have been met.

3. The method blank was below the reporting limits for all target compounds.

4. All surrogate recoveries were within acceptance criteria.

5. All blank spike recoveries were within acceptance criteria.

6. All initial calibrations associated with this data set were within acceptance criteria.

7. All continuing calibration standards analyzed prior to sample extracts were within acceptance criteria.
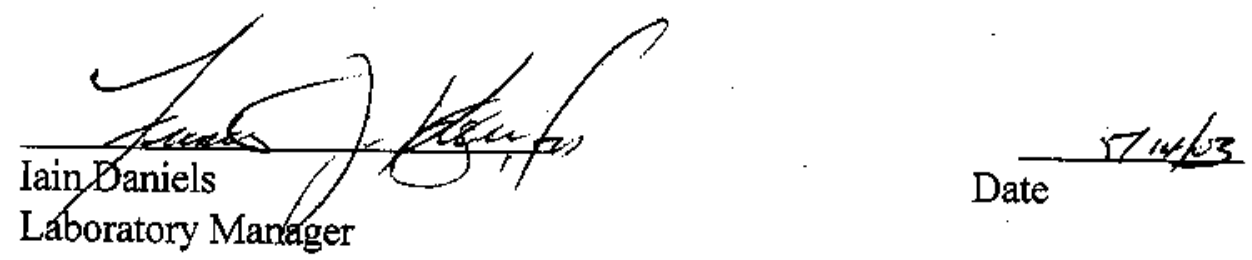

Lionville Laboratory Incorporated

pef'Riysouphdatalgroibechirelito4L-282.doc

The results presented in this report relate only to the analytical testing and conditions of the samples at receipt and duing storage. . 


\section{GLOSSARY OF GASOLINE RANGE ORGANICS DATA}

\section{DATA QUALIFIERS}

$\mathrm{U}=$ Indicates that the compound was analyzed for but not detected. The minimum detection limit for the sample (not the method detection limit) is reported with the $\mathrm{U}$ (e.g., 10U).

$\mathbf{J}=$ Indicates an estimated value. This flag is used in cases where a target analyte is detected at a level less than the lower quantification level. If the limit of quantification is $10 \mathrm{ug} / \mathrm{L}$ and a concentration of $3 \mathrm{ug} / \mathrm{L}$ is calculated, it is reported as $3 \mathrm{~J}$.

B = This flag is used when the analyte is found in the associated blank as well as in the sample. It indicates possible/probable blank contamination.

$\mathbf{E}=$ Indicates that the compound was detected beyond the calibration range and was subsequently analyzed at a dilution.

I $=$ Interference.

\section{ABBREVIATIONS}

BS = Indicates blank spike in which reagent grade water is spiked with the CLP matrix spiking solutions and carried through all the steps in the method. Spike recoveries are reported.

BSD $=$ Indicates blank spike duplicate.

MS = Indicates matrix spike.

MSD $=\quad$ Indicates matrix spike duplicate.

DL = Indicates that recoveries were not obtained because the extract had to be diluted for analysis.

NA $=$ Not Applicable.

DF $\quad=\quad$ Dilution Factor.

$\mathbf{N R}=\quad$ Not Required.

SP $=$ Indicates Spiked Compound. 


\section{SAMPLE DATA FOR EACH SAMPLE}


Lab Name: Ifionville Labs, Inc. Work Order: 60052001001

Client: BECHTEL NEVADA V1964

Matrix:

SOIL

Sample wt/vol:

$\underline{5.07}(\mathrm{~g} / \mathrm{mL}) \underline{\mathrm{G}}$

Level: (low/med) LOW

\% Moisture: not dec. 7

Column: (pack/cap) CAP.

CAS NO.

COMPOUND
Lab Sample ID: 0304L282-003

Lab File ID: BLKLACHJ

Date Received: $04 / 25 / 03$

Date Analyzed: $05 / 06 / 03$

Dilution Factor: 1,00

CONCENTRATION UNITS:

(ug/I or $u g / \mathrm{Kg}$ ) $\underline{\mathrm{UG} / \mathrm{KG}}$

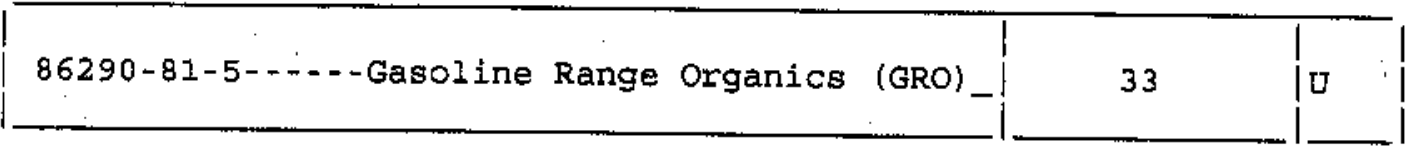

12/88 Rev. 
Lab Name: Iionville Labs. Inc. Work Order: 60052001001

Client: BECHTEL NEVADA V1964

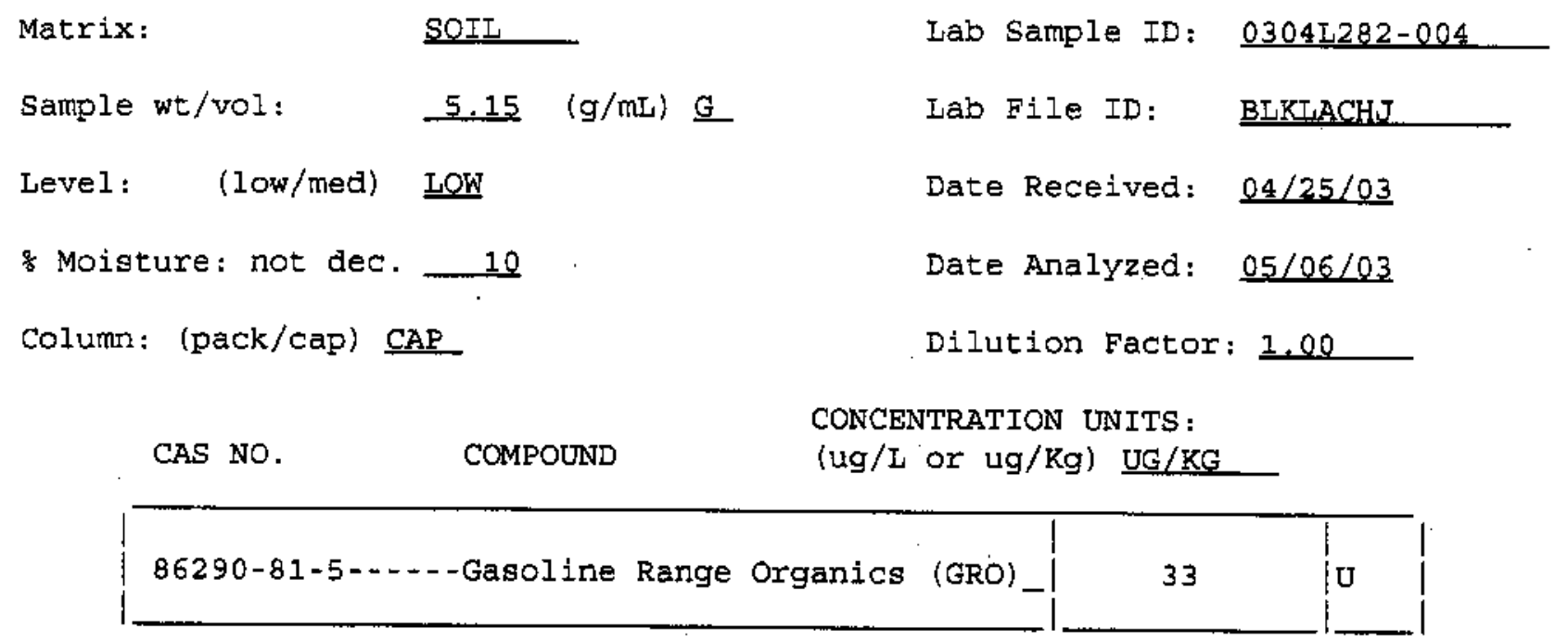

12/88 Rev. 
GC VOLATILES SHEET

Lab Name: Lionville Labs, Inc. Work Order: 60052001001

Client: BECHTEL NEVADA V1964

Matrix:

SOIL

Sample wt/vol:

$\underline{5.21}(\mathrm{~g} / \mathrm{mL}) \underline{\underline{G}}$

Level: (low/med) LOW

6

Column: (pack/cap) CAP

COMPOUND

\%oisture: not dec.
CLIENT SAMPLE NO.

|060204-T9

Lab Sample ID: 0304L282-005

Lab File ID: BLKLACHJ

Date Received: $24 / 25 / 03$

Date Analyzed: 05/06/03

Dilution Factor: 1.00

CONCENTRATION UNITS :

(ug/L or ug/Kg) UG/KG 
Lab Name: Ifonville Labs, Inc, Work Order: 60052001001

Matrix:

SOIL

Sample wt/vol: $5.19(\mathrm{~g} / \mathrm{mL}) \mathrm{G}$

Level: (low/med) LOW

\% Moisture: not dec.

7

Column: (pack/cap) cap

CAS NO

COMPOEND
Lab Sample ID: 0304 L282-0.06

Lab File ID: BLKLACHJ

Date Received: $\underline{04 / 25 / 03}$

Date Analyzed: $\underline{05 / 06 / 03}$

Dilution Factor: 2,00

CONCENTRATION UNITS: (ug/I or $\mathrm{ug} / \mathrm{kg}$ ) UG/KG
86290-81-5-..--Gasoline Range Organics (GRO)

(86290-81-5- - - Gasoline Range Organics (GRO) -
30

12/88 Rev. 
CLOSURE REPORT - CAU 330

Section: Appendix B

Revision: 0

Date: July 2003

\section{SAMPLE DELIVERY GROUP}

\section{V1965}


CLOSURE REPORT - CAU 330

Section: Appendix B

Revision: 0

Date: July 2003

\section{THIS PAGE INTENTIONALLY LEFT BLANK}




\section{$S C E A$ s. Comve Assouns}

May 23, 2003

Mr. Ted Redding

USDOE Zone 1

Bldg. 652, Room 2

M/S NTS 273

Mercury, NV 89023

Dear Mr. Redding:

On April 25, 2003, two soil samples, (SDG V1965) were received for analysis at the Sanford Cohen and Associates (SC\&A) Southeastern Environmental Laboratory. The samples were assigned Laboratory Report Identification Code 4277. Enclosed the Sample Data Package containing the results of the analyses of these samples.

If you have any questions please do not hesitate to call.

Sincerely,

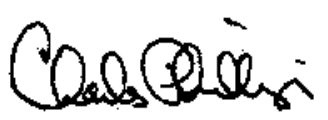

Charles Phillips

Vice President 


\title{
COVER PAGE
}

\author{
Sanford Cohen \& Associates \\ Southeastern Environmental Laboratory \\ 1000 Monticello Court \\ Montgomery, Alabama 36117
}

Laboratory Code: SCA Subcontract Number: 30025

Laboratory Report Identification Code: 4277 SDG: V1965

Sample Matrix: Soil

\begin{tabular}{|l|c|}
\hline \multirow{2}{*}{ Site Sample Numbers } & Laboratory Sample Number \\
\cline { 2 - 2 } & Gamma Spectrometry \\
\hline \hline $060204-\mathrm{T} 7$ & NTS03-4277-01 \\
\hline $060204-\mathrm{TR}$ & $\mathrm{NTS03-4277-02}$ \\
\hline
\end{tabular}

Comments: There were no problems encountered during sample receiving.

"I certify that this sample data package is in compliance with SOW requirements, both technically and for completeness, other than the conditions detailed above. Release of the data contained in this hard-copy sample data package and the computer-readable EDD, as applicable, submitted on diskette or by modem, has been authorized by the laboratory Manager or the Manager's designee, as verified by the following signature."
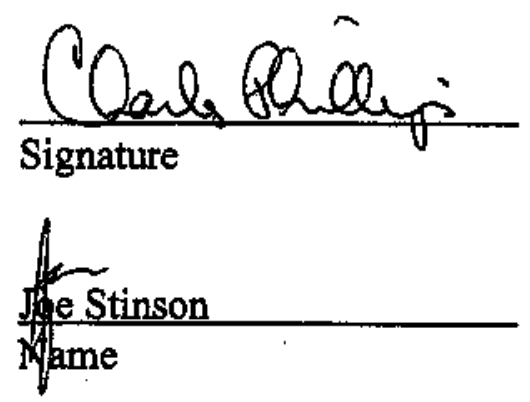

Laboratory Manager

Title $\underline{5 / 23 / 03}$

Date 


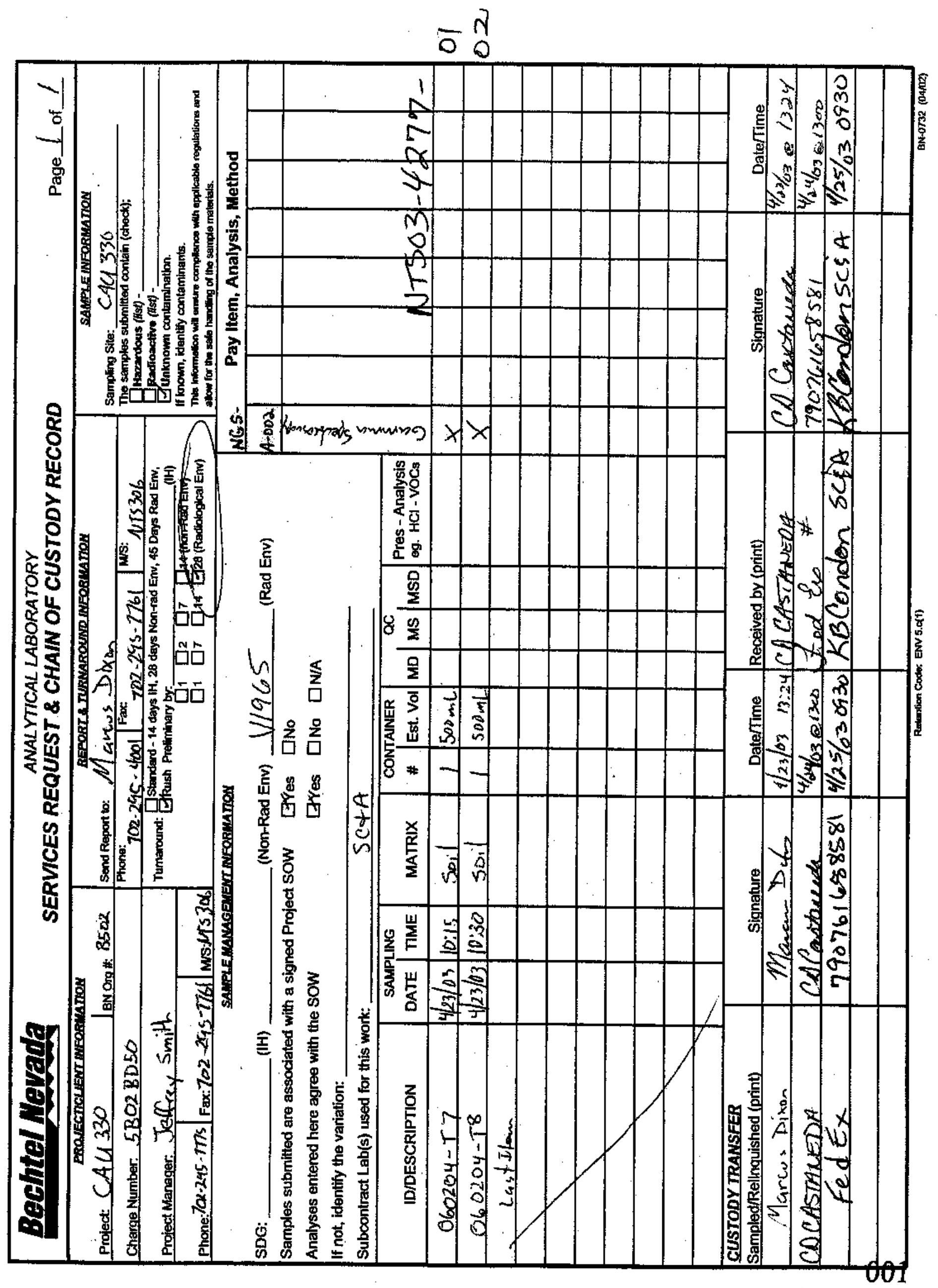




\section{CASE NARRATIVE \\ SDG V1965 \\ Laboratory Report Identification Number: $\mathbf{4 2 7 7}$}

May 23, 2003

\section{Introduction}

On April 25, 2003, two soil samples, (SDG V1965), were received for analysis at the Sanford Cohen and Associates (SC\&A) Southeastern Environmental Laboratory, located in Montgomery, Alabama. The samples were analyzed in accordance with the Bechtel Nevada Services Subcontract Task Order Agreement Form, Exhibit B, Statement of Work and Specifications, Rev 1, 1/23/01.

\section{Analytical Methodology}

The radioanalytical results reported for each sample include the site and laboratory sample identification numbers, collection date, method of analysis, and the quality control samples that were analyzed concurrently. Samples were analyzed in accordance with the following method.

\begin{tabular}{||c|c|l|l||}
\hline Radionuclide & \multicolumn{1}{|c|}{$\begin{array}{c}\text { Method } \\
\text { Number }\end{array}$} & \multicolumn{1}{|c|}{$\begin{array}{c}\text { Method } \\
\text { Name }\end{array}$} & \multicolumn{1}{c|}{$\begin{array}{c}\text { Counting } \\
\text { Method }\end{array}$} \\
\hline \hline $\begin{array}{l}\text { Gamma Emitting } \\
\text { Radionuclides }\end{array}$ & EPA 901.1 & $\begin{array}{l}\text { Gamma Emitting } \\
\text { Radionuclides }\end{array}$ & $\begin{array}{l}\text { Gamma } \\
\text { Spectrometry }\end{array}$ \\
\hline
\end{tabular}

\section{Analytical Results}

Deficiencies

None.

\section{Matrix Interferences}

There were no indications of matrix interference.

Dilutions

There were no dilutions.

\section{Detection Limits}

The required detection limits (RDL) were met for all analyses. 
$\underline{\text { Reanalysis }}$

There were no reanalysis.

Deviations from Protocols

There were no deviations from the written protocols and analytical methods.

Contacts with the CTR

There was no contact with the CTR regarding these samples.

\section{Quality Control}

Site Samples Used for Quality Control Samples:

\begin{tabular}{|c|c|c|}
\hline Site Sample Number & Laboratory Sample Number & $\begin{array}{c}\text { Type of Quality Control Analysis } \\
\text { Sample }\end{array}$ \\
\hline Laboratory Type II Water & SCAQC-4277-LCl & Laboratory Control Sample \\
\hline 060204-T7 & SCAQC-4277-LD1 & Laboratory Duplicate Sample \\
\hline Laboratory Type II Water & SCAQC-4277-PB & Preparation Blank \\
\hline
\end{tabular}

The analytical results of all quality control samples met the acceptance criteria specified in the SOW.

Sincerely,

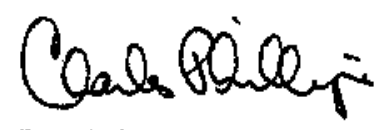

Joe Stinson $5 / 23 / 03$

Laboratory Manager

Date 


\section{Sanford Cohen \& Associates \\ Southeastern Environmental Laboratory}

Radloanalytical Results

Report Identification Number: V1965

\begin{tabular}{|c|c|c|c|c|c|c|}
\hline $\begin{array}{l}\text { Project Name: } \\
\text { Site Sample ID: } \\
\text { Other Sample ID: }\end{array}$ & $\begin{array}{l}\text { Eechtel Nevada } \\
60204=T 7\end{array}$ & \multicolumn{3}{|c|}{ Chain-of-Custody Number: NONE } & \multicolumn{2}{|c|}{ Matrlx: soil } \\
\hline Method Number & Radionuclide & $\begin{array}{l}\text { Laboratory } \\
\text { Sample ID }\end{array}$ & $\begin{array}{l}\text { Activily } \\
(0 \mathrm{c} i(\alpha))\end{array}$ & $\begin{array}{l}2 \text { व TPU } \\
(\mathrm{gCl} / \mathrm{g})\end{array}$ & $\begin{array}{c}\text { Total Ertor } \\
\text { (ocilg) }\end{array}$ & $\begin{array}{c}\mathrm{MDA} \\
\langle 0 \mathrm{C} / \mathrm{g})\end{array}$ \\
\hline EPA 901.1 & $K-40$ & NTS03-4277-01 & 26.0 & 2.44 & 3.57 & 0.259 \\
\hline EPA 901.1 & CO-60 & NTS03-4277-01 & -0.004 & 0.024 & 0.024 & 0.033 \\
\hline EPA 901.1 & $Y-88$ & NTS03-4277-01 & 0.003 & 0.016 & 0.016 & 0.029 \\
\hline EPA 901.1 & RU-108 & NTS03-4277-01 & 0.004 & 0.162 & 0.162 & 0.269 \\
\hline EPA 901.1 & SB-125 & NTS03-4277-01 & 0.026 & 0.046 & 0.046 & 0.079 \\
\hline EPA 901.1 & CS-134 & NTS03-4277-01 & 0.005 & 0.018 & 0.018 & 0.027 \\
\hline EPA 901.1 & $\operatorname{cs}-137$ & NTS03-4277-01 & -0.018 & 0.017 & 0.017 & 0.028 \\
\hline EPA 901.1 & CE-144 & NTS03-4277-01 & 1.72 & 1.87 & 1.88 & 0.215 \\
\hline EPA 901.1 & PM-144 & NTS03-4277-01 & -0.011 & 0.017 & 0.017 & 0.026 \\
\hline EPA 901.1 & PM-146 & NTS03-4277-01 & 0.024 & 0.021 & 0.021 & 0.038 \\
\hline EPA 901.1 & EU-152 & NTS03-4277-01 & -0.009 & 0.047 & 0.047 & 0.079 \\
\hline EPA 901.1 & EU-154 & NTS03-4277-01 & 0.000 & 0.000 & 0.000 & 0.057 \\
\hline EPA 901.1 & EU-155 & NTS03-4277-01 & 0.280 & 0.108 & 0.111 & 0.102 \\
\hline EPA 901.1 & PB-212 & NTS03-4277-01 & 1.76 & 0.433 & 0.467 & 0.048 \\
\hline EPA 901.1 & AC-228 & NTS03-4277-01 & 1.83 & 0.243 & 0.304 & 0.110 \\
\hline EPA 901.1 & TH-234 & NTS03-4277-01 & 1.31 & 0.481 & 0.499 & 0.534 \\
\hline EPA 901.1 & U-235 & NTS03-4277.01 & 0.155 & 0.047 & 0.050 & 0.040 \\
\hline EPA 901.1 & $U-238$ & NTS03-4277-01 & 2.83 & 3.28 & 3.29 & 5.84 \\
\hline EPA 901.1 & AM-241 & NTS03-4277-01 & 0.043 & 0.128 & 0.128 & 0.187 \\
\hline
\end{tabular}

\begin{tabular}{|c|c|c|c|c|}
\hline \multicolumn{5}{|c|}{ Qually Control Samplos } \\
\hline $\begin{array}{l}\text { Radionucdide } \\
\text { Gamma }\end{array}$ & $\begin{array}{l}\text { Laboratory Control(LC) } \\
\text { SCAQC-4277-LC1 }\end{array}$ & $\begin{array}{l}\text { Laboratory Duplicate (LD) } \\
\text { SCAQC-4277-LD1 }\end{array}$ & Matrix Soike (MS) & $\begin{array}{l}\text { Preparation Biank (PB) } \\
\text { SCAQC-4277+PB }\end{array}$ \\
\hline
\end{tabular}




\section{Sanford Cohen \& Associates \\ Southeastern Environmental Laboratory \\ Radioanalytlcal Results}

Report identification Number: V1965

\begin{tabular}{|c|c|c|c|c|c|c|}
\hline \multicolumn{2}{|c|}{$\begin{array}{l}\text { Project Name: Bechtel Nevada } \\
\text { Site Sample ID: 060204-T8 } \\
\text { Other Sample ID: }\end{array}$} & \multicolumn{3}{|c|}{ Chain-of-Custody Number. NONE } & \multicolumn{2}{|c|}{ Matrix: Soll } \\
\hline Method Number & Radlonuclide & $\begin{array}{l}\text { Laboratory } \\
\text { Sample ID }\end{array}$ & $\begin{array}{l}\text { Activity } \\
\text { (ocila) }\end{array}$ & $\begin{array}{l}2 \sigma \text { TPU } \\
(\circ \mathrm{C} / q)\end{array}$ & $\begin{array}{l}\text { Total Error } \\
(\mathrm{p} C \mathrm{C} / \mathrm{g})\end{array}$ & $\begin{array}{c}\text { MDA } \\
\text { (pCi/g) }\end{array}$ \\
\hline EPA 901.1 & $K-40$ & NTS03-4277-02 & 24.7 & 2.33 & 3.39 & 0.247 \\
\hline EPA 901.1 & $\mathrm{CO}-60$ & NTS03-4277-02 & -0.008 & 0.024 & 0.024 & 0.032 \\
\hline EPA 901.1 & Y-88 & NTS03-4277-02 & -0.002 & 0.015 & 0.015 & 0.027 \\
\hline EPA 901.1 & RU-106 & NTSO3-4277-02 & -0.164 & 0.160 & 0.161 & 0.263 \\
\hline EPA 901.1 & SB-125 & NTSO3-4277-02 & 0.016 & 0.047 & 0.047 & 0.079 \\
\hline EPA 901.1 & CS-134 & NTS03-4277-02 & -0.001 & 0.018 & 0.018 & 0.027 \\
\hline EPA 901.1 & CS-137 & NTS03-4277-02 & -0.006 & 0.019 & 0.019 & 0.032 \\
\hline EPA 901.1 & CE-144 & NTSO3-4277-02 & -0.718 & 2.01 & 2.01 & 0.234 \\
\hline EPA 901.1 & PM-144 & NTS03-4277-02 & -0.006 & 0.018 & 0.018 & 0.028 \\
\hline EPA 901.1 & $P M-146$ & NTS03-4277-02 & 0.012 & 0.023 & 0.023 & 0.039 \\
\hline EPA 901.1 & EU.152 & NTS03-4277-02 & 0.012 & 0.051 & 0.051 & 0.082 \\
\hline EPA 901.1 & EU-154 & NTS03-4277-02 & 0.000 & 0.000 & 0.000 & 0.057 \\
\hline EPA 901.1 & EU-155 & NTS03-4277-02 & 0.546 & 0.105 & 0.119 & 0.124 \\
\hline EPA 901.1 & PB-212 & NTS03-4277-02 & 1.74 & 0.512 & 0.540 & 0.051 \\
\hline EPA 901.1 & AC-228 & NTS03-4277-02 & 1.74 & 0.248 & 0.303 & 0.116 \\
\hline EPA 901.1 & TH-234 & NTS03-4277-02 & 1.22 & 0.444 & 0.461 & 0.517 \\
\hline EPA 901.1 & U-235 & NTS03-4277-02 & 0.196 & 0.052 & 0.056 & 0.041 \\
\hline EPA 901.1 & U.238 & NTS03-4277-02 & 1.68 & 3.40 & 3.40 & 5.89 \\
\hline EPA 901.1 & AM-241 & NTS03-4277-02 & -0.043 & 0.109 & 0.109 & 0.160 \\
\hline
\end{tabular}

\begin{tabular}{|c|c|c|c|c|}
\hline \multicolumn{5}{|c|}{ Quality Control Samples } \\
\hline Badionuclide & Laboratory Control (LC) & Laboratory Duplleate (L) & Matrix Splke (MS) & Preparation Plank (PB) \\
\hline
\end{tabular}


CLOSURE REPORT - CAU 330

Section: Appendix B

Revision: 0

Date: July 2003

\section{THIS PAGE INTENTIONALLY LEFT BLANK}


CLOSURE REPORT - CAU 330

Section: Appendix B

Revision: 0

Date: July 2003

\section{SAMPLE DELIVERY GROUP}

\section{V1755}


CLOSURE REPORT - CAU 330

Section: Appendix B

Revision: 0

Date: July 2003

\section{THIS PAGE INTENTIONALLY LEFT BLANK}


Marcos Dixon

Bechtel Nevada

P.O. Box $98521, \mathrm{M} / \mathrm{S}$ NTS273

Las Vegas, NV 89193-8521

TEL: (702) 295-4001

RE Project: CAU330

Order No.: L0210409

Dear Marcos Dixon:

NEL Laboratories, Las Vegas received 3 samples on 10/28/02 for the analyses presented in the following report.

There were no problems with the analyses and all data for associated QC met EPA or laboratory specifications unless noted in the Case Narrative.

If you have any questions regarding these tests results, please feel free to call.

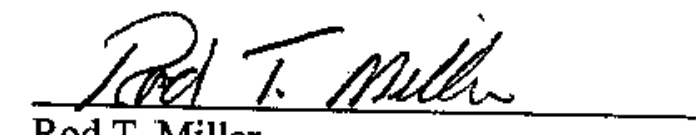

Rod T. Miller

Laboratory Director

Certifications:

Arizona

California

Idaho

Montana

Nevada

New Mexico
AZ0518
2002
Certified
Certified
NV052
Certified 
NEL Laboratories, Las Vegas

Date: $31-0 c t-02$

CLIENT: Bechtel Nevada

Project: CAU330

Lab Order: L L210409

CASE NARRATIVE

Attached are the analytical results for samples in support of the above referenced project.

The samples submitted for this project were not sampled by NEL. Should you have any questions or comments, please feel free to contact our Client Services Department.

Analytical Comments: None. 


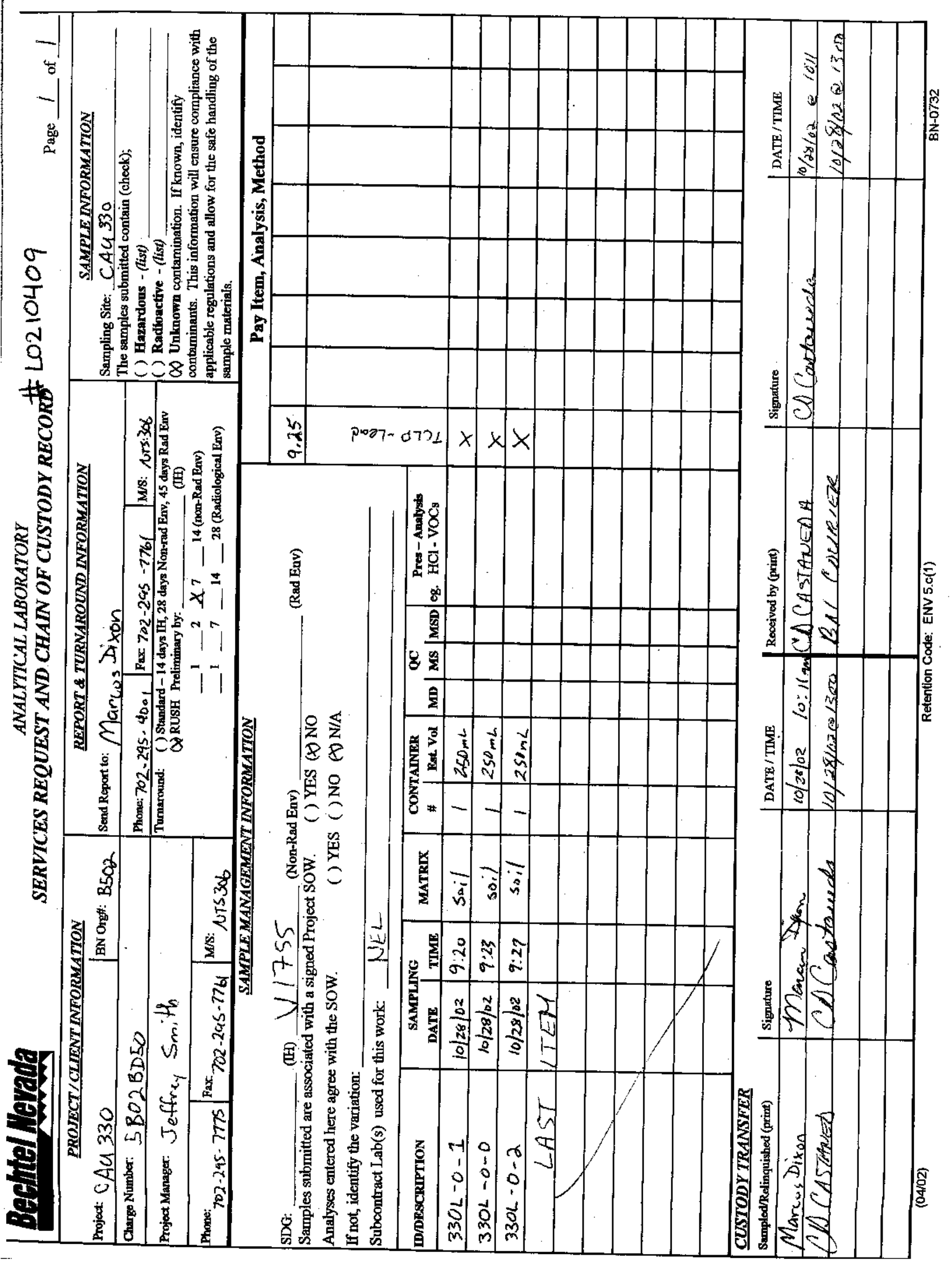


NEL LABORATORIES

$\begin{array}{lllc}\text { CLIENT: } & \text { Bechtel Nevada } & \text { CLIENT ID: } & \text { 330L-0-1 } \\ \text { PROJECT ID: } & \text { CAU330 } & \text { DATE SAMPLED: } 10 / 28 / 02 \\ \text { PROJECT \#: } & \text { B502 } & \text { NEL SAMPLE ID: } \text { L0210409-001A } \\ \text { MATRIX: } & \text { SOLID (TCLP) } & \end{array}$

$\frac{\text { Parameter }}{\text { Lead }} \quad \frac{\text { Result }}{0.77} \frac{\underline{\text { Units }}}{\mathrm{mg} / \mathrm{L}} \quad \frac{\underline{\text { Limit }}}{0.050} \quad \frac{\underline{D F}}{1} \quad \frac{\text { Method }}{\text { sW 6010B-Tot }} \quad \frac{\text { PrepDate }}{10 / 30 / 02} \quad \frac{\text { Analyzed }}{10 / 30 / 02} \quad \frac{\text { Analyst }}{\text { VVG-LV }}$

ND - Not Detected at the Reporting Limit DF - Dilution Factor

Date: $31-$ Oct -02
B - Analyte detected in the associated Method Blank

S. Spike Recovery outside accepted recovery limits

E - Value above quantitation range

Page 1 of 3 


\section{NEL LABORATORIES}

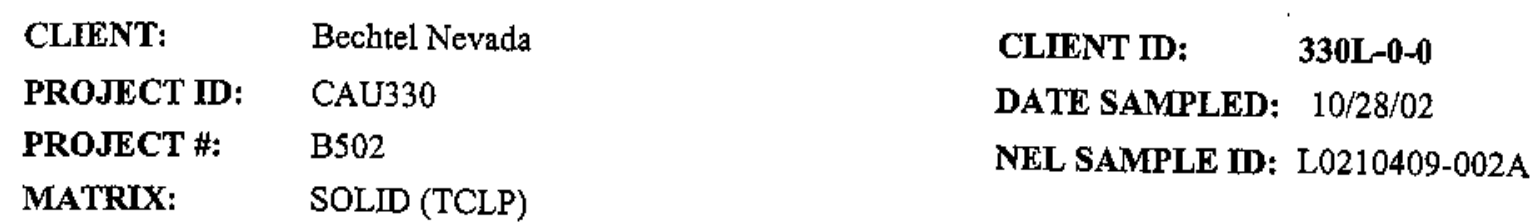

\section{Parameter}

Lead
Result Units

$1.2 \mathrm{mg} / \mathrm{L}$

\section{Reporting}

$\underline{\text { Limit }}$

0.050
DF Method Prep Date

1 SW 6010B-Tot
Analyzed

$10 / 30 / 02$
Analyst

VVG-LV

\footnotetext{
ND - Not Detected at the Reporting Limit DF - Dilution Factor
}

Date: $31-\mathrm{Oct}-02$
B - Analyte detected in the associated Method Blank

S - Spike Recovery outside accepted recovery limits

E - Value above quantitation range 
NEL LABORATORIES

$\begin{array}{lllc}\text { CLIENT: } & \text { Bechtel Nevada } & \text { CLIENT ID: } & \text { 330L-0-2 } \\ \text { PROJECT ID: } & \text { CAU330 } & \text { DATE SAMPLED: } 10 / 28 / 02 \\ \text { PROJECT \#: } & \text { B502 } & \text { NEL SAMPLE ID: } & \text { L0210409-003A } \\ \text { MATRIX: } & \text { SOLID (TCLP) } & \end{array}$

Parameter

Lead

\section{Reporting}

$\underline{\text { Result Units }}$

$0.62 \mathrm{mg} / \mathrm{L}$ $\underline{\text { Limit }}$

0.050 $\frac{\text { DF }}{1} \frac{\text { Method }}{\text { SW 6010B-Tot }} \frac{\text { Prep Date }}{10 / 30 / 02}$

Analyzed

10/30/02
Analyst

VVG-LV

\footnotetext{
ND - Not Detected at the Reporting Limit DF - Dilution Factor
}

Date: 31-Oct-02
B - Analyte detected in the associated Method Blank

S - Spike Recovery outside accepted recovery limits

$\mathrm{E}$ - Value above quantitation range 
CLOSURE REPORT - CAU 330

Section: Appendix B

Revision: 0

Date: July 2003

\section{SAMPLE DELIVERY GROUP}

1916 
CLOSURE REPORT - CAU 330

Section: Appendix B

Revision: 0

Date: July 2003

\section{THIS PAGE INTENTIONALLY LEFT BLANK}


Mr. Theodore Redding

Bechtel Nevada Corporation

2621 Losee Road

Mail Stop NTS273

Las Vegas, NV 89030-4134

RE: Subcontract No. 30028, Task Order No. 1

Data Report for LVL Batch 0303E928

SDG\#: V1916

Chain: Project CAU 330

Dear Mr. Redding:

Enclosed please find the data report for 18 soil samples received 12 March 2003 for analysis for TPH DRO/ORO on a 28 day turnaround time. The invoice is enclosed. An EDD is not required.

Please do not hesitate to contact me at (610) 280-3029 with any questions or at any time we may be of service.

Very truly yours,

Lionville Laboratory Incorporated

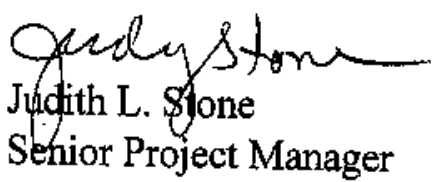

Enclosure: 


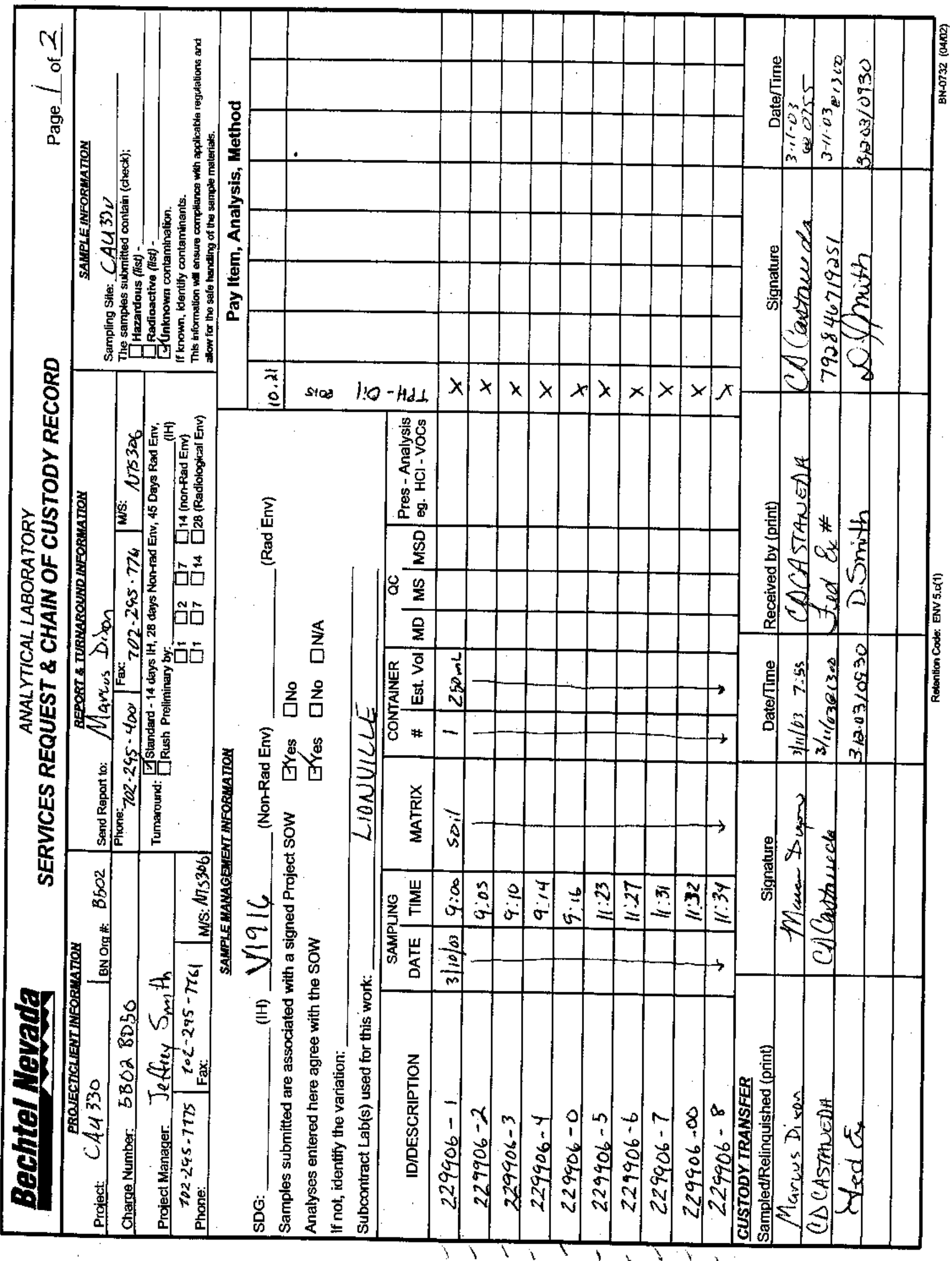




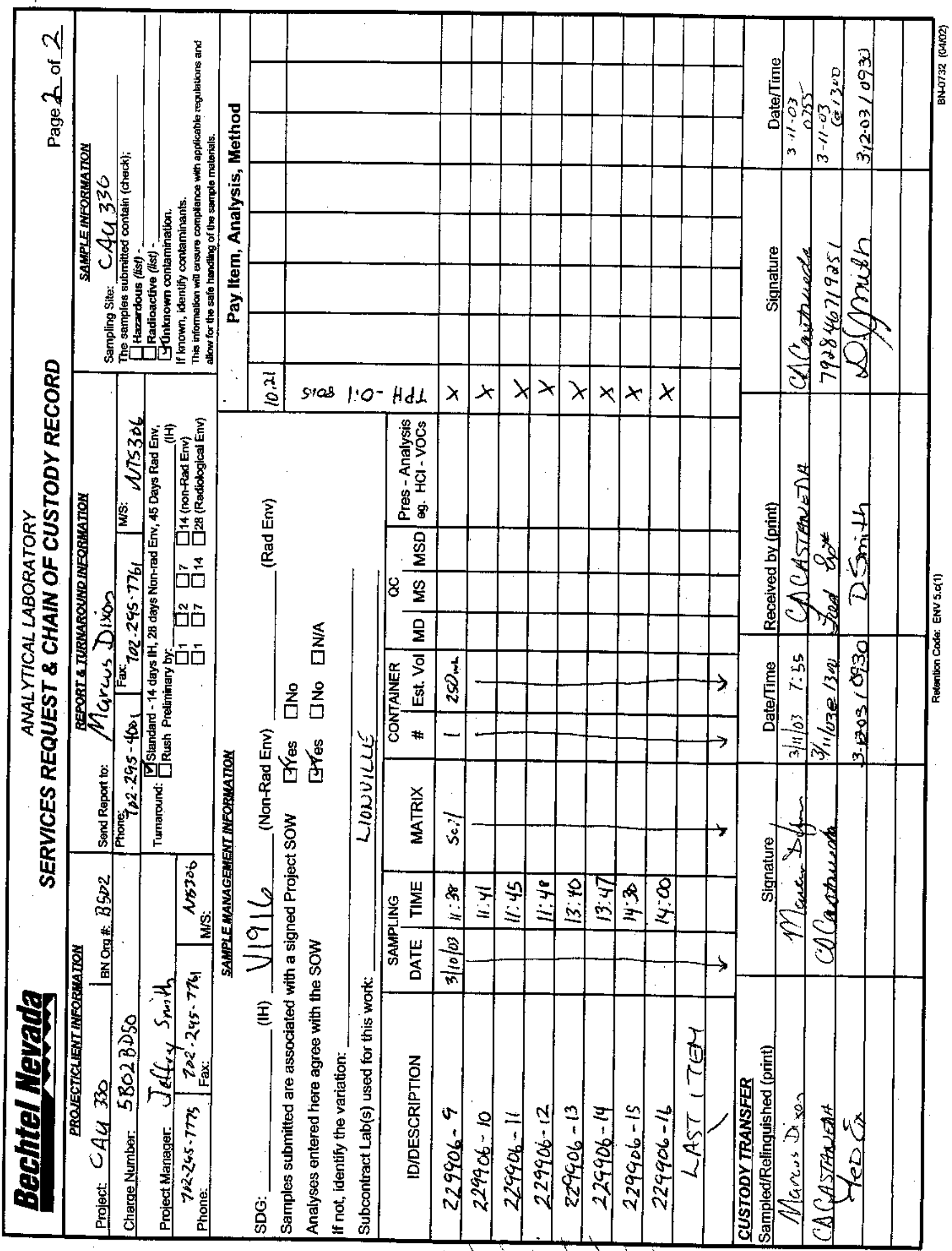


CASE NARRATIVE 


\section{$3 / V L I$ \\ LIONVIII. IABOKAIOKY INC.}

\section{Analytical Report}

Client: BECHTEL-NEVADA V1916

LVL \#: 0303L928

W.O. \#: 60052-001-001-0001-00

Date Received: 03-12-03

\section{DIESEL RANGE ORGANICS}

The set of samples consisted of eighteen (18) soil samples collected on 03-10-03.

The samples and their associated QC samples were extracted on 03-13-03 and analyzed according to Lionville Laboratory OPs on $03-15,23-24$. The extraction procedure was based on method 3540 and the extracts were analyzed based on method 8015B for Diesel Range Petroleum Hydrocarbons.

1. All results presented in this report are derived from samples that met LvLI's sample acceptance policy.

2. All required holding times for extraction and analysis have been met.

3. The method blank was below the reporting limits for all target compounds.

4. All surrogate recoveries were within acceptance criteria.

5. The blank spike recovery was within acceptance criteria.

6. All matrix spike recoveries were within acceptance criteria.

7. All initial calibrations associated with this data set were within acceptance criteria.

8. All continuing calibration standards analyzed prior to sample extracts were within acceptance criteria.

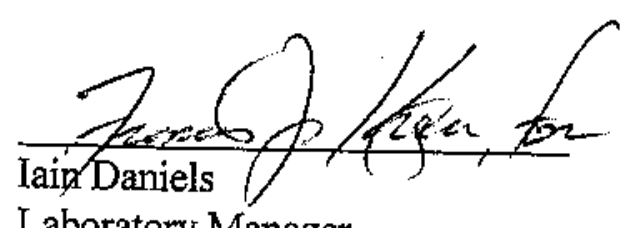

Laboratory Manager

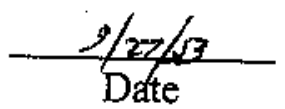

Lionville Laboratory Incorporated

peff::trouptatatdro'bechtel103L-928doc

The results presented in this report relate only to the analytical testing and conditions of the samples at receipt and during storage. 


\section{GLOSSARY OF DIESEL RANGE ORGANICS DATA}

\section{DATA QUALIFIERS}

$\mathbf{U}=$ Indicates that the compound was analyzed for but not detected. The minimum detection limit for the sample (not the method detection limit) is reported with the $\mathrm{U}$ (e.g., 10U).

$\boldsymbol{J}=\quad$ Indicates an estimated value. This flag is used in cases where a target analyte is detected at a level less than the lower quantification level. If the limit of quantification is $10 \mathrm{ug} / \mathrm{L}$ and a concentration of $3 \mathrm{ug} / \mathrm{L}$ is calculated, it is reported as $3 J$.

B = This flag is used when the analyte is found in the associated blank as well as in the sample. It indicates possible/probable blank contamination.

$\mathbf{E}=$ Indicates that the compound was detected beyond the calibration range and was subsequently analyzed at a dilution.

I $=$ Interference.

\section{ABBREVIATIONS}

BS = Indicates blank spike in which reagent grade water is spiked with the CLP matrix spiking solutions and carried through all the steps in the method. Spike recoveries are reported.

BSD = Indicates blank spike duplicate.

MS $=$ Indicates matrix spike.

MSD $=$ Indicates matrix spike duplicate. DL = Indicates that recoveries were not obtained because the extract had to be diluted for
analysis.

NA $=$ Not Applicable.

DF $=$ Dilution Factor.

NR $=$ Not Required.

SP $=$ Indicates Spiked Compound. 


\section{GLOSSARY OF DIESEL RANGE ORGANICS DATA}

D = This flag identifies all compounds identified in an analysis at a secondary dilution factor.

C $=$ This flag applies to a compound that has been confirmed by GC/MS. 
SAMPLE DATA FOR EACH SAMPLE 
Lab Name: Lionville Labs, Inc. Work Order: 60052001001

Client: BECHTEL NEVADA V1916

Matrix:

SOIL

$\underline{25.0}(\mathrm{~g} / \mathrm{mL}) \underline{\mathrm{G}}$

Sample wt/vol:

Level: $\quad$ (low/med) LOW

s Moisture: not dec.

3

Column: (pack/cap) CAP
Lab Sample ID: $03031928-001$

Iab File ID: BLKIACHJ

Date Received: $\quad 03 / 12 / 03$

Date Analyzed: $03 / 15 / 03$

Dilution Factor: 1,00

CONCENTRATION UNITS : (ug/L or $u g / \mathrm{Kg}) \mathrm{mg} / \mathrm{kg}$
CAS NO.

COMPOUND

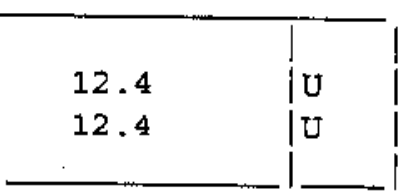

12/88 Rev. 
ORGANICS ANALYSIS SHEET

Lab Name: Lionville Labs. Inc. Work Order: 60052001001

Client: BECHTEL NEVADA V1926

Matrix: $\quad$ SOIL

Sample wt/vol: $\quad \underline{25.0}(\mathrm{~g} / \mathrm{mL}) \mathrm{G}$

Level: (low/med) LOW

\%oisture: not dec. 3

Column: (pack/cap) CAP

CAS NO.

COMPOUND
CLIENT SAMPLE NO.

$229906-2$

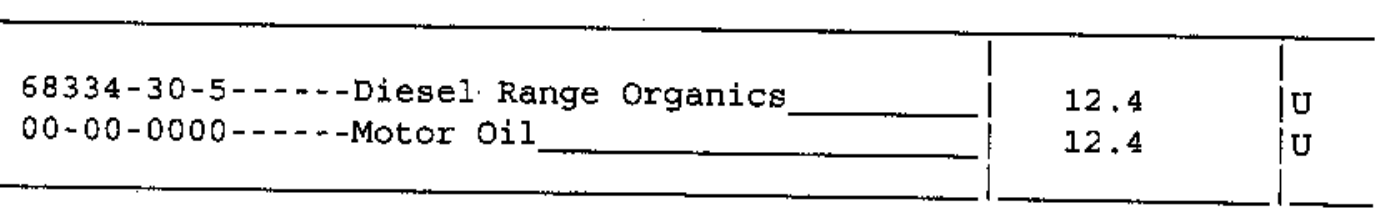

12/88 Rev. 
Lab Name: Lionville Labs, Inc. Work Order: 60052001001

Client: BECHTEL NEVADA V1916

Matrix:

SQIL

$25.0(\mathrm{~g} / \mathrm{mL}) \mathrm{G}$

Sample wt/vol:

Level: (low/med) LOW

\& Moisture: not dec. 2

Column: (pack/cap) CAP
Lab Sample ID: 0303L928-003

Lab File ID: BLKLACHJ

Date Received: $03 / 12 / 03$

Date Aralyzed: $03 / 15 / 03$

Dilution Factor: 1.00

CONCENTRATION UNITS:

CAS NO.

(ug/L or $\mathrm{ug} / \mathrm{kg}$ ) mg/kg

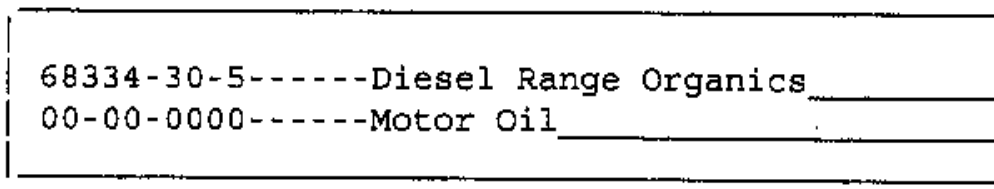

12.2

12.2

12/88 Rev. 
ORGANICS ANALYSIS SHEET

Lab Name: Lionville Labs, Inc, work Order: 60052001001

Client: BECHTEL NEVADA V1916

Matrix:

SOIL

Lab Sample ID: 0303L928-004

Sample wt/vol: $\underline{25.0}(\mathrm{~g} / \mathrm{mL}) \mathrm{G}$

Level: (low/tned) LOW

Lab. File ID:

Date Received: $03 / 12 / 03$

\& Moisture: not dec. 5

Column: (pack/cap) CAP

CAS NO.

COMPOUND

Date Analyzed: $\underline{03 / 15 / 03}$

Dilution Factor: 1.00

CONCENTRATION UNITS:

(ug/L or $\mathrm{ug} / \mathrm{Kg}$ ) $\mathrm{mg} / \mathrm{kg}$
CLIENT SAMPLE NO.

229906-4

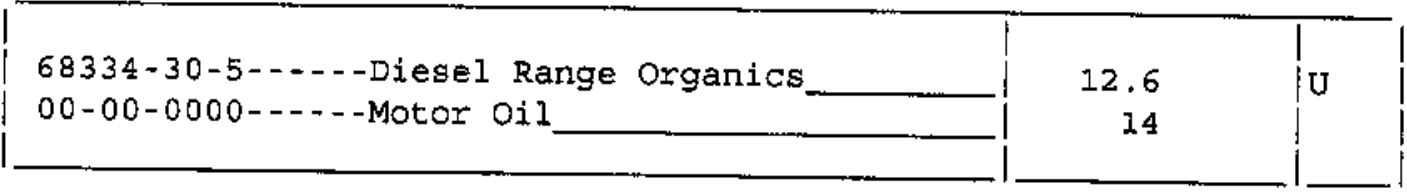

12/88 Rev. 
Lab Name: Lionville Labs, Inc, Work Order: 60052001001

Client: BECHTEL NEVADA V1916

Matrix:

Sample wt/vol:

Level: $\quad$ (low/med) ILOW

s Moisture: not dec. 5

Column: (pack/cap) CAP

CAS NO.

COMPOUND
Lab Sample ID: 0303L928-005

Lab File ID:

BIKLACHJ

Date Received: $03 / 12 / 03$

Date Analyzed: $\underline{03 / 15 / 03}$

Dilution Factor: 1.00

CONCENTRATION UNITS :

(ug/L or $\mathrm{ug} / \mathrm{Kg}$ ) $\mathrm{mg} / \mathrm{kg}$

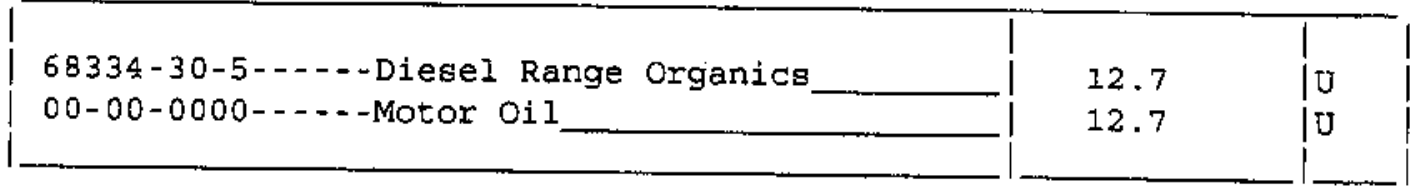

$12 / 88$ Rev. 
ORGANICS ANALYSIS SHEET

Lab Name: Lionville Labs. Inc. Work Order: 60052001001

Client: BECHTEL NEVADA V1916

Matrix:

SOTI

Lab Sample ID: 0303L928-006

Sample wt/vol: $\underline{25.0}(\mathrm{~g} / \mathrm{mI}) \mathrm{G}$

Level: (low/med) LOW 3

\% Moisture: not dec.

Column: (pack/cap) CAP

CAS NO.

COMPOUND

Lab File ID: BLKLACHJ

Date Received: 03/12/03

Date Analyzed: $\underline{03 / 15 / 03}$

Dilution Factor: 1.00

CONCENTRATION UNITS :

(ug/L or ug/ $\mathrm{kg}$ ) $\mathrm{mg} / \mathrm{kg}$
CLIENT SAMPLE NO.

229906-5

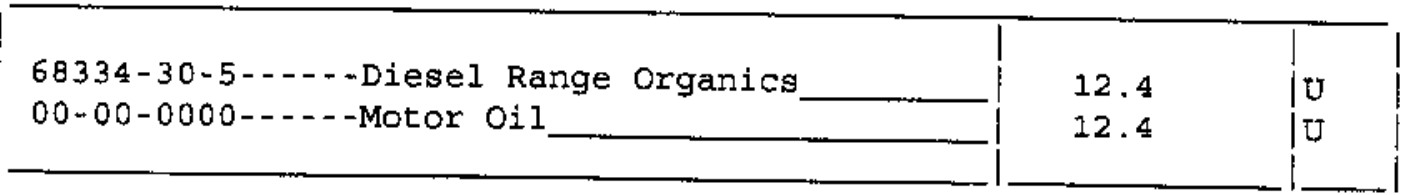

12/88 Rev. 
Lab Name: Lionville Labs, Inc, Work Order: 60052001001

Client: BECHTEL NEVADA V1916

Matrix:

SOIL

$25.0(\mathrm{~g} / \mathrm{mL}) \mathrm{G}$

Sample wt/vol:

Level: (low/med) LOW

Moisture: not dec. 3

Column: (pack/cap) CAP'
Lab Sample ID: 0303L928-007

Lab File ID: BLKLACHU

Date Received: $03 / 12 / 03$

Date Analyzed: $03 / 15 / 03$

Dilution Factor: 1.00

CAS NO.

COMPOUND

CONCENTRATION UNITS:

(ug/L or $\mathrm{ug} / \mathrm{kg}$ ) $\mathrm{mg} / \mathrm{kg}$

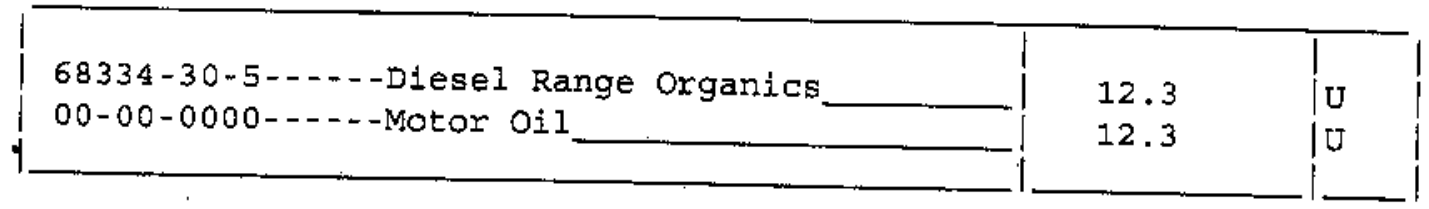

12/88 Rev. 
Lab Name: Lionville Labs, Inc. Work Order: 60052001001 229906-7

Client: BECHTEL NEVADA V1916

Matrix :

SOIL

$25.0 \quad(\mathrm{~g} / \mathrm{mL}) \mathrm{G}$

Sample wt/vol:

(low/med) LOW

3

\% Moisture: not dec.

Column: (pack/cap) CAP

CAS NO.

COMPOUND
Lab Sample ID: 03032928-008

Lab File ID: BLKIACHJ

Date Received: $03 / 12 / 03$

Date Analyzed: $03 / 24 / 03$

Dilution Factor: 1,00

CONCENTRATION UNITS:

(ug/L or $u g / \mathrm{Kg}$ ) $\mathrm{mg} / \mathrm{kg}$

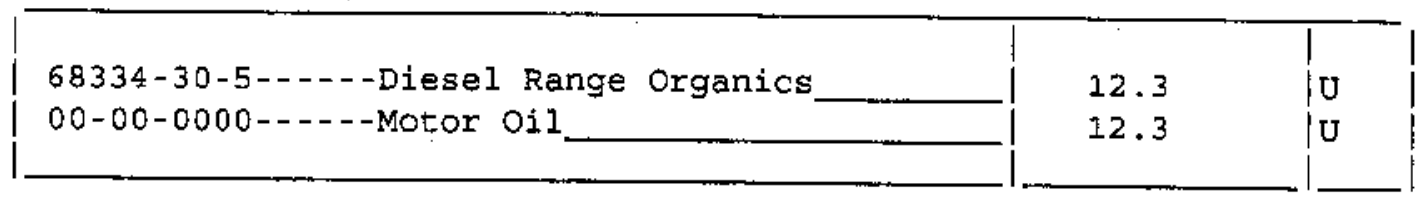

12/88 Rev. 


\section{ORGANICS ANALYSIS SHEET}

Lab Name: Lionville Labs, Inc. Work Order: 60052001001

Client: BECHTEL NEVADA V1916

Matrix :

Sample wt/vol:

Level: (low/med) IOW

\%oisture: not dec.

Column: (pack/cap) CAP
SOIL

$\underline{25.0}(\mathrm{~g} / \mathrm{mL}) \mathrm{G}$

2

CAS NO.
COMPOUND
Lab Sample ID: 0303L928-009

Iab File ID: BLKLACHJ

Date Received: $03 / 22 / 03$

Date Analyzed: $\underline{03 / 24 / 03}$

Dilution Factor: 1.00
CONCENTRATION UNITS: (ug/L or $\mathrm{ug} / \mathrm{Kg}$ ) $\mathrm{ma} / \mathrm{kg}$

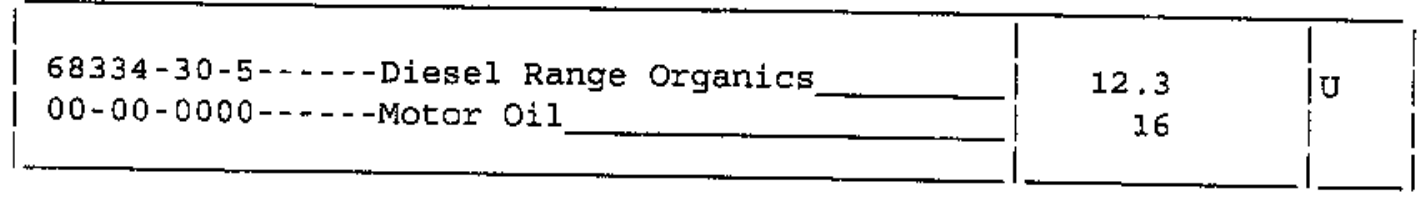

12/88 Rev. 


\section{ORGANICS ANALYSIS SHEET}

Lab Name: Lionville Labs. Inc. Work Order: 60052001001
CLIENT SAMPLE NO.

Client: BECHTEL NEVADA V1916

Matrix:

SOIL

$\underline{25.0} \cdot(\mathrm{g} / \mathrm{mL}) \mathrm{G}$

Sample wt/vol:

(low/med) . LOW

Level:

\% Moisture: not dec.

Column: (pack/cap) CAP

CAS NO.

COMPOUND

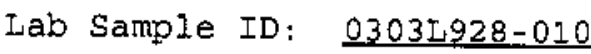

Lab File ID: BLKLACHJ

Date Received: $\quad 03 / 12 / 03$

Date Analyzed: $03 / 24 / 03$

Dilution Factor: 1.00

CONCENTRATION UNITS:

(ug/L or $u g / \mathrm{Kg}$ ) $\mathrm{mg} / \mathrm{kg}$

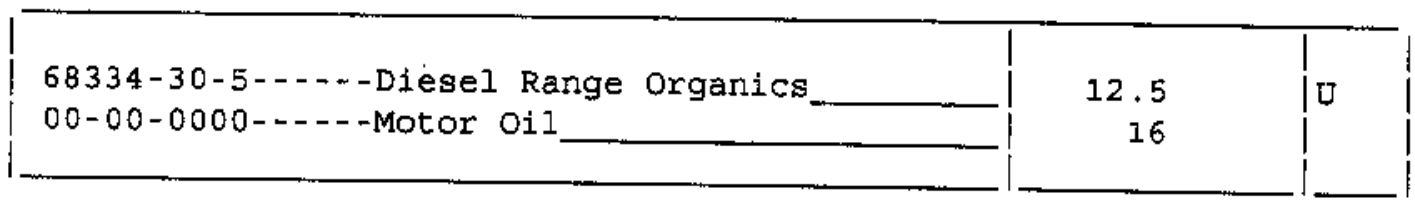

12/88 Rev. 
Lab Name: Lionville Labs, Inc, work order: 60052001001

Client: BECHTEL NEVADA V1916

Matrix:

SOIL

$25.0(\mathrm{~g} / \mathrm{mL}) \mathrm{G}$

Sample wt/vol:

(low $/ \mathrm{med}$ )

LOW

\&oisture: not dec. 4

Column: (pack/cap) CAP

CAS NO.

COMPOUND
Lab Sample ID: 0303L928-011

Lab File ID: BLKLACHJ

Date Received: $\quad 03 / 12 / 03$

Date Aralyzed: $03 / 24 / 03$

Dilution Factor: 1.00

CONCENTRATION UNITS: (ug/L or $\mathrm{ug} / \mathrm{Kg}$ ) $\mathrm{mg} / \mathrm{kg}$

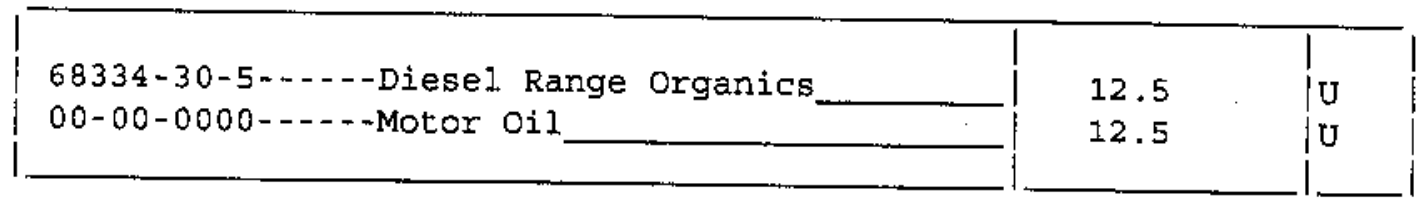

12/88 Rev. 


\section{ORGANICS ANALYSIS SHEET}

Lab Name: Lionville Labs, Inc. Work Order: 60052001001
CIIENT SAMPLE NO.

$$
\text { 229906-10 }
$$

\section{Client: BECHTEL NEVADA V1916}

Matrix:

SOIL

Sample wt/vol:

$\underline{25.0}(\mathrm{~g} / \mathrm{mL}) \mathrm{G}$

Level: (low/med) LOW

\% Moisture: not dec.

Column: (pack/cap) CAP

COMPOUND

Lab Sample ID: 0303L928-012

Lab File ID:

BLKLACHJ

Date Received: $0.3 / 12 / 03$

Date Analyzed: 03/23/03

Dilution Factor: 1,00
CONCENTRATION UNITS: (ug/L or $\mathrm{ug} / \mathrm{Kg}$ ) $\mathrm{ma} / \mathrm{kg}$

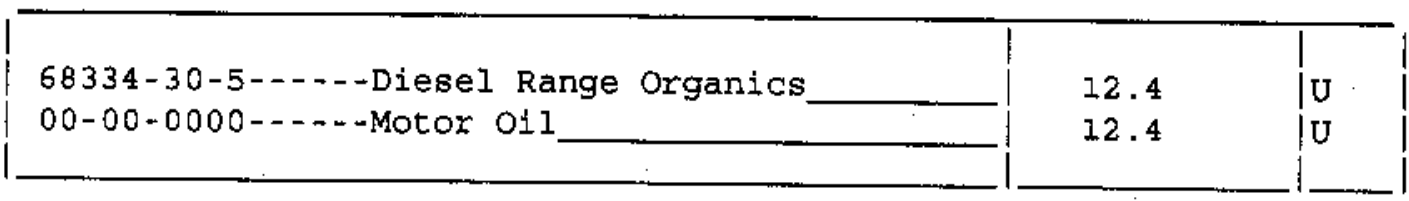

12/88 Rev. 
ORGANICS ANALYSIS SHEET

Lab Name: Lionville Labs, Inc, Work order: 60052001001

Client: BECHTEL NEVADA V1916

Matrix:

SOIL

$25.0 \quad(\mathrm{~g} / \mathrm{mL}) \mathrm{G}$

Sample wt/vol:

Level: (low/med) LOW

$\%$ Moisture: not dec.

5

Column: (pack/cap) CAP

CAS NO.

COMPOUND
Lab Sample ID: 0303L928-013.

Lab File ID: BLKLACHJ

Date Received: $\underline{03 / 12 / 03}$

Date Analyzed: $23 / 23 / 03$

Dilution Factor: 1.00

CONCENTRATION UNITS:

(ug/ $\mathrm{L}$ or $\mathrm{ug} / \mathrm{Kg}$ ) $\mathrm{mg} / \mathrm{kg}$

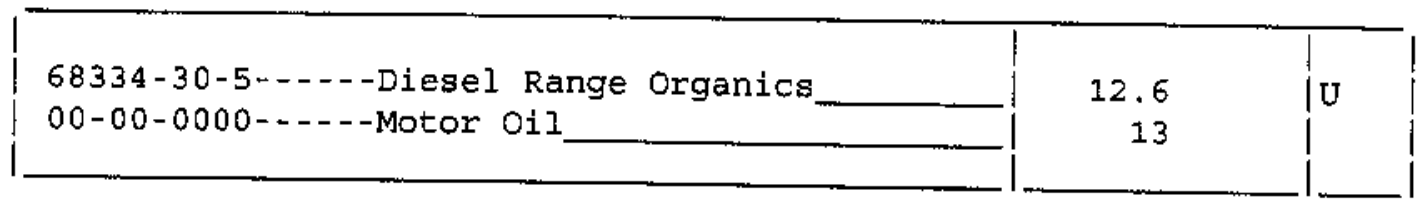

$12 / 88$ Rev. 
Lab Name: Lionville Labs, Inc. Work Order: 60052001001

Client: BECHTEL NEVADA V1916

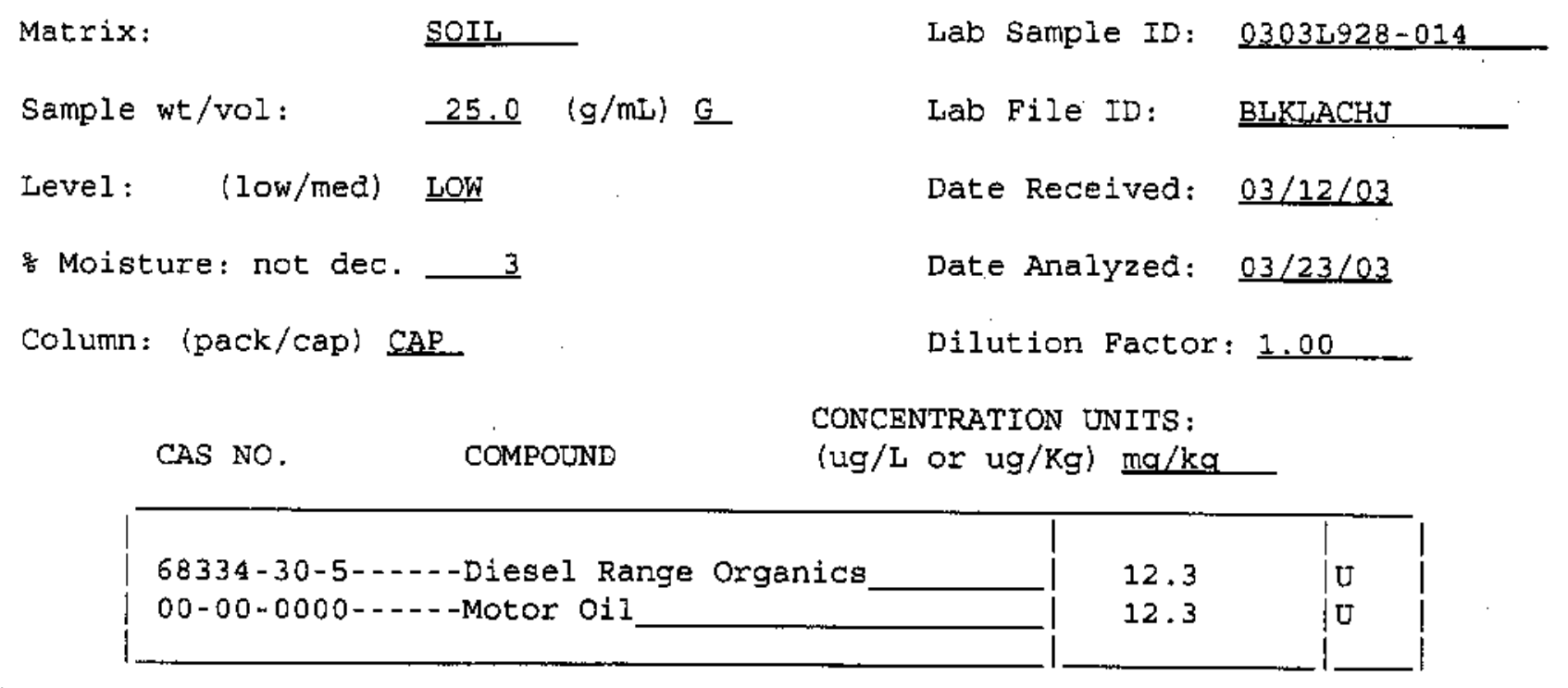

$12 / 88$ Rev. 
Lab Name: Lionville Labs, Inc. Work Order: 60052001001

Client: BECHTEL NEVADA V1916

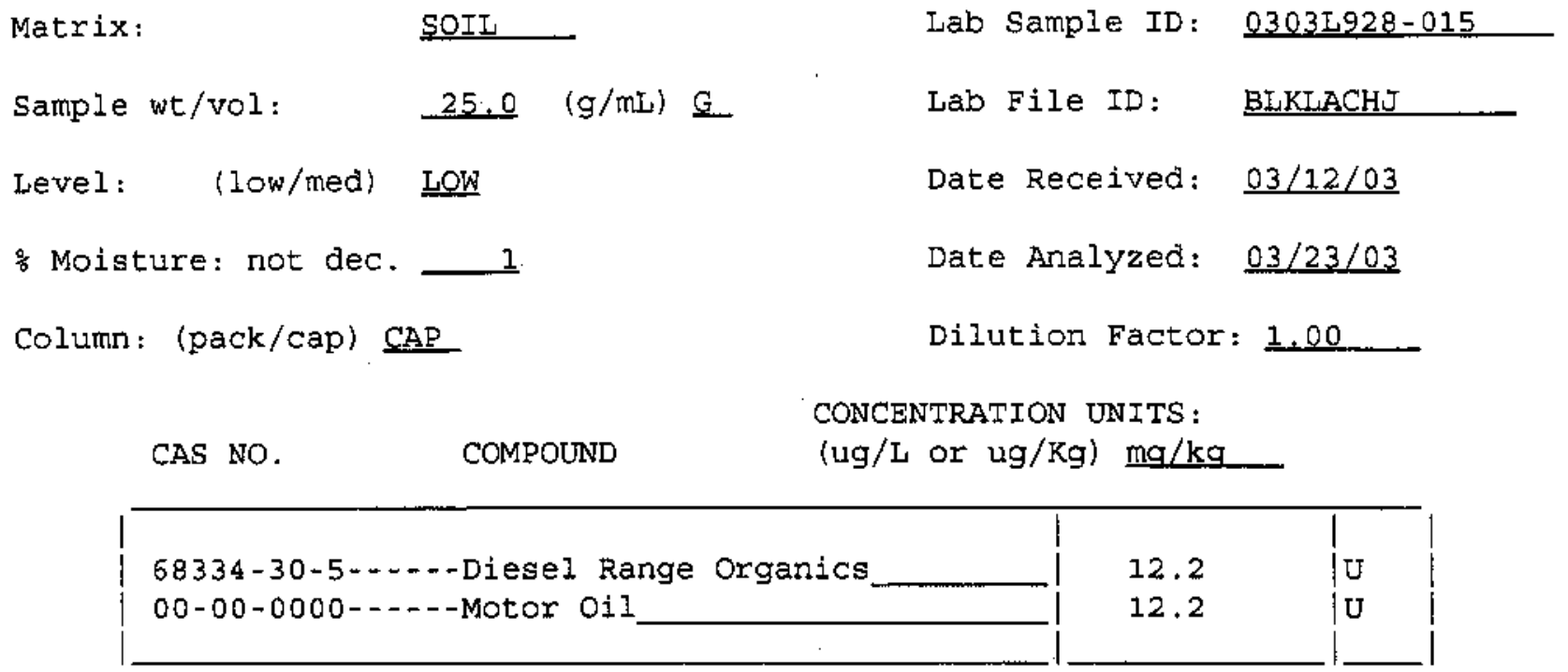

$12 / 88$ Rev. 


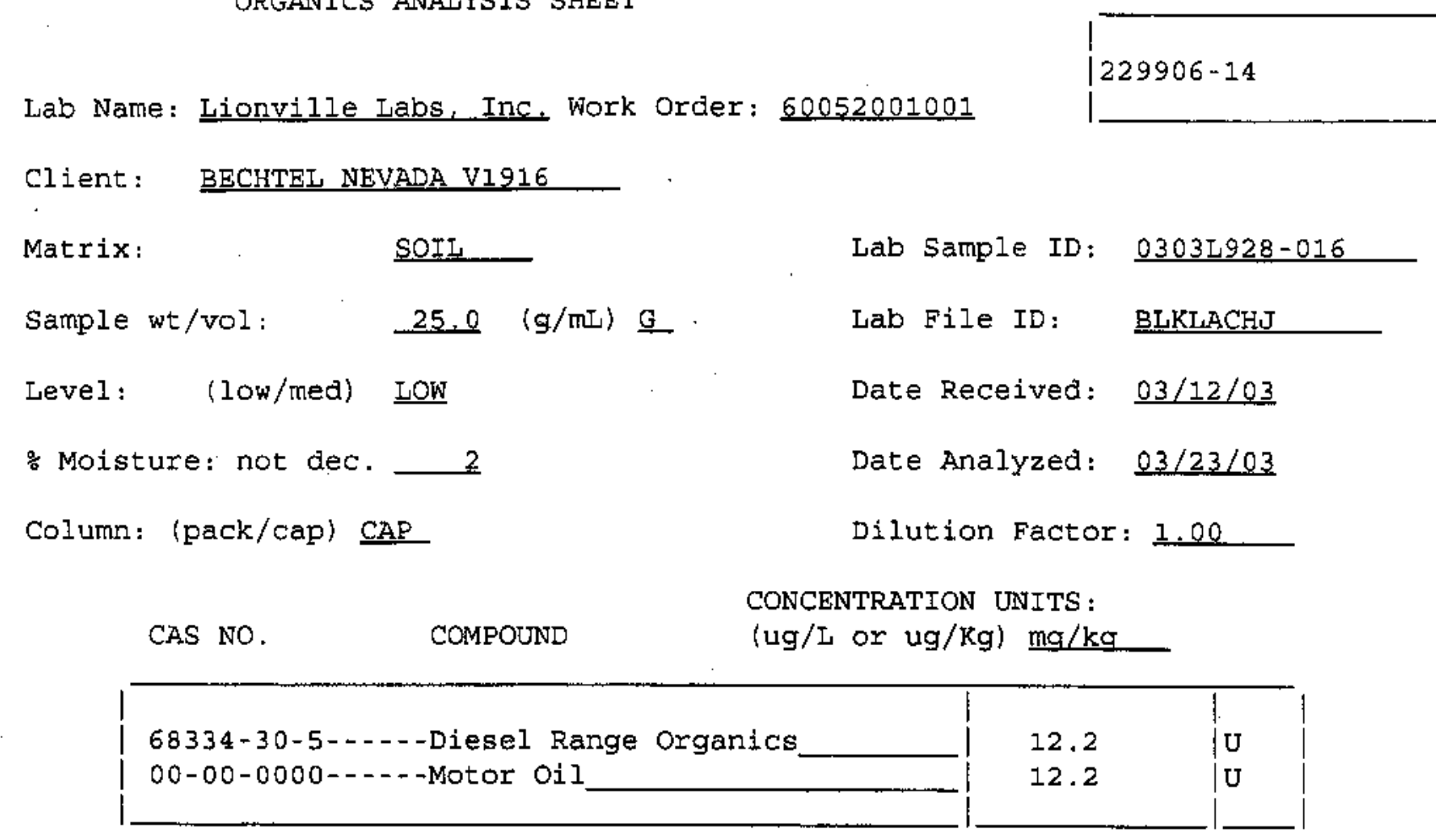

12/88 Rev. 
Lab Name: Lionville Labs...Inc. Work Order: 60052001001

$$
\text { 229906-15 }
$$

Client: BECHTEL NEVADA V1916

Matrix:

SOII

Sample wt/vol: $\underline{25.0}(\mathrm{~g} / \mathrm{mL}) \underline{G}$

Level:

(10w/med) LOW

\% Moisture: not dec. 3

Column! (pack/cap) CAP

CAS NO.

COMPOUND
Lab Sample ID: 0303I928-017

Lab File ID: BLKLACHJ

Date Received: $\underline{03 / 12 / 03}$

Date Analyzed: $03 / 23 / 03$

Dilution Factor: 1.00

CONCENTRATION UNITS :

$(u g / \mathrm{L}$ or $u g / \mathrm{Kg}) \mathrm{mg} / \mathrm{kg}$

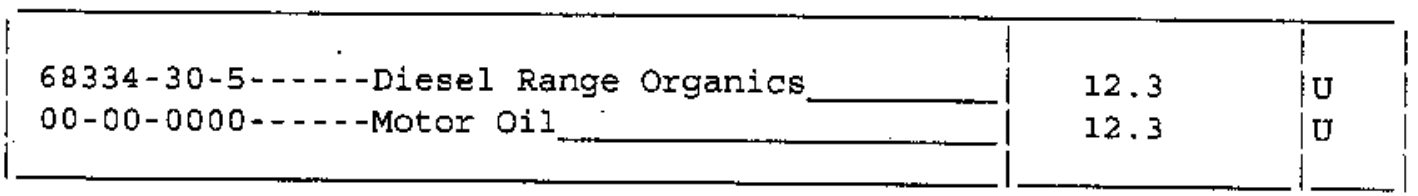

$12 / 88$ Rev. 
Lab Name: Itonville Labs, Inc. Work Order: 60052001001

\section{6-16}

Client: BECHTEL NEVADA V1916

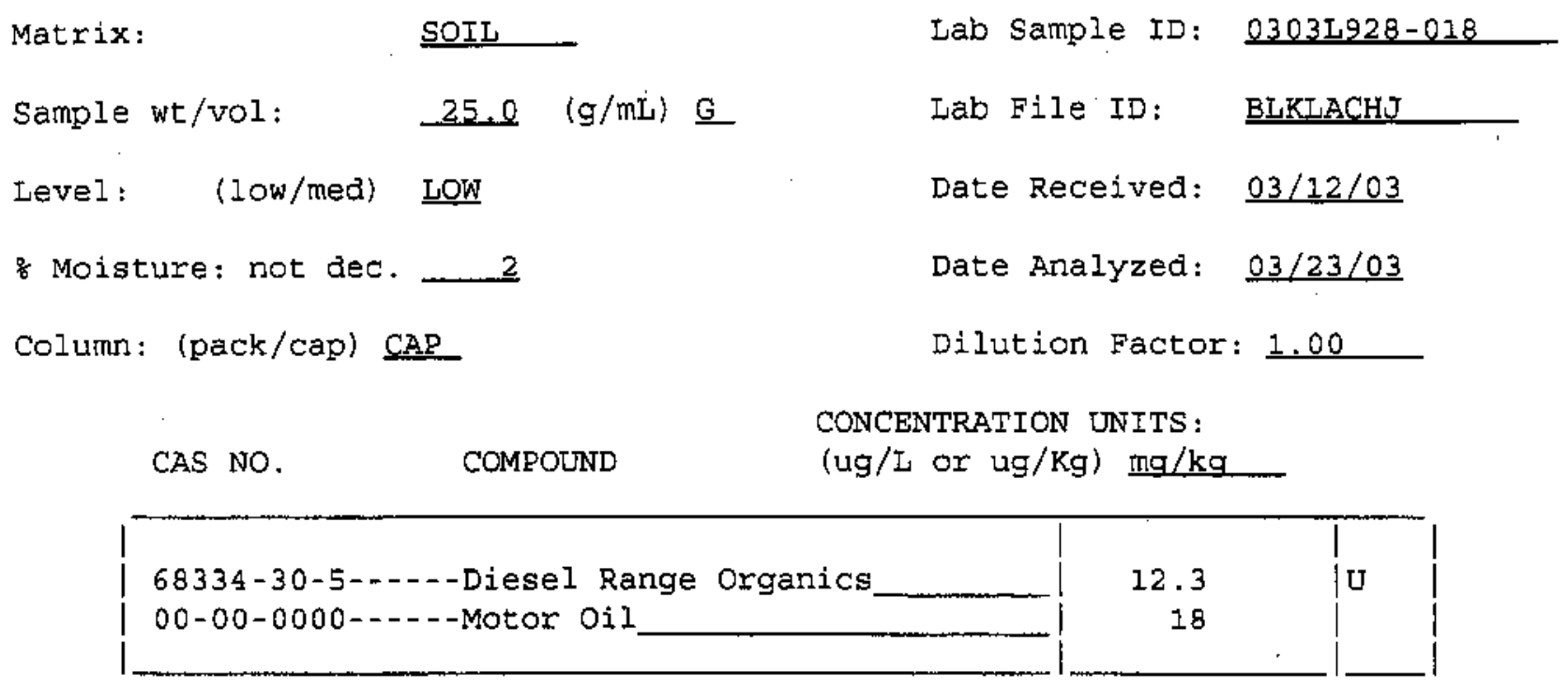

12/88 Rev. 
CLOSURE REPORT - CAU 330

Section: Appendix B

Revision: 0

Date: July 2003

\section{SAMPLE DELIVERY GROUP}

V1926 
CLOSURE REPORT - CAU 330

Section: Appendix B

Revision: 0

Date: July 2003

\section{THIS PAGE INTENTIONALLY LEFT BLANK}




\section{( $)$}

26 March 2003

Mr. Theodore Redding

Bechtel Nevada Corporation

2621 Losee Road

Mail Stop NTS273

Las Vegas, NV 89030-4134

RE: Subcontract No. 30028, Task Order No. 1

Data Report for LVL Batch 0303L968

SDG\#: V1926 Chain: Project CAU 330

Dear Mr. Redding:

Enclosed please find the data report for 10 soil samples received 18 March 2003 for analysis for TPH GRO and TPH DRO/ORO on a 7 day turnaround time. The invoice is enclosed. An EDD is not required. Data were faxed 25 March.

Please do not hesitate to contact me at (610) 280-3029 with any questions or at any time we may be of service.

Very truly yours,

Lionville Laboratory Incorporated

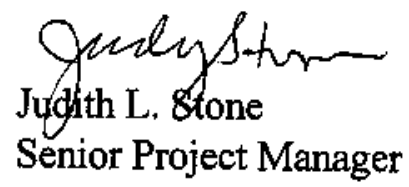

Enclosure: 


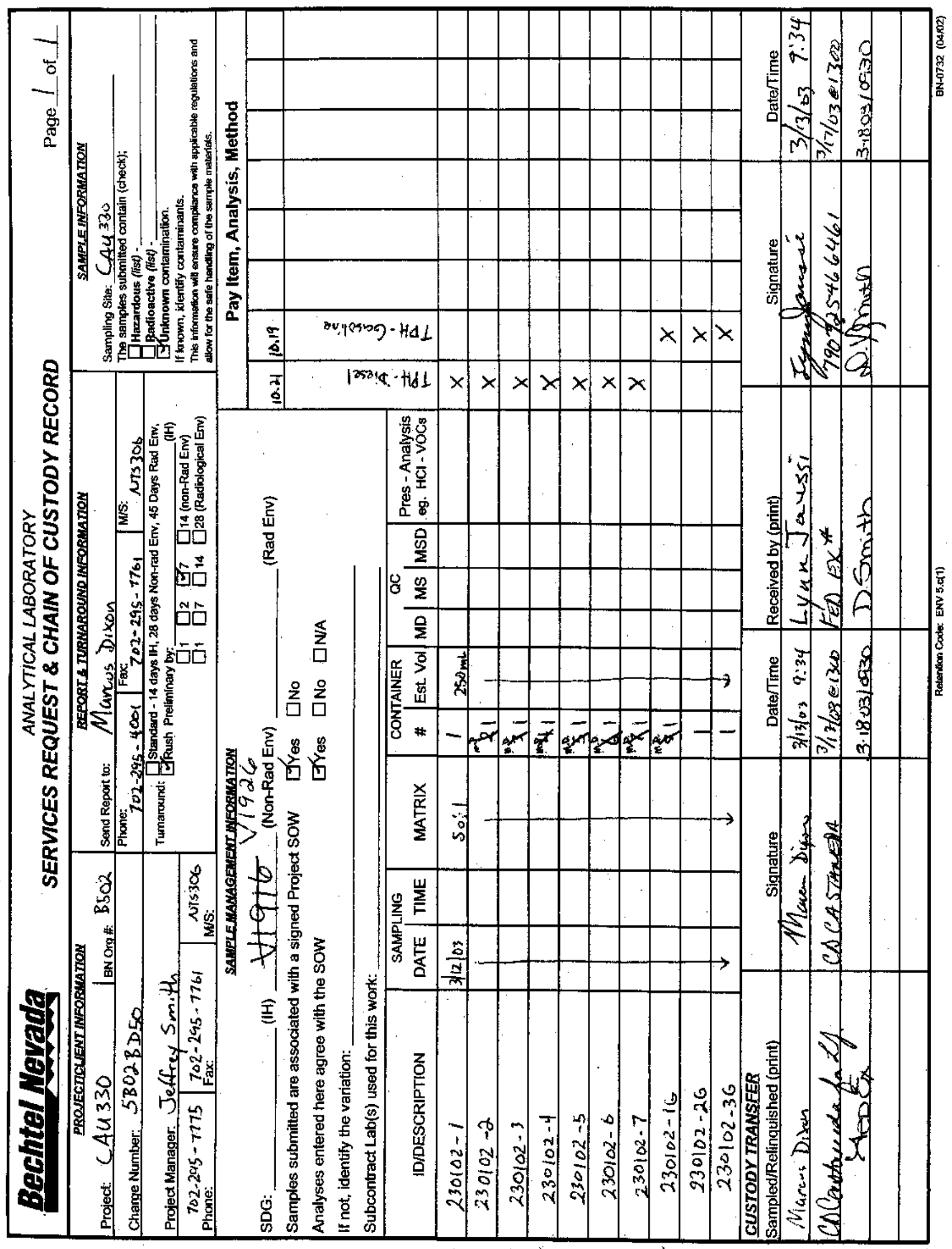


CASE NARRATIVE 


\section{Analytical Report}

LONVILLE LABORATORY INC.

Client: BECHTEL-NEVADA V1926

W.o. \#: 60052-001-001-0001-00

LVL \#: 0303L968

Date Received: 03-18-2003

\section{DIESEL RANGE ORGANICS}

Seven (7) soil samples were collected on 03-12-2003.

The samples and their associated QC samples were extracted on 03-18-2003 and analyzed according to Lionville Laboratory OPs on $03-22,23-2003$. The extraction procedure was based on method 3540 and the extracts were analyzed based on method 8015B for Diesel Range Petroleum Hydrocarbons.

1. All results presented in this report are derived from samples that met LvLI's sample acceptance policy.

2. The required holding time for extraction and analysis has been met.

3. The method blank was below the reporting limits for all target compounds.

4. All surrogate recoveries were within acceptance criteria.

5. The blank spike recovery was within acceptance criteria.

6. The matrix spike recoveries were within EPA QC limits.

7. All initial calibrations associated with this data set were within acceptance criteria.

8. All continuing calibration standards analyzed prior to sample extracts were within acceptance criteria.

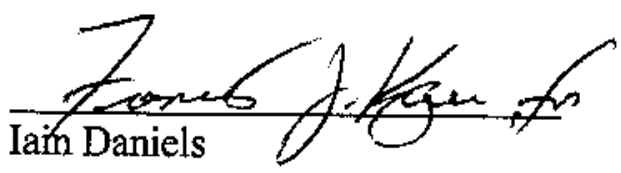

Laboratory Manager

Lionville Laboratory Incorporated

somir: itroupldataidroibechtel: $0303-968$. doc

The resuits presented in tivis report relate only to the analytical testing and conditions of the samples at receipt and during storage. 


\section{GLOSSARY OF DIESEL RANGE ORGANICS DATA}

\section{DATA QUALIFIERS}

$\mathbf{U}=$ Indicates that the compound was analyzed for but not detected. The minimum detection limit for the sample (not the method detection limit) is reported with the $\mathrm{U}$ (e.g., 10U).

$\mathbf{J}=$ Indicates an estimated value. This flag is used in cases where a target analyte is detected at a level less than the lower quantification level. If the limit of quantification is $10 \mathrm{ug} / \mathrm{L}$ and a concentration of $3 \mathrm{ug} / \mathrm{L}$ is calculated, it is reported as $3 \mathrm{~J}$.

B $=$ This flag is used when the analyte is found in the associated blank as well as in the sample. It indicates possible/probable blank contamination.

$\mathbf{E}=$ Indicates that the compound was detected beyond the calibration range and was subsequently analyzed at a dilution.

I $=$ Interference.

\section{ABBREVIATIONS}

BS = Indicates blank spike in which reagent grade water is spiked with the CLP matrix spiking solutions and carried through all the steps in the method. Spike recoveries are reported.

BSD = Indicates blank spike duplicate.

MS $=$ Indicates matrix spike.

MSD $=$ Indicates matrix spike duplicate.

DL = Indicates that recoveries were not obtained because the extract had to be diluted for analysis.

$\mathbf{N A}=$ Not Applicable.

DF $=$ Dilution Factor.

$\mathbf{N R}=$ Not Required.

SP $=$ Indicates Spiked Compound. 


\section{GLOSSARY OF DIESEL RANGE ORGANICS DATA}

D $=$ This flag identifies all compounds identified in an analysis at a secondary dilution factor.

C = This flag applies to a compound that has been confirmed by GC/MS. 
SAMPLE DATA FOR EACH SAMPLE 
Lab Name: Lionville Labs, Inc. Work Order: 60052001001

Client: BECHTEL NEVADA V1926

Matrix:

SOIL

Sample wt/vol:

$25.0(\mathrm{~g} / \mathrm{mL}) \mathrm{G}$

Level: (low/med) LOW

Moisture: not dec. 3

Column: (pack/cap) CAP

CAS NO.

COMPOUND
Lab Sample ID: 0303L968-001

Lab File ID: BLKLACHJ

Date Received: $03 / 18 / 03$

Date Analyzed: 03/22/03

Dilution Factor: 1,00

CONCENTRATION UNITS :

(ug/L or $\mathrm{ug} / \mathrm{kg}$ ) $\mathrm{mg} / \mathrm{kg}$

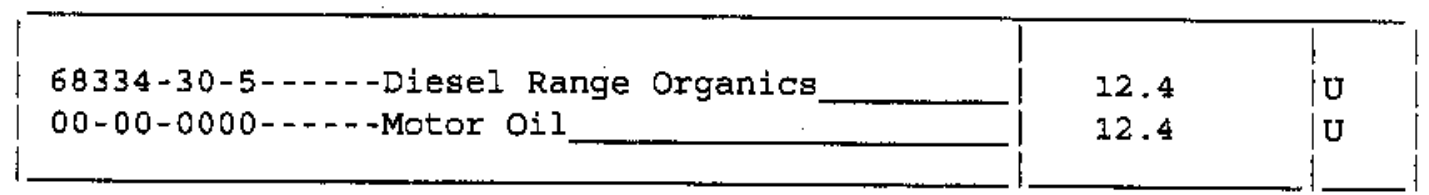

$12 / 88$ Rev. 
Lab Name: Lionville Labs, Inc. Work Order: 60052001001

Client: BECHTEL NEVADA V1226

Matrix:

SOIL

Lab Sample ID: 0303L968-002

Sample wt/vol:

$\underline{25.0}(\mathrm{~g} / \mathrm{mL}) \mathrm{G}$

Lab File ID

BIKLACHJ

Level: (low/med) LOW

Date Receivea: $\quad \underline{03 / 18 / 03}$

\& Moisture: not dec.

5

Date Analyzed: $\quad \underline{03 / 22 / 03}$

Column: (pack/cap) CAP

Dilution Factor: 1.00

CONCENTRATION UNITS:

CAS NO.

COMPOUND

(ug/L or $\mathrm{ug} / \mathrm{Kg}$ ) $\mathrm{mg} / \mathrm{kg}$

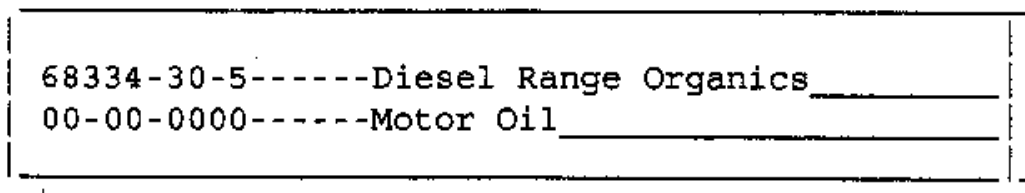

12.6

12.6

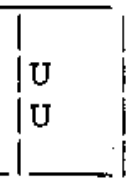

$12 / 88$ Rev. 


\section{ORGANICS ANALYSIS SHEET}

Lab Name: Lionville Labs. Inc. Work order: 60052001001
CLIENT SAMPLE NO.

$$
\text { 230102-3 }
$$

Client: BECHTEL NEVADA V1926

Matrix:

SOIJ

Lab Sample ID: 0303L968-003

Sample $\omega t / v o l:$

$25.0(\mathrm{~g} / \mathrm{mL}) \underline{\mathrm{G}}$

Lab File ID:

BLKLACHJ

Level: (low/med) LOW

Date Received: $\underline{03 / 18 / 03}$

늠 Moisture: not dec.

Date Analyzed: $\underline{03 / 22 / 03}$

Column: (pack/cap) CAP

Dilution Factor: 1.00

CONCENTRATION UNITS:

CAS NO.

COMPOUND

(ug/L or $\mathrm{ug} / \mathrm{Kg}$ ) $\mathrm{mg} / \mathrm{kg}$

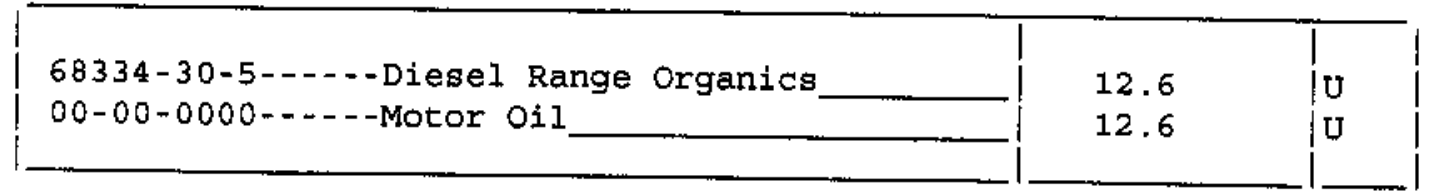

$12 / 88$ Rev. 


\section{ORGANICS ANALYSIS SHEET}

Lab Name: Iionville.Labs, Inc. Work Order: 60052001001
CLIENT SAMPLE NO.

230102-4

Client: BECHTEL NEVADA V1926

Matrix:

SOIL

Sample wt/vol:

$-25.0(\mathrm{~g} / \mathrm{mL}) \mathrm{G}$

Level: (low/med) LOW

: Moisture: rot dec.

5

Column: (pack/cap) CAP

COMPOUND

Lab Sample ID:

$0303 L 968-004$

Lab File ID: BLKLACHJ

Date Received: $\underline{03 / 18 / 03}$

Date Analyzed: $03 / 22 / 03$

Dilution Factor: 1.00

CONCENTRATION UNITS:

(ug/I or ug/ $\mathrm{Kg}$ ) $\mathrm{mg} / \mathrm{kg}$

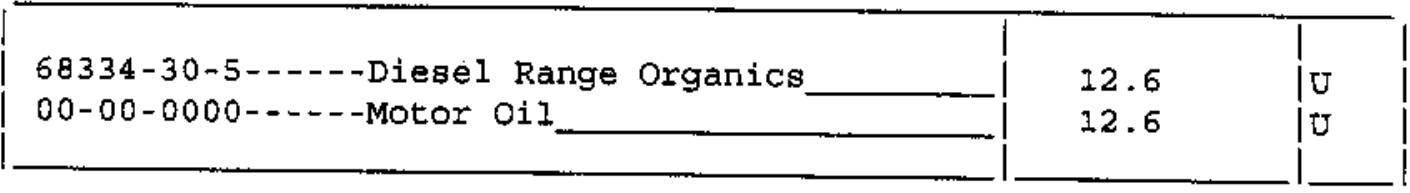

12/88 Rev. 
Lab Name: Lionville Labs, Inc. Work Order: 60052001001 $230102-5$

Client: BECHTEL NEVADA V1926

Matrix:

SOIL

Sample wt/vol:

$25,0(\mathrm{~g} / \mathrm{mL}) \mathrm{G}$

Level: (low/med) LOW

: Moisture: not dec. 4

Column: (pack/cap) CAP

CAS NO.

COMPOUND
Lab Sample ID: 0303L968-005

Lab File ID: BIKIACHU

Date Received: $\underline{03 / 18 / 03}$

Date Analyzed: $03 / 22 / 03$

Dilution Factor: 1,00

CONCENTRATION UNITS:

(ug/L or $u g / \mathrm{kg}$ ) $\mathrm{mg} / \mathrm{kq}$

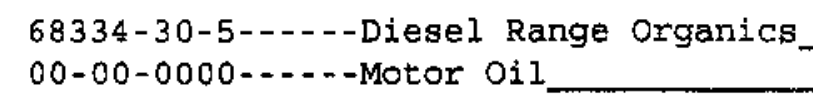

12/88 Rev.
12.5

12.5

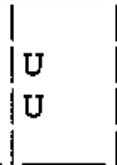


Lab Name: Iionville Labs, Inc. Work Order: 50052001001

Client: BECHTEL NEVADA V1926

Matrix:

SOIL

Sample wt/vol: $\underline{25.0}(\mathrm{~g} / \mathrm{mI}) \mathrm{G}$

Level: (low/med) LOW

客 Moisture: not dec. 5

CoIumn: (pack/cap) CAP

CAS NO.

COMPOUND
Lab Sample ID: 0303L968-006

Lab File ID: BLKLACHJ

Date Received: $\underline{03 / 18 / 03}$

Date Analyzed: 03/22/03

Dilution Factor: 1.00

CONCENTRATION UNITS :

(ug/I or $u g / \mathrm{kg}$ ) $\mathrm{mg} / \mathrm{kg}$

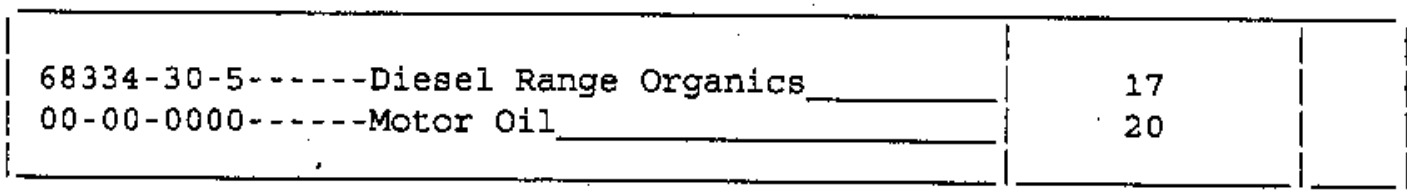

$12 / 88$ Rev. 
Lab Name: Lionville Labs, Inc. Work Order: 60052001001

Client: BECHTEL NEVADA V1226

Matrix:

SOIL

Sample $\omega t /$ vol:

$\underline{25.0}(\mathrm{~g} / \mathrm{mL}) \underline{\mathrm{G}}$

Level: (low/med) LOW

\%oisture: not dec. 6

Column: (pack/cap) CAP

CAS NO.

COMPOUND
Lab Sample ID: 0303L968-007

Lab File ID: BLKIACHJ

Date Received: $\underline{03 / 18 / 03}$

Date Analyzed: $\underline{03 / 23 / 03}$

Dilution Factor: 1.00

CONCENTRATION UNITS :

(ug/L or $\mathrm{ug} / \mathrm{Kg}$ ) $\mathrm{mg} / \mathrm{kg}$

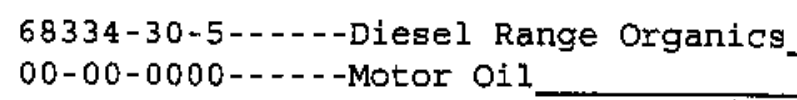

12.7

12/88 Rev. 
CASE NARRATIVE 


\section{Analytical Report}

LIONVIIII. LABORAIOKY INC:

Client: BECHTEL-NEVADA V1926

LVL \#: 0303L968
W.O. \#: 60052-001-001-0001-00

Date Received: 03-18-2003

\section{GRO}

Three (3) soil samples were collected on 03-12-2003.

The samples and their associated QC samples were analyzed according to Lionville Laboratory OPs based on SW-846 method 8015 for Gasoline range organics (GRO) on 03-22-2003.

The following is a summary of the QC results accompanying these sample results and a description of any problems encountered during their analyses:

1. All results presented in this report are derived from samples that met LVLI's sample acceptance policy.

2. Samples were analyzed within required holding time.

3. The method blank was below the reporting limits for all target compounds.

4. All surrogate recoveries were within acceptance criteria.

5. The blank spike recovery was within acceptance criteria.

6. The matrix spike recoveries were within acceptance criteria.

7. All initial calibrations associated with this data set were within acceptance criteria.

8. All continuing calibration standards analyzed prior to sample extracts were within acceptance criteria.
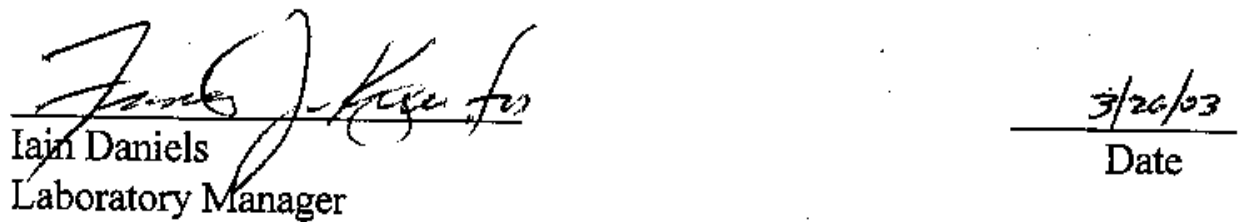

Lionville Laboratory Incorporated

The results presented in this report relate only to the analytical testing and conditions of the samples at receipt and during storage. 


\section{DATA QUALIFIERS}

$\mathbf{U}=$ Indicates that the compound was analyzed for but not detected. The minimum detection limit for the sample (not the method detection limit) is reported with the $\mathrm{U}$ (e.g., 10U).

$\mathbf{J}=$ Indicates an estimated value. This flag is used in cases where a target analyte is detected at a level less than the lower quantification level. If the limit of quantification is $10 \mathrm{ug} / \mathrm{L}$ and a concentration of $3 \mathrm{ug} / \mathrm{L}$ is calculated, it is reported as $3 \mathrm{~J}$.

B = This flag is used when the analyte is found in the associated blank as well as in the sample. It indicates possible/probable blank contamination.

$\mathbf{E}=$ Indicates that the compound was detected beyond the calibration range and was subsequently analyzed at a dilution.

I $=$ Interference.

\section{ABBREVIATIONS}

BS $=$ Indicates blank spike in which reagent grade water is spiked with the CLP matrix spiking solutions and carried through all the steps in the method. Spike recoveries are reported.

BSD $=$ Indicates blank spike duplicate.

MS $=$ Indicates matrix spike.

MSD = Indicates matrix spike duplicate.

DL = Indicates that recoveries were not obtained because the extract had to be diluted for analysis.

$\mathbf{N A}=$ Not Applicable.

DF $=$ Dilution Factor.

$\mathbf{N R}=\quad$ Not Required.

SP $\quad=\quad$ Indicates Spiked Compound. 


\section{GLOSSARY OF GASOLINE RANGE ORGANICS DATA}

D $=$ This flag identifies all compounds identified in an analysis at a secondary dilution factor.

C = This flag applies to a compound that has been confirmed by GC/MS. 
SAMPLE DATA FOR EACH SAMPLE 
Lab Name: Lionville Labs. Inc. Work Order: 60052001001 $230102-1 \mathrm{G}$

Client: BECHTEL NEVADA V1926

Matrix:

SOIL

Lab Sample ID: 0303L968-008

Sample wt/vol: $4.86(\mathrm{~g} / \mathrm{mL}) \mathrm{G}$

Lab File ID:

BLKIACHJ

Level : (low/med) LOW

Date Received: $\underline{03 / 18 / 03}$

\& Moisture: not dec. 3

Date Analyzed: $03 / 22 / 03$

Column: (pack/cap) CAP

Dilution Factor: 1.00

CONCENTRATION UNITS:

CAS NO. COMPOUND (ug/I or $\mathrm{ug} / \mathrm{Kg}$ ) UG/KG

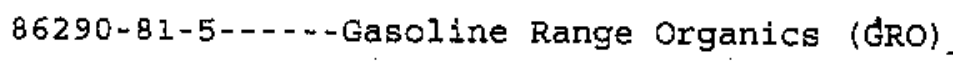

12/88 Rev. 
Lab Name: Lionville Labs, Inc. Work order: 60052001001

Client: BECHTEL NEVADA V1926

Matrix:

SOIL

Sample wt/vol: $\underline{5.25}(\mathrm{~g} / \mathrm{mL}) \mathrm{G}$

Level: (low/med) LOW

\& Moisture: not dec. 4

Column: (pack/cap) CAP

COMPOUND
Lab Sample ID: 0303L968-009

Lab File ID: BLKLACHJ

Date Received: $\underline{03 / 18 / 03}$

Date Analyzed: $03 / 22 / 03$

Dilution Factor: 1.00

CONCENTRATION UNITS :

(ug/L or ug/Kg) UG/KG.

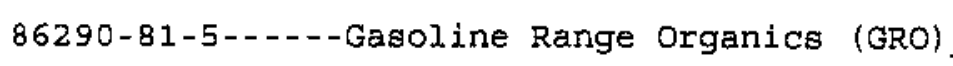

12/88 Rev. 
Lab Name: Lionville Jabs, Inc, work Order: 60052001001

Client: BECHTEL NEVADA V1926

Matrix:

Sample wt/vol:

Level: (low/med) LOW

\% Moisture: not dec.

4

Column: (pack/cap) CAㅗ

CAS NO. COMPOUND
Lab Sample ID: 0303 L268-010

Lab File ID:

BLKLACHJ

Date Received: $03 / 18 / 03$

Date Analyzed: $03 / 22 / 03$

Dilution Factor: 1.00

CONCENTRATION UNITS:

(ug/L or $u g / K g$ ) $\mathrm{UG} / \mathrm{KG}$

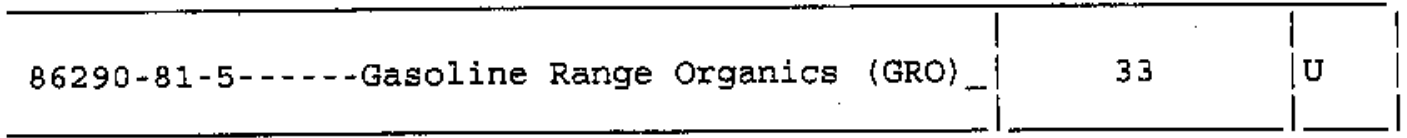

$12 / 88$ Rev. 
CLOSURE REPORT - CAU 330

Section: Appendix B

Revision: 0

Date: July 2003

\section{SAMPLE DELIVERY GROUP}

\section{V1805}


CLOSURE REPORT - CAU 330

Section: Appendix B

Revision: 0

Date: July 2003

\section{THIS PAGE INTENTIONALLY LEFT BLANK}




\section{Case Narrative}




\section{Analytical Report}

IIONVIIF LABOKATORY INC:

Client: BECHTEL NEVADA V1805

LVL\#: 0212L341

W.O.\#: 60052-001-001-0001-00

Date Received: 12-13-2002

\section{DIESEL RANGE ORGANICS}

The set of samples consisted of one (1) oil and one (1) water samples collected on 12-11-2002.

The samples and their associated QC samples were extracted on 12-11-2002 and analyzed on 1218,21,27-2002 according to Lionville Laboratory OPs. The extraction procedures were based on method 3520 and $3580 \mathrm{a}$ (waste dilution- $1 \mathrm{~g}$ into $10 \mathrm{~mL}$ ); and the extracts were analyzed based on method 8015B for Diesel Range Petroleum Hydrocarbons.

1. All results presented in this report are derived from samples that met LvLI's sample acceptance policy.

2. The required holding time for extraction and analysis has been met.

3. The method blank was below the reporting limits for all target compounds.

4. All obtainable surrogate recoveries were within acceptance criteria.

5. The blank spike recovery was within acceptance criteria.

6. Both samples required instrument dilution due to high concentration of target analytes. Reporting limits have been adjusted to reflect the necessary dilutions.

7. All initial calibrations associated with this data set were within acceptance criteria.

8. All : continuing calibration standards analyzed prior to sample extracts were within acceptance criteria.
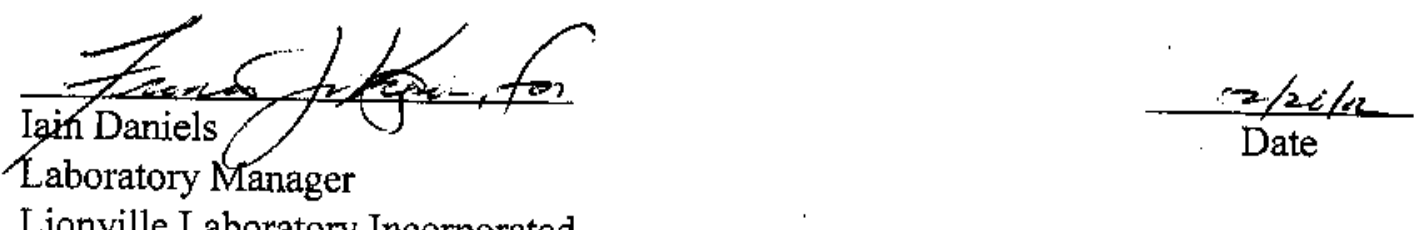

Lionville Laboratory Incorporated

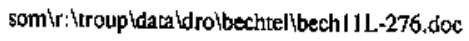

The results presented in this report relate only to the analytical testing and conditions of the samples at receipt and during storage. 


\section{GLOSSARY OF DIESEL RANGE ORGANICS DATA}

\section{DATA QUALIFIERS}

$\mathbf{U}=$ Indicates that the compound was analyzed for but not detected. The minimum detection limit for the sample (not the method detection limit) is reported with the $U$ (e.g.; 10U).

$\mathbf{J}=$ Indicates an estimated value. This flag is used in cases where a target analyte is detected at a level less than the lower quantification level. If the limit of quantification is $10 \mathrm{ug} / \mathrm{L}$ and a concentration of $3 \mathrm{ug} / \mathrm{L}$ is calculated, it is reported as $3 \mathrm{~J}$.

B $=$ This flag is used when the analyte is found in the associated blank as well as in the sample. It indicates possible/probable blank contamination.

$\mathbf{E}=$ Indicates that the compound was detected beyond the calibration range and was subsequently analyzed at a dilution.

I $=$ Interference.

\section{ABBREVIATIONS}

BS $=$ Indicates blank spike in which reagent grade water is spiked with the CLP matrix spiking solutions and carried through all the steps in the method. Spike recoveries are reported.

BSD $=$ Indicates blank spike duplicate.

MS = Indicates matrix spike.

MSD = Indicates matrix spike duplicate.

DL = Indicates that recoveries were not obtained because the extract had to be diluted for analysis.

NA $=$ Not Applicable.

DF $=$ Dilution Factor.

NR $=$ Not Required.

SP = Indicates Spiked Compound. 


\section{GLOSSARY OF DIESEL RANGE ORGANICS DATA}

D = This flag identifies all compounds identified in an analysis at a secondary dilution factor.

$\mathrm{C}=$ This flag applies to a compound that has been confirmed by GC/MS. 


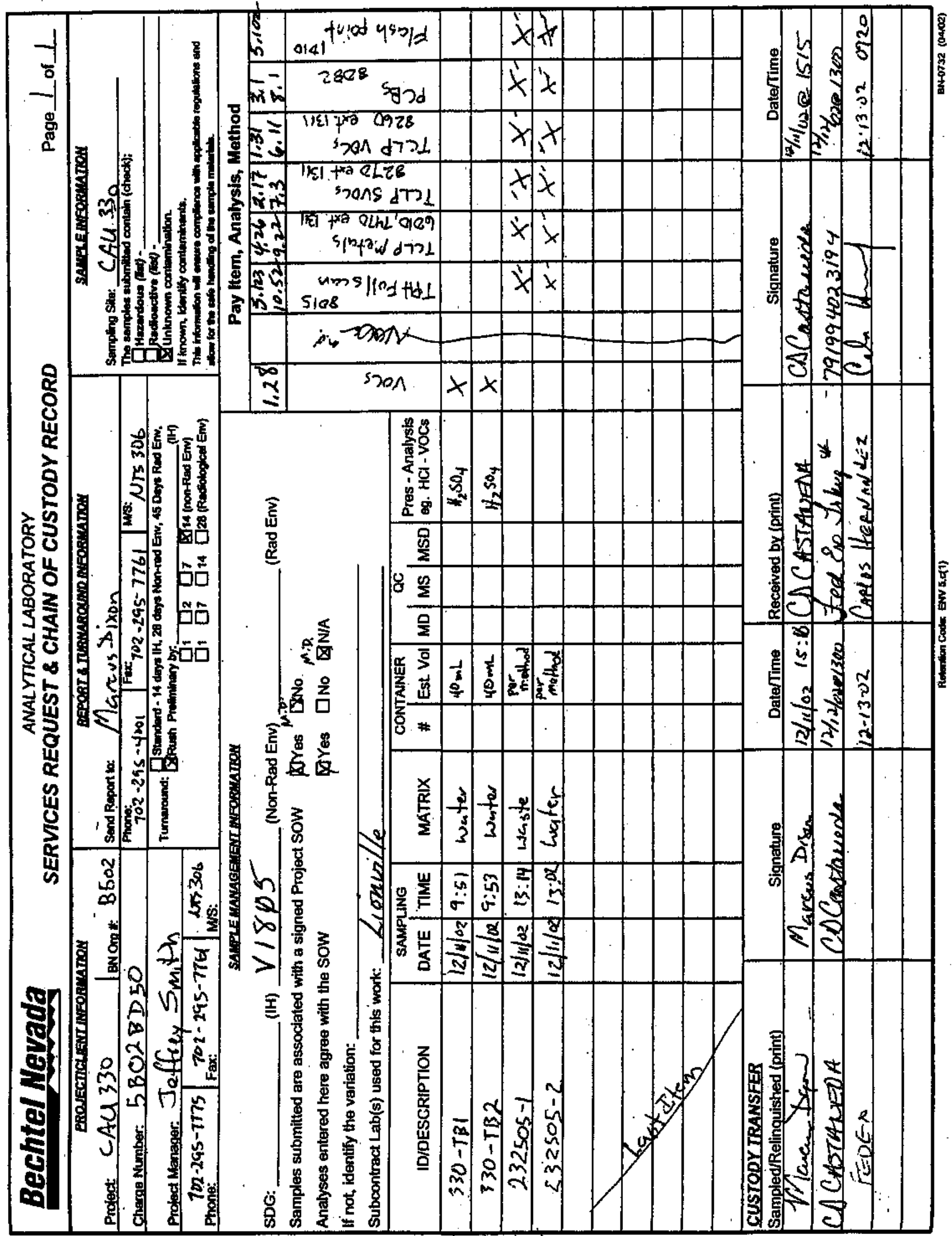


Sample Data

20 
Lab Name: Lionville Labs. Inc. Work Order: 60052001001 232505-1

Client: BECHTEL NEVADA V1805

Matrix:

OIL

Lab Sample ID: 0212L34L-003

Sample wt/vol: $1.00(\mathrm{~g} / \mathrm{mL}) \underline{\mathrm{G}}$ Lab File ID:

BLKLACHJ

Level: (low/med) LOW

Date Received: $12 / 13 / 02$

\%oisture: not dec. 100

Date Analyzed: 12/21/02

Column: (pack/cap) CAP

Dilution Factor: 10.0

CONCENTRATION UNITS:

CAS NO.

COMPOUND

(ug/L or $u g / \mathrm{kg}$ ) $\mathrm{mg} / \mathrm{kg}$

68334-30-5-2--Diesel Range Organics
00-00-0000----Motor Oil

120000

700000

12/88 Rev. 
Lab Name: Iionville Labs, Inc. Work Order: 60052001001

Client: BECHTEL NEVADA V1805

Matrix:

WATER

Lab Sample ID: 0212L341-004

Sample wt/vol:

$100(\mathrm{~g} / \mathrm{mL}) \mathrm{ML}$

Leve1: (low/med) LOW

\% Moisture: not dec.

Column: (pack/cap) CAP

CAS NO.

COMPOUND
Lab File ID: BLKIACH

Date Received: $12 / 13 / 02$

Date Analyzed: $12 / 21 / 02$

Dilution Factor: 10.0
CONCENTRATION UNITS : (ug/I or $u g / \mathrm{Kg}$ ) ug $/ \mathrm{I}$

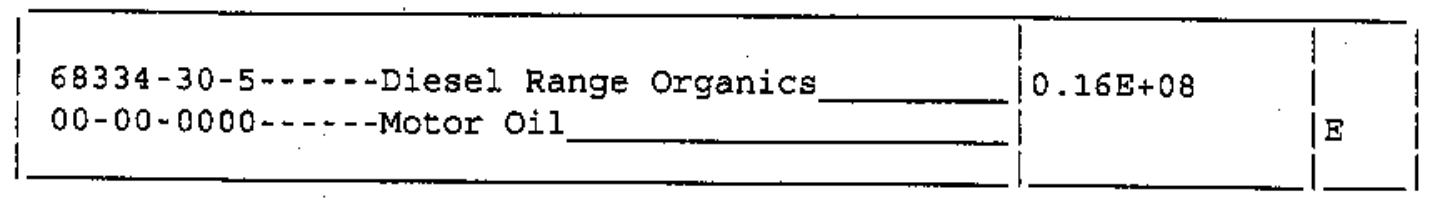

12/88 Rev. 
Lab Name: Lionville Labs, Inc. Work Order: 60052001001 232505-2DL

Client: BECHTEL NEVADA V1805

Matrix:

Sample wt/vol:

Level: (low/med) LOW

\%oisture: not dec.

Column: (pack/cap) CAP

CAS NO.
WATER

$100(\mathrm{~g} / \mathrm{mI}) \mathrm{ML}$

Lab Sample ID: 0212L341-004 DL

Lab File ID

BILKLACH.J

Date Received: 12/13/02

Date Analyzed: $12 / 23 / 02$

Dilution Factor: 100

CONCENTRATION UNITS: (ug/L or $u g / \mathrm{kg}$ ) ug/L

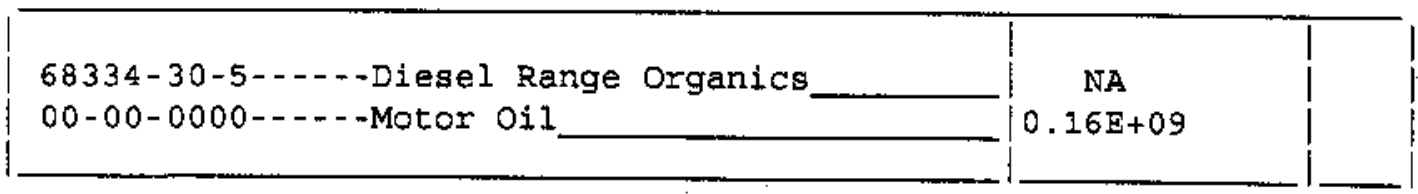

12/88 Rev. 
Case Narrative 


\section{(3) $/ V L I$ \\ IIONVIIF LABORAIORY INC.}

Client: BECHTEL NEVADA V1805

LVL\#: 0212L341

W.O.\#: 60052-001-001-0001-00

Date Received: 12-13-2002

\section{GC/MS VOLATILE-TCLP}

The set of samples consisted on one (1) leachate and three (3) water samples collected on 12-11-2002.

The leachate sample was generated on 12-18-2002 from an oil sample.

The samples and their associated QC samples were analyzed according to criteria set forth in Lionville Laboratory OPs based on SW 846 Method 8260B for TCLP Volatile target compounds on 12-16,17,182002.

The following is a summary of the QC results accompanying the sample results and a description of any problems encountered during their analyses:

1. All results presented in this report are derived from samples that met LvLI's sample acceptance policy.

2. The required holding time for analysis was met.

3. The leachate samples were analyzed at five-fold dilution due to the leachate matrix. Sample $232505-2$ contained 2 layers, oil and aqueous. The water layer was prepared, diluted 100 -fold due to high levels of target compounds and reported as per client instruction.

4. All surrogate recoveries were within EPA QC limits.

5. Matrix spike analyses are associated with LVL \# 0212L340.

6. All blank spike recoveries were within EPA QC limits.

7. Internal standard area and retention time criteria were met.

8. Manual integrations are performed according to OP L-QA-125 to produce quality data with the utmost integrity. All manual integrations are required to be technically valid and properly documented. Appropriate technical flags are defined in the Glossary ("Technical Flags For Manual Integration").
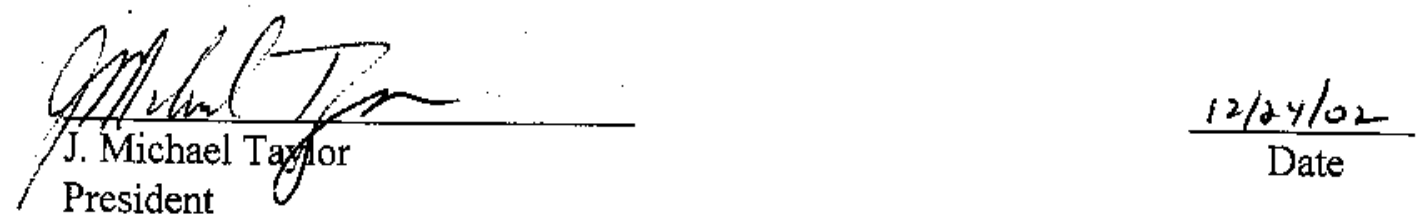

Lionville Laboratory Incorporated

somigroupldataibnatbectel-nevadai02 2 2-34!.doc

The results presented in this report relate onfy to the analytical testing and conditions of the samples at receipt and during storage. 


\section{GLOSSARY OF VOA DATA}

\section{DATA OUALIFERS}

U Compound was analyzed for but not detected. The associated numerical value is the estimated sample quantitation limit which is included and corrected for dilution and percent moisture.

Indicates an estimated value. This flag is -used under the following circumstances: 1) when estimating a concentration for tentatively identified compounds (TICs) where a $1: 1$ response is assumed; or 2) when the mass spectral data indicate the presence of a compound that meets the identification criteria but the result is less than the specified detection limit but greater thari zero. For example, if the limit of detection is $10 \mathrm{ug} / \mathrm{L}$ and a concentration of $3 \mathrm{ug} / \mathrm{L}$ is calculated, it is reported as $3 \mathrm{~J}$.

This flag is used when the analyte is found in the associated blank as well as in the sample. It indicates possible/probable blank contamination. This flag is also used for a TIC as well as for a positively identified $\mathrm{TCL}$ compound.

E - Indicates that the compound was detected beyond the calibration range and was subsequently anslyzed at a dilution.

D = Identifies all compounds identified in an analysis at a secondary dilution factor.

$1 . \quad$ Interference.

NQ $\quad$ Result qualitatively confirmed but not able to quantify.

$\mathrm{N} \quad=$ Indicates presumptive evidence of a compound. This fag is only used for tentatively identified compounds (TMCs), where the identification is based on a mass spectral library search. It is applied to all TC results. For generic characterization of a TIC, such as chlorinated hydrocarbon, the N code is not used.

$\mathrm{X} \quad=\quad$ This flag is used for a TIC compound which is quantified relative to a response factor generated from a daily calibration standard (rather than quantified relative to the closest intemal standard).

$\mathbf{Y}=\quad$ Additional qualifiers used as required are explained in the case narrative. 


\section{GLOSSARY OF VOA DATA}

\section{ABBREVIATIONS}

BS = Indicates blank spike in which reagent grade water is spiked with the CLP matrix spike solutions and carried through all the steps in the method. Spike recoveries are reported.

BSD = Indicates blank spike duplicate.

MS $=\quad$ Indicates matrix spike.

MSD = Indicates matrix spike duplicate.

DL - Suffix added to sample number to indicate that results are from a diluted analysis.

NA $=\quad$ Not Applicable.

DF = Dilution Factor.

NR $\quad=\quad$ Not Required.

SP, Z = Indicates Spiked Compound. 
Sample Data for each Sample 
$1 \mathrm{~A}$

VOLATILE ORGANICS ANALYSIS SHEET

Lab Name: Lionville Labs. Inc. Contract: 60052001001

BPA SAMPLE NO.

$330-T B 1$
Lab Code: Lionyi Case No.:

Matrix: (so11/water) WATER

Sample wt/vol:

$5,00 \quad(g / m L) ~ M t$

Level: (Iow/med) LOW

\%. Moisture: not dec.

Columin: (pack/cap) cap
SAS NO.:

Lab Sample ID: 0212I,341-001

Irab File ID:

$q 121616$

Date Received: $12 / 13 / 02$

Date Analyzed: $\quad 12 / 16 / 02$

Dilution Factor: 1.00
CONCENTRATION UNITS :
(ug/L or $u g / \mathrm{Kg}) \mathrm{MG} / \mathrm{I}_{\text {m }}$
CAS NO.
COMPOUND

0.010

75-01-4--n--vinyl Chloride

0.005

75-35-4-.---1, 1-D1 chloroethene

67-66-3---2--Chloroform

107-06-2-1---1, 2-Dichloroethane

78-93-3--n---2-Butanone

56-23-5--2---Carbon Tetrachloride

79-01-6--..--Trichloroethene

71-43-2------Benzene

127-18-4------Tetrachloroethene

108-90-7 .....-Chlorobenzene.

0.005

0.005

0.010

0.005

0.005

0.005

0.005

0.005

FORM $1 \mathrm{~V}-1$

1/87 Rev. 
$1 \mathrm{~A}$

VOEATILE ORGANICS ANALYSIS SHEET
EPA SAMPLE NO.

$$
330-732
$$

Lab Name: L10nville Labs, Inc. Contract: 60052001001

Lab Code: ILonv1 Case No.:

Matrix: (goil/water) WATER

Sample wt/vol:

$5.00 \quad(g / m L) \mathrm{ML}$

Level:

(1ow/med)

LOW

\& Moisture: not dec.

Column: (pack/cap) CAP
SAS NO.:

SDG No.:

Lab Sample ID: $021214341-002$

Lab File ID: $\quad$ g121617

Date Received: $12 / 13 / 02$

Date Analyzed: $\quad 12 / 16 / 02$

Dilution Factor: 1.00

CONCENTRATION UNTTS:

(ug/L or $\mathrm{ug} / \mathrm{Kg}$ ) $\mathrm{MG} / \mathrm{L}$

CAS NO.

COMPOUND

0.010

0.005

0.005

0.005

0.010

0.005

0.005

0.005

0.005

0.005

108-90-7------Chlorobenzene

FORM 1 V-1

1/87 Rev. 
$1 \mathrm{~A}$

VOLATILE ORGANICS ANALYSIS SHEET

Lab Name: Lionyille Labs, Inc. Contract: 60052001001

Lab Code: Lionvi Case No.:

SAS NO.:

EPA SAMPLE NO.

Matrix: (soil/water) WATRR

Lab Sample ID: 0212L341-004

Sample wt/vol:

$5.00(\mathrm{~g} / \mathrm{mL}) \mathrm{ML}$

Level: (Low/med) Low

* Molsture: not dec.

Column: (pack/cap) CAP
$232505-2$
Lab File ID: $\quad 0121710$

Date Received: $122 / 13 / 02$

Date Analyzed: $12 / 27 / 02$

Dilution Factor: 100
SDG No.:

CONCENTRATION UNITS:

CAS NO.

COMPOUND

(ug/L or $u g / \mathrm{Kg}$ ) $\mathrm{MG} / \mathrm{L}$

\begin{tabular}{|c|}
\hline 75-01-4-m----viryl Chloride. \\
\hline $75-35-4-\cdots-1,1-D i c h l o r o e t h e n e$ \\
\hline $67-66-3=\ldots----C h l o r o f o r m$ \\
\hline $107-06-2-\cdots--1,2-$ Dichloroethane \\
\hline $78-93-3------2$-Butanone \\
\hline 56-23-5-..--Carbon Tetrachloride \\
\hline 79-01-6-..--Trichloroethene \\
\hline $71-43-2----\cdots$ Benzene \\
\hline 127-18-4----Tetrachloroethene \\
\hline $108 \times 90-7-----$ Chlorobenzene \\
\hline
\end{tabular}

FORM $1 \mathrm{~V}-1$

\section{0}

0.50

0.50

0.50

2.8

0.50

0.50

0.50

0.50

0.50 
$1 \mathrm{~A}$

VOIATILE ORGANICS ANALYSIS SHEET

Lab Name: Lionv111e Jabs. Inc. Contract: 60052001001

SAS NO.: EPA SAMPLE NO.

Lab Code: Ifonvi Case No.:

Lab Sample ID: $02121341-005$

Matrix: (so11/water) WATER

Lab File ID: $\quad$ G121808

Sample wt/vol:

$5.00(\mathrm{~g} / \mathrm{mL}) \mathrm{ML}$

Date Received: $12 / 13 / 02$

Level: (low/med) LOW

Date Analyzed: $12 / 18 / 02$

\& Moisture: not dec.

Dilution Factor: 5,00

CONCENTRATION UNITS:

CAS NO.

COMPOUND

(ug/L or $u g / \mathrm{Kg}$ ) $\mathrm{MG} / \mathrm{I}$

75-01-4-...-.vinyl Chloride

75-35-4--...-1,1-D1chloroethene

67-66-3--..--Chioroform

107-06-2---n-1, 2-Dichloroethane

78-93-3-..---2-Butanone.

56-23-5-1----Carbon Tetrachloride

79-01-6-..--.-Trichloroethene

71-43-2-....---Benzene

127-18-4--..--Tetrachloroethene

108-90-7-...-Chlorobenzene

FORM $1 \mathrm{~V}-1$

1/87 Rev

0.050

0.025

0.025

0.025

0.042

0.025

0.025

0.025

0.025

0.025 
Case Narrative 


\section{S $\mid V L I$ \\ LIONVILLE LABORATORY INC:}

\section{Analytical Report}

Client: BECHTEL NEVADA V 1805

LVL \#: 0212L34]
W.O.\#: 60052-001-00J-0001-00

Date Received: 12-13-02

\section{SEMTVOLATILE}

The set of samples consisted of one (1) water sample and one (1) filtrate sample generated on 12-18-02 from a water sample. Both samples were collected on 12-11-02.

The samples and their associated QC samples were extracted according to Lionville Laboratory OPs based on method 3520 on 12-18-02 and analyzed according to criteria set forth in Lionville Laboratory OPs based on SW 846 Method $8270 \mathrm{C}$ for client specified TCLP Semivolatile target compounds on 12-20-02.

The following is a summary of the $\mathrm{QC}$ results accompanying the sample results and a description of any problems encountered during their analyses:

1. All results presented in this report are derived from samples that met LvLI's sample acceptance policy.

2. Samples were extracted and analyzed within required holding time.

3. Non-target compounds were not reported as per client request.

4. Sample 232505-2 was diluted 5-fold due to high levels of non-target compounds. The final extracted volume was $20 \mathrm{mLs}$.

4. All obtainable surrogate recoveries were within EPA. QC limits.

5. One (1) of twenty-four (24) blank spike recoveries was outside EPA QC limits.

6. Internal standard area and retention time criteria were met.

7. Manual integrations are performed according to OP L-QA-125 to produce quality data with the utmost integrity. All manual integrations are required to be technically valid and properly documented. Appropriate technical flags are defined in the Glossary ("Technical Flags For Manual Integration").

8. The filtrate blank associated with sample 232505-1 was inadvertently not extracted for Semivolatiles. Since no target compounds in this sample are above regulatory limits, there is minimal impact on the data.

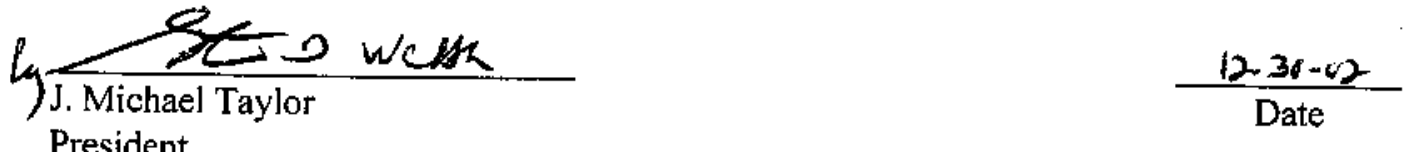

President

Lionville Laboratory Incorporated

peftrigrouplotatabnalbeclitel nevadcal02:12-341.doc

The restits presented in this report relate only to the analytical testing and conditions of the samples at receipt and duning storage. 


\section{GLOSSARY OF BNA DATA}

\section{DATA OUALIFIERS}

U = Compound was analyzed for but not detected. The associated numerical value is the estimated sample quantitation limit which is included and corrected for dilution and percent moisture.

J = Indicates an estimated value. This flag is used under the following circumstances: 1) when estimating a concentration for tentatively identified compounds (TICs) where a 1:1 response is assumed; or 2) when the mass spectral data indicate the presence of a compound that meets the identification criteria but the result is less than the specified detection limit but greater than zero. For example, if the limit of detection is $10 \mathrm{ug} / \mathrm{L}$ and a concentration of $3 \mathrm{ug} / \mathrm{L}$ is calculated, it is reported as 33 .

B . = This flag is used when the analyte is found in the associated blank as well as in the sample. It indicates possible/probable blank contamination. This flag is also used for a TIC as well as for a positively identified TCL compound.

E $\quad=\quad$. Indicates that the compound was detected beyond the calibration range and was subsequently analyzed at a ditution.

D = Jdentifies all compounds identified in an analysis at a secondary dilution factor.

1. Interference.

NQ = Result qualitatively confirmed but not able to quaritify.

A = Indicates that a TJC is a suspected aldol-condensation product.

N . Indicates presumptive evidence of a compound. This flag is only used for tentatively jdentified compounds (TICs), where the identification is based on a mass spectral library search. It is applied to all TIC results. For generic characterization of a TIC, such as chlorinated hydrocarbon, the $N$ code is not used.

$\mathbf{X}=\quad$ This flag is used for a TIC compound which is quantified relative to a response factor generated from a daily calibration standard (rather than quantified relative to the closest internal standard).

Y $\quad$ Additional qualifiers used as required are explained in the case narrative. 


\section{GLOSSARY OF BNA DATA}

\section{ABBREVIATIONS}

BS $\quad=\quad$ Indicates blank spike in which reagent grade water is spiked with the CLP matrix spike solutions and carried through all the sieps in the method. - Spike recoveries are reported.

BSD $=$ Indicates blank spike duplicate.

MS = Indicates matrix spike.

MSD - Indicates matrix spike duplicate.

DL - Suffix added to sample number to indicate that results are from a diluted analysis.

NA $=$ Not Applicabie.

DF $\quad=\quad$ Dilution Factor.

NR $=$ Not Required.

$\dot{\mathbf{S} P}, \mathbf{Z}=$ Indicates Spiked Compound. 


\section{TECHNICAL FLAGS FOR MANUAL INTEGRATION}

Manual quantitation modifications or integrations are performed routinely to improve the data quality for a variety of technical reasons. Documentation of these modifications should be clear and concise. The following "flags" are used to indicate the technical reasons for quantitation modifications:

MP - Missed Peak: manually added peak not found by automatic quantitation program.

PA - Peak Assignment: quantitation report was changed to reflect correct peak assignment.

RI - Routine Integration: routine integrations are performed for some analytes that are consistently integrated improperly by the automatic integration programs. Examples are the dichlorobenzene isomers on the VOA packed column and benzo(b)fluoranthene/benzo(k)fluoranthene which are poorly resolved on the BNA column.

SP - Split Peak: the automatic integration improperly split the peak; a manual integration was performed to get the correct area.

CB - Coelution/Background: peak was manually integrated to eliminate contribution from coeluting compounds, background signal, or other interference.

Pl - Proper Integration: a peak with poor or inconsistent integration (e.g., excessive tail) was properly integrated manually. 
Sample Data for each Sample 
Lab Name: Lionville Labs, Inc. Work Order: 60052001001

Client: BECHTEL NEVADA V1805

Matrix: (soil/water) WATER

Lab Sample ID: 0212L341-004

Sample wt/vol: ـــ $200 \quad(\mathrm{~g} / \mathrm{mL})$ ML

Lab File ID: $\quad$ A122011

Level: (low/med) LoW

Date Received: 12/13/02

\% Moisture:

decanted: $(\mathrm{Y} / \mathrm{N})$

Date Extracted: $12 / 18 / 02$

Concentrated Extract volume: 1000 (uL)

Date Analyzed: $12 / 20 / 02$

Injection volume: $\underline{2} .0$ (uI)

Dilution Factor: 100

GPC Cleanup: $\quad(\mathrm{Y} / \mathrm{N}) \underline{\underline{\mathrm{N}}}$

$\mathrm{pH}: \quad 7.0$

CAS NO.

COMPOUND

CONCENTRATION UNITS :

(ug/L or $\mathrm{ug} / \mathrm{Kg}$ ) $\mathrm{MG} / \mathrm{L}$

$Q$

110-86-1-1.-.-Pyxidine

106-46-7-..---1,4-Dichlorobenzene

95-48-7-2.--2-Methylphenol

106-44-5-1----3- and/or 4-Methylphenol

67-72-1-2..--Hexachloroethane

98-95-3-...--Nitrobenzene

87-68-3--1---Hexachlorobutadiene

88-06-2--...-2, 4,6-Trichlorophenol

95-95-4-...--2, 4,5-Trichlorophenol

121-14-2-----2,4-Dinitrotoluene

218-74-1--_-..Hexachlorobenzene

87-86-5- ....-. Pentachlorophenol

1

FORM I SV-1

RFW (v3.3) 
1B

SEMIVOLATILE ORGANICS ANALYSIS DATA SHEET

Lab Name: Eionville Labs, Inc. Work Order: 60052001001
CLIENT SAMPLE NO.

232505-1

Client: BECHTEL NEVADA V1805

Matrix: (soil/water) WATER

Lab Sample ID: $\underline{0212 L 341-006}$

Sample wt/vol: $100 \quad(\mathrm{~g} / \mathrm{mL}) \mathrm{ML}$

Lab File ID: $\underline{\text { A.22012 }}$

Level: (low/med) LOW

Date Received: $12 / 13 / 02$

\% Moisture:

decanted: $(\mathrm{Y} / \mathrm{N})$

Date Extracted: 12/18/02

Concentrated Extract volume: 1000 (uL)

Date Analyzed: $12 / 20 / 02$

Injection volume: $2.0(\mathrm{uL})$

Dilution Factor: 1.00

GPC Cleanup: (Y/N) $\underline{\mathrm{N}}$

$\mathrm{pH}: \quad 7,0$

CONCENTRATION UNITS:

CAS NO.

COMPOUND

(ug/L or $\mathrm{ug} / \mathrm{Kg}) \mathrm{MG} / \mathrm{L}$

Q

\begin{tabular}{|c|}
\hline $110-86-1-\ldots--$-Pyridine. \\
\hline $106-46-7-\ldots-1,4$-Dichlorobenzene \\
\hline $95-48-7-\ldots-2-2-$ Methylphenol \\
\hline $106-44-5 \ldots \ldots-1-3$ and/or 4-Methylphenol \\
\hline $67-72-1---1$ - Hexachloroethane \\
\hline $98-95-3-\ldots-N i t r o b e n z e n e$ \\
\hline $87-68-3-\ldots-$ Hexachlorobutadiene. \\
\hline 88-06-2-1----2,4,6-Trichlorophenol. \\
\hline $95-95-4----2,4,5-T r i c h l o r o p h e n o l$ \\
\hline 121-14-2-1--1-2,4-Dinitrotoluene \\
\hline $118-74-1 \ldots-$-Hexachlorobenzene \\
\hline 87-86-5--1-Pentachlorophenol \\
\hline
\end{tabular}

FORM 1 SV-1

$0.10 \mid \mathrm{U}$

$0.10 \mid \mathrm{U}$

$0.0081 \mathrm{~J}$

$0.016 \mid \mathrm{J}$

$0.10 . \mathrm{U}$

$0.101 \mathrm{~J}$

$0.101 \mathrm{U}$

$0.10 \mid \mathrm{U}$

$0.251 \mathrm{U}$

$0.10 \mid \mathrm{U}$

$0.101 \mathrm{U}$

$0.25 \mid \mathrm{U}$

RFW (v3.3) 


\section{Case Narrative}




\section{Analytical Report}

LIONVIILE LABORAIORY INC:

Client: BECHTEL NEVADA V1805

LVL\#: 0212L341

W.O.\#: 60052-001-001-0001-00

Date Received: 12-13-2002

GRO

One (1) water and one (1) oil samples were collected on 12-11-2002.

The samples and their associated QC samples were analyzed according to Lionville Laboratory OPs based on SW-846 method 8015 for Gasoline range organics (GRO) on 12-17-2002.

The following is a summary of the QC results accompanying these sample results and a description of any problems encountered during their analyses:

1. All results presented in this report are derived from samples that met LVLI's sample acceptance policy.

2. The required holding time for analysis has been met.

3. Sample 232505-2 required a 5-fold instrument dilution due to the high concentration of target analytes. Sample 232505-1 also required a medium level analysis due to the chromatographic anomalies, high concentration of target and non-target analytes. A copy of the Sample Discrepancy Report (SDR) has been enclosed.

4. The method blanks were below the reporting limits for all target compounds.

5. Four (4) of ten (10) obtainable surrogate recoveries were outside acceptance criteria. A copy of the Sample Discrepancy Report (SDR) has been enclosed.

6. All blank spike recoveries were within acceptance criteria.

7. All initial calibrations associated with this data set were within acceptance criteria.

8. All continuing calibration standards analyzed prior to sample extracts were within acceptance criteria.

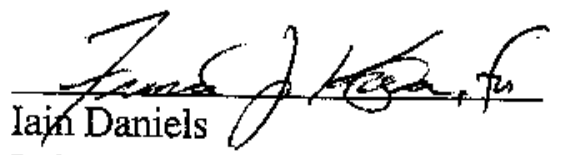

Laboratory Manager

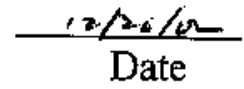

Lionville Laboratory Incorporated

The results presented in this repoit relate only to the analytical testing and conditions of the samples at receipt and duning storage. $\mathrm{h}$ 


\section{GLOSSARY OF GASOLINE RANGE ORGANICS DATA}

\section{DATA QUALIFIERS}

U = Indicates that the compound was analyzed for but not detected. The minimum detection limit for the sample (not the method detection limit) is reported with the $\mathrm{U}$ (e.g., 10U).

$\mathbf{J}=$ Indicates an estimated value. This flag is used in cases where a target analyte is detected at a level less than the lower quantification level. If the limit of quantification is $10 \mathrm{ug} / \mathrm{L}$ and a concentration of $3 \mathrm{ug} / \mathrm{L}$ is calculated, it is reported as $3 J$.

B = This flag is used when the analyte is found in the associated blank as well as in the sample. It indicates possible/probable blank contamination.

$\mathbf{E}=$ Indicates that the compound was detected beyond the calibration range and was subsequently analyzed at a dilution.

$\mathbf{I}=$ Interference.

\section{ABBREVIATIONS}

BS = Indicates blank spike in which reagent grade water is spiked with the CLP matrix spiking solutions and carried through all the steps in the method. Spike recoveries are reported.

BSD $=$ Indicates blank spike duplicate.

MS = Indicates matrix spike.

MSD $=\quad$ Indicates matrix spike duplicate.

DL = Indicates that recoveries were not obtained because the extract had to be diluted for analysis.

$\mathbf{N A}=\quad$ Not Applicable.

DF $=$ Dilution Factor.

$\mathbf{N R}=$ Not Required.

SP $\quad=\quad$ Indicates Spiked Compound. 


\section{GLOSSARY OF GASOLINE RANGE ORGANICS DATA}

D $=$ This flag identifies all compounds identified in an analysis at a secondary dilution factor.

C = This flag applies to a compound that has been confirmed by GC/MS. 
Sample Data 
Lab Name: Lionville Jabs, Inc. Work Order: 50052001001

Client: BECHTEL NEVADA V1805

Matrix:

OIL

$\underline{4.98}(\mathrm{~g} / \mathrm{mL}) \mathrm{G}$

Level: (low/med) MED

Goisture: not dec. 100

Column: (pack/cap) CAP

CAS NO.

COMPOUND

CONCENTRATION UNITS :

(ug/I or $\mathrm{ug} / \mathrm{Kg}$ ) $\mathrm{UG} / \mathrm{KG}$

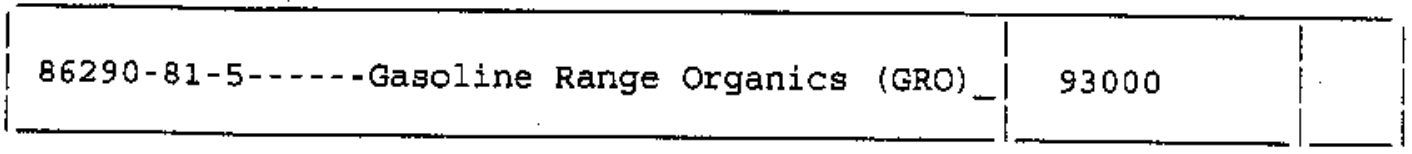

$12 / 88$ Rev. 
Lab Name: Lionvilie Labs, Inc. Work Order: 60052001001

Client: BECHTEL NEVADA V1805

Matrix:

Sample wt/vol:

WATER

$\underline{5.00}(\mathrm{~g} / \mathrm{mL}) \underline{\mathrm{ML}}$

Level: (low/med) LOW

o Moisture: not dec.

Column: (pack/cap) CAP
COMPOUND
Lab Sample ID: 0212L341-004

Lab File ID:

Date Received: $12 / 13 / 02$

Date Analyzed: $\underline{12 / 17 / 02}$

Dilution Factor: 1,00

CONCENTRATION UNITS: (ug/L or $\mathrm{ug} / \mathrm{Kg}$ ) $\underline{\mathrm{UG}} / \mathrm{I}$

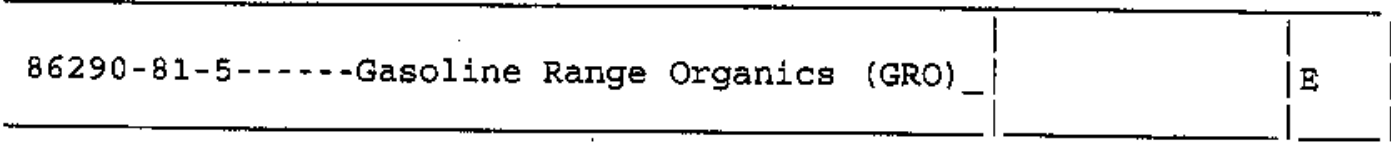

12/88 Rev. 
GC VOLATILES SHEET

CLIENT SAMPLE NO.

232505-2DL

Lab Name: Lionville Labs. Inc. Work Order: 60052001001

Client: BECHTEI_NEVADA V1805

Matrix :

WATER

Lab Sample ID: $0212 \mathrm{~L} 341-004 \mathrm{DL}$

Sample wt/vol:

$5.00 \quad(\mathrm{~g} / \mathrm{mL}) \mathrm{ML}$

Lab File ID: BLKIACHJ

Level: $\quad$ (low/med) LOW

Date Received: $12 / 13 / 02$

\& Moisture: not dec.

Date Analyzed: $12 / 17 / 02$

Column: (pack/cap) CAP

Dilution Factor: 5.00

CONCENTRATION UNITS:

CAS NO. COMPOUND

(ug/I or $u g / \mathrm{Kg}$ ) UG/L

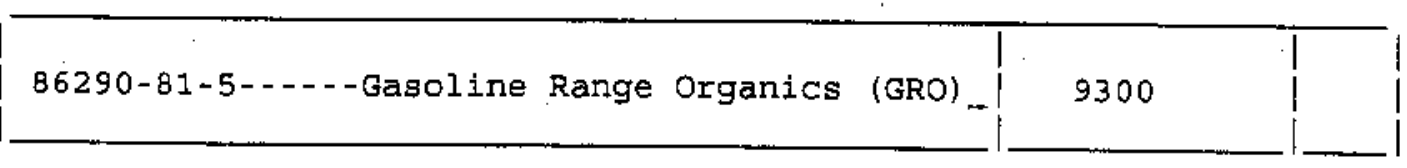

12/88 Rev. 


\section{Analytical Report}

Client: BECHTEL NEVADA V1805

LVL\#: 0212L341
W.O.\#: 60052-001-001-0001-00

Date Received: 12-13-02

\section{INORGANIC NARRATIVE}

1. This narrative covers the analysis of 1 oil sample and 1 water sample.

2. The samples were prepared and analyzed in accordance with the method indicated on the attached glossary.

3. Sample holding times as required by the method and/or contract were met.

4. The results presented in this report are derived from samples that met LvLI's sample acceptance policy.

5. The Laboratory Control Sample (LCS) was within the laboratory control limits.

6. The replicate analysis for sample 232505-1 was within the $20 \%$ Relative Percent Difference (RPD) control limit.
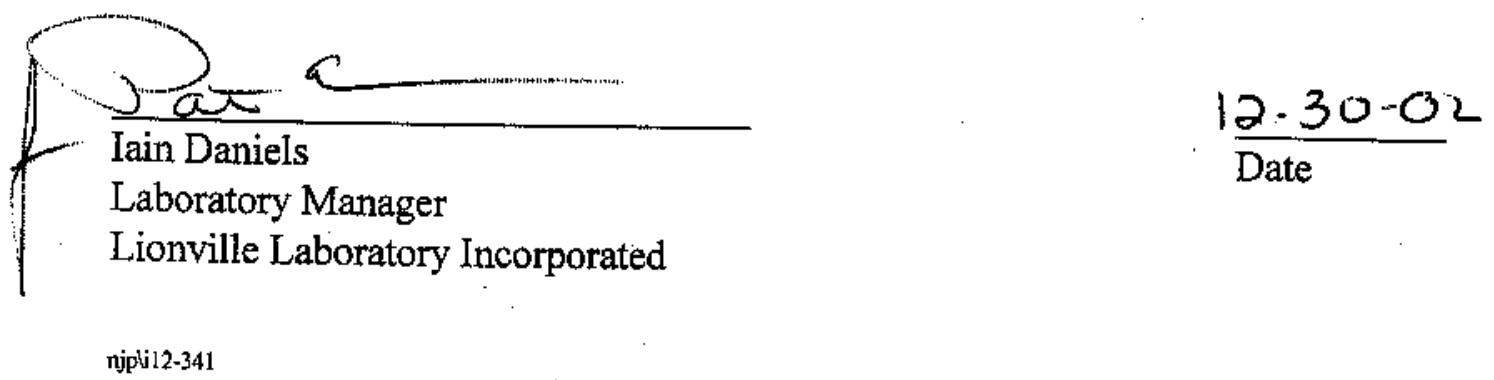

njpli12-341

The results presented in this report relate to the analytical testing and concitions of the samples upon receipt and during storage. of 


\section{Inorganic Data Summary Report \\ Physical Testing Observation}

Client: BECTHEL NEVADA V1805

LVL\#: 0212L341

Analyte:

Flash Point

njpłi12-341.pt2
W.O.\#: 60052-001-001-0001-00

Date Received: 12-13-02

\section{Observation:}

No Flash Point observed for sample 232505-2.

The sample was heated to approximately $200^{\circ} \mathrm{F}$. 
Lionville Laboratory, Inc.

INORGANICS DATA SUMMARY REPORT 12/24/02

CLIENT: BBCHTBI NBVADA V1805

WORK ORDER: 60052-001-001-0001-00

\begin{tabular}{|c|c|c|}
\hline SAMPLE & SITB ID & ANALYTB \\
\hline$=m$ & 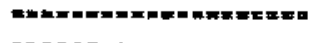 & $=0-m=x$ \\
\hline
\end{tabular}

LVL LOT \#: 0212L343

\begin{tabular}{|c|c|c|c|}
\hline & & REPORTING & DILUTION \\
\hline BSULT & UNITS & LIMIT & BACTOR \\
\hline & 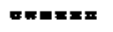 & 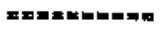 & --+o- \\
\hline 1.4 & $D B G E$ & 40.0 & 1.0 \\
\hline
\end{tabular}


Llonville Laboratoxy, Inc.

INORGANICS PRBCISION RBPORT $12 / 24 / 02$

CLIENT: BECHTEL NBVADA V1805

WORK ORDER ? 60052-001-001-0001-00

SAMPLE SITE ID

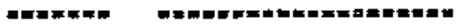

-003RBP 232505-1
LVL IOT \#: 0212L341

\begin{tabular}{|c|c|}
\hline RESULT & REPLICATB \\
\hline 54,4 & 53,4 \\
\hline
\end{tabular}

DILUTION

FACTOR (RBP)

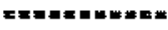


Case Narrative

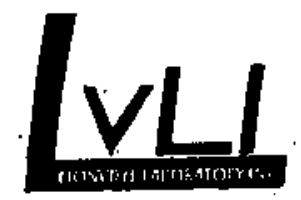




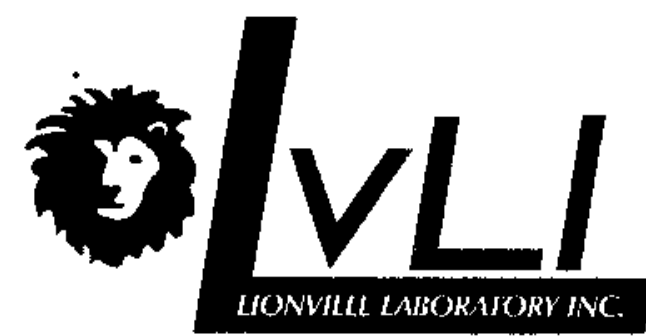

Analytical Report
Client : BECHTEL NEVADA V1805
LVL\# : $0212 \mathrm{~L} 341$
W.O.\# : 60052-001-001-0001-00
Date Received : 12-13-02

\section{SW846 METALS}

1. This narrative covers the analyses of 1 water sample and 1TCLP leachate sample.

2. The samples were prepared and analyzed in accordance with SW-846 protocol and reported with a CLP deliverable. An aliquot of the total sample was preserved prior to digestion. All samples were prepared with a dilution due to sample matrix.

The total samples and the TCLP leachate samples have been reported on separate sets of forms.

3. ICVs, CCVs, and LCSs stock standards were purchased from Inorganic Ventures Laboratory and High Purity.

4. All analyses were performed within the required holding times.

5. All results presented in this report are derived from samples that met LvLI's sample acceptance policy.

6. All Initial and Continuing Calibration Verifications (ICV/CCVs) were within control limits.

7. All Initial and Continuing Calibration Blanks (ICB/CCBs) were within method criteria.

8. All preparation/method blanks were within method criteria. Refer to form 3 .

9. All ICP Interference Check Standards were within control limits. Refer to form 4.

10. All laboratory control samples (LCS) were within the $80-120 \%$ control limits. Refer to form 7 .

11. All serial dilution percent differences were within $\mathrm{SW}-846$ control limits. Refer to form 9 .

12. The TCLP extract from sample 232505-1 was selected for the matrix spike (MS) for this analytical batch. The MS recoveries for all analytes in the TCLP extract were above $50 \%$ per method criteria. 
13. All sample IDs were changed to accommodate the EPA naming convention which allows a maximum of 6 characters on all CLP Forms. Refer to the comments section of form 1 for the original ID.

14. Recoveries on the Laboratory Summary Report and CLP forms will vary depending on the number of significant figures used in the recovery calculation.
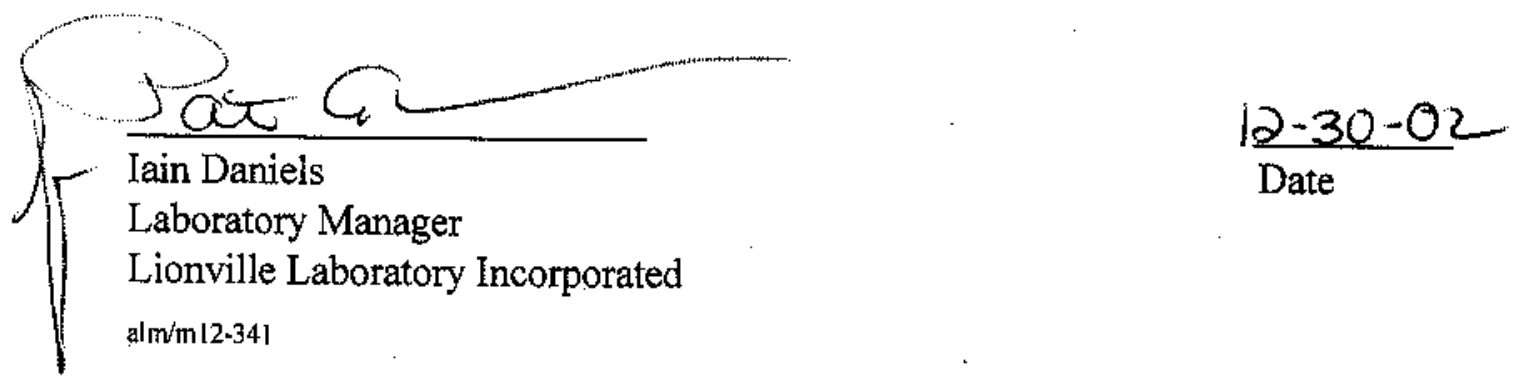

Date 


\section{METHOD REFERENCES AND DATA QUALIFIERS}

\section{DATA QUALIFIERS}

$\mathrm{U}=$ Indicates that the parameter was not detected at or above the reported limit. The associated numerical value is the sample detection limit.

$\mathrm{B}=$ Indicates that the parameter was between the Instrument Detection Limit (IDL) and the Contract Required Detection Limit (CRDL)

\section{O OUALIFIERS}

$E=\quad$ The reporied value is estimated because of the presence of interference.

$\mathbf{M}=$ Duplicate injection precision not met.

$\mathrm{N}=$ Spiked sample recovery not within control limits.

$S=\quad$ The reported value was determined by the Method of Standard Additions (MSA).

$\mathrm{W}=$ Post Digestion spike for Fumace AA analysis is out of control limits (85-115\%), while sample absorbance is less than $50 \%$ of spike absorbance.

* = Duplicate analysis not within control limits.

$+=$ Correlation coefficient for the MSA is less than 0.995 .

\section{ABBREVTATONS}

PB = Method or Preparation Blank.

S = Matrix Spike.

$T=$ Matrix Spike Duplicate.

R:or D : Sample Replicate

\section{ANALYTTCAL METAL METEODS.}

1. Not included in the method element list.

2. Modified $\mathrm{Hg}$. $\mathrm{Hgl}$ and $\mathrm{Hg} 2$ require less total volume of digestate due to the autosampler analysis. Sample volumes and reagents for mercury determinations in water and soil have been proportionately scaled down to adapt to this semiautomated technique. The sample volume used for water analysis is $33 \mathrm{~mL}$. For soils, 0.1 grams of sample is taken to a final volume of $50 \mathrm{~mL}$ (including all resgents).

3. Modified $\mathrm{Hg}: \mathrm{Hgl}$ and $\mathrm{Hg} 2$ require less total volume of digestate due to the autosampler analysis. Sample volumes and reagents for mercury determinations in water and soil have been proportionately scaled down to adapt to this semiautomated technique. The sample volume used for water analysis is $33 \mathrm{~mL}$. For soils, three 0.1 gram of sample is taken to a final volume of $50 \mathrm{~mL}$ (including all reagents).

4: Flane AA

5. Graphite Furnace AA. 
INORGANIC ANALYSES DATA SHEET

Lab Name: IIONVILLE LABORATORY

Lab code: LVII

Matrix (soil/water): WATER

Level (low/med):

solids:
IOW

$0 \overline{0}$
1

EPA SAMPLE NO.

\section{2}

Contract: $60052-1$

SAS No.:

Lab Sample ID: $0212 \mathrm{~L} 341-004$

Date Received: $12 / 13 / 02$

Concentration Units (ug/L or $\mathrm{mg} / \mathrm{kg}$ dry weight): UG/L_

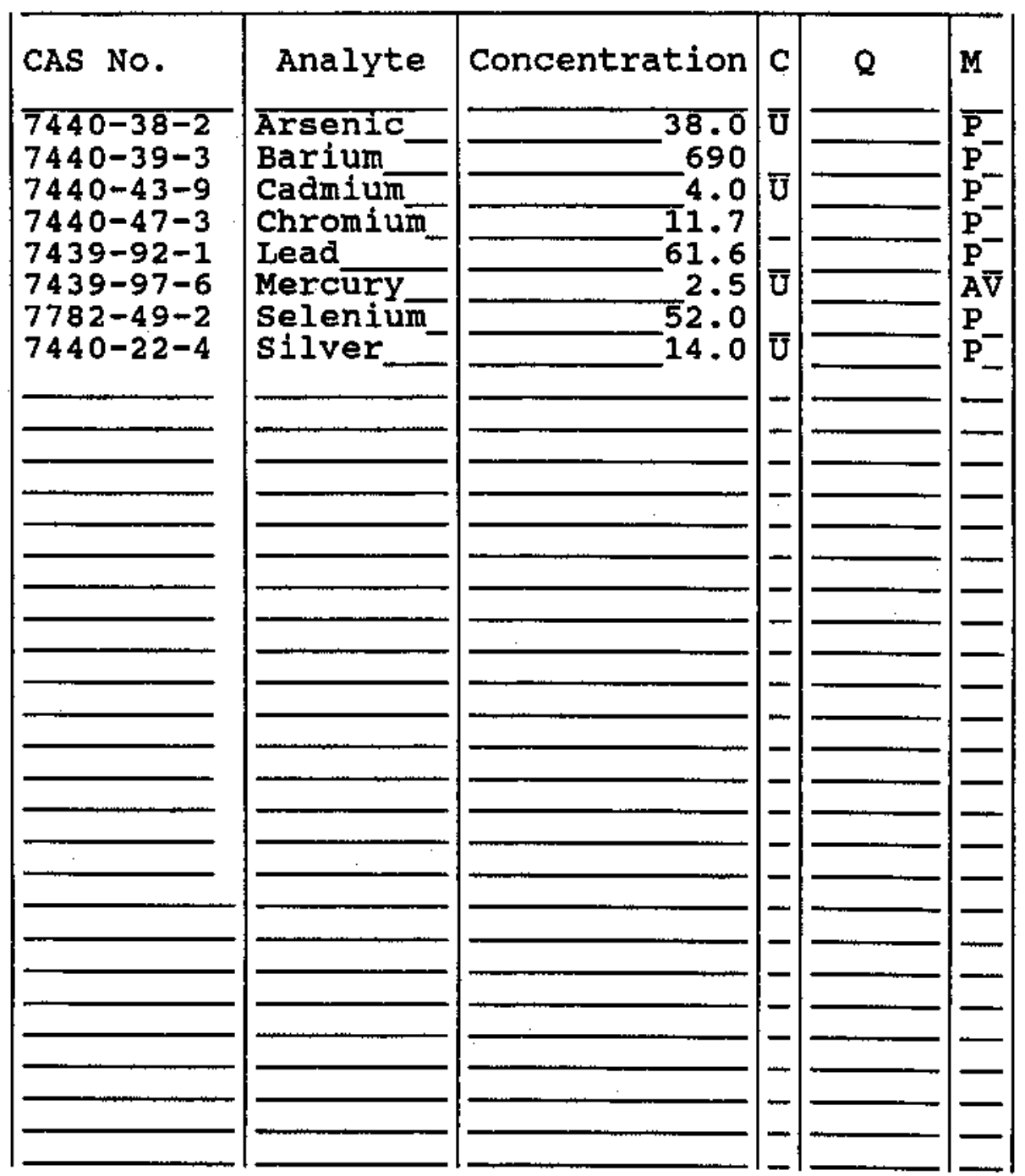

Color Before: Color After:
Clarity Before:

Clarity After:
Texture: Artifacts:

\section{Comments :}

232505-2 
1

INORGANIC ANALYSES DATA SHEET
EPA SAMPLE NO.

\section{1}

Contract: $60052-1$

SAS No.:

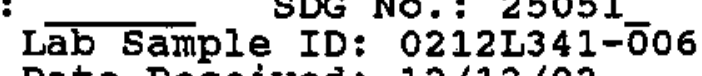

Date Received: $12 / 13 / 02$
Lab Name: IION

Matrix (soil/water): WATER

Level (low/med):

solids:
LOW

$0 . \overline{0}$

Concentration Units (ug/L or $\mathrm{mg} / \mathrm{kg}$ dry weight): UG/L_

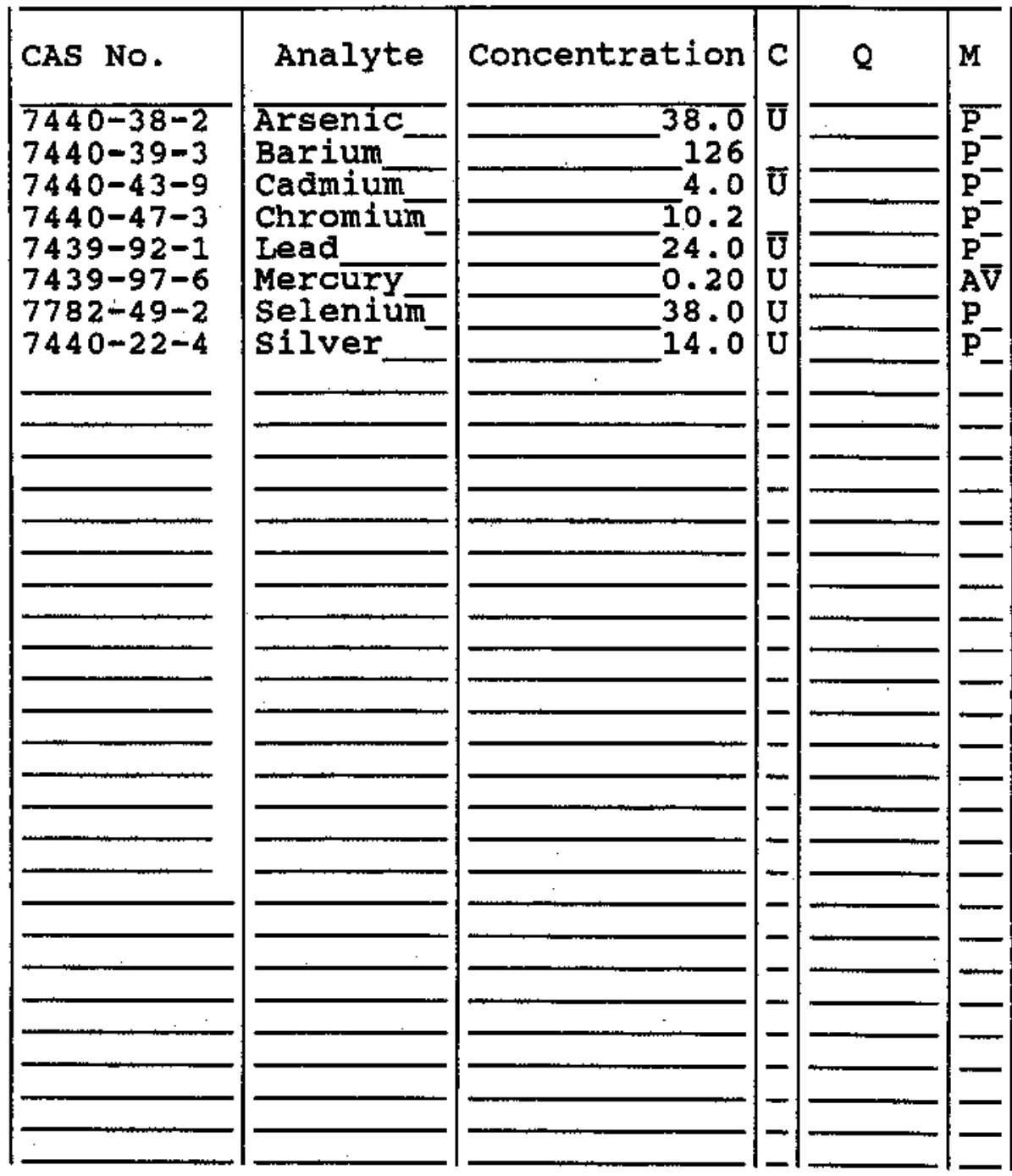

Clarity Before: clarity After:
Texture: Artifacts :
Color Before: Color After:

\section{Comments:}

\section{TCLP_OF_SAMPLE_003}


Case Narrative 


\section{Analytical Report}

IIONVIIE IAKOKAIOKY INC:

Client: BECHTEL NEVADA V1805

LVL\#: 0212L341

W.O.\#: 60052-001-001-0001-00

Date Received: 12-13-2002

PCB

The set of samples consisted of one (1) oil and one (1) water samples collected on 12-11-2002.

The samples and their associated QC samples were extracted on 12-16,17-2002 and analyzed on 1218,20-2002 according to Lionville Laboratory OPs. The extraction procedures were based on method 3520 and $3580 \mathrm{a}$ (waste dilution- $1 \mathrm{~g}$ into $10 \mathrm{~mL}$ ); and the extracts were analyzed based on method 8082 for Aroclors only.

The following is a summary of the QC results accompanying the sample results and a description of any problems encountered during their analyses:

1. All results presented in this report are derived from samples that met LVLI's sample acceptance policy.

2. The required holding time for extraction and analysis has been met.

3. The samples and their associated QC samples received a Sulfuric acid and Sulfur cleanup.

4. The method blanks were below the reporting limits for all target compounds.

5. Four (4) of fourteen (14) obtainable surrogate recoveries were outside acceptance criteria. A copy of the Sample Discrepancy Report (SDR) has been enclosed.

6. All blank spike recoveries were within acceptance criteria.

7. All initial calibrations associated with this data set were within acceptance criteria.

8. All continuing calibration standards analyzed prior to sample extracts were within acceptance criteria.

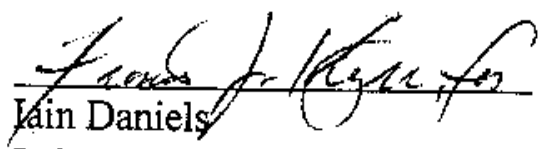

Laboratory Manager

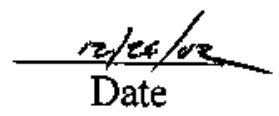

Lionville Laboratory Incorporated

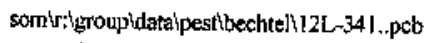

The resilts presented in this repont relate only to the analytical testing and conditions of the samples at receipt and during storage. A. 


\section{GLOSSARY OF PESTICIDE/PCB DATA}

\section{DATA QUALIFIERS}

$\mathbf{U}=$ Indicates that the compound was analyzed for but not detected. The minimum detection limit for the sample (not the method detection limit) is reported with the $U$ (e.g., 10U).

$\mathbf{J}=$ Indicates an estimated value. This flag is used in cases where a target analyte is detected at a level less than the lower quantification level. If the limit of quantification is $10 \mathrm{ug} / \mathrm{L}$ and a concentration of $3 \mathrm{ug} / \mathrm{L}$ is calculated, it is reported as 3J.

B = This flag is used when the analyte is found in the associated blank as well as in the sample. It indicates possible/probable blank contamination.

$\mathbf{E}=$ Indicates that the compound was detected beyond the calibration range and was subsequently analyzed at a dilution.

$1=$ Interference.

\section{ABBREVIATIONS}

BS = Indicates blank spike in which reagent grade water is spiked with the CLP matrix spiking solutions and carried through all the steps in the method. Spike recoveries are reported.

BSD $=$ Indicates blank spike duplicate.

MS = Indicates matrix spike.

MSD = Indicates matrix spike duplicate.

DL = Indicates that recoveries were not obtained because the extract had to be diluted for analysis.

NA $=$ Not Applicable.

DF $=$ Dilution Factor.

$\mathbf{N R}=$ Not Required.

SP $=$ Indicates Spiked Compound. 


\section{GLOSSARY OF PESTICIDE/PCB DATA}

$\mathbf{P} \quad=\quad$ This flag is used for an PESTICIDE/PCB target analyte when there is greater than $25 \%$ difference for detected concentrations between the two GC columns (see Form X). The lower of the two values is reported on Form I and flagged with a "P".

D $=$ This flag identifies all compounds identified in an analysis at a secondary dilution factor.

C = This flag applies to a compound that has been confirmed by GC/MS. 


\section{Sample Data}


1D

PESTICIDE ORGANICS ANALYSIS SHEET

Lab Name: Lionville Labs, Inc. Work Order: 60052001001

\section{Client: BECHTEL NEVADA V1805}

Matrix:

Sample wt/vol:

LeveI:

(low/med) LOW

: Moisture: not dec. 100 dec.

Extraction: (SepF/Cont/Sonc) SONC

GPC Cleanup: $\quad(\mathrm{Y} / \mathrm{N}) \mathbb{N}$
$\underline{O I L}$

$1.00(\mathrm{~g} / \mathrm{mL}) \mathrm{G}$

$\mathrm{pH}: \quad 7.0$
CIIENT SAMPLE NO.

$05-1$
Lab Sample ID: 0212L341-003

Lab File ID: BLKO833.0.01

Date Received: $12 / 13 / 02$

Date Extracted: 12/17/02

Date Analyzed: $\underline{12 / 20 / 02}$

Dilution Factor: 1.00

CAS NO.

COMPOUND

CONCENTRATION UNITS:

(ug/I or $\mathrm{ug} / \mathrm{Kg}$ ) UG/KG

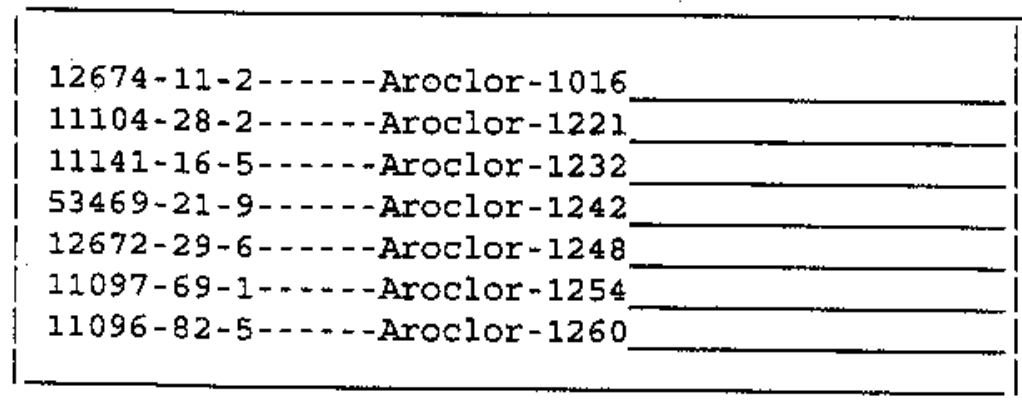

FORM 1 PEST
1000

2000

1000

1000

1000

1000

1000

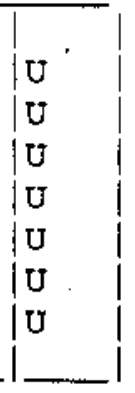

12/88 Rev. 
10

PESTICIDE ORGANICS ANALYSIS SHEET

Lab Name: Lionville Iabs, Inc. Work Order: 60052001001
CLIENT SAMPLE NO.

$$
\text { 232505-2 }
$$

Client: BECHTEL NEVADA V1805

Matrix:

WATER

Sample wt/vol: $\quad \quad 350(\mathrm{~g} / \mathrm{mL}) \mathrm{ML}$

Level: (low/med) LOW

dec.

\% Moisture: not dec.

Extraction: (SepF/Cont/Sonc) CONT

Extraction: (SepF/Cont/Sonc) CONT

Lab Sample ID: 0212L341-004

Lab File ID: BLKO8330.01

GPC Cleanup: (Y/N) $\underline{\mathrm{N}}$

$\mathrm{pH}: \quad 7.0$
Date Received: $12 / 13 / 02$

Date Extracted: 12/16/02

Date Analyzed: 12/18/02

Dilution Factor: 1.00

CAS NO.

COMPOUND

CONCENTRATION UNITS:

(ug/L or ug/Kg) UG/L

\begin{tabular}{|c|c|c|}
\hline . & & \\
\hline $12674-11-2 \ldots-A r o c l o r-1016$ & 11 & U U \\
\hline $11104-28-2-\cdots-$ Axoclor -1221 & 23 & iU \\
\hline $11141-16-5-\ldots-$ Aroclor -1232 & 11 & |U \\
\hline $53469-21-9 \cdots-$ Aroclor -1242 & 11. & U \\
\hline $12672-29-6-\ldots-$ Aroclor -1248 & 11 & $\mathrm{U}$ \\
\hline $11097-69-1----$ Aroclor -1254 & 11 & $\mathrm{U}$ \\
\hline $11096-82-5---$ Aroclor -1260 & 11 & | \\
\hline
\end{tabular}


CLOSURE REPORT - CAU 330

Section: Appendix B

Revision: 0

Date: July 2003

\section{THIS PAGE INTENTIONALLY LEFT BLANK}


CLOSURE REPORT - CAU 330

Section: Appendix B

Revision: 0

Date: July 2003

\section{SAMPLE DELIVERY GROUP}

V1806 
CLOSURE REPORT - CAU 330

Section: Appendix B

Revision: 0

Date: July 2003

\section{THIS PAGE INTENTIONALLY LEFT BLANK}




\section{PARAGON ANALYTICS, INC.}

225 Commerce Drive $\bullet$ Fort Collins, CO $80524 \bullet(800)$ 443-1511 $\bullet$ (970) 490-1511 $\bullet$ FAX (970) 490-1522

January 13,2003

Mr. Ted Redding

Bechtel Nevada

US DOE Zone 1, Bldg. 652, Rm 2, M/S NTS273

Mercury, NV, 89023

RE: Paragon Workorder: 02-12-064

Client Project Name: CAU 330

Client Project Number: V1806

Dear Mr. Redding:

One solid and one liquid sample was received from Bechtel Nevada on December 13, 2002. The samples were scheduled for Gamma Spectroscopy (pages 1-158) analysis. The results for this analysis are contained in the enclosed reports.

Thank you for your confidence in Paragon Analytics, Inc. Should you have any questions, please call.

Sincerely,

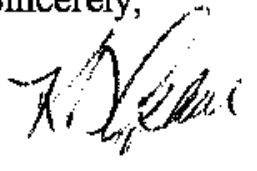

Paragon Analytics, Inc.

Ken Campbell

Project Manager

$\mathrm{KDC} / \mathrm{hc}$

Enclosure: Report 


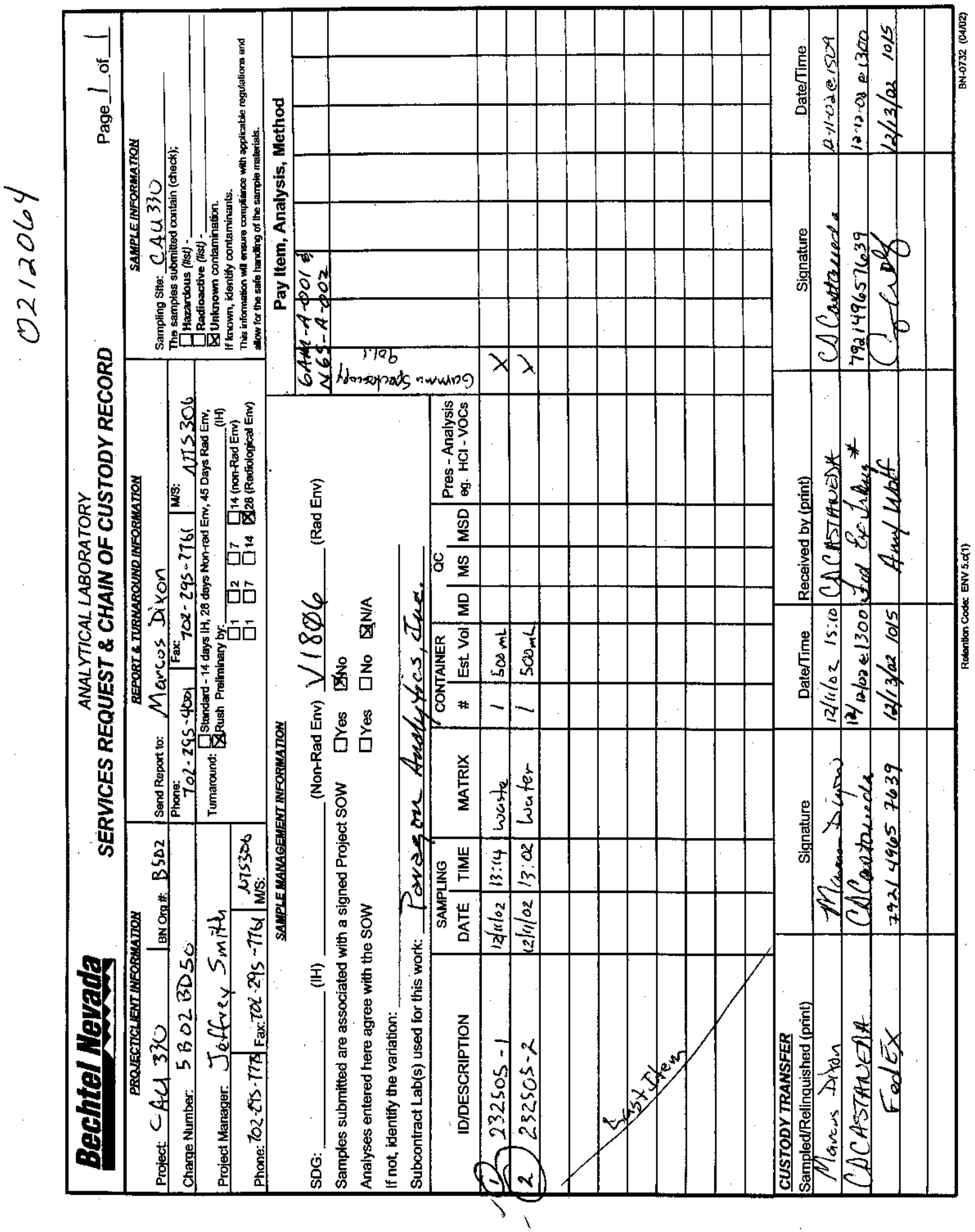




\title{
Paragon Analytics, Inc. Radiochemistry Case Narrative Gamma Spectroscopy
}

\section{Bechtel Nevada}

\author{
CAU 330 / V1806
}

Paragon Work Order 0212064

1. This report consists of analysis results for one solid sample and one liquid sample received by Paragon on $12 / 13 / 02$. The analysis results for these samples are reported on an 'as received' basis in units of $\mathrm{pCi} / \mathrm{gram}$.

2. These samples were prepared according to Paragon Analytics, Inc. procedure PAI SOP739R5.

3. The samples were analyzed for the presence of gamma emitting radionuclides according to Paragon Analytics, Inc. procedure PAI SOP713R7. The analyses were completed on 12/31/02.

4. The samples were analyzed using Seeker Version 2.2, which is a product of Vertechs Software Solutions, Inc.

5. Sample volumes were insufficient to allow preparation of duplicates. Duplicate analyses of samples 232505-1 and 232505-2 (PAI ID 0212064-1 and -2) were performed in lieû of preparation duplicates.

6. Due to current software limitations, the DER determinations in this report were calculated using the 2 sigma TPU. The SOW indicates that the 1 sigma TPU be used in the DER determination. However, the requested DER limit of less than 3 at the 1 sigma level (which is equivalent to 1.5 at the 2 sigma level) was achieved. Data quality is not affected.

7. The efficiencies used in the activity calculations for these samples were obtained using a NIST traceable mixed gamma source spiked into $500 \mathrm{~g}$ of sand. Due to differences between the calibration standard and the samples, the analytical results may be biased.

8. There are cases where the magnitude of the negative activity is greater than the 2 sigma TPU. The analyst's review of the data does not indicate a problem with the instrument data or the subsequent reporting systems. The data quality is not believed to be affected and the results are submitted without qualification. Under typical conditions, where background level sample data is normally distributed and analyzed by paired observations, this event is likely to occur at least $2.5 \%$ of the time.

9. No problems were encountered with either the client samples or the associated quality control samples. All quality control criteria were met.

The data contained in the following report have been reviewed and approved by the personnel listed below. In addition, Paragon Analytics, Inc. certifies that the analyses reported herein are true, complete and correct within the limits of the methods employed.
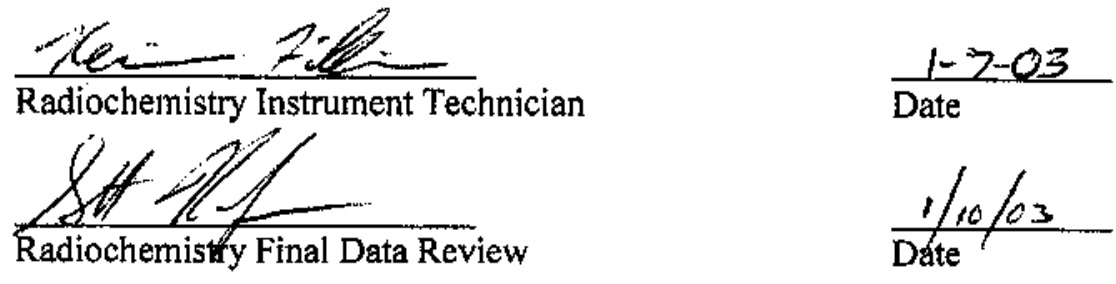


\section{PARAGON ANALYTICS, INC. \\ Radiochemistry Data Package}

Section 3

\section{INDIVIDUAL SAMPLE RESULTS}




\section{Gamma Spectroscopy Results}

\section{Method PAI 713R7}

\section{Sample Results}

Client Name: Bechtel Nevada

Client Project Name: CAU 330

Page: 1 of 4

Reported on: Tuesday, January 07, 2003

10:59:36

Laboratory Name: Paragon Analytlcs, Inc.

PAl Work Order: 0212064

Sample Matrix: Solid

Date Prepared: 30-Dec-02

Prep SOP: PAI 739R5

Prep Batch: GS01837
Date Collected: 11-Dec-02

Dato Analyzed: 31-Dec-02

Analytical SoP: PAI 713R7

Spectrum Code: 021300D01A
FInal Aliquot: $332.3 \mathrm{~g}$

Report Basis: As Recelved Count TIme (min.): 30

Library: GAM-A-001.LI

\begin{tabular}{|c|c|c|c|c|}
\hline Target Nucllde & Result $+1-2$ \& TPU & MDC & $\begin{array}{c}\text { Reporting } \\
\text { Unlts }\end{array}$ & Lab Quallfier \\
\hline $\mathrm{Ac}-228$ & $6.55 \mathrm{E}-02+/-1.76 \mathrm{E}-01$ & 3.03E-01 & $\mathrm{pCl} / \mathrm{g}$ & $\mathrm{U}$ \\
\hline Am-241 & $-5.65 \mathrm{E}-02+1-1.70 \mathrm{E}-01$ & $3.10 \mathrm{E}-01$ & $\mathrm{pCi} / \mathrm{g}$ & U \\
\hline Co-144 & $8.77 E-02+1-1.92 E-01$ & $3.26 E-01$ & $\mathrm{pCl} / \mathrm{g}$ & U \\
\hline $\cos 60$ & $-6.04 E-03+/-3.78 E-02$ & 7.18E-02 & $\mathrm{pCi} / \mathrm{g}$ & U. \\
\hline Cs-134 & $-4.15 \mathrm{E}-02+/-4.90 \mathrm{E}-02$ & 9.05E-02 & $\mathrm{pCi} / \mathrm{g}$ & ע \\
\hline$C \$-137$ & $2.34 \mathrm{E}-02+/-4.61 \mathrm{E}-02$ & $7.79 E-02$ & $\mathrm{pCl} / \mathrm{g}$ & U \\
\hline Eu-152 & $6.65 E-02+/-1.64 E-01$ & 2.89E-01 & $\mathrm{pCl} / \mathrm{g}$ & U \\
\hline Eu-154 & $8.86 E-02+/=\quad 1.98 E-01$ & 3.41E-01 & $\mathrm{pC} / \mathrm{g}$ & $\mathrm{U}$ \\
\hline Eu-155 & $-7.92 E-02+/-1.17 \mathrm{E}-01$ & $2.16 \mathrm{E}-01$ & $\mathrm{pCi} / \mathrm{g}$ & $U$ \\
\hline $\mathrm{K}-40$ & $-4.22 \mathrm{E}-02+\%-5.47 \mathrm{E}-01$ & $9.88 \mathrm{E}-01$ & $\mathrm{pCl} / \mathrm{g}$ & 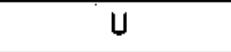 \\
\hline $\mathrm{Pb}-212$ & $-1.75 E-02+1-5.47 E-02$ & $9.98 \mathrm{E}-02$ & $\mathrm{pCl} / \mathrm{g}$ & $\mathrm{u}$ \\
\hline$P m=144$ & $2.59 E-02+j-3.97 E-02$ & $6.60 \mathrm{E}-02$ & $\mathrm{pCl} / \mathrm{g}$ & U \\
\hline Pm-146 & $2.98 E-02+1-4.68 E-02$ & $7.79 E-02$ & $\mathrm{pCl} / \mathrm{g}$ & $\mathrm{U}$ \\
\hline$R \amalg-106$ & $2.03 E-02+/-3.97 E-01$ & 7.04E-01 & $\mathrm{pCl} / \mathrm{g}$ & $\mathrm{U}$ \\
\hline Sb-125 & $-5.24 E-03+/-8.45 E-02$ & 1.54E-01 & $\mathrm{pCl} / \mathrm{g}$ & $\mathrm{U}$ \\
\hline Th-234 & 4.29E-02 +/- 7.41E-01 & $1.28 E+00$ & $\mathrm{pCl} / \mathrm{g}$ & $\mathrm{U}$ \\
\hline$U-235$ & $9.26 \mathrm{E}-03+/-2.03 \mathrm{E}-01$ & $3.56 \mathrm{E}-01$ & $\mathrm{pCi} / \mathrm{g}$ & $\mathrm{U}$ \\
\hline$Y-88$ & $1.25 \mathrm{E}-02+/-5.05 \mathrm{E}-02$ & $8.84 E-02$ & $\mathrm{pCl} / \mathrm{g}$ & $\mathrm{U}$ \\
\hline
\end{tabular}

Data Package ID: GSS0212064-1 


\section{Gamma Spectroscopy Results}

\section{Method PAI 713R7}

\section{Sample Results}

Client Name: Bechtel Novada

Client Project Name: CAU 330 Cllent Project Number: V1806
Page: 2 of 4

Reported on: Tuesday, January 07, 2003 10:59:36

Laboratory Name: Paragon Analytics, Inc.

PAl Work Order: 0212064

\begin{tabular}{|c|}
\hline 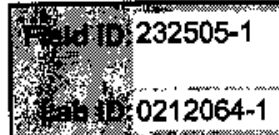 \\
\hline
\end{tabular}

Sample Matrix: Solid

Date Prepared: 30-Dec-02

Prep SOP: PAI 739R5

Prep Batch: GS01837
Date Collected: 11-Dec-02

Date Analyzed: 31-Dec-02

Analytical SOP: PAI 713R7

Spectrum Code: 021300D01A
Final Aliquot: $332.3 \mathrm{~g}$

Report Basis: As Recelved

Count Time (min.): 30

Library: GAN-A-001.LI

\begin{tabular}{|l|l|l|l|l|}
\hline Target Nuclide & Result +/- 2 s TPU & MDC. & $\begin{array}{c}\text { Reporting } \\
\text { Unlts }\end{array}$ & Lab Qualifier \\
\hline
\end{tabular}

\section{Comments:}

\section{Qualfilena/Fiags:}

U - Result ia less then the semple apocific MDC or less than the s8sociated TPU.

Y1 - Chemical Yiold is in control at 100-110\%. Quantlattve Yiald is assumed.

Y2 - Chemlcal Yield outside dofault limits.

LT - Resuly is less then Requesied MDC, greater than sample specinc MDC.

SQ - Spectral quality prevents accurate quantitation.

S: - Nuclide identiflcation andiox quentitution is tentative.

TI - Nuclido identlfication is tentative.

R - Nucilda has exceeded $B$ halilives.

\section{Abbreviatlons:}

TPU - Totel Propsgated Uncertainty (see PAI SOP 743)

MDC - MInImum Detectable Concentration (se0 PAI SOP 709)

Data Package ID: GSS0212064-1 


\section{Gamma Spectroscopy Results}

\section{Method PAI 713R7}

\section{Sample Results}

Client Name: Bechtel Nevada

Client Project Name: CAU 330

Client Project Number: V1806
Page: 3 of 4

Reported on: Tuesday, January 07, 2003

t0:59:37

Laboratory Name: Paragon Analytics, Inc.

PAI Work Order: 0212064

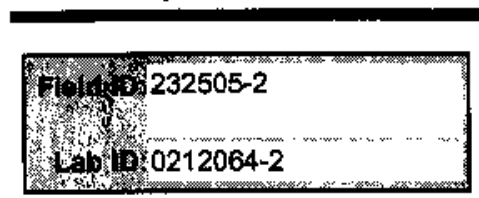

Sample Matrix: Liquid

Date Prepared: 30-Dec-02

Prep sOP: PAI 739R5

Prep Batch: GS01838
Date Collected: 11-Dec-02

Date Analyzed: 31-Dec-02

Analytical SOP: PAI 713R7

Spectrum Code: 021423D07A
Final Aliquot: $323.2 \mathrm{~g}$

Report Basis: As Received Count Time (min.): 30

Librany: GAM-A-001.L!

\begin{tabular}{|c|c|c|c|c|}
\hline Target Nuclide & Result +/- 2 s TPU & MDC & $\begin{array}{c}\text { Reporting } \\
\text { Units }\end{array}$ & Lab Qualifler \\
\hline Ac-228 & $-1.46 \mathrm{E}-01+/-1.85 \mathrm{E}-01$ & $4.65 \mathrm{E}-01$ & $\mathrm{pCl} / \mathrm{g}$ & $U$ \\
\hline Am-241 & $-3.85 E-03+1-6.01 E-02$ & $1.16 \mathrm{E}-01$ & $\mathrm{pCi} / \mathrm{g}$ & $U$ \\
\hline $\mathrm{Ce}-144$ & $2.14 \mathrm{E}-02+i-1.68 \mathrm{E}-01$ & $3.18 \mathrm{E}-01$ & $\mathrm{pCl} / \mathrm{g}$ & $\bar{U}$ \\
\hline Co- 60 & $-7.76 \mathrm{E}-03+/-5.87 \mathrm{E}-02$ & $1.33 \mathrm{E}-01$ & $\mathrm{pCl} / \mathrm{g}$ & $U$ \\
\hline Cs-134 & $6.08 E-03+1-6.08 E-02$ & $1.14 \mathrm{E}-01$ & $\mathrm{pCl} / \mathrm{g}$ & $\mathrm{U}$ \\
\hline Cs-137 & $-7.40 \mathrm{E}-03+1-5.74 \mathrm{E}-02$ & $1.17 E-01$ & $\mathrm{pCl} / \mathrm{g}$ & u \\
\hline Eu-152 & $-1.74 E-01+/-3.08 E-01$ & $7.59 E-01$ & $\mathrm{pCl} / \mathrm{g}$ & $U$ \\
\hline Eu-154 & $1.01 \mathrm{E}-01+i-3.19 \mathrm{E}-01$ & $6.05 E-01$ & $\mathrm{pCi} / 9$ & $U$ \\
\hline Eu-155 & $3.16 \mathrm{E}-02+/-9.14 \mathrm{E}-02$ & $1.63 \mathrm{E}-01$ & $\mathrm{pCl} / 9$ & $U$ \\
\hline$K-40$ & $-1.94 \mathrm{E}-02++-5.99 \mathrm{E}-01$ & $1.31 E+00$ & $\mathrm{pCi} / \mathrm{g}$ & $U$ \\
\hline $\mathrm{Pb}-212$ & $-6.84 \mathrm{E}-02+1-7.95 \mathrm{E}-02$ & $1.64 \mathrm{E}-01$ & $\mathrm{pCi} / \mathrm{g}$ & $u$ \\
\hline$P m-144$ & $-6.90 \mathrm{E}-03+/-7.44 E-02$ & $1.43 \mathrm{E}_{-01}$ & $\mathrm{pCl} / \mathrm{g}$ & $U$ \\
\hline $\mathrm{Pm}-146$ & $-8.25 \mathrm{E}-03+1-5.75 \mathrm{E}-02$ & $1.17 \mathrm{E}_{-01}$ & $\mathrm{pCl} / \mathrm{g}$ & $U$ \\
\hline Ru-106 & $1.80 \mathrm{E}-01+/-4.57 \mathrm{E}-01$ & 8.28E-01 & $\mathrm{pCl} / \mathrm{g}$ & $U$ \\
\hline Sb-125 & $2.69 \mathrm{E}-02+i-1.30 \mathrm{E}-01$ & $2.43 E-01$ & $\mathrm{pCi} / \mathrm{g}$ & $\mathrm{U}$ \\
\hline Th-234 & 1.63E-01 +/- 4.98E-01 & $8.69 \mathrm{E}-01$ & $\mathrm{pCl} / \mathrm{g}$ & u \\
\hline U-235 & $-1.55 \mathrm{E}-01+/-1.86 \mathrm{E}-01$ & 4.00E-01 & $\mathrm{pCi} / \mathrm{g}$ & u \\
\hline $\mathrm{Y}-88$ & $-3.24 E-02+/-5.99 E-02$ & $1.42 E-01$ & $\mathrm{pCl} / \mathrm{g}$ & $\bar{U}$ \\
\hline
\end{tabular}

Data Package ID: GSS0212064-1 


\section{Gamma Spectroscopy Results}

\section{Method PAI 713R7}

\section{Sample Results}

Client Name: Bechtel Nevada

Client Project Name: CAU 330
Page: 4 of 4

Reported on: Tuesday, January 07, 2003 10:59:37

Laboratory Name: Paragon Analytics, inc.

PAI Work Order: 0212064
Date Collected: 11-Dec-02

Date Analyzed: 31-Dec-02

Analytical SOP: PAl 713R7

Spectrum Code: 021423D07A
Final Allquot: $323.2 \mathrm{~g}$

Report Basis: As Recelved Count Time (mln.): 30

Prep soP: PAI 739R5

Prep Batch: GS01838

LLbrary: GAM-A-001.LI

\section{Result +/- 2 s TPU}

\section{MDC}

\section{Reporting} Units

\section{Lab Qualifier}

\section{Comments:}

Qualtilertiflaps:

$U$-Result is less then the sample specific MDC or less than the associeted TPU.

Y1 - Chemical Yield is in control at 100-110\%. Quantitutive Yield is asesumed.

Y2 - Chemical Yleid cutside defoult limits.

LT - Result is less than Requested MDC, oreater than ample specific MOC

SO - Spectral quality prevents accurate quantlation.

SI - Nuclide Identification andior quantilation Is tentetive.

YI - Nuclide idientification la tontatve.

$R$ - Nuctide has exceaded 8 halifilves.
Abbreviatlons:

TPU - Totel Propagated Uncerteinty (sse PAI SOP 743)

MDC - Minimum Detectable Concentration (ste PA SOP 709) 
CLOSURE REPORT - CAU 330

Section: Appendix B

Revision: 0

Date: July 2003

\section{SAMPLE DELIVERY GROUP}

V1879 
CLOSURE REPORT - CAU 330

Section: Appendix B

Revision: 0

Date: July 2003

\section{THIS PAGE INTENTIONALLY LEFT BLANK}




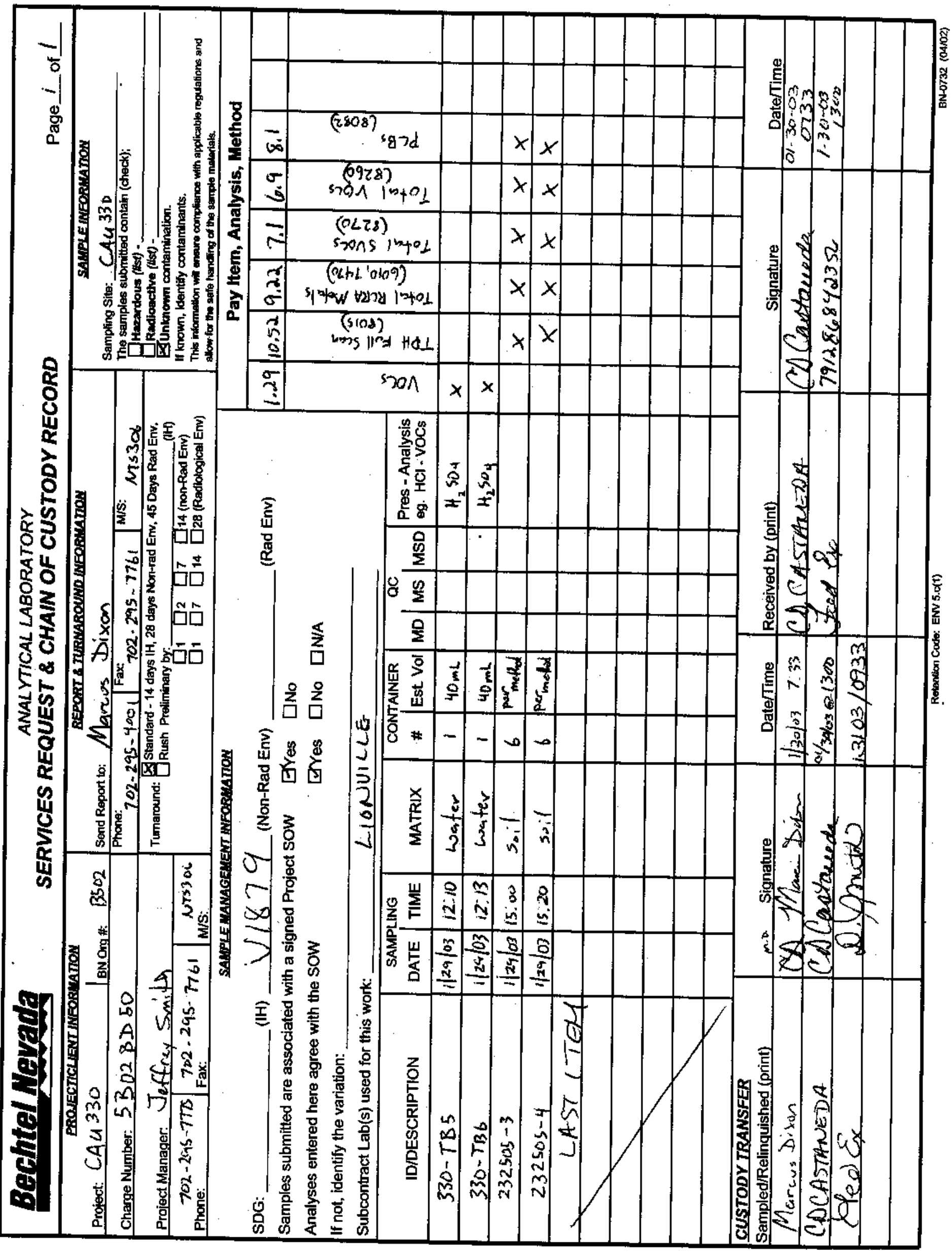


Case Narrative 


\section{$0 / V L I$ \\ LONVIIIF IABCHAIORV INC.}

Client: BECHTEL-NEVADA V1879

LVL \#: 0301L631

W.o. \#: 60052-001-001-0001-00

Date Received: 01-31-2003

\section{GC/MS VOLATILE}

Two (2) water and two (2) soil samples were collected on 01-29-2003.

The samples and their associated QC samples were analyzed according to criteria set forth in Lionville Laboratory OPs based on SW 846 Method 8260B for TCL Volatile target compounds on 02-05,06-2003.

The following is a summary of the QC results accompanying the sample results and a description of any problems encountered during their analyses:

1. All results presented in this report are derived from samples that met LvLI's sample acceptance policy.

2. The required holding time for analysis was met.

3. Non-target compounds were detected in the samples.

4. All surrogate recoveries were within EPA QC limits.

5. All matrix spike recoveries were within EPA QC limits.

6. All blank spike recoveries were within EPA QC limits.

7. The method blanks contained the common laboratory contaminant Methylene Chloride at levels less than $3 x$ the CRQL.

8. Internal standard area criteria were not met for sample 232505-4. The analysis of associated matrix spike samples fulfills the reanalysis requirement.

9. Manual integrations are performed according to OP L-QA-125 to produce quality data with the utmost integrity. All manual integrations are required to be technically valid and properly documented. Appropriate technical flags are defined in the Glossary ("Technical Flags For Manual Integration").

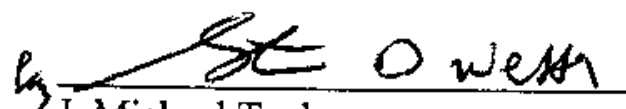

J. Michael Taylor

President

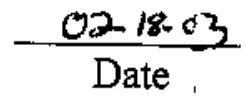

Lionville Laboratory Incorporated

somigroupidata'buaibectel-13evada $0301-631$.doc

The resuls presented in this report relate only to the analytical testing and conditions of the samples at receipt and during storage. 


\section{GLOSSARY OF VOA DATA}

\section{DATA OUALIFIERS}

$\mathbf{U}=$ Compound was analyzed for but not detected. The associated numerical value is the estimated sample quantitation limit which is included and corrected for dilution and percent moisture.

$\mathbf{J}=$

Indicates an estimated value. This flag is -used under the following circumstances: 1) when estimating a concentration for tentatively identifjed compounds (TICs) where a l:1 response is assumed; or 2) when the mass spectral data indicate the presence of a compound that meets the identification criteria but the result is less than the specified detection limit but greater thari zero: For example, if the limit of detection is $10 \mathrm{ug} / \mathrm{L}$ and a concentration of $3 \mathrm{ug} / \mathrm{L}$ is calculated, it is reported as 3J.

B - This flag is used when the analyte is found in the associated blank os well as in the sample. It indicates possible/probable blank contamination. This flag is also used for a TIC as well as for a positively identified TCL compound.

E = Indicates that the compound was detected beyond the calibration range and was subsequently analyzed at a dilution.

D = ldentifies all compounds identified in an analysis at a secondary dilution factor.

$1 . \quad$ Interference.

NQ = Result qualitatively confirmed but not able to quantify.

N = Indicates presumptive evidence of a compound. This flag is only used for tentatively identified compounds (TICs), where the identification is based on a mass spectral librory search. II is applied to all TIC results. For generic characterization of a TIC, such as chlorinated hydrocarbon, the N code is nol used.

X = This flag is used for a TIC compound which is quantified relative to a response factor generated from a daily calibration standard (rather than quantified relative to the closest intemal standard).

$\mathbf{Y} \quad$ - Additional qualifiers used as required are explained in the case narrative. 


\section{GLOSSARY OF VOA DATA}

\section{ABBREVIATIONS}

BS = Indicates blank spike in which reagent grade water is spiked with the CLP matrix spike solutions and carried through all the steps in the method. Spike recoveries are reported.

BSD $=$ Indicates blank spike duplicate. $\ldots, \ldots \ldots$

MS = Indicates matrix spike.

MSD = Indicates matrix spike duplicate.

DL = Suffix added to sample number to indicate that results are from a diluted analysis.

NA $=$ Not Applicable.

DF $\quad=$ Dilution Factor.

NR $\quad-\quad$ Not Required.

SP, $\mathbf{Z} \quad$ - Indicotes Spiked Compound. 
Sample Data for each Sample 
$1 \mathrm{~A}$

VOLATILE ORGANICS ANALYSIS SHEET
EPA SAMPLE NO.

$330-$ TB5

Lab Name: Lionville Labs. Inc. Contract: 60052001001

Lab Code: Lionvi Case No.:

Matrix: (soil/water) WATER

Sample wt/vol:

$5.00(\mathrm{~g} / \mathrm{mL}) \mathrm{ML}$

Level: (low/med). LOW

Moisture: not dec.

Columin: (pack/cap) CAP
SAS NO.:

Lab Sample ID: 03011631-001

Lab File ID: $\quad$ x020520

Date Received: 01/31/03

Date Analyzed: 02/05/03

Dilution Factor: 1.00

CAS NO.

COMPOUND

CONCENTRATION UNITS:

(ug/L or $u g / \mathrm{Kg}$ ) $u q / \mathrm{L}$

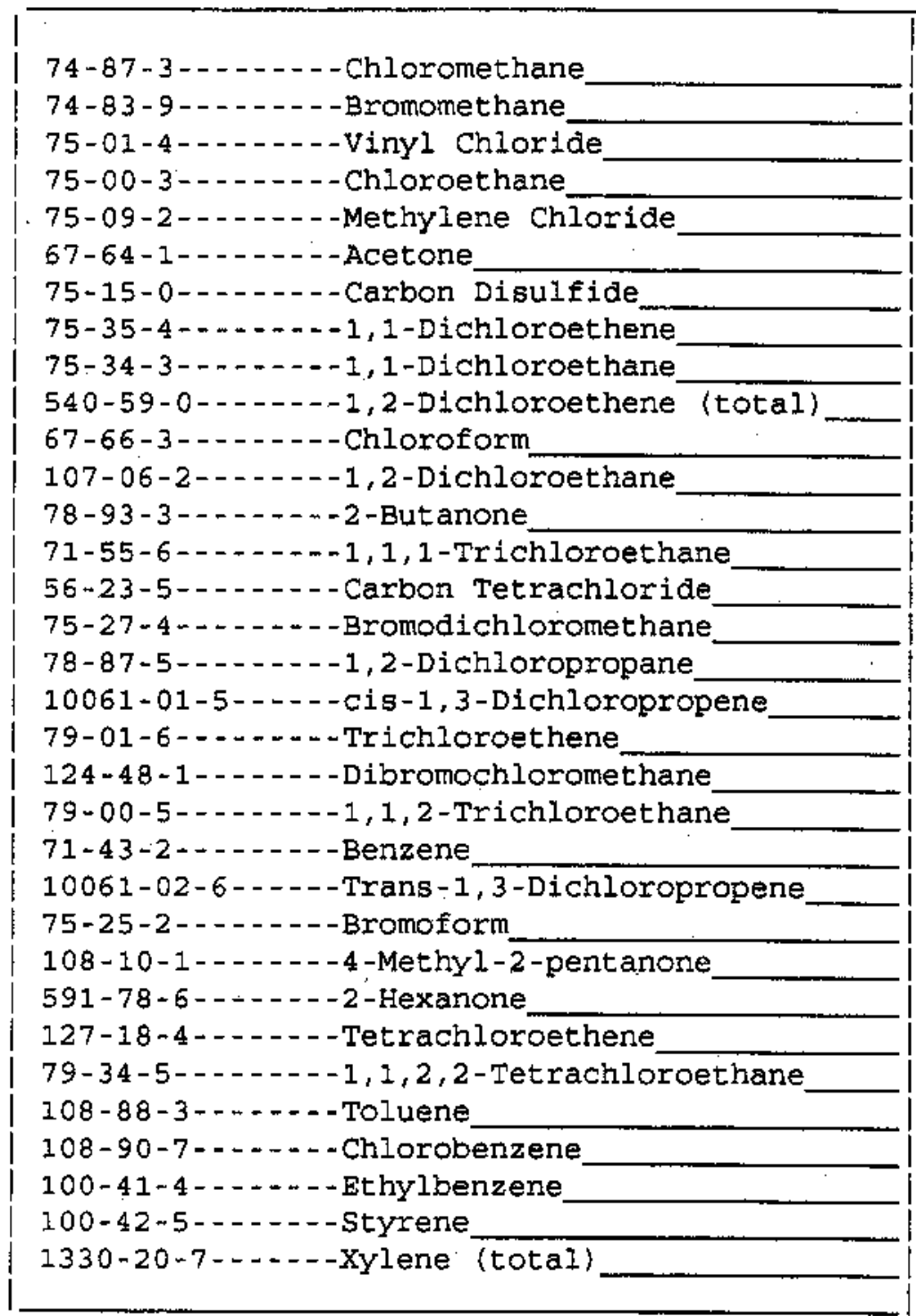

\begin{tabular}{|c|c|}
\hline 10 & | \\
\hline 10 & | \\
\hline 10 & |U \\
\hline 10 & iu \\
\hline 9 & $B$ \\
\hline 10 & | \\
\hline 5 & |U \\
\hline 5 & 10 \\
\hline 5 & iu \\
\hline 5 & $\mathrm{U}$ \\
\hline 5 & U \\
\hline 5 & U \\
\hline 10 & $\mid \mathrm{U}$ \\
\hline 5 & |u \\
\hline 5 & |U \\
\hline 5 & |u \\
\hline 5 & | U \\
\hline 5 & |U \\
\hline 5 & |U \\
\hline 5 & U \\
\hline 5 & U \\
\hline 5 & | U \\
\hline 5 & | U \\
\hline 5 & U \\
\hline 10 & $\mid U$ \\
\hline 10 & $\mid \mathrm{U}$ \\
\hline 5 & U \\
\hline 5 & $u$ \\
\hline 5 & | \\
\hline 5 & | \\
\hline 5 & |U \\
\hline 5 & | U \\
\hline 5 & |U \\
\hline
\end{tabular}

1/87 Rev. 
$1 \mathrm{~A}$

VOLATIIE ORGANICS ANALYSIS SHEET

Lab Name: Lionvilie Labs, Inc. Contract: 60052001001
SAS NO.:

Lab Sample ID: $\quad 03015633-002$

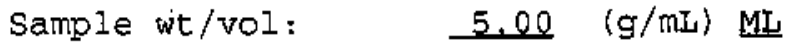

Level: (low/med) LOW

\% Moisture: not dec.

Column: (pack/cap) CAP

Lab Code: Lionvi Case No:

Matrix: (soil/water) WATER

Lab File ID:

Date Receivea: $\quad 01 / 31 / 03$

Date Analyzed: $02 / 05 / 03$

Dilution Factor: 1.00
EPA SAMPLE NO.

$330-$ TB6

CAS NO.

COMPOUND

CONCENTRATION UNITS :

$(\mathrm{ug} / \mathrm{L}$ or $\mu \mathrm{g} / \mathrm{kg}$ ) $\mathrm{ug} / \mathrm{L}$

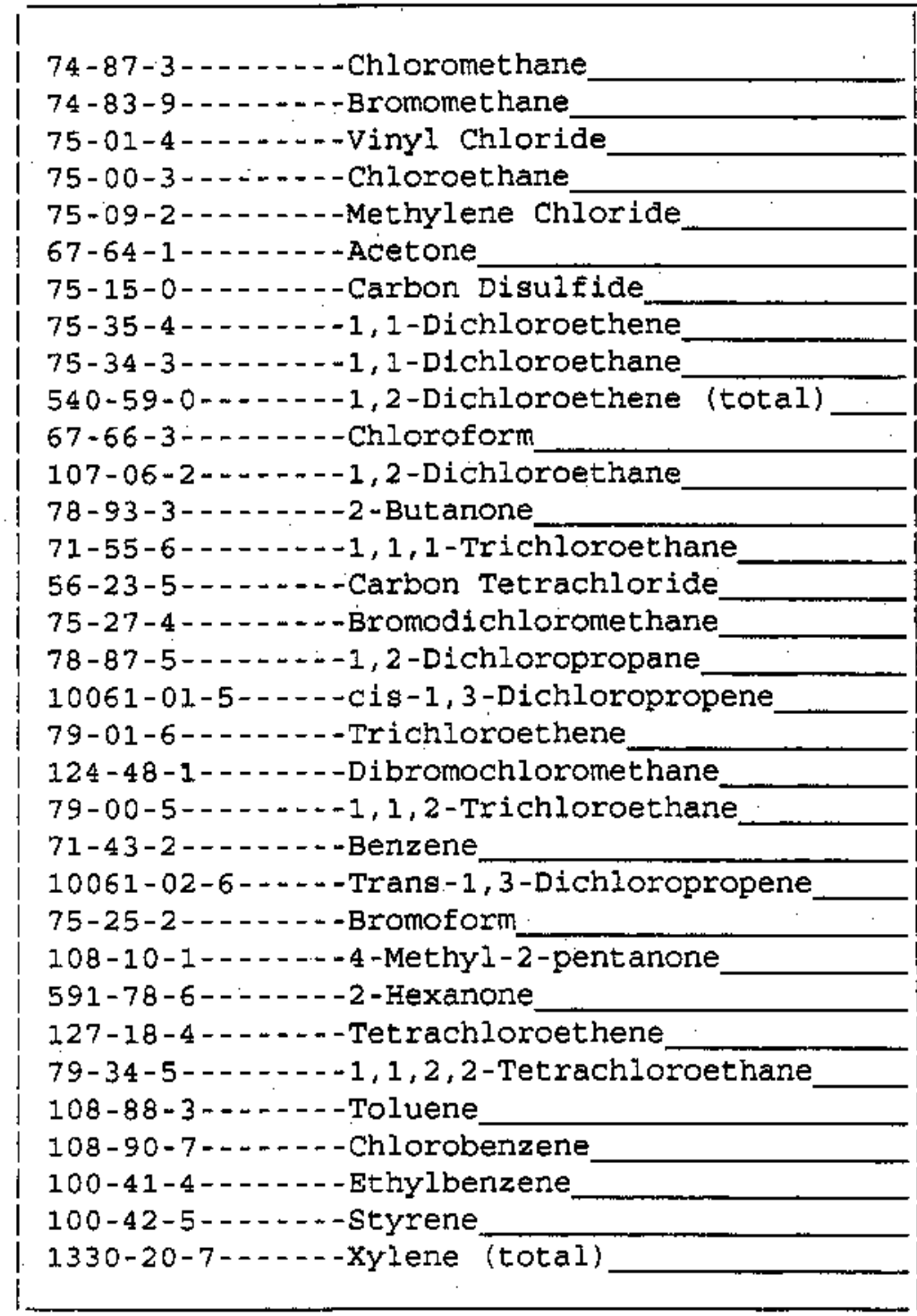

FORM $1 \mathrm{~V}-1$

1/87 Rev. 
Lab Name: Lionvilie Labs. Inc. Contract: 60052001001

Lab Code: Lionvi Case No.:

Matrix: (soil/water) SoIL

Sample wt/vol: $\quad \underline{5.30}(\mathrm{~g} / \mathrm{mL}) \mathrm{G}$

Level: (low/med) LOW

\%oisture: not dec. 1

Column: (pack/cap) CAP
SAS NO. :

Lab Sample ID: 03015631-003

Lab File ID: $\quad \mathbf{0 0 2 0 6 2 2}$

Date Received: $\underline{0.131 / 03}$

Date Analyzed: $02 / 06 / 03$

Dilution Factor: 0.943

SDG No.:

CAS NO.

COMPOUND

CONCENTRATION UNITS :

(ug/L or $u g / \mathrm{Kg}$ ) $\mathrm{ug} / \mathrm{Kg}$

\begin{tabular}{|c|}
\hline $74-87-3-1--C h l o r o m e t h a n e$ \\
\hline 74-83-9--1--Bromomethane \\
\hline 75-01-4-------vinyl Chloride. \\
\hline $75-00-3---1-$ Chloroethane \\
\hline 75-09-2-1.-.-Methylene chloride. \\
\hline $67-64-1-\cdots$ Acetone \\
\hline $75-15-0 \ldots \ldots$ Carbon Disulfide \\
\hline $75-35-4=\ldots-1,1-$ - ichloroethene. \\
\hline $75-34-3-\cdots-1,1-$ Dichloroethane. \\
\hline $540-59-0 \cdots \cdots-\ldots 1,2-D i c h l o r o e t h e n e$ (total) \\
\hline $67-66-3 \ldots-\cdots-C h i o r o f o r m$ \\
\hline 107-06-2-1.-1,2-Dichloroethane. \\
\hline $78-93-3------2$-Butanone \\
\hline $71-55-6 \cdots 1,1,1-$ Trichloroethane \\
\hline 56-23-5-.----Carbon Tetrachloride. \\
\hline $75-27-4-----$-Bromodichloromethane \\
\hline 78-87-5--1--1,2-Dichloropropane_ \\
\hline 10061-01-5-----cis-1, 3-Dichloropropene \\
\hline $79-01-6-\ldots-m-$ Trichloroethene \\
\hline $124-48-1-\cdots-$ Dibromochloromethane \\
\hline $79-00-5 \cdots-1,1,2-T r i c h l o r o e t h a n e$ \\
\hline $71-43-2---1-$-Benzene \\
\hline 10061-02-6--CTrans-1, 3-Dichloropropene \\
\hline $75-25-2--1-$ Bromoform \\
\hline 108-10-1------4-Methyl-2-pentanone \\
\hline $591-78-6------2-$ Hexanone \\
\hline $127-18-4 \cdots--T e t r a c h l o r o e t h e n e$ \\
\hline 79-34-5-----1,1,2,2-Tetrachloroethane_ \\
\hline $108-88-3-----$ Toluene \\
\hline $108 \cdot 90-7-\ldots-$ Chlorobenzene \\
\hline 100-41-4------Ethylbenzene. \\
\hline $100+42-5-\ldots-\ldots$ Styrene_ \\
\hline $1330-20-7 \cdots-.-$ XYlene (total) \\
\hline
\end{tabular}

FORM 1 V-1

\section{$232505-3$}


$1 \mathrm{~A}$

VOLATILE ORGANICS ANALYSIS SHEET
EPA SAMPLE NO.

$232505-4$

Lab Name: Lionville Labs, Inc. Contract: 60052001001

Lab Code: Lionvi Case No.:

Matrix: (soil/water) SoIL

Sample wt/vol: $\quad 5.60 \quad(\mathrm{~g} / \mathrm{mL}) \mathrm{G}$

Level: (low/med) ' $\mathrm{LOW}$

\% Moisture: not dec. 1

Column: (pack/cap) CAP
SAS NO. :

Lab Sample ID:

Lab File ID:

Date Received: $01 / 31 / 03$

Date Analyzed: $02 / 06 / 03$

Dilution Factor: 0.893

CAS NO

COMPOUND

CONCENTRATION UNITS :

(ug/L or $u g / \mathrm{Kg}$ ) ug/Kg

\begin{tabular}{|c|c|}
\hline \multicolumn{2}{|l|}{ 74-87-3--------Chloromethane } \\
\hline \multicolumn{2}{|l|}{ 74-83-9-------Bromomethane } \\
\hline \multicolumn{2}{|l|}{ 75-01-4-..---vinyl Chloride. } \\
\hline \multicolumn{2}{|l|}{$75-00-3------C h l o r o e t h a n e$} \\
\hline \multicolumn{2}{|c|}{ 75-09-2-------Methylene Chloride } \\
\hline \multicolumn{2}{|l|}{$67-64-1-------$ Acetone_. } \\
\hline \multicolumn{2}{|l|}{$75-15-0-\cdots--C a r b o n$ Disulfide } \\
\hline \multicolumn{2}{|c|}{$75-35-4---\cdots 1,1-D i c h l o r o e t h e n e$} \\
\hline \multicolumn{2}{|c|}{ 75-34-3-------1,1-Dichloroethane. } \\
\hline \multicolumn{2}{|c|}{$540-59-0-\cdots-1,2-$ Dichloroethene (total) } \\
\hline \multicolumn{2}{|c|}{$67-66-3-\cdots-$ ChIoroform } \\
\hline \multicolumn{2}{|c|}{ 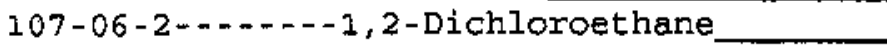 } \\
\hline \multicolumn{2}{|l|}{$78-93-3-------2-$ Butanone } \\
\hline \multicolumn{2}{|c|}{$71-55-6-------1,1,1-\operatorname{Tr} i \mathrm{chloroethane}$} \\
\hline \multicolumn{2}{|c|}{ 56-23-5---n-Carbon Tetrachloride } \\
\hline \multicolumn{2}{|c|}{ 75-27-4---n. Bromodichloromethane_ } \\
\hline \multicolumn{2}{|c|}{ 78-87-5----n 1, 2-Dichloropropane } \\
\hline \multicolumn{2}{|c|}{ 10061-01-5-n-cis-1,3-Dichloropropene } \\
\hline \multicolumn{2}{|l|}{$79-01-6 \cdots-\cdots-\operatorname{Tr} i c h l o r o e t h e n e_{m}$} \\
\hline \multicolumn{2}{|c|}{$124-48-1-\ldots-$ Dibromochloromethane } \\
\hline \multicolumn{2}{|c|}{$79-00-5 \cdots \ldots-1,1,2$-Trichloroethane } \\
\hline \multicolumn{2}{|c|}{$71-43-2-------$ Benzene } \\
\hline \multicolumn{2}{|c|}{ 10061-02-6-----Trans-1, 3-Dichloropropene } \\
\hline \multicolumn{2}{|l|}{$75-25-2------$ Bromoform } \\
\hline \multicolumn{2}{|c|}{ 108-10-1-------4-Methyl-2-pentanone } \\
\hline \multicolumn{2}{|l|}{$591-78-6------2-$ Hexanone } \\
\hline \multicolumn{2}{|l|}{ 127-18-4------Tetrachloroethene } \\
\hline \multicolumn{2}{|c|}{$79-34-5 \ldots-1,1,2,2$-Tetrachloroethane } \\
\hline \multicolumn{2}{|l|}{ 108-88-3- - - - Toluene } \\
\hline \multicolumn{2}{|l|}{ 108-90-7-------Chlorobenzene } \\
\hline \multicolumn{2}{|l|}{$100-41-4------$ Ethylbenzene } \\
\hline \multicolumn{2}{|l|}{$100-42-5 \cdots \cdots-$ Styrene } \\
\hline $1330-20-7 \ldots-\ldots y$ - Xye (total) & \\
\hline
\end{tabular}

FORM $1 \mathrm{~V}-1$

\begin{tabular}{|c|c|c|}
\hline 9 & & U \\
\hline 9 & & $\mathrm{U}$ \\
\hline 9 & & $\mathrm{U}$ \\
\hline 9 & & $\mathrm{U}$ \\
\hline 20 & & |B \\
\hline 9 & & $\mathrm{U}$ \\
\hline 4 & & |u \\
\hline 4 & & $\mathrm{U}$ \\
\hline 4 & & $\mid \mathrm{U}$ \\
\hline 4 & & $\mid v$ \\
\hline 4 & & $\mathrm{U}$ \\
\hline 4 & & $\mid \mathrm{J}$ \\
\hline 9 & & $\mathrm{U}$ \\
\hline 4 & & U \\
\hline 4 & & 0 \\
\hline 4 & & |u \\
\hline 4 & & $\mathrm{U}$ \\
\hline 4 & & u \\
\hline 4 & $i$ & | U \\
\hline 4 & & U \\
\hline 4 & & $\mathrm{U}$ \\
\hline 4 & & $\mathrm{U}$ \\
\hline 4 & & $\mathrm{U}$ \\
\hline 4 & & iu \\
\hline 9 & & iu \\
\hline 9 & & U \\
\hline 4 & & i \\
\hline 4 & & | \\
\hline 4 & & |U \\
\hline 4 & & ש' \\
\hline 4 & & |t \\
\hline 4 & & i \\
\hline 4 & & |U \\
\hline
\end{tabular}

1/87 Rev. 
Case Narrative 


\section{SLI \\ IIONVIIIE LABORAIORY INC.}

Client: BECHTEL-NEVADA V1879

LVL \#: $0301 \mathrm{~L} 631$

W.O. \#: 60052-001-001-0001-00

Date Received: 01-31-2003

\section{SEMYVOLATILE}

Two (2) soil samples were collected on 01-29-2003.

The samples and their associated QC samples were extracted according to Lionville Laboratory OPs based on method 3550 on $02-03-2003$ and analyzed according to criteria set forth in Lionville Laboratory OPs based on SW 846 Method 8270C for TCL Semivolatile target compounds on 02-04-2003.

The following is a summary of the QC results accompanying the sample tesults and a description of any problems encountered during their analyses:

1. All results presented in this report are derived from samples that met LvLI's sample acceptance policy.

2. Samples were extracted and analyzed within required holding time.

3. Non-target compounds were detected in the samples.

4. All surrogate recoveries were within EPA QC limits.

5. All matrix spike recoveries were within EPA QC limits.

6. All blank spike recoveries were within EPA QC limits.

7. The method blank contained the common laboratory contaminant Bis (2-Ethylhexyl) phthalate at a level less than the CRQL.

8. Internal standard area criteria were not met for the method blank and the blank spike; however, the GC/MS instrument was inspected for possible malfunction and was judged to be functioning properly and all surrogate recoveries were within QC limits; consequently, the samples were not reanalyzed.

9. Manual integrations are performed according to OP L-QA-125 to produce quality data with the utmost integrity. All manual integrations are required to be technically valid and properly documented. Appropriate technical flags are defined in the Glossary ("Technical Flags For Manual Integration").

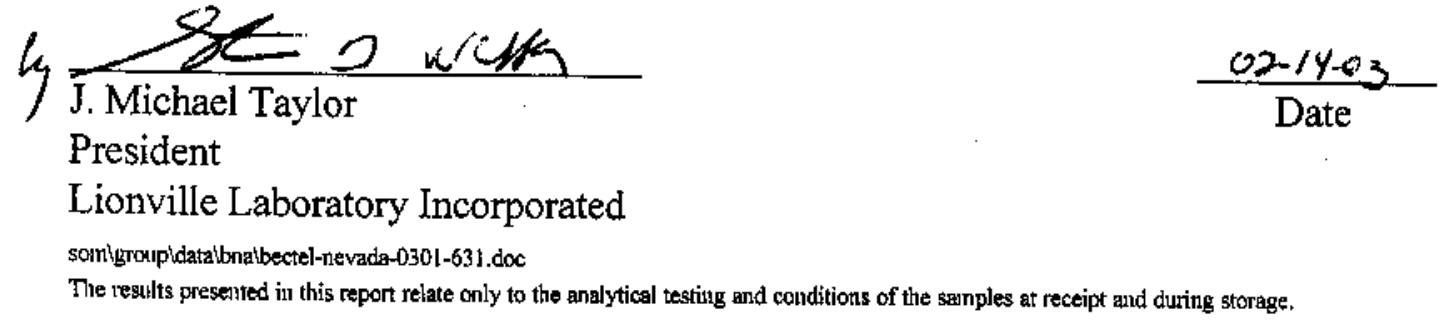




\section{GLOSSARY OF BNA DATA}

\section{DATA OUALIFIERS}

U = Compound was analyzed for but not detected. The associated numerical value is the estimated sample quantitation limit which is included and corrected for dilution and percent moisture.

J Indicates an estimated value. This flag is used under the following circumstances: 1) when estimating a concentration for tentatively identified compounds (TICs) where a $1: 1$ response is assumed; or 2) when the mass spectral data indicate the presence of a compound that meets the identification criteria but the result is less than the specified detection. limit but grealer than zero. For example, if the limit of detection is $10 \mathrm{ug} / \mathrm{L}$ and a concentration of $3 \mathrm{ug} / \mathrm{L}$ is calculated, it is reporied as 33.

B - This flag is used when the analyte is found in the associated blank as well as in the sample. It indicates possible/probable blank contamination. This flag is also used for a TIC well as for a positively identified TCL compound.

E $\quad$ - Indicates that the compound was detected beyond the calibration range and was subsequently analyzed a dilution.

D Jontifies all compounds identified in an analysis at a secondary dilution factor.

1 . Interference. .

NQ = Result qualitatively confirmed but not able to quantify.

A = Indicates that a TIC is a suspected aldol-condensation product.

N - Indicates presumptive evidence of a compound. This flag is only used for tentatively identified compounds (TICs), where the identification is based on a mass spectral library search. It is applied to ail TIC results. For generic characterization of a TIC, such as chlorinated hydrocarbon, the $N$ code is not used.

X - This flag is used for a TIC compound which is quantified relative to a response factor generated from a daily caljbration standard (rather than quantified relative to the closest intemal standard).

y = Additional qualifiers used as required are explained in the case narrative. 


\section{GLOSSARY OF BNA DATA}

\section{ABBREVIATIONS}

BS = Indicates blank spike in which reagent grade water is spiked with the CLP matrix spike solutions and carried through all the steps in the method. 'Spike recoveries are reported.

BSD ${ }^{*}=$ Indicates blank spike duplicate.

MS = Indicates matrix spike.

MSD = Indicates matrix spike duplicate.

DL = Suffix added to sample number to indicate that results are from a diluted analysis.

NA $=$ Not Applicable.

DF = Dilution Factor.

NR $=$. Not Required.

SP, $\mathbf{Z}=$ Indicstes Spiked Compound. 
Sample Data for each Sample 
Lab Name: Lionville Labs, Inc. Work Order: 60052001001

Client: BECHTEL NEVADA V1879

Matrix: (soil/water) SQIL

Sample wt/vol: $30.0(\mathrm{~g} / \mathrm{mU}) \mathrm{G}$

Level: $\quad$ (IOw/med) LOW

\% Moisture: 1 decanted: $(\mathrm{Y} / \mathrm{N})$

Concentrated Extract Volume: 1000(uJ)

Injection volume: $2.0(u L)$

GPC Clearup: $(\mathrm{Y} / \mathrm{N}) \underline{\mathrm{N}}$

CAS NO.
Iab Sample ID: 0301L631-003

Lab File ID: $\quad$ A020410

Date Received: $\quad 01 / 31 / 03$

Date Extracted: $02 / 03 / 03$

Date Analyzed: $02 / 04 / 03$

Dilution Factor: 1.00

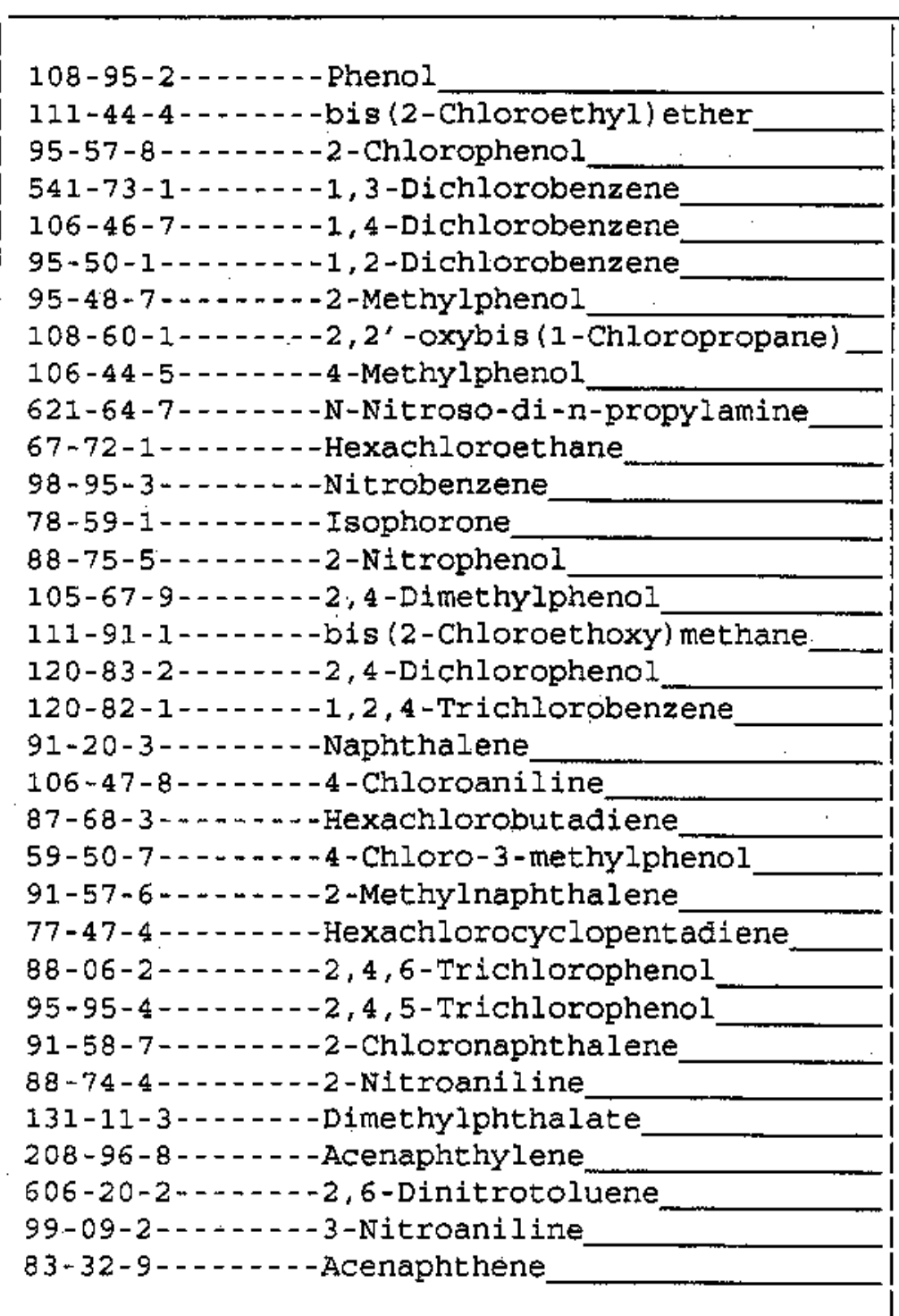

CONCENTRATION UNITS: (ug/L or $u g / \mathrm{Kg}$ ) UG/KG 
Lab Name: Lionville Labs, Inc. Work Order: 60052001001

Client: BECHTEL NEVADA V1879

Matrix: (soil/water) SOIL

Sample wt/vol: $30.0 \quad(\mathrm{~g} / \mathrm{mL}) \mathrm{G}$

Level: (low/med) LOW

\% Moisture: 1 decanted: $(Y / N)$

Concentrated Extract Volume: 1000 (uL)

Injection volume: $\underline{2.0}$ (uL)

GPC Cleanup: $\quad(\underline{Y} / \mathrm{N}\rangle \underline{\underline{N}}$

CAS NO.

COMPOUND

$\mathrm{pH}: \quad 7.0$
Lab Sample ID: 0301.4631-003

Lab File ID: $\underline{\text { A020410 }}$

Date Received: $\underline{01 / 31 / 03}$

Date Extracted: $02 / 03 / 03$

Date Analyzed: $\quad 02 / 04 / 03$

Dilution Factor: 1.00

\begin{tabular}{|c|}
\hline $5 i-28-5-----2,4-$ Dinitrophenol \\
\hline $100-02-7-\ldots-m-$ Nitrophenol \\
\hline $1.32-64-9 \ldots--$-Dibenzofuran \\
\hline $121-14-2 \cdots--2,4-$ Dinitrotoluene \\
\hline $84-66-2 \ldots \ldots-\ldots$ Diethylphthalate \\
\hline 7005-72-3----4-Chlorophenyl-phenylether \\
\hline $86-73-7------$ Fluorene \\
\hline 100-01-6------4-Nitroaniline \\
\hline $534-52-1------4,6$-Dinitro-2-methylphenol \\
\hline 86-30-6---ne-Nitrosodiphenylamine (1) \\
\hline 101-55-3----4-Bromophenyl-phenylether \\
\hline 118-74-1-------Hexachlorobenzene \\
\hline 87-86-5------Pentachlorophenol. \\
\hline 85-01-8------Phenanthrene \\
\hline 120-12-7-----Anthracene. \\
\hline 86-74-8-------Carbazole \\
\hline $84-74-2-\cdots-n-$ Di-n-butylphthalate \\
\hline 206-44-0------Fluoranthene. \\
\hline $129-00-0-----$ Pyrene. \\
\hline 85-68-7-------Butylbenzylphthalate \\
\hline $91-94-1-------3,3^{\prime}$-Dichlorobenzidine \\
\hline $56-55-3------B e n z o$ (a) anthracene \\
\hline 218-01-9--------Chrysene. \\
\hline $117-81-7-\ldots$-bis (2-Ethylhexyl) phthalate \\
\hline $117-84-0-\cdots---D i-n-o c t y l$ phthalate \\
\hline 205-99-2------Benzo (b) fluoranthene_ \\
\hline 207-08-9-----Benzo (k) fluoranthene \\
\hline $50-32-8------$ Benzo (a) pyrene \\
\hline $193-39-5 \cdots \cdots-\ldots$ Indeno $(1,2,3-c d)$ pyrene \\
\hline 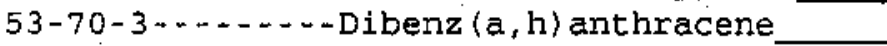 \\
\hline $191-24-2 \ldots-\cdots$ Benzo $(g, h, i)$ perylene \\
\hline
\end{tabular}

(1) - Cannot be separated from Diphenylamine FORM 1 SV-2
CONCENTRATION UNITS:

$(\mathrm{ug} / \mathrm{L}$ or $\mathrm{ug} / \mathrm{Kg}) \mathrm{JG} / \mathrm{KG} \quad Q$ 
Lab Name: Lionvilie Labs, Inc. Work Order: 6005200100I

Client: BECHTEL NEVADA V1879

Matrix: (soil/water) SOIL

Sample wt/vol: $30.0 \quad(\mathrm{~g} / \mathrm{mL}) \mathrm{G}$

Level: (low/med) IOW

은 Moisture: 1

Concentrated Extract Volume: 1000(uL)

Injection volume: $\underline{2,0}(u \dot{L})$

GPC Cleanup: (Y/N) $\underline{\mathrm{N}}$

CAS NO.
Lab Sample ID: 0301L631-004

Lab File ID: $\quad$ A020413

Date Received: $\quad 01 / 31 / 03$

Date Extracted: $02 / 03 / 03$

Date Aralyzed: $02 / 04 / 03$

Dilution Factor: 1.00

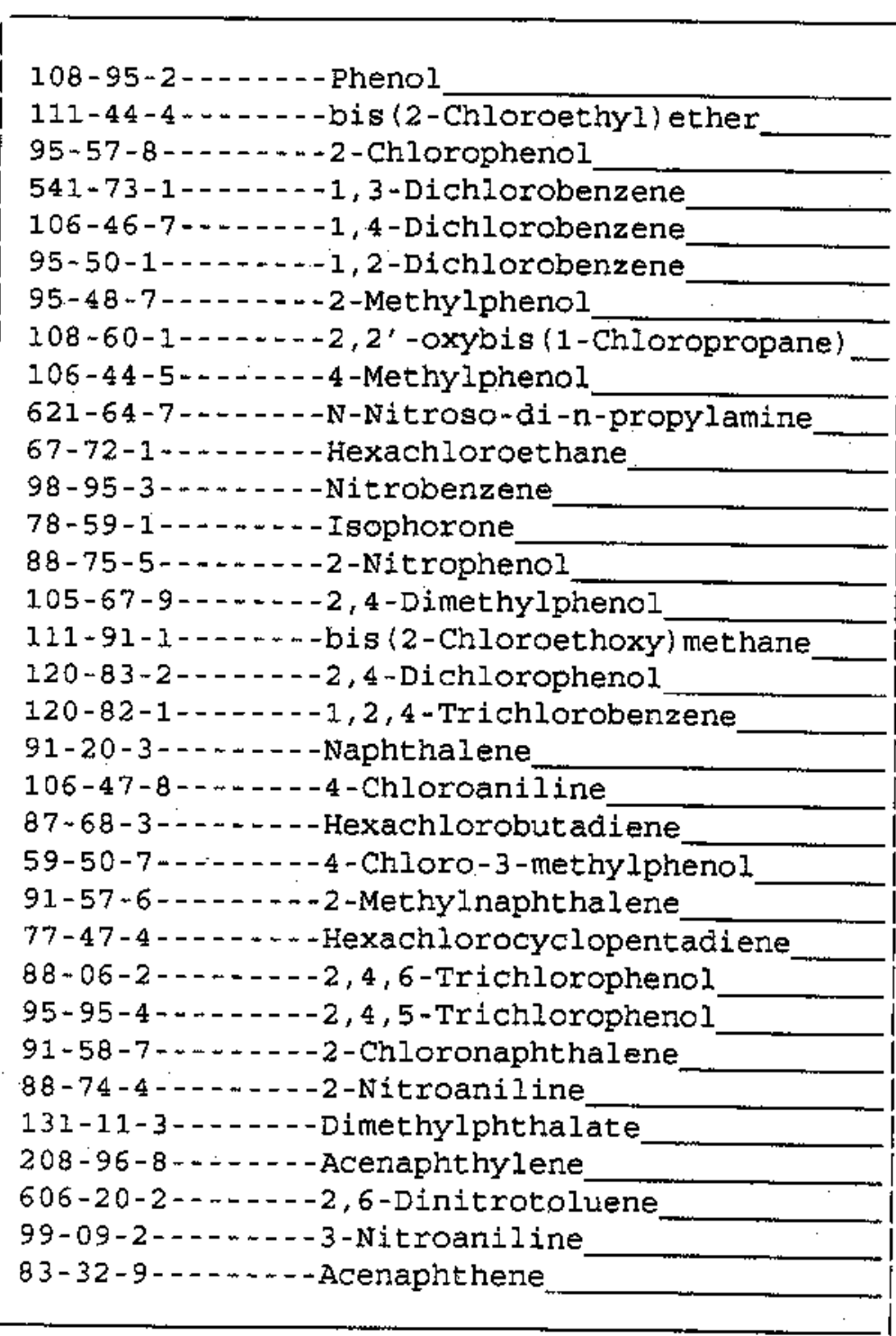

FORM I SV-1
CONCENTRATION UNI'TS:

(ug/L or $\mathrm{ug} / \mathrm{Kg}$ ) UG/KG 
$1 \mathrm{C}$

SEMIVOLATILE ORGANICS ANALYSIS DATA SHEET

Lab Name: Lionville Labs, Inc. Work Order: 60052001001
CEIENT SAMPLE NO.

$232505-4$

\section{Client: BECHTEL NEVADA V1879}

Matrix: (soil/water) SOIN

Sample wt/vol: $30.0 \quad(\mathrm{~g} / \mathrm{mI}) \underline{\mathrm{G}}$

Level: (low/med) LOW

\& Moisture: 1 decanted: $(\mathrm{Y} / \mathrm{N})$

Concentrated Extract Volume: 1000 (uI)

Injection Volume: $\underline{2.0}(u L)$
Lab Sample ID: 0301L631-004

Lab File ID: $\quad \underline{020413}$

Date Received: $\underline{01 / 31 / 03}$

Date Extracted: $02 / 03 / 03$

Date Analyzed: $\underline{02 / 04 / 03}$

Dilution Factor: 1.00

GPC Cleanup: (Y/N) $\underline{\mathrm{N}} \quad \mathrm{pH}: \underline{7.0}$

CAS NO.

COMPOUND

CONCENTRATION UNITS:

(ug/L or $u g / \mathrm{Kg}$ ) $\mathrm{UG} / \mathrm{KG}$

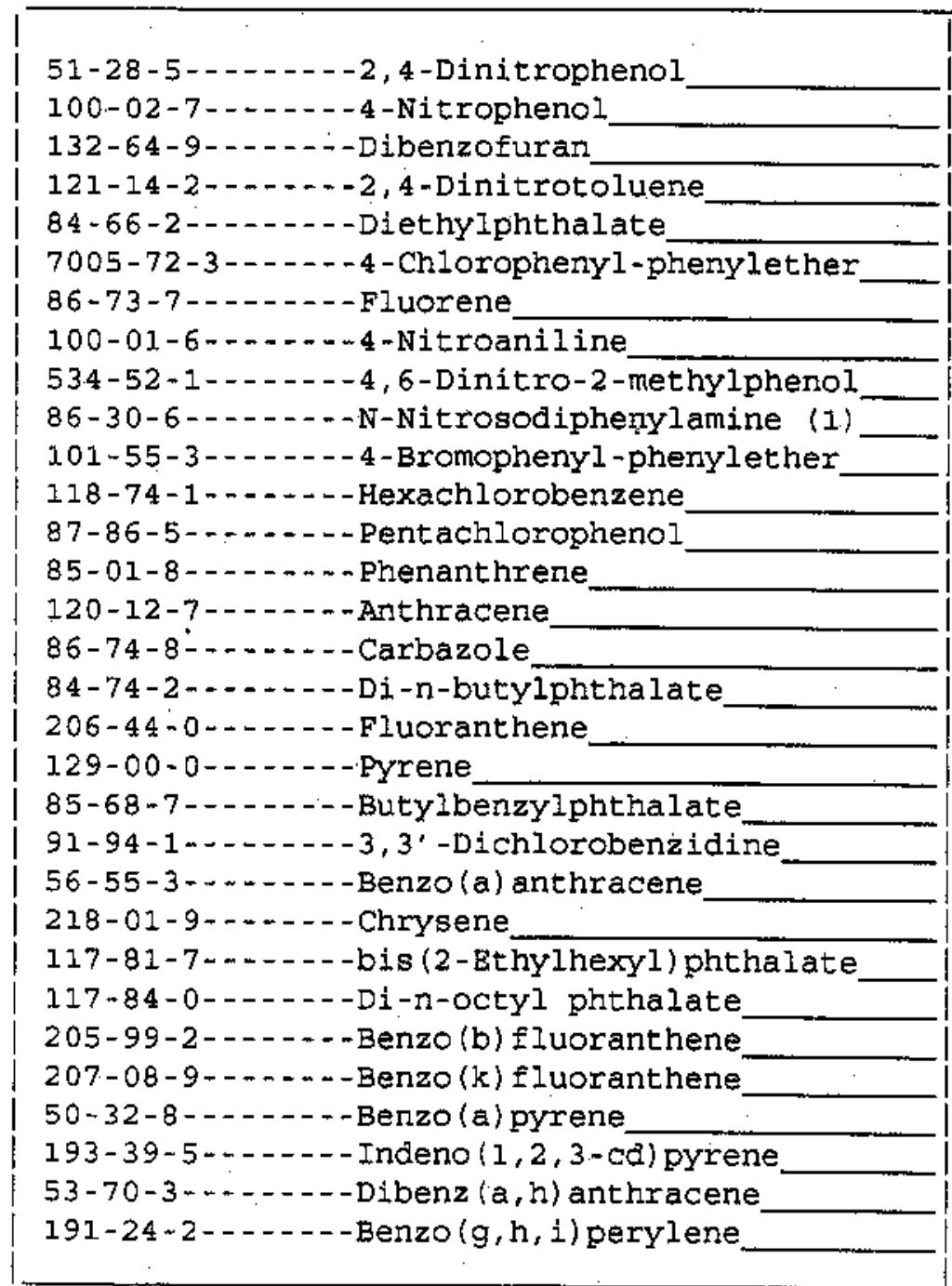

(1) - Cannot be separated from Diphenylamine FORM 1 SV-2

RFW (v3.3) 
Case Narrative 


\section{Analytical Report}

LIONVIIIT LABOKAIOKY INC

Client: BECHTEL NEVADA V1879

LVL\#: 0301L631
W.0.\#: 60052-001-001-0001-00

Date Received: 01-31-2003

\section{PCB}

Two (2) soil samples were collected on 01-29-2003.

The samples and their associated QC samples were extracted on 02-03-2003 and analyzed according to Lionville Laboratory OPs on 02-05,06-2003. The extraction procedure was based on method 3540 and the extracts were analyzed based on method 8082 for Aroclors only.

The following is a summary of the QC results accompanying the sample results and a description of any problems encountered during their analyses:

1. All results presented in this report are derived from samples that met LVLI's sample acceptance policy.

2. The required holding time for extraction and analysis has been met.

3. The samples and their associated QC samples received a Sulfuric Acid cleanup.

4. The method blank was below the reporting limits for all target compounds.

5. Nine (9) of fourteen (14) surrogate recoveries were outside acceptance criteria. A copy of the Sample Discrepancy Report (SDR) has been enclosed.

6. All blank spike recoveries were within acceptance criteria.

7. All initial calibrations associated with this data set were within acceptance criteria.

8. All continuing calibration standards analyzed prior to sample extracts were within acceptance criteria.

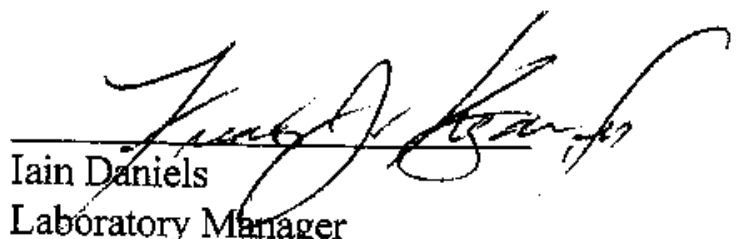

Laboratory Manager

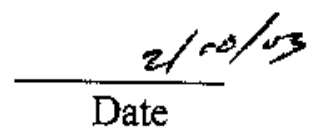

Lionville Laboratory Incorporated

somir: Groupldatahpestibeclitel $0301-631 . . p c b$

The results presented in this report relate only to the analytical testing and conditions of the samples at receipt and during storage. 


\section{GLOSSARY OF PESTICIDE/PCB DATA}

\section{DATA QUALIFIERS}

$\mathbf{U}=$ Indicates that the compound was analyzed for but not detected. The minimum detection limit for the sample (not the method detection limit) is reported with the $U$ (e.g., 10U).

$\mathbf{J}=$ Indicates an estimated value. This flag is used in cases where a target analyte is detected at a level less than the lower quantification level. If the limit of quantification is $10 \mathrm{ug} / \mathrm{L}$ and a concentration of $3 \mathrm{ug} / \mathrm{L}$ is calculated, it is reported as $3 \mathrm{~J}$.

B = This flag is used when the analyte is found in the associated blank as weil as in the sample. It indicates possible/probable blank contamination.

$\mathbf{E}=$ Indicates that the compound was detected beyond the calibration range and was subsequently analyzed at a dilution.

$I=$ Interference.

\section{ABBREVIATIONS}

BS = Indicates blank spike in which reagent grade water is spiked with the CLP matrix spiking solutions and carried through all the steps in the method. Spike recoveries are reported.

BSD $=$ Indicates blank spike duplicate.

MS = Indicates matrix spike.

MSD = Indicates matrix spike duplicate.

DL = Indicates that recoveries were not obtained because the extract had to be diluted for analysis.

NA $=$ Not Applicable.

DF $=$ Dilution Factor.

NR $=$ Not Required.

SP $\quad=\quad$ Indicates Spiked Compound. 


\section{GLOSSARY OF PESTICIDE/PCB DATA}

$\mathbf{P}=$ This flag is used for an PESTICIDE/PCB target analyte when there is greater than $25 \%$ difference for detected concentrations between the two $G C$ columns (see Form X). The lower of the two values is reported on Form I and flagged with $a$ "P".

D = This flag identifies all compounds identified in an analysis at a secondary dilution factor.

C $=$ This flag applies to a compound that has been confirmed by GC/MS. 
Sample Data 
10

PESTICIDE ORGANICS ANALYSIS SHEET

Lab Name: Lionville Labs. Inc. Work Order: 60052001001
CIIENT SAMPLE NO.

232505-3

Client: BECHTEL NEVADA V1879

Matrix:

SQIE

Sample wt/vol: $\quad 30.0 \quad(\mathrm{~g} / \mathrm{mL}) \mathrm{G}$

Level: (low/med) LOW

\% Moisture: not dec. 11 dec.

Extraction: (SepF/Cont/Sonc) N/A

GPC Cleanup: $(\mathrm{Y} / \mathrm{N}) \underline{\mathrm{N}}$

$\mathrm{pH}: \quad 7.0$
Lab Sample ID: $0301 L 631-003$

Lab File ID: BLKLACHU.02

Date Received: $01 / 31 / 03$

Date Extracted: 02/03/03

Date Analyzed: $02 / 05 / 03$

Dilution Factor: 1.00
CAS NO.

COMPOUND
CONCENTRATION UNITS :

(ug/L or $\mathrm{ug} / \mathrm{Kg}$ ) $\mathrm{JG} / \mathrm{KG}$

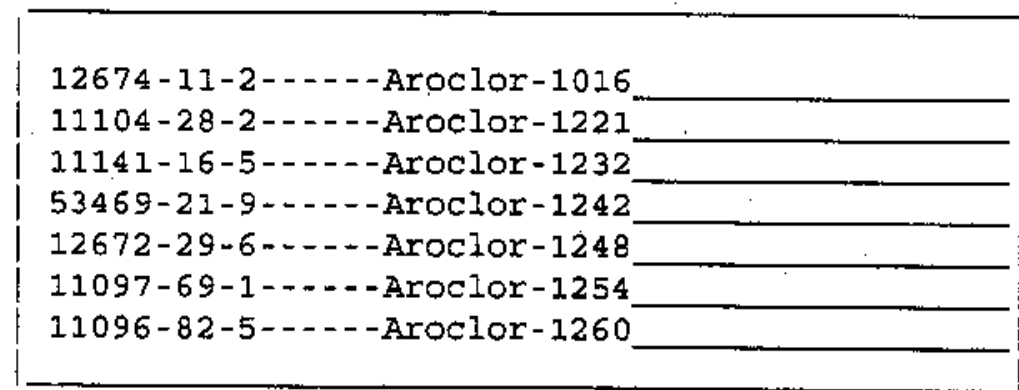

FORM 1 PEST

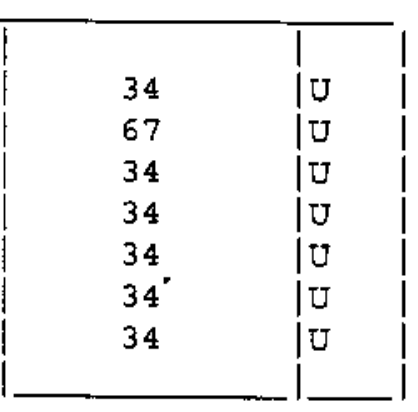

$12 / 88$ Rev. 
Lab Name: Lionville Labs, Inc. Work Order: 60052001001 $232505-4$

\section{Client: BECHTEL NEVADA V1879}

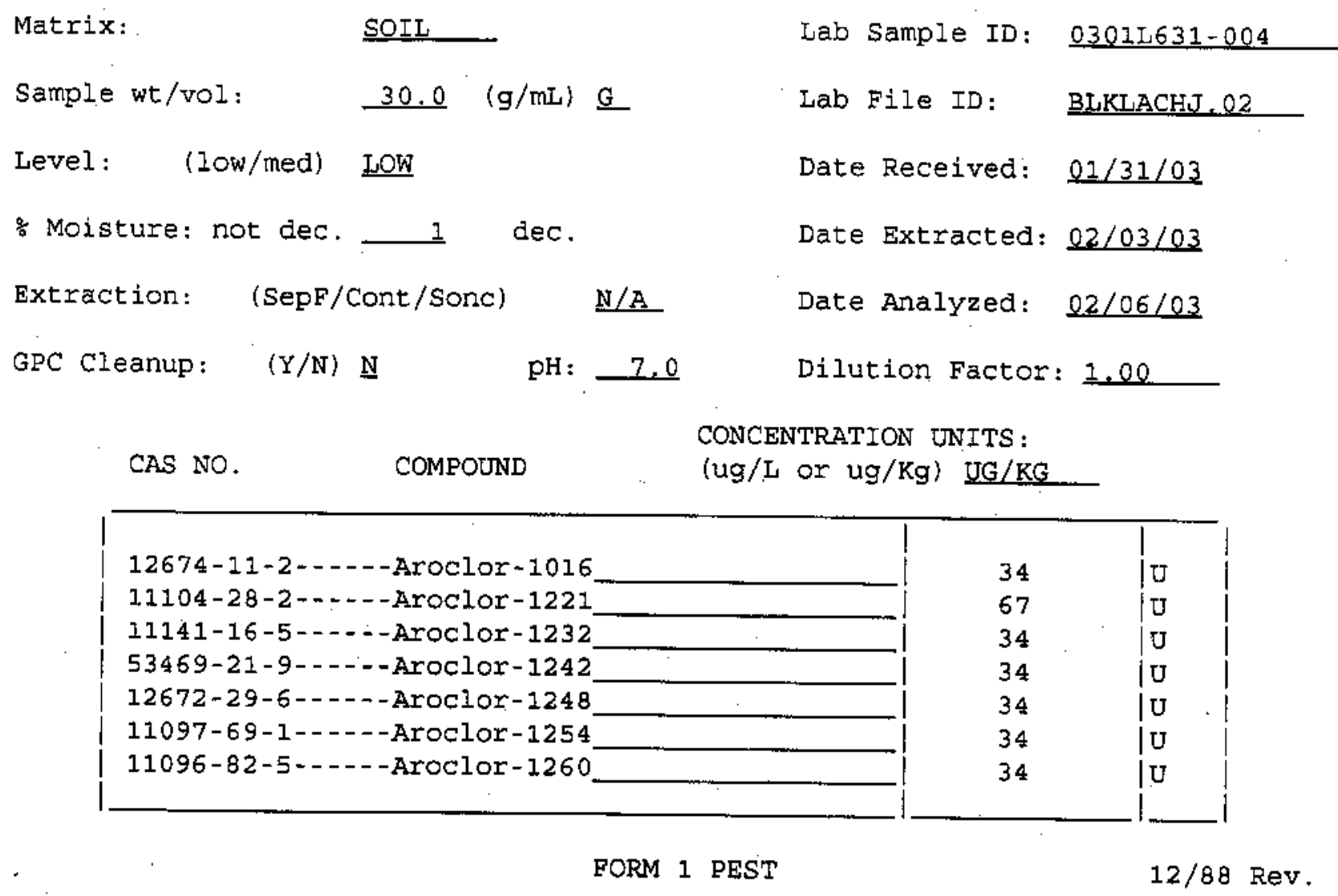


Case Narrative 


\section{Analytical Report}

IIONVHIE LABORATORY INC

Client: BECHTEL-NEVADA V1879

LVL \#: 0301L631
W.O. \#: 60052-001-001-0001-00

Date Received: 01-31-2003

\section{GRO}

Two (2) soil samples were collected on 01-29-2003.

The samples and their associated QC samples were analyzed according to Lionville Laboratory OPs based on SW-846 method 8015 for Gasoline range organics (GRO) on 02-06-2003.

The following is a summary of the QC results accompanying these sample results and a description of any problems encountered during their analyses:

1. All results presented in this report are derived from samples that met LVLI's sample acceptance policy.

2. The required holding time for analysis has been met.

3. One (1) of five (5) surrogate recoveries was outside acceptance criteria.

4. One (1) of two (2) blank spike recoveries was outside acceptance criteria. A copy of the Sample Discrepancy Report (SDR) has been enclosed.

5. All initial calibrations associated with this data set were within acceptance criteria.

6. All continuing calibration standards analyzed prior to sample extracts were within acceptance criteria.

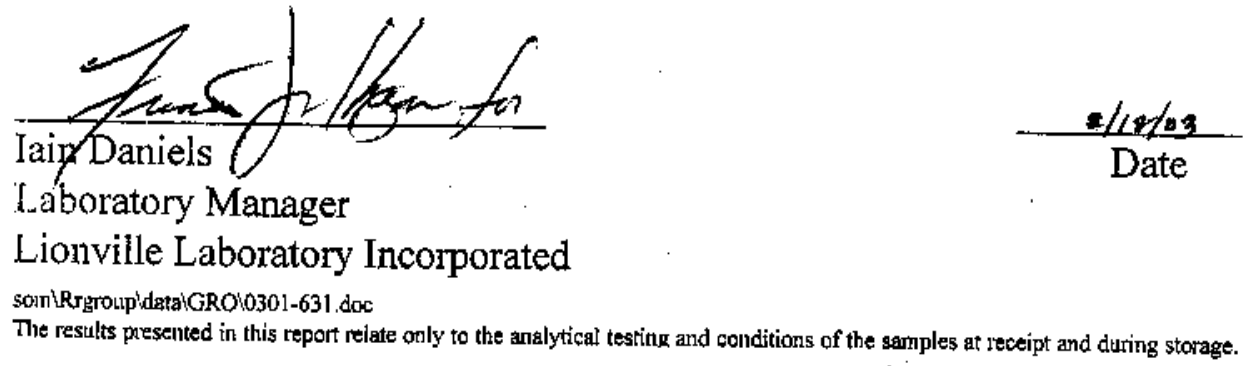




\section{GLOSSARY OF GASOLINE RANGE ORGANICS DATA}

\section{DATA QUALIFIERS}

$\mathbf{U}=$ Indicates that the compound was analyzed for but not detected. The minimum detection limit for the sample (not the method detection limit) is reported with the $U$ (e.g., 10U).

$\mathbf{J}=$ Indicates an estimated value. This flag is used in cases where a target analyte is detected at a level less than the lower quantification level. If the limit of quantification is $10 \mathrm{ug} / \mathrm{L}$ and a concentration of $3 \mathrm{ug} / \mathrm{L}$ is calculated, it is reported as $3 \mathrm{~J}$.

B = This flag is used when the analyte is found in the associated blank as well as in the sample. It indicates possible/probable blank contamination.

$\mathbf{E}=$ Indicates that the compound was detected beyond the calibration range and was subsequently analyzed at a dilution.

I $=$ Interference.

\section{ABBREVIATIONS}

BS = Indicates blank spike in which reagent grade water is spiked with the CLP matrix spiking solutions and carried through all the steps in the method. Spike recoveries are reported.

BSD $=$ Indicates blank spike duplicate.

MS $=$ Indicates matrix spike.

MSD = Indicates matrix spike duplicate.

DL = Indicates that recoveries were not obtained because the extract had to be diluted for analysis.

NA $=$ Not Applicable.

DF $=$ Dilution Factor.

$\mathbf{N R}=\quad$ Not Required.

SP $\quad=\quad$ Indicates Spiked Compound. 


\section{GLOSSARY OF GASOLINE RANGE ORGANICS DATA}

D $=$ This flag identifies all compounds identified in an analysis at a secondary dilution factor.

C = This flag applies to a compound that has been confirmed by GC/MS. 
Sample Data

17 
Lab Name: Lionville Labs, Inc. Work Order: 60052001001

Client: BECHTEL NEVADA V1879

Matrix:

SOIL

Sample wt/vol:

$5.01(\mathrm{~g} / \mathrm{mL}) \mathrm{g}$

Level: (low/med) LOW

Moisture: not dec. 1

Columr: (pack/cap) CAP

CAS NO.

COMPOUND

(ug/L or $\mathrm{ug} / \mathrm{Kg}$ ) UG/KG
Lab Sample ID: 0301L631-003

Lab File ID:

BLKLACHU

Date Received: 01/31/03

Date Analyzed: $\underline{02 / 06 / 03}$

Dilution Factor: 1.00

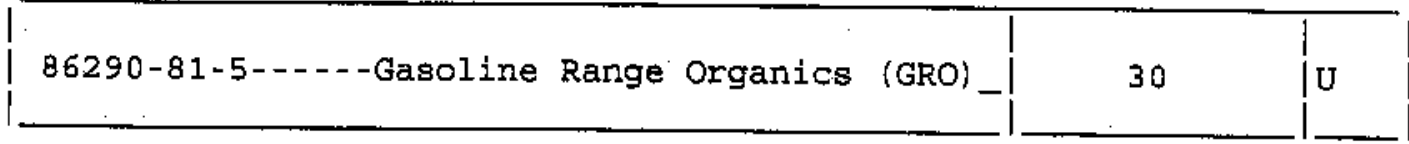

12/88 Rev. 
Lab Name: Lionville Labs, Inc. Work Order: 60052001001

Client: BECHTEL NEVADA V1879

Matrix:

SOIL

Sample $\omega t / v o l:$

5.02 $(\mathrm{g} / \mathrm{mL}) \mathrm{G}$

Level: (low/med) LOW

\% Moisture: not dec. 1

Column: (pack/cap) CAP

CAS NO.

COMPOUND
Lab Sample ID: 0301L631-004

Lab File ID: BIKLACHJ

Date Rece1ved: $01 / 31 / 03$

Date Analyzed: $02 / 06 / 03$

Dilution Factor: 1,00

CONCENTRATION UNITS:

(ug/L or $\mathrm{ug} / \mathrm{Kg}$ ) UG/KG

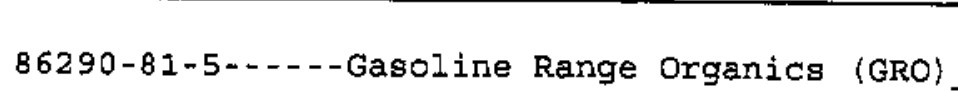

12/88 Rev. 


\section{Case Narrative}




\section{Analytical Report}

LONVILE LABORAIOKY INC

Client: BECHTEL-NEVADA V1879

LVL \#: 0301L631

W.O. \#: 60052-001-001-0001-00

Date Received: 01-31-2003

\section{DIESEL RANGE ORGANICS}

Two (2) soil samples were collected on 01-29-2003.

The samples and their associated QC samples were extracted on 02-03-2003 and analyzed according to Lionville Laboratory OPs on $02-11,12-2003$. The extraction procedure was based on method 3540 and the extracts were analyzed based on method 8015B for Diesel Range Petroleum Hydrocarbons.

1. All results presented in this report are derived from samples that met LvLI's sample acceptance policy.

2. The required holding time for extraction and analysis has been met.

3. The method blank was below the reporting limits for all target compounds.

4. All surrogate recoveries were within acceptance criteria.

5. The blank spike recovery was within acceptance criteria.

6. The matrix spike recoveries were within EPA QC limits.

7. All initial calibrations associated with this data set were within acceptance criteria.

8. All continuing calibration standards analyzed prior to sample extracts were within acceptance criteria.
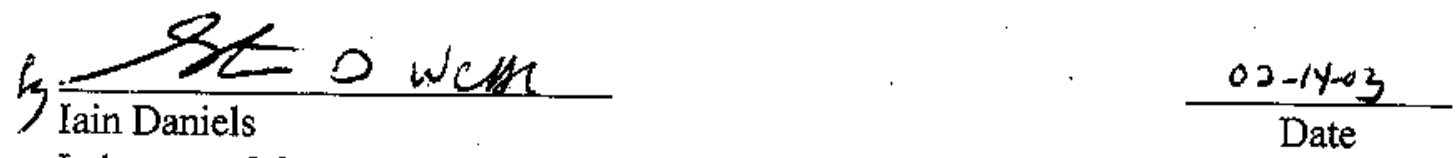

Laboratory Manager

Lionville Laboratory Incorporated

somir:troupldata idro bechtet $0301-631 . \mathrm{doc}$

The results presented in this report relate only to the analytical testing and conditions of the samples at receipt and during storage. 


\section{GLOSSARY OF PESTICIDE/PCB DATA}

\section{DATA QUALIFIERS}

$\mathbf{U}=$ Indicates that the compound was analyzed for but not detected. The minimum detection limit for the sample (not the method detection limit) is reported with the $U$ (e.g., 10U).

$\mathbf{J}=$ Indicates an estimated value. This flag is used in cases where a target analyte is detected at a level less than the lower quantification level. If the limit of quantification is $10 \mathrm{ug} / \mathrm{L}$ and a concentration of $3 \mathrm{ug} / \mathrm{L}$ is calculated, it is reported as 3J.

B = This flag is used when the analyte is found in the associated blank as well as in the sample. It indicates possible/probable blank contamination.

$\mathbf{E}=$ Indicates that the compound was detected beyond the calibration range and was subsequently analyzed at a dilution.

$\mathbf{I}=$ Interference.

\section{ABBREVIATIONS}

BS = Indicates blank spike in which reagent grade water is spiked with the CLP matrix spiking solutions and carried through all the steps in the method. Spike recoveries are reported.

BSD = Indicates blank spike duplicate.

MS $\quad=\quad$ Indicates matrix spike.

MSD $=$ Indicates matrix spike duplicate.

DL = Indicates that recoveries were not obtained because the extract had to be diluted for analysis.

NA $=$ Not Applicable.

DF $=$ Dilution Factor.

NR $=$ Not Required.

SP = Indicates Spiked Compound. 


\section{GLOSSARY OF PESTICIDE/PCB DATA}

$\mathbf{P}=$ This flag is used for an PESTICIDE/PCB target analyte when there is greater than $25 \%$ difference for detected concentrations between the two GC columns (see Form X). The lower of the two values is reported on Form I and flagged with a "P".

D = This flag identifies all compounds identified in an analysis at a secondary dilution factor.

C = This flag applies to a compound that has been confirmed by GC/MS. 
Sample Data 
Lab Name: Lionville Labs, Inc. Work Order: 60052001001

$$
\text { 232505-3 }
$$

Client: BECHTEI NEVADA V1879

Matrix:

SOIL

$\underline{25.0}(\mathrm{~g} / \mathrm{mL}) \mathrm{G}$

Sample wt/vol:

Level: (low/med) LoW

\% Moisture: not dec.

1

Column: (pack/cap) CAP

CAS NO.

COMPOUND
Lab Sample ID: $0301 \mathrm{~L} 631-003$

Lab File ID: BLKLACHU

Date Received: $01 / 31 / 03$

Date Analyzed: $02 / 11 / 03$

Dilution Factor: 1,00

CONCENTRATION UNITS :

(ug/L or $u g / \mathrm{Kg}$ ) $\mathrm{mg} / \mathrm{kg}$

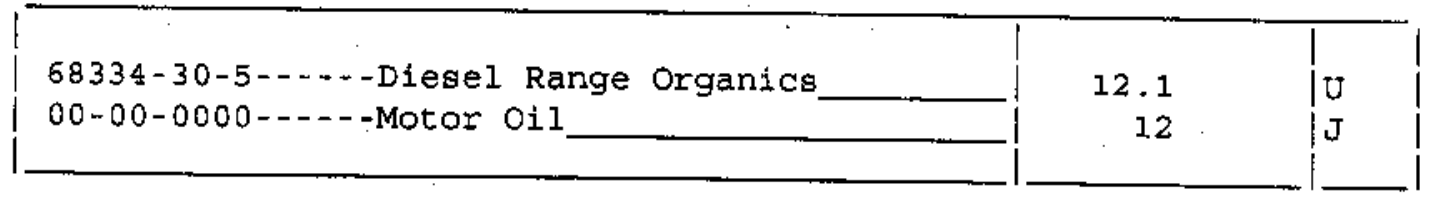

12/88 Rev. 
Lab Name: Lionville Labs, Inc. Work order: 60052001001 232505-4

Client: BECHTEL NEVADA V1879

Matrix:

SOII

Lab Sample ID: 0301L631-004

Sample wt/vol:

$\underline{25.0}(\mathrm{~g} / \mathrm{mL}) \mathrm{G}$

Lab File ID:

BLKLACHJ

Level: (low/med) LOW

Date Received: $01 / 31 / 03$

\% Moisture: not dec.

1

Date Analyzed: $\quad 02 / 12 / 03$

Column: (pack/cap) CAP

Dilution Factor: 1.00

CAS NO.

COMPOUND

CONCENTRATION UNITS :

(ug/L or $\mathrm{ug} / \mathrm{kg}$ ) $\mathrm{mg} / \mathrm{kg}$

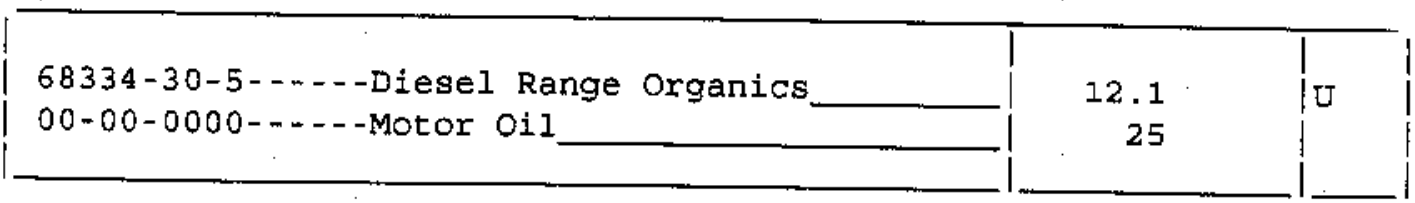

12/88 Rev. 


\section{Case Narrative}




\section{$9 / V L I$ \\ LIONVILE LABORATORY INC.}

Analytieal Report

Client : BECHTEL NEVADA V1879

LVL\# : 0301L631
W.O.\# : 60052-001-001-0001-00

Date Received : 01-31-03

\section{SW846 METALS}

1. This narrative covers the analyses of 2 soil samples.

2. The samples were prepared and analyzed in accordance with SW-846 protocol and reported with a CLP deliverable.

3. ICVs, CCVs, and LCSs stock standards were purchased from Inorganic Ventures Laboratory and High Purity.

4. All analyses were performed within the required holding times.

5. All results presented in this report are derived from samples that met LvLI's sample acceptance policy.

6. All Initial and Continuing Calibration Verifications (ICV/CCVs) were within control limits with the exception of the final CCV for Cadmium. All samples were surrounded by QC in control.

7. All Initial and Continuing Calibration Blanks (ICB/CCBs) were within method criteria.

8. All preparation/method blanks were within method criteria. Refer to form 3.

9. All ICP Interference Check Standards were within control limits. Refer to form 4.

10. All laboratory control samples (LCS) were within the $80-120 \%$ control limits. Refer to form 7 .

11. All sample IDs were changed to accommodate the EPA naming convention which allows a maximum of 6 characters on all CLP Forms. Refer to the comments section of form 1 for the original ID.

12. All matrix spike, duplicate and serial dilution analyses were performed on Bechtel Nevada, LvLI batch\# 0301L596 within the same digestion batch. Please refer to this package for the associated QC forms. 
13. Recoveries on the Laboratory Summary Report and CLP forms will vary depending on the number of significant figures used in the recovery calculation.

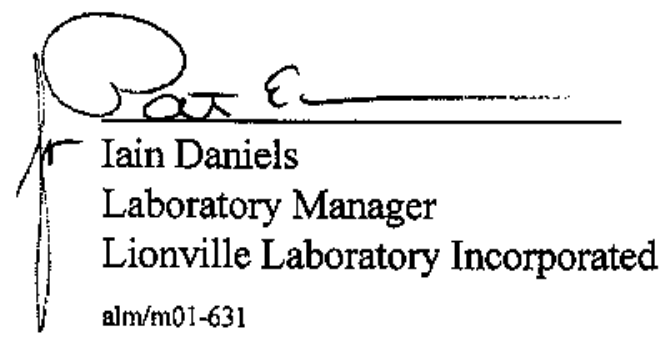

$$
\frac{02-14-03}{\text { Date }}
$$




\section{METHOD REFERENCES AND DATA QUALTFWRS}

\section{DATA QUALIFLERS}

$\mathrm{U}=$ Indicates that the parameter was not detected at or above the reported limit. The associated numerical value is the sample detection limit.

$\mathrm{B}=$ Indicates that the parameter was between the Instnument Detection Limit (DL) and the Contract Required Detection Limit (CRDL)

\section{Q QUALIFERS}

$E=\quad$ The reporied value is estimated because of the presence of interference.

$\mathrm{M}=$ Duplicate injection precision not met.

$\mathrm{N}=\quad$ Spiked sample recovery not within control limits.

$S=\quad$ The reported value was determined by the Method of Standard Additions (MSA).

$W=$ Post Digestion spike for Fumace AA anslysis is out of control limits $(85-115 \%)$, while sample absorbance is less than $50 \%$ of spike absorbance.

*.= Duplicate analysis not within control limits.

+ Correlation coefficient for the MSA is less than 0.995 .

\section{ABBREVIATIONS}

PB = Method or Preparation Blank.

S - Matrix Spike.

$T=$ Matrix Spike Duplicate.

Rior D - Sample Replicate

\section{ANALYTICAL METAL MOTRODS.}

1. Not included in the method element list.

2. Modified $\mathrm{Hg}$ : $\mathrm{Hgl}$ and $\mathrm{Hg} 2$ require less total volume of digestate due to the autosampler analysis. Sample volumes and reagents for mercury determinations in water and soil have been proportionately scaled down to adapt to this semiautomated technique. The sample volume used for water analysis is $33 \mathrm{~mL}$. For soils, 0.1 grams of sample is taken to a final volume of $50 \mathrm{~mL}$ (including all reagents).

3. Modified $\mathrm{Hg}$ : $\mathrm{Hg} 1$ and $\mathrm{Hg} 2$ require less total volume of digestate due to the autosampler analysis. Sample volumes and reagents for mercury determinations in water and soil have been proportionately scaled down to adapt to this semiautomated technique. The sampie volume used for water analysis is $33 \mathrm{~mL}$. For soils, three 0.1 gram of sample is taken to a final volume of $50 \mathrm{~mL}$ (including all reagents).

4. Flame AA.

5. Graphite Fumace AA. 
U.S. EPA.

Lab Name: IIONVILIE_ILABORATORY Iab Code: LVuI Matrix (soil/water): SoIL Level (low/med) : LOW oे Solids :

$-99.1$
1

INORGANIC ANALYSES DATA SHEET
Contract : $60052-1$ SAS NO.:

Lab Sample ID: 0301L631-0003

Date Received: 01/31/03
EPA SAMPLE NO.

$$
505-3
$$

Concentration Units (ug/L or $\mathrm{mg} / \mathrm{kg}$ dry weight): MG/KG

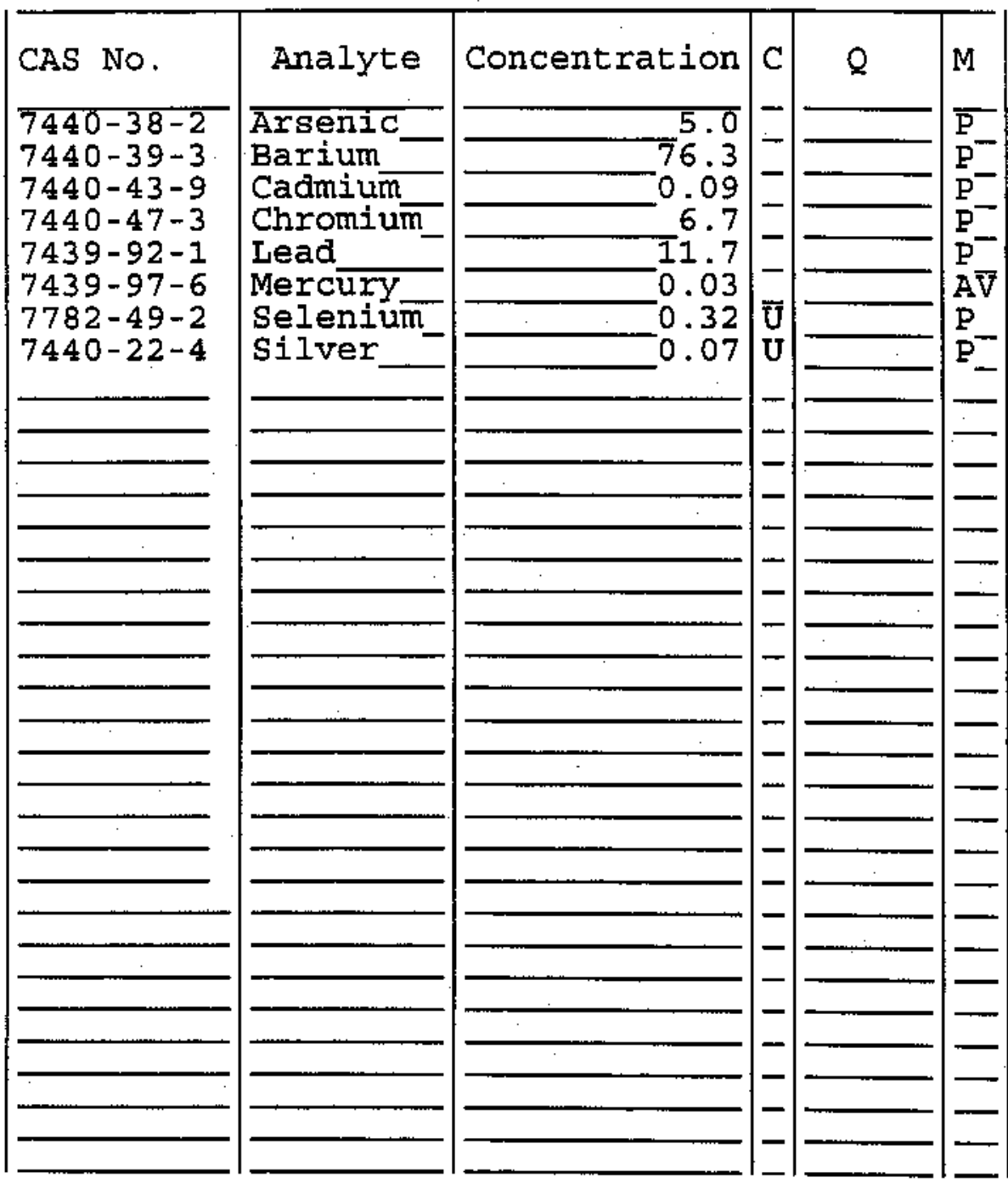

Color Before:

Clarity Before:

Color After:

Clarity After:

Texture:

Artifacts:

\section{Comments}

232505-3 
1 INORGANIC ANALYSES DATA SHEET
EPA SAMPLE NO.

$$
505-4
$$

Contract: $60052-1$

SAS NO.:

Lab Sample ID: 0301L631-0004

Date Received: 01/31/03
Lab Code: IVLI

Matrix (soil/water): SOIL

Level (low/med):

\% Solids :
Case No.: V1879

$$
\begin{aligned}
& \text { LOW } \\
& -99.0
\end{aligned}
$$

Concentration Units (ug/L or mg/kg dry weight): MG/KG

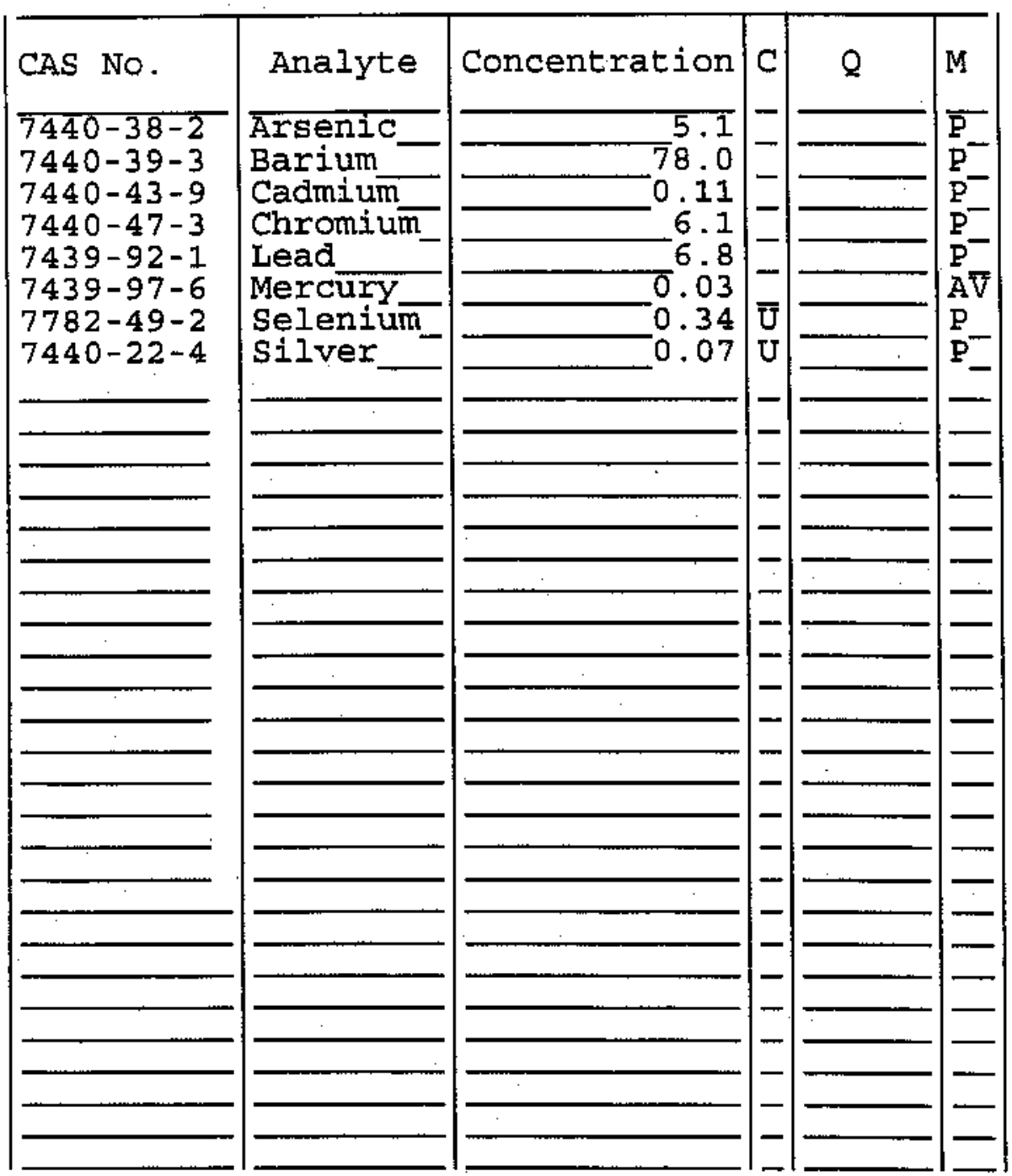

Color Before:

Color After:

Comments :

232505-4
Clarity Before:

Clarity After:
Texture:

Artifacts : 
CLOSURE REPORT - CAU 330

Section: Appendix B

Revision: 0

Date: July 2003

\section{SAMPLE DELIVERY GROUP}

\section{V1880}


CLOSURE REPORT - CAU 330

Section: Appendix B

Revision: 0

Date: July 2003

\section{THIS PAGE INTENTIONALLY LEFT BLANK}


March 14, 2003

Mr. Ted Redding

Bechtel Nevada

US DOE Zone 1, Bldg 652, Rm 2, M/S NTS273

Mercury NV 89023

RE: Paragon Workorder: 03-01-162

Client Project Name: CAU 330

Client Project Number: V1880

Dear Mr. Redding:

Two soil samples were received from Bechtel Nevada on January 31, 2003. The samples were scheduled for Gamma Spectroscopy (pages 1-136) analysis. The results for this analysis are contained in the enclosed reports.

Thank you for your confidence in Paragon Analytics, Inc. Should you have any questions, please call.

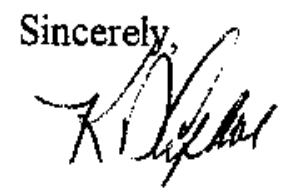

Paragon Analytics, Inc.

Ken Campbell

Project Manager

$\mathrm{KDC} / \mathrm{hc}$

Enclosure: Report 


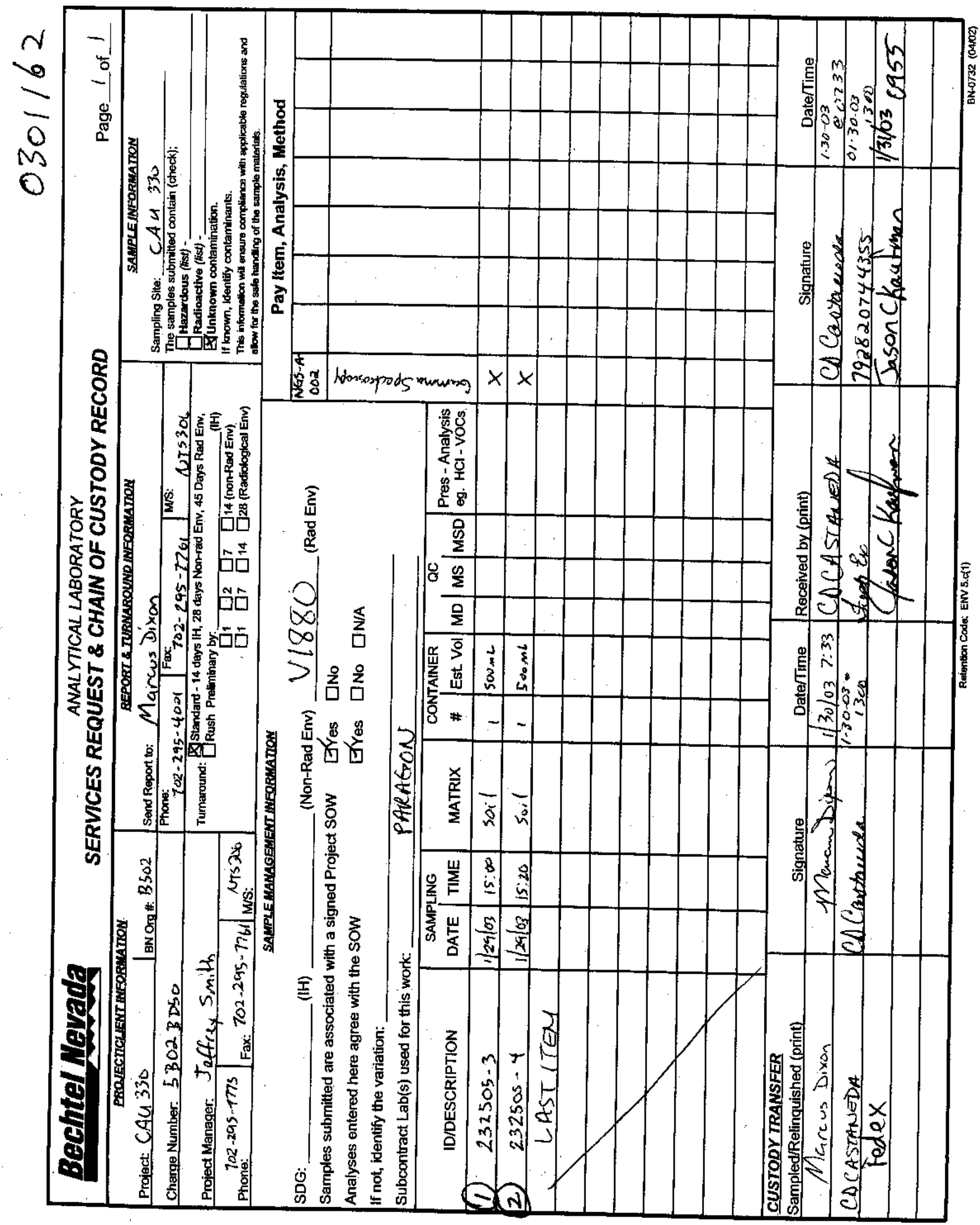




\section{Paragon Analytics, Inc. Radiochemistry Case Narrative Gamma Spectroscopy}

\section{Bechtel Nevada \\ CAU 330 / V1880}

Paragon Work Order 0301 162

1. This report consists of analysis results for two soil samples received by Paragon on 1/31/03. The analysis results for these samples are reported on a 'dry weight' basis in units of pCi/gram.

2. These samples were prepared according to Paragon Analytics, Inc. procedure PAI SOP739R5.

3. The samples were analyzed for the presence of gamma emitting radionuclides according to Paragon Analytics, Inc. procedure PAI SOP713R7. The analyses were completed on $3 / 10 / 03$.

4. The samples were analyzed using Seeker Version 2.2, which is a product of Vertechs Software Solutions, Inc.

5. Sample volumes were insufficient to allow preparation of a duplicate. A duplicate analysis of sample 232505-3 (PAI ID 0301162-1) was performed in lieu of a preparation duplicate.

6. Due to current software limitations, the DER determinations in this report were calculated using the 2 sigma TPU. The SOW indicates that the I sigma TPU be used in the DER determination. However, the requested DER limit of less than 3 at the 1 sigma level (which is equivalent to 1.5 at the 2 sigma level) was achieved. Data quality is not affected.

7. Activity concentrations above the $2 \sigma$ TPU are reported in some instances where minimum nuclide identification criteria are not met. Such tentative identifications result when the software attempts to calculate net activity concentrations for analytes where either one or both of the following criteria are not satisfied: the 'diagnostic' peak for a nuclide must be identified above critical level (generally the most abundant, interference-free photopeak), or the minimum library peak tolerance of $75 \%$ must be attained. These data have been flagged
with a "TI" qualifier.

8. There are cases where the magnitude of the negative activity is greater than the 2 sigma TPU. The analyst's review of the data does not indicate a problem with the instrument data or the subsequent reporting systems. The data quality is not believed to be affected and the results are submitted without qualification. Under typical conditions, where background level sample data is normally distributed and analyzed by paired observations, this event is likely 
9. No further problems were encountered with either the client samples or the associated quality control samples. All remaining quality control criteria were met.

The data contained in the following report have been reviewed and approved by the personnel listed below. In addition, Paragon Analytics, Inc. certifies that the analyses reported herein are true, complete and correct within the limits of the methods employed.

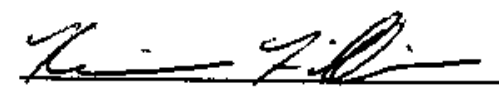

Radiochemistry Instrument Technician

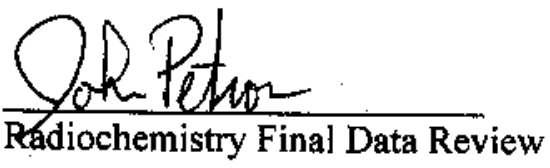

$3-11003$

Date

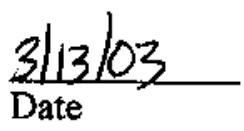




\section{PARAGON ANALYTICS, INC. \\ Radiochemistry Data Package}

Section 3

\section{INDIVIDUAL \\ SAMPLE RESULTS}




\section{Gamma Spectroscopy Results}

\section{Method PAI 713R7}

\section{Sample Results}

Client Name: Bechtel Nevada

Client Project Name: CAU 330

Cllent Project Number: V1880
Page: 1 of 4

Reported on: Tuesday, March 11, 2003 09:49:43

Laboratory Name: Paragon Analytics, Inc.

PAI Work Order: 0301162

\begin{tabular}{|c|}
\hline 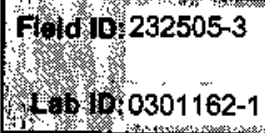 \\
\hline
\end{tabular}

Sample Matrlx: Soll

Date Prepared: 26-Feb-03

Prep SOP: PAl 739R5

Prep Batch: G\$01911
Date Collected: 29-Jan-03

Date Analyzed: 10-Mar-03

Analytical SOP: PAI 713R7

Spectrum Code: 030351D10A
Final Allquot: $508.1 \mathrm{~g}$

Report Basis: Dry Weight Count Time (m/n.): 30

Library: GAM-A-001.LI

\begin{tabular}{|c|c|c|c|c|}
\hline Target Nucllde & Result +/- 2 s TPU & MDC & $\begin{array}{c}\text { Reporting } \\
\text { Units }\end{array}$ & Lab Qualifier \\
\hline$A c-228$ & $3.59 E-01+/-1.40 \mathrm{E}-01$ & $3.09 E-01$ & $\mathrm{pCl} / \mathrm{g}$ & \\
\hline Am-241 & $3.20 \mathrm{E}-02+/-1.26 \mathrm{E}-01$ & 2.14E-01 & $\mathrm{pCl} / \mathrm{g}$ & $\mathrm{U}$ \\
\hline $\mathrm{Ce}-144$ & $-1.51 \mathrm{E}-01+/-1.86 \mathrm{E}-01$ & $3.35 \mathrm{E}-01$ & $\mathrm{pCi} / \mathrm{g}$ & $\mathrm{U}$ \\
\hline Co-60 & $2.67 \mathrm{E}-02+/-3.37 \mathrm{E}-02$ & 5.48E-02 & $\mathrm{pCl} / \mathrm{g}$ & U \\
\hline Cs-134 & $-1.10 E-02+/-5.34 E-02$ & $9.33 E-02$ & $\mathrm{pCl} / \mathrm{g}$ & $U$ \\
\hline Cs-137 & 3.49E-02 +/- 3.96E-02 & $6.40 \mathrm{E}-02$ & $\mathrm{pCi} / \mathrm{g}$ & $\mathrm{U}$ \\
\hline$E\lfloor-152$ & $-1.18 E-02+/-1.88 E-01$ & $3.40 \mathrm{E}-01$ & $\mathrm{pCi} / \mathrm{g}$ & $U$ \\
\hline Eu-154 & $0.00 \mathrm{E}+00+/-1.88 \mathrm{E}-01$ & $3.35 E-01$ & $\mathrm{pCl} / \mathrm{g}$ & $\mathrm{U}$ \\
\hline Eu-155 & $-1.02 \mathrm{E}-02+/-1.02 \mathrm{E}-01$ & $1.76 \mathrm{E}-01$ & $\mathrm{pCl} / \mathrm{g}$ & $U$ \\
\hline $\mathrm{K}-40$ & $5.65 \mathrm{E}+00+/-1.24 \mathrm{E}+00$ & $8.35 \mathrm{E}-01$ & $\mathrm{pCl} / \mathrm{g}$ & \\
\hline $\mathrm{Pb}-212$ & $4.35 \mathrm{E}-01+/-1.08 \mathrm{E}-01$ & 1.01E-01 & $\mathrm{pCl} / \mathrm{g}$ & \\
\hline $\mathrm{Pm}-144$ & $2.15 E-02+/-3.15 E-02$ & $5.20 \mathrm{E}-02$ & $\mathrm{pCl} / \mathrm{g}$ & $\mathrm{U}$ \\
\hline Pm-146 & $-1.69 \mathrm{E}-03+/-3.77 \mathrm{E}-02$ & $6.68 \mathrm{E}-02$ & $\mathrm{pCi} / \mathrm{g}$ & $\mathrm{U}$ \\
\hline Ru-106 & $-3.06 \mathrm{E}-01+/-3.21 \mathrm{E}-01$ & $6.04 \mathrm{E}-01$ & $\mathrm{pCi} / \mathrm{g}$ & $U$ \\
\hline Sb-125 & $2.86 \mathrm{E}-02+/-8.34 \mathrm{E}-02$ & $1.43 E-01$ & $\mathrm{pCl} / \mathrm{g}$ & $\mathrm{U}$ \\
\hline Th-234 & $1.39 \mathrm{E}-01+1-6.65 \mathrm{E}-01$ & $1.12 E+00$ & $\mathrm{pCi} / \mathrm{g}$ & $\mathrm{U}$ \\
\hline $\mathrm{U}-235$ & $8.19 E-02+/-1.87 E-01$ & $3.14 E-01$ & $\mathrm{pCl} / \mathrm{g}$ & $\mathrm{U}$ \\
\hline$Y-88$ & $2.50 \mathrm{E}-03+/-3.89 \mathrm{E}-02$ & $6.98 \mathrm{E}-02$ & $\mathrm{pCl} / \mathrm{g}$ & $\mathrm{U}$ \\
\hline
\end{tabular}

Data Package ID: GSS0301162-1

Paragon Analytics Inc. 


\section{Gamma Spectroscopy Results}

\section{Method PAl 713R7 .}

\section{Sample Results}

Client Name: Bechtel Nevada

Cirent Project Name: CAU 330 Cllent Project Number: V1880
Page: 2 of 4

Reported on: Tuesday, March 11, 2003 $09: 49: 43$

Laboratory Name: Paragon Analytics, Inc.

PAl Work Order: 0301162

\begin{tabular}{|c|}
\hline 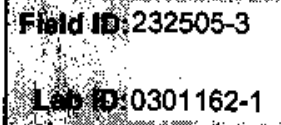 \\
\hline
\end{tabular}

Sample Matrix: Soil

Date Prepared: 26-Feb-03

Prep SOP: PAI 739R5

Prep Batch: GS01911
Date Collected: 29-Jan-03

Date Analyzed: 10-Mar-03

Analytical SOP: PAI 713R7

Spectrum Code: 030351D10A
Final Aliquot: $508.1 \mathrm{~g}$

Report Basis: Dry Welght Count Time (min.): 30 Library: GAM-A-001.LI

\begin{tabular}{|l|l|l|l|l|}
\hline Target Nuclide & Result +1- 2 s TPU & MDC & $\begin{array}{c}\text { Reporting } \\
\text { Units }\end{array}$ & Lab Qualifler \\
\hline
\end{tabular}

\section{Comments:}

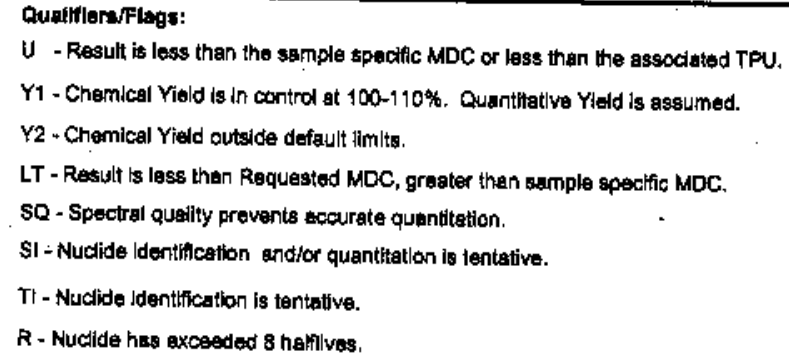

Abbraviations:

TPU - Total Propagated Uncertainty (see PAI SOP 743)

MDC - Minimum Detecteble Concentration (see PAI SOP 709) 


\section{Gamma Spectroscopy Results}

\section{Method PAI 713R7}

\section{Sample Results}

Client Name: Bechtel Nevada

Cllent Project Name: CAU 330

Client Project Number: V1880
Page: 4 of 4

Reported on: Monday, March 03, 2003 10:24:06

Laboratory Name: Paragon Analytlcs, Inc.

PAI Work Order: 0301162

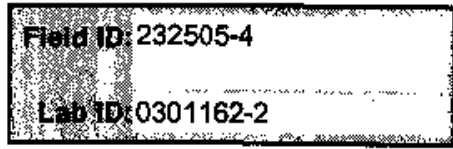

Sample Matrix: Soll

Date Prepared: 26-Feb-03

Prep SOP: PAI 739R5

Prep Batch: GS01911
Date Collected: 29-Jan-03

Date Analyzed: 27-Feb-03

Analytical SOP: PAI 713R7

Spectrum Code: 030311010A
FInal Aliquot: $504.0 \mathrm{~g}$

Report Basis: Dry Weight

Count Time (mIn.): 30

Lilbrary: GAM-A-C01.LI

\section{\begin{tabular}{l|l} 
Target Nucllde & Result +/- 2 s TPU
\end{tabular}}

MDC

Reporting Units

\section{Lab Quallfler}

\section{Comments:}

Qualfioruflage:

U - Result is less then the sample specific MDC or less than the essociated TPU.

Y1 - Chomical Yeld is in control at 100-110\%. Quanttative Yield is assumed.

Y2 - Chemicai Yeld outside default limlts.

LT - Rasult is less than Requested MDC, greater than sample specific MDC.

SQ - Spectral quality prevents accurate quantitation.

SI - Nuclide Identification andior quentitation is tantative.

TI - Nuclide Identification is tentallve.

R - Nuclide has excesded a hathives.
Abbreviations:

TPU - Total Propagated Uncertainly (see PAI SOP 743)

MDC * Minimum Detectable Concentration (see PAI SOP 709)

Data Package ID: GSS0301162-1 
CLOSURE RE PORT - CAU 330

Section: Appendix C

Revision : 0

Date: July 2003

\section{APPENDIX C}

\section{WASTE DISPOSITION DOCUMENTATION}


CLOSURE RE PORT - CAU 330

Section: Appendix C

Revision : 0

Date: July 2003

\section{THIS PAGE INTENTIONALLY LEFT BLANK}




\section{Bechtel Nevada}

\section{NONRADIOACTIVE WASTE CERTIFICATION}

03N25

Associated Onsite Manifest

1. Is this waste considered abandoned?

QYes $\square$ No

2. Has any of the waste listed on the attached manifest been used or stored in

a Controlled Waste Management Area (CWMA) as defined below?

Yes $\mathbb{X}$ No

A CWMA is "an area in which the potential exists for contamination due to presence of unencapsulated or unconined radioactive material or an area that is exposed to beams or other sources of partlcles capable of causing activation, i.e. neutrons, protons, etc.

3. Has any of the waste listed on the attached manifest been used or stored in any other posted or suspected radiological control area?

4. Has any of the waste listed on the attached manifest commingled with any radioactive mixed waste?

Yes $X$ No

5. Has any of the waste listed on the attached manlfest commingled with loose radioactive contamination?

Yes $\square$ No

6. Has any of the waste listed on the attached manifest commingled with fixed radioactive contamination?

Yes $X$ No

1. Generator able to certify waste as nonradioactive:

Based upon the knowledge of the origin, storage, use and potential exposure of the waste, I CERTIFY THAT NO RADIOACTIVITY HAS BEEN ADOED TO THE WASTE LISTED ON THE ATTACHED MANIFEST.

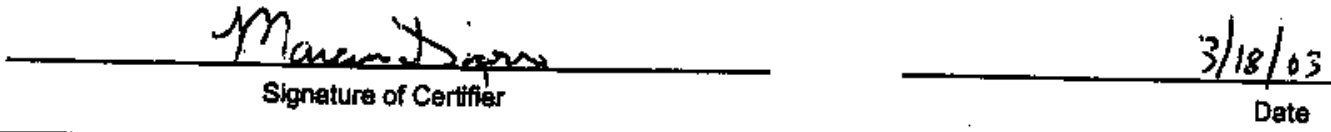

2. To be completed by Hazardous Waste Operations personnel only

4 No further analysis required, all process knowledge is present and documented and the waste

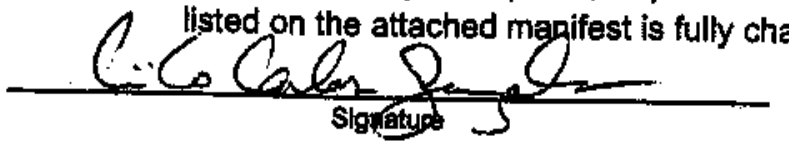

ized Slgivatyon

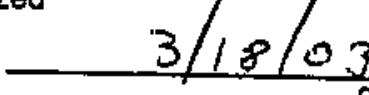

Date IF ANY OF THE ABOVE QUESTIONS ARE ANSWERED "YES," THE WASTE WILL REQUIRE ONE OF THE
FOLLOWING:

1. DOCUMENTATION DEMONSTRATING THAT NO POTENTIAL FOR INTERNAL CONTAMINATION EXISTS (PROCESS KNOWLEDGE); OR

2. RESULTS OF RADIOANALYSES PERFORMED ON THE WASTE. 


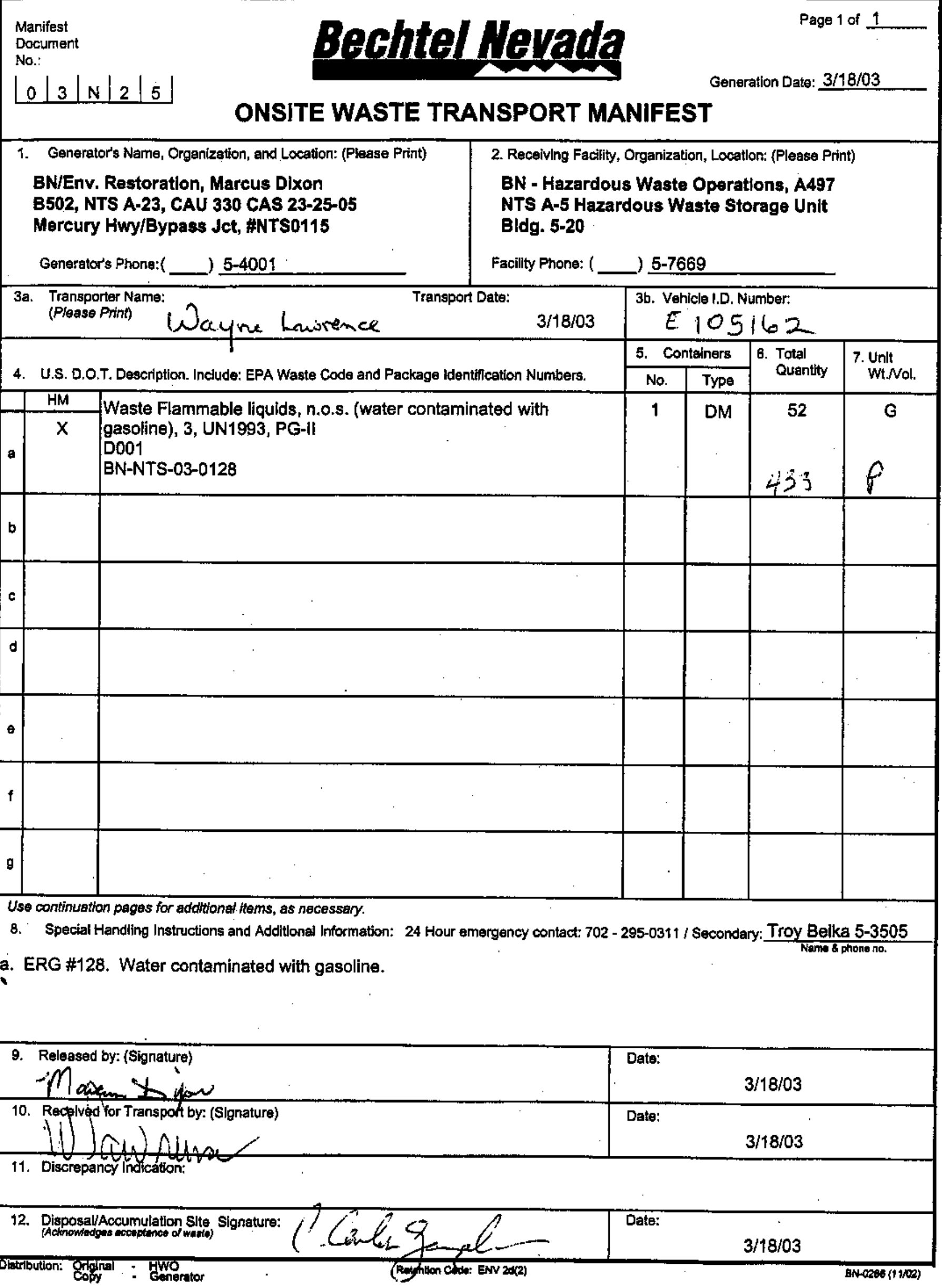


CLOSURE RE PORT - CAU 330

Section: Appendix D

Revision : 0

Date: July 2003

\section{APPENDIX D}

\section{FIELD PHOTOGRAPHS}


CLOSURE RE PORT - CAU 330

Section: Appendix D

Revision : 0

Date: July 2003

\section{THIS PAGE INTENTIONALLY LEFT BLANK}




\section{PHOTOGRAPH LOG}

\begin{tabular}{|c|c|c|}
\hline $\begin{array}{c}\text { PHOTOGRAPH } \\
\text { NUMBER }\end{array}$ & DATE & DESCRIPTION \\
\hline \multicolumn{3}{|r|}{ CAS 06-02-04 } \\
\hline 1 & $04 / 21 / 2003$ & Excavating pipe \\
\hline 2 & $06 / 04 / 2003$ & Excavation backfilled \\
\hline 3 & $04 / 22 / 2003$ & Excavating Underground Storage Tank \\
\hline 4 & $06 / 04 / 2003$ & Excavation backfilled \\
\hline \multicolumn{3}{|r|}{ CAS 22-99-06 } \\
\hline 5 & $03 / 10 / 2003$ & Excavating fuel spill \\
\hline 6 & $04 / 09 / 2003$ & Excavation backfilled \\
\hline \multicolumn{3}{|r|}{ CAS 23-01-02 } \\
\hline 7 & $02 / 13 / 2003$ & Demolishing fill stand \\
\hline 8 & $04 / 28 / 2003$ & Fill stand removed \\
\hline 9 & $02 / 13 / 2003$ & Demolishing/removing piping \\
\hline 10 & $04 / 28 / 2003$ & Piping removed \\
\hline 11 & $02 / 24 / 2003$ & Demolishing Diesel AST \\
\hline 12 & $04 / 28 / 2003$ & Diesel AST removed \\
\hline 13 & $02 / 20 / 2003$ & Demolishing Gasoline AST \\
\hline 14 & $04 / 28 / 2003$ & Gasoline AST removed \\
\hline \multicolumn{3}{|r|}{ CAS 23-25-05 } \\
\hline 15 & $01 / 29 / 2003$ & Transfer and removal of 55-gal drum \\
\hline 16 & $03 / 19 / 2003$ & 55-gal drum removed \\
\hline 17 & $03 / 11 / 2003$ & Excavating/removing asphalt oil/tar and concrete \\
\hline 18 & $03 / 20 / 2003$ & Asphalt oil/tar and concrete removed \\
\hline
\end{tabular}


CLOSURE RE PORT - CAU 330

Section: Appendix D

Revision : 0

Date: July 2003

\section{THIS PAGE INTENTIONALLY LEFT BLANK}


CLOSURE REPORT - CAU 330

Section: Appendix D

Revision: 0

Date: July 2003
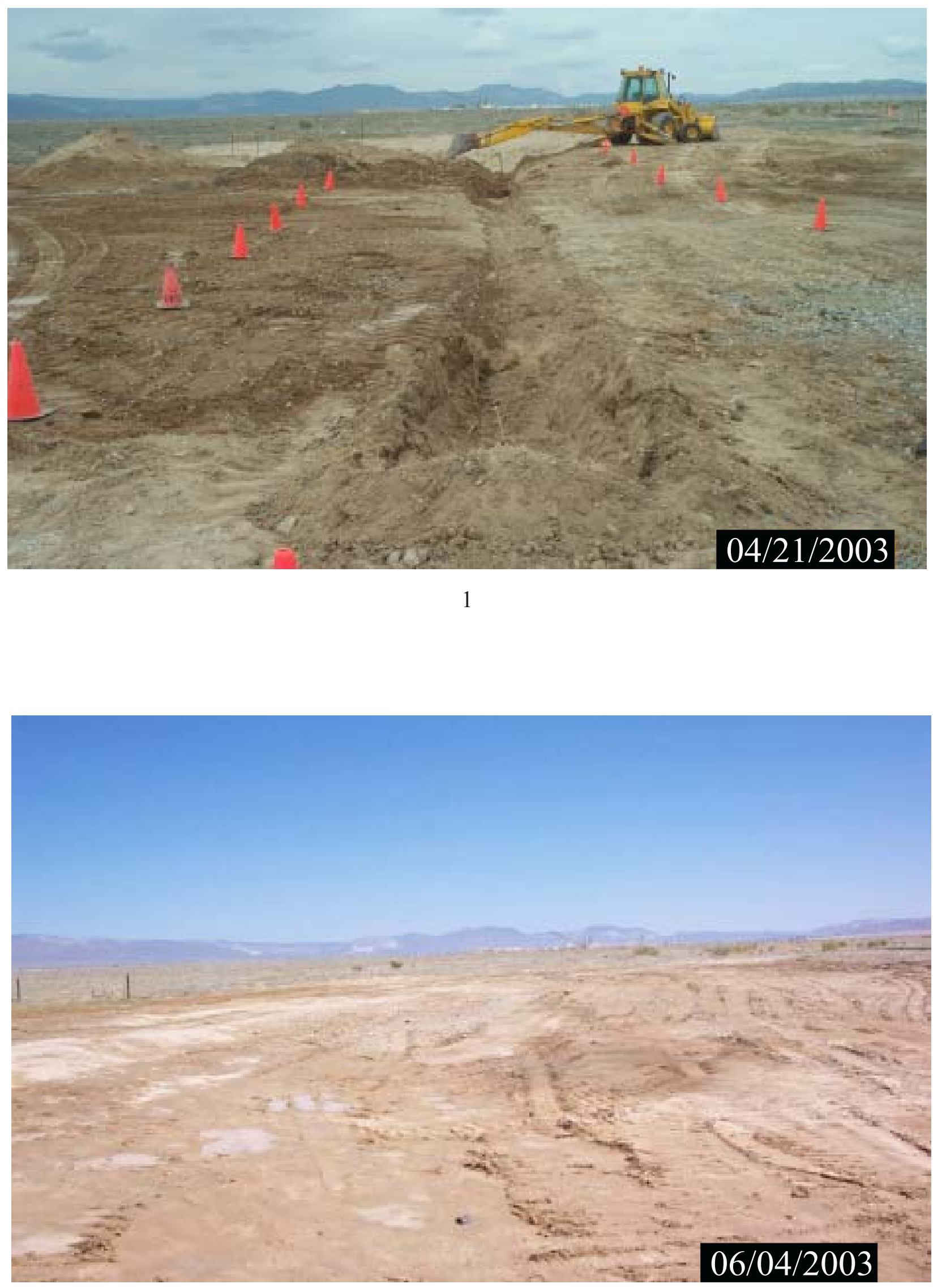
CLOSURE REPORT - CAU 330

Section: Appendix D

Revision: 0

Date: July 2003
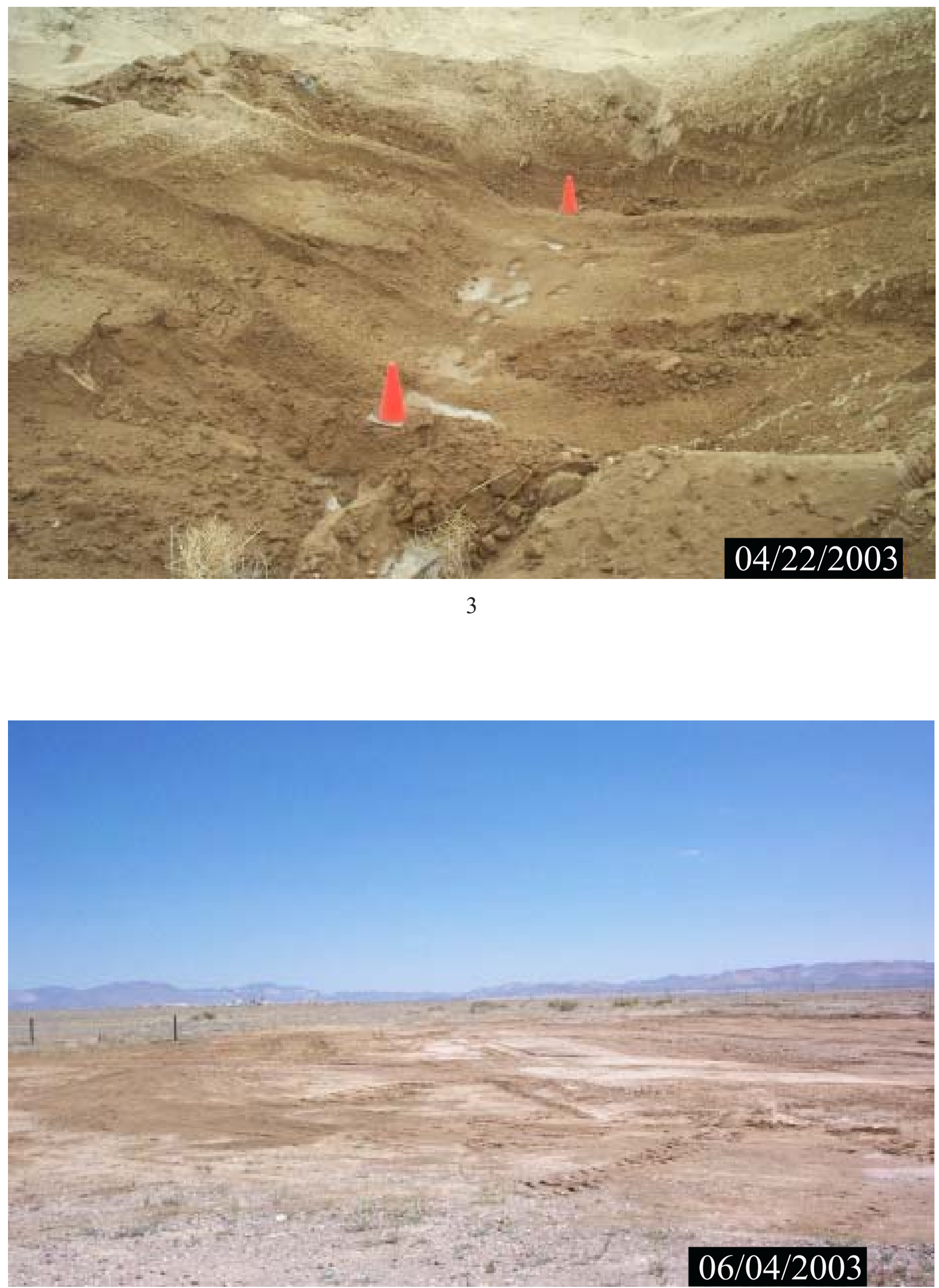

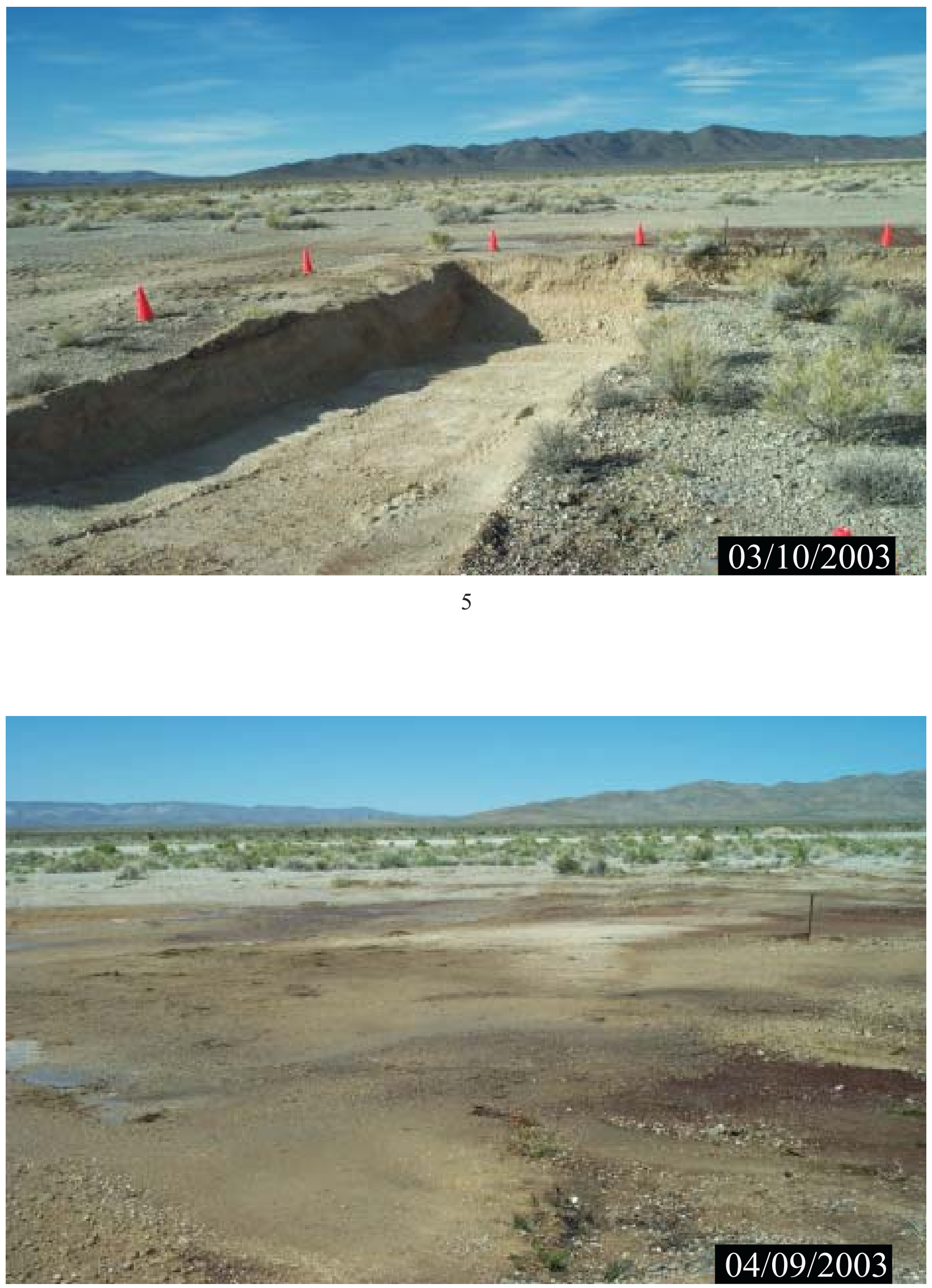
CLOSURE REPORT - CAU 330

Section: Appendix D

Revision: 0

Date: July 2003
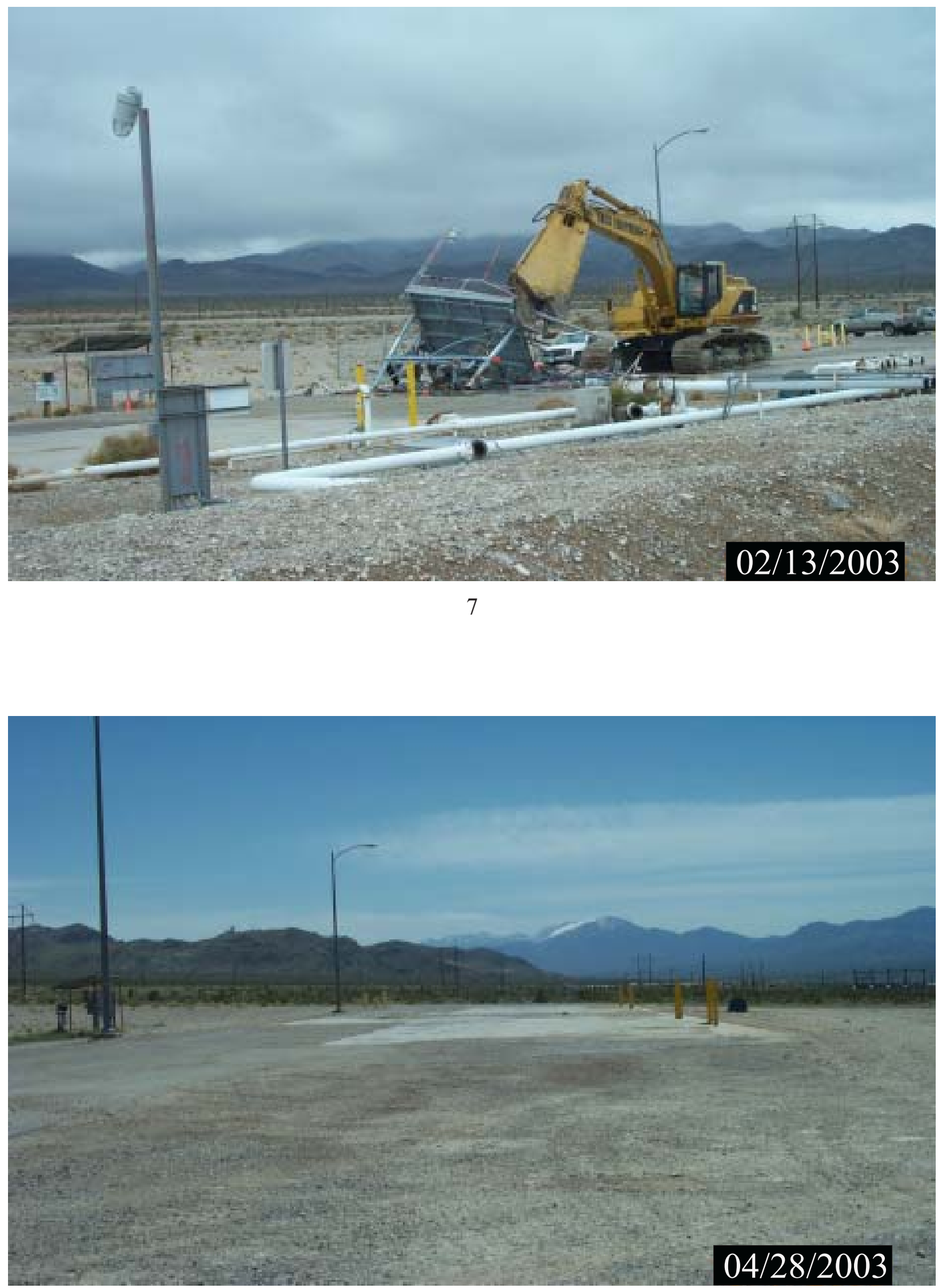


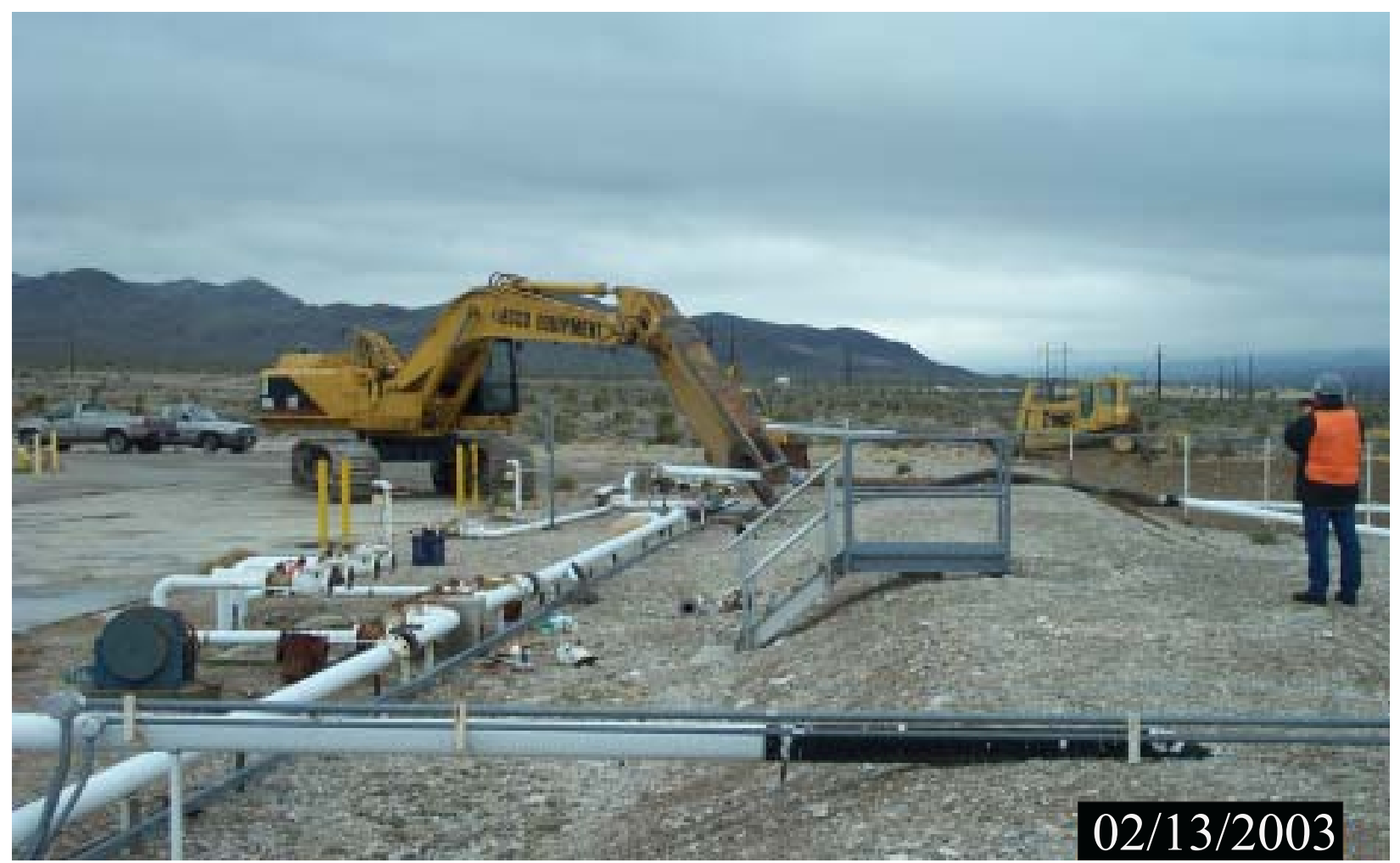



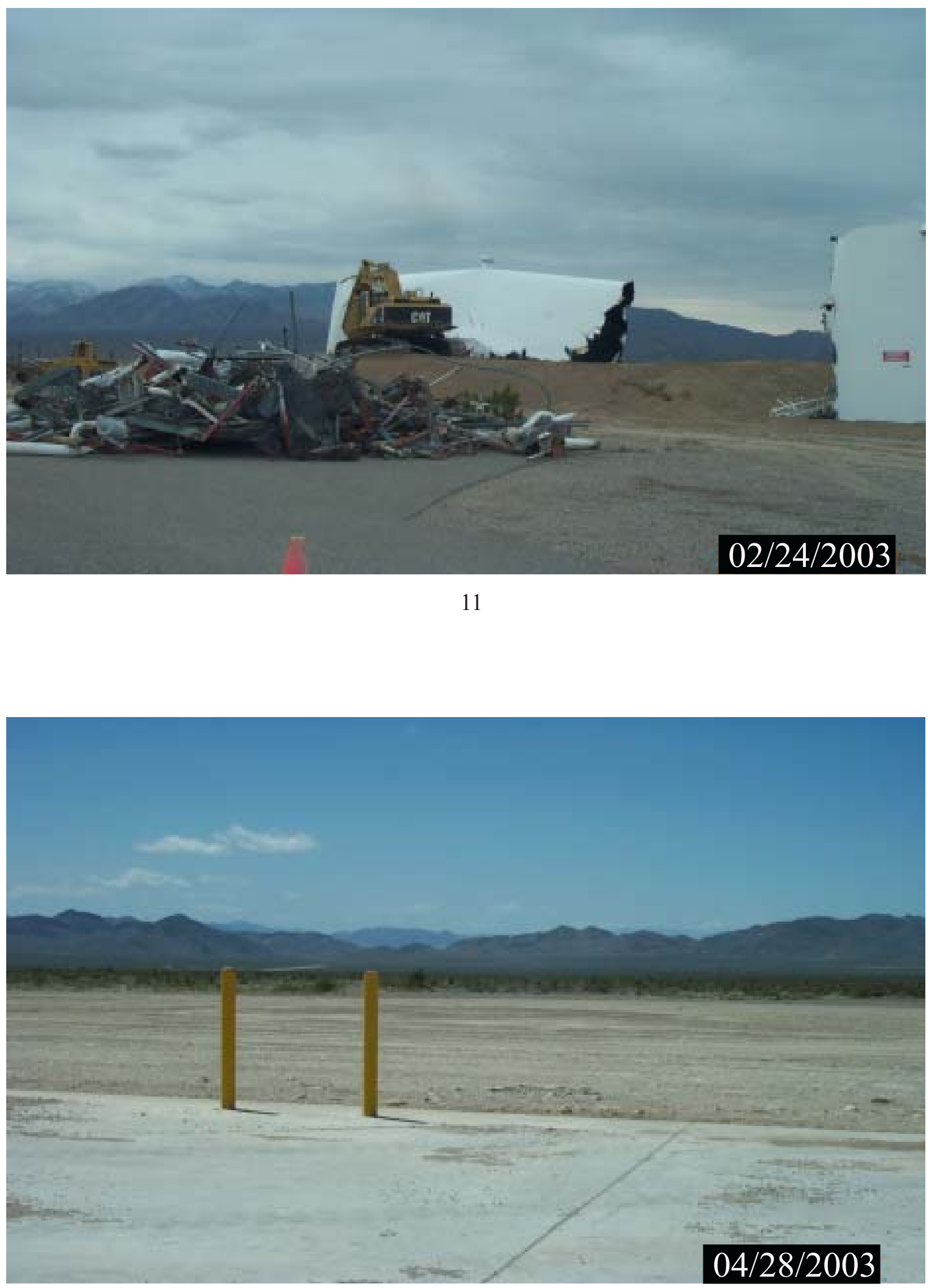


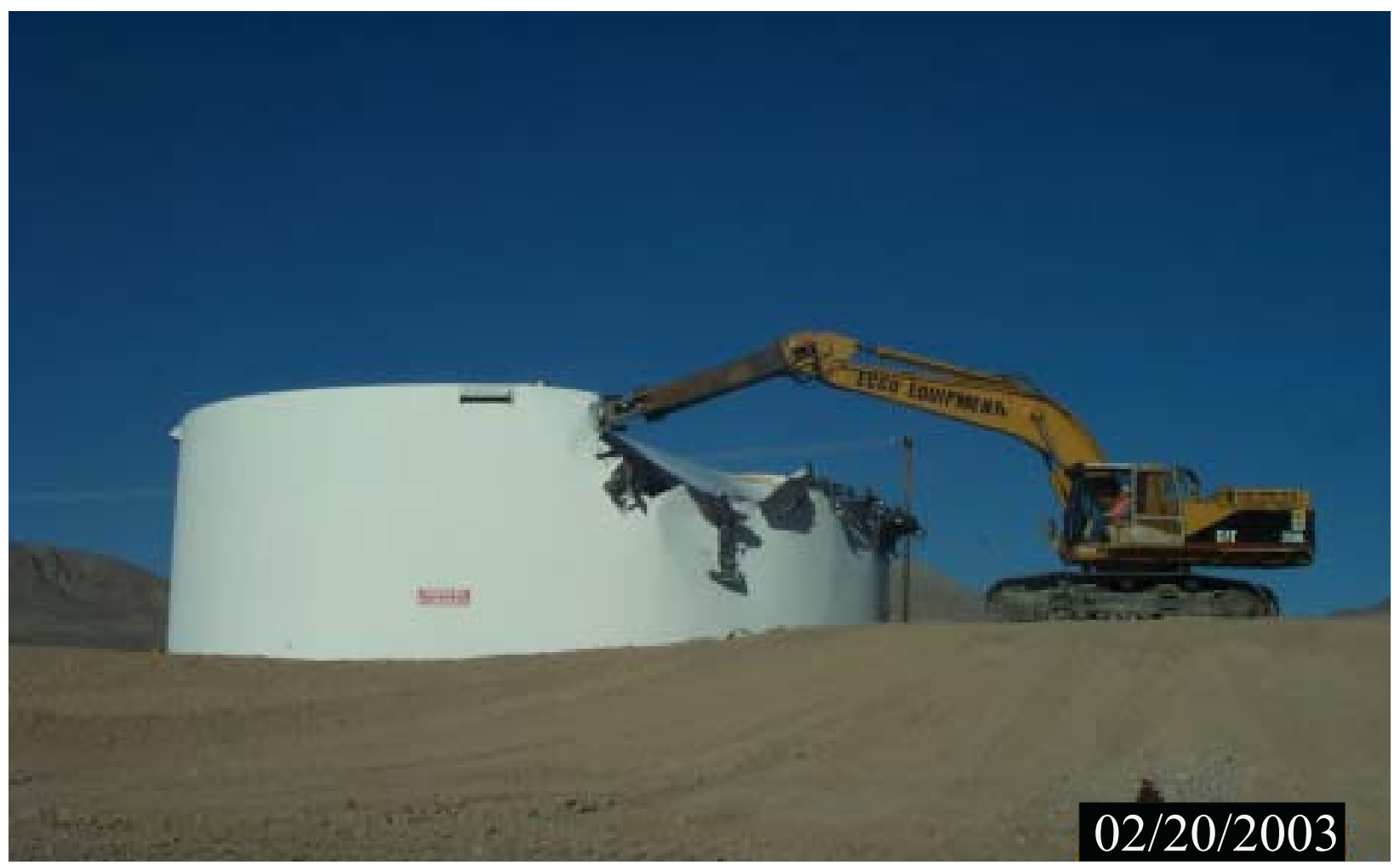

13

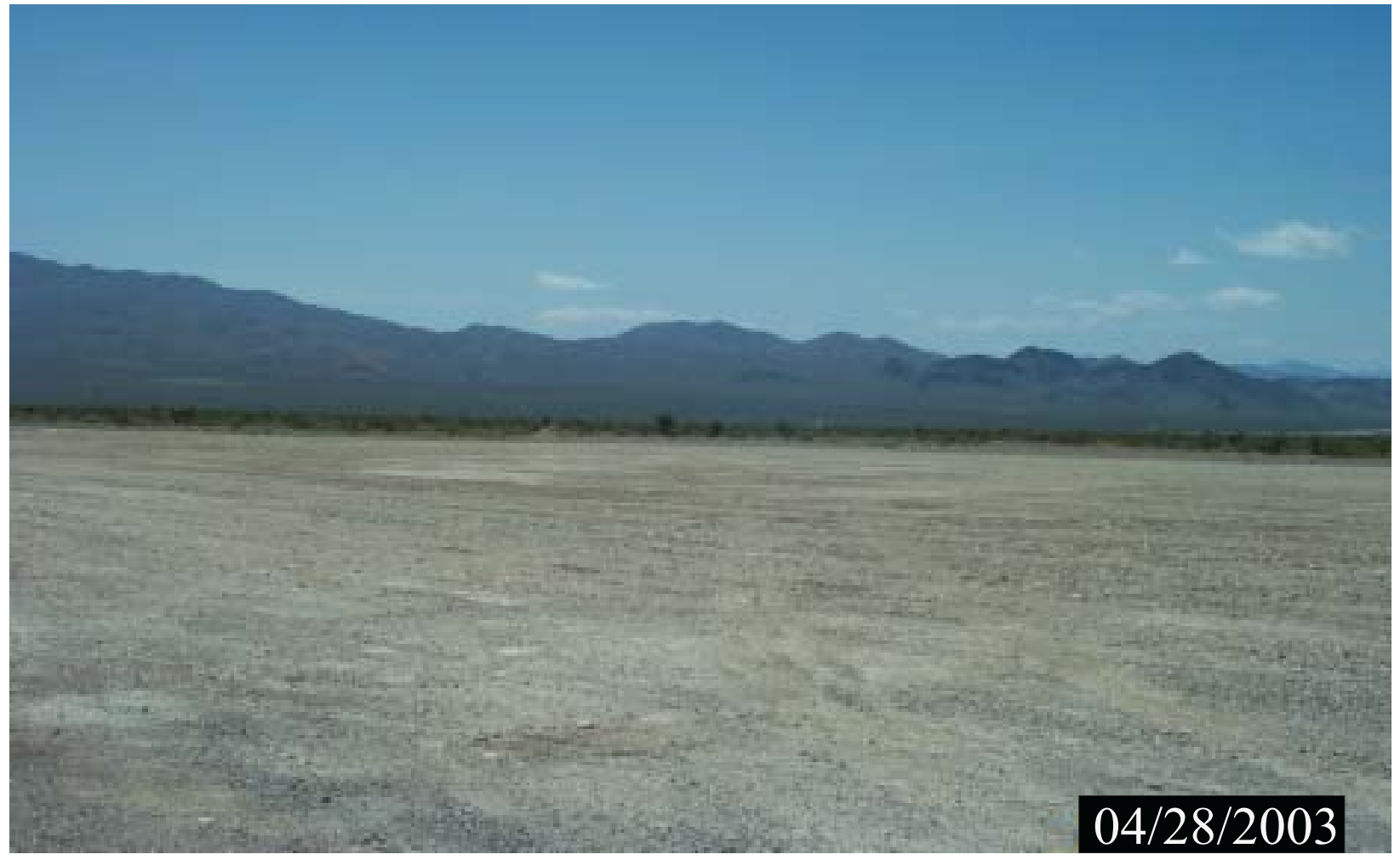


CLOSURE REPORT - CAU 330

Section: Appendix D

Revision: 0

Date: July 2003
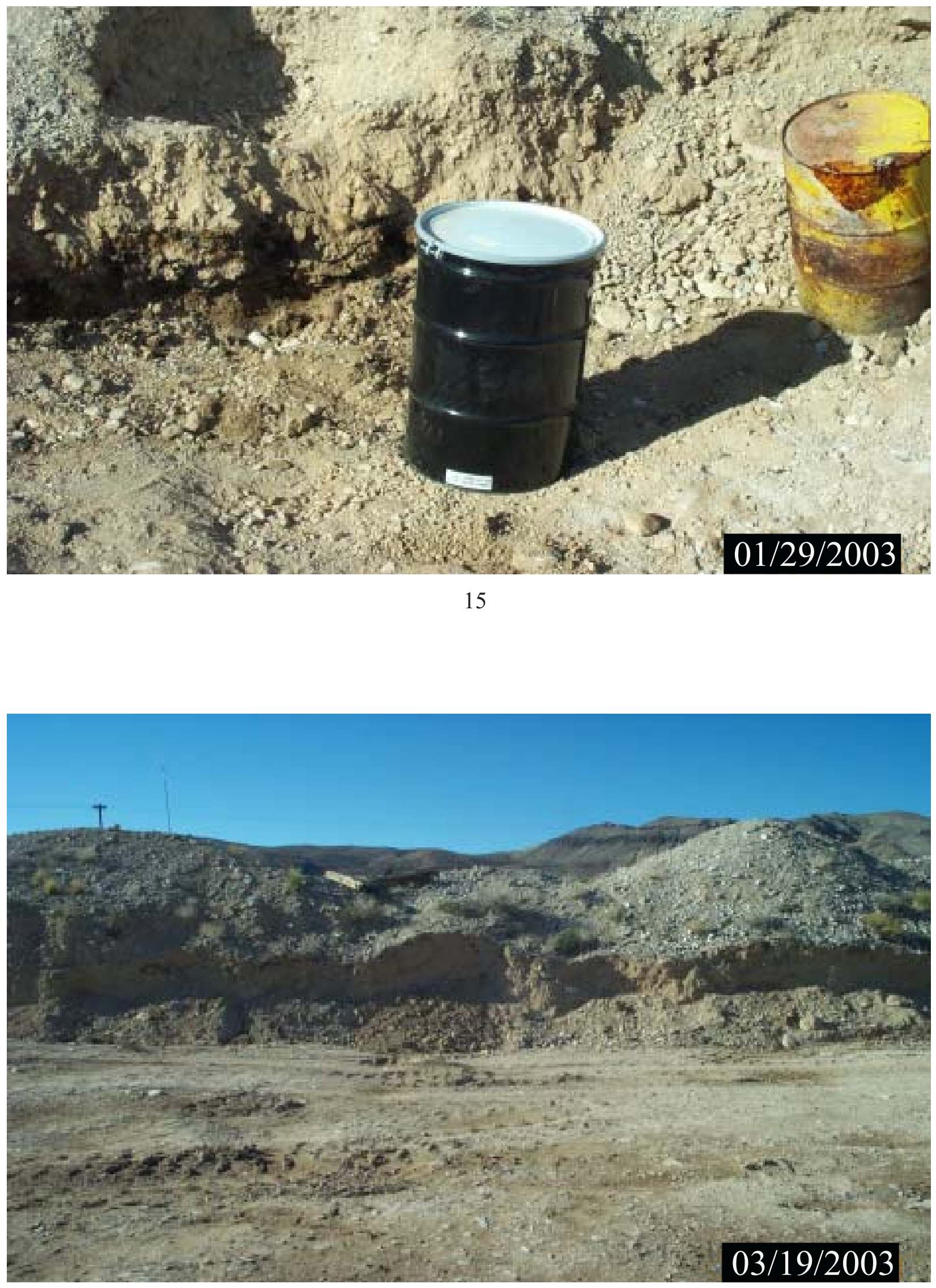


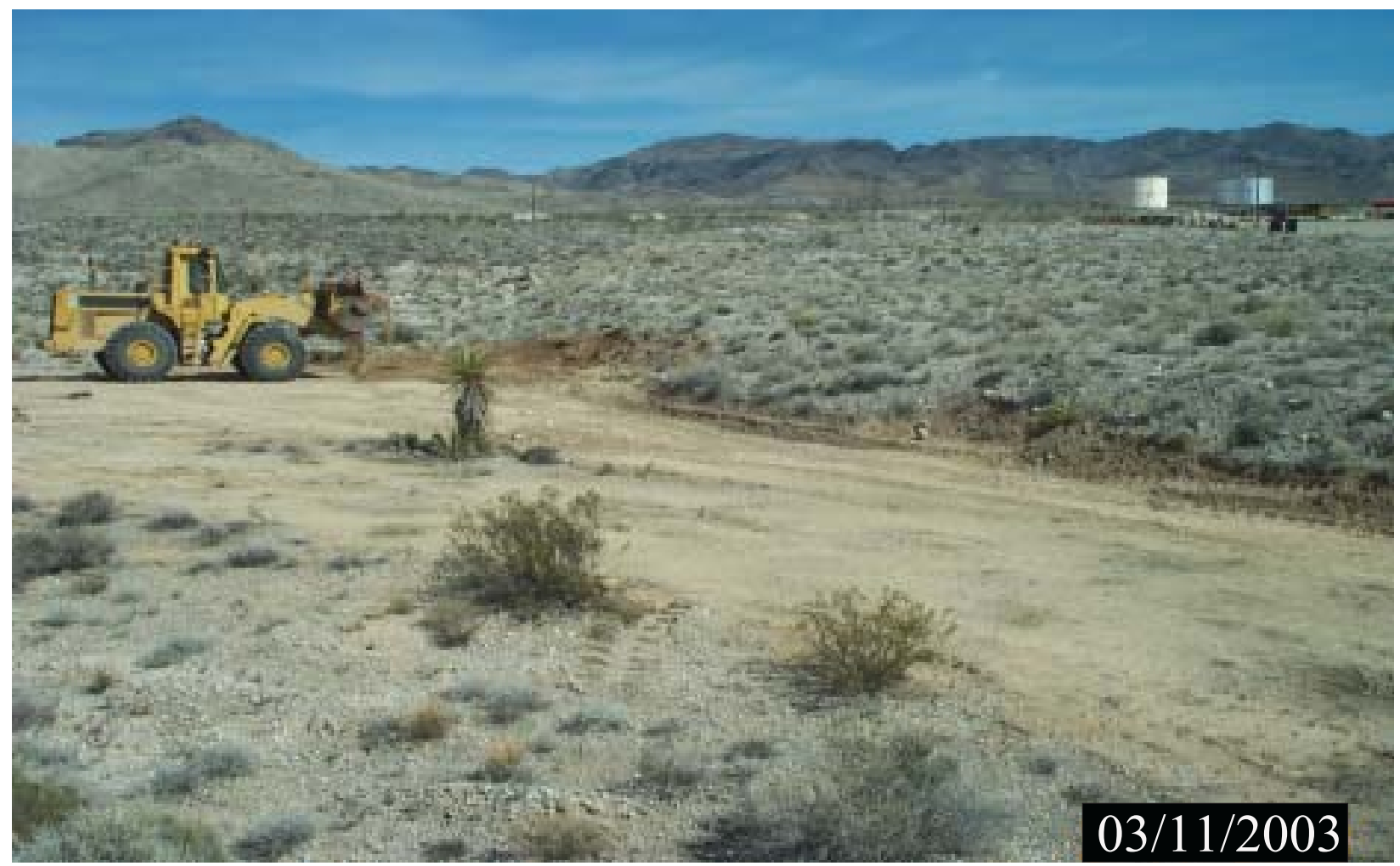

17

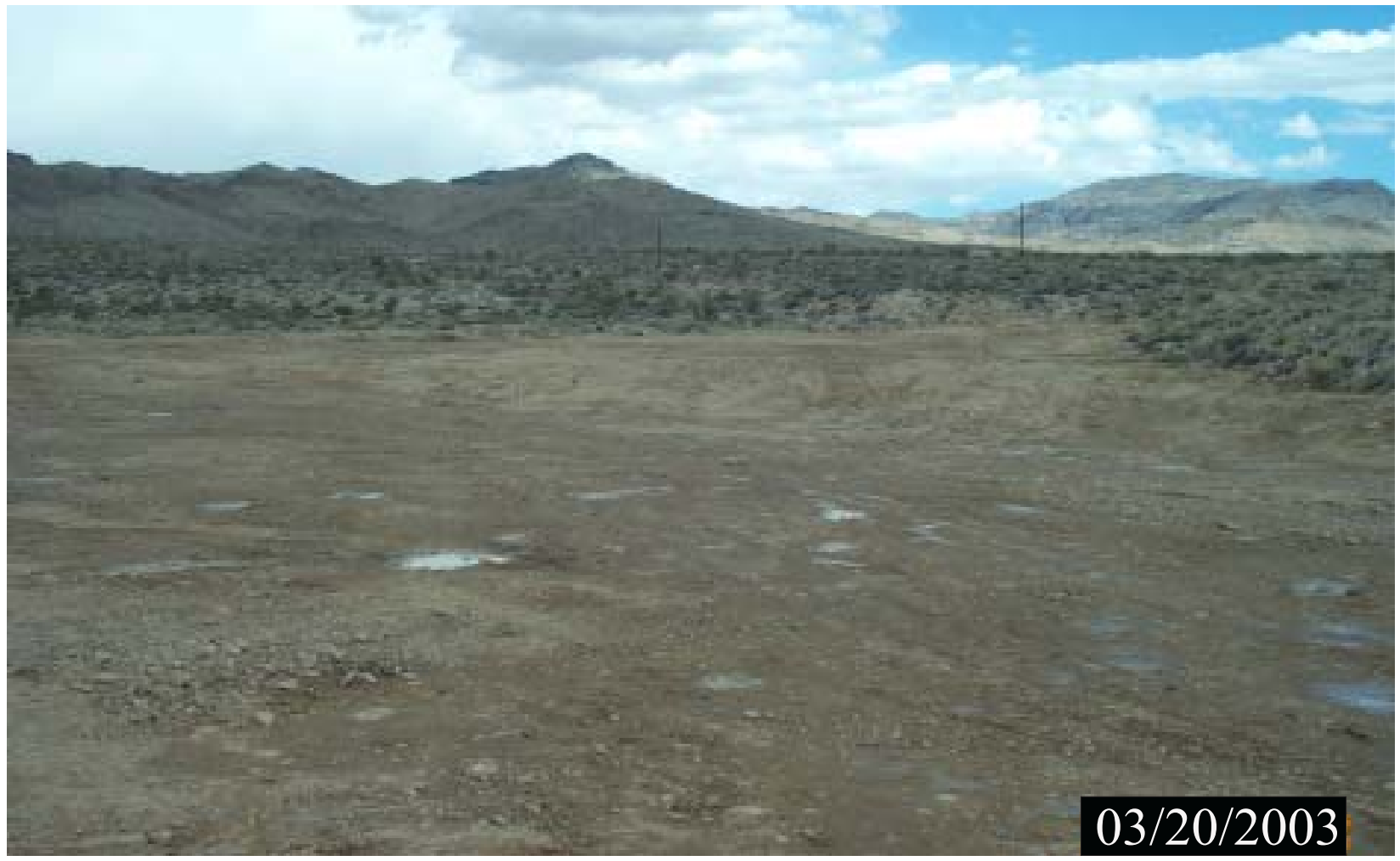




\section{APPENDIX E}

\section{CLOSURE CERTIFICATION*}

*As referenced in Section 1.3 of this CR, a Closure Certification is not applicable to the closure of CAU 330. No Closure Certification is required or necessary for closure of CAU 330. 
CLOSURE RE PORT - CAU 330

Section: Appendix E

Revision : 0

Date: July 2003

\section{THIS PAGE INTENTIONALLY LEFT BLANK}




\section{APPENDIX F}

\section{AS-BUILT DOCUMENTATION*}

*As referenced in Section 1.3 of this CR, As-Built Documentation is not applicable to the closure of CAU 330. No engineered structures were constructed during the closure of CAU 330. 
CLOSURE RE PORT - CAU 330

Section: Appendix F

Revision : 0

Date: July 2003

\section{THIS PAGE INTENTIONALLY LEFT BLANK}




\section{APPENDIX G}

\section{MODIFICATIONS TO THE POST-CLOSURE PLAN*}

*As referenced in Section 1.3 of this CR, CAU 330 was clean closed; no post-closure monitoring is required. 
CLOSURE RE PORT - CAU 330

Section: Appendix G

Revision : 0

Date: July 2003

\section{THIS PAGE INTENTIONALLY LEFT BLANK}




\section{APPENDIX H}

\section{NEVADA ENVIRONMENTAL RESTORATION PROJECT DOCUMENT REVIEW SHEET}


CLOSURE RE PORT - CAU 330

Section: Appendix H

Revision : 0

Date: July 2003

\section{THIS PAGE INTENTIONALLY LEFT BLANK}




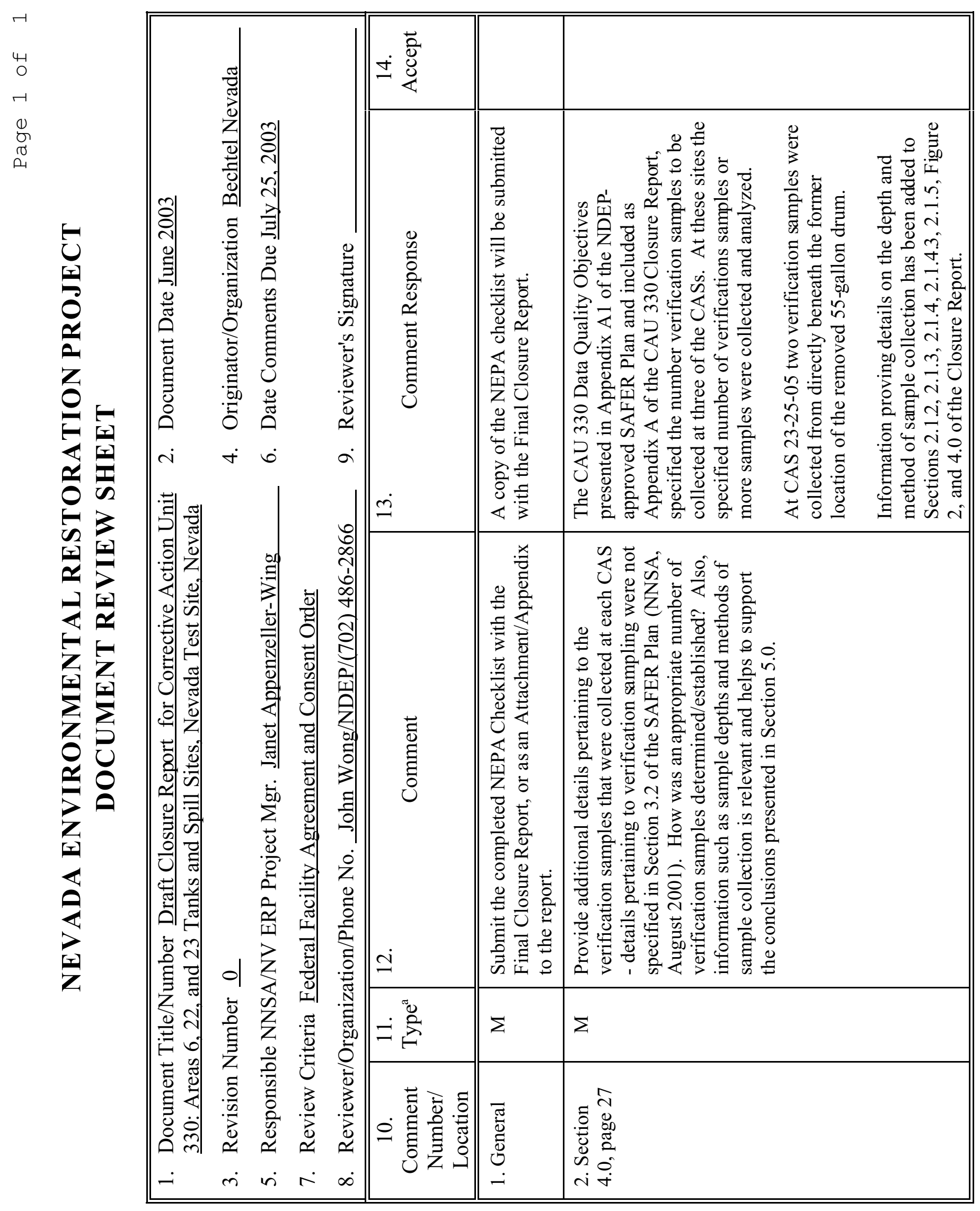

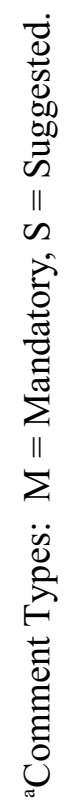


THIS PAGE INTENTIONALLY LEFT BLANK 
CLOSURE RE PORT - CAU 330

Section: Distribution List

Revision : 0

Date: July 2003

\section{DISTRIBUTION LIST}


CLOSURE RE PORT - CAU 330

Section: Distribution List

Revision : 0

Date: July 2003

\section{THIS PAGE INTENTIONALLY LEFT BLANK}


*Provide copy of initial distribution of all revisions; others receive NDEP-approved revision only.

\section{$\underline{\text { Nevada Division of Environmental Protection }}$}

Paul Liebendorfer

1 (Controlled)*

Bureau of Federal Facilities

Division of Environmental Protection

333 W. Nye Lane, Room 138

Carson City, NV 89706-0866

Donald Elle

Bureau of Federal Facilities

1 (Controlled)*

Division of Environmental Protection

1771 E. Flamingo Road, Suite 121-A

Las Vegas, NV 89193-0837

\section{U.S. Department of Energy}

Janet Appenzeller-Wing

1 (Uncontrolled)*

Environmental Restoration Division

U.S. Department of Energy

National Nuclear Security Administration

Nevada Site Office

P.O. Box 98518, M/S 505

Las Vegas, NV 89193-8518

Sabine Curtis

1 (Uncontrolled)*

Environmental Restoration Division

U.S. Department of Energy

National Nuclear Security Administration

Nevada Site Office

P.O. Box 98518, M/S 505

Las Vegas, NV 89193-8518

Sabrina Lawrence

1 (Controlled)*

Environmental Restoration Division

U.S. Department of Energy

National Nuclear Security Administration

Nevada Site Office

P.O. Box 98518, M/S 505

Las Vegas, NV 89193-8518 


\section{$\underline{\text { U.S. Department of Energy (continued) }}$}

U.S. Department of Energy

National Nuclear Security Administration

Nevada Site Office

Southern Nevada Public Reading Facility

$\mathrm{C} / \mathrm{O}$ Nuclear Testing Archive, M/S 400

P.O. Box 98521

Las Vegas, NV 89193-8521

U.S. Department of Energy

National Nuclear Security Administration

Nevada Site Office

Technical Library

P.O. Box 98518

Las Vegas, NV 89193-8518

U.S. Department of Energy

Office of Scientific and Technical Information

P.O. Box 62

Oak Ridge, TN 37831-0062

\section{Bechtel Nevada}

Correspondence Control

Bechtel Nevada

P.O. Box 98521, M/S CF008

Las Vegas, NV 89193-8521

Environmental Management Library

Bechtel Nevada

P.O. Box 98521, M/S NLV080

Las Vegas, NV 89193-8521

Kevin Campbell

Bechtel Nevada

P.O. Box 98521, M/S NTS306

Las Vegas, NV 89193-8521

Marcus Dixon

Bechtel Nevada

P.O. Box 98521, M/S NTS306

Las Vegas, NV 89193-8521
1 (Controlled) \&

1 (Uncontrolled) 


\section{DISTRIBUTION LIST (continued)}

\section{$\underline{\text { Bechtel Nevada (continued) }}$}

Wayne Johnson

1 (Uncontrolled)*

Bechtel Nevada

P.O. Box 98521, M/S NLV080

Las Vegas, NV 89193-8521

Steve Nacht

1 (Uncontrolled)*

Bechtel Nevada

P.O. Box 98521, M/S NTS306

Las Vegas, NV 89193-8521

Allison Urbon

1 (Uncontrolled)*

Bechtel Nevada

P.O. Box 98521, M/S NTS306

Las Vegas, NV 89193-8521

Shaw Environmental, Inc.

FFACO Coordinator

1 (Controlled)

Shaw Environmental

P.O. Box 93838, M/S 439

Las Vegas, NV 89193-3838

John Stokowski

1 (Uncontrolled)*

Shaw Environmental

P.O. Box 93838, M/S 439

Las Vegas, NV 89193-3838

\section{$\underline{\text { State of Nevada }}$}

Manager, Northern Nevada

1 (Uncontrolled)

FFACO Public Reading Facility

Nevada State Library and Archives Federal Publications

100 North Stewart Street

Carson City, NV 89701-4285 
CLOSURE RE PORT - CAU 330

Section: Distribution List

Revision : 0

Date: July 2003

\section{THIS PAGE INTENTIONALLY LEFT BLANK}

